
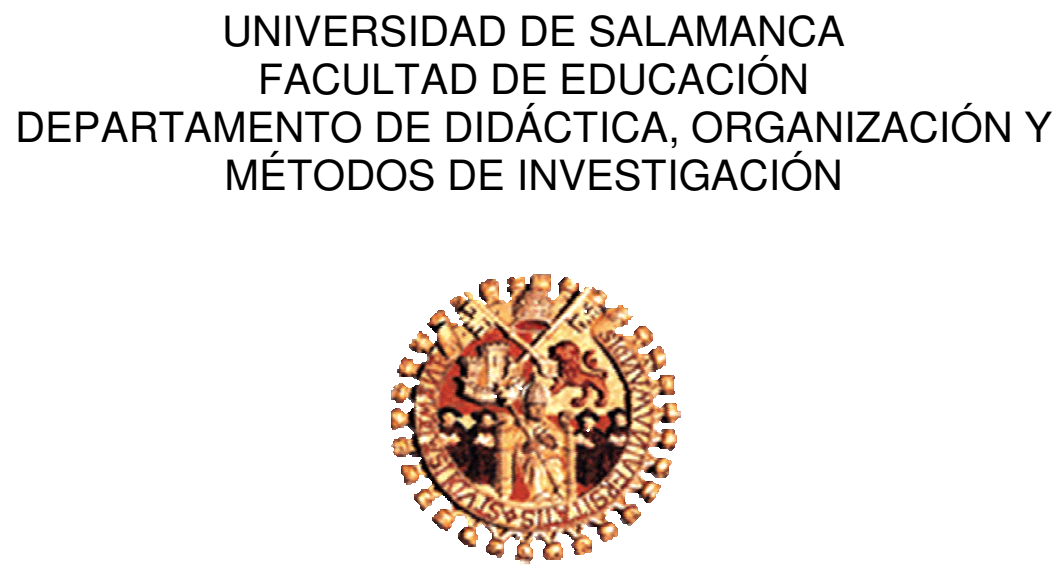

Tesis Doctoral

EL USO DE LAS TICs EN LA ASESORÍA TÉCNICA DE EDUCACIÓN ESPECIAL EN EL ESTADO DE CHIHUAHUA (MÉXICO) COMO ESTRATEGIA DE MEJORA Y OPTIMIZACIÓN DEL SERVICIO.

Autora: Magda Ofelia Longoria Gandara Directora: Dra. Ana García-Valcárcel Muñoz-Repiso 



\section{VNIVERSIDAD \\ B SALAMANCA}

FACULTAD DE EDUCACIÓN

Departamento de Didáctica, Organización y Métodos de Investigación

Dña. Ana García-Valcárcel Muñoz-Repiso, profesora titular de Didáctica y Organización Escolar en la Universidad de Salamanca,

Hace constar que la Tesis Doctoral titulada "El uso de las TICs en la Asesoría Técnica de Educación Especial en el Estado de Chihuahua (México) como estrategia de mejora y optimización del Servicio", realizada bajo mi dirección por Dña. Magda Ofelia Longoria Gándara, reúne, desde mi punto de vista, todas las condiciones exigibles para ser presentada y defendida públicamente, tanto por la relevancia del tema estudiado como por el procedimiento metodológico utilizado: revisión teórica adecuada, contextualización, definición de objetivos, variables estudiadas y estructuración del análisis de los datos pertinente a la naturaleza de la información recogida, así como las conclusiones aportadas.

Por todo ello manifiesto mi acuerdo para que sea autorizada la presentación del trabajo referido.

Salamanca, 28 de noviembre de 2008

LA DIRECTORA DE TESIS

Fdo. Ana García-Valcárcel Muñoz-Repiso 

A mi familia y amigos. 

En primer lugar, deseo expresar una profunda gratitud a Dra. Ana GarcíaValcárcel Muñoz-Repiso por su infinita dedicación, compromiso y generosidad a la hora de dirigirme el presente trabajo.

Igualmente agradezco a la jefa del Departamento de Educación Especial Lic. Ma del Rosario Ríos Rangel, su gran apoyo y participación sin el cual está investigación no hubiera sido posible.

Así mismo, quiero expresar mi gratitud a comisión paritaria SEECH-SENTE, ya que con la concesión de una licencia de beca comisión, ha hecho posible que pudiera realizar los estudios de doctorado en mejores condiciones.

Me gustaría también expresar mi gratitud a todos los compañeros que fundamentalmente han colaborado a lo largo de esta tesis, aportando toda la información y ayuda solicitada de manera generosa e incondicional.

También muestro un profundo agradecimiento a mi familia y amigos por estar presentes manteniendo ese hilo invisible de la amistad, ofreciéndome constantemente su ayuda y su cariño, especialmente a Chayo y Oly. 


\section{ÍNDICE GENERAL}

Introducción

I MARCO TEÓRICO 11

CAPÍTULO 1 LAS TECNOLOGIAS DE LA INFORMACIÓN Y LA 11 COMUNICACIÓN EN EDUCACIÓN ESPECIAL

1.1 La Tecnología de la Información y la Comunicación. 11

1.2 Las TIC en Educación 12

1.2.1 Las TIC en el Aula 18

1.3 Las TIC en la Educación Especial 26

1.3.2 Asistencia Tecnológica 31

1.3.2 Las Ayudas Técnicas 35

1.3.3 El Profesor en el campo de las TIC y la

Discapacidad. 38

1.4 Propuestas e Investigaciones de TIC relacionadas a la 47 atención de las NEE y a la Discapacidad.

1.4.1 Experiencias educativas con alumnos

superdotados en el uso de las Nuevas

Tecnologías. 47

1.4.2 Las TIC en las Inteligencias Múltiples. 49

1.4.3 Las Tecnologías de la Información y la

Comunicación y los Trastornos Generalizados

del Desarrollo. 57

1.4.4 Las TIC y las personas con Discapacidad

Visual.

1.4.5 Programa Informático de Estimulación Visual

Temprana en niños con Baja Visión.

1.4.6 Las Nuevas Tecnologías como recurso de apoyo para alumnos con Discapacidad Motora y Psíquica.

1.4.7 Las TIC como herramienta de los Trastornos de la Audición y el Lenguaje. 
1.4.8 Las TIC y la Estimulación Sensoriomotriz en

niños con Plurideficiencias.

1.4.9 Nuevas Tecnologías y aprendizaje matemático

en niños con Síndrome de Down:

Generalización para la autonomía.

1.4.10 Programa para manejar el móvil con chicos con Síndrome de Down.

1.4.11 La investigación Educativa en el Aula

Hospitalaria: Estudio de caso de intervención escolar, de glioma óptico mediante video conferencia.

102

1.5 Guía para Profesionales y Padres de Personas con Discapacidad.

1.6 Diseño de software y páginas Web accesibles. 111

1.7 Las TIC en la Formación Continua y Permanente. 119

\section{MARCO CONTEXTUAL}

\section{CAPÍTULO 2 LA EDUCACIÓN ESPECIAL EN CHIHUAHUA}

\section{MÉXICO}

2.1 Educación Especial en México

2.1.1 Contexto Internacional

2.1.2 Contexto Nacional

2.1.3 Contexto Estatal

2.2 La Educación Especial en Chihuahua 150

2.2.1 Plan Estratégico de Transformación Escolar 152

2.2.2 La Evaluación en el Proceso Enseñanza 155 Aprendizaje

2.2.3 Adecuaciones Curriculares

2.2.4 Organización de Educación Especial 167

2.2.4.1 Servicios de Educación Especial 171

2.3 La Formación Continua en Educación Básica 180

2.3.1 Asesoría Técnica Pedagógica 181 


\section{INVESTIGACIÓN}

3.1.1.1 Identificación del problema de estudio y diagnostico de la situación actual.

3.1.1.2 Objetivos

3.1.1.4 Planificación de los procedimientos de intervención

3.1.1.5 Muestra e Instrumentos utilizados

3.1.1.5.1 Análisis de la Política Educativa del Estado de Chihuahua México, sobre el uso de las TIC en la modalidad de Educación Especial de 1996 a 2010

3.1.1.5.2 Análisis del contexto de la modalidad de la Educación Especial en el Estado de Chihuahua en relación a los aspectos técnicos operativos y el impacto de la capacitación y actualización de la Asesoría Técnica.

3.1.1.5.3 Diseño, aplicación y evaluación de un recurso digital como propuesta para mejora y optimizar la asesoría y capacitación técnica, en la modalidad de Educación Especial.

3.1.1.6 Técnica e Instrumentos para la recogida de datos. 
3.1.1.6.1 Análisis de la Política Educativa del

Estado de Chihuahua México, sobre el uso de las TIC en la modalidad de Educación Especial de 1996 a 2010

3.1.1.6.2 Análisis del contexto de la modalidad de la Educación Especial en el Estado de Chihuahua en relación a los aspectos técnicos operativos y el impacto de la capacitación y actualización de la Asesoría Técnica

3.1.1.6.2 Diseño, aplicación y evaluación de un recurso digital como propuesta para mejora y optimizar la asesoría y capacitación técnica, en la modalidad de Educación Especial.

\section{CAPÍTULO 4 ANÁLISIS DE RESULTADOS DE LA} INVESTIGACIÓN

4.1 Análisis de la Política Educativa del Estado de Chihuahua México, sobre el uso de las TIC en la modalidad de Educación Especial de 1996 a 2010

4.2 Análisis del contexto de la modalidad de Educación Especial en el Estado de Chihuahua en relación a los aspectos técnicos operativos y el impacto de la capacitación y actualización de la Asesoría Técnica

4.3 Diseño, aplicación y evaluación de un recurso digital como 
propuesta para mejora y optimizar la asesoría y capacitación técnica, en la modalidad de Educación Especial

4.3.1 Informe de los resultados de la evaluación del diseño y utilidad del sitio Web de Educación Especial

5.1 Conclusiones de las hipótesis 329

5.2 Conclusiones 330

5.3 Recomendaciones 333

REFERENCIAS

ANEXOS 353

I Comunidades de los Centros de Atención Múltiple 354

II Comunidades Unidades de Servicio de Apoyo a la Escuela Regular

III Organigrama de Educación Especial 359

IV Cuestionario Evaluación del Contexto 361

V Encuesta de Evaluación del Diseño del Sitio Web 387

VI Encuesta de Evaluación de la Utilidad del Sitio Web 394

VII Codificación de las Unidades de Registro de los 400 documentos sujetos de análisis 


\section{INTRODUCCIÓN}

La época actual podría caracterizarse como el periodo en el que se han experimentado los cambios más vertiginosos en todos los planos, pero especialmente en lo que se refiere a la tecnología en los diferentes ámbitos.

Las Ilamadas Nuevas Tecnologías, han sido la causa de la revolución digital, consiguiendo cambios y transformaciones conformando la Tecnología de la Información y de la Comunicación (TIC), representando hoy en día una fuerza determinante en el cambio social, siendo un sostén de un nuevo tipo de sociedad de la información y comunicación. El Internet se ha desarrollado de tal manera que ha llegado a incorporarse a la vida cotidiana de los ciudadanos de forma vertiginosa, las aplicaciones y efectos del Internet en todos los sectores, se han manifestado en menos de una década. Se observan a nuestro alrededor muchos cambios en la forma de comunicarse, de organizarse, de trabajar o de divertirse, convirtiéndose en una sociedad que se caracteriza por tener la posibilidad de acceder a volúmenes enormes de información y de conectarse y comunicarse con otros, sin límites de espacio ni tiempo.

La relación de las TIC y Educación Especial conlleva implicaciones de mayor peso e importancia debido a las necesidades que presenta la población que atiende. Cabero (2001) enuncia que hablar de medios de comunicación y nuevas tecnologías aplicadas a sujetos con necesidades educativas especiales es una doble necesidad, por un lado, porque estos sujetos se beneficien de los medios utilizados en un marco general y por otro lado, la necesidad de diseñar y producir medios específicos que puedan ser de gran apoyo y ayuda para esta población.

Los esfuerzos de las personas con discapacidad, de sus familias, de las agencias que los apoyan, de los maestros y maestras, del personal de Educación Especial, han promovido cambios en las actitudes sociales, en la legislación, en las oportunidades para el trabajo y en la educación. El Programa Nacional de Fortalecimiento de la Educación Especial y de la Integración Educativa (SEP, 2002) promueve que la formación inicial y la actualización del personal de Educación Especial deben estar encaminadas a dar una respuesta educativa adecuada a las necesidades específicas que presentan los niños, las 
niñas y los jóvenes con discapacidad, así como a aquellos que presentan necesidades educativas especiales derivadas de otros factores.

Es necesario potencializar el uso de las Tecnologías de la Información y la Comunicación en el ámbito de la Educación, específicamente en la formación continua, posibilitando el incremento de información que pueden tener a sus disposición estudiantes y profesores, además de que se puede acceder a diferentes tipos de contenidos y estructuras, desde fuentes documentales de información, hasta de ejemplificación y ejercitación, la información no sólo es cuantitativa, sino cualitativa debido a no es sólo textual, sino también visual y auditiva, admitiendo la descolocación del conocimiento, permitiendo romper el espacio y el tiempo, para introducirnos en una comunidad del conocimiento. Chacón (2007) plantea que las TIC son también parte integral de la educación, que su inclusión y uso en este campo permitirá agilizar la divulgación de los hechos, así como también compartir y usar nuevos métodos y estrategias didácticas, así mismo intercambiar experiencias.

El Programa Sectorial de la Educación Sectorial de Educación de la Secretaria de Educación Pública 2007-2012, establece que México debe hacer de la educación, de la ciencia y la tecnología, los pilares de su desarrollo, dependiendo de ellas la calidad de vida de la población, de igual manera el Programa de Educación 2001-2006, desde su enfoque educativo que el Sistema Educativo para el año 2025, se organizará en función de los valores de calidad y equidad, brindando una educación pertinente a toda la población del país, incluyente e igualmente formativa, que contribuya al eje fundamental del desarrollo cultural, científico, tecnológico, económico y social del país. Promoviendo en relación a la calidad y la equidad, que los aprendizajes de los estudiantes serán el centro de atención, asegurando el dominio de conocimientos, habilidades y valores, con propuestas innovadoras utilizando las TIC, con un enfoque pedagógico, por medio del cual los educadores se actualicen y las instituciones aprendan, las innovaciones serán un elemento natural en la educación, donde las aulas no serán sólo los lugares de aprendizaje, sino que se enlazarán con redes de información y comunicación multimedia. La web ha hecho posible poner al alcance de muchos la información, los recursos, herramientas y posibilidades de comunicación, que hasta antes de que apareciera era un privilegio para una minoría. 
Esta investigación plantea la importancia de desarrollar una propuesta para mejorar y optimizar la asesoría técnica en la modalidad de Educación Especial a través del uso de las TIC, dada las necesidades de actualización y capacitación en esta modalidad educativa, para lograr impactar en la calidad de la educación de los niños niñas y jóvenes con necesidades educativas especiales prioritariamente asociadas a la discapacidad y las aptitudes sobresalientes.

\section{Razones del estudio}

El objetivo de la educación es que cada persona desarrolle su personalidad, las aptitudes y la capacidad mental y física, hasta el máximo de sus posibilidades, así como prepararles para asumir una vida responsable dentro de la sociedad. Han pasado más de cincuenta años y los avances alcanzados no han sido suficientes para hacer frente a los retos de crecimiento demográfico, y el desarrollo cultural, tecnológico, social y político de México.

La visión del Sistema Educativo Nacional plasmado en el Programa Nacional de Educación 2001-2006 se establece como una educación con equidad, de buena calidad y de vanguardia, afronta tres grandes retos, la cobertura con equidad, calidad en los procesos educativos y niveles de aprendizaje, e integración y funcionamiento del sistema educativo.

En congruencia el Programa Estatal de Educación 2005-2010 en su visión, objetivos y líneas de acción, promueve un marco necesario para impulsar y renovar la perspectiva de la Integración Educativa, con el fin de mejorar las condiciones en que se atienden a los niños, niñas y jóvenes con necesidades educativas especiales, prioritariamente los que presentan discapacidad.

Partiendo de esta visión global, la Educación Especial en la actualidad, de acuerdo a Torres (1999), se desenvuelve entre dos enfoques, uno basado en el déficit y el enfoque cultural-integrador que plantea la orientación centrada en el curriculum como respuesta educativa a la diversidad. El Programa Estatal de Fortalecimiento de la Educación Especial y de la Integración Educativa 20052010 informa sobre las dificultades que se han presentado en el Estado para el logro de la integración y la inclusión educativa, uno de estos aspectos es la dificultad de la incorporación de una visión curricular, en la atención de los 
niños, niñas y jóvenes con necesidades educativas especiales con discapacidad en los servicios escolarizados de Educación Especial, por los diferentes profesionales.

Desde la perspectiva socioeducativa y del respeto a la diversidad, el currículo tiene que albergar esa diversidad y utilizar planteamientos que respondan y recojan la complejidad que implica la atención de esa diversidad, de acuerdo a Alba (2006) las TIC utilizadas para dar respuesta a la diversidad, ofrecen mejores opciones para todos.

El Programa Estatal de Fortalecimiento de la Educación Especial y de la Integración Educativa 2005-2010 reconoce como uno de sus retos realizar más acciones relacionadas con la producción y dotación de recursos y materiales didácticos y específicos, tanto para los servicios de Educación Especial, como para las escuelas integradoras. Ya que en la mayoría de estos servicios, el personal docente muestra desconocimiento sobre las necesidades que tienen para la atención de la población, en relación con los materiales, las adecuaciones arquitectónicas o la accesibilidad.

Las nuevas tecnologías no sólo facilitan el funcionamiento del mundo productivo, sino que, aplicadas a la educación en general, ayudan a los procesos de aprendizaje, tratándose de Educación Especial en particular, hay que añadir un esfuerzo más para mejorar las interfaces, de manera que cualquier niño o niña con discapacidad tenga la misma accesibilidad que todos, para mejorar sus procesos de aprendizaje, Chacón (2007) establece que si se planifica la introducción de las TIC, en el campo de la atención a las necesidades educativas especiales, desde un punto de vista que no se busque la normalización, sino como una herramienta que contribuye al desarrollo personal, y el disfrute de su propia individualización, participando activamente en su entorno. Estos cambios permitirán que las personas con discapacidad desarrollen de esta manera una vida más plena, autónoma, aumentando su dignidad y su autoconsideración.

Uno de los principales problemas de esta modalidad educativa en el Estado de Chihuahua, es la cobertura y distribución de los servicios, al igual que la calidad de la atención que recibe la población infantil y adolescente. En esté sentido la Secretaria de Educación Publica reconoce que el personal que realiza labores de apoyo técnico pedagógico, no tienen definido el rol que desempeñan, se 
improvisa, se le releva constantemente y carece, en muchos de los casos de preparación específica y competencias mínimas para llevar acabo la formación docente en servicio (SEP, 2003), admitiendo además que una parte importante del tiempo de los Asesores Técnico Pedagógicos (ATP), adscritos a la supervisión de zona y jefaturas de sector se dedican a labores administrativas y sólo de manera excepcional atiende las demandas de asesoría y acompañamiento, por lo que no se ha logrado impactar en las condiciones para el aprendizaje de los directivos y docentes, mucho menos en la transformación de sus prácticas. Además en la modalidad de la Educación Especial en el Estado de Chihuahua, se presenta la dificultad de la ubicación de las 19 zonas escolares y los servicios en el Estado, abarcando 28 comunidades dificultando el acompañamiento en las actividades de asesoría y capacitación de los ATP, Estatales, Regionales y de zona.

Durante más de una década la autora de este trabajo ha tenido la oportunidad de trabajar en la modalidad de Educación Especial en el Estado de Chihuahua, atendiendo diferentes funciones como maestro, directivo, subjefe operativo, y ATP Estatal, etc., lo que ha permitido tener una visión amplia del funcionamiento de la modalidad en el Estado, en relación al impacto de la asesoría y capacitación de los diferentes profesionales, en la atención de los alumnos con necesidades educativas especial de los diferentes servicios. La asesoría técnica que se proporciona a los diferentes profesionales no es suficiente, al igual que el seguimiento, debido por un lado, a que la estrategia de capacitación y actualización es en corresponsabilidad, esto es, que solamente algunos de los servicios por zona se capacitan directamente por los ATP Estatales y la implementación de dicha capacitación, así como el seguimiento a la misma, queda a cargo en segundo lugar de ATP de región y de zona escolar, que a su vez realizan la asesoría y capacitación directa en ocasiones a todos o algunos de los servicios, al igual que el seguimiento, de tal manera que tanto la capacitación, como el seguimiento, quedan a cargo principalmente del directivo del servicio correspondiente, por otro lado, influye de manera significativa también la falta de recursos humanos, materiales y financieros, para la realización de las visitas de asesoría, capacitación, acompañamiento y seguimiento, tomando en cuenta las distancias que hay entre cada comunidad de el Estado . 
En definitiva, al aunar nuestra inquietud investigadora de mejorar la asesoría técnica pedagógica y el uso de las TIC, lo que pretendemos es que nuestro estudio ofrezca posibles líneas de actuación en el camino de la asesoría técnica de Educación Especial, propiciando en la práctica, por medio de la utilización de las TIC, una mejor calidad en los procesos de asesoría y capacitación de los diferentes profesionales de la modalidad de Educación Especial del Estado de Chihuahua en México, de tal manera que se logren establecer las condiciones de aprendizaje y autoaprendizaje, de los directivos, docentes y demás profesionales, de tal manera que se transformen su práctica.

\section{Objetivos del estudio y desarrollo de la investigación}

Como se puede deducir en las razones expuestas anteriormente, el objetivo principal de este estudio ha sido la desarrollar, una propuesta de optimización y mejora de la asesoría técnica en la modalidad de Educación Especial a través del uso de las TIC, diseñando para ello un recurso digital en la red.

Ante tal perspectiva y según se especifica en el apartado referido a la metodología y al diseño de la investigación, el punto de partida ha consistido en la realización de un análisis documental de contenido de los documentos oficiales afines a la Política Educativa de la modalidad de Educación Especial en el Estado de Chihuahua, en relación al uso de las TIC, desde una visión educativa, para ellos se seleccionaron los documentos nacionales y estatales, referidos a Leyes de Educación, Leyes de para las Personas con Discapacidad, Programas Educativos y Programas de Fortalecimiento de la Educación Especial y la integración educativa, del periodo de 1996 a 2010.

La siguiente fase ha consistido en enviar un cuestionario a diferentes profesionales de las 19 zonas de Educación Especial, para recabar la información necesaria que nos permita poner de manifiesto el estado actual de Educación Especial, en relación a los aspectos técnicos operativos, así como el impacto en la capacitación y actualización de la asesoría técnica. 
En esta fase hemos realizado una investigación y análisis de los recursos digitales en la red que están orientados a la capacitación y actualización de los docentes en el ámbito de la Educación Especial principalmente, en cuanto a su diseño, propósitos, contenido, recursos y herramientas que proporcionan.

En la siguiente fase, nos dimos a la tarea de investigar las condiciones y requisitos necesarias para diseñar un recursos digital oficial, como son; colores, logotipos, correo electrónico, contenido, objetivo, presentación, etc., para continuar con diseñar un recurso digital en red para el Departamento de Educación Especial de los Servicios Educativos del Estado de Chihuahua, como una propuesta para apoyar los procesos de capacitación y actualización de la asesoría técnica de los diferentes profesionales.

La fase siguiente fue la implementación del recurso digital diseñado, el cual se instalo desde el servidor de los Servicios Educativos del Estado de Chihuahua, previa solicitud de autorización por parte de la jefa del Departamento de Educación Especial.

Una vez instalado el recurso digital en red, pasamos a la evaluación del diseño del mismo por parte de expertos en el tema de TIC y de Educación Especial, por medio de la selección y adecuación de una encuesta que permitió valorar aspectos funcionales, técnicos y pedagógicos del diseño del sitio web, dando como resultado entre otras cosas, la necesidad de ampliar y diversificar los recursos, mejorar la ejecución, la presentación y la calidad de los elementos multimedia, etc.

Después en esta fase, hemos recogido la opinión de diferentes profesionales de Educación Especial del Estado, en relación a la utilidad del sitio web, por medio de la selección y adecuación de una encuesta, evaluando los aspectos funcionales, técnicos y estéticos y pedagógicos de la utilidad del sitio web, para la optimización de la asesoría y capacitación de la asesoría técnica en Educación Especial.

Es, no obstante, el contaste entre los datos obtenidos, en una y otra búsqueda, y la utilización de diferentes técnicas metodológicas, lo que nos van a dar la clave de la utilidad de el uso de las TIC en la Asesoría Técnica. 


\section{Sinopsis y estructura de la tesis}

El contenido del estudio se refleja al hablar del mismo en los puntos anteriores, no obstante, a continuación pasamos a exponer la sinopsis de cada uno de los capítulos de esta tesis.

En capítulo 1 se presentan presupuestos teóricos relacionados a la importancia de las Tecnologías de la Información y de la Comunicación (TIC) en la sociedad actual del conocimiento, para después hacer una relación con las TIC en el ámbito educativo, después se abordan aspectos relacionados al binomio TIC y Educación Especial, planeando aspectos específicos relacionados a los aspectos técnicos en la en la atención de las necesidades educativas especiales principalmente asociadas a la discapacidad, utilizando la asistencia tecnológica, además que se presenta una segunda parte donde se presentan una serie de propuestas e investigaciones, sobre la utilización de las TIC en atención especifica de áreas de discapacidad y relacionadas a las necesidades educativas especiales, además de sugerencias para los padres y aspectos relacionados a la accesibilidad de los sitios web, por ultimo en una tercera parte se abordan aspectos relacionados a las TIC y la formación continua, especificando temas relacionados a la asesoría técnica y la formación con y para las TIC, de profesionales en el ámbito educativo.

El capítulo 2 presenta información relacionada al contexto donde se desarrollo la investigación, primeramente con una reseña de la Política Educativa que sustenta la Educación Especial en México, tomando en cuenta los planteamientos Internacionales, Nacionales y Estatales, sobre la operatividad de los servicios, establecidos en documentos legales y en Programas Educativos, también presentamos un panorama general, estableciendo el contexto social, económico, organizacional y funcional, de la modalidad de la Educación Especial del subsistema federalizado en el Estado de Chihuahua, con información sobre las características del Estado, para después ir adentrándonos en los aspectos técnicos y operativos de la Educación Especial, relacionados a la operatividad y funcionamiento de los servicios escolarizados, de apoyo y de orientación que la integran. De igual 
manera consta de una segunda parte de aspectos técnicos y operativos de la formación continua de los diferentes profesionales, y la participación, organización e impacto, de los Asesores Técnicos Pedagógicos en los procesos de capacitación y actualización, de los diferentes niveles y modalidades de Educación Básica, entre ellos específicamente Educación Especial, así como los problemas y necesidades que se presentan.

Los capítulo 3 y 4 están destinados a detallar el diseño experimental que se lleva a cabo y que pertenece a una investigación educativa cuantitativa y cualitativa, por medio de los siguientes pasos: 1) Identificación del problema y diagnostico, 2) Formulación de las hipótesis, 3) Planificación de las estrategias, 4) Instrumentos de obtención de la información, 5) Recogida de datos, 6) Análisis e interpretación de datos y resultados, 7) Confirmación o refutación de hipótesis, 8) Conclusiones y propuestas de futuras investigaciones.

El capítulo 3 recoge los 4 primeros pasos del desarrollo del mismo, que van a ser los siguientes; la identificación del problema por medio de los instrumentos apropiados y formulación del diagnostico, en segundo lugar desarrollar una propuesta de solución y en base a ésta hacer la formulación de las hipótesis, la planificación de estrategias, primeramente conociendo el planteamiento de la Política Educativa de la Educación Especial en relación al uso de las TIC, desde el punto de vista educativo, así como el contexto técnico operativo y el impacto de la asesoría técnica, diseñando y evaluando la propuesta de mejora y optimización de la asesoría y capacitación en Educación Especial. Por ultimo establecer los diferentes instrumentos de obtención de la información.

El capítulo 4 aborda la metodología de investigación utilizada, exponiendo los resultados obtenidos y la interpretación que se puede hacer de ellos, esto último se realiza en distintas fases. En primer lugar se ofrece un análisis de contenido cualitativo de la Política Educativa de la modalidad de Educación Especial, en relación a la utilización de las TIC desde una visión educativa. En segundo lugar, se aplica un análisis descriptivo cuantitativo y de contenido cualitativo, sobre la operatividad técnica de los servicios de Educación Especial y el impacto de la asesoría técnica. En tercer lugar se hace un análisis 
estadístico descriptivo de los datos cuantitativos, relacionados por un lado, a la evaluación del diseño del sitio web, por expertos y por otro lado, a la evaluación de la utilidad del sitio web, por profesionales de Educación Especial como usuarios del mismo.

En el capítulo 5 a la vista de las interpretaciones de los resultados, se confirman las hipótesis de partida y para finalizar se recogen las conclusiones, así como recomendaciones en relación al tema y a futuras investigaciones. 


\section{MARCO TEÓRICO}

\section{CAPÍTULO 1: LAS TECNOLOGIAS DE LA INFORMACIÓN Y LA COMUNICACIÓN EN EDUCACIÓN ESPECIAL}

El tema central de la presente tesis es el uso de las TIC en la Asesoría Técnica. Una propuesta de mejora y optimización de la asesoría y capacitación en la Educación Especial en el Estado de Chihuahua México, por tanto para situar esta investigación, es importante situar las TIC dentro de la educación y específicamente en la Educación Especial. Para tal fin, comenzaremos este capítulo examinando la importancia de las TIC en la sociedad actual del conocimiento, para después hacer una relación de las mismas en el ámbito educativo, luego entrar a abordar aspectos importantes del uso de las TIC en el aula, después se aborda de manera especial y especifica el binomio TIC y Educación Especial, presentando la utilidad del uso de las tecnologías de apoyo para las personas con discapacidad, presentando una serie de investigaciones y propuestas específicas para personas con discapacidad o necesidad educativa especial, de igual manera se presentan sugerencias para los maestros y padres de familia, sobre la importancia de las TIC y el uso que se le puede dar dentro de la Educación Especial. Por ultimo se aborda el tema de la asesoría técnica y la formación continua en Educación Básica y los beneficio que aportan las TIC.

\subsection{La Tecnología de la Información y de la Comunicación.}

Las llamadas Nuevas Tecnologías en las últimas décadas del siglo XX han sido la causa de la llamada Revolución Digital, que a diferencia de otras ha conseguido que los cambios y las transformaciones derivados de lo que se llama Tecnología de la Información y de la Comunicación (TIC) se hayan producido rápidamente en todos los ámbitos de la sociedad. Representando hoy en día una fuerza determinante del proceso de cambio social, surge como un sostén de un nuevo tipo de sociedad, como lo es la sociedad de la información y la civilización cognitiva (Pozo, Martín y Puy, 2002). 
Se denomina Tecnología de la Información y las Comunicaciones (TIC) al conjunto de tecnologías que permiten la adquisición, producción, almacenamiento, tratamiento, comunicación, registro y presentación de informaciones, en voz, imágenes y datos contenidos en señales de naturaleza acústica, óptica o electromagnética (García-Valcárcel ,2003).

Las tecnologías se refieren a tres dominios distintos como son: el procesamiento, almacenamiento y búsqueda de la información realizados por la computadora; el control y automatización de máquinas, herramientas y procesos, incluyendo la robótica; y la comunicación incluyendo la transmisión y circulación de la información de maneras gráficas en video o impresas.

La economía actualmente depende y se apoya principalmente en la tecnología, prestando servicios a través de Internet y de las comunicaciones, al realizar la comercialización de productos electrónicamente, de igual manera que son utilizadas por aquellas empresas que desarrollan contenidos, entretenimiento y software. Han logrado invadir nuestro mundo, no solo en el sector empresarial. Las TIC han originado un cambio, una revolución en muchos profesionales y actividades como son: la investigación científica, la práctica médica, las empresas, el periodismo, la administración pública, la producción artística, etc. Estas actividades se pueden realizar por una sola persona, utilizando una computadora y sus respectivos dispositivos periféricos.

En la educación, las TIC así como apoyan también generan problemas, como con los software que ofrecen y prometen mucho, pero que dan muy poco, pagando una gran cantidad por ellos, para después descubrir que no son útiles para los objetivos y/o propósitos que fueron diseñados, sobre todo son las expectativas y mitos que se han creado de su uso lo que han generado los problemas, por ello es necesario conocer realmente el alcance y las implicaciones de todo tipo de estas tecnologías.

\subsection{Las TIC en la Educación}

Las tecnologías han transformado los lugares de trabajo, las comunicaciones y actividades comerciales, sociales, políticas etc. por lo que es necesario que los cambios sean comparables en las escuelas. Por ello los apoyos que se están estableciendo para sustentar la reforma educativa se va concretando poco a 
poco, a la vez que se aprovechan las experiencias de los proyectos y de las instituciones educativas que han puesto en marcha innovaciones tecnológicas, como el Programa Enciclomedia de México. Este programa ofrece una estrategia educativa basada en un sistema articulador de recursos que, mediante la digitalización de los libros de texto, ha vinculado a sus lecciones diversos materiales multimedia con la finalidad de mejorar las formas de enseñar y de aprender, así como fomentar el uso de las TIC como un recurso de apoyo para el aprendizaje, en educación básica, entre muchos otros programas.

El Internet se ha desarrollado y se ha incorporado a la vida de los ciudadanos de una forma vertiginosa. Los efectos que el Internet y sus múltiples aplicaciones tienen, tanto en la vida de los ciudadanos, como en las empresas, en las instituciones y en los gobiernos, se han manifestado en menos de una década. Se observan a nuestro alrededor muchos cambios en la forma de comunicarse, de organizarse, de trabajar o de divertirse, convirtiéndose en una sociedad que se caracteriza por la posibilidad que tiene de acceder a volúmenes enormes de información y de conectarse y comunicarse con otros colectivos o ciudadanos sin límites de espacio y de tiempo. Las tecnologías no son por si mismas determinantes en la historia y la evolución social, hay más bien una relación de interdependencia entre la tecnología y la sociedad, porque la tecnología para que nazcan, necesita un contexto social especifico, y a la vez con su presencia, se configuran nuevos modelos sociales, culturales, y económicos. Las tecnologías no son autónomas ni independientes de los factores y fuerzas sociales que las han creado, llegando a configurar nuevas formas de relación (Cabero, 2004).

La escuela como organización social es una realidad social, construida por los miembros que la integran, a través de los procesos de interacción social y en relación con los contextos y ambientes en que funciona. Como organización constituida de este modo, la escuela genera estructuras, roles, normas, valores y redes de comunicación informales a su interior (Bautista, 1994).

La tarea de lograr la calidad de la educación, no solo depende de los profesores, sino también de las autoridades educativas. Por ello la dirección escolar debe motivar, promover la utilización de los recursos existentes por 
toda la comunidad educativa. Los recursos son medios que contribuyen de manera importante en la calidad de la educación.

En este sentido el Programa Sectorial de Educación de la Secretaria de Educación Pública 2007-2012, enuncia que México debe hacer de la educación, la ciencia y la tecnología los pilares de su desarrollo, dependiendo de ellas la calidad de vida de la población. En la misma línea, el Programa Nacional de Educación 2001-2006, en su enfoque educativo, establece que el Sistema Educativo para el 2025 será organizado en función de los valores de equidad y calidad, brindando una educación pertinente a toda la población del país, incluyente e igualmente formativa, que constituya el eje fundamental del desarrollo cultural, científico, tecnológico, económico y social del país. Algunas de las concepciones pedagógicas que se enuncia en dicho programa son relacionadas con la equidad y calidad, con que funcionará el enfoque educativo del siglo XXI siendo:

- Efectivas; porque los aprendizajes de los estudiantes serán el centro de la atención asegurando el dominio de conocimientos, habilidades y valores.

- Innovadoras; no solo por integrar las TIC, sino porque serán utilizadas con un enfoque pedagógico, los educadores se actualizaran permanentemente y las instituciones aprenderán, las innovaciones serán un componente natural de la educación, las aulas no serán solo los lugares de aprendizaje, se enlazarán con redes de información y comunicación multimedia.

En el Programa Sectorial de Educación 2007-20012 se presentan los resultados del programa 2006, en cuanto a equipamiento y capacitación de las TIC en Educación Básica, informando que el porcentaje de las aulas de medios equipadas con telemática educativa para primaria y secundaria se realizo en un $51.9 \%$, y se plantea completar el $100 \%$ para el año 2012 . El porcentaje de docentes de primaria y secundaria, capacitados en el uso educativo de tecnologías de la información y la comunicación en el aula era hasta el 2006 de $24.2 \%$, y de igual manera para el 2012 se pretende capacitar a un $75 \%$ de docentes. 
Las tecnologías de la información y la comunicación representan un hecho evidente en nuestra sociedad, ya que su difusión nos conduce a importantes reformas y mejoras en la calidad de vida de las personas.

En el Programa Nacional de Educación 2001-2006 se establece que la educación debe constituir el eje fundamental del desarrollo social, cultural, científico tecnológico económico y político de la nación apoyándose en los principios fundamentales de:

- Educación para todos

- Educación de calidad

- Educación de vanguardia.

Apoyándose en estos principios, el Programa de Estatal de Educación del Estado de Chihuahua 2005-2010 plantea una educación de calidad para todos, generando las condiciones que permitan proveer y optimizar la infraestructura y el equipamiento, impulsando el desarrollo y aplicación de la ciencia, la tecnología y la innovación en la Educación Básica, considerando que uno de los cambios acelerados y sin precedente en la sociedad actual son las TIC, así como la acumulación y diversificación del conocimiento.

La tecnología en la actualidad se considera un instrumento muy útil para mejorar la calidad de la educación, sin embargo la tecnología no es ni el fin, ni la respuesta a todos los problemas educativos, su uso requiere un proceso de selección y de decisiones con respecto a qué tecnología es la más apropiada, quién la utilizara y para qué, así como también es importante saber para que tipo de contenidos. Si su uso está bien analizado, organizado, planeado y se encuentra sujeto a evaluación y renovación permanente, por los cambios o adecuaciones que requiera, la tecnología puede ofrecer posibilidades de mejorar la calidad de la educación, ya que el uso de la tecnología motiva al alumno a ser mucho más creativo utilizando más su imaginación, también ofrece nuevas oportunidades de aprendizaje, como puede ser la enseñanza en línea, por sistemas audiovisuales y otros medios.

Al relacionar la educación y la tecnología, destaca la importancia y necesidad de que los docentes tomen la iniciativa en la investigación en el campo de la educación y brinden nuevas maneras de aprender, en lugar de esperar que se les diga que hacer y cómo deben hacerlo. 
Las transformaciones científico-tecnológicas requieren analizar los cambios educativos que se consideran necesarios en nuestro país y en nuestro cada vez más globalizado mundo, el sistema educativo se caracteriza por una fuerte inercia que dificulta su adaptación a una realidad cambiante. Dicha inercia puede resultar grave en un momento en que las transformaciones científicotecnológicas han adquirido una aceleración, que modifica profunda y permanentemente nuestras vidas (Ramonet, 1997).

La globalización de las nuevas tecnologías de la información y la comunicación, no se puede traducir por si misma en igualdad de oportunidades de las personas, los grupos y los países, solamente para aquellos grupos y países que ya gozan de oportunidades en igualdad de condiciones. En este sentido la escuela como institución debe cumplir el papel que la sociedad le asigna, pero adaptándose al contexto social y tecnológico en el que se desarrolla, resulta especialmente importante que dentro de los sistemas educativos públicos se posibilite tanto el aprendizaje, como la formación, en y con las TIC (García-Valcárcel, 2003).

Es indudable que las TIC llegaron a la educación para quedarse, siendo importante aceptar los retos y oportunidades que representan y enfocar su uso en su propia dinámica. Además es necesario darse a la tarea de rediseñar programas y didácticas específicas para emplearlas integralmente, partiendo de investigaciones serias que retroalimentar su aplicación y delimitar con mayor claridad sus logros.

Una de las necesidades para el uso de las TIC, que el Programa Nacional de Educación 2001-2006 se plantea, es la de abrir un amplio debate sobre el papel de las TIC y en especial de los medios de comunicación, con el fin de definir una política nacional que permita orientar las potencialidades de las nuevas tecnologías en beneficio de la sociedad y el desarrollo nacional.

La relación que se ha establecido entre la educación y las transformaciones científico-tecnológicas, aparece como una relación compleja, que va abriendo perspectivas para el desarrollo de los seres humanos, pero que, sin embargo, encierra también peligros a los que debemos atender $y$ hacer frente, reflexionando críticamente acerca de cómo la institución escolar y sus prácticas curriculares, pueden hacerse permeables a los cambios que está generando la 
presencia masiva de las llamadas nuevas tecnologías de la información (San Martín y Salinas, 1997).

Una realidad que no podemos negar del sistema educativo es la diversidad de características de los centros escolares que van más allá de de las contextuales. Se presentan, por lo general, diferencias relacionadas con la infraestructura escolar, la formación de los docentes, el papel del director, el acercamiento con la comunidad, la población escolar, el trabajo académico, entre otras. Conforme las instituciones vayan incorporando las TIC en este contexto, será necesario también construir espacios de innovación y de comunicación, que favorezcan la expresión de creatividad, la reflexión crítica y realización de proyectos.

Todo proyecto curricular que quiera promover nuevos valores educativos necesita tanto de cambios organizativos, como también la definición de roles. Por tanto la innovación está ligada al desarrollo del currículo y a la evaluación del mismo. La innovación educativa es una forma más plena, un cambio dentro de las escuelas en la forma de proceder dentro de los procesos de enseñanza y aprendizaje, en la interpretación y comprensión de los diversos contextos, significados e implicaciones de los procesos de cambio, que suponen cambios en la organización o de coordinación, originalidad, especificidad, indagación colectiva por medio del dialogo, la reflexión y el análisis crítico. De manera comprometida se puede definir la innovación como cambios no sólo en los materiales, sino en las prácticas pedagógicas y en las teorías que los sustentan.

No se trata de que los materiales didácticos multimedia y los entornos virtuales de aprendizaje vayan a remplazar la figura del profesor o la enseñanza presencial, es necesario y razonable no negar las posibilidades de estos recursos con los cuales se enriquece la actividad docente, integrándolos donde resulten más eficaces, compaginándolos con otros recursos y modos de realizar las actividades planeadas.

Corresponde a las autoridades responsables de la educación impulsar el cambio, facilitando los medios y las infraestructuras necesarias, dotando por ello a los centros de aulas de informática y promoviendo la formación de los profesores. De igual manera es misión de las autoridades educativas diseñar, 
desarrollar y mantener portales educativos, que proporcionen a los miembros de la comunidad educativa docente, los recursos didácticos necesarios.

Las autoridades educativas y los directivos de los centros, tienen un papel importante en la consecución del cambio que supone la integración del potencial de los recursos digitales en la actividad docente, sin embargo, son los docentes los que tienen en sus manos que el cambio llegue a materializarse. Sólo con al integración real de los recursos, así como la coherencia entre mensajes y práctica, se podrá evolucionar en el modelo educativo para equipararlo a los cambios socioculturales que la sociedad esta viviendo desde el siglo XX. Bax (2003) plantea el concepto de normalización para referirse al momento que está por llegar, más o menos próximo, donde la tecnología educativa se encuentre perfectamente integrada en la actividad docente, dentro y fuera del aula, de manera que pase desapercibida.

\subsubsection{Las TIC en el Aula}

La situación social actual se caracteriza por nuevos modelos familiares, nuevos entornos profesionales y una mayor diversidad del alumnado, exigiendo un nuevo sistema educativo que regido por el principio de igualdad de oportunidades y no discriminación, dé respuesta a la nueva sociedad de la información en la que vivimos, donde la implementación y uso de las TIC se plantean cambios profundos en la educación.

Gobiernos y educadores en su mayoría han reconocido que la utilización de las TIC en la enseñanza mejora su calidad. Sin embargo, no sólo se trata de enseñar $y$ formarse en habilidades y destrezas que son necesarias para desenvolverse con soltura, sino dar un paso más y entender que utilizar las TIC en el aula implica seleccionar algunas herramientas que ofrecen las TIC y usarlas desde una perspectiva pedagógica, no como un complemento de la enseñanza tradicional, sino más a fondo, como una innovación, donde se incorporen la tecnología en el currículo, propiciando mejorar los procesos de enseñanza- aprendizaje y los progresos escolares de los alumnos.

No se trata de trasmitir sólo datos predeterminados para que el alumno los reproduzca, se trata de enseñar a aprender a lo largo de toda la vida, para ello 
es necesario trasmitir capacidades o habilidades que permitan al alumno adaptarse a una sociedad en constante evolución y movimiento.

Al respecto García -Valcárcel (2003) propone que para la integración de las TIC es preciso el análisis de los aspectos didácticos y organizativos a nivel de aula, ciclo, centro, y para ello los elementos claves son tanto la interpretación del potencial curricular, como la propia toma de decisiones.

La teoría e investigación en el campo de la educación han proporcionado una importante fuente de ideas para implementar metodologías de enseñanza y aprendizaje, donde se aprovechen los recursos y entornos tecnológicos de forma efectiva. De igual manera los adelantos en otras ramas como la psicología cognoscitiva han incrementado la comprensión sobre la naturaleza del desarrollo intelectual y han mantenido como base los ambientes necesarios para favorecerlo. Educadores y psicólogos (Resnick, 1989; Carretero, 1993; Pozo, 1994; Lipman, 1998; Meece, 2000) establecen un acuerdo acerca de que las habilidades avanzadas de comprensión, el razonamiento, indagación, composición y experimentación, no son adquiridas a través de la transmisión unilateral de hechos, sino a través de la interacción del propio aprendiz con el objeto de conocimiento. El aprendizaje centrado en el alumno, dentro de la propuesta constructivista, se presenta en una propuesta educativa, cuyo propósito central es el desarrollo de las habilidades básicas dentro de los contextos, con la puesta en práctica de procesos de pensamiento de experto, modelados y construcción de imágenes mentales, mediante la colaboración y los apoyos externos necesarios, permitiendo a los alumnos logros intelectuales.

La educación obligatoria en México es la Educación Básica, que incluye a los niveles de educación preescolar, primaria y de secundaria. El Estado debe asegurar que todos los educandos accedan a la escuela, permanezcan en ella, egresen con oportunidades de cada nivel educativo, garantizando también la igualdad de oportunidades para aprender. Se ha de conseguir que todos los educandos logren los aprendizajes propuestos en el currículo nacional, referidos al desarrollo de competencias para la vida. Que se sustentan en un conjunto de conocimientos, habilidades, actitudes y valores. Las modalidades de la Educación Básica como la Educación Especial de igual manera, tienen como misión responder a los requerimientos y condiciones de los diferentes sectores de la población a fin de lograr los propósitos establecidos. 
Los nuevos objetivos educativos plantean la necesidad de dotar a los alumnos de las capacidades y de los conocimientos necesarios para aprovechar al máximo las posibilidades de las TIC. Marqués (2007), sintetiza tales habilidades y conocimientos en:

- Saber utilizar las principales herramientas de Internet.

- Conocer las características básicas de los equipos.

- Diagnosticar qué información se necesita en cada caso.

- Saber encontrar la información.

- Saber resistir la tentación de dispersarse al navegar por Internet.

- Evaluar la calidad y la idoneidad de la información obtenida.

- Saber utilizar la información.

- Saber aprovechar las posibilidades de comunicación de Internet.

- Evaluar la eficacia y eficiencia de la metodología empleada.

Estas habilidades y conocimientos permitirán que los alumnos se familiaricen pronto con las TIC y les saquen partido, siendo también necesarias para el aprendizaje a lo largo de la vida, importantes y necesarias en una sociedad en constante cambio.

Las tecnologías y la reforma no necesariamente van de la mano, los resultados de la tendencia en abanderar la tecnología educativa aseguraban que la introducción de las tecnologías en el aula iban a lograr revolucionarla, como la televisión en los años sesenta, computadoras en los años setenta, videodisco e inteligencia artificial en los noventa, pero no ha sido así. La investigación informa de proyectos específicos donde se participo con la tecnología, con la idea de cambiar la escuela o el aula, encontrando que los equipos se guardaban en un armario o que utilizaban la tecnología para hacer las mismas cosas que tradicionalmente habían hecho (Trahtemberg, 2002).

Al usar los procesadores de palabras y de manejo de información los alumnos pueden encontrar vías que les permitan observar de cerca cómo el conocimiento se ha ido desarrollando a través de la historia y tener acercamientos a las áreas que sean de su mayor interés. Las posibilidades de expresión y de comunicación de los alumnos pueden mejorar notablemente si se aprovecha positivamente el acceso a la información. 
La enseñanza y el aprendizaje se deben convertir en un proceso continuo de traducción de lenguajes, códigos y canales, del visual al verbal, del audiovisual al escrito y viceversa. La comunicación se enriquece, los conocimientos se consolidan, la información que se adquiere fuera del aula se integra en la que se trabaja dentro de ella (Prats, 2000).

En la última década, los estudios de usos institucionales de la tecnología han tomado un nuevo giro, mostrando los efectos que la tecnología produce en los procesos de enseñanza y aprendizaje, así como también la transformación de los roles de los actores primordiales del proceso educativo en el aula. Las investigaciones sobre el tema reportan que cuando se utiliza, de manera que es compatible con el estudiante, la tecnología apoya los tipos de cambios que una reforma actual de la educación promueva, tomando en cuenta los papeles de los actores educativos, el clima de organización de la institución escolar, la gestión escolar, la comprensión de los resultados educativos de parte de la sociedad, el logro de los aprendizajes, el aprendizaje, etc.

En ocasiones se presupone que es posible prescindir del profesor y de la interacción social en el aula. Sin embargo el profesor desempeña un papel fundamental en el aula, no está acotado al proceso de enseñanza, sino que también se relaciona con la construcción de las relaciones afectivas y emocionales que se llegan a establecer con los alumnos, de igual manera que la constante negociación de los significados que se van realizando con el profesor. Al respecto Pozo (1994) promueve que la interacción de los alumnos con sus colegas es igualmente esencial para un adecuado desarrollo cognitivo y afectivo. El profesor puede utilizar Internet en el aula para complementar, para enseñar su asignatura, o para reforzar el trabajo de algunos alumnos que tengas dificultades, pudiendo apoyarse en los materiales existentes o creando los suyos tomando en cuenta los propósitos y necesidades de los alumnos.

Las TIC han servido también para introducir una nueva práctica escolar relacionada con aspectos del curriculum, como es la evaluación que se aplica de manera tradicional, con la intención de comprobar los aprendizajes de los alumnos. Pero lejos de provocar alteraciones en el fondo del currículo y en la vida escolar, estas tecnologías son utilizadas más como un asunto que se consideran de manera habitual. Es necesario que los profesores tengan conocimientos de cómo, para qué y cuando utilizarlas. Pueden ser 
contempladas en la escuela como una herramienta de trabajo, en actividades profesionales de naturaleza técnica, administrativa, y en la investigación científica. Existen muchos programas para uso profesional que son de aprendizaje, relativamente simples, que permiten realizar una amplia variedad de tareas, como el procesamiento de un texto, una hoja de cálculo, las bases de datos, y los programas de presentación, tratamiento de imagen, y tratamiento estadístico de información. Hay otros programas, concebidos específicamente, centrados en la enseñanza de algunos contenidos, que se pueden utilizar para explorar e investigar. Las TIC permiten ser utilizadas de manera libre y creativa por profesores y alumnos, en la realización de las diversas actividades.

La utilización efectiva de las TIC en el aula implica un profundo cambio en ella. De Basterrechea (2004) establece que las aplicaciones didácticas de las tecnologías digitales están imponiendo, casi sin darnos cuenta, un cambio radical en la manera de abordar la práctica docente. Por una parte requiere la revisión de los contenidos de los cursos y el diseño de estrategias didácticas específicas, que permitan tanto al profesor como al alumno, posibilidades de interacción al máximo (Ogborn y Millar, 1994). Se requiere una renovación de la dinámica del aula, en donde la actividad sea un trabajo colaborativo, la presencia de la tecnología implica un cambio en los roles tradicionales entre los alumnos de un grupo y donde el profesor sea capaz de escucharlos, ayudarlos, apoyarlos oportunamente.

Demandas largamente expuestas en el plano teórico, como la importancia de centrar la actividad didáctica en el alumno, de estimular su capacidad para construir conocimientos significativos, de fomentar el desarrollo de su autonomía, de atender a su estilo y ritmo de aprendizaje, a sus necesidades, dificultades e intereses específicos, en definitiva, de flexibilizar y adaptar la oferta a las características de la demanda cada vez es más compleja, exigente y variada, pueden abordarse en la práctica de manera más eficaz gracias a las posibilidades de la tecnología educativa. Implica también una reflexión y reconsideración del significado y formas de evaluación donde se aprovechen eficazmente las capacidades que ofrecen las TIC. Sobre todo exige maestros bien preparados en sus disciplinas y motivados para enfrentar la capacitación 
continua que la dinámica del uso de la tecnología exige y políticas escolares que favorezcan esta capacitación (Stevenson y Hasell, 1994; Bonilla, 2000).

La información también puede ser trasmitida de manera oral. La imagen también era en gran medida el soporte de la información que llegaba a la mayor parte de habitantes. Hoy esto esta cambiando, en el campo profesional y académico, el soporte de la información evoluciona hacia sistemas multimedia, con un gran peso en las palabras escritas en algunos casos, pero con un peso creciente de la imagen en otros. La evolución hacia una sociedad audiovisual, dominada por los medios, especialmente por al televisión, en el mundo familiar y social ya se ha producido. La valoración de la información implica tener criterios de valor y habilidades para saber aplicarlos, cuestión que no es común en las prácticas pedagógicas.

La sociedad de la información y de la comunicación, impulsada por el avance científico y la voluntad de globalización económica y cultural, entre sus rasgos principales, tiene la extraordinaria penetración en todos los ámbitos de los medios de comunicación de masas, los ordenadores y las redes de comunicación. En esta la información, cada vez más audiovisual, multimedia e hipertextual, se almacena, procesa y trasporta sobre todo en formato digital, con la ayuda de las TIC. Es por ello que este nuevo contexto nos obliga a adquirir nuevas competencias personales, sociales y profesionales, aunque siempre han sido necesarias, hoy por hoy resultan imprescindibles.

En la siguiente figura se presentan con más detalles las habilidades que debemos cultivar clasificadas a partir de cuatro ámbitos (Delors, 1996; Marqués, 2006a; Morín, 1999; y Castells, 1997):

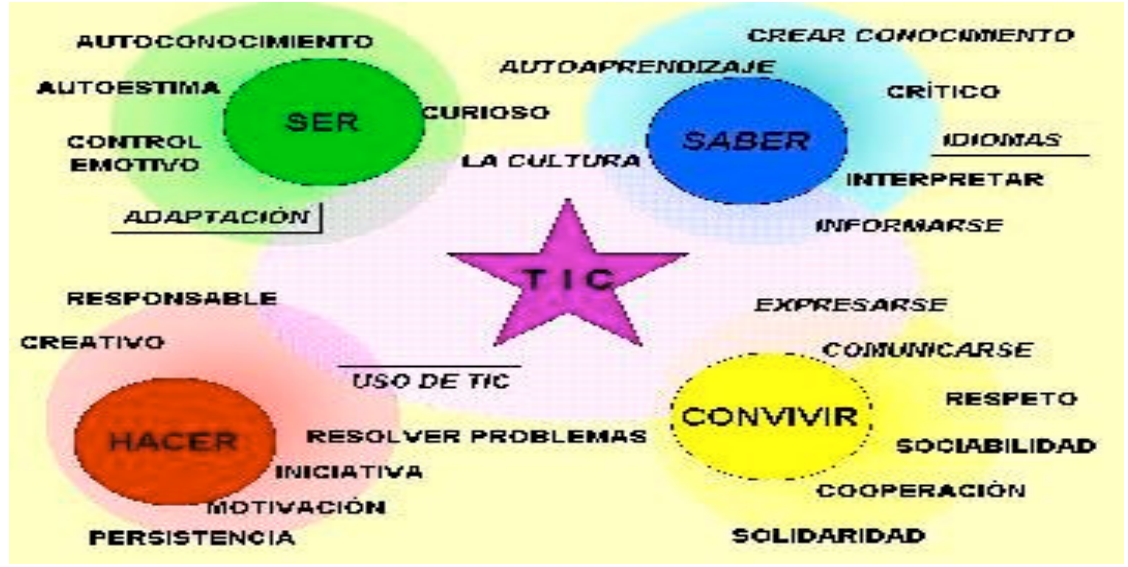

Figura 1 Habilidades que debemos cultivar (Delors, 1996; Marqués, 2006a; Morín, 1999; y Castells, 1997): 
- Aprender a ser, desarrollar la personalidad para actuar con una cada vez mayor capacidad de autonomía, de juicio y de responsabilidad personal.

- Aprender a saber, conocer, compaginar una cultura amplia con la posibilidad de estudiar a fondo los materiales y aprender a aprender para poder seguir este proceso a lo largo de la vida.

- Aprender a hacer, de tal manera que permita afrontar las diversas situaciones que se presenten.

- Aprender a convivir, a vivir juntos, conociéndonos y comprendiendo mejor a los demás, respetando las diferencias y las interdependencias que se producen a todos los niveles. También es necesario trabajar en equipo.

La Comisión Internacional sobre la Educación para el siglo XXI va más allá y afirma que el aprendizaje a lo largo de la vida, así como la participación en la sociedad del conocimiento, son elementos claves para enfrentar los desafíos planteados por un mundo en rápida evolución, haciendo hincapié en cuatro pilares del aprendizaje que son; aprender a vivir juntos, aprender a conocer, aprender a hacer y aprender a ser (ECD-TIC ,2008).

El gran momento tecnológico que vivimos, donde se pueden emitir materiales de contenido educativo a miles de sitios ubicados a cientos de kilómetros unos de otros, donde los alumnos puede ver y actuar recíprocamente en ambientes virtuales creados por las computadoras, en un mundo tridimensional artificial. Las herramientas que se utilizan para apoyar las aplicaciones de las computadoras pueden hacer posible que los alumnos puedan comunicarse con alumnos de otras partes del mundo, así como diseñar sus propios materiales con diversos programas.

Marqués (2006b) presenta las metas de aprendizaje asociadas a la alfabetización digital necesarias para todos los ciudadanos. 


\section{Competencias básicas en TIC}

- Conocimientos básicos del sistema informático: elementos del hardware, tipos de software, redes....

- Gestión básica del equipo: administración de archivos y carpetas antivirus...

- Uso del procesador de textos: correctores...

- Navegación por internet: búsqueda de y selección de información, telegestiones...

- Uso de correo electrónico.

- Creación, captura y tratamiento de imagen digital

- Elaboración de documentos multimedia: presentaciones, páginas web

- Conocimiento básico de la hoja de cálculo y las bases de datos.

Cuadro 1: Competencias Básicas en TIC (Marqués, 2006b).

En general, editoriales, universidades, colegios e instituciones educativas están impulsando en gran medida el desarrollo de materiales digitales para ser utilizados en el aula.

Peula, (2000) pone como ejemplos algunos títulos de programas de uso general, presentando el siguiente cuadro:

\begin{tabular}{|c|c|}
\hline Nombre & Descripción \\
\hline Serie ADIBÚ & $\begin{array}{l}\text { Entorno multimedia que abarca las áreas básicas de } 1^{\circ} \text { y } \\
2^{\circ} \text { de primaria. }\end{array}$ \\
\hline Serie A & $\begin{array}{l}\text { Entorno multimedia que abraca las áreas básicas de 3ํㅜ } \\
\text { de primaria hasta Secundaria. }\end{array}$ \\
\hline Leo-Leo & Lectoescritura. \\
\hline Serie Trampolín & $\begin{array}{l}\text { Actividades generales de Educación Infantil de } 2 \text { a } 6 \\
\text { años. }\end{array}$ \\
\hline La Gran aventura de las palabras & Actividades DE lenguaje para niños y niñas de 6 a 9 años \\
\hline Escribo con Pepo & Lectura y escritura. \\
\hline Serie PHONOS & Simulación y aprendizaje del lenguaje. \\
\hline Leer mejor & Lectura. \\
\hline Hamlet & Conceptualización fonológica. \\
\hline Serie PNTIC-98 & $\begin{array}{l}\text { Colección de } 2 \text { CDs donde se encuentran diferentes } \\
\text { programas relacionados con la comunicación. }\end{array}$ \\
\hline Creative Write & Procesador de textos para niños. \\
\hline Serie LALO & Estructuras sintácticas, morfológicas y juegos de lectura. \\
\hline
\end{tabular}


Para la creación de materiales, actualmente existen en el mercado reproductores de música, editor de video, de páginas web y de imágenes, herramientas para el diseño, para crear mapas etc. Algunos de los portales creativos son; EducaRed, Scoilnet, Inclusión Supporting Individual Learning Needs, Becta, etc., ponen a disposición del usuario información sobre programas y sistemas para desarrollar presentaciones y materiales interactivos.

\subsection{Las TIC en la Educación Especial}

Es indudable que las TIC, junto con otras tecnologías, están cambiando profundamente la sociedad en la vivimos, dentro de la educación sería importante primero establecer el sistema educativo que se requiere en esta sociedad actual, antes que establecer la utilización de esas tecnologías en el sistema educativo. Por una parte, se han estudiado como posibles instrumentos didácticos y se pone énfasis en las habilidades que se requieren para su óptima utilización. Sin embargo, es necesario reflexionar más a fondo sobre los modelos pedagógicos más idóneos o convenientes para usar estas tecnologías, cómo introducir las TIC en la enseñanza obligatoria, que se debe enseñar y cómo, cómo participa el maestro, cuáles son los apoyos que se pueden obtener con las TIC, etc.

Cuando se habla de TIC aplicadas a la educación y sobre todo a la educación especial tiene una implicación de mayor peso e importancia, dadas las necesidades que presenta esta población. Cabero (2001) señala que hablar de medios de comunicación y nuevas tecnologías aplicadas a sujetos con necesidades educativas especiales, es una doble necesidad, ya que estos sujetos se benefician de los medios utilizados en un marco general y, por otra, la necesidad de diseñar y producir medios específicos que puedan ser de gran ayuda y beneficio para las personas con necesidades educativas especiales.

Son innegables y bien conocidas las posibilidades que las tecnologías ofrecen para recabar información y contrastarla, para la retroalimentación, o algunas de ellas para simular y visualizar situaciones, y muy particularmente para conectar con el interés que los medios electrónicos despiertan en los alumnos (Barberá y Sanjosé, 1990). 
Las prácticas pedagógicas uniformes y homogeneizadoras no son validas, no todos los alumnos aprenden de la misma forma, no tienen la misma motivación, ni tienen las mismas capacidades, las TIC como herramienta permiten integrar diferentes sistemas simbólicos que favorecen y estimulan a los alumnos en su desarrollo integral. Es un cambio profundo en la metodología, que logre afectar la enseñanza, en la atención de las necesidades individuales de los alumnos, a través de la interactividad, fomentando el trabajo colaborativo y sobre todo que sea una metodología creativa y flexible que contempla la diversidad y las necesidades educativas especiales. Se trata de enseñar con TIC y a través de las TIC, además de sobre las TIC o de las TIC.

La posibilidad de poder simular con una computadora conductas inteligentes, ha conducido a modelos cognitivos de aprendizaje, denominados de "procesamiento de información" (Pozo, 1994), basados en la metáfora de la mente humana como sistemas computacionales. Esta ubicación teórica ha aportado cuestiones de sumo interés, sobre todo en lo referente a la comprensión de cómo se organizan los conocimientos adquiridos en la memoria a largo plazo y cómo se recuerdan estos conocimientos para utilizarlos en un momento determinado. Para algunos investigadores, los modelos de procesamiento de la información, junto con los modelos constructivitas, constituyen hoy las dos perspectivas fundamentales de la investigación y de la innovación en la enseñanza de las ciencias (Gruender y Tobin, 1991; Driut, 2003).

Las Normas Uniformes sobre la Igualdad de Oportunidades para las Personas con Discapacidad, de la ONU (1993), cuya finalidad es garantizar que niñas y niños, mujeres y hombres con discapacidad, como ciudadanos de sus respectivas sociedades, que pueden tener los mismos derechos y obligaciones que los demás, estableciendo que "Es responsabilidad de los Estados adoptar medidas adecuadas para eliminar esos obstáculos", "Las personas con discapacidad y las organizaciones que las representan deben desempeñar una función activa como copartícipes en ese proceso". "Es importante estimular el desarrollo y la fabricación de recursos auxiliares más sencillos y menos costosos, en lo posible, mediante la utilización de materiales y medios de producción local". "Las personas con discapacidad podrían participar en la fabricación de esos artículos". 
En este sentido la inclusión de estudiantes con necesidades educativas especiales (NEE), mejora cuando los centros tratan de responder a todos los aspectos de su diversidad. La educación inclusiva implica, de acuerdo a Booth y Ainscow (2000):

- Procesos para aumentar la participación de los estudiantes y la reducción de su exclusión, en la cultura, en los currículos y en las comunidades de las escuelas locales.

- Reestructurar la cultura, la política y las prácticas de los centros educativos para que puedan atender la diversidad de alumnos de su localidad.

- Se refiere al aprendizaje y a la participación de todos los estudiantes vulnerables que pueden ser sujetos de exclusión, no sólo aquellos con deficiencias o etiquetados como con necesidades educativas especiales.

- Se refiere a la mejora de las escuelas tanto para el personal docente como para el alumnado.

- La preocupación por superar las barreras para el acceso y la participación de un alumno en particular, puede ayudar a revelar las limitaciones más generales que presenta el centro a la hora de atender la diversidad de su alumnado.

- Todos los alumnos tienen derecho a una educación en su localidad.

- La diversidad no se considera como un problema a resolver, sino como una riqueza para apoyar el aprendizaje de todos.

- Se refiere al refuerzo mutuo de relaciones entre los centros escolares y sus comunidades.

- La escuela inclusiva es un aspecto de la sociedad inclusiva.

En la escuela inclusiva, se hace necesario contar con una diversidad de medios y recursos para responder a las necesidades de los que participan en ella y donde estos medios y recursos puedan adaptarse a las necesidades de los receptores de la comunicación (Cabero y otros 2000). En este contexto las TIC pueden llegar a ser un elemento importante para mejorar la calidad de vida 
de las personas con discapacidad, en algunos casos puede ser una de las pocas opciones de acceder al curriculum escolar, haciendo posible su comunicación, o facilitando su integración social y laboral.

La misión de la escuela sigue siendo complementar la educación familiar, preparando personas abiertas, equilibradas, con conocimientos básicos científicos y humanísticos de nuestra cultura, con actitudes y recursos procedimentales que les permita, paso a paso, completar su formación de acuerdo al proyecto de vida que decidan en esta sociedad cambiante (Marqués, 2008a).

\section{OBJETIVOS DE LA ESCUELA}

ABIERTA AL ENTORNO, INCLUSIVA Y COMPENSATORIA

- Desarrollo integral de las personas: desarrollo físico y salud, inteligencia e imaginación, emotividad y sentimientos, voluntad y capacidad de adaptación social....

- Culturización del estudiante: comprensión de las ideas, uso de los instrumentos (comunicativos, TIC, ciberespacio), forja de valores acordes a los tiempos y respetuoso con personas y culturas.

- Integración de los estudiantes en los entornos cultural y social (presencial y virtual), orientando su actuación social (felicidad y mejora de la sociedad).

- Preparación para el aprendizaje a lo largo de toda la vida.

Cuadro 3: Objetivos de la escuela (Marqués, 2008a).

Es importante tener presentes los siguientes conceptos relacionados con la Educación Especial como son (Marqués, 2008b):

- Deficiencia; pérdida o anormalidad de una estructura o función psicológica, fisiológica o anatómica.

- Discapacidad: restricción o ausencia (causada por una deficiencia) de la capacidad de realizar una actividad normalmente.

- Minusvalía: situación de desventaja de una persona que, a consecuencia de una deficiencia o discapacidad, tiene limitado o impedido el desarrollo de sus roles habituales. 
La Clasificación Internacional del Funcionamiento, de la Discapacidad y de la Salud (CIF), Organización Mundial de la Salud (2001) establece los fundamentos del nuevo paradigma de discapacidad y se centra en valorar la condición física de las personas, su salud y los efectos que presentan en la vida cotidiana, así como sus repercusiones en las actividades y participación. En el funcionamiento se incluyen funciones corporales, estructuras corporales, actividad y participación. Implica los aspectos positivos de la interacción entre el individuo con una determinada condición de salud y su contexto, ambiental o personal.

El nuevo paradigma de la discapacidad se define como el resultado de la interacción entre una persona con una disminución y las barreras del medio ambiente y de actitud que esa persona puede enfrentar. Presenta una relación estrecha entre los factores contextuales, personales y ambientales que condicionan e influyen en la calidad de vida (SEP, 2006b). Este paradigma plantea una nueva forma de planear y organizar los servicios y apoyos que se ofrecen a la población, esto ha sido el resultado de un proceso en el cual han participado las personas con discapacidad y sus familias, investigadores, especialistas, instituciones, gobiernos y la misma sociedad, buscando la integración de está población al ámbito social, educativo y laboral.

La nueva conceptualización de la discapacidad, desde una perspectiva incluyente, ha significado un cambio en la forma de ver y analizar las relaciones entre la sociedad, las barreras que existen y la discapacidad. Para el logro de la integración educativa de las personas con discapacidad, es necesario implementar cambios en las políticas públicas educativas, pero no solo con estos cambios es suficiente, lo más importante es el cambio de actitud de todos los actores involucrados en los centros educativos, ya que de esta manera se podrá conseguir que cada uno asuma su responsabilidad de lo que le toca hacer, creando mejores oportunidades y proporcionando a las personas con discapacidad los apoyos que requieren, tanto naturales, materiales 0 tecnológicos, con el fin de propiciar una mayor independencia, acceso a la información, mejorando su calidad de vida. 


\subsubsection{Asistencia Tecnológica}

En México a través del Programa Nacional de Fortalecimiento de la Educación Especial y de la Integración Educativa (2002), presentan el Manual de Asistencia Tecnológica (SEP, 2006) dirigido al personal de educación regular y especial de todos los estados, con el propósito de brindar elementos básicos conceptuales y prácticos que permitan tener conocimiento de los apoyos específicos para los alumnos con necesidades educativas especiales asociados o no a la discapacidad.

En él se define la Asistencia Tecnológica como:

"Todo tipo de equipo o servicio que puede ser usado con el objetivo de suplir, aumentar, mantener o mejorar las capacidades funcionales de las personas con discapacidad; provee de accesibilidad para la vida independiente en diversas áreas como la comunicación, el posicionamiento y movilidad, para el aprendizaje, el hogar, el trabajo, las actividades del diario vivir, el juego y la recreación, entre otros. Su uso es importante y necesario, ya que sus recursos permiten que los niños, niñas y jóvenes logren la funcionalidad e independencia deseada, al ser potenciadas sus capacidades" (p.15).

Vigotsky (1995) establece que los niños con deficiencia alcanzan el desarrollo de un modo diferente, por otra vía, con otros medios y para el pedagogo es muy importante conocer las peculiaridades de la vía por la cual él debe conducir al niño. La ley de la transformación del "menos" de la deficiencia, al "más" de la compensación proporciona la clave para llegar a su peculiaridad.

Las nuevas tecnologías de asistencia como un medio integrador, si se desarrollan adecuadamente, podrían desempeñar un papel importante, para afrontar y superar alunas barreras que afrontan las personas con discapacidad (Cabra de Luna, 2002). La tecnología no pueden considerarse por sí misma asistencia tecnológica, sino hasta que se utilizan para suplir, aumentar, mantener, etc., y más si requiere adaptaciones para su control. Son muchos los recursos tecnológicos que permiten a las personas con discapacidad participar 
de la cultura informática, de esta manera existen ayudas técnicas que permiten la utilización adaptada de recursos generales y específicos.

La asistencia tecnológica, se puede clasificar en alta, media y baja, dependiendo el nivel de sofisticación en su funcionamiento y su costo (SEP, 2006b).

- Alta Tecnología: Todos los programas y equipos electrónicos o mecánicos que se utilizan de forma alternativa, para mantener o aumentar las capacidades funcionales de las personas con discapacidad. Los costos son elevados tanto para su adquisición como para el mantenimiento, normalmente se requiere de capacitación para su uso, tanto para los usuarios como para la familia y asistentes. En México, los equipos son difíciles de adquirir, debido a que la mayoría son importados y de alto costo, como pueden ser: las sillas de ruedas motorizadas y guiadas por control remoto, los tableros de comunicación con voz digital, las adaptaciones para vehículos, controladores de voz para aparatos electrodomésticos, entre otros.

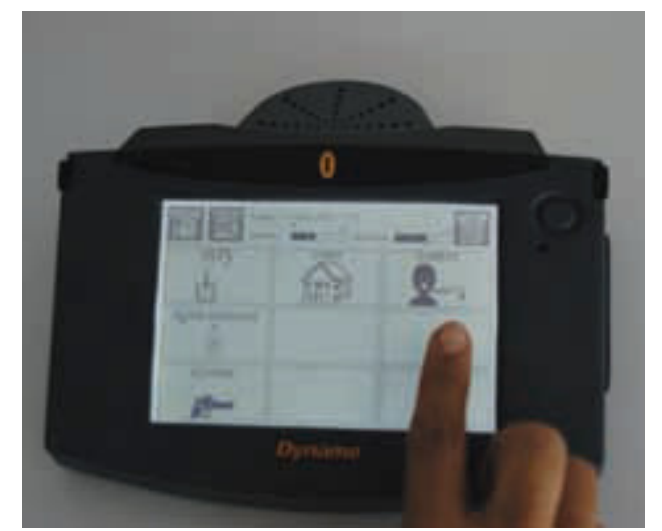

Figura 2: Alta Tecnología. Comunicador Dynamo digital Manual de Asistencia Tecnológica (SEP, 2006b).

- Tecnología media: Tiene que ver con equipos y programas que en general pueden ser accesibles, su desarrollo es de mediano costo. En este sentido podemos encontrar: los comunicadores de voz digital con un número limitado de mensajes, sillas de ruedas no automatizadas, minigrabadoras, calculadoras parlantes, termómetros parlantes, etc. También software educativo e interactivo. La mayoría de tecnología de este tipo corresponde a distintas culturas, con parámetros diferentes, en 
México se han utilizado estas tecnologías por terapeutas y especialistas, pero en número limitado, debido a su costo, por su complejidad o por estar en otro idioma.

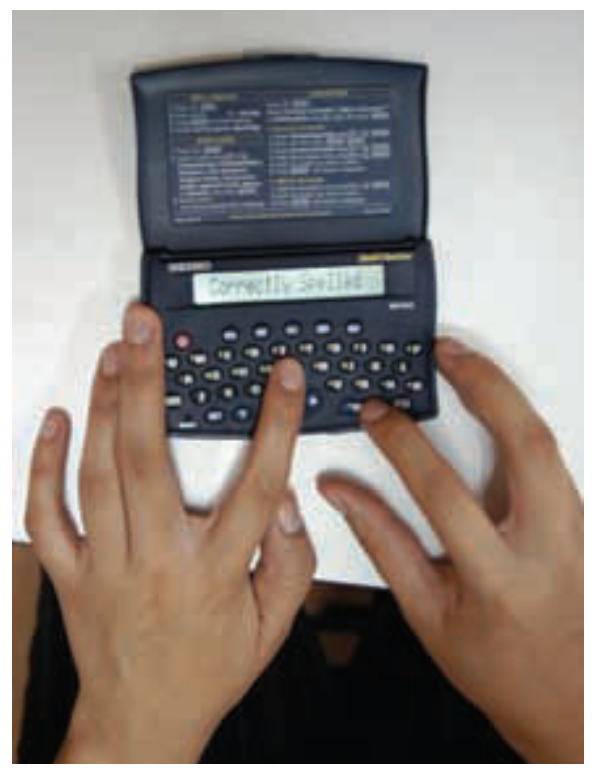

Figura 3: Media Tecnología. Diccionario adaptado como comunicador, Manual de Asistencia Tecnológica (SEP, 2006b).

- Baja tecnología: Se caracteriza por ser la más accesible y personalizada, consiste en aplicaciones o creaciones a bajo costo que generalmente sustituyen, en la medida de lo posible las tecnologías media y alta, son fáciles de fabricar o de comprar, pudiendo ser de diseños muy simples como: un comunicador que se hace con materiales de fácil adquisición, con una base de cartón, se pegan imágenes cortadas de una revista o dibujadas, sustituyendo algún problema de comunicación en el ordenador.

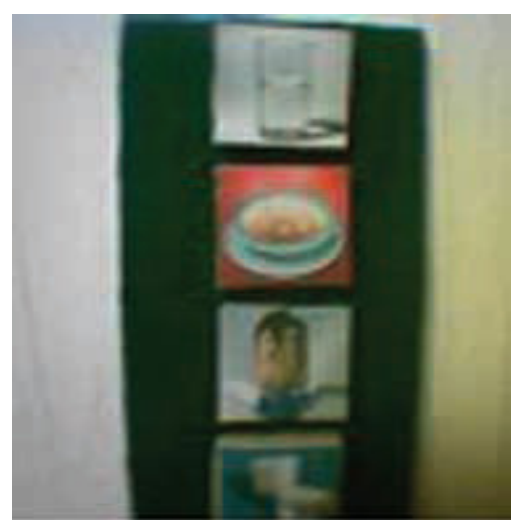

Figura 4: Baja Tecnología. Comunicador de bajo costo, de cartón, Manual de Asistencia Tecnológica (SEP, 2006b). 
Alba (2001) asevera que para muchas de personas con discapacidad, las tecnologías pueden ser una vía de comunicación y acceso al resto del mundo, a sistemas de educación flexibles, sin barreras arquitectónicas, siendo un valioso recurso y opción para aquellas personas que no pueden asistir a los centros donde se imparte la enseñanza de manera presencial.

El uso de las TIC como una herramienta se puede ubicar como parte de las actividades planeadas y como recursos de investigación y comunicación, pero también pueden ser utilizadas para aprendizajes más simples, para procesos formales y repetitivos. Lo cual implica reflexionar entre los nuevos roles de la escuela, sobre los propósitos de la educación en una sociedad de la información y de la comunicación, así como sobre culturas emergentes sobre el aprendizaje. Las TIC ayudan al aprendizaje de una gran cantidad de contenidos, recurriendo a técnicas de simulación y de modelación cognitiva que coadyuven a la decodificación e interpretación de lenguajes gráficos a través del uso de calculadoras gráficas y de software poderoso (Rojano, 2000)

La Ley General de las Personas con Discapacidad (2005), enuncia en su artículo 1, que las disposiciones de esta ley son de orden público, de interés social y de observancia general en los Estados Unidos Mexicanos. Su objetivo es "establecer las bases para la inclusión plena de las personas con discapacidad, en un macro de igualdad y equiparación de oportunidades en todos los ámbitos de la vida". De esta manera plantea que la educación deberá contribuir al desarrollo integral del ser humano, para potenciar y ejercer plenamente sus capacidades, habilidades y aptitudes, para ello se contara con ayudas técnicas como son: los dispositivos tecnológicos y materiales que permiten habilitar rehabilitar o compensar una o mas limitaciones funcionales motrices sensoriales o intelectuales de las personas con discapacidad.

En el inciso II del artículo 2 se refiere a las ayudas técnicas como: "dispositivos tecnológicos y materiales que permiten habilitar, rehabilitar 0 compensar una o más limitaciones funcionales, motrices, sensoriales 0 intelectuales de las personas con discapacidad". De igual manera en el inciso VIII del capítulo III de la Educación, se pide proporcionar a los estudiantes con discapacidad materiales que apoyen su rendimiento académico. 
En congruencia, el Programa Estatal de Fortalecimiento de la Educación Especial y de la Integración Educativa 2005-2010, establece en la línea 4, relacionada a la producción y gestión de recursos;

"producir y gestionar recursos materiales y apoyos técnicos necesarios para los servicios de educación especial y las escuelas de educación inicial y educación básica, a fin de asegurar que cuenten con mejores condiciones para el aprendizaje de los niños, niñas y jóvenes con necesidades educativas especiales, primordialmente con discapacidad y aptitudes sobresalientes" ( p.38).

El uso de la tecnología ha generado avances o artefactos no para dar respuesta a las necesidades de las distintas personas que conviven en una cultura, si no que es a la inversa. Se han generado nuevos avances sociotécnicos, que luego pueden ser aprovechados para fines diferentes a los previstos, o que tienen que ser adaptados porque tal y como se conciben no tienen en cuenta la diversidad de la población (Alba 2001).

\subsubsection{Las Ayudas Técnicas}

En la utilización de las TIC, el ordenador no solo puede ser utilizado por cualquier sujeto, sea cual sea su capacidad sensorial, intelectual o motórica, sino que para muchos sujetos, los recursos tecnológicos informáticos posibilitan la única vía para expresarse, comunicarse, trabajar o aprender.

Alba (2006) plantea que en el ámbito educativo son especialmente importantes todas las ayudas técnicas que permitan a los estudiantes acceder y participar significativamente en los procesos de enseñanza y aprendizaje, para cada edad y en cada nivel educativo, entre los que tiene un papel relevante el ordenador. Así pues, la educación debe encaminarse hacia la formación integral del individuo, desarrollando su autonomía y su integración social, integrando las TIC como una respuesta educativa a la diversidad, pues se convierten en una vía de acceso preferente para la participación del alumnado con necesidades educativas. 
Esto supone un gran cambio en la concepción de la educación de las personas con necesidades educativas especiales, a la vez que posibilita un mayor acceso a la participación en los distintos niveles de la sociedad. La utilización didáctica de los recursos tecnológicos debe estar orientada a propósitos más ambiciosos y ligados a la importancia del respeto a la diversidad y a la necesidad de construir una sociedad inclusiva (Alba 2001).

Para apoyar el aprendizaje de los alumnos con necesidades individuales, es prioritario que el software pueda adaptarse a los requerimientos de aprendizaje individual. Además, la disponibilidad de un software variado se ajusta a los objetivos del currículum y de las metas de estudio individuales. Podría considerarse que el objetivo de la utilización de las TIC en los servicios de Educación Especial, ayuda a satisfacer las necesidades individuales de los alumnos con necesidades educativas especiales, a través de una infraestructura técnica personal apropiada. La provisión de esta infraestructura técnica requiere la consideración de principios clave de aprendizaje y enseñanza, así como la identificación de estilos individuales de abordaje y aprendizaje.

La Tecnología de Ayuda, como todos los elementos tecnológicos tiene como objetivo incrementar las capacidades de las personas que, por cualquier situación, no alcanzan los niveles necesarios de ejecución, que de acuerdo a su edad y sexo le corresponderían a la población en general. Las TIC aparecen como un medio tecnológico de compensación y apoyo, en la atención educativa de los alumnos con necesidades educativas especiales (Alcantud, 2000).

El proyecto ALDICT (Access for Persons with Intellectual Disability to Information and Communication, 2000) ha hecho posible la elaboración de un software - Writing with Symbols 2000- que facilita el intercambio de información por Internet a personas con dificultades de comunicación y aprendizaje. Han creado una interfaz amigable, que toma como referencia los sistemas de símbolos PCS, Rebus y PIC, y hace posible un nivel de comunicación amplia abarcando desde expresiones de necesidades básicas hasta las que requieren mayor competencia cognitiva, además facilita la traducción simultanea de los mensajes emitidos por el usuario al resto de los que participan a través de Internet (Sánchez, 2002). 
Amanda Watkins, Directora de Proyectos de la Agencia Europea para el Desarrollo de la Educación Especial (2002) presenta el resumen del proyecto sobre la aplicación de las Nuevas Tecnologías (NNTT) a la educación de alumnos con necesidades educativas especiales durante el periodo 1999-2000 e informa que la oferta educativa para los alumnos con necesidades especiales varia en Europa, ya que depende de las diferentes políticas educativas. Todos los países de la Unión Europea coinciden en que satisfacer las necesidades educativas individuales de cada uno de los alumnos, puede considerarse como un elemento importante de garantía de calidad de vida de los ciudadanos europeos. Y en relación a ello las NNTT aparecen como una herramienta para hacer frente a este reto. Así mismo se hace referencia al estudio Eurydice ICT@Europe.edu: Nuevas Tecnologías en los sistemas educativos europeos (2001), en el cual se afirma que con la sola introducción de las NNTT en los sistemas educativos de los países europeos, no se producirán grandes cambios, a menos que se explore a mayor profundidad como una herramienta de aprendizaje.

Los alumnos con necesidades educativas especiales utilizan la tecnología de apoyo a sus actividades, ya sean formativas, profesionales, laborales, sociales, etc., esta tecnología se le conoce como tecnología asistida o de apoyo, en el ámbito educativo. Esta puede estar considerada como el uso de tecnología para ayudar a alumnos bien con problemas sensoriales, físicos, cognitivos, de aprendizaje, o de habla, para realizar actividades y tareas escolares que de otra manera serian imposibles de realizar. Puede suponer la adaptación de un ordenador con hardware específico para que el alumno pueda trabajar en él, o la utilización de un software especial que le ayude a leer, escribir o realizar alguna actividad con el ordenador (Toledo y otros, 2007). 


\subsubsection{El Profesor en el campo de las TIC y la Discapacidad.}

Es común que en estos tiempo se dé importancia al uso de la tecnología y sus virtudes, sus capacidades, sus prestaciones, sin tomar en cuenta demasiado que todo ello es posible debido a la dedicación de profesionales, que participan en el diseño, adquisición, modificación, dotación, etc., para ser utilizados en personas con discapacidad. Escoin (2002) señala que los profesionales en el campo de la tecnología y la discapacidad, utilizan mayormente la autoformación o formación autodidacta, complementando esta preparación autónoma con cursillos, jornadas y talleres. Desafortunadamente, el manejo de tecnología de ayuda requiere tener conocimiento de la tecnología informática que va más allá del elemental conocimiento del usuario, requiere que el profesional de la escuela sea un buen conocedor de la tecnología que utiliza, atendiendo no sólo al campo de la tecnología de ayuda sino a nivel general.

En México es poca la orientación y capacitación sobre el uso de la asistencia tecnológica tanto en educación regular como en Educación Especial, el conocimiento que se tiene sobre la gama de recursos y adecuaciones para los alumnos con discapacidad es limitada.

Por ello el Programa Nacional de Fortalecimiento de la Educación Especial y de la Integración Educativa (2002) establece en uno de sus objetivos específicos: "proporcionar a los maestros de educación especial, de educación inicial y educación básica los recursos para mejorar la atención de los alumnos y alumnas con necesidades educativas especiales, dando prioridad a los que presentan discapacidad". En congruencia el Programa Nacional de Fortalecimiento de la Educación Especial y de la Integración Educativa, de la Subsecretaria de Educación Básica, propone en una de sus metas la dotación de recursos y apoyos técnicos necesarios, que permitan asegurar la mejor atención de los alumnos con discapacidad, tanto en educación inicial y básica como en los Centros de Atención Múltiple, así mismo ofrece opciones de actualización al personal de educación regular acerca de estrategias especificas que permitan dar respuesta educativa adecuada a las necesidades especificas de cada alumno.

Es importante y evidente la incorporación sistemática de las TIC en las escuelas, para ello se requiere por parte de los profesores, conocimientos en 
cuanto a su utilización y puesta en marcha, con esto se perdería por parte de algunos de los docentes el miedo que existe en su utilización, dado que ven la inclusión de las TIC como un obstáculo más que como un recurso importante e imprescindible sobre todo para determinados alumnos, ya que puede representar una respuesta educativa a las necesidades de los alumnos, generando calidad, siendo un importante recurso que sabiéndola utilizar se convierte en un poderoso recurso para el profesorado. Es trascendental que el conocimiento sobre las TIC se lleve a cabo como una propuesta del centro, con diferentes modalidades de formación, dado que el centro concretamente plantea sus necesidades, con los recursos humanos y materiales que tiene, organizando la inclusión curricular y la respuesta educativa para sus alumnos, Hurtado (2003).

Es Importante reconocer que todos los elementos que forman parte del sistema educativo como el programa curricular, modelo educativo, la vida escolar, las normas de la institución, interactúan y se llegan a afectar entre ellos. Aun y cuando el proceso de enseñanza y aprendizaje es el que le aporta el sentido y el valor al sistema educativo. Este proceso puede ser visto desde la perspectiva de los actores involucrados en él, los alumnos, profesores, y cuerpo de conocimientos. Si se asume que el conocimiento es el resultado de un aprendizaje, que se ve reflejado en las competencias desarrolladas, donde el alumno desarrolla habilidades y actitudes a partir de determinados conocimientos (Schmelkes, 1997). La interacción entre el conocimiento y los alumnos es importante, por ello se requiere de una educación personalizada donde se establezca una relación cercana entre el profesor y el alumno, donde el profesor sea capaz de flexibilizar y mejorar sus programas, en respuesta al ritmo, estilo, capacidades, necesidades y experiencia de los estudiantes.

En el mundo actual interconectado por redes, el profesor debe saber diseñar estrategias diversas, seleccionar medios y materiales para facilitar el aprendizaje significativo en sus alumnos. Es tarea del profesor realizar un diseño contextualizado de guías metodológicas, para ello debe de considerar las características del alumno, sus estilos de aprendizaje, y sus conocimientos previos. Según Alba (2006) las TIC, desde un diseño curricular accesible, posibilita respuestas variadas, permitiendo diversas formas de presentación de la información, maneras diversificadas de expresión y aprendizaje, así como 
múltiples formas de implicación, para permitir dar respuesta a la complejidad del aprendizaje y la enseñanza. El docente ha de tener presente los objetivos educativos, las características de los distintos estudiantes, sus necesidades y posibilidades, partiendo de estos aspectos plantear diferentes formas de presentación de la información, de procesamiento de la misma por sus estudiantes y de presentación de sus resultados.

En las escuelas las prácticas docentes se diseñan en torno a un proyecto educativo que permite una aproximación a las diferentes dimensiones de la sociedad y la cultura del contexto escolar donde se realiza. La globalización cultural se ha instaurado como ampliación a un fenómeno inicialmente económico, consistiendo en la liberación del sistema económico y financiero a escala mundial. Este nuevo marco socioeconómico ha representado, sin duda nuevos retos para las instituciones educativas. Esta nueva realidad plantea otro tipo de preparación cognitiva, social y afectiva. Identificando nuevas competencias y habilidades, cada vez más relacionadas a la capacidad de adaptación a las situaciones cambiantes. Las tecnologías del conocimiento, que permiten transformar los aspectos de la realidad en objetos de estudios constituyen un componente clave en esta nueva realidad. Sin estas tecnologías el desarrollo seria más lento, dado que la utilización de tales tecnologías ha influido sobre el propio saber producido, pudiendo definirlo en un campo especifico, permitiendo su control y uso (de Pablos, 2006).

La tecnología de la información y la comunicación, es considerada como un gran motor de la revolución, provocando la aparición de una nueva sociedad marcada por los cambios de la globalización, las innovaciones tecnológicas que inciden en la competitividad y en la calificación, y la información que incide en las transformaciones, así como en el rápido crecimiento del conocimiento, etc. Como consecuencia los nuevos seres humanos serán personas con mayor información y nuevos métodos de tratamiento de la información, afectados por el desarrollo de la tecnología de la información y la comunicación, prediciendo un gran crecimiento de la información y de las posibilidades de la comunicación, así como también convertir el conocimiento en un recurso. En la actualidad el crecimiento del Internet y la aparición de servicios telemáticos hacen inminente esta visión del futuro. 
Las TIC proporcionan múltiples funcionalidades a las personas con discapacidad o que requieren una atención especial, pudiendo facilitar (Marqués, 2008a):

- La comunicación.

- El acceso/proceso de la información.

- El desarrollo cognitivo.

- La realización de todo tipo de aprendizajes.

- La adaptación y autonomía ante el entorno.

- Ocio.

- Instrumentos de trabajo, posibilidades de realizar actividades laborales.

Las aportaciones en el campo de la discapacidad, se pueden lograr con programas, recursos, aplicaciones, etc., consideradas ayudas técnicas, como establece Chacón (2007) las ayudas técnicas son los medios y herramientas creados por el hombre para permitir o facilitar la realización de determinadas acciones, de tal manera que sin su uso, serian imposibles o muy difícil de realizar para una persona en una situación determinada.

La gran cantidad de situaciones, sujetos y elementos de ayudas técnicas están determinadas por factores (Peula, 2000) como:

- El tipo de ayuda necesario para poder establecer la comunicación: Son las condiciones que vienen determinadas por la complejidad técnica de construcción del dispositivo del que se trate y la adaptación menor o mayor de acuerdo a las necesidades educativas especiales del sujeto.

- La capacidad de uso del locutor alternativo: Esta determinada por la capacidad del usuario de usar directamente la ayuda, a través de un dispositivo específico, o la necesidad de un elemento intermedio que facilite el acceso de ayuda y/o la elección.

- La motivación y competencia interpretativa del interlocutor: Se relaciona a la atención o a la destreza del interlocutor para decodificar los mensajes del usuario de la ayuda técnica, debido a que algunos de los sistemas que se utilizan, usan un lenguaje de códigos que impedirá la comunicación si no son conocidos por el interlocutor. 
Existen diferentes autores que han trabajado sobre la complejidad de las ayudas técnicas (Chacón, 2007), clasificación más compleja sobre las ayudas técnicas, estableciendo tres grandes categorías:

- Ayudas básicas: Imprentillas y otros utensilios de escritura, Tarjetas de comunicación, Pizarras férricas y materiales imantados, Tableros de comunicación, Regletas braille.

- Mecánicas, eléctricas, ópticas: Timbres, zumbadores, señalizadores, Máquina Perkins, Dial scan, Comunicadores electrónicos, Herramientas de ampliación (Sistemas ópticos, sistemas eléctricos).

- Complejas: tienen un mayor peso específico, se consigue mayor variedad y calidad de las adaptaciones, así como controlar el entorno de manera más eficaz;

a) Electrónicas:

-Prótesis auditivas.

-Ayudas para deficientes visuales; Adaptaciones de bajo nivel diseñado para personas ciegas o con baja visión y Adaptaciones de alto nivel.

-Comunicadores electrónicos.

b) Ayudas para el acceso al ordenador y a los sistemas informáticos.

- Emuladores de teclado y ratón.

- Computadores, pulsadores.

- Teclado de conceptos.

- Acceso al juego.

c) Software.

En la atención de las necesidades educativas especiales, uno de los primeros pasos en la detección inicial o exploratoria y la evaluación psicopedagógica como proceso que implica conocer las características de los alumnos, en interacción con el contexto social, escolar y familiar al que pertenece, identificando las barreras que impiden su participación y aprendizaje, también establecer los recursos profesionales, materiales, arquitectónicos y/o curriculares que se necesitan para que logre los propósitos educativos. Los aspectos que se consideran al realizar la evaluación psicopedagógica son: 
contexto del aula y de la escuela, el contexto social y familiar; el estilo de aprendizaje del alumno y alumna, sus intereses y motivación para aprender, y su nivel de competencia curricular. Posteriormente se realiza el Informe de la evaluación psicopedagógica, donde se recupera la información obtenida en la evaluación psicopedagógica, precisando los recursos profesionales: equipo de educación especial, materiales como: mobiliario específico, prótesis, material didáctico, etc., arquitectónicos como: rampas, aumento de dimensión de puertas, etc., y curriculares como: adecuaciones en la metodología, evaluación, contenidos y propósitos, que se necesitan para que el alumno y alumna con necesidades educativas especiales logre los propósitos educativos. Partiendo de este informe, se elabora la Propuesta Curricular Adaptada como instrumento donde se especifican los apoyos y recursos que la escuela brinda al alumno y alumna que presentan necesidades educativas especiales para lograra su participación y aprendizaje, por lo que su elaboración y seguimiento es indispensable (SEP, 2007c).

Se establecen las adecuaciones curriculares, para dar respuesta a las necesidades educativas de los estudiantes, de tal manera que la enseñanza se ajusta al estilo de aprendizaje de cada alumno. Las adecuaciones curriculares deben de responder al qué es lo que se desea enseñar, cómo se llega al objetivo, en qué momento se presenta el material y cuándo se evalúa. Por otra parte las adecuaciones de acceso pueden modificar la forma en que se presentan los materiales, permitiendo a que el alumno tenga acceso a la información, o la forma en que el alumno responde, no implica que necesariamente se tenga que modificar el contenido y criterios de todas la tareas con las que se enfrenta el alumno. Una adecuación de acceso, puede ser cualquier medio, recurso, ayudas técnicas, equipo, producto, etc., adquirido comercialmente, adaptado o construido, con el propósito de aumentar, mantener o mejorar las capacidades funcionales de los alumnos con necesidades educativas especiales, así como cualquier servicio que contribuya directamente al alumno en la selección, adquisición o uso de un equipo de asistencia tecnológica, con el propósito de facilitarles el acceso al currículo regular (SEP, 2006d).

El profesor juega un papel fundamental en la selección y el uso de la tecnología que utiliza en la educación de los alumnos, más aún cuando estos 
tienen necesidades educativas especiales, en el proceso de selección del uso de la tecnología deben conocer las soluciones potenciales que ofrecen las diferentes tecnologías y determinar cual es la tecnología más adecuada de acuerdo a las necesidades de cada uno de sus alumnos. Además de tener un claro conocimiento de las funciones y características de la tecnología, los profesores deben de dominar su uso antes de integrarla en el currículo o de utilizarlas (Toledo y Hervás, 2007).

Partiendo de la clasificación anterior, se presentan algunos casos concretos de ayudas técnicas (Marqués, 2008b):

- Discapacidad física:

* Problemáticas visuales

- Lectores de texto, periférico para la lectura de Braille, impresora Braille.

- Calculadoras parlantes.

- Procesadores/gestores de textos y otros programas standard manejados por voz.

- Detectores de obstáculos para guiar a las personas.

- Lupas amplificadoras de pantalla y otros adaptadores para personas con baja visión.

- Problemáticas auditivas (parciales o totales):

- Teléfonos con transcripciones de texto, programas para la conversión de voz a texto.

- Herramientas standard de correo electrónico y chat.

- Generadores de ondas de sonido (para el entrenamiento del habla).

- Sistemas de amplificación electrónica para hipoacusias.

* Problemáticas motóricas:

- Teclados alternativos adaptados, donde se modifica la velocidad de repetición de las teclas. 
- Interruptores, punteros, carcasas, licornios, etc., para quienes no pueden mover los dedos.

- Programas de reconocimiento de voz.

- Programas standard adaptados.

- Instrumentos de control remoto para el desplazamiento de sillas, control de luces y otros interruptores, etc.

* Problemáticas de la expresión verbal (parcial o total)

- Sintetizadores de voz.

- Discapacidad psíquica (emotivas o sociales):

- Autismo

- Uso de algunos programas y recursos TIC como medio de expresión personal y con una función mediadora.

Hiperactividad y déficit de atención.

* Otros problemas conductuales (psicosis, inadaptación social, etc.)

- Instrumento para el acceso a la información y la comunicación en general.

- Uso de algunos programas y recursos TIC como medio de expresión personal y refuerzo de la autoestima.

- Discapacidades mentales

* Dificultades de aprendizaje:

- Nuevos entornos de aprendizaje virtuales

- Programas de refuerzo y ejercitación.

* Dislexia y disgrafía:

- Programas específicos para diagnostico y recuperación.

* Problemas psicomotrices.

- Programas de entrenamiento psicomotriz. 
Deficiencias mentales graves (Síndrome Dawn, atrasos mentales, amnesia, etc.).

- Instrumentos para el acceso a la información y la comunicación en general.

- Programas específicos para el diagnostico y tratamiento de algunas deficiencias.

- Material didáctico de refuerzo.

En relación a estos programas y aplicaciones, en el siguiente cuadro se presentan algunos ejemplos de programas específicos (Chacón, 2007).

\begin{tabular}{|l|l|l|l|}
\hline Nombre & S. Operativo & \multicolumn{1}{|c|}{ Descripción } & Dispositivos de acceso \\
\hline Hola Amigo & MS-DOS & Programa elaborado a partir del S.RC & Teclado o conmutador \\
\hline Tcomunica & Windows & $\begin{array}{l}\text { Programa para el aprendizaje y uso } \\
\text { de lenguajes alternativos. }\end{array}$ & $\begin{array}{l}\text { Teclado, teclado } \\
\text { conceptos, ratón adaptado. }\end{array}$ \\
\hline Sergio & MS-DOS & Procesador de textos & Pulsador o teclado \\
\hline Lápiz 3 & MS-DOS & Procesador de textos & Pulsador o teclado \\
\hline Proyecto Tecla & MS-DOS & $\begin{array}{l}\text { Desarrollo de aprendizaje para } \\
\text { personas con deficiencias motóricas }\end{array}$ & Pulsador o teclado \\
\hline L.A.O. & MS-DOS & Desarrollo del lenguaje & Pulsador o teclado o ratón \\
\hline SIFO. & MS-DOS & Segmentación sílabica & Pulsador o teclado o ratón \\
\hline P.E.L. & MS-DOS & Lectoescritura & Teclado \\
\hline Cobra & MS-DOS & Conversión de textos braille & Teclado, ratón, \\
\hline Lupa & MS-DOS & Amplía caracteres de pantalla & Teclado, ratón. pulsador \\
\hline Zoomtext Plus & Windows & Ampliador de caracteres & Teclado, ratón \\
\hline $\begin{array}{l}\text { Visualizador } \\
\text { fonético }\end{array}$ & MS-DOS & Análisis gráfico y auditivo de voz IBM & Micrófono \\
\hline Mac-apple & Apple-Mac & Edición de textos y dibujos & Conmutador, teclado \\
\hline Cuadro 4: Prog
\end{tabular}

Cuadro 4: Programas Específicos propuestos por Chacón (2007). 


\subsection{Propuestas e investigaciones de TIC relacionadas a la atención de las NEE y a la Discapacidad.}

A continuación presentamos una serie de investigaciones y propuestas de educativas, relacionadas a las Tecnologías de la Información y de la Comunicación para la atención de personas con necesidades educativas especiales asociadas a discapacidad y a otros factores.

\subsubsection{Experiencias educativas con alumnos superdotados en el uso de las Nuevas Tecnologías (Alonso, J. 2004).}

En los últimos años la educación de los alumnos superdotados como alumnos de necesidades educativas especiales ha tenido un movimiento considerable generando gran cantidad de publicaciones e investigaciones que han facilitado a las administraciones educativas de cada país la puesta en marcha de leyes que contemplen a este tipo de alumnos.

Es indudable que como para cualquier colectivo de estudiantes las Nuevas tecnologías han abierto unas amplias e importantes posibilidades no sólo en lo que se refiere a la educación en el ámbito cognitivo de estos estudiantes sino sobre todo y especialmente, en lo vinculado a su desarrollo social y afectivo.

A continuación, concretamente y de forma sucinta dentro del ámbito cognitivo podemos reseñar la utilización de las Nuevas Tecnologías:

\section{A. Dentro del ámbito cognitivo:}

a) Programas de enriquecimiento dentro del aula como:

- La utilización de programas educativos a niveles avanzados en formato $C D$.

- Utilización de producción multimedia en formato CD de niveles avanzados en edades más tempranas.

- En el alumno superdotado es importante estimular la investigación y el estudio independiente. Estos alumnos desde edades muy cortas aproximadamente a los 4 años son capaces de manejar el ordenador. Por ello en el nivel 
de primaria puede utilizar internet y presentar sus trabajos en power point, etc. Las investigaciones pueden ser diseñados siguiendo los niveles de desarrollo de habilidades cognitivas de la Taxonomía de Bloom (estrategias cognitivas que permitirán adquirir a quien las utiliza un camino hacia lo fundamental en una investigación y por tanto dará como resultado un conocimiento más extenso sobre un elemento especifico que se elaboro de forma sistemática).

b) Programas de enriquecimiento fuera del aula.

Es imprescindible utilizar programas:

- Programas educativos complejos

- Productos multimedia de nivel avanzado a edades más tempranas.

- Estimular la investigación.

\section{B. Desarrollo socioafectivo.}

En los alumnos superdotados una de las áreas vulnerables es el sentimiento de sentirse diferente. Una de las claves para hacer frente a este sentimiento, es encontrar a otros estudiantes que tengan sus mismos intereses y habilidades.

Los niños y jóvenes superdotados necesitan reunirse con otros iguales a ellos para:

- Verificar su propia realidad, sin necesidad de sentirse solo y sin reprimir sus capacidades.

- Al experimentar un apoyo emocional, se sienten aceptados como individuos, mejorando su capacidad de aceptación, autoimagen y autoestima.

La utilización de las nuevas tecnologías son:

a) Creación de videos

b) Desarrollo de páginas web, con la finalidad de compartir con otros compañeros que no tienen información sobre el tema, seguir en contacto con ellos, colgar su propio álbum de fotos, juegos, canciones etc. 
En ambos casos se realiza con el fin de atender el deseo de comunicación y necesidad de estar en contacto con otros, además de que se enfrenten por si solos a retos que esto puede suponer.

c) Es importante cuidar el área afectiva de estos estudiantes dada la disincronía de estos alumnos, es necesario trabajar con ellos esta área tanto en el sentido personal como de relaciones.

La utilización de escenificaciones de dilemas morales, con sus correspondientes grabaciones y posteriormente proyecciones y la utilización de otras herramientas audiovisuales son algunas de las tecnologías que se pueden utilizar.

d) En la educación de estos alumnos una especial incidencia tiene tanto el desarrollo de la capacidad cognitiva como el desarrollo de valores y respeto a los demás, lo que se puede usar es los debates una propuesta para alumnos de más edad que al hacen uso de la investigación y el ingenio en diferentes producciones multimedia, medios audiovisuales, internet, uso de correo electrónico, Messenger, etc., para compartir la información dada la diferentes procedencias de los estudiantes.

Las TIC han abierto unas posibilidades educativas muy importantes y necesarias para estos alumnos, la importancia no está en la posibilidad de implementar programas educativos de mejora cognitiva, sino lo importante es la posibilidad que las TIC brindan al desarrollo socioafectivo de estos estudiantes

\subsubsection{Las TIC en las Inteligencias Múltiples (Sánchez, 2002).}

Al hablar de las inteligencias múltiples, Gardner (1997) afirma que las personas no tenemos una sola inteligencia de tipo general, medible según los tradicionales test de inteligencia, sino que la inteligencia tiene una estructura múltiple y actúa como un sistemas cerebrales semi-autónomos. En el siguiente cuadro se muestran estos siete módulos mentales o inteligencias: musical, lógico-matemática, lingüística, intrapersonal, interpersonal, corporal-cinestésica y espacial. Para cada una de estas inteligencias se presentan los recursos tradicionales y las nuevas tecnologías que pueden ayudar a su desarrollo. 


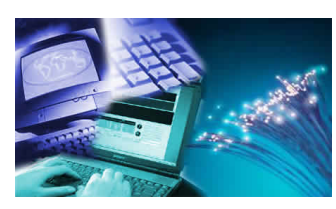

Centro de actividades de Inteligencias Múltiples

\begin{tabular}{|c|c|c|}
\hline Inteligencia & Recursos Tradicionales & Recursos TIC \\
\hline $\begin{array}{l}\text { - Lógico- } \\
\text { matemática }\end{array}$ & $\begin{array}{l}\text { - Calculadoras, material } \\
\text { manipulable de } \\
\text { matemáticas, etc. }\end{array}$ & $\begin{array}{l}\text { Lenguaje Logo, hojas } \\
\text { de cálculo, tutorias, } \\
\text { simuladores. }\end{array}$ \\
\hline - Musical & $\begin{array}{l}\text { Instrumentos musicales, } \\
\mathrm{CD} \text {, grabadoras. }\end{array}$ & $\begin{array}{l}\text { Editores musicales, } \\
\text { secuenciadores, } \\
\text { editores de sonido. }\end{array}$ \\
\hline - $\quad$ Lingüística & $\begin{array}{l}\text { - Rincón de libros o áreas } \\
\text { de biblioteca }\end{array}$ & $\begin{array}{l}\text { Procesador de textos, } \\
\text { libros electronicos, } \\
\text { diseñador de Web, } \\
\text { juego de palabras. }\end{array}$ \\
\hline 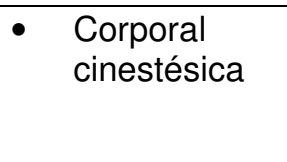 & $\begin{array}{l}\text { - Materiales para } \\
\text { construir, plastilina, } \\
\text { barro, etc. }\end{array}$ & $\begin{array}{l}\text { Simuladores de } \\
\text { movimientos, realidad } \\
\text { virtual, microrobótica, } \\
\text { etc. }\end{array}$ \\
\hline - Espacial & $\begin{array}{l}\text { Gráficos, mapas, } \\
\text { videos, Lego, útiles de } \\
\text { dibujos, etc. }\end{array}$ & $\begin{array}{l}\text { - Programas de } \\
\text { animación. Dibujo } \\
\text { gráfico, etc. }\end{array}$ \\
\hline - Interpersonal & $\begin{array}{l}\text { - Espacios que facilitan el } \\
\text { trabajo en grupo. }\end{array}$ & $\begin{array}{l}\text { - Programa de socio- } \\
\text { gramas como el } \\
\text { Sociowin. }\end{array}$ \\
\hline - Intrapersonal & $\begin{array}{l}\text { Diarios, recursos para } \\
\text { trabajar en los proyectos } \\
\text { individuales. }\end{array}$ & $\begin{array}{l}\text { Programas de } \\
\text { orientación vocacional, } \\
\text { decisión personal. }\end{array}$ \\
\hline
\end{tabular}

Cuadro 5: Centro de Actividades de las Inteligencias Múltiples (Sánchez, 2002).

Ante cualquier tarea, estas inteligencias interactúan entre sí y el fruto de su éxito es de todas ellas. Hasta hace poco se consideraba la inteligencia como algo innato e inamovible, la educación no podía cambiar esto. Hoy en día al considerarla como capacidades cognitivas, éstas si se pueden desarrollar, con lo que se mejoran las competencias en determinadas destrezas o habilidades.

Los recursos que plantea Sánchez (2002) se utilizan con una doble vertiente, por un lado como mediadores e instrumentos psicológicos en el sentido vygostkiano y como Centros Estimuladores de las Inteligencias, es decir como elementos que favorecen la adaptación del individuo.

Este programa de adaptación tiene un carácter amplio y es necesario realizarlo para compensar las restricciones a las que el alumno está sometido como consecuencia de su deficiencia. Para llevar acabo dicho programa se requiere contar con personal especialmente preparado, que pueda diseñar en caso necesario, un plan para modificar los espacios físicos, adaptar el 
equipamiento con mobiliario apropiado para las características físicas y sensoriales de los alumnos, para que les resulte fácil acceder al equipo informático, adecuar el tiempo a cada alumno, así como incluir ayudas pedagógicas, como pudieran ser actividades complementarias para el aprendizaje de braille, lengua de signos, recursos informáticos, etc., y seleccionar una metodología que incluya, modifique o excluya los contenidos que los profesionales consideren convenientes.

Para incluir las TIC establece que su uso seria similar a pesar de su potencia y flexibilidad a otros recursos utilizados en el proceso de enseñanza y aprendizaje, para que sea eficaz se necesita conectarlo al currículo escolar.

\begin{tabular}{|ll|}
\hline FASES & \\
\hline & Pre-ordenador \\
\hline Con ordenador \\
\hline Post-ordenador \\
\hline
\end{tabular}

En las programaciones de aula incluimos actividades de:

\begin{tabular}{|c|c|c|c|c|c|}
\hline [a] & [b] & [c] & [d] & [e] & [f] \\
\hline $\begin{array}{l}\text { Introducción } \\
\text {-motivación } \\
\text { La finalidad } \\
\text { es introducir } \\
\text { a los alumnos } \\
\text { en el objeto } \\
\text { de estudio. }\end{array}$ & $\begin{array}{l}\text { Conocimiento } \\
\text { s previos } \\
\text { Orientadas a } \\
\text { conocer las } \\
\text { ideas opiniones } \\
\text { e intereses de } \\
\text { los alumnos. }\end{array}$ & $\begin{array}{l}\text { Desarrollo } \\
\text { Permitirán el } \\
\text { aprendizaje de } \\
\text { conceptos, } \\
\text { procedimientos } \\
\text {, actitudes y la } \\
\text { comunicación } \\
\text { de } \\
\text { experiencias. }\end{array}$ & $\begin{array}{l}\text { Consolida } \\
- \\
\text { ción } \\
\text { Para } \\
\text { contrastar } \\
\text { las nuevas } \\
\text { ideas con } \\
\text { las ideas } \\
\text { previas del } \\
\text { alumnado. }\end{array}$ & $\begin{array}{l}\text { Recupera- } \\
\text { ción } \\
\text { Orientadas } \\
\text { a los } \\
\text { alumnos } \\
\text { que no han } \\
\text { conseguido } \\
\text { los } \\
\text { aprendizaje } \\
\text { s previstos. }\end{array}$ & $\begin{array}{l}\text { Amplia- } \\
\text { ción } \\
\text { Permiten } \\
\text { construir } \\
\text { nuevos } \\
\text { conocimientos } \\
\text {. }\end{array}$ \\
\hline
\end{tabular}

Aunque empleemos diversas estrategias, procuramos que las actividades garanticen: (*) El mantenimiento de una línea metodológica básica acorde con los principios didácticos

$\left({ }^{\star}\right)$ Que se pueden alcanzar los conceptos 0 destrezas siguiendo caminos distintos, realizando para ello las actividades que mejor se adapten a los recursos informáticos disponibles y las condiciones concretas del aula.

Cuadro 6: Fases de programación con el ordenador (Sánchez, 2002)

Sánchez presenta esta propuesta citando un proyecto del Orase Mann School de Boston (EE.UU.). En este centro se combinan varios recursos de las TIC para que los alumnos desarrollen habilidades cognitivas, haciendo hincapié 
en los refuerzos visuales del ordenador, habilidades socioafectivas, fomentando el trabajo en equipo y el respeto a las normas y las habilidades relativas al desarrollo de la comunicación y el lenguaje con el aprendizaje y uso de la lengua de signos.

\begin{tabular}{|l|c|}
\hline \multicolumn{1}{|c|}{ Propuesta de actividades } & Tipo \\
\hline $\begin{array}{l}\text { Ver un vídeo en el que un Cuentacuentos narra, en la lengua de } \\
\text { signos, una historia (observar las partes, diálogos, explicaciones, etc.) }\end{array}$ & [a] \\
\hline $\begin{array}{l}\text { Todos comparten la historia. La profesora hace preguntas, les plantea } \\
\text { dudas y les motiva a que lo expliquen al resto de sus compañeros. }\end{array}$ & [ b, c, d ] \\
\hline $\begin{array}{l}\text { El alumno, al dar su versión, se convierte en protagonista y emisor de } \\
\text { mensajes didácticos. }\end{array}$ & [ b, c, d ] \\
\hline $\begin{array}{l}\text { Las grabaciones de la profesora pretenden corregir y favorecer el } \\
\text { intercambio. }\end{array}$ & [ c,e, d ] \\
\hline $\begin{array}{l}\text { Para trabajar diferentes códigos de representación la profesora les } \\
\text { motiva para que usen el ordenador y escriban la historia, incluyendo } \\
\text { secuencias de video, fotos, etc. }\end{array}$ & [ b, c, e, f ] \\
\hline
\end{tabular}

Cuadro 7: Propuestas de actividades con el ordenador (Sánchez, 2002)

Este autor presenta diferentes actividades tomando como referencia los Diseños curriculares de las diferentes materias. Presentándolas separadas por inteligencias aunque se sabe que el proceso de aprendizaje se produce de forma compleja.

- Espacial y corporal-cinestésica : Dibujar en el ordenador muchas veces es el primer contacto que muchas personas tienen con la máquina, lo que les resulta gratificante, por el sencillo manejo y que les permite hacer volar su imaginación y expresión artísticamente en el lienzo de la pantalla. Por otro lado el profesor atento al aprendizaje de sus alumnos, puede introducir además de colores, conceptos como grande/pequeño, grueso/delgado, claro/oscuro, dentro/fuera, transparente/opaco, etc., Cuando el alumno a superado este nivel, puede pasar a otras actividades, como hacer determinadas formas, como producir imágenes simétricas, etc.

El proyecto alemán Mai Kiez trabaja con planos de Berlín y los participantes deben señalar el barrio y los lugares que visitan regularmente. Los dibujos- planos son colgados en Internet. 
Sánchez establece que para estimular las inteligencias es necesario disponer de una cierta variedad de dispositivos de entrada y de salida además de los programas adecuados.

Se puede utilizar el uso del teclado para que el usuario refuerce su capacidad de coordinar sus movimientos oculares con otras partes del cuerpo. Es importante el desarrollo de las habilidades motrices en los aprendizajes. A los alumnos con discapacidad motora (Eduardo, 1992) el lenguaje Logo les permite la posibilidad de controlar espacios que normalmente están fuera de su alcance. Les ayuda para establecer relación entre la idea de su proyecto, que esta en su mente y su resultado concreto en el ordenador.

> El uso del tablero de conceptos supone, entre muchas cosas, trabajar la estructura espacial en relación con el espacio inmediato (el individuo como referente), el espacio circundante (otro objeto o sujeto) y la actividad relacionada con el espacio gráfico desde niveles distintos (el plano de la pantalla y de las láminas del tablero).

Los conceptos espaciales y los colores pueden ser presentados de una nueva forma con la pantalla táctil. Al ser la interacción del alumno con la pantalla tan intuitiva se conseguían, con pocas palabras y sin previo entrenamiento, unas actitudes muy positivas hacia el aprendizaje.

- Lingüístico-Verbal: La lengua es una herramienta de gran utilidad para la comunicación y el aprendizaje y un conjunto cerrado de conocimientos que el niño memoriza. Por ello un buen software será aquel que induzca a pensar con una mente abierta, a expresarse con confianza y facilite el escuchar a los compañeros teniendo en cuenta sus puntos de vista. La escritura y la lectura son estrategias complejas, en las que la inteligencia lingüística-verbal se relaciona con todas las demás, especialmente con la lógico-matemática y la cinestésica corporal, facilitando lazos entre la acción-reacción del ordenador y el usuario. 


\begin{tabular}{|c|c|c|c|c|c|}
\hline \multicolumn{6}{|c|}{ LECTURA Y ESCRITURA } \\
\hline \multicolumn{6}{|c|}{ TAREAS } \\
\hline Lingüística & Musical & $\begin{array}{c}\text { Lógico- } \\
\text { matemática }\end{array}$ & Espacial & $\begin{array}{c}\text { Corporal } \\
\text { cinestésica }\end{array}$ & $\begin{array}{l}\text { Interpersonal } \\
\text { Intrapersonal }\end{array}$ \\
\hline $\begin{array}{l}\text { Competencia } \\
\text { semántica } \\
\text { significante } \\
\text { significado. } \\
\text {-Sintaxis } \\
\text { correcta }\end{array}$ & $\begin{array}{l}\text { Discriminación } \\
\text { auditiva. } \\
\text {-Integración } \\
\text { auditiva. } \\
\text {-Memoria } \\
\text { auditiva. }\end{array}$ & $\begin{array}{l}\text {-Operación de } \\
\text { correspondencia } \\
\text { significante- } \\
\text { significado. } \\
\text {-Operación de } \\
\text { seriación } \\
\text { fonemas- } \\
\text { sílabas, sílabas } \\
\text { y palabras. }\end{array}$ & $\begin{array}{l}\text { Orientación } \\
\text { espacial } \\
\text {-Constancia } \\
\text { de la forma } \\
\text { - } \\
\text { Descrimina- } \\
\text { ción figura } \\
\text { fondo }\end{array}$ & $\begin{array}{l}\text {-Estructura- } \\
\text { ción } \\
\text { temporal y } \\
\text { rítmica } \\
\text {-Motricidad } \\
\text { dinámica. }\end{array}$ & $\begin{array}{l}\text { Concentración } \\
\text {-Adaptación } \\
\text { escolar } \\
\text {-Control } \\
\text { emocional. }\end{array}$ \\
\hline
\end{tabular}

Cuadro 8: Técnicas para la reeducación de alumnos disléxicos (Sánchez, 2002).

En el cuadro 8 de lectura y escritura se muestran algunas técnicas para la reeducación de alumnos disléxicos. Los modelos multisensoriales favorecen la creación de imágenes visuales, auditivas, cenestésicas, táctiles y articulatorias que facilitan al alumno la tarea de diferenciar y reconocer correctamente los grafemas y discriminar fonemas, etc., (Sánchez, 2002).

Los alumnos con necesidades educativas especiales necesitan mayor número de experiencias para aprender y las percepciones multisensoriales evitan, la rutina y el aburrimiento. Los resultados son aún mejores si se rodean las TIC de pictogramas, objetos y materiales que pueden ser manipulados y refuercen las destrezas y habilidades que pretende desarrollar el software. Con la metodología adecuada se pueden superar resistencias por falta de motivación o por el temor al fracaso.

Los alumnos con problemas ortográficos suelen tener déficit en la discriminación visual, auditiva y/o en el lenguaje oral. Es por eso que se considera adecuado utilizar programas que, en un contexto de animación, pueda ofrecer al alumno imágenes que representen sustantivos, verbos, adjetivos, etc. Por medio del diálogo con la máquina, aprenden a trabajar con los significados y las categorías sintácticas que representan. Sánchez (2002) establece que si hay problemas visuales seria mejor enfatizar la enseñanza en 
la modalidad auditiva, luego poco a poco, ir entrenando las capacidades visuales. De igual manera menciona que en alumnos con dislexia visual puede ser apropiado el método fonético, que enseña la correspondencia grafemafonema antes que el nombre de cada palabra.

- Musical: Hay una relación muy estrecha entre lenguaje y sonido pues ambos son procesos secuénciales. La percepción auditiva se ha trabajado por psicólogos, pedagogos y logopedas con el fin de facilitar al alumno el proceso de decodificación de las notas acústicas. Esta es una operación muy compleja ya que los sonidos no están tan claramente separados como las letras del discurso escrito.

Los programas que incluyen además de sonidos, imágenes en movimiento, llamativos y estructurados textos, etc., hacen que estos programas se conviertan en un excelente recurso didáctico.

Los alumnos con deficiencia mental suelen tener problemas para captar bien los sonidos y procesar la información auditiva, por lo que es conveniente reforzar la memoria inmediata antes de pasar a la secuencial. Es importante recordar que para la adquisición de las habilidades lectoras, cada segmento de palabra grafema-fonema debe ser guardado en la memoria mientas los nuevos segmentos son procesados.

- Lógico-matemática: Las TIC tienen la habilidad para manipular símbolos y datos, que ha hecho que se asocien muchas veces con la inteligencia lógico-matemática en el terreno educativo. El micromundo generado por el ordenador obliga al alumno a interactuar con él según unas determinadas reglas asociadas a destrezas que se requieren en este ámbito como son: capacidad de abstracción, dominio jerárquico de los contenidos, ausencia de ambigüedades y contradicciones, etc. Es necesario que el usurario tenga desarrolladas esas habilidades denominadas herramientas lógicas en la línea de los conocimientos de las matemáticas, para aprovechar al máximo la potencia de las TIC.

Cuando un alumno tiene dificultades en el área lógico-matemática se puede apoyar desde las inteligencias que tengas más desarrolladas. Por 
ejemplo desde la espacial se puede ayudar con el uso de diagramas o gráficos, desde la musical pueden ser los instrumentos musicales usados como herramientas matemáticas, desde la corporal-cinestésica el juego con diferentes objetos. El resultado con esto se potenciara cuanto más conectado estén con su vida cotidiana.

Con el programa Playroom, por ejemplo se crea un entorno en donde están activando muchas inteligencias. Aun y cuando el propósito sea estimular la lógico-matemática, se pueden trazar puentes cognitivos desde una a las otras.

No se trata de establecer tipos de alumnos, sino de conocer su estilo de aprendizaje, cómo aprende mejor y apoyarnos en el lenguaje de la inteligencia en la que se siente más seguro y que sea él quien descubra y construya su propio conocimiento. De esta manera el software gráfico será más efectivo para alumnos con orientación espacial, pero quizás tenga un efecto diferente para aquellos que están inclinados hacia lo físico o verbal.

Se propone tener un escenario donde un software apropiado, junto a la metodología adecuada, facilite la comunicación y a partir de ahí se podrá trabajar por una igualdad de oportunidades.

Las TIC ponen énfasis en las destrezas y habilidades que el individuo pueda desarrollar, no en los aspectos relativos a su incapacidad. Proporcionan un marco en el que los alumnos pueden aprender a manejar sus dificultades. Se parte de sus puntos fuertes, de su estilo preferido de aprendizaje, y en función de éstos se seleccionan los recursos; software, comunicadores, hardware, vídeos, mapas, etc., y con estrategias didácticas que les ayuden a estimular sus inteligencias desarrollando las más efectivas a niveles aún más altos y trazando puentes cognitivos, que les ayuden a mejorar las que presentan graves dificultades. 


\subsubsection{Las Tecnologías de la Información y la Comunicación y los Trastornos Generalizados del Desarrollo (Alcantud, 2004).}

Investigación y revisión del desarrollo y la aplicación de las TIC en el ámbito de la intervención psicoeducativa en personas con trastornos generalizados del desarrollo o del espectro autista.

Se podría clasificar las líneas de desarrollo de las aplicaciones y usos de las TIC en cuatro grandes grupos, a saber.

a. El primer grupo consistiría en los desarrollos que intentan eliminar las barreras de acceso de las mismas TIC.

b. El segundo grupo incluiría todos los desarrollos, principalmente software, que intentan mediar en el aprendizaje o la habilidad de las personas con trastornos del desarrollo, interviniendo tanto directamente con el usuario como ayudando al profesional en la confección de materiales.

c. El tercer grupo se refiere a las herramientas que ayudan al profesional en el desarrollo de su función.

d. El cuarto grupo hace referencia al uso de las TICs en la formación de profesionales y en la orientación, asesoramiento e intervención con las familias.

De acuerdo a estos cuatro grupos se presentan una serie de programas y aplicaciones:

- Acceso al ordenador. a la hora de utilizar las TIC con las personas con discapacidad, uno de los principales problemas es el acceso a las mismas. El ordenador dispone de elementos input, que generalmente son el teclado convencional y el ratón, y también unos dispositivos output, que generalmente son el monitor y la impresora, estos dispositivos plantean serios problemas de manipulación 0 de comprensión. Actualmente se han desarrollado otros dispositivos menos convencionales que se están incorporando progresivamente, como el reconocimiento de voz como input y la síntesis de voz como output. Existe un arsenal de diferentes sistemas de acceso directo o de acceso por barrido, emuladores de teclado, emuladores de ratón, etc. Este desarrollo tecnológico está permitiendo que personas que no podían 
manipular el teclado o que no podían acceder a un computador convencional lo pueden hacer ahora. Berg, Junker, Rothman, Leininge y McMillian (1999) han desarrollado y evaluado un sistema (Ciberlink) para controlar el ordenador mediante ondas del electroencefalograma, electromiógrafo o electrooculografía. Este sistemas surge de la investigación militar, se encuentra en fase experimental, puede tener grandes aplicaciones en las personas con daño cerebral consecuencia de los primeros estadios de su rehabilitación.
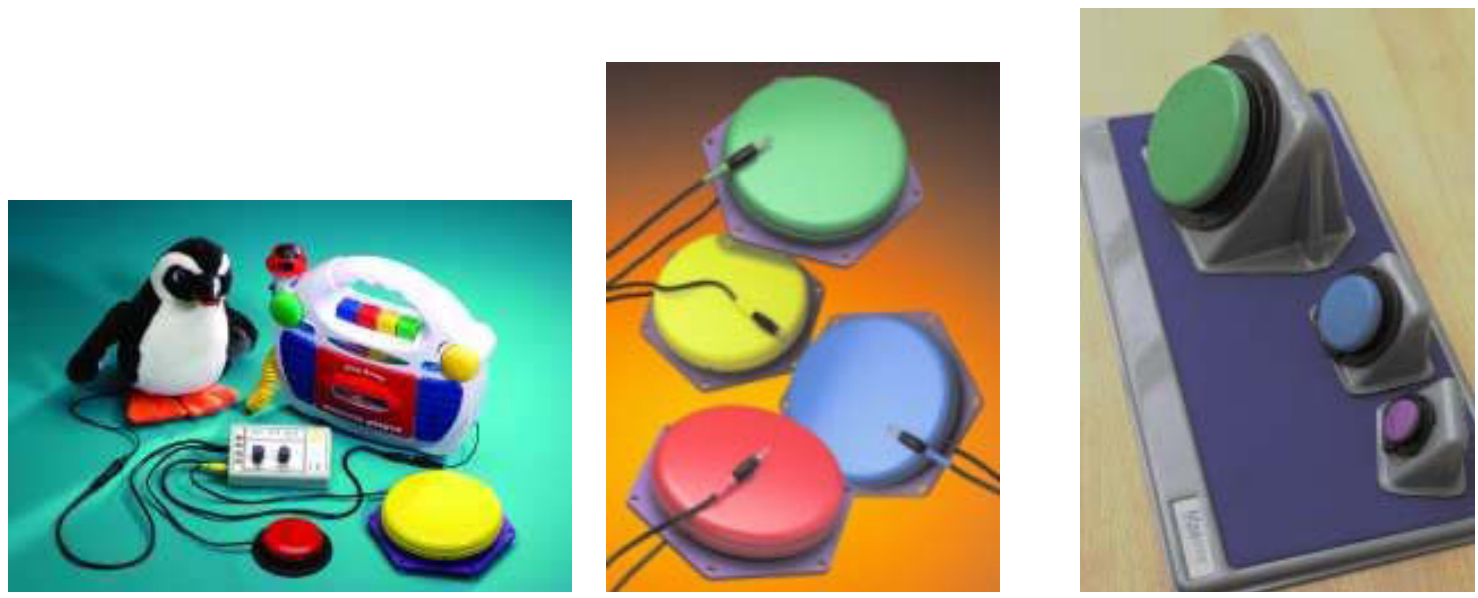

Figura 5: Ejemplo de diferentes switches (computadores) utilizados para el acceso del ordenador y para estructurar la respuesta (http://www.inclusiveTLC.com).(Alcantud,2004)

Trecce, Gips, Olivieri, Pok y Consiglio (1998) han desarrollado un sistema para mover el cursor del ordenador con el movimiento del ojo. Se puede utilizar en casos de personas tetrapléjicas sin posibilidad de movimiento en ningún miembro. Una cámara en miniatura, adosada al armazón de unas gafas o en una posición que capta el campo de visión de la persona afectada, se conecta al ordenador, quien mediante un programa reconoce la imagen y el movimiento del ojo, de forma que asocia el desplazamiento derecha-izquierda y arribaabajo con los respectivos movimientos del cursor. El mecanismo de selección se asocia con el parpadeo voluntario. Estos sistemas requieren un programa de entrenamiento para su uso. Una versión económica de estos sistemas son los que utilizan la webcam como sistema de captación de la imagen del usuario. Mediante una cámara de video, se selecciona la parte de la cara que se desea, nariz, ojos, etc., y cuyo movimiento se desea asociar al movimiento del ratón. 

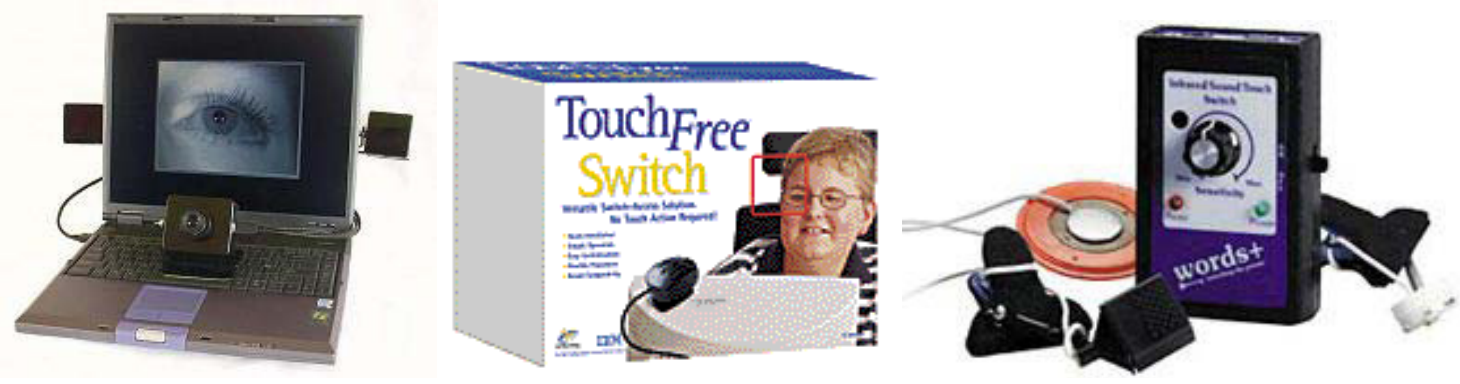

http://www.words-plus.com/website/products/input/isiswtch.htm

Figura 6: Ejemplo de diferentes mouses emulados por la mirada utilizados para facilitar el acceso al ordenador y para mejorar la atención (http://www.crea-si.com ).(Alcantud,2004)

En la figura 5 se presentan sistemas de acceso pensado para combinarse con programas que presentan los elementos a seleccionar mediante un sistema de barrido (scan). Lancioni, O Reilly, Oliva y Coopa (2001) han utilizando switch múltiple o computador múltiple como sistema de acceso al ordenador, consiguen generar respuestas diferenciales en niños con plurideficiencias (el retraso mental y el déficit de manipulación). Así mismo utilizaban también el mismo sistema para generar respuestas vocales en niños sin habla. Lancioni, O Reilly, y Basili (2001) informan que en la revisión de los trabajos que se realizaron desde 1986 hasta 1999, encuentran numerosas aplicaciones de sistemas de acceso al ordenador mediante switches que en combinación con programas de comunicación alternativa o emuladores de teclado con síntesis de voz o voz digitalizada, permite reducir la soledad e incomunicación de personas con profundos trastornos físicos, intelectuales 0 plurideficiencias.

La Pantalla táctil es otro tipo de periférico que se esta utilizando, emula el comportamiento del ratón del ordenador. La manipulación sobre la pantalla acerca la respuesta al usuario, por lo que se incrementa la atención en la tarea.

Huguenin (2000) utiliza la pantalla táctil con personas con trastornos del desarrollo y déficits de atención. Establece que la atención selectiva en adolescentes con trastornos del desarrollo no es una característica inmodificable, ua que la administración de estímulos simples en periodos de tiempo de entrenamiento largos y presentaciones repetidas mediante el ordenador, puede permitir desarrollar estilos de atención esenciales para aprender tareas educativas que involucren tareas complejas. 
Los sistemas de apoyo denominados dispositivos de ayuda portátiles o PAD, como organizadores electrónicos, localizadores GSM y dispositivos de telefonía móvil de tercera generación, ofrecen nuevas oportunidades a las personas con trastornos del desarrollo para facilitar su relación y comunicación con su entorno. Facilitando el flujo de información que va desde el entorno hasta la persona y el flujo inverso (Herrera y Labajo, 2001). Las agendas electrónicas están abriendo un gran número de posibilidades tanto para la comunicación aumentativa y alternativa, como también para la estructuración y programación de tareas. Es importante mencionar que los dispositivos de ayuda portátil pueden permitir observar, a través de video o fotografía, el uso que se supone tienen los objetos o la utilización conjunta de diversos objetos para la realización de una tarea, así como indicaciones sobre la localización de los mismos en el momento de realizar la tarea.

Loveland (2001) plantea que existen tres tipos de oportunidades de percepción-acción del entorno;

- Del mundo físico; dan la posibilidad de saber, por su forma y tacto, qué cosas pueden ser cogidas y/o manipuladas.

- Culturales; reflejan las interacciones estándar con los objetos aunque no sean las únicas posibles.

- Sociales; reflejan el significado de la actividad humana para otros humanos. Esta referida a la capacidad de las personas para percibir las oportunidades de interacción que las otras personas nos ofrecen.

En muchas de las ocasiones las alteraciones conductuales y emocionales de las personas con trastornos del desarrollo, son consecuencia de una inadecuada adaptación curricular. Kern y otros (2001) manifiesta que existen evidencias que han demostrado que estas personas con capaces de mantener un nivel de atención en la tarea adecuada cuando ésta se les presenta mediante un ordenador, manifestando su preferencia de trabajar con él en la clase, a hacerlo con los recursos convencionales.

Ejemplos demostrativos del uso de la tecnología en el aprendizaje de personas con trastornos del desarrollo con el fin de mejorar sus habilidades;

- El sistema de predicción de palabras de MacArthur (1999). 
- La instrucción de frases en niños con autismo seleccionando las partículas de conexión a partir de estímulos visuales presentados en la pantalla del ordenador de Yamamoto y Miyra (1999).

- La adquisición de las reglas de correspondencia entre grafema y morfema, discriminación fonológica, en niños afásicos, mediante el uso de tareas administrativas por ordenador en las que se debe juzgar la correspondencia entre sonido y el símbolo gráfico expuesto de Magnan y Bouchafa (1998).

- La mejora de la comprensión lectora en personas sordas usuarias del lenguaje de signos, con el empleo de sistemas multimedia donde se utiliza como apoyo grabaciones de intérpretes de lenguas de signos describiendo el significado de vocabulario explicito de Alcantud, Ferrer, Romero Y Asensi (1999).

Algunos sistemas de signos se han especializado para personas con autismo, como el sistema de comunicación total de B. Schaeffer (Schaeffer, B.1986) o el sistema de comunicación por intercambio de imágenes.
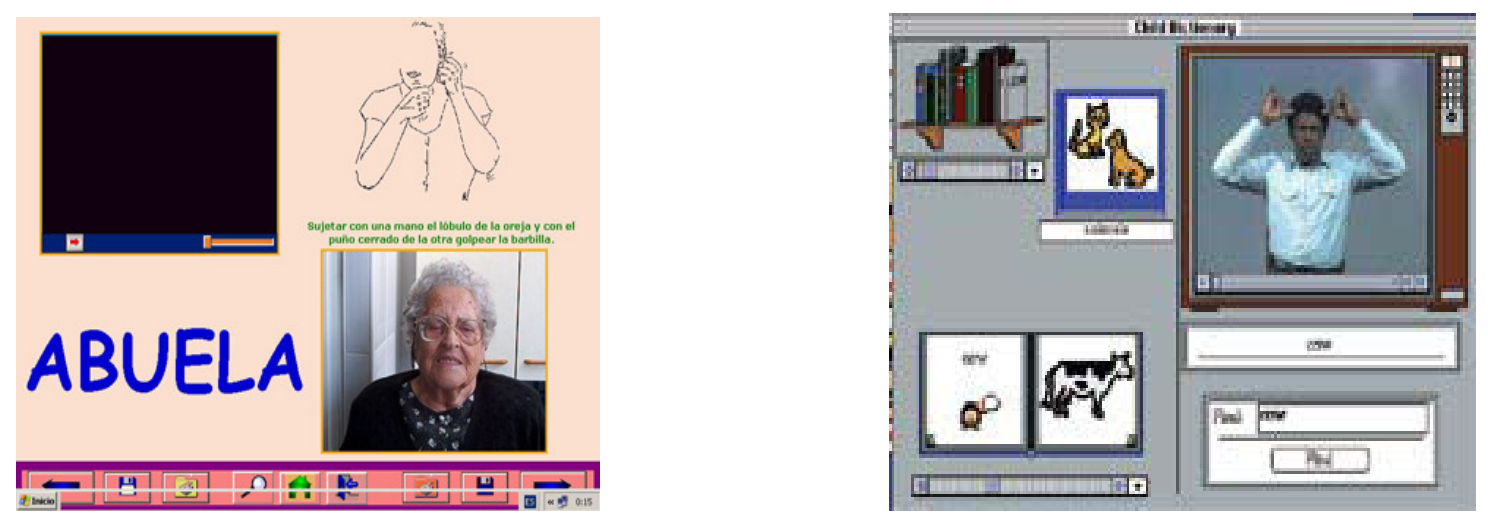

Figura 7: Imagen del diccionario multimedia de signos del programa de comunicación total de B. Schaeffer (Gómez 2002).

La comunicación es uno de los aspectos más importantes, al ser un vehiculo de trasmisión de información y de la interacción social permitiendo el establecimiento de vinculaciones afectivas y del desarrollo intelectual. Alcantud (2004) establece que una de las líneas de estudio de más importancia es la implementación temprana de los sistemas de comunicación alternativa para evitar el rechazo de los niños con trastornos del desarrollo. Así mismo enuncia que otra línea de desarrollo es el apoyo a los profesionales en el desarrollo de 
tableros de comunicación, facilitando el acceso a catálogos de símbolos y construcción de paneles de comunicación. El BroadMaker de Mayer-Johnson Inc, que se puede consultar en http://www.mayer-johnson.com o el tablero construido por Jordi Lagares en http://www.lagares.org, el coste de los comunicadores electrónicos hace emerger software de autor para construir comunicadores soportados por el propio ordenador. Entre estos este autor señala el sistema S.A.W. (Switch Access to Windows de ACE Centre http://www.ace-centre.org.uk/ ) o el SICLA (Sistema de Comunicación para Lenguajes Aumentativos de Fundación Telefónica.

( http://www.fundacion.telefonica.com/programas sociales/sicla.html ). Con estos sistemas y software, el ordenador, y en particular los ordenadores portátiles y los sistemas PAD se convierten en sistemas alternativos a los comunicadores electrónicos con más presentación y menos coste.
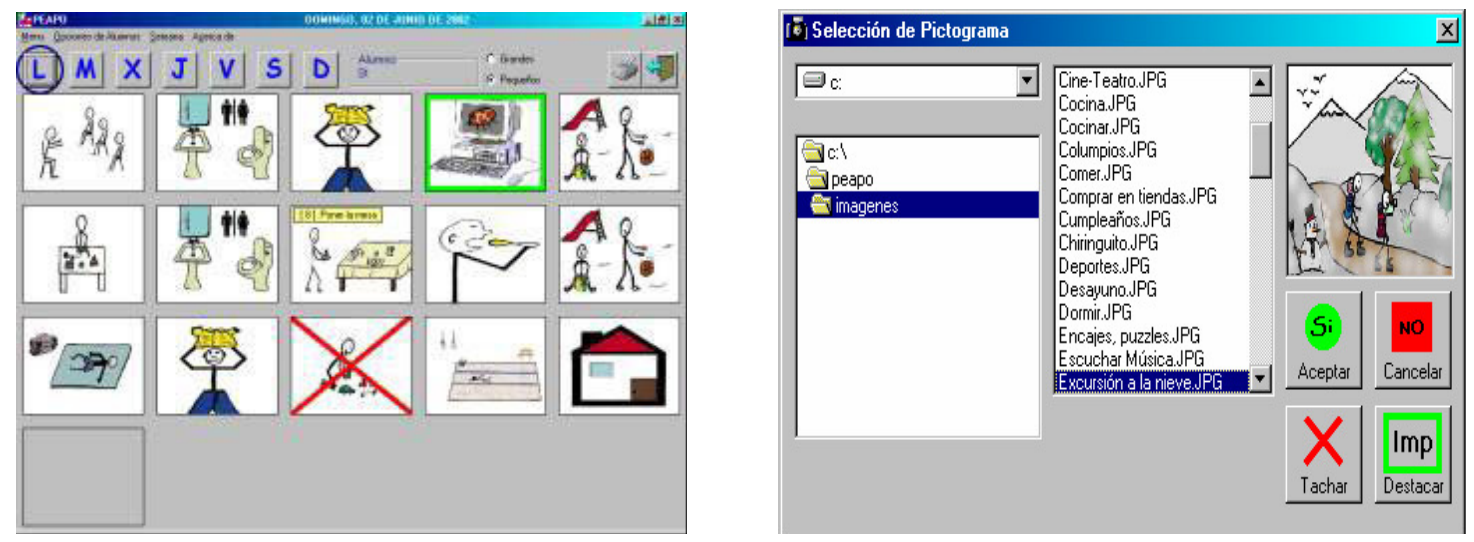

Figura 8: Ejemplo del programa PEAPO una de las primeras aplicaciones de software especificas para personas con trastornos del espectro Autista en España. (Alcantud, 2004).

Al margen de los sistemas dirigidos específicamente para la comunicación alternativa y aumentativa, también existen sistemas desarrollados para facilitar la elaboración de agendas y organizadores de trabajo, así como el Sistema de Comunicación por intercambio de imágenes PECS (Picture Exchange Communication System), o el sistema Make-A-Schedule o el sistema PEAPO es un Programa de Estructuración Ambiental Por Ordenador (Ver Figura 8). Este programa supone la traducción y adaptación de algunos sistemas de intervención específicos para personas con Trastornos del Espectro Autista TEA. Programas de estructuración, sistemas de anticipación, agendas personales. 


\subsubsection{Las TIC y las personas con Discapacidad visual, ACCEDO-ONCE (Gastón, 2008 y García, 2004).}

En la actualidad la evolución de las tecnologías digitales, en el ámbito educativo y su implementación en los centros escolares esta influyendo en los modelos actuales de enseñanza y aprendizaje, desarrollando cambios en la metodología de trabajo, en los profesores como en los alumnos. La implementación de las tecnologías implican nuevos modelos de estudio, nuevas formas de trabajar en equipo, diferentes métodos y técnicas de estudiar, de preparar la asignatura, de examinarse, etc.

El momento actual en el que el propio Sistema Educativo está en situación de cambio, implica que en la implantación de las tecnologías en el aula, habrá que hacer convivir elementos clásicos de la escuela con nuevos sistemas, tanto de trabajo como organizativos. Por lo tanto el Sistema Educativo tiene que proporcionar la formación y las herramientas necesarias para cambiar las políticas educativas tradicionales por otras con enfoques totalmente diferentes e innovadores (García, 2004).

Los estudiantes con discapacidad visual se encuentran en una gran desventaja en el uso de la tecnología, independientemente de lo accesible que pueden ser o no las páginas web a las aplicaciones educativas, los contenidos que se encuentran incluidos en estas no lo son en un $100 \%$ de los casos.

En los casos de alumnos ciegos y deficientes visuales habría necesidad de incorporar en el aula según las necesidades del alumno; impresora braille, pantalla de ordenador de mayor tamaño, escáner con sistema lector incorporado, etc., por ello las redes informáticas del centro deberá tener la capacidad de soportar tanto el software, como el hardware correspondiente.

A la hora de definir el tipo de puesto de estudio de un alumno con discapacidad visual, se deben tener en cuenta los siguientes parámetros (García, 2004):

- Tipo de visión y características de restos visuales, en su caso.

- Sistema de lectoescritura (tinta-braille). Se debe tomar en cuenta que hay niños que utilizan ambos sistemas en función de la tarea que van a realizar. 
- Nivel y etapa del alumno.

- Características del aula (iluminación, mobiliario, superficie, etc.).

- Metodología de trabajo en el aula y tipo de tareas a desarrollar.

La determinación de los aspectos de la adaptación del puesto de estudio, debe ser definida por el Maestro de Apoyo, asesorado por los Técnicos de Rehabilitación y Tiflotecnología, determinando las herramientas y materiales que requiere el alumno en cada caso.

Para los alumnos con discapacidad visual leve, que pueden utilizar los libros y materiales de tinta, se requiere para el puesto de estudio:

- Iluminación general del aula adecuada a su resto visual, con independencia de un flexo para su trabajo individual.

- El alumno deberá estar ubicado a una distancia apropiada de la pizarra y centrado respecto a ésta, siguiendo el trabajo que se realiza.

- Un lugar en la clase que facilite la comunicación alumno-profesor.

- No deberá estar aislado respecto a sus compañeros.

Las herramientas de trabajo usadas para los alumnos con discapacidad visual leve son:

- Mesa de trabajo amplia, que permita utilizar las herramientas necesarias.

- Pantalla de ordenador TFT o PLASMA de 21 pulgadas (a determinar en cada caso).

- Teclado de ordenador.

- Atril de lectura, independiente de la mesa.

- Flexo (características a determinar).

- Magnetófono de 4 pistas.

- Alta voces de ordenador y cascos de audio.

Para la atención de los alumnos con ceguera total se debe tener en cuenta los siguientes aspectos, que sean accesibles y facilite sus desplazamientos 
autónomo por el aula y el transporte de material que favorezca la comunicación alumno-profesor y proximidad e interrelación con otros compañeros.

En este caso para su puesto de estudio ha de tomarse en cuenta (García, 2004).

- Mesa de trabajo adecuada al material que usa.

- Pantalla de ordenador para seguimiento del profesor y trabajo en equipo.

- Línea braille.

- Máquina de escribir braille.

- Magnetófono de 4 pistas.

- Tablero de dibujo y herramientas (goma de caucho, compás, punzones, ruedas dentadas, papel plástico, etc.).

- Altavoces del ordenador y casco de audio.

- Caja de matemáticas y ábaco.

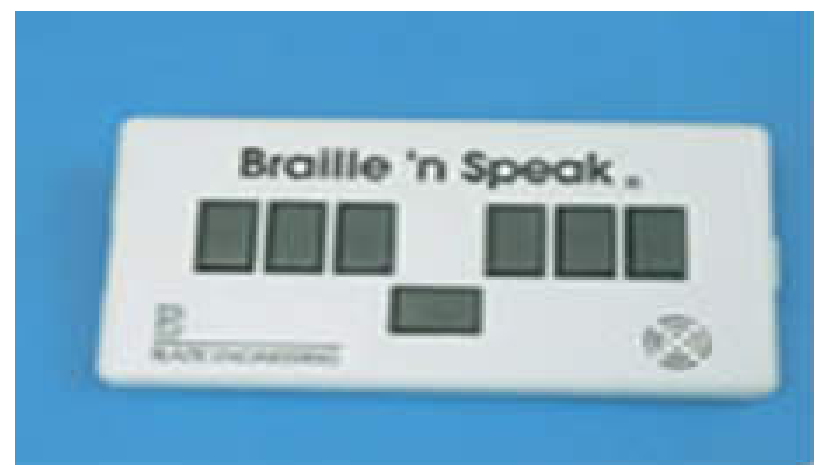

Figura 9: Ordenador braille hablado (García 2004).

Ejemplo; Pequeño ordenador portátil $(20,6 \mathrm{~cm} \times 10,6 \mathrm{~cm} \times 2,4 \mathrm{~cm}$ y unos 300 gramos de peso) con gran capacidad de almacenamiento y posibilidad para más de 30 horas. Consta de seis teclas correspondientes a los seis puntos del sistema braille y una séptima tecla para el espaciador.

La salida se produce por una síntesis de voz. Puede conectarse con un ordenador y se le puede conectar una unidad de disco propia. Sus funciones principales son: tratamiento de textos, reloj, cronómetro, alarma, calendario, directorio telefónico y calculadora convencional y científica.

El acceso real a la tecnología ayuda a la integración de las personas, mientras que la falta de está propicia la exclusión. La ONCE Organización 
Mundial de Ciegos de España, ha formado el grupo ACCEDO (ACcesibilidad a Contenidos EDucativos ONCE), cuyo objetivo es ayudar a los creadores de contenidos tecnológicos educativos a hacer estos contenidos accesibles para los niños y jóvenes con cualquier tipo de discapacidad visual.

La Accesibilidad a los contenidos educativos, va más allá de la propia accesibilidad a la herramienta y al manejo de la misma. Se refiere a que un alumno con cualquier tipo de discapacidad visual pueda utilizar el mismo programa que su compañero vidente, de forma simultánea con el mismo, compartiendo un ordenador y consiguiendo los objetivos para los cuales está diseñada la actividad. Esto se puede lograr desde el diseño de la actividad, la programación, la adaptación de contenidos y la utilización en algunos casos de herramientas de apoyo.

Para ayudar a los diseñadores y programadores se ha desarrollado un documento llamado "Pautas para el diseño de entornos educativos accesibles para personas con discapacidad visual", en este documento se abordan diferentes tipos de aplicaciones que en función de la edad y la experiencia pueden utilizar los alumnos, y la forma en que pueden ser accesibles unas $y$ otras (Gastón, 2008).

- Las aplicaciones no dirigidas son aplicaciones estándar, pueden ser manejadas con un revisor de pantalla. Estas son adecuadas para alumnos con un manejo suficiente del teclado y del revisor de pantalla, por ello no son aconsejables para los primeros cursos escolares.

- Las aplicaciones dirigidas son accesibles por sí mismas, sin ayuda de revisor de pantalla. Una locución o un personaje va dirigiendo al alumno en la realización de las actividades propuestas y dándole información sobre los resultados.

\section{Ventajas del usar el ordenador:}

Se pueden encontrar grandes ventajas en el uso de la tecnología por las personas sin visión, como hacer la compra, consultar al ayuntamiento, leer la factura, estos son algunos ejemplos de lo que supone la informática en su vida cotidiana. 
En la escuela en los últimos años el desarrollo tecnológico ha facilitado la vida escolar con herramientas como el braille hablado, la línea braille, el escáner, etc. Los revisores de pantallas han permitido a los estudiantes sin visión acceder a gran cantidad de información a través de Internet, a la comunicación a través del correo electrónico, etc.

A nivel personal y social, los beneficios son tan importantes como el acceso y manejo de la información que aporta la tecnología a los alumnos con discapacidad visual. El tener la posibilidad de compartir herramientas y actividades de forma real con los compañeros videntes, eleva su autoestima y la sensación de competencia, mejorando su integración. Así mismo las posibilidades de comunicación que permite la tecnología, facilitar las relaciones sociales y la participación ciudadana.

La informática deja de ser un material de apoyo para convertirse en una herramienta ordinaria para el uso de todas las asignaturas.

El problema actual radica en que la utilización eficiente de los contenidos insertados en los programas educativos, son prácticamente imposibles para los niños son visión.

\section{Problemas fundamentales en el manejo del ordenador.}

Es necesario conocer las posibilidades actuales que la tecnología ofrece a las personas sin visión, esto nos permite tener presentes las dificultades que tienen para su manejo y de esta manera poder llegar a resolverlas. Las fundamentales:

- La visión globalizada, el oído y el tacto no. Añadiendo que no todo lo visual es comprensible ni al tacto ni al oído. El diseño habrá de tener esto en cuenta, aportando la información necesaria pero no de forma invasiva.

- En las aplicaciones educativas no es suficiente el manejo del teclado, ni las locuciones, ya que el desarrollo de la percepción táctil es un objetivo que nos e puede obviar. Se deberá investigar la forma de permitir al niño ciego explorar tactilmente lo que los demás pueden observar visualmente. 
- El uso del ratón habitual es imposible para los niños son visión, habrá que investigar nuevas herramientas que permitan de localización y arrastre.

- El lenguaje que se utiliza es confuso para los niños que no ven (pinchar, coger, soltar, etc.) además de la imposibilidad o dificultad de la imitación visual. Por lo que se requiere que las explicaciones previas a la utilización de la aplicación sean claras y que los maestros ayuden a los alumnos en su inicio.

Posibles soluciones:

Las soluciones son diversas como los problemas y se analizan desde diferentes ángulos:

* Sensibilización; en este sentido es importante que los programas educativos sean realmente accesibles, por ello se requiere en primer lugar que la sociedad tenga claro que los niños sin visión tienen las mismas necesidades y los mismos derechos a utilizar y aprovechar los recursos tecnológicos de la misma manera que las demás personas.

* Formación y Asesoramiento; Los diseñadores y programadores deben tomar en cuenta para que público están programando. Deben conocer la edad, así como las características de los alumnos y sus necesidades. En este caso también es importante que tengan nociones sobre la forma de percibir de los niños y jóvenes con discapacidad visual. La formación en este tema es larga y muy especifica, por ello es necesario que los especialistas en el tema les presten ayuda y asesoramiento. La forma de hacerlo depende de cada país e institución, es importante considerar que los programas solo pueden ser accesibles si se hace la programación desde un principio.

Programación; En el desarrollo de estas aplicaciones se toman en cuenta una serie de requisitos que deben reunir los programas para que sean accesibles y que están relacionados con el lenguaje utilizado, los ejercicios a realizar, el contraste cromático, el tipo de letra, las formas de manejo de las aplicaciones, las herramientas de acceso a utilizar etc. 
La forma de trabajo habitual que se realiza es por el grupo ACCEDO:

1. El desarrollador de contenidos, por lo general es un maestro que elabora un guión. En el se aportan orientaciones pedagógicas relacionadas con la discapacidad visual, apoyando en al selección de actividades y en la adaptación de las mismas.

2. Una vez que se haya elaborado el guión, los diseñadores realizan los dibujos tal y como se los han descrito; en este paso se dan orientaciones relacionadas con los colores, tamaños, contrastes, etc., para que el aspecto visual de la aplicación sea manejable por el alumno con cualquier patología visual.

3. Por último, el guión y el diseño pasan a la fase de programación. En este momento se dan orientaciones técnicas a los programadores para que todos los elementos estén etiquetados, permitiendo que el programa se pueda manejar simultáneamente con ratón y con teclado, para que cada pantalla tenga una locución que explique su contenido, etc.

Investigación de nuevas herramientas: La accesibilidad en los programas se puede conseguir mediante el manejo del teclado en algunas actividades. Pero hay otras en las que se requiere necesariamente otro tipo de herramientas de apoyo, que pueden ser de manejo con el ratón o porque requieren de alguna manera del uso del tacto de los niños ciegos. Muchas de estas se encuentran en el mercado, permitiendo costes mas baratos y ayudando a la normalización y la integración de los alumnos.

- Tabla digitalizadora; es una plancha magnética de material plástico sobre la que se refleja el área de la pantalla del ordenador que se desee, en el se puede dibujar, escribir, navegar, etc., mediante un lápiz magnético qye hace las veces de ratón. Con está muchos de los ejercicios presentes en la pantalla pueden adaptarse para hacerlos en relieve de forma, de tan 
manera que lo que trabaje el niño ciego sea exactamente lo mismo que trabaja el niño con visión. Esta adaptación puede adaptarse y se hace relieve mediante diferentes medios; con texturas de distintos tipos, con horno fuser, maquina de escritura braille, con pauta, etc., permitiendo adecuar el gasto a las posibilidades de cada uno.

- Tablet pc: es un ordenador portátil cuya pantalla de 12,2" es interactiva por medio de un lapicero magnético. Presenta las mismas funciones que cualquier ordenador portátil, permitiendo además interactuar con la pantalla. Su manejabilidad, luminosidad y resolución facilita el trabajo, siendo una herramienta muy motivadora para los alumnos con discapacidad visual ligera y moderada. Ellos pueden colocar el Tablet PC en la posición que sea más adecuada en cuanto a la iluminación, brillos, etc.

La posibilidad de poder trabajar directamente con un lapicero sobre la pantalla a modo de ratón, facilita mucho el trabajo de los alumnos, necesitando menos esfuerzo viso-motor y es más directo que el uso del ratón.

En el mercado existen pantallas y pizarras interactivas que pueden ser útiles $\mathrm{e}$ interesantes para los alumnos con discapacidad visual.
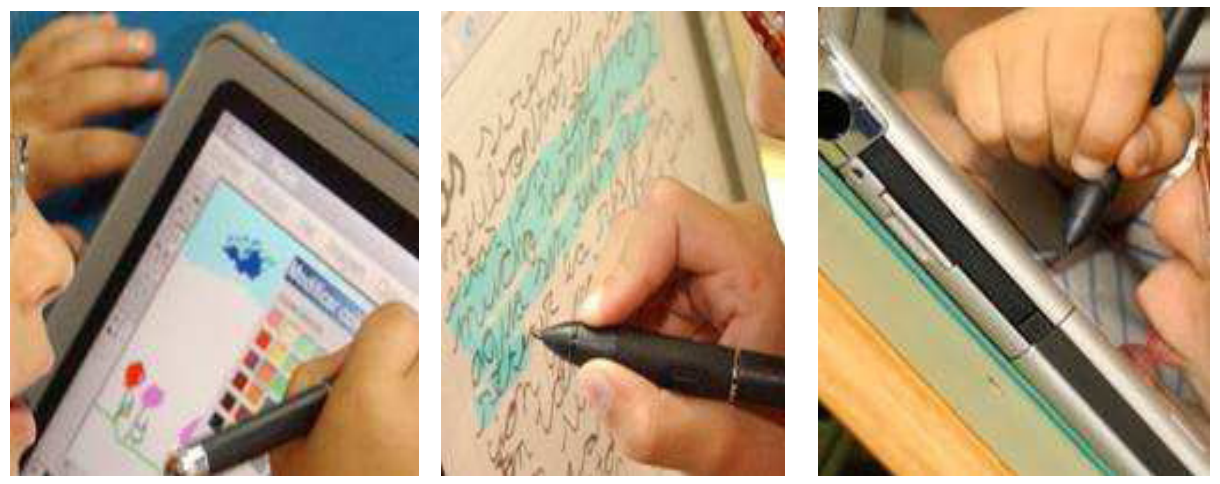

Figura 10: Fotografías de niños utilizando el tablet pc programa de dibujo. Windows joumail y ejemplo de distancia de trabajo, Gastón (2008).

La accesibilidad real a los contenidos ha de hacerse trabajando en equipo, asumiendo cada uno su responsabilidad, de esta manera se podría 
comprender las necesidades y derechos de los estudiantes con discapacidad visual para trabajar en igualdad de oportunidades que el resto del grupo.

* Ventajas de la accesibilidad de contenidos;

- Integración: Los alumnos con discapacidad visual podrán utilizar los mismos programas que el resto de sus compañeros.

- Normalización: Las herramientas de apoyo se encuentran en el mercado ordinario.

- Solidaridad y generalización: El trabajo que se realice en red, poder compartir los materiales accesibles con otros profesionales de otras ciudades o países.

- Abaratamiento de costos. La utilización de los recursos en la web y de las herramientas que se utilizan habitualmente permitirá abaratar el coste de la producción, llegando a un mayor número de alumnos.

\section{Retos actuales:}

Técnicos:

- Contar con un validador de contrastes no sólo para textos, sino para los diferentes tamaños de figuras, formas, de tan manera que cualquier diseñador pueda hacer pruebas con los colores que elija y compruebe su grado de accesibilidad.

- Investigar sobre impresoras en relieve que permita un trazado de gráfico más real de lo que lo permiten las actuales.

- Desarrollar programas de conversión de caracteres de tinta braille de 6 y 8 puntos para iniciar la lectoescritura con la línea braille.

- Que los programas de autor incluyan herramientas de accesibilidad fáciles de manejar para los maestros y demás profesionales que les interese programar.

\section{Pedagógicos:}

- La introducción de la tecnología de la información en el aula como herramienta cotidiana en el proceso enseñanza- 
aprendizaje, producirá cambios en la metodología por lo que será necesario analizarlos y adaptase a ellos.

- Tomar decisiones y estudiar sobre algunos de los aprendizajes específicos, como el braille de 6 u 8 puntos, el cálculo, etc.

- Es necesario investigar sobre la edad más adecuada para la introducción de las diferentes herramientas de apoyo que están surgiendo.

- Plantearse los cambios que se producirán en las estructuras de apoyo, con la incorporación de las tecnologías como herramienta de uso habitual.

\subsubsection{Programa informático de estimulación visual temprana en niños con baja visión (Urbina y Ortego, 2008).}

El programa se plantea como un punto de partida, con propuestas y sugerencias que cada profesional debe adaptar, completar o desarrollar en función de las características individuales y del entorno de cada niño.

Todos los programas para trabajar con niños con dificultades visuales tienen en común el objetivo de ayudar al niño a desarrollar al máximo su potencial y conseguir un nivel óptimo de funcionalidad visual. Su aparición está determinada por la posibilidad de entrenar al sujeto para que se aproveche de mejor manera la información óptica que recibe (Urbina y Ortego,2008).

Para poder alcanzar este objetivo se plantean diferentes propuestas de ejercicios y actividades, indicando los materiales. Al tratarse de recursos didácticos de uso general algunos pueden encontrarse comercializados, de igual manera otros aunque sean específicos, también están comercializados. Algunos pueden encontrarse fácilmente y otros requieren de su elaboración manual.

Respecto a los materiales informáticos para niños con dificultades visuales, algunos son comercializados, por sus características de color, tamaño, color, forma, etc., pueden ayudar a estimular la visión de los alumnos con discapacidad visual. Muchas veces sólo se aprovechan en determinadas actividades, ya que no se tienen en cuenta los principios de contraste, tamaño, 
color, simplicidad de formas, no demasiada información visual, elementos básicos de los programas específicos. Por otra parte los pocos materiales editados se encuentran en otros idiomas, entre ellos podemos encontrar:

- Lilly \& Gopo programa multimedia de un conjunto de materiales; películas de video, objetos, laminas de ilustraciones, juegos de ordenador, y otros. Los juegos de ordenador utilizan para su diseño el mismo material gráfico empleado en los demás soportes. Ya que la justificación para la realización de este medio es la motivación para los niños, comparable con la televisión. Algunos de los juegos propuestos permiten la realización de dibujos o la selección de objetos que aparecen al azar por la pantalla, etc., permitiendo entrenar la visión, aprovechando sus posibilidades interactivas, a la vez que se enseña al niño técnicas de búsqueda visual y al mismo tiempo, puede ser una herramienta para detectar posibles deterioros en el campo visual.

Urbina y Ortego (2008) recopilan una investigación descrita por Hammarlund terapeuta visual del Tomteboda Resource Centre de Suecia. La investigación consiste en une studio de evaluación para el diseño de programas específicos para la estimulación visual de niños de 2 y 6 años de edad. Concluyendo que los elementos gráficos de estos programas deben tener los contornos muy definidos y un alto contraste, afectando también los colores y formas. El estudio mostró que el ordenador añade especial atractivo a las tareas de ejercitación visual a partir de la incorporación de sonido y movimiento, lo que induce a mantener la atención.

Se observa en general una tendencia progresiva a la utilización de materiales informáticos en las aulas, desde las primeras etapas educativas. Experiencias actuales confirman que el uso del ordenador despierta una gran motivación desde edades tempranas y su gran utilidad para trabajar múltiples aspectos curriculares.

Existen dificultades cuando se intenta trabajar con alumnos con baja visión en actividades con el ordenador, impidiendo que se puedan integrar a ellas. Dificultades que se podrían salvarse si se cuenta con materiales que tuvieran en cuenta sus necesidades, como las recomendadas anteriormente. 


\subsubsection{La Nuevas Tecnologías como recurso de apoyo para alumnos con discapacidad motora y psíquica (Fernández, 2004).}

En Educación Especial hablar de Nuevas Tecnologías implica tener en cuenta algunas consideraciones con respecto a estos términos. Anteriormente se concebía la educación especial con respecto a grupos y colectivos de alumnos, tipificados y clasificados según sus características que influían negativamente o problemáticamente en su aprendizaje. Hoy en día se conciben las necesidades educativas especiales como una posibilidad abierta a cualquier alumno 0 alumna que, en un momento determinado, de manera más o menos permanente, requiere de algún tipo de apoyo o atención complementaria a la acción educativa común y ordinaria.

Los medios de comunicación y nuevas tecnologías en el contexto de la escuela, donde todos los alumnos tengan cabida, es apuntar una doble necesidad, por una parte, a que todos los sujetos se puedan beneficiar de los medios utilizados dentro de un marco general, y por otro lado, la necesidad de diseñar y producir medios específicos que pueden ser de ayuda y beneficio a las personas con necesidades educativas especiales.

De acuerdo al concepto de necesidades educativas especiales, las derivadas de una discapacidad motora, hacen referencia a un grupo de alumnos y alumnas muy heterogéneo, pudiendo oscilar desde los especiales requerimientos que presenta un niño con alteración ósea (baja talla), hasta una persona con secuela de parálisis cerebral o espina bifida (daño derivado de una lesión en el sistema nervioso central). Muchos alumnos presentan discapacidad motora como consecuencia de una discapacidad física asociada a un retraso mental. En este caso su capacidad para manifestar conductas intelectuales y sociales presenta una disincronía, un retraso o dificultad, de acuerdo a su edad, para adquirir determinadas conductas básicas como el lenguaje oral (la expresión y la comprensión verbal), el desarrollo físico y motor (autonomía motriz), determinados comportamientos sociales, la autonomía personal, etc. Esta heterogeneidad requiere una diversidad de necesidades como son: 
$>$ Adquirir, desarrollar y utilizar el lenguaje oral y escrito, comprensivo y expresivo.

> En los casos de alumnos no vocales, se realiza a través de sistemas de comunicación alternativos o aumentativos.

$>$ Desarrollar las capacidades perceptivas, sensomotoras y cognitivas que permitan la interacción con el medio, la movilidad y las destrezas motoras funcionales para sobre el contexto próximo.

> Necesidad de adquirir el repertorio conductual y de habilidades sociales que hagan posible el control y la regulación conductual autónomas y la interacción con sus iguales y con los adultos.

Existen diferentes dispositivos especiales que permiten a los sujetos interactuar con los ordenadores, como los licornios (adaptadores situados a modo de corona en la cabeza de los individuos, facilitando las interacciones con el ordenador) y las varillas bucales. Además de estas adaptaciones también existen teclados específicos adecuados a las necesidades del sujeto.

En la página web del Centro de Autonomía Personal y Ayudas Técnicas ( http://www.ceapat.org/index.jsp ) cuyo misión es la de contribuir a mejorar la calidad de vida de todos los ciudadanos, con especial apoyo a personas con discapacidad y personas mayores, a través de la accesibilidad universal, el diseño para todos y la tecnología de apoyo. En esta Web se pueden encontrar teclados amplios que poseen una distribución especial en las teclas y requieren menor amplitud de movimiento para abarcarlas; teclados especiales; teclados para una sola mano; teclados de conceptos, es un tablero sensible a la presión, tamaño DIN-A3, dividido en 8 filas por 16 columnas, 128 teclas, pudiendo programar cadenas de caracteres o funciones asociadas a una 0 a varias teclas, y teclados virtuales, en la pantalla de un ordenador aparece un teclado. Es un programa que trabaja simultáneamente con las aplicaciones estándar, siendo el dispositivo con el que se va a manejar el teclado virtual o el ratón o pulsador.

Dado que muchos paralíticos cerebrales son muy lentos en sus movimientos de manos y dedos, por lo que necesitan varios segundos para levantar el dedo y volver a pulsar, para ellos existen programas informáticos que evitan que se repita automáticamente una tecla; un ordenador que no utilice estos programas 
repetirá automáticamente la tecla a una velocidad de diez caracteres por segundo, siempre que esté pulsada durante más de medio segundo.

También existen adaptaciones en los ratones, como:

- El "fiel" comercializado por la empresa Logitech, gracias a un motor incorporado transmite al sujeto sensaciones táctiles, para describirle de esta forma los objetos diferenciados que aparecen en la pantalla.

- Los "TrackBall" son ratones con la bola invertida y que sirven de gran utilidad, y los ratones cefálicos, que funcionan con tecnología de infrarrojos.

Los sistemas aumentativos de voz también son de gran ayuda, facilitando la autonomía y comunicación del alumno, los sistemas de símbolos como el Bliss que es fácil de usar y además no es necesario que el sujeto sepa leer para utilizarlo, pues se ha comprobado que las personas con discapacidad con un adiestramiento previo, son capaces de utilizarlo con mucha habilidad, por medio de tableros convencionales.

Los softwares específicos se utilizan en un gran número de adaptaciones, para sujetos con discapacidad motriz.

Fernández (2004) presenta una muestra de diferentes software, para alumnos con discapacidad motora y psíquica, entre otros, de la Junta de Andalucía (2003).

\begin{tabular}{|c|c|}
\hline $\begin{array}{l}\text { Teclado virtual } \\
\text { (Versión 2003) } \\
\text { Autor: Miguel } \\
\text { Aragüez Nieto }\end{array}$ & $\begin{array}{l}\text { Destinatarios: Alumnos con discapacidad motora severamente } \\
\text { afectados: parálisis cerebral, esclerosis lateral amiotrófica, etc. } \\
\text { Utilidad/finalidad: Acceso a lectoescritura; Comunicador para } \\
\text { personas no vocales; Acceso a utilidad lúdica con un sistema de } \\
\text { barrido (visualización de fotos, audición de CDs y juegos para } \\
\text { desarrollar las capacidades cognitivas básicas). }\end{array}$ \\
\hline $\begin{array}{c}\text { Navegante } \\
\text { Autor: Isabel Rey } \\
\text { Fernández }\end{array}$ & $\begin{array}{l}\text { Destinatarios: Personas con una gran afectación en la movilidad. } \\
\text { Utilidad/finalidad: Navegación por Internet. }\end{array}$ \\
\hline $\begin{array}{c}\text { Actividades de } \\
\text { lectoescritura para } \\
\text { motóricos. } \\
\text { Autor: Miguel }\end{array}$ & $\begin{array}{l}\text { Destinatarios: Alumnado con dificultades motoras. } \\
\text { Utilidad/finalidad: Iniciación al aprendizaje de la lectoescritura. }\end{array}$ \\
\hline
\end{tabular}




\begin{tabular}{|c|c|}
\hline Aragüez Nieto & \\
\hline $\begin{array}{c}\text { Juegos para la } \\
\text { estimulación } \\
\text { perceptiva y } \\
\text { cognitiva. } \\
\text { Autor: Jorge Arévalo } \\
\text { Millet. }\end{array}$ & $\begin{array}{l}\text { Utilidad/finalidad: Estimación perceptiva y cognitiva. } \\
\text { RELACIÓN DE PROGRAMAS: } \\
\text { - Juegos de percepción de figuras geométricas, simetrías y } \\
\text { orientación: Arquitectura ( } 1 \text { y } 2) \text {, Cruz, Espejos, Gusanito, } \\
\text { Horizontal, Simetrías, Tamaños, Túneles, Vertical. } \\
\text { - Juegos de esfuerzo de la lectura integral: Casa, } \\
\text { Comevocales, Rana. } \\
\text { - Juegos relacionados con el dibujo: Colección Dibuja (1, 2, } \\
\text { 3, y4). } \\
\text { Juegos sobre conceptos matemáticos básicos y de } \\
\text { iniciación a las matemáticas. Cantidades, Colores, Compras, } \\
\text { Flechas, Formas, Plantas, Rompecabezas 12, Tren de contar, } \\
\text { Tren de sumar. }\end{array}$ \\
\hline $\begin{array}{c}\text { Programas y } \\
\text { aplicaciones } \\
\text { informáticas para el } \\
\text { acceso a las } \\
\text { Tecnologías de la } \\
\text { Comunicación y la } \\
\text { Información. } \\
\text { Autor: Jordi Lagares }\end{array}$ & $\begin{array}{l}\text { Destinatarios: Personas con discapacidad motriz y control muy } \\
\text { limitado de su motricidad que no pueden comunicarse mediante la voz. } \\
\text { Utilidad/finalidad: Facilitar la accesibilidad y la comunicación a las } \\
\text { personas no orales. } \\
\text { PROGRAMAS: } \\
\text { Plaphoons. Un nuevo sistema de comunicación para personas con } \\
\text { dificultades motoras y/o dificultades en el habla. También facilita el } \\
\text { aprendizaje de la lectoescritura. } \\
\text { Kanghooru. Su utilidad es realizar el barrido automático de cualquier } \\
\text { programa. El nombre lo toma del canguro porque el programa consiste } \\
\text { en hacer saltar al mouse mediante barrido automático por los lugares } \\
\text { de la pantalla. Está pensado para que las personas con discapacidad } \\
\text { motriz puedan controlar cualquier programa que funcione mediante el } \\
\text { "clicqueado" en distintas zonas de la pantalla. } \\
\text { Teclado silábico. Es un programa para facilitar la escritura a personas } \\
\text { que no pueden acceder a un teclado normal pero si pueden controlar } \\
\text { dispositivos tipo joystick, que simula el mouse, o al clic del mouse } \\
\text { mediante un conmutador, en este caso el programa deberá de } \\
\text { funcionar mediante la modalidad de automático. } \\
\text { Controlador del Mouse. La finalidad de este programa es controlar el } \\
\text { mouse mediante la voz. Es decir, con un micrófono podemos controlar } \\
\text { los movimientos del mouse: izquierda, derecha, sube, baja, clic. Está } \\
\text { pensado para personas con discapacidad que no pueden controlar el } \\
\text { mouse de forma normal y tengan control de su voz. } \\
\text { Controlador de un Teclado (TOTlpm). El teclado omnipresente para } \\
\text { trabajos informáticos, para personas con minusvalías, es un simulador }\end{array}$ \\
\hline
\end{tabular}




\begin{tabular}{|c|c|}
\hline & $\begin{array}{l}\text { que permite disponer de un teclado en pantalla, cuando el usuario no } \\
\text { puede utilizar el teclado ordinario. } \\
\text { Pasapáginas para leer libros, o ser leídos por el programa. Permite la } \\
\text { visualización y lectura de libros a través de un teclado que funciona por } \\
\text { barrido automático y activación por conmutador. }\end{array}$ \\
\hline $\begin{array}{c}\text { Programas y } \\
\text { aplicaciones de } \\
\text { Innovación } \\
\text { Management Group, } \\
\text { Inc. }\end{array}$ & $\begin{array}{l}\text { Destinatarios: Alumnos de diferentes etapas educativas con } \\
\text { discapacidad motriz que presente dificultades para el acceso al } \\
\text { ordenador a través de teclado y los periféricos habituales. } \\
\text { PROGRAMAS: } \\
\text { My-T-Mouse. Es un programa para el acceso a la lectoescritura que } \\
\text { consiste en un simulador que representa el teclado en una porción de } \\
\text { la pantalla. } \\
\text { Joystick-To-Mouse. Con este programa, cualquier aplicación } \\
\text { informática puede ser manejada con Joystick, desplazando el puntero } \\
\text { por la pantalla para apuntar y pinchar como un ratón. } \\
\text { My-T-Mouse for Kids. Es una versión sencilla del My-T-Mouse con las } \\
\text { siguientes utilidades: Tres opciones de teclado en la pantalla (ABCS, } \\
\text { QWERTY y cadena musical), teclas de información verbal con voces } \\
\text { de niños, teclas y paneles de colores, botones para el manejo del ratón } \\
\text { y un magnificador de caracteres. }\end{array}$ \\
\hline
\end{tabular}

\begin{tabular}{|c|c|}
\hline $\begin{array}{c}\text { Programas y } \\
\text { aplicaciones de } \\
\text { Oxford Ace Centre. }\end{array}$ & $\begin{array}{l}\text { EI Oxford ACE Centre es un centro para la promoción del uso de } \\
\text { tecnología para la comunicación y la educación especial de los jóvenes } \\
\text { con discapacidad motriz y dificultades para la comunicación. } \\
\text { Destinatarios: Alumnos de diferentes etapas educativas con } \\
\text { discapacidad motriz, que presente dificultades para el acceso al } \\
\text { ordenador a través del teclado y los periféricos habituales. } \\
\text { RELACION DE PROGRAMAS: } \\
\text { - Saw. Esta aplicación informática permite utilizar cualquier } \\
\text { programa comercial con la ayuda de un sistema de barrido, } \\
\text { utilizando uno o varios pulsadores. } \\
\text { - Number Navigator. El programa facilita a los escolares con } \\
\text { discapacidad motriz la realización de operaciones aritméticas } \\
\text { en la pantalla del ordenador. Puede ser manejado con el } \\
\text { teclado o con pulsadores. } \\
\text { AccessMaths4. Es una aplicación informática muy útil en el } \\
\text { área de matemáticas, hace posible el trabajo con las formas } \\
\text { geométricas empleando sólo el ratón o un pulsador. }\end{array}$ \\
\hline
\end{tabular}




\begin{tabular}{|c|c|}
\hline $\begin{array}{c}\text { Programas y } \\
\text { aplicaciones } \\
\text { "Inclusive } \\
\text { Technology" th } \\
\text { especial needs } \\
\text { people. }\end{array}$ & $\begin{array}{l}\text { Destinatarios: Alumnado de diferentes etapas educativas con } \\
\text { discapacidad motriz que presentan dificultades para el acceso al } \\
\text { ordenador a través del teclado y los periféricos habituales. } \\
\text { RELACION DE PROGRAMAS: } \\
\text { - CD Player. Esta aplicación ofrece una reproductora de audio } \\
\text { para el lector de CD, que se puede utilizar con uno o dos } \\
\text { conmutadores, ratón o un teclado de conceptos. } \\
\text { - Serial Switch Driver. Programa para manejar el ordenador } \\
\text { con pulsadores. Permite programar el uso de las teclas } \\
\text { ENTER y BARRA ESPACIADORA, en dos pulsadores que se } \\
\text { activan con presión continua o con una o dos pulsaciones. } \\
\text { Talking Face. Facilita la grabación y escucha de los sonidos, } \\
\text { simultáneamente se puede visualizar una cara animada que } \\
\text { reproduce los gestos faciales de la articulación de la palabra. } \\
\text { Para hacerlo más divertido, la imagen del personaje que habla } \\
\text { se puede modificar seleccionando un alienígena, un payaso, } \\
\text { un robot, Papá Noel, etc. } \\
\text { SENSwitcher. Se trata de un conjunto de programas } \\
\text { diseñados para ayudar en la enseñanza rápida de las TIC a } \\
\text { toda clase de alumnos y alumnas con múltiples y profundas } \\
\text { dificultades de aprendizaje. Contiene } 132 \text { actividades } \\
\text { animadas de alta calidad gráfica. Se puede utilizar con } \\
\text { diferentes tipos de pulsadores y adaptadores de acceso. Es } \\
\text { gratuita su difusión. Se acompaña de un manual para } \\
\text { profesorado de } 18 \text { páginas en ingles que se puede bajar } \\
\text { también gratuitamente de la web de Northern Grid for } \\
\text { Learning: www.noetherngrid.org }\end{array}$ \\
\hline
\end{tabular}

\begin{tabular}{||c||l||}
\hline & $\begin{array}{l}\text { Destinatarios: Alumnos de diferentes etapas educativas con } \\
\text { discapacidad motriz que presenten dificultades para el acceso al } \\
\text { ordenador a través del teclado y los periféricos habituales. } \\
\text { Programas y }\end{array}$ \\
aplicaciones de & EI mono PROGRAMAS: \\
Irdata & encaminadas al desarrollo de capacidades como memoria \\
& visual. \\
EI conejo "Marmolejo". Trabaja aspectos matemáticos y de \\
las áreas transversales del curriculum.
\end{tabular}

Cuadro 9: Muestra de diferentes software (Junta de Andalucía, 2003 ). 
Las nuevas tecnologías constituyen hoy en día uno de los apoyos imprescindibles para los alumnos que presentan discapacidad motora y psíquica, pudiendo poner en manos de los usuarios la posibilidad de presentar, manipular, analizar, calcular, investigar, dialogar, y controlar toda clase de equipos periféricos de entrada, salida y almacenamiento de la información.

Es indudable la imperiosa necesidad de posibilitar el acceso a las nuevas tecnologías a las personas con discapacidad, de otra manera se contribuye a la creación de más diferencias y con ello desigualdad en la educación.

\subsubsection{Las TIC como herramienta en los Trastornos de la Audición y el Lenguaje (Navarro, 2000).}

En la actualidad existe un amplio consenso que destaca la importancia de los aspectos comunicativos y funcionales en el desarrollo del lenguaje. De esta manera se asume para la enseñanza de la lengua un enfoque comunicativo y funcional. En diferentes campos y disciplinas se han realizado aportaciones sobre los fenómenos de la expresión y de la comunicación, respecto a como se adquiere y se desarrolla el lenguaje, así como acerca del papel que desempeña en todos estos procesos la interacción social.

Los medios tecnológicos no ofrecen una interacción humana natural en el lenguaje, sin embargo si puede estimular otros procesos interactivos que favorecen el aprendizaje y el desarrollo del alumnado en general y en particular a los alumnos que presentan necesidades educativas especiales.

La interactividad deberá de ser valorada, no sólo en la relación programaalumno, sino con otro referente como es profesor -alumno y alumnadoalumnado, El hecho de centrarse solamente en la interacción ordenador usuario limita la posibilidad de la capacidad de acción intelectual personal y de diálogo. En relación al lenguaje, los ordenadores pueden mejorar las condiciones de uso, creando entornos sociales y propiciando actividades compartidas, donde los alumnos puedan hablar sobre ellas. Se deben tener presentes algunos criterios metodológicos útiles en este sentido como, el trabajo en pequeños grupos, que posibilita el trabajo cooperativo, así como el intercambio entre el grupo. 
Es recomendable evitar la utilización excesiva individualizada del software educativo, una vez que se ha elegido éste recurso, se organiza el trabajo en grupos alrededor del ordenador y se motiva a los alumnos promoviendo el trabajo colaborativo. El hecho de que los profesores fomenten actitudes cooperativas, cortando la verticalidad entre profesor-alumno y pueda convertir en destinatarios a los textos o tareas que realicen, centrando su interés en contenido comunicativo que han producido, ofreciendo ayudas y orientación en función de las necesidades de los alumnos, definiendo su estilo pedagógico y de relación con los medios que utiliza, en este caso informáticos.

Los ordenadores pueden desempeñar el rol de animar el uso del lenguaje. Es importante tener presente la relación afectiva y de diálogo, principalmente en lo que se refiere al lenguaje que se plantea en la relación entre personas. De esta manera, hay que tener presentes los diferentes estilos didáctico-pedagógicos que favorecen la interactividad y el proceso de enseñanza -aprendizaje.

Las funciones de los recursos tecnológicos para la intervención de los trastornos de audición y lenguaje son:

\section{Medios de acceso y ayuda a la comunicación:}

- Programas emuladores de teclado: la representación del teclado se visualiza en la pantalla. El usuario elige las opciones pulsando alguna tecla estándar, la barra espaciadora o bien a través de algún conmutador.

- Programa de predicción de palabras: consiste en mostrar palabras por la letra elegida anteriormente para continuar seleccionando una de ellas. Se mejora el sistema de barrido que lo hacia más lento.

- Síntesis de voz: el ordenador lee en voz alta el texto escrito en la pantalla o las instrucciones de un programa (conversador texto-voz).

- Reconocimiento de voz: permite que las visualizaciones y explicaciones se conviertan en textos escritos en la pantalla del ordenador.

- Boardmaker: programas editores de sistemas de comunicación aumentativa/alternativa.

- Procesadores de textos adaptados para personas con problemas motóricos. 
2. Ayudas para el aprendizaje y reeducación del lenguaje oral y escrito: recursos específicos logopédico y otros de uso educativo general:

- Visualización de la voz y el habla: Estas se han desarrollado desde las llamadas tarjetas de voz. Se pueden trabajar aspectos como: Cualidades del sonido, visualización; presencia-ausencia de sonido, sonoridad, intensidad, tono, ataque o comienzo de voz. Control de parámetros de la voz: visualización y ejercicios; control y modulación del tono, intensidad, control y modulación de emisión de sonidos (respiración, ritmo), pronunciación de sonidos y discriminación fonológica.

- Software específico.

- Proyecto LAO (Logopedia Asistida por Ordenador) se planteo en su momento como un instrumento de ayuda para la rehabilitación del alumnado con deficiencias auditivas (Comisión Técnica del Proyecto LAO, 1994).

- El sistema EL o generador de Entornos Lingüísticos. Permite al profesor y logopedas crear aplicaciones para realizar actividades de desarrollo de lenguaje.

- Aplicación La casa y la familia: aplicación generada con el sistema EL y dirigida para niños y niñas prelectores. Las actividades de este centro de interés se agrupan por bloques; desarrollo del vocabulario, secuenciación temporal, capacidad auditiva, comunicación oral y juegos de memoria.

- SIFO: se trabaja el aspecto fonológico a través de actividades de segmentación silábica y fonológica. Este programa dispone de una base de datos gráfica y una base de datos textuales, a partir de ellas se seleccionan las palabras-objetos a trabajar en las diferentes actividades que se agrupan en dos bloques; sílaba y fonema.

- INTELEX: programa pensado en alumnos sordos que ya tienen un cierto dominio de la lectura pero que siguen teniendo problemas de comprensión. Se compone de varias partes: 
- INTELEX diccionario: ofrece información textual y gráfica sobre 12,000 términos de carácter abstracto y figurado en castellano, así como expresiones lingüísticas o modismos. Además ofrece la categoría gramatical a la que pertenece, su género, si es un verbo su conjugación y, en algunos casos si es, una palabra coloquial, culta o es un tecnicismo. Permite buscar sinónimos antónimos, familias semánticas. También incorpora el signo correspondiente de la Lengua Española de Signos (L.S.E.) de aquellas palabras y expresiones que tienen traducción directa.

- INTELEX didáctico: es complementario al diccionario, aun y cuando es autónomo. Realiza y ejecuta aplicaciones con textos, frases y palabras de la lengua castellana utilizando los recursos que incorpora el diccionario Intelex. Un programa que prepara ejercicios, lecciones y textos (Editor) y un programa de creación interactiva de cuentos, que permite la composición rápida y simple de infinidad de cuentos bajo una estructura presentación, nudo y desenlace.

Después de estos programas, se generaron programas desarrollados con los Entornos Lingüísticos (E.L.) y se encuentran a disposición en Internet, en el servidor del PNTIC: Pili y Chema, HALE, Bla, bla, bla, etc.

- El proyecto MUSA; ofrece material avanzado, basado en la informática, para la rehabilitación de personas con problemas de audición y lenguaje. (Ruiz, 1994). Contiene un Modulo Phonos Voz y Módulo Phonos Lenguaje. Con módulo de voz se pueden trabajar los atributos del habla como; intensidad y duración de la producción vocal, entonación, estructuras rítmicas simples o complejas, sonidos sonoros/sordos, sonidos fricativos.

El módulo del lenguaje, está compuesto por los ficheros lingüísticos relativos a dos campos semánticos (animales y familia). Se pueden trabajar ejercicios dirigidos al desarrollo de la competencia lingüística, léxico, reconocimiento semántico, secuenciación, relaciones. 
Existen un conjunto de desarrollos que tienen como perspectiva, desarrollar programas específicos con soporte informático para la percepción auditiva, como es el proyecto IMASON, se desarrollan actividades en relación a; identificación de sonidos, loto, memoria auditiva, historias sonoras, etc.

El programa Hamlet es un programa destinado para ser trabajado con alumnos con algún tipo de necesidad especial de carácter logopédico. El software se adapta a cualquier Sistema Educativo http://www.elogopedia.net/soft/analisis/hamlet.html tiene el propósito de favorecer la conceptualización fonológica.

Existen programas de tipo tutorial para el aprendizaje de elementos valiosos por parte de la comunidad sorda, como son; código dactilológico y lengua de signos. Permiten visualizar el signo en movimiento, representación de códigos dactilológico, significado de la palabra, información general etc., y permite visualizar parámetros formativos quinésicos 0 articulatorios, con un análisis detallado de la realización de cada signo.

De igual manera también se cuenta con programas específicos para trabajar contenidos muy concretos como la iniciación a la lectura labial (DI), enseñanza de la articulación (Ear), etc. El programa GRAM-prácticas de lenguaje escrito; desarrollado para alumnos con deficiencia auditiva, esta diseñado para trabajar los tiempos y las personas del verbo, así como también la comprensión lectora y de familiarización con los restantes elementos sintácticos.

\subsubsection{Las TIC y la Estimulación Sensoriomotriz en niños con Plurideficiencias (Martínez, 2004).}

La atención de los niños con plurideficiencia o gravemente afectados requiere necesariamente conocer el funcionamiento de la percepción y su relación con las sensaciones, dado que este aspecto permitirá la intervención en este campo, en espacial con aquellas personas que por su alto grado de discapacidad, tienen graves alteraciones en el proceso perceptivo, siendo necesaria la intervención en la producción de estímulos que ayuden a potenciar el desarrollo de canales sensoriales, que por cualquier causa son inoperantes. 
La percepción esta ligada a las funciones cognitivas más que a cualquier tipo de pulsión. A diferencia de otras funciones cognitivas, la percepción se caracteriza por tener su origen en la interacción física que da entre el medio y el organismo por medio de los sentidos.

García-Albea (1999) presenta las siguientes ideas sobre el estudio de la percepción.

I. La percepción es una actividad del sujeto, es una actividad que se manifiesta a través de movimientos de orientación y exploración, en prácticamente todas las modalidades perceptivas.

II. La percepción es una actividad interna de carácter típicamente computacional, en la medida que se opera formalmente sobre representaciones y va más allá de la mera actividad sensorial tomando como punto de partida el datos sensorial, lo que transforma y transciende, por el uso de una información adicional, llegando a representar estable y consistente el mundo real.

III. La actividad está constituida por toda una serie de procesos que son, en su mayoría de carácter inconscientes, aún y cuando el resultado al final normalmente alcanza el lumbral de la conciencia.

IV. Más que la dimensión consciente 0 inconsciente de la actividad perceptiva, lo importante desde el punto de vista funcional son las restricciones externas, que proceden del estimulo, e internas, propias del sistema, a las que esta sujeta ésta actividad.

V. En la percepción se dan rasgos comunes a distintas modalidades perceptivas y unos rasgos específicos de cada una de ellas en dominios informativos bien determinados.

VI. La percepción varía con la edad y las características del sujeto. Mientras que la percepción de un adulto normal es estable, en los bebés se van sucediendo una serie de estadios en el desarrollo perceptivo y en las personas que presentan alguna lesión en el sustrato neurofisiológico se dan alteraciones patológicas en el proceso perceptivo.

En el proceso perceptivo, además de la presencia física del objeto se requiere la intervención directa de los sentidos. La presencia física del objeto 
es efectiva para la percepción, en la medida que el sujeto dispone el equipamiento indispensable para acceder a dicho objeto.

La actividad sensorial es condición necesaria de la percepción y mantiene, una determinada relación causal, no se limita al hecho de que la actividad sensorial construya la implementación física de la actividad perceptiva, implica una cierta forma de conexión informativa que viene a relacionar el output perceptivo con el input sensorial.

El desarrollo de un individuo en condiciones normales, en sus primeros meses de vida se puede considerar como una integración de diferentes aspectos como los procesos de maduración, la estimulación sensoriomotriz y los procesos de percepción derivados de la propia actividad. Todo esto dentro de un contexto social, en el que existan personas que deben propiciar la asistencia, comunicación y estimulación a ese nuevo ser. En esta etapa o en momentos posteriores, podemos encontrar niños que presentan simultáneamente discapacidades motóricas, afectación sensorial y retraso mental. Esta situación determina una plurideficiencia, que en algunos casos llega a ser muy grave, alejando bastante al niño del desarrollo que experimenta un sujeto sano, dificultándose por ello, la los niveles mínimos de integración socio-educativa.

Las TIC introducen cambios significativos en el proceso de enseñanzaaprendizaje, destacando el aumento de la actividad por parte de los sujetos que aprenden, por lo que hace se necesario adaptarlo a su ritmo, posibilitando un mayor control en el proceso de recepción de la información. Por otra parte, la motivación del sujeto que aprende se ve incrementada con el uso de las TIC.

La atención educativa de las personas con discapacidad, específicamente las que presentan plurideficiencia y grave afectación, desarrollan su currículo en un Centro de Educación Especial, siendo los recursos técnicos y electrónicos y los recursos informáticos, herramientas claves para que puedan lograr tener cierta calidad de vida.

El ordenador puede mejorar el proceso de enseñanza- aprendizaje en cualquier individuo, sin importan su edad o posibles limitaciones (Sánchez, 1997). Durante las ultimas décadas se ha puesto mucha atención al desarrollo y evaluación del uso de microcomputadores, para ayudar a niños y adultos con múltiple discapacidades severas y profundas, a salir de su asilamiento y 
obtener por sus propios medios, cierto grado de la estimulación ambiental deseada (Crawford y Schuster, 1993, Kinsley y Langone, 1995, Lancioni, O'Reilly, Singh, Oliva y Groeneweg, 2002). La base de estas personas para utilizar este tipo de recursos técnicos, está en su capacidad de percibir e interesarse por el medio ambiente que lo rodea, éste es el trabajo que tendría que realizarse desde el campo educativo y desde las primeras edades, como un objetivo de intervención con los niños con grave y múltiple discapacidad.

En trabajo educativo con este tipo de población, es habitual la utilización de la metodología de Estimulación Basal propuesta por Andreas Frohlich (Frohlich, 1993, 1994, Frohlich y Haupt, 1982). En trabajos anteriores se han presentado propuestas concretas para la planificación curricular en los tres ámbitos básicos de la estimulación basal, percepción somática, vestibular y vibratoria (Martínez, 2001), así como en las modalidades sensoriales de estimulación visual, auditiva y táctil (Martínez y García, 2002).

El ordenador podría ser especialmente útil en el caso de niños con plurideficiencia y grave afectación, como al utilizarla en edades muy tempranas, cuando se utiliza con la finalidad de favorecer una estimulación sensorial con fines educativos y de potenciar el desarrollo de la percepción sensorial.

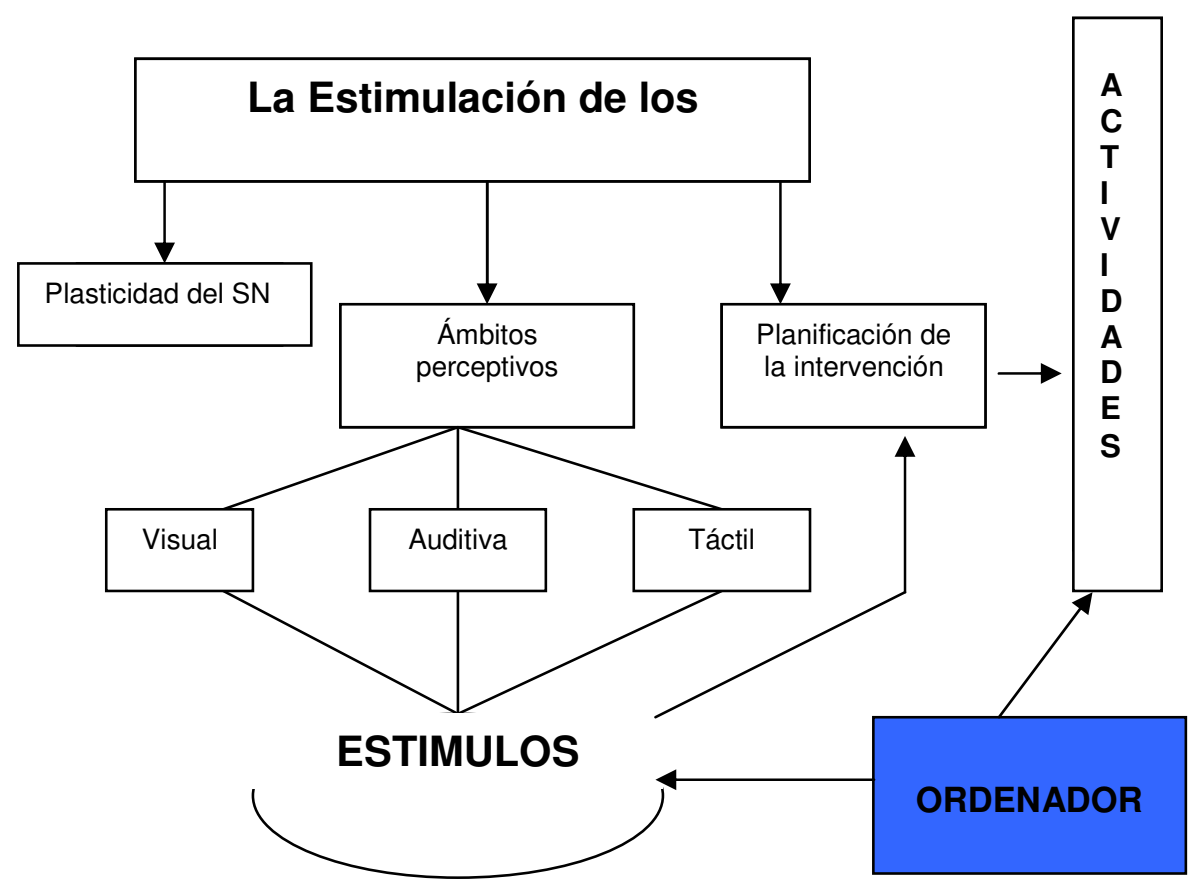

Figura 11: Estimulación de los sentidos por medio del ordenador (Martínez, 2004). 
El desarrollo de los sistemas básicos facilita la interacción del niño con su entorno al favorecer la percepción de los diferentes estímulos que éste le pueda enviar a cualquier situación.

Se considera que con los niños con plurideficiencia o grave afectación es oportuno realizar una intervención tempranamente y que potencie el desarrollo, desde un principio, de los canales sensoriales, así como la adquisición de habilidades compensatorias entre ellos (Martínez y García, 2002). Si se tienen en cuenta cuáles son los estímulos que predominan cuando entramos en contacto con el ordenador, podremos señalas como canales activos a la recepción de sensaciones, la vista, el oído y el tacto (Ver Figura 11).

Por ello partiendo de los ámbitos sensoriales visual, auditivo y táctil, se establecen unos objetivos para organizar y dirigir la estimulación de los mismos y centrándolos en el ordenador como una fuente de estímulo, determinando aquellos contenidos que podrían trabajar con él y que, al mismo tiempo, permitirían alcanzar los objetivos propuestos para la estimulación de los ámbitos señoriales antes mencionados. Todo ello, recogido en una Herramienta Multimedia de estimulación Sensoriomotriz (HMES) que propicie la estimulación de los canales sensoriales a través del uso del ordenador.

A través de la HMES para la estimulación visual se consideran los siguientes elementos curriculares:

\begin{tabular}{|c|c|c|c|}
\hline \multicolumn{4}{|c|}{ Área Visual } \\
\hline \multirow[b]{2}{*}{ Objetivos } & \multicolumn{3}{|c|}{ Contenidos } \\
\hline & Conceptuales & Procedimentales & Actitudinales \\
\hline $\begin{array}{l}{ }^{*} \text { Facilitar que el niño pueda ver a } \\
\text { las personas y a los objetos como } \\
\text { unidades que se destacan de su } \\
\text { entorno y que permanecen } \\
\text { idénticas en distintos sitios y bajo } \\
\text { diferentes situaciones. } \\
\text { *Aprender a dirigir los movimientos } \\
\text { visuales de una manera } \\
\text { coordinada. }\end{array}$ & $\begin{array}{l}\text {-Luminosidad- } \\
\text { obscuridad. } \\
\text {-Blanco -negro }\end{array}$ & $\begin{array}{l}\text {-Desarrollo de la } \\
\text { capacidad de } \\
\text { diferenciación a } \\
\text { partir de dos } \\
\text { ofertas ópticas } \\
\text { distintas. } \\
\text {-Discriminación } \\
\text { de blanco, negro } \\
\text { y colores. }\end{array}$ & $\begin{array}{l}\text {-Manifestación } \\
\text { de interés hacia } \\
\text { los estímulos } \\
\text { ópticos } \\
\text { presentados. } \\
\text {-Disfrute en la } \\
\text { percepción de } \\
\text { imágenes que } \\
\text { representan }\end{array}$ \\
\hline
\end{tabular}




\begin{tabular}{|c|c|c|c|}
\hline $\begin{array}{l}\text { *Transmitir al niño la sensación de } \\
\text { que los estímulos visuales pueden } \\
\text { ser interesantes y que toda la } \\
\text { visión de claro-obscuro puede ser } \\
\text { captada de una manera más } \\
\text { diferenciada. }\end{array}$ & $\begin{array}{l}\text {-Colores y } \\
\text { formas. } \\
\text {-Rostros y } \\
\text { objetos }\end{array}$ & $\begin{array}{l}\text {-Reconocimiento } \\
\text { de rostros de } \\
\text { referencia. } \\
\text {-Discriminación } \\
\text { alternativa de } \\
\text { rostros y objetos. }\end{array}$ & $\begin{array}{l}\text { rostros } \\
\text { familiares. } \\
\text { Predisposición } \\
\text { positiva a la } \\
\text { participación de } \\
\text { actividades que } \\
\text { pretendan una } \\
\text { actividad visual. }\end{array}$ \\
\hline
\end{tabular}

Cuadro 10: Estimulación del Área Visual por medio del HMES a través del ordenador (Martínez, 2004).

De acuerdo a las pautas evolutivas que se dan en el desarrollo de la percepción auditiva y para la intervención en el ámbito educativo, se detallan los elementos curriculares que subyacen a la estimulación del ámbito auditivo utilizando la HMES:

\begin{tabular}{|c|c|c|c|}
\hline \multicolumn{4}{|c|}{ Área Auditiva } \\
\hline \multirow[b]{2}{*}{ Objetivos } & \multicolumn{3}{|c|}{ Contenidos } \\
\hline & Conceptuales & Procedimentales & Actitudinales \\
\hline $\begin{array}{l}{ }^{*} \text { Ofrecer a los niños tonos, sonidos } \\
\text { articulados y ruidos que les } \\
\text { permitan aprender informaciones } \\
\text { significativas para ellos. } \\
\text { *Hacer alcanzar a los niños una } \\
\text { percepción puramente acústica } \\
\text { que les permita captar la voz } \\
\text { humana. } \\
\text { *Adquirir una orientación acústica } \\
\text { en el espacio. } \\
\text { *Producir activamente ruidos y } \\
\text { sonidos articulados. }\end{array}$ & $\begin{array}{l}\text {-Sonidos } \\
\text { humanos/voces. } \\
\text {-Ruidos del } \\
\text { entorno próximo. } \\
\text {-La música. } \\
\text {-El silencio. }\end{array}$ & $\begin{array}{l}\text {-Seguimiento de } \\
\text { sonidos con los } \\
\text { ojos, cabeza o } \\
\text { cuerpo. } \\
\text {-Producción de } \\
\text { sonidos con el } \\
\text { propio cuerpo, } \\
\text { percutiendo o a } \\
\text { partir del propio } \\
\text { movimiento. } \\
\text {-Audición de } \\
\text { secuencias } \\
\text { sonoras en las } \\
\text { que se alterne } \\
\text { sonidos con } \\
\text { silencio. }\end{array}$ & $\begin{array}{l}\text {-Colaboración en } \\
\text { la producción de } \\
\text { sonidos. } \\
\text {-Predisposición } \\
\text { positiva hacia la } \\
\text { participación en } \\
\text { situación que } \\
\text { requiera la } \\
\text { audición sonora. } \\
\text {-Atención ante la } \\
\text { audición de } \\
\text { sonidos } \\
\text { externos. }\end{array}$ \\
\hline
\end{tabular}

Cuadro 11: Estimulación Auditiva por medio del HMES a través del uso del ordenador (Martínez, 2004). 
Estimulación táctil utilizando la herramienta multimedia, tomando en cuenta diferentes elementos curriculares.

\begin{tabular}{|c|c|c|c|}
\hline \multicolumn{4}{|c|}{ Área Táctil } \\
\hline \multirow[b]{2}{*}{ Objetivos } & \multicolumn{3}{|c|}{ Contenidos } \\
\hline & Conceptuales & Procedimentales & Actitudinales \\
\hline $\begin{array}{l}\text { *Posibilitar la abertura y } \\
\text { movimiento de las manos, de } \\
\text { modo que se potencie la actividad } \\
\text { de las mismas. } \\
\text { *Hacer que los niños tomen } \\
\text { conciencia de las partes sensibles } \\
\text { de sus manos. } \\
{ }^{*} \text { Experimentar que determinados } \\
\text { objetos o materiales pueden tener } \\
\text { un tacto característico, o bien } \\
\text { parecido a otros. } \\
\text { *Desarrollar en el niño la } \\
\text { posibilidad de sujetar objetos, } \\
\text { cogerlos y dejarlos caer } \\
\text { voluntariamente. } \\
\text { *Desarrollar formas de presión } \\
\text { más avanzada y movimientos más } \\
\text { coordinados. }\end{array}$ & $\begin{array}{l}\text {-Las manos y los } \\
\text { dedos. } \\
\text {-El tacto en las } \\
\text { palmas de las } \\
\text { manos y parte } \\
\text { interior de los } \\
\text { dedos. } \\
\text {-La presión } \\
\text { sobre los } \\
\text { objetos. }\end{array}$ & $\begin{array}{l}\text {-Alternancia en } \\
\text { los movimientos } \\
\text { de abertura y } \\
\text { cierre de las } \\
\text { manos. } \\
\text {-Estimulación de } \\
\text { la palma de la } \\
\text { mano con } \\
\text { diferentes } \\
\text { objetos. } \\
\text {-Presionar } \\
\text { objetos. }\end{array}$ & $\begin{array}{l}\text {-Predisposición } \\
\text { positiva hacia la } \\
\text { participación en } \\
\text { situaciones en } \\
\text { las que se } \\
\text { realizan } \\
\text { exploraciones o } \\
\text { contacto con } \\
\text { objetos. } \\
\text {-Disfrute en la } \\
\text { percepción de } \\
\text { sensaciones } \\
\text { táctiles que } \\
\text { resultan } \\
\text { agradables. }\end{array}$ \\
\hline
\end{tabular}

Cuadro 12: Estimulación Táctil por medio del HMES a través del uso del ordenador (Martínez, 2004).

La Herramienta Multimedia de Estimulación Sensoriomotriz (HMES) puede reunir las características de usabilidad, ya que permite su utilización con sujetos independientemente del grado de discapacidad que estos puedan presentar, al mismo tiempo que da la posibilidad de que cualquier profesional pueda intervenir en su configuración adaptándola al máximo a las características del usuario. Estos aspectos pueden ser generalizados en su utilización por los profesionales que deseen usar el ordenador en situaciones educativas para potenciar la estimulación sensorial.

La HMES está constituida por imágenes y sonidos con una estructura lineal, en apartados a los que se accede de manera secuencial. Tomando en cuenta la corta edad, en algunos casos, de los niños para quienes va destinada esta 
herramienta, o por el grado de afectación que presentan otros, la única posibilidad de interacción que permiten al usuario de la herramienta será lo de pasar de un fragmento a otro obteniendo un refuerzo positivo (visual o auditivo). La estimulación táctil es motivada a partir de la emisión de estímulos visuales y auditivos, de modo que, en la mayoría de los casos el niño comienza a utilizar la herramienta ayudado por un adulto, en las sesiones para su implementación va ganando movilidad e intencionalidad en los ejercicios de movimiento, terminado por accionar el pulsador por si mismo, en la mayoría de los casos.

La herramienta multimedia se basa en una sucesión de imágenes, que toman en cuenta las características evolutivas que suceden en el desarrollo de la visión, dichas imágenes se acompañan de movimientos de ayuda, según los casos, para focalizar la atención en un punto, realizar seguimientos visuales, percibir contrastes, diferenciar rostros e identificar objetos próximos al niño.

De igual manera los sonidos desempeñan un papel importante en la estimulación, van unidos a movimientos o desplazamientos que sufren las imágenes dentro del campo visual del niño y se hacen presentes a partir de la manipulación del periférico. La complementación de los sonidos con las imágenes en movimiento constituyen los estímulos sensoriales que en la mayoría de los casos hacen precipitar una respuesta, generalmente motóricamente en el niño.

La HMES esta conformada por cuatro apartados/bloques que pueden ser utilizados de modo independiente. En su conjunto representa la evolución que sufre la visión en los primeros meses del niño. A continuación se describen los diferentes bloques de dicha herramienta.

1. Herramienta Multimedia para la estimulación de los contrastes en Blanco y Negro. Contiene 12 pantallas diferentes que se utilizan sólo en blanco y negro. Las imágenes de fondo negro, con figuras blancas en movimiento, van realizando desplazamientos con el propósito de captar la atención visual del niño. También se dan cambios de fondo figura alternando el blanco y negro, en todo momento existen sonidos que se unen a esta progresión visual. Los sonidos pueden ser pulsaciones sonoras rítmicas y monótonas, sonidos impactantes, 
breves sonidos ambientales, etc. De vez en cuando entre las distintas pantallas aparece una pantalla toda negra, incluyendo sólo un estimulo sonoro, evitando la habituación al estimulo y la pérdida de atención por la secuencia. Esta parte de la herramienta se utiliza al inicio y precipita mayores respuestas en los sujetos cuyo nivel evolutivo sea más bajo.
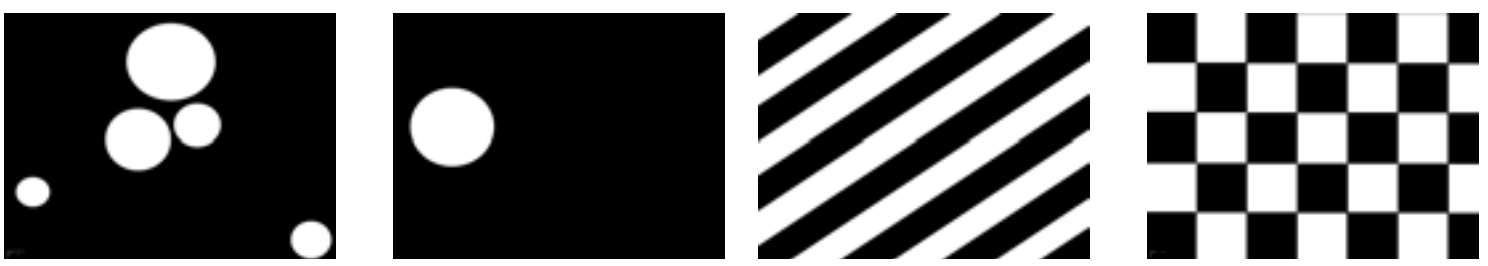

Fig. 12

2. Herramienta Multimedia para la estimulación a través de los contrastes de color. Consta de una sucesión de 14 pantallas diferentes, se parece a la anterior en cuanto a las formas, movimientos y sonidos, también e la utilización de pantallas neutras posibilitando la desacomodación del estímulo visual, la diferencia de ella es la utilización de colores. Los colores que aparecen en cada pantalla siempre son dos, escogidos por complementariedad.
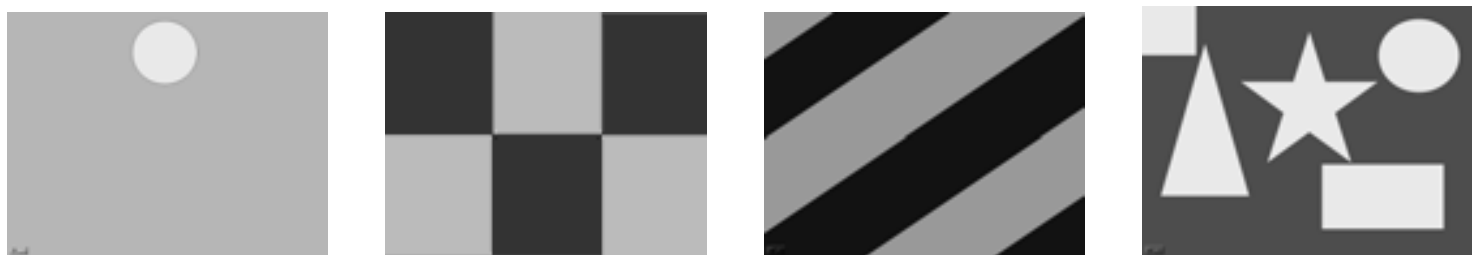

Fig. 13

3. Herramienta Multimedia para la estimulación a través de la utilización de rostros. A diferencia de los anteriores, la herramienta se elabora de modo personal para cada usuario, utilizando rostros de personas próximas y significativas para él, que pertenezcan a su entorno familiar y escolar. Los sonidos que se utilizan son las voces de las personas que aparecen en las imágenes. Las pantallas de rostros se van alternando con otras en las que aparecen efectos de color en movimiento. El tamaño de la herramienta depende de cada caso, del sujeto y de la cantidad de diferentes rostros que este pueda reconocer, habitualmente 
es contener $15 \circ 20$ pantallas diferentes. En la figura 14 se puede apreciar los cuatro diferentes momentos en que aparece el rostro en la pantalla.

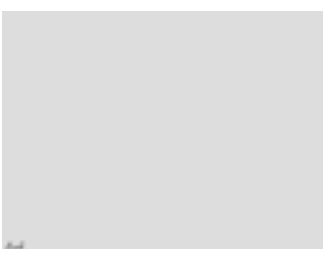

1

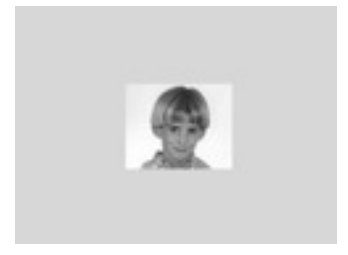

2

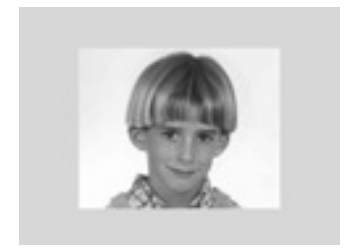

3

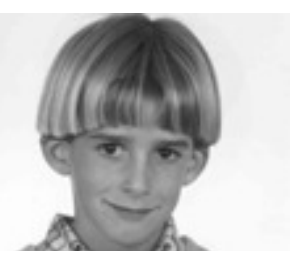

4

Fig. 14

4. Herramienta Multimedia para la estimulación a través de la utilización de objetos. Se utilizan imágenes de objetos que son significativos para el sujeto, de su entorno próximo. Al igual que en el bloque anterior los sonidos van estrechamente relacionados al objeto, puede ser el sonido del propio objeto. El tamaño del bloque es variable, dependiendo del sujeto. En algunos casos entre las imágenes se suele introducir aluna pantalla con rostros o bien pantallas de colores con efecto sonoro y movimiento.
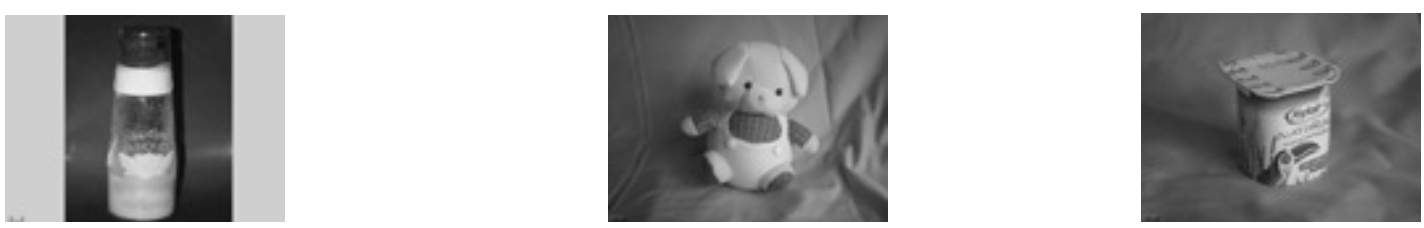

Fig. 15

HMES puede ser fácilmente modificado por el profesional que la utilice, adaptando determinados estímulos en busca de alcanzar la máxima motivación del sujeto. Por su manejo a través de un pulsador se puede adaptar a los restos motores de cualquier persona, aunque al inicio los sujetos necesitan ayuda externa para su utilización. 


\subsubsection{Nuevas Tecnologías y Aprendizaje Matemático en niños con Síndrome de Dawn: Generalización para la Autonomía (Ortega-Tudela y Gómez, 2007).}

Los niños con Síndrome Down (SD) presentan serias dificultades de generalización de los conocimientos en contextos distintos a los utilizados durante el proceso de adquisición. Debido a esto que es considerada es uno de los mayores retos en la enseñanza de estas personas.

Una de las áreas del conocimiento en la que se tiene mayor dificultad de aprendizaje y generalización de los conocimientos es la de las matemáticas. Varios autores enfatizan que las personas muestran problemas incluso con la adquisición de conceptos y habilidades matemáticas fundamentales, contenidos considerados como la base tanto para el posterior aprendizaje de nuevos y más complejos conceptos matemáticos, como también para su desenvolvimiento y desarrollo social.

Un estudio reciente de Faragher y Brown (2005) sugiere la importancia de considerar la habilidad numérica de calidad de vida para las personas con SD. Hace referencia de termino numeracy (alfabetización numérica) que desde los cincuenta ha sido considerada como el equivalente, en el ámbito de las matemáticas, a lo que se conoce en el ámbito de la lectura y escritura.

No parece ser suficiente que las personas realicen sumas perfectamente sobre el papel, si no son capaces de realizar esa actividad en situaciones problemáticas en el supermercado. La idea seria diseñar condiciones y situaciones de aprendizaje orientadas hacia la aplicación a la vida cotidiana. No obstante, para ello se debe tomar en cuenta las características de las personas con SD, haciendo la planeación en función de ellas (Borbones y Golano, 1998).

\section{El ordenador como facilitador del aprendizaje.}

Existen una gran cantidad de estudios que demuestran la bondad del ordenador como herramienta de contenidos matemáticos en niños con y sin necesidades educativas especiales (Boone, Higgins y Notari; Chen y BernandOpitz, 1993; Davidson, Elcock y Noyes, 1996; Heimann y otros, 1995; Shilling, 1997; Talley, Lancy y Lee, 1997). 
En conjunto todos estos estudios permiten dar la importancia al uso que podría tener el ordenador para la enseñanza de conceptos matemáticos en personas con SD. Además la de las posibilidades de individualización que presenta este medio seria sencillo conseguir la simulación de múltiples contextos, proporcionando mejores condiciones para la posterior generalización de los contenidos y habilidades aprendidas.

El principal objetivo de este trabajo es explorar las posibilidades del ordenador como instrumento de enseñanza que ayude en la posterior generalización de conocimientos y habilidades matemáticas.

Para optimizar el proceso de enseñanza y aprendizaje de las personas con SD han de contemplarse algunas de sus características que, de otra manera, podrían limitar sus posibilidades de aprendizaje.

Algunas de estas características podrían contrarrestarse con el uso del ordenador, por ejemplo al permitir la adaptación de la presentación de la información a las necesidades del usuario. En esta línea, Buckley (1995) atribuyo la facilitación del aprendizaje proporcionada por el ordenador al hecho de que la mayor parte de la información sea presentada por el canal visual.

Por otro lado, los problemas en el funcionamiento de la memoria de trabajo que presentan las personas con SD (Byrne y otros, 1995; Flórez, 1990) requerirían el uso de materiales que fueran presentados en forma reiterada y flexible para facilitar su organización y elaboración. Además, sus dificultades de atención sugieren la necesidad de ayudarles a focalizarse sobre los elementos relevantes de la tarea (Flórez, 1990; Nadel, 1988; Rondal y otros, 1997). En este sentido, la individualización y secuenciación de las tareas que permiten el uso del ordenador, podría ayudar a solucionar estas dificultades mediante la presentación de la información relevante en el momento y forma oportunos.

El software multimedia presenta entre otras posibilidades, la de ser motivador, con el uso de una metodología adecuada, que utilice material multimedia como instrumento formativo, podría facilitar el acceso a la información y el aprendizaje de las personas con SD, siempre y cuando estos materiales resulten accesibles para las personas con SD.

Los resultados de esta investigación apuntan a señalar, un efecto beneficioso de la metodología de enseñanza multimedia en el aprendizaje de conceptos 
matemáticos simples de niños con SD. Sugiere los beneficios de esta tipo de metodologías para trasferir lo aprendido a nuevas situaciones.

Algunos estudios señalan la importancia de las nuevas tecnologías para el aprendizaje de poblaciones con necesidades educativas especiales (Bernardo, Bernardo y Herrero, 2005).

\subsubsection{Programa para manejar el móvil con chicos con Síndrome de Down (Gorreto, 2004).}

El aprendizaje de las Nuevas Tecnologías supone un reto para esta asociación que trabaja con personas con el Síndrome de Down, desde hace más de 20 años, a continuación se presenta un programa para que un grupo de adolescentes se familiarizaran y aprendieran el manejo de una nueva tecnología como lo es la telefonía móvil, lo cual supuso un gran reto de gran motivación para ellos, así como también un ejemplo para la sociedad.

ASSIDO es una asociación que empezó trabajando con niños con Síndrome Down en 1981 para después hacerlo con jóvenes y adultos, respondiendo a sus necesidades. Sus objetivos prioritarios son, el mejorar la calidad de vida de estas personas y romper todas aquellas barreras que pudieran entorpecer una integración social plena y satisfactoria.

Las TIC empezaron a aparecer en 1990 de manera significativa, principalmente irrumpió de manera significativa el PC como herramienta facilitadora que con el tiempo esta presente en todos los ámbitos prácticamente, desarrollándose un gran numero de software educativos que complementan y enriquecen el material didáctico clásico, motivando a los alumnos y educadores a trabajar con ellos. Pero los profesionales que trabajábamos directamente con niños y jóvenes en asociaciones percibimos que las TIC podrían volverse en nuestra contra, por ello sin perder de vista el objetivo de la asociación empezamos a plantearnos el uso de las TIC como un elemento con el que nuestra población debería familiarizarse y empezar a manejar, si no se quería alejar a esta población del resto y crear una brecha discriminatoria. Consientes de la importancia se programaron junto con los talleres tradicionales de expresión plástica, jardinería, herramientas, secretaría, etc., talleres de informática en dónde los jóvenes se familiarizarán con el 
hardware y el software, manejándolos de manera independiente y autónoma con lo cual se beneficiaban participando de una realidad social, de una denominada sociedad de la Información y la Tecnología.

Con el propósito de no perder el rumbo de la integración, se decidió no quedarse solamente con el trabajo con el PC, ya que siguen irrumpiendo otras tecnologías de que deben beneficiarse esta población, por lo que surge la idea de crear un nuevo taller para un grupo de adolescentes.

\section{Organización del taller.}

Los talleres tienen un marcado carácter funcional y están organizados siempre en consonancia con los intereses y motivaciones de los chicos, con un margen de flexibilidad para posibles mejoras. Estos talleres están conformados por grupos reducidos favoreciendo la individualización, en este caso los componentes son seis chicos con edades comprendidas entre 15 y 16 años todos integrados en la E.S.O. y con una escritura funcional adquirida.

El grupo informa que le gustaría aprender a manejar el móvil al igual que sus compañeros de clase. A partir de aquí se plantea la posibilidad de programar un taller de teléfono móvil incluyéndolo dentro del taller de Nuevas Tecnologías con los siguientes objetivos.

\section{Programación:}

Objetivo General: Conseguir que los alumnos se familiaricen con las Nuevas Tecnologías y concretamente con el teléfono móvil, dotando a los alumnos de los conocimientos necesarios para manejarlo, favoreciendo su inclusión en la sociedad y mejorando su autoestima.

\section{Objetivos Específicos:}

1) Conocer los diferentes elementos del teléfono móvil, montando y desmontando estos.

2) Valorar el cuidado del teléfono móvil.

3) Conocer y emplear las funciones básicas del teléfono.(fecha y hora, ajustes de personalización como el tono, volumen, melodía, alarma, etc., y aquellas por las que el alumno tiene interés)

4) Desarrollar Habilidades Sociales y de Comunicación básicas para un empleo correcto y maduro del teléfono.

5) Elaborar una agenda personal y buscar números de teléfono.

6) Realizar llamadas de teléfono utilizando la agenda del teléfono.

7) Crear y recibir mensajes.

Actividades: 
1.1.- El profesor animará a los alumnos a que desmonten el teléfono móvil y descubran los diferentes elementos que conforman el teléfono sin los cuales no funcionaría o lo haría de manera defectuosa.

1.2.- Los alumnos realizaran esta actividad las veces que se crea conveniente hasta que sean capaces de hacerlo solos.

1.3.- El profesor mientras desmontan el móvil les comunicará en voz alta el nombre de las diferentes partes entre las que destacamos la tapa trasera que protege la batería, batería, tapa frontal, tarjeta SIM, teclado, etc.

1.4.- El profesor pedirá a los alumnos que obtengas la tarjeta SIM y comentará con ellos lo importante que es esta pieza, la cual es fundamental para el correcto funcionamiento de todo el sistema, además de que tiene un gran valor económico y supondría la perdida de información confidencial y personal.

\section{Comentarios didácticos:}

Los elementos que conforman un móvil son a menudo muy pequeños y estos tienden a reducirse aún más; dado que los beneficios del programa son población con Síndrome Down, es ya conocido el problema que tienen para manipular objetos pequeños, lo cual supondrá un handicap a la hora de realizar esta tarea, por ello el profesor dará tiempo y mostrara estrategias para que puedan ayudar a realizar esta tarea.

2.1.- El profesor comentará a los alumnos que para que el teléfono funcione bien deberán cuidar de este, limpiando periódicamente los diferentes elementos (trabajados en la unidad anterior).

2.2.- El profesor comprará el teléfono con cualquiera otra maquina y hará reflexionar a estos sobre el cuidado que requieren estas para que funcionen cuando recurrimos a ellas.

2.3.- Los alumnos limpiaran con papel, con un pincel, nunca con agua, la parte externa, así como las pequeñas piezas interiores y aconsejará a los alumnos a que realicen estas tareas de manera sistemática al menos una o dos veces por semana o bien cuando adviertan que lo requiere.

\section{Comentarios didácticos:}

El aseso y la higiene personal, así como el cuidado de sus pertenencias es un objetivo prioritario en la atención de los alumnos, siendo este un factor fundamental de ayuda en la socialización y adquisición de conductas autónomas, pues bien está tarea supone generalizar y/o funcionarizar este tipo de objetivos y la interiorización de estos aspectos básicos en nuestra labor de normalización.

3.1.- El profesor propondrá una tarea que consiste en "darle un toque personal" al móvil, lo cual facilitará al alumno el reconocimiento de ciertos elementos como suyos y lo más importante, elegido por ellos mismos, evitando el profesor implicarse en esta tarea de expresión y personalización. 
3.2.- Empezaremos buscando la melodía que ellos elegirán entre las disponibles por modelo de teléfono, el profesor se mantendrá neutral.

3.3.- La siguiente tarea consistirá en el ajuste del volumen del teléfono, comentando el profesor que el volumen excesivo puede llegar a ser molesto y si el volumen es escaso, quizás no se escuche; d esta manera ellos deberán elegir el que creean más apropiado. Se puede mostrar el modo silencio y vibrador, como alternativa a ciertas situaciones que se trabajarán más adelante.

3.4.- La siguiente actividad consistirá en ajustar la hora del reloj, así como la fecha; ajustándose esta actividad programada en los grupos en relación a la Autonomía Personal y al Manejo y Funcionamiento de aprendizaje. Esta actividad tendrá su continuidad con la actividad de ajuste de la alarma que podrá ser muy útil, funcional y significativa al ser empleada por los chicos cada mañana antes de ir al colegio o instituto, además el modo Cita será útil para recordar fechas o tareas importantes.

\section{Comentarios didácticos:}

Al inicio de esta actividad los alumnos comienzan a familiarizarse con el teclado e irán aprendiendo de manera espontánea funciones de subir, bajar menús, seleccionar, retroceder al paso anterior, etc.

4.1.- El profesor, realizará una dramatización en la que se simularán llamadas de teléfono desarrollando habilidades comunicativas y sociales necesarias para establecer una conversación telefónica correcta.

4.2.- El profesor invitará a que creen parejas, una vez resuelto esto, cada uno de los miembros de la pareja adoptará un rol (receptor de la llamada o emisor) y se irán dando pautas necesarias para una comunicación correcta y fluida. Se irán cambiando los roles y las parejas continuamente para hacerlo más dinámico y enriquecedor.

\section{Comentarios didácticos:}

Esta actividad debe estar coordinada de manera especial con el servicio de logopedia, ya que estamos trabajando un objetivo de gran importancia en este servicio como es el dialogo, además deben aprender las expresiones adecuadas para la llamada y la recepción de ésta, ya que corresponde con unas pautas sociales establecidas.

Esta actividad es de simulación debido a que supondría un gasto importante en el saldo de las tarjetas. Cuando hayamos realizado la actividad varias veces podríamos concluirla, para motivar a los chicos con una llamada real, no obstante dejaremos esta actividad para una sesión posterior.

5.1.- El profesor pedirá en la sesión anterior que traigan varios números de teléfono (familiares, amigos, compañeros de clase y otros de que pueden ser de utilidad como la policía, etc.).

5.2.- Se indicará a los alumnos que busquen en el menú principal el modo de agenda o guía y seleccionen Crear o Introducir nombres (esta función varia dependiendo del modelo de 
teléfono) y que vayan introduciendo los nombres elegidos. En este momento surgirá una dificultad en el sistema y es el sistema de escritura del teléfono, ya que cada tecla contiene varias letras e incluso diferentes signos, los chicos deberán familiarizarse con este sistema que supone que estos tengan bastante agilidad y rapidez a la hora de ir buscando la letra necesaria, por ello se dará el tiempo que necesite.

5.3.- Una vez creado el nombre, se pulsará OK o Selección (dependerá del modelo) y se introducirá el teléfono, familiarizándose los chicos con la disposición de los números. Una vez introducido este, se pulsará la tecla de confirmación que dependerá del modelo, normalmente OK o Selección. Deberán repetir esta tarea para cada número del teléfono. El profesor supervisará constantemente que los chicos vayan introduciendo los datos correctamente.

5.4.- Para concluir la tarea, el profesor pedirá a cada uno de los chicos que busquen en la agenda de teléfono a elegir por ellos.

\section{Comentarios didácticos:}

Dado que el tamaño de la letra y números es muy reducido, podremos dibujar primero el teclado de un teléfono en la pizarra o cartulina grande e ir repasando con ellos las teclas y que vayan interiorizando su distribución, a continuación puede pasar a trabajar en el propio móvil e ir tecla por tecla viendo la función de cada una de estas, ya que cada tecla contiene además los diferentes signos de puntuación, espacio, etc.

Es importante informar a los padres sobre el programa y las actividades, para que en la próxima sesión los chicos traigan las tarjetas con saldo disponible.

6.1.- El profesor pedirá a los chicos que conecten el teléfono y comprueben la carga de batería. A continuación deberán desbloquear el teléfono si fuera necesario.

6.2.- Se pedirá a los chicos que busquen en la agenda un teléfono a elegir por ellos, una vez seleccionado, deberán pulsar la tecla llamada que suele ser de un teléfono de color verde.

6.3.- A continuación se establecerá la llamada con la persona elegida y se mantendrá una pequeña conversación.

6.4.- Para concluir finalizara la llamada pulsando la tecla correspondiente (normalmente un teléfono rojo) esto es de gran relevancia, ya que si no cuelgan en crédito de la tarjeta podría seguir reduciéndose y quedarse sin crédito.

\section{Comentarios didácticos:}

Antes de comenzar la actividad deberá trabajar con los chicos ciertos aspectos relacionados con el dinero, la responsabilidad en el manejo de este, etc., Podría ser extensible a estas actividades alguna salida a recargar su teléfono. También observamos la conversación que establecen con el receptor, tomando notas para posibles correcciones.

\section{Crear-Enviar mensajes}

7.1.- Debemos indicar a los chicos que busquen en el menú del teléfono el modo Mensajes y pulsar OK o Selección.

7.2.- A continuación pulsarán el modo Mensaje de texto-Selección y a continuación Crear 
mensaje-Selección.

7.3.- Una vez seguida esta secuencia podremos empezar a escribir el mensaje que o bien dicte el profesor o bien el que elijan los chicos.

7.4.- Por último, una vez escrito seleccionarán el modo Opciones y elegirán Enviar-Selección apareciendo la opción Buscar la cual nos introducirá en la agenda de teléfonos, pudiendo buscar con las flechas arriba-abajo o bien, se les indicará que si marcan la letra inicial del nombre aparecerá este. De una u otra manera una vez apareciendo el nombre seleccionarán Aceptar y el mensaje será enviado.

Recibir mensajes.

7.5.- El profesor informará a los chicos de que cuando un mensaje es recibido, este emite un sonido y además aparece un sobre dibujado en la pantalla.

7.6.- En los modelos de móvil que los chicos emplearon aparecía además un texto en la pantalla que indicaba Leer mensaje, los chicos solo deberían pues pulsar OK o aceptar para leer el texto. Pulsando otra vez OK optarían por borrar o guardar.

\section{Comentarios didácticos:}

La actividad de escribir mensaje es de gran motivación para los chicos y favorece la maduración del proceso de escritura, reforzándose la funcionalización de esta.

Cuadro 13: Plan de clase para manejo del móvil.

\section{Metodología}

La metodología empleada partía del propio interés de los chicos favoreciéndose que el aprendizaje fuera significativo.

La metodología es activa, participativa y flexible, siendo los alumnos los protagonistas que asumen la responsabilidad de su formación, adoptando el maestro el rol de dinamizador, estimulando a que exploren, cometan errores y siendo conscientes los corrijan.

\section{Resultados}

La experiencia ha sido gratificante para los alumnos, realizando con agrado las actividades propuestas, mejorando la confianza en ellos mismos y en consecuencia su autoestima se ha visto reforzada. Además se han conseguido objetivos que nos e habían planteado a priori como la mejoría en las relaciones en el grupo que antes solo se limitaba a las sesiones de trabajo y ahora con el empleo del móvil se relacionan fuera de este especio. Por otra parte los padres 
confían más en su seguridad ya que Iso pueden localizar o buen ellos mismos les pueden llamar, habiendo incidido en su autonomía y en un descanso en la ansiedad de los padres.

Consideramos que es una buena experiencia para trabajar con los jóvenes que asisten en los Centros de Atención Múltiple de en el área laboral de Educación Especial en México.

\subsubsection{La investigación Educativa en el Aula Hospitalaria: Estudio de caso de intervención escolar, de glioma óptico infantil mediante video conferencia (López, M. y Lorenzo, D. 2008).}

La presente investigación se presenta desde algunos aspectos que permiten reivindicar la video conferencia como una alternativa escolar, bien como recursos o estrategia, como técnica o medio de trabajo y como contenido o enfoque apropiado para el desarrollo del trabajo escolar desde las aulas hospitalarias.

La video conferencia como alternativa escolar.

La experiencia se desarrolla en el Hospital Universitario Virgen Nieves de Granada, sobre atención escolar a través de videoconferencia, se lleva a cabo durante el curso escolar 2003-2004, destinada a una alumna que padece un tumor cerebral y a consecuencia del mismo perdió totalmente la visión.

\section{Situación de partida.}

Durante estos años escolares, se detecta la enfermedad, siendo intervenida quirúrgicamente. Aunque hay cierta visión la alumna sigue su cursos normal. La alumna asume el proceso con valentía, aun y cuando aguanta ciertas burlas de sus compañeros de clase, se enfrenta con una entereza sorprendente para sus diez años de edad.

En el siguiente curso la perdida de visión es mayor y se requiere de ayudas ópticas para su desenvoltura social y escolar. Pérdida que va aumentando durante el transcurso del año, requiriendo ciertas adaptaciones de acceso e interviniendo la maestra itinerante de la ONCE. El último trimestre no es 
suficiente con las ayudas ópticas puestas en juego, siendo preciso recurrir a ciertas adaptaciones. Es importante reconocer que su maestra de grupo se enfrenta a la situación escolar en su año de jubilación, con muy buen talante, esfuerzo y acompañamiento escolar.

Finalizando el curso la alumna se ve sometida a nueva intervención quirúrgica en Madrid. Tras ella no sólo no hay recuperación visual, sino que la ceguera se hace patente. Se produce el alta médica y justo al iniciarse el nuevo curso es ingresada nuevamente.

Inicia el nuevo curso desde el aula hospitalaria, tratando de asumir el cambio de hospital y a su situación de ceguera, así como su privación escolar.

La niña esta altamente motivada por lo escolar y por la socialización que representa la asistencia escolar, y se ve desarmada. Su ilusión es volver a la escuela, salir del hospital reencontrarse con sus iguales y superar la situación con la ayuda de la ONCE. Se ve frustrada por la nueva medida de privación escolar, rechazando la misma y cuestionándose qué será de ella, que ya ni al colegio puede asistir.

Dada la situación de tal motivación de la alumna por la continuidad de su proceso escolar en las condiciones más normales posibles, se estudia la posibilidad de plantear la videoconferencia, para que pueda seguir el proceso escolar con sus iguales y normalizando, aún más si cabe, el proceso de enfermedad-escolaridad.

\section{Descripción genérica.}

La insistencia de la familia y la seguridad de la alumna hacen que la idea tome cuerpo y se presente ante la delegación provincial de educación para su viabilidad. Tras la autorización y estudiar su formato, se opta por llevar a cabo la conexión a través de la fibra óptica. Nos encontramos que aún no existe línea ADSL.

Con esfuerzos que superan las administraciones y el respaldo de la ONCE se hace realidad contando con la disponibilidad de la maestra tutora.

Tres elementos necesarios: motivación de la alumna, disponibilidad y red de cable harán posible la conexión entre dos escenarios principales en hogar (puesto de trabajo) y la clase (pupitres virtuales). 
Elementos necesarios más no suficientes. Se requiere de elementos multimedia competentes. En este caso ordenador, micrófono y cámara web. A través del ordenador -previa llamada telefónica- por una de las partes, la casa o la clase, se transfiere la información y se provoca la conexión. A través del micrófono, la voz y el sonido son recogidos para su reproducción. La cámara permite recoger las imágenes que son reproducidas- en tiempo real- en un monitor. El micrófono inalámbrico permitió la movilidad de la maestra y compañeros, sin estar sujetos a un espacio físico concreto. La cámara-si bien la alumna no la necesitaba- facultó a los compañeros tener presente - a través de su pupitre virtual - a la alumna como sí allí estuviese. En relación al ordenador, el del centro a través del programa "Netmeeting" permitía transferir la información. El de la alumna requirió su adaptación a fin de que la interacción con el ordenador- desde su deficiencia visual- permitiera acceder a la información escrita en él recibida, o al contrario.

Aspecto esencial en el caso particular - dado el problema visual del que se parte- que la ONCE respondió con creces con los dispositivos necesarios. En este caso se contó con que la alumna sabía mecanografiar con una excelente calidad, así que se valió del teclado normal, incorporando en el software el lector y revisor de pantalla y en el hardware síntesis y digitalización de voz. Al mismo tiempo se le facilitaron los libros de texto en cinta gravados y la madre fue escaneándo todo el material curricular de clase, que posteriormente a través de texto hablado accedía a su información. El curso pasado se logro que las editoriales facilitaran el material y la ONCE lo adaptara. La alumna entre tanto aprende informática básica para su desenvoltura lo más autónoma posible y braille que será su nuevo medio de comunicación y lectoescritura.

La figura de la maestra, su disponibilidad y entrega a fin de hacer posible y factible que la alumna participara de la dinámica de la clase, es una condición imprescindible, además de que sus compañeros se adaptaran al nuevo enfoque didáctico e interactuaran con la compañera, dos objetivos esenciales de la alternativa.

La alumna participa de la planificación normal de la clase. Desde un enfoque comprensivo, la descripción se presenta y ejemplifica en torno a los momentos claves de la jornada escolar, como a continuación se presenta: 
*La entrada: Los alumnos acceden a la clase desde el exterior, ella lo hace a través de la red. Se prepara para entrar sin retraso, y ser puntual. De hecho- cuando por alguna circunstanciallegó tarde se le advirtió como a otros alumnos. La alumna recobró el ánimo ante esta situación pues antes andaba por casa, como si tal cosa, como quisiese. Ahora - tras la videoconferencia- ella se arregla y acicala porque la van a ver- dice- vuelve a recobrar coquetería y modales habituales de presentación.

*EI saludo: La alumna participa del encuentro con sus compañeros y conocimientos de las ausencias correspondientes. Igual que éstos sobre su compañera que está en casa. Pues cuando por circunstancias la alumna falta (normalmente por visitas al hospital) todos están pendientes de la pantalla o de su retraso (en su caso).

*Las tareas o deberes del día anterior: Normalmente tras los buenos días, la maestra procedía a recoger las tareas o deberes de casa. Sus compañeros las entregan en su mano, la alumna lo hace a través de la red. Y ella junto con sus compañeros proceden a la puesta en común, a la aclaración de dudas, respuestas dadas a los ejercicios planteados, en suma a la corrección oral, con bastante normalidad.

*La lectura: Los compañeros van siguiendo una lectura en voz alta y ella la sigue desde su casa. (En un principio ella no lee pues no tiene aún el dominio del braille y el lector de pantalla en paralelo provocan un bloqueo y mala audición). Tras la misma, se realizan las actividades de comprensión que- como una alumna más- responde ante las mismas en la dinámica que se establece por parte de la maestra.

*Las explicaciones igual que el resto de sus compañeros. A través de la vos, la alumna sigue las exposiciones, aclaraciones y descripciones que la maestra haga sobre la unidad o tema. Ella en su casa lleva a cabo anotaciones que posteriormente servirán bien para facilitar la comprensión a la hora del estudio, para la realización de las actividades o para hacer preguntas tras la explicación. Éstas se apoyan en la pizarra, en las ilustraciones o en material concreto (mapas, etc.).

*La pizarra es un elemento muy utilizado en el proceso didáctico. Ella tiene el inconveniente de no poder acceder a él. Para ello la maestra procedió a que cada vez que era utilizada tanto por ella como por los niños y niñas de clase, se procediera a verbalizar y explicar el contenido que se iba escribiendo en ella.

*Las ilustraciones son otro elemento al que la alumna no puede acceder. En este caso se recurrió a la técnica de la descripción. Los alumnos, tras una breve parada, han de fijarse en los dibujos e ilustraciones y, tras cerrar el libro, deben ser capaces de enumerar sus partes y contenido. Describir a fin de que la alumna obtuviese información- lo más fiel posible- de lo que tenían entre manos, siempre con la orientación de la maestra. La alumna tenía material en relieve, pudiendo situarse desde su puesto de trabajo en las explicaciones dadas por la maestra. Apoyándose en ellos, accede a su información a través del tacto.

*La ejecución de tareas. La alumna con sus compañeros- aunque en diferentes espacios- al mismo tiempo procede a realizar tareas indicadas por la maestra. En este caso sus ejercicios 
si son del libro, pues ella los abre a través de su ordenador, y aunque accede de forma diferente al resto de sus compañeros y compañeras, no impide su realización. Si es alguna actividad dictada o tomada de la pizarra la maestra la envía a través del programa y la alumna accede a ella de igual forma.

* La puesta en común, pues exactamente se procede de igual forma que con la lectura o la solicitud del trabajo del día anterior. Por indicación de la maestra va requiriendo la respuesta de sus alumnos y de ella- como uno más- y por turnos (en lugar de levantar la mano pronuncia el nombre) van solicitando la intervención exponiendo el contenido del trabajo o sus aportaciones particulares.

${ }^{*}$ El trabajo en grupo también tiene cabida. La clase se divide en grupos, pues ella participa en uno de ellos. Como en el juego potaje que- habitualmente hacían- como recapitulación de los contenidos trabajados. Se lleva a cabo a término, incluyendo preguntas de todas las áreas, de entretenimiento, de memoria, etc. Las preguntas van pasando de grupo en grupo, reflexionando la respuesta entre sus componentes y apartándola. La alumna se motivo bastante con su contribución.

*Los controles programados- o las sorpresas-también están en esta dinámica del proceso. La alumna se ve sometidos a ellos -igual que el resto de sus compañeros-sólo permitiéndole un poco más de tiempo. A ella se le enviaban a través de correo o del programa con el que trabajaba en conexión. Una vez realizado, lo envía al aula para su posterior corrección y calificación.

Cuadro 14: Plan de Clase utilizando una video conferencia.

En relación al segundo objetivo pretendido, la interacción con sus compañeros, también se posibilitó desde una alternativa, lográndose de forma satisfactoria. Desde la síntesis con la que se expone la presente investigación.

${ }^{*}$ Ruptura con el asilamiento. La videoconferencia supuso que los compañeros percibieran y vieran "con sus ojos" a la compañera no tan enferma como ellos pensasen, ni tan mal como se comentaba. Ven a la niña que no puede asistir a clase por prevención a un tratamiento, pero que- como ellos- tiene sus ganas de compartir ratos y acontecimientos con ellos.

*Encuentros. Supuso buscar momentos de coincidencia entre los compañeros y entre los allegados. Permitió que sus iguales se pusieran en contacto con ella o viceversa a través de la red- en primer lugar- en momentos como la salida al recreo o al finalizar la clase. Alguno se queda a hablar con ella, o ella pedía a alguno que se quedara a comentar cualquier cosa. En segundo lugar produjo que sus iguales se pasaran más a su casa y reanudaran la relación perdida.

${ }^{*}$ Convivencia: Supuso que la alumna participara del mismo proceso educativo que sus iguales, asumiendo las mismas funciones y responsabilidades. Supuso proseguir en compañía 
de sus compañeros y compañeras su proceso de socialización: moda, reglas, novedades, ídolos, inquietudes, comentarios, chistes, etc.

${ }^{*}$ Cotidianeidad. Permitió que la alumna interactuara con lo cotidiano, con los acontecimientos diarios que día a día surgen en el entorno escolar. Fundamentalmente acontecimientos, incidencias y ocurrencias. A través de los primeros tiene la oportunidad de seguir alguna charla ofrecida por el colegio. Desde el segundo comparte y conoce los sucesos que sobrevienen a lo largo de la jornada escolar; una visita, un castigo, una fechoría, una risotada, una anécdota. A través de las ocurrencias la alumna vivencia las ideas inesperadas que ponen en marcha sus compañeros como al asentarse la maestra.

Cuadro 15: Resultados de la Interacción

Actualmente la alumna asiste al instituto y reconocemos el gasto de la administración educativa al dar un paso más, instalando desde el inicio del curso otro sistema- a través de antenas- ya desde ADSL quedando establecidas de forma permanente la conexión entre el Instituto y su casa, además de brindarle otras oportunidades de conexión y contactos.

La conexión para proseguir el proceso didáctico vía videoconferencia, se llevó a cabo en tiempo real, pero no contó con la implicación de todos los docentes por sus resistencias hacia las tecnologías, por lo que no pudieron abordarse todas las materias del curriculum. En su caso, se organizo un horario de conexión agrupando en días durante las sesiones de mañana. En paralelo a ello contó con apoyo escolar desde el centro y atención domiciliaria.

Ya desde la red tiene posibilidades escolares, sociales y personales. A ello hay que reconocer también la nueva iniciativa de la ONCE. La alumna queda conectada a una página web que se llama tiftolibro, una biblioteca sonora con más de ocho mil volúmenes.

Desde el centro educativo, tras la experiencia el curso anterior, se abren las puertas de par en par para participar desde esta modalidad educativa. Reconocemos que ya unos profesores están totalmente más receptivos.

Si bien desde su estancia en el Hospital no fue posible, actualmente en el curso 07-08 estamos tratando de llevar a cabo una experiencia similar desde la modalidad educativa. 


\subsection{Guía para Profesionales y Padres de Personas con Discapacidad.}

Como se ha mencionado, una de las funciones de las TIC es mejorar la comunicación entre las personas que se encuentran diseminadas geográficamente. Las personas con discapacidad tienen esta característica. Los profesionales deben enfrentar una intervención para lo que en la mayoría de las ocasiones no tienen formación especifica. Al hablar de personas con trastornos del desarrollo se puede decir que en general esta población se encuentra diseminada geográficamente lo que obliga profesional o a la familia a una peregrinación costosa. El desarrollo de las TIC, en particular con la red, ha permitido que se generen servicios de apoyo virtual. Condillac (1999) realiza estudios del apoyo y asesoramiento recibido por las familias desde diferentes sitios web a la hora de elegir el tratamiento de sus hijos. Algunos centros de recursos y apoyos han desarrollado servicios asistidos por la web como el Missouri Developmental Disability Resource Center http://www.moddrc.org Missouri Centro de Recursos para la Discapacidad, también se han desarrollado sistemas informativos para profesionales y familias en soporte $C D$ para apoyar la medida en la adquisición de Tecnología de Ayuda, sobre todo en sistemas alternativos de comunicación (Hourcade, J. J. y Parette, P. 2001). En la actualidad se dispone de numerosos y potentes bases de datos on line que facilitan esta información en http://www.ceapat.org/catalogo.do Centro Estatal de Autonomía Personal y Ayudas Técnicas, en España, la misión del Ceapart es contribuir a mejorar la calidad de vida de todos los ciudadanos, con especial apoyo a las personas con discapacidad y personas mayores, por medio de la accesibilidad integral, el diseño para todos y la tecnología de apoyo.

En Alemania el Ministerio de Trabajo y Asuntos Sociales ha desarrollado una importante base de datos que ofrece además información sobre las ayudas técnicas, ejemplos prácticos y legislación en http://db1.rehadat.de/rehadat/index.jsp Rehadat es un Sistema Informático para la rehabilitación profesional de personas discapacitadas, la base de datos esta disponible en alemán e inglés, en castellano se puede encontrar una breve descripción de los contenidos de la base de datos, así como también documentos a titulo de ejemplo. 
En España, se han desarrollado sistemas tutores que ayudan en la toma de decisiones en la adquisición de ayudas técnicas para el acceso al ordenador en http://www.ceapat.org/ALBOR Es un espacio virtual en internet que sirve de herramienta básica a los profesionales de la evaluación de personas con discapacidad y la adaptación de su acceso a elementos técnicos.
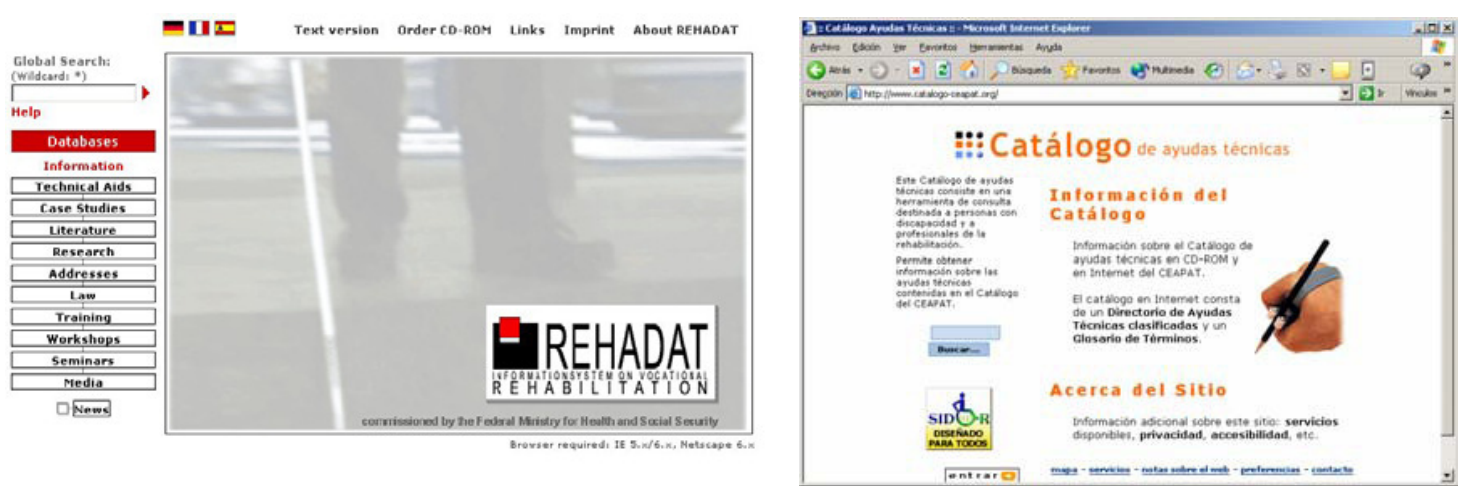

Figura 16: Base de datos de Rehadat y catalogo de ayudas técnicas del CEAPAT (Alcantud, 2004).

El Simulations in Developmental Disabilities

http://www.behaviordevelopmentsolutions.com/products sidd.html es un software multimedia que proporciona a los estudiantes o personal la oportunidad de realizar prácticas sobre el asesoramiento y la toma de desiciones en el tratamiento de personas con trastornos del desarrollo. Desrochers, Clemmons Grady y Justicice (2000) evaluaron este sistema manifestando que los estudiantes que utilizaron el sistema de simulación, obtienen puntuaciones significativamente más altas que nos que no lo utilizaron.

Reedy y otros (2001), estudian la influencia de sistemas de formación continua en la realización de tareas de gestión y administración de centros residenciales de personas con trastornos de desarrollo. La información recogida estructurada para alimentar la base de datos, el feedback con información y documentación de actividades instruccionales, mejora la realización de las competencias del personal dedicado a la atención directa.

La página de la asociación de Autismo de Burgos http://www.autismoburgos.org Es una página de la Asociación de Padres de 
personas con Autismo en Burgos España, donde se puede encontrar cursos de formación de autismo on line, muestras internacionales de arte, novedades, documentos, inserción laboral, etc.

Alcantud (2004) establece que uno de los problemas de la investigación de trastornos del desarrollo, es el desarrollo de sistemas de registro lo suficientemente fiables para, a partir de su análisis, poder desarrollar pruebas de la eficiencia de los tratamientos o de su influencia en el desarrollo de la persona.

Alcantud (2002) han desarrollado el sistema Win Watch para integrar imágenes de video, audio y registro de la observación en situaciones de laboratorio, que permite analizar la interacción entre el usuario y el ordenador. Este sistema es factible de ser utilizado en cualquier aula para registrar las conductas de los alumnos y poder, después confirmar la observación mediante el uso de jueces.
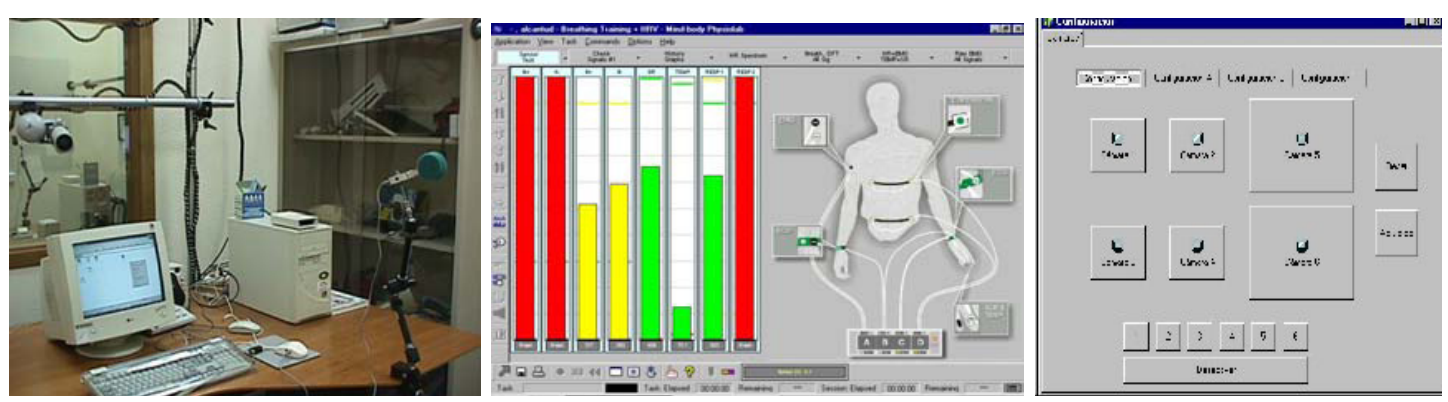

Figura 17: Diferentes componentes del sistema de registro automático Win Watch (http://acceso.uv.es/usabilidad) (Alcantud, 2004).

Existe un gran abanico de aplicaciones en la intervención de personas con trastornos del desarrollo. La dificultad de la implementación de estas tecnologías esta en el coste de las mismas, la falta de formación técnica de los profesionales o de las nuevas figuras profesionales que den apoyo técnico en los centros, por otro lado esta la corta vida media de estos productos, dada la rapidez con que evoluciona la tecnología (Alcantud y otros 2001a). 


\subsection{Diseño de SOFTWARE y páginas web accesibles.}

Los nuevos canales de comunicación a través de las redes aportan un nuevo y amplio abanico de posibilidades de acceso a la información y de intercambio experiencias y comunicaciones con personas o grupos que tengan intereses comunes. Una de las principales ventanas del mundo es la Web, donde se publica una gran cantidad de información, que puede ser inicial o continúa de diversos temas y campos, etc., estableciendo comunicación a través de correo electrónico. Las posibilidades de información y comunicación por este medio son de suma importancia, para que no pueda ser estar a la mano de todas las personas.

La vigencia de los textos de las Naciones Unidad es más significativa al marcar "accesible a todos, sobre la base de la capacidad de cada uno, por cuantos medios sean apropiados". El acceso para todos, el diseño accesible para todos son conceptos claves en la utilización de tecnología y respeto a la diversidad, de igual manera es la clave para que las TIC puedan ser un elemento que permita el acceso a la educación y a la participación activa en la sociedad de la información (Alba, 2004).

En este sentido, Chacón (2007) asevera que la Accesibilidad indica la facilidad con la que algo puede ser usado, visitado o accedido en general por todas las personas, especialmente aquellas que poseen discapacidad.

Un sitio accesible es aquel cuyo contenido puede ser usado correctamente por el mayor número de usuarios, lo más importante es comprender que la gente accede a la Web de modos muy distintos (Romero, 2001). El acceso a la información de la red es un problema especial para las personas con discapacidad, ya que el entorno gráfico y textual de la World Wide Web impide o dificulta el acceso sobre todo a las personas que tienen discapacidad visual o problemas en la decodificación de los mensajes escritos (Alcantud, 2004).

La importancia de la accesibilidad a la red ha hecho que se desarrollen normas internacionales sobre los requisitos técnicos básicos, se puede consultar http://www.w3.org/WAl donde se pueden encontrar estrategias, pautas y recursos para hacer la Web accesible a las personas con discapacidad. 
Las acciones son la Iniciativa mundial para la Accesibilidad de Internet (WAI) del W3C; la elaboración de documentos para definir las pautas que garanticen la accesibilidad de los espacios Web como son las Directrices de Accesibilidad para el Contenido Web 1.0, Directrices de Accesibilidad para XML, Tabla de Puntos de Verificación para las Pautas de Accesibilidad de Contenido de la Web 1.0, o los programas y robots de revisión automática como TAW, Boddy, Validator, etc., estos permiten que los particulares o diseñadores puedan realizar la evaluación y diagnóstico de la accesibilidad de las páginas que estén diseñando (Alba, 2004).

El grupo Didáctica i Multimedia (DiM) propone algunas pautas de accesibilidad para hacer accesibles los contenidos de las páginas Web, traducida de Web Content Accessibility Guidelines 1.0:

1. "Proporcionar alternativas equivalentes para el contenido visual y auditivo".

2. "Asegurar que toda la información transmitida a través de los colores también esté disponible sin color, por ejemplo por medio de el contexto o marcadores".

3. "Utilice marcadores y hojas de estilo y hágalo apropiadamente".

4. "Identifique el idioma utilizado".

5. "Cree tablas que se transformen correctamente".

6. "Asegurarse que las páginas sean accesibles incluso cuando no se soportan las tecnologías más modernas 0 éstas estén desconectadas".

7. "Asegurar al usuario el control sobre los cambios de los contenidos tempo-dependientes".

8. "Asegurar la accesibilidad directa de las interfaces de usuario incrustadas".

9. "Diseñe para la independencia del dispositivo".

Las normas por si solas no garantizan la total accesibilidad, es necesario continuar investigando sobre el diseño del sitio en interacción con los diferentes tipos de usuarios. Entre algunas de las recomendaciones que se han elaborado 
de cómo hacer posible la accesibilidad de la Web, se encuentran las aportaciones de Romero (2001), que señala la necesidad de dotar a las páginas de modo texto, buscar el máximo contraste primer plano-fondo, enlaces con textos significativos y claros, evitar elementos no estándares que los lectores de pantalla no puedan interpretar, igualmente evitar uso de marcos, utilizar una herramienta de autor que facilite la incorporación de las opciones de accesibilidad y realizar una validación de accesibilidad de la página.

Se ha investigado la incorporación de navegadores especiales para personas ciegas y de las condiciones especiales del diseño del contenido para que estos navegadores funcionen eficientemente (Alcantud y otros 2001). Estos autores establecen que otra de las investigaciones es el acceso a las presentaciones multimedia por estudiantes con discapacidad visual, aunque no se presenten necesariamente mediante la red, si es verdad que la tecnología actual lo permite. Así mismo citan que Corn y Wall (2002), han estudiado alternativas como el texto complementario, en formato audio e impresión braille. Otros estudios se centran en el acceso y control a determinados tipos de información existente en la red y su efecto sobre adolescentes con trastornos del desarrollo. Davies y otros (2001) han evaluado el Web Trek en comparación con el navegador de estándar Microsoft Explorer, con un grupo de personas con retraso mental, obteniendo como resultado mejores tiempos en la navegación, además de facilidades en la estructuración de la información y en el almacenamiento de la dirección (Ver Figura 18).

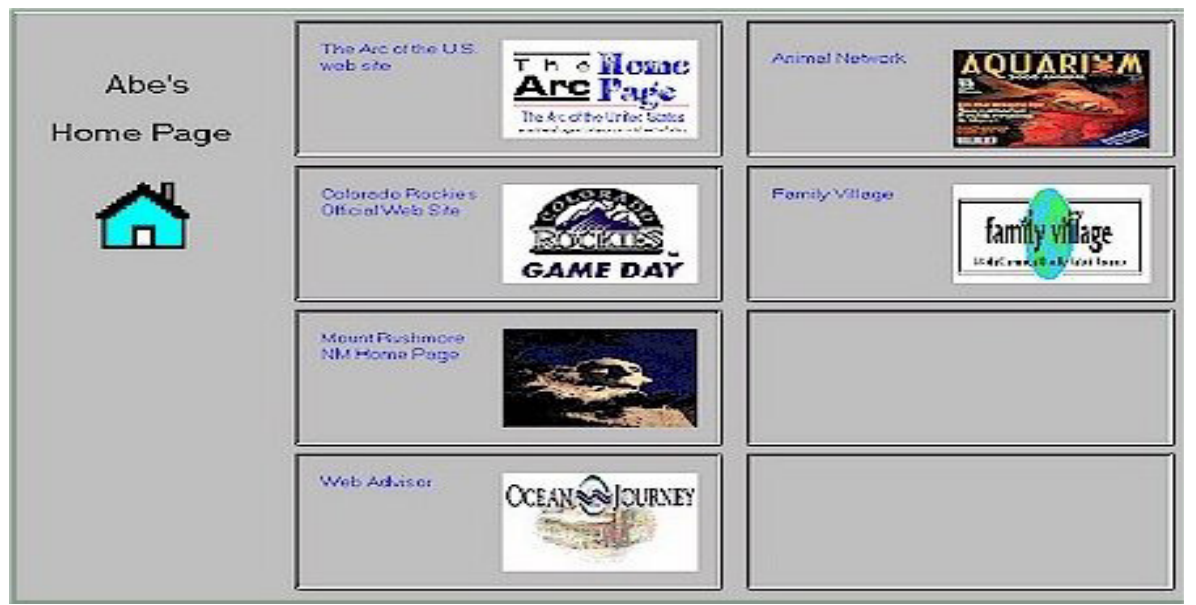

Figura 18: Navegador adaptado Web Trek http://www.ablelinktech.com Se observa como se ha simplificado la tarea de navegación. 
Las personas con discapacidad se encuentran dispersas geográficamente, en algunas ocasiones presentando problemas de desplazamiento a los centros de formación presencial y con una programación temporal de trabajo muy personalizada, por lo requieren una formación a distancia. Las aplicaciones dirigidas a la formación a distancia mediante TIC, teleformación o e-learning, han sido las que mas se han beneficiado del desarrollo tecnológico de la red (Reiser y Dempsey, 2002).

Alba (2004) establece que en los escasos publicados sobre accesibilidad de espacios y páginas web educativos de (Toledo, 2001; Alba, 2001) se manifiesta la falta de accesibilidad de estas páginas web y de los servicios que en ella se ofrecen en el ámbito universitario o en las páginas dirigidas al edutainment $o$ entretenimiento infantil. De igual manera manifiesta que los niños, niñas, estudiantes $\mathrm{o}$ adultos con discapacidad que deseen utilizar las páginas de entretenimiento, realizar actividades, obtener información sobre centros educativos, etc., en la mayoría de los casos no podrá utilizar este medio, quedando excluidos de la posibilidad de participar en cursos o actividades que se desarrollen a través de plataformas virtuales de formación, dado que muchas de ellas no son accesibles.

Alba (2004) presenta algunos ejemplos de buenas prácticas de cómo se esta construyendo la accesibilidad en la Red, que sirven como referencia para construir espacios educativos virtuales, que cumplan con los requisitos de un diseño técnico y educativo de calidad.

Dentro de las consideradas buenas prácticas se pueden encontrar páginas de instituciones públicas relevantes que diseñan sus páginas web siguiendo las normas y recomendaciones de las pautas de accesibilidad y explicitan su compromiso de forma de compromiso institucional; La página del Parlamento Australiano (http://www.aph.gov.au). 


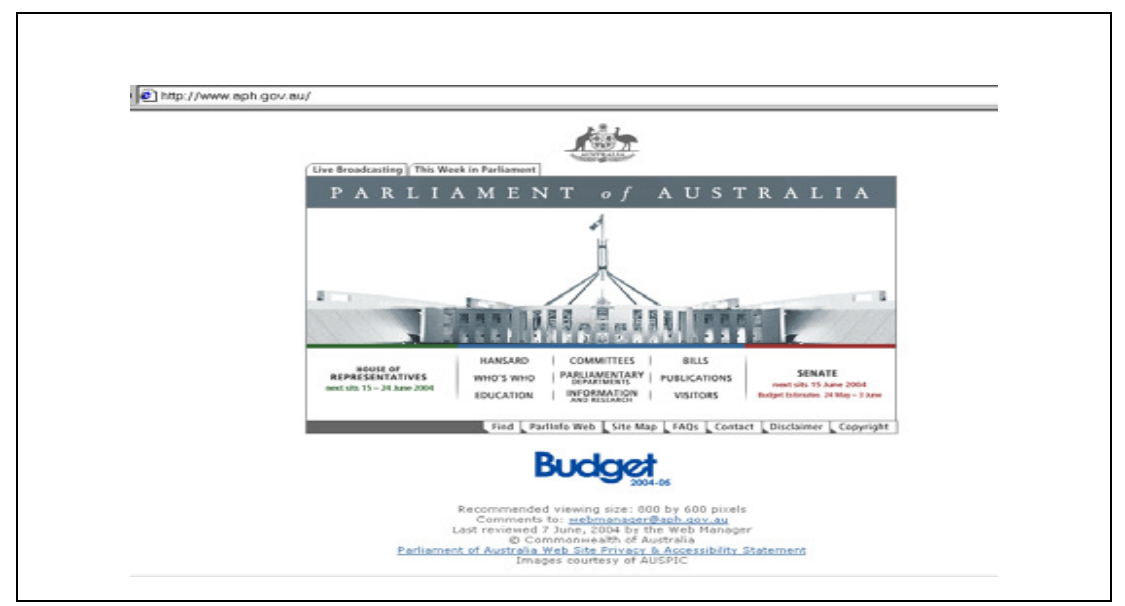

Figura 19: Imagen de la página web del Parlamento Australiano (Alba, 2004).

En España, un ejemplo institucional es la página del IMSERSO, que incluye el icono que indica que se ha validado según las pautas de la WAI a través del programa TAW 1.1. En el diseño de las plantillas se han respetado las Directrices de accesibilidad WAI 1.0 acreditándose en la actualidad el nivel A en todas las páginas y el AAA en la mayor parte de ellas, de esta manera se continúa trabajando para consolidar el nivel AAA en toda la página (http://www.seg-social.es/imserso )

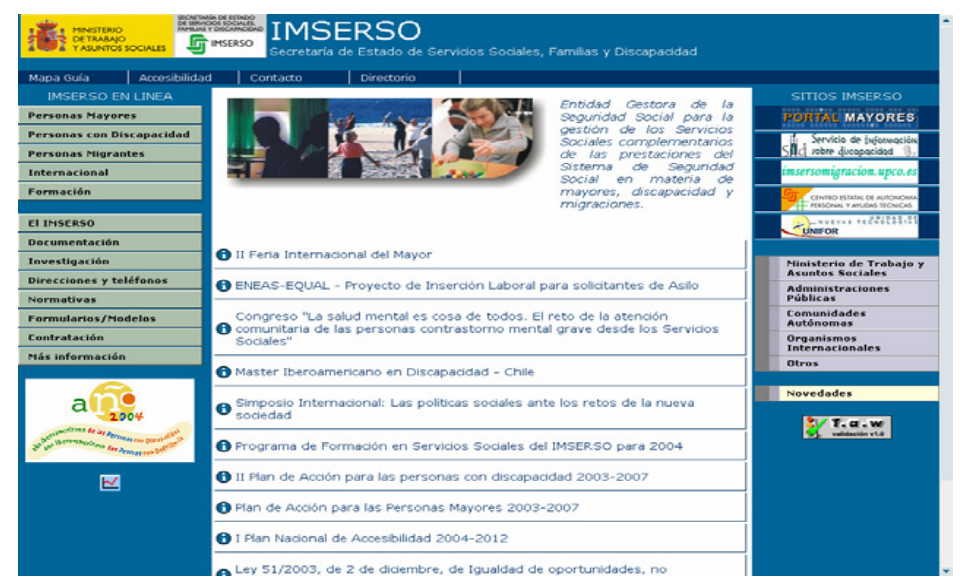

Figura 20: Imagen de la página web de la institución IMSERSO validada por la WAI (Alba, 2004).

Otro ejemplo de una institución directamente relacionada con el tema de la accesibilidad, es el Centro Estatal de Autonomía Personal y Ayuda Técnica CEAPAT (http://www.ceapat.org/verlndex.do ). En su web se observan tres iconos diferentes indicando las revisiones que se han realizado para garantizar su accesibilidad: el programa TAW y el programa Bobby y su adecuación al 
nivel A.A. de las Directrices de Accesibilidad para el contenido establecidas por la WAI (WCAG 1.0).

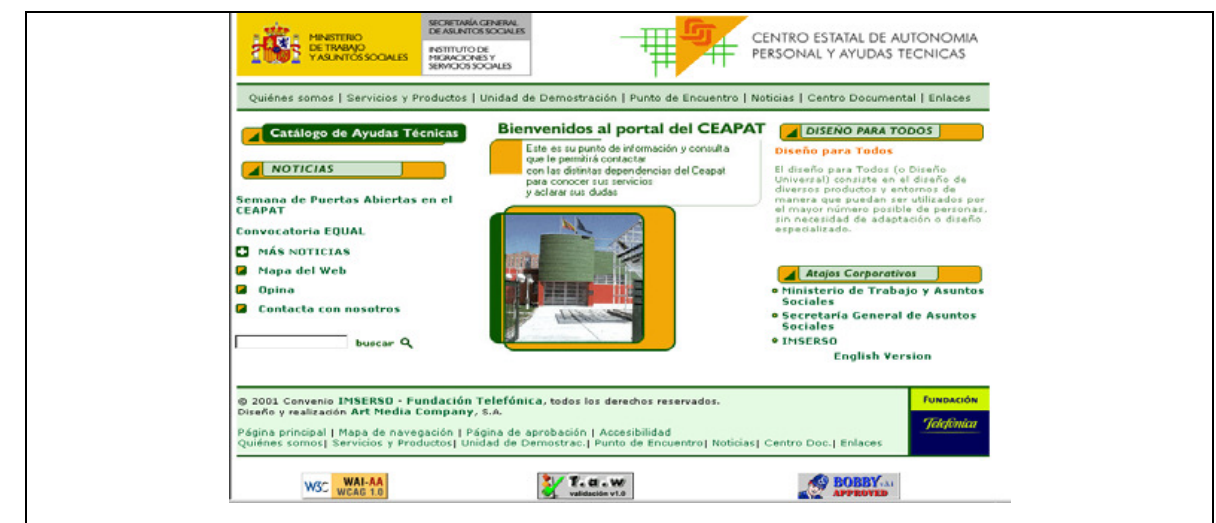

Figura 21: Imagen de la página web de CEAPAT que cumplen las normas de accesibilidad (Alba, 2004).

Estas son algunas de las pocas páginas institucionales con diseño accesible, pese a que ya son muchos años en vigor de las pautas de accesibilidad.

En el campo de la educación en más notable la ausencia de páginas accesibles, aun y cuando se diseñen páginas para los diferentes niveles educativos.

Uno de los ejemplos excepcionales es el I.E.S. Puerta Bonita, aparecen los iconos de validación de HTML, Hoja de estilo y de conformidad con el nivel AA de las directrices de accesibilidad de la WAL (http:/www.iespuertabonita.com/web0001/principal.htm ) este portal tiene la intención de ser accesibles para todos, para ello utilizara en lo posible, formatos estándar establecidos por el W3C (World Wide Web Consortium) para el diseño de páginas Web de las Administraciones Publicas.

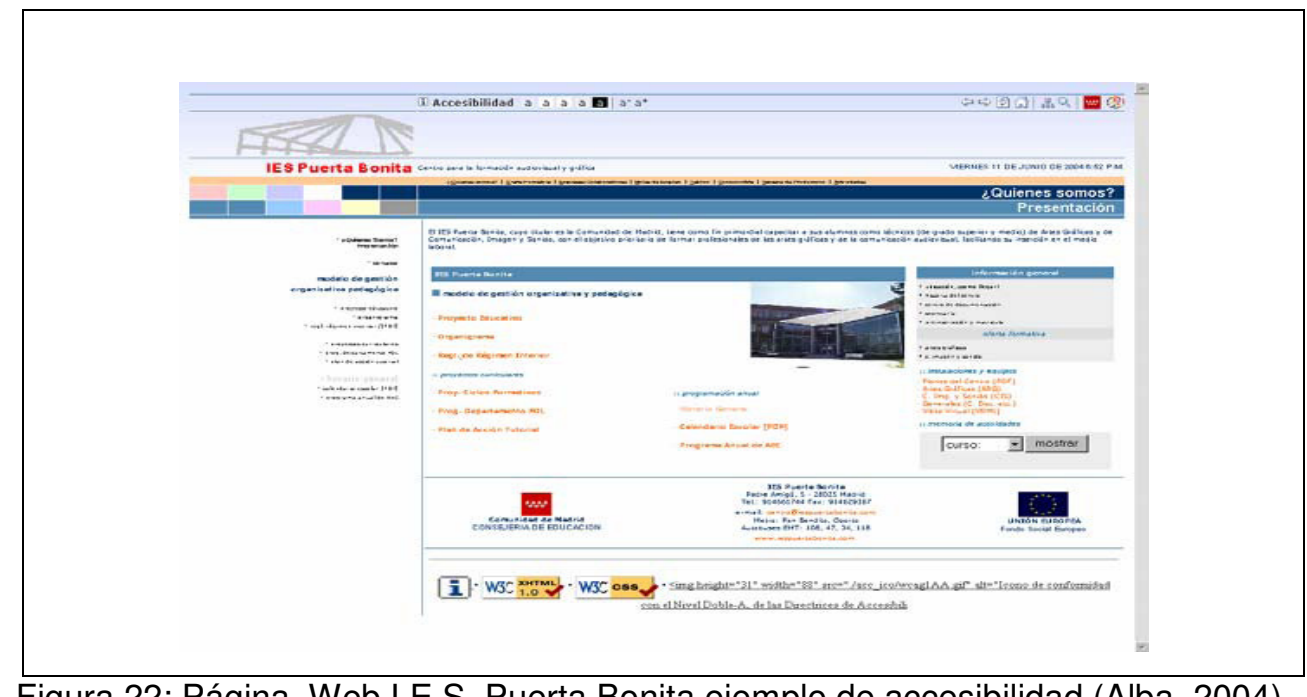

Figura 22: Página Web I.E.S. Puerta Bonita ejemplo de accesibilidad (Alba, 2004) 
Alba (2004) señala que en el nivel universitario tampoco está generalizado el respeto al diseño accesible, algo que seria importante potenciar para las personas que tienen dificultades de acceder a los contextos formativos presenciales, de la información y las ofertas formativas que tienen como soporte el Internet.

El junio del 2008 en el boletín de noticias del Instituto Universitario de Integración en la Comunidad INICO, se publico la noticia de que los visitantes del CERMI eligieron la web del Servicios de Información sobre Discapacidad (SID) como la más accesible, aun y cuando su creación fue en 1999 el SID a cuidado la accesibilidad de sus contenidos, haciendo un gran esfuerzo por facilitar el acceso a la información contenida en el servicio para todas las personas, independientemente de cómo se consulte la web.

Toda la página del SID ha sido validada como XHTML 1.0 tradicional. Todas las páginas utilizan etiquetas de estructuración semántica. Las etiquetas H2 han sido utilizadas para los títulos principales de cada página. Las etiquetas H3 han sido utilizadas para los subtítulos. Cualquier lector de pantalla puede avanzar de sección en sección presionando ALT-INSERT+2.

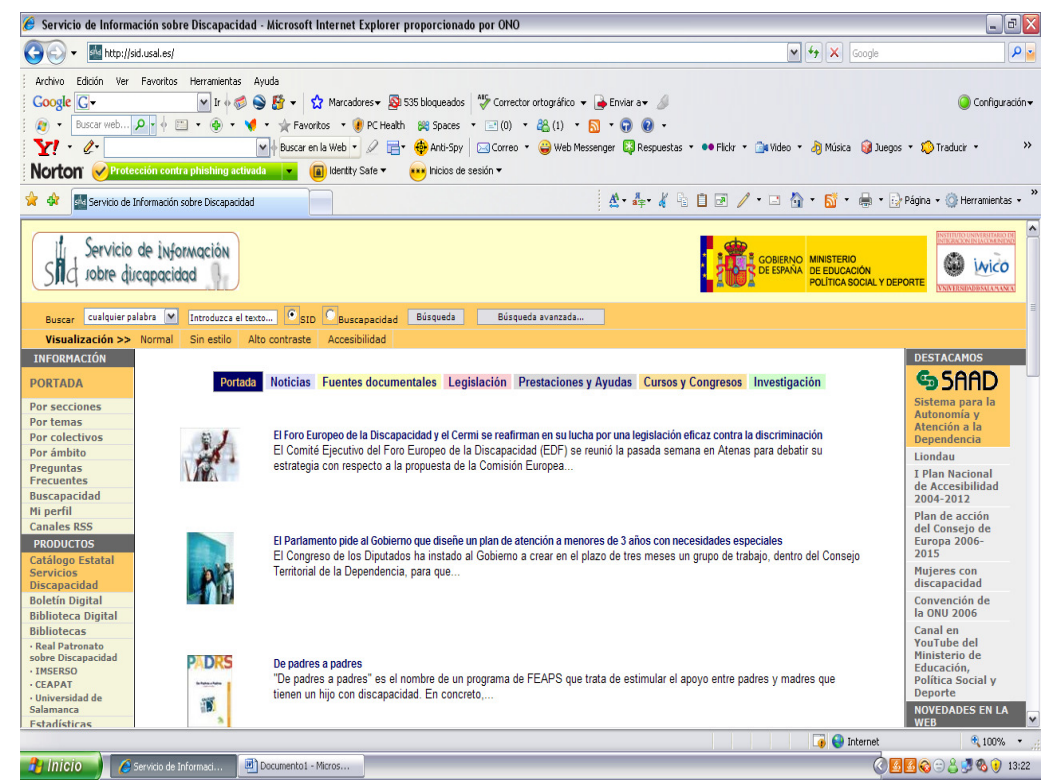

Figura 23: Página del Servicio de Información sobre Discapacidad (SID). 
Algunas de las universidades que están poniendo accesibles sus páginas web y los servicios que ofrecen son:

- Universidad de Connecticut, que además del diseño accesible de su web, se incorporan servicios específicos para estudiantes con discapacidad facilitando su incorporación y participación dentro del principio de igualdad de oportunidades.

- Universidad de Pompeu además de tener una página accesible, presenta una declaración de su política y compromiso de accesibilidad (http://www.upf.edu ). Por ello utilizaron los estándares que establece el W3C y las Directrices de para la accesibilidad al contenido de la página web, versión 1.0 (versión catalana publicada en la Web de la Universidad de Barcelona).

En las Universidades se han creado unidades y servicios especializados sobre accesibilidad en la Red, a través de los cuales se puede obtener información de interés y contactos con equipos especializados en el tema. La Unidad de Investigación de Acceso de la Universidad de Valencia, es otro de los casos de páginas web accesible, en ella aparecen los iconos de cumplir con los requisitos de accesibilidad según la herramienta de revisión automática TAW v.1.0, de verificación de las hojas de estilo CSS y el icono de accesibilidad internacional (Alba, 2004).

Los grandes beneficios del Internet que se han mencionado son innegables, más sin embargo la falta de accesibilidad en los diseños de páginas web en todos los contextos, principalmente en el que ahora nos interesa en la educación, ponen de manifiesto la inaccesibilidad y barreras que esto representa para muchas de las personas con discapacidad, es necesario que la cultura de accesibilidad para todos y cualquier persona llegue a ser un interés de todos, no solo de unos cuantos. 


\subsection{Las TIC en la Formación Continua y Permanente.}

La incorporación de las TIC para ser bien aprovechadas requiere que el profesor entienda su labor como asesor y guía del auto-aprendizaje, motivador y facilitador de recursos, diseñador de nuevos entornos de aprendizaje con las TIC, adaptador de materiales de diferentes soportes, productor de materiales didácticos en nuevos soportes, evaluador de los procesos que se producen en estos nuevos entornos con estos recursos, poseer una concepción docente basada en el autoaprendizaje permanente sobre o apoyado en las TIC. Estos aspectos plantean que los profesores tengan nuevas competencias docentes relacionadas con (Cebrían, 2003):

> Conocimientos sobre los procesos de comunicación y de significación de los contenidos que generan las distintas TIC, así como también un aprovechamiento equilibrado de sus mensajes. Desarrollar las competencias para la comprensión y el uso correcto de los mensajes que producen las TIC.

> Conocimientos sobre las diferentes formas de trabajar las nuevas tecnologías en las distintas áreas y disciplinas.

> Conocimientos sobre la planificación y organización de las TIC en el aula y en el centro. Una mala gestión y organización de los recursos en los proyectos de centro y en la programación del aula ocasionan muchas de las veces deficiencias y subutilización de los equipos.

> El futuro del docente debería poseer criterios válidos para la selección de materiales, así mismo tener conocimientos técnicos suficientes que le permitan rehacer y estructurar materiales existentes en el mercado, adaptándolo a sus necesidades, o crear uno nuevo.

> Conocimiento técnico a nivel de los usuarios. Cualquier profesión requiere conocimiento de herramientas y técnicas. Los profesores necesitan tener conocimientos de hardware y mantenimiento básico de los equipos, dominar el software más común y específico de acuerdo a sus intereses, niveles 0 áreas de conocimiento. Así como las herramientas de enseñanza a distancia. 
> Saber elaborar nuevos materiales desde y para diferentes soportes. Saber qué dejar para lo presencial y qué para los espacios virtuales, así como elaborar material par la red.

> Fortalecer su desarrollo profesional de manera permanente a través de la red, en cualquier espacio y tiempo. Cambios en las formas de producción y difusión de conocimientos que las tecnologías están produciendo en el mundo laboral.

Es necesario que los profesores tengan conocimientos sobre los procesos de comunicación, así como de la significación de los contenidos que generan las distintas TIC, con capacitación para comprender y utilizar correctamente los mensajes que estas producen y vehiculan, así como conocimientos sobre distintas formas de trabajar las nuevas tecnologías en las diferentes áreas y disciplinas, de igual manera conocimientos organizativos y didácticos sobre el uso de las TIC, para la planificación tanto del aula como del centro de trabajo, ya que muchas de las deficiencias e infrautilización de los equipos responden a una mala gestión y organización de los recursos con los que se cuenta, tanto en los proyectos de centro, como en los de aula, se debe en ocasiones a desconocimientos de fondo sobre todas las posibilidades de los recursos tecnológicos, y en otras ocasiones por falta de ajustes en las aulas de los nuevos recursos utilizando las mismas metodologías (González y otros,2004).

El papel del profesor como asesor, guía, orientador frente a los recursos digitales y las tecnologías, es en cierto sentido nuevo y por ello se une al aprendizaje mutuo con los alumnos, porque para todos siempre hay algo nuevo que aprender. Por un lado ayudar al alumno a construir su conocimiento, a buscarlo, a utilizar nuevos soportes tanto para la enseñanza como para el aprendizaje, es una gran oportunidad para aprender con los alumnos.

El aprendizaje colaborativo se sustenta en teorías cognoscitivas. Para Piaget (1969) hay cuatro factores que intervienen e inciden en la modificación de las estructuras cognoscitivas; la maduración, la experiencia, el equilibrio y la transmisión social. Todos ellos se pueden propiciar a través de ambientes colaborativos. En la teoría constructivista el aprendiz necesita la acción de un agente mediador para acceder a la zona de desarrollo próximo, éste será el 
responsable de ir tendiendo un andamiaje que proporcione seguridad y permita que el aprendiz se apropie del conocimiento y lo transfiera a su propio entorno.

Es importante que los maestros tengan conocimientos teóricos -prácticos que les permita analizar, comprender, y poder tomar decisiones de enseñanza aprendizaje utilizando las TIC y un dominio permanente del uso de estas para la comunicación y la información permanentemente, lo que requiere una nueva visión de la formación inicial y continua del profesorado. En el futuro se hace necesario buscar el equilibrio entre el aprendizaje no presencial y el aprendizaje en el aula convencional, aprovechando todos los recursos que proporciona la tecnología, con la dirección y supervisión de profesionales de la educación (González y otros, 2004).

La filosofía de autoaprendizaje y la formación a lo largo de la vida profesional, es de suma importancia, dado que siempre será insuficiente la formación inicial para hacer frente a estos nuevos retos, no favoreciendo las estrategias de trabajo aislado y desvinculado de la labor docente. Los profesores como cualquier otro profesional no puede olvidarse que como parte de su responsabilidad es ocuparse del reciclaje profesional, actualizar sus conocimientos y exigir a los empleadores que se facilite el acceso a la formación permanente. Dado que una de las características de este momento son los cambios que se producen cada vez con mayor rapidez y las necesidades de actualización son cada vez más necesarias.

Al no ser éste la única fuente del saber, especialmente desde que se ha generalizado el acceso a la sociedad de la información. Esto supone que hay un cambio, al dejar de ser únicamente trasmisor de conocimientos, para pasa a ser un filtro, mediador, dinamizador, facilitador, y asesor del proceso en el que, debido a la abundancia de las fuentes, a menudo carentes de un criterio y de garantía, su papel sigue siendo tan importante como siempre y su labor es más rica en matices y en posibilidades (Ortega, 2005).

Los nuevos canales de la comunicación y de la información, como las redes telemáticas, considerada como un conjunto de ordenadores y dispositivos que se funcionan autónomamente, pero que también se encuentran interconectados, pudiendo compartir recursos, tanto software como hardware, presentando valores añadidos como la disponibilidad de estos, el ahorro económico y un acercamiento y superación de barreras espacio - temporales, 
tienen como una de sus principales características la rapidez e inmediatez de la trasmisión de la información y la comunicación, al mismo tiempo son las tecnologías más fácil de adaptarse a las características cronológicas, psicológicas y culturales de los usuarios, no solamente por la cantidad de la información sino también por los temas simbólicos que pueden adaptarse a los usuarios, una de las más conocidas es Internet, el cual tiene dentro de sus aplicación y herramientas por un lado podemos encontrar aplicaciones básicas, como una de las más extendidas que es el correo electrónico, y otras herramientas que aporta el Internet para la navegación y búsqueda de información pueden ser, Word Wide Web; sistema global de información distribuida, que permite navegar por Internet, Archie; servicio de búsqueda que facilita buscar ficheros FTP, Wais permite buscar un determinado documento por el contenido del mismo no por su extensión (Cabero y otros 1999).

Son muchas las posibilidades que pueden aportar las nuevas tecnologías, entre ellas una de las más importantes en el ámbito de la educación, es la posibilidad del incremento de información que pueden tener a su disposición estudiantes y profesores. Se puede acceder a diferentes tipos de contenidos y estructuras, desde fuentes documentales de información, hasta de ejemplificación y ejercitación, la información que se puede encontrar no solo es cuantitativa, sino cualitativa ya que no es solo textual, sino también visual y auditiva, es importante mencionar que las nuevas tecnologías actualmente permiten la deslocalización del conocimiento, permitiendo romper el espacio y tiempo para introducirnos en una comunidad de conocimiento.

Hoy en día hay mensajes multimedia y sistemas de conferencias que permiten a los usuarios poder enviar no solo un texto, sino imágenes, gráficos, voz, video, etc. El ordenador se ha convertido en un nuevo medio de comunicación, facilitando lo que tradicionalmente se ha utilizado textos en papel. Los lectores y los autores pueden ahora utilizar el mismo conjunto de herramientas para crear, explorar y desarrollar textos. Ellos pueden utilizar material creado por otras personas, hacer sus propias anotaciones y enlaces, así como fusionar el material con sus propios escritos. Por ello los límites entre autor y lector pueden comenzar a desaparecer.

El desarrollo de la web en las últimas décadas ha ido cambiando nuestros conceptos de textos, documentos y medios de comunicación, las redes 
electrónicas cada vez se están utilizando más para comunicación entre estudiantes y profesores. Las investigaciones que se han realizado exploran diferentes maneras de organizar este tipo de redes, algunas se centran en tareas específicas, otras tienen una estructura de conferencias flexibles. La web ofrece posibilidades ilimitadas para la comunicación, existen un número crecientes de herramientas que permiten la construcción de páginas web, estas herramientas aun cuando el objetivo es la construcción de un sitio web para la comunicación, también puede utilizarse solo para la construcción (Bruce y Levin, 2003).

Las tecnologías pueden ser utilizadas como medios de comunicación para el aprendizaje a través de la construcción, dado el actual hincapié en los enfoques constructivitas de la construcción del conocimiento, a través de la utilización de las nuevas tecnologías, el aprendizaje también puede ser cualitativamente diferente, dado que el proceso de aprendizaje en las aulas pueden considerarse más ricos cuando los estudiantes tienen acceso a nuevos y diferentes tipos de información (Levin y Bruce ,2001).

La UNESCO establece en el documento de Estándares de Competencias en TIC para Docentes (2008), que tanto los programas de desarrollo profesional para docentes en ejercicio, como los programas de formación inicial para futuros profesores deben contemplar en todos los elementos de capacitación experiencias enriquecidas con TIC. Los estándares y recursos del proyecto "Estándares UNESCO de Competencias en TIC para Docentes" (ECD-TIC) ofrecen orientaciones para los docentes y sobre todo, directrices para planear programas de formación del profesorado y selección de cursos que les permitirá prepararlos para desempeñar un papel esencial en la capacitación tecnológica de los estudiantes. En la actualidad los docentes en ejercicio necesitan estar preparados para ofrecer a sus estudiantes oportunidades de aprendizaje apoyadas en TIC, tener conocimientos para utilizarlas y para saber cómo pueden contribuir al aprendizaje de los estudiantes, estas capacidades de los docentes forman parte integral del catalogó de competencias profesionales básicas de un docente.

El proyecto ECD-TIC (2008) tiene una visión general de mejorar la práctica de los docentes en todas la áreas de su desempeño profesional, combinando las competencias en TIC, con las innovaciones pedagógicas, el currículo y la 
organización escolar, aunado al objetivo de lograr que los docentes utilicen los recursos y las competencias en TIC, para mejorar sus estrategias de enseñanza, cooperar con sus compañeros y poder convertirse en lideres de la innovación en sus instituciones. Por ello el objetivo general de este proyecto, no es solo mejorar la práctica docente, sino también ayudar a mejorar la calidad del Sistema Educativo, a fin de que éste contribuya al desarrollo económico del país. La formación docente se encuentra dentro de la reforma educativa, en un momento en que los países afinan sus sistemas educativos para desarrollar las habilidades indispensables para el siglo XXI, necesaria para contar con una fuerza laboral competitiva, así como es necesaria para la cohesión social y para el desarrollo individual.

Los economistas definen tres factores que conducen a un crecimiento basado en capacidades humanas acrecentadas que son; profundizar en capital, mejorar la calidad del trabajo, e innovar tecnológicamente. Estos tres factores de productividad sirven de base para tres enfoques complementarios:

- Incrementar la comprensión tecnológica de estudiantes, ciudadanos y fuerza laboral, integrando las TIC en los planes de estudios.

- Acrecentar la capacidad de estudiantes, ciudadanos y fuerza laboral para tener conocimientos, con el fin de adicionar valor a la sociedad y a la economía, aplicando estos en problemas complejos y reales.

- Incrementar la capacidad a estudiantes, ciudadanos y fuerza laboral para producir, innovar nuevos conocimientos.

La Comisión Internacional sobre la Educación para el siglo XXI va más allá y afirma que el aprendizaje a lo largo de la vida, así como la participación en la sociedad del conocimiento, son elementos claves para enfrentar los desafíos planteados por un mundo en rápida evolución, haciendo hincapié en cuatro pilares del aprendizaje que son; aprender a vivir juntos, aprender a conocer, aprender a hacer y aprender a ser (ECD-TIC ,2008).

Las nuevas tecnologías, favorecen tanto el aprendizaje cooperativo como el autoaprendizaje, favoreciendo y posibilitando formas más creativas de aprender, permitiendo la interacción independientemente del tiempo y el espacio entre sus usuarios (Cabero, 1998). Pueden producirse experiencias 
positivas de aprendizaje cuando los alumnos comparten sus descubrimientos, se brindan apoyo para resolver problemas y trabajan en proyectos conjuntos. Por otra parte esta tecnología interactiva permite desarrollar, extender y profundizar las habilidades interpersonales y penetra las barreras culturales a medida que los estudiantes y docentes aprendan a comunicarse por este medio.

De Pablos (1996) establece que el aprendizaje situado es concreción del enfoque constructivista en la búsqueda de alternativa, frente al paradigma cognitivo del aprendizaje, y sobre todo del denominado procesamiento de la información, cuyo enfoque se establece con la importancia de los ambientes y de la expresión hablada, el reconocimiento de de la importancia de situaciones informales de enseñanza, por tanto de la cognición cotidiana de cualquier modalidad de aprendizaje, las claves para identificar un hipotético modelo basado en este aprendizaje que son: aprendizaje, colaboración, iniciación, práctica múltiple, articulación de destrezas de aprendizaje. Además las historias causales y estructuras narrativas vinculadas a estas claves, resultan importantes para la construcción social del conocimiento. Los videos o programas multimedia, como medios de enseñanza soportan una actividad instructiva contextualizada.

En este sentido Sánchez y Romance (2000) definen como sistema multimedia, a aquel sistema que es capaz de presentar información textual, sonora y audiovisual de modo integrado y coordinado, por lo que su principal característica es la integración de lenguajes expresados en diferentes códigos.

Estos autores mencionan a Gallego y Alonso (2000) para destacan cuatro características fundamentales de los programas multimedia como son:

- Interactividad; posibilidad de establecer una comunicación reciproca. Esta es una de las características educativas básicas muy potenciada con los sistemas multimedia, permitiendo al usuario buscar información, tomar decisiones y responder a las distintas propuestas que le ofrece el sistema.

- Ramificación; capacidad del sistema para responder a las peticiones del usuario, con el objetivo de encontrar datos concretos entre todo el volumen de información disponible, descartando los datos que no le 
interesan, acotando la búsqueda de la información a un menor número de datos.

- Transparencia; al buscar la información el usuario no debe verse obstaculizado por la complejidad del sistema con el que interactúa, debiendo ser lo más transparente posible, facilitando la búsqueda de los datos.

- Navegación; los sistemas multimedia deben permitir una navegación accesible donde el usuario no pierda el rumbo, en todo el volumen de la información que proporciona.

Las ventajas de los sistemas multimedia son varias dadas las aplicaciones que puede tener, en este sentido Domingo y Gallegos, (1997), presentan las siguientes ventajas:

1. Presenta las ventajas comunes a todas las tecnologías, además de que permite mayor interacción.

2. Permite la posibilidad de controlar el flujo de la información.

3. Debido a que la información se encentra almacenada en un disco óptico, por ello ofrece rapidez de acceso y durabilidad.

4. Contiene todas las posibilidades de la información y de los medios audiovisuales.

5. La información audiovisual puede ser utilizada para varias finalidades.

6. El programa multimedia bien diseñado no corre el peligro de ser obsoleto, dado que pueden actualizarse constantemente los contenidos con pequeños cambios en le software.

La gran capacidad de almacenamiento de los sistemas multimedia, unido a la rapidez con que se puede tener acceso a la información, lo convierte en un sistema idóneo para albergar contenidos de tipo documental e informativo.

Las TIC favorecen la formación continua, al ofrecer herramientas como los entornos virtuales de aprendizaje, libres de restricciones del tiempo y del espacio que exige la enseñanza presencial. Brinda la posibilidad de actualizarse, de aprender ya sea por medio de cursos on-line organizados por 
centros, o de forma más informal, participando en foros, redes telemáticas, chats o comunicaciones de correo electrónico entre colegas nacionales 0 extranjeros, no hay fronteras.

Cada vez se crean más redes de colaboración intranets, redes locales e incluso nacionales o internacionales. Existen redes de maestros que trabajan en proyectos conjuntos, sobre todo suelen promoverse por universidades, fundaciones o por algún grupo de profesores. Por ejemplo a nivel europeo; la European Schoolnet, en su portal Schoolnet ofrece un espacio de colaboración, de encuentro y trabajo en equipo para los profesores. La web Profesores Innovadores que está asociada al portal de EducaRed, presenta una vía para esta posibilidad de colaboración entre profesores y centros, la acción europea de herramientas escolares eTwinning, etc.

Cebreiro y otros (2003) plantean la formación continua como la permanente actualización de los conocimientos y habilidades necesarias para el desarrollo del ejercicio profesional, representando una inherente necesidad al modelo de sociedad actual en la que nos encontramos inmersos. Por tanto este tipo de formación tiene que dar respuesta a los nuevos retos que plantea la sociedad de actualización y reformulación constante del conocimiento, convirtiéndose en imprescindible para aquellas empresas que pretendan competir, ya que deberán tomar en cuenta el factor humano y la mejora de sus cualificaciones y competencias.

Aportaciones de las TIC

Las aportaciones de las TIC son muchas y de muy diversas índoles. En el ámbito de la docencia son varios los aspectos en los que su incidencia es más significativa como (De Basterrechea, y Juan Lázaro, 2005):

- Accesibilidad y difusión;

Por la capacidad de la red para el almacenamiento, actualización, difusión, búsqueda y recuperación de información. Tomando en cuenta el volumen y la variedad de la información disponible y las posibilidades de acceso. El profesor hace tiempo que ha dejado de ser la fuente de información del saber, tiene implicaciones importantes que van desde el replanteamiento del modelo de enseñanza, pasando por la redefinición del modelo de enseñanza, así como la redefinición del papel del profesor y los espacios físicos donde se verifica el 
proceso de enseñanza y aprendizaje. Supone que el profesor acceda a páginas, portales weblogs, etc. con contenidos y actividades didácticas elaboradas por instituciones, asesores, profesores, etc., de las diferentes áreas y niveles educativos, puestas a disposición de la comunidad docente para su uso, sin limitaciones, sin problemas de derechos de autor y con gran facilidad para la reedición y adaptación a las necesidades educativas de cada uno.

Los profesores, que a menudo imparten su docencia en circunstancias que les hace sentir muchas de las veces aislados del resto del colectivo al que pertenecen, las TIC les ofrece la posibilidad de que puedan recuperar el contacto, el intercambio y la sensación de pertenencia a través de numerosos foros profesionales, listas de distribución y medios de comunicación en la red.

Internet permite a los profesores gestionar su propio aprendizaje y reciclaje profesional. La oferta en la red incluye muchas fuentes de formación, bibliográficas, etc., Por ello es un instrumento indispensable en la actualización para el profesorado y por ello es responsabilidad de los centros de formación facilitar la formación y el acceso de los profesores a estos recursos, y por parte de los profesores aprovechar las oportunidades para incorporar a su acervo el uso apropiado de estos medios.

\section{* Multimedia, interactividad}

Una de las principales características de los recursos didácticos en formato digital es su capacidad para integrar todo tipo de elementos multimedia y de topologías de interactividad. Música, sonido, video, imagen, animación, junto con una gama amplia de posibilidades que permite interactuar y manipular los materiales, con las implicaciones didácticas que ello supone (Ayers y Grisham; 2004), esto tiene utilidad al programar el diseño de una secuencia de actividad didáctica. El diseño de recursos didácticos con formato de recursos digital, permite aplicar los mismos principios metodológicos con los que se han elaborado tradicionalmente los materiales en soporte papel, pero con mucha mayor eficacia. Por ejemplo al utilizar en el libro de texto fotografías relacionadas al tema, se puede utilizar un video integrado con imágenes sobre el tema, etc., ofreciendo un escenario mucho más rico con el que deducir el valor comunicativo de los términos y expresiones que son el objeto de aprendizaje. 
Estos materiales tienen la posibilidad de ser susceptibles de ser actualizados y modificados en cualquier momento, sin necesidad de esperar a la siguiente edición. Contando con los medios adecuados, los materiales didácticos digitales se utilizaran con éxito en el aula tradicional, en el aula multimedia o desde el propio ordenador del alumno. El coste superior de elaboración se compensa en parte, con el ahorro en impresión y distribución de los materiales. La elaboración de estos materiales digitales admite distintos niveles de elaboración o acabado. Se pueden elaborar desde la institución o editorial que emplea un amplio equipo interdisciplinar con autores, editores, diseñadores gráficos, marquetadores, animadores, dibujantes y programadores, para llegar a producir materiales con un alto nivel de sofisticación y complejidad, a un profesor o un equipo de profesores que utilizando alguna herramienta de autor o un simple procesador de texto preparan actividades para sus alumnos. Las dos formas de elaborar materiales se complementan, y se adecuan a las necesidades de acuerdo a las necesidades específicas de los alumnos de un grupo o de un centro educativo.

\section{* Comunicación}

Otra de las grandes aportaciones de las TIC son los nuevos sistemas de comunicación. Las herramientas de comunicación asíncronas, como es el correo electrónico o los foros, y las sincronías, como el Chat, el audio conferencia o la videoconferencia, que se han extendido rápidamente. Estas tienen gran importancia cuando se trata de fomentar la adquisición de competencias comunicativas funcionales.

En cuanto a la organización de la actividad docente, la comunicación sobre todo, asíncrona, por medio de la web, tienen la posibilidad de permitir la interacción entre alumnos y maestros, entre asesores técnicos y maestros, más allá de los limites que en el tiempo y espacio imponen los modelos basados en actividades que se desarrollan directamente en el aula. Anuncios, avisos, propuestas, materiales, consultas, respuestas, etc., se pueden trasmitir por medio de la red. 


\section{* Globalización}

Con las TIC desaparecen las distancias y las fronteras. Todo lo que sucede puede ser viable, experiencias, materiales, actividades, problemas y soluciones son compartidas a largo de toda la geografía. Todo lo que existe está a disposición de todos los que participan en el proceso, por ello no importan donde están los protagonistas, el proceso puede continuar.

El modo de vida competitivo y acelerado también influye en la demanda de formación del profesorado, especialmente en la formación continua asociada al desempeño profesional. En este ámbito de la enseñanza cabe la posibilidad de que los docentes asuman el liderazgo que les corresponde, definiendo el papel y el sitio de los recursos digitales o dejar que otros, informáticos, ingenieros o políticos sean los que tomen las decisiones.

Las Redes de Comunicación para la formación docente.

Las Redes de comunicación ofrecen grandes posibilidades para la educación en general y para la formación profesional continua en particular. Cabero (2001) y Salinas (1996) resaltan las siguientes posibilidades:

- De crear entornos multimedia de comunicación.

- De utilizar entornos de comunicación sincrónicos y asincrónicos

- De deslocalizar la información de los contextos cercanos

- Facilitar que los alumnos se conviertan en constructores activos de su propio proceso de aprendizaje

- Construir entornos no lineales sino hipertextuales de información

- Actualizar de forma inmediata la información y atender las nuevas necesidades educativas que la evolución de la sociedad impone

- La formación tiende a ser más individualizada, ajustada a las necesidades y características de los usuarios.

Algunas de estas posibilidades también las ofrecía la formación continua a distancia tradicional. Estos medios proporcionan a los usuarios el acceso flexible a la formación, como la capacidad de interacción y reflexión compartida en el proceso de enseñanza. 
Por otro lado Cebreiro y otros (2003) enuncian algunas de las ventajas específicas que ofrece para las empresas, la formación profesional continua en red dirigida a profesionales en activo como son;

- Permite llegar a numerosos empleados rápidamente, facilita la introducción de cambios de estrategia corporativa o tecnológica, permitiendo a la empresa adaptarse a los nuevos requerimientos del entorno.

- Mantiene a sus profesionales actualizados en nuevos conocimientos.

- Reduce los costos de formación de sus empleados (evita desplazamientos).

- La empresa puede asegurar la formación profesional continua de sus trabajadores y favorecer así que se mantenga o aumente la competitividad con avances e innovaciones.

\section{Las TIC en los procesos educativos en México}

La incorporación de las TIC a los procesos educativos en México ha sido una preocupación constante de la de la SEP, una muestra de ello es haber considerado este aspecto en las líneas de política educativa desde 1995 y haber impulsado varias acciones en este campo, como la creación de la Red Escolar, a través del Instituto Latinoamericano de Comunicación Educativa (ILCE). La Coordinación General de Actualización y Capacitación de Maestros, encargada del Programa Nacional para la Actualización Permanente de Maestros en Servicio (PRONAP), elaboró en 1999 una propuesta piloto para utilizar las TIC dentro de la actualización, a través del proyecto Centro de Maestros Virtual, el cual diseño una página web con el apoyo del ILCE. En mayo del 2000 se montó en un servidor del ILCE la página PRONAP en línea http://pronap.ilce.edu.mx/ , la finalidad es ofrecer a los actualizadores, directivos, personal de apoyo técnico-pedagógico y maestros de educación básica lo siguiente:

- Información: Datos generales y específicos sobre el Pronap (programas de estudio, Centros de Maestros, exámenes nacionales y materiales de apoyo). 
- Actualización y capacitación: Opciones de actualización en línea, etc

- Asesoría y seguimiento: Posibilidades de diálogo, a través del correo electrónico, para solicitar información, compartir experiencias, plantear necesidades, etc.

- Promoción de materiales: Acercamiento y manejo cotidiano de los acervos publicados por la SEP para profesores de Educación Básica, como materiales de apoyo, la Biblioteca de Actualización, las series de videos y material multimedia, etc.

El Programa Nacional de Educación 2007-2012 establece en su objetivo 1: "Elevar la calidad de la educación para que los estudiantes mejoren su nivel de logro educativo, cuenten con medios para tener acceso a un mayor bienestar y contribuyan al desarrollo nacional". Por ello en Educación Básica pretende dentro de sus estrategias por un lado experimentar e interactuar con los contenidos educativos incorporados a las TIC, así mismo identificar las necesidades de formación continua y superación profesional de los docentes, y de esta manera poner en marcha un programa de capacitación de docentes para la atención adecuada de las innovaciones curriculares, de gestión y especialmente del uso de las TIC. Se pretende concretar una plataforma de servicios de formación continua para los equipos técnicos estatales, asesores y docentes en servicio, así como una oferta de opciones a distancia, mediante el uso de las TIC en todo el país.

De ahí la importancia del uso de la tecnología como un medio para propiciar comunidades de aprendizaje entre los docentes de Educación Básica. Las implicaciones son un trabajo intensivo con el personal técnico pedagógico, que tienen dentro de su función elaborar las propuestas académicas para apoyar el trabajo en las escuelas y del aula. Por otro lado plantea la necesidad de fortalecer las acciones de capacitación y actualización que hasta el momento se han realizado directamente con los maestros de grupo.

Es necesario que además de los profesores frente a grupo, se elaboren estrategias para el personal de apoyo técnico-pedagógico de las regiones, zonas y directivos, entre ellos los supervisores y directores, incorporando el uso de las tecnologías en sus labores cotidianas y puedan ser aprovechadas para compartir experiencias en torno al trabajo en el aula y la gestión escolar. 
Las posibilidades que ofrecen las redes, para educación en general y para las necesidades educativas especiales en particular, son muchas entre las que se puede citar (Chacón, 2007):

- Acceso a páginas y directorios con diversidad de información, donde se encuentran documentos o enlaces a centros, instituciones o personas que relacionadas específicamente con los diferentes campos de la Educación Especial, como por ejemplo:

1) PNTIC: http://www.cnice.mec.es/

2) Directorio de Recursos en Internet http://roble.pntic.mec.es/ fsoto/indice.htm

3) PNFEEIE http://normalista.ilce.edu.mx/normalista/index.htm

- Disponibilidad de software de libre distribución e información de programas comerciales, diseñados para las necesidades educativas especiales, como por ejemplo: Programa "Clic" es un software educativo, permite crear aplicaciones adaptadas a nuestras necesidades y graduadas al ritmo del alumno http://centros6.pntic.mec.es/cpee.alborada/recursos.htm ; "zonaClic" es de libre uso y amplia difusión en la red. Se puede encontrar en la Red Telemática de Cataluña España http://clic.xtec.net/es permitiendo construir diversos tipos de actividades multimedia.

- Acceder de manera gratuita a la lista de distribución de correo; Esta lista de distribución permite estar informados de cualquier evento, publicación o noticias que cualquier componente de la lista haga público. La "Red Iris “ de España http://www.rediris.es/list tiene un numerosos grupo de listas de distribución de diferentes temáticas. La lista "edulist" se encuentran temas relacionados a la educación y las nuevas tecnologías http://www.rediris.es/list/info/edulist.es.html . "logopedia” lista de distribución electrónica dedicada a los trastornos del lenguaje, el habla y la voz http://www.rediris.es/list/info/logopedia.es.html ."PAIDOS-NEE" lista dedicada a la educación especial y a las necesidades educativas especiales http://www.rediris.es/list/info/paidos-nee.es.html . etc. 
- Participación en foros de debate que permiten entrar con otros profesionales sobre temas de interés a través del chat: En algunos de los casos se informa del canal que se ha elegido para participar y en otros puede ser un chat especial, el cual se establece desde la propia página web de una persona u organización.

- Consultar en las ediciones electrónicas de algunas revistas que tienen colgados artículos, o revistas completas en la red. En algunos casos requiere de subscripción y en otros es de libre acceso, por ejemplo la revista Ibero-americana publicada por la OIE http://www.rieoei.org/deloslectores.htm

- El uso de los motores de búsqueda en red como; Ole, Ozú, Lycos, HispaVista, AltaVista, entre otros, permiten realizar búsquedas utilizando palabras claves y operadores que las combinen.

La Web es una fuente casi inagotable de información actualizada continuamente, que ofrece una gran diversidad de información, documentación, software y enlaces a centros, instituciones o personas relacionadas con los diferentes campos de trabajo.

Los siguientes cuadros son un ejemplo de algunas páginas nacionales e internacionales, de instituciones, organismos, bibliotecas, programas, etc., que consideramos de interés entre muchos otros, para los maestros en general y para los profesionales de Educación Especial en particular.

\begin{tabular}{||l||l||}
\hline \multicolumn{1}{|c|}{ Nombre de la Página } & \multicolumn{1}{c|}{ Propósito } \\
\hline \hline $\begin{array}{l}\text { Centro Nacional de Información y Comunicación } \\
\text { Educativa (CNICE) del Ministerio de Educación de } \\
\text { España. } \\
\text { http://www.cnice.mec.es }\end{array}$ & $\begin{array}{l}\text { Ofrece una serie de recursos y } \\
\text { materiales para Profesores- Centros, } \\
\text { niños y niñas, jóvenes, padres de } \\
\text { familia y personas adultas, } \\
\text { relacionados con la Información y la } \\
\text { Comunicación Educativa. }\end{array}$ \\
\hline $\begin{array}{ll}\text { EducaRed } \\
\text { http://www.educared.net }\end{array}$ & $\begin{array}{l}\text { Facilitar el uso educativo de Internet en } \\
\text { la escuela, como herramienta de } \\
\text { innovación y formación pedagógica } \\
\text { entre profesores, padres y alumnos de } \\
\text { primaria, secundaria, bachillerato y } \\
\text { ciclos formativos de grado medio. }\end{array}$ \\
\hline \hline Eleducador & $\begin{array}{l}\text { Información y servicios educativos } \\
\text { para docentes de América Latina. }\end{array}$ \\
\hline http://www.eleducador.com/col/portal/default.aspx & \\
\hline
\end{tabular}




\begin{tabular}{|c|c|}
\hline $\begin{array}{l}\text { - } \quad \text { Teem } \\
\text { http://www.teem.org.uk/ } \\
\end{array}$ & $\begin{array}{l}\text { Portal ingles, ofrece un guía de } \\
\text { recursos para enseñar con TIC, } \\
\text { eficientemente. }\end{array}$ \\
\hline $\begin{array}{c}\text { Becta } \\
\text { http://www.becta.org.uk/ }\end{array}$ & $\begin{array}{l}\text { Portal ingles, que impulsa a nivel } \\
\text { nacional el uso eficaz e innovador de } \\
\text { la tecnología a través del aprendizaje. }\end{array}$ \\
\hline $\begin{array}{l}\text { - Scoilnet } \\
\text { http://www.scoilnet.ie/ }\end{array}$ & $\begin{array}{l}\text { Portal Irlandés que orienta a los } \\
\text { docentes sobre los materiales } \\
\text { didácticos en la Red. }\end{array}$ \\
\hline $\begin{array}{l}\text { ONCE } \\
\text { http://www.once.es/new } \\
\end{array}$ & $\begin{array}{l}\text { Fundación ONCE para la cooperación } \\
\text { e integración social de las personas } \\
\text { con discapacidad, España; información } \\
\text { sobre servicios sociales especializados } \\
\text { prestados por la ONCE a las personas } \\
\text { con discapacidad visual. }\end{array}$ \\
\hline $\begin{array}{c}\text { INICO } \\
\text { http://inico.usal.es } \\
\end{array}$ & $\begin{array}{l}\text { Instituto Universitario de Integración en } \\
\text { la Comunidad, Salamanca España. } \\
\text { Información relacionada con } \\
\text { investigaciones, noticias, } \\
\text { publicaciones, etc., encaminadas a } \\
\text { potenciar, facilitar y mejorar las } \\
\text { condiciones de vida de las personas } \\
\text { en situación de desventaja social en } \\
\text { distintos contextos y a lo largo de todo } \\
\text { su ciclo de vida. }\end{array}$ \\
\hline $\begin{array}{l}\text { SEP } \\
\text { http://www.sep.gob.mx/index.jsp }\end{array}$ & $\begin{array}{l}\text { Portal de la Secretaria de Educación } \\
\text { Pública de México, donde los usuarios } \\
\text { pueden encontrar información para el } \\
\text { personal docente y estudiantes, desde } \\
\text { el nivel básico hasta superior; becas, } \\
\text { programas de apoyo, convocatorias } \\
\text { relacionadas con el sector educativo. }\end{array}$ \\
\hline $\begin{array}{l}\text { ProNAP } \\
\text { http://pronap.chihuahua.gob.mx }\end{array}$ & $\begin{array}{l}\text { Unidad estatal de formación continúa } \\
\text { de los docentes. Información relevante } \\
\text { sobre UEFC, así como información de } \\
\text { los centros de maestros, cursos de } \\
\text { carrera magisterial. }\end{array}$ \\
\hline $\begin{array}{l}\text { INEE } \\
\text { http://www.inee.edu.mx }\end{array}$ & $\begin{array}{l}\text { Instituto Nacional de Evaluación de la } \\
\text { Educación, presenta información } \\
\text { relacionada con publicaciones, bases } \\
\text { de datos de las evaluaciones, } \\
\text { proyectos y actividades. }\end{array}$ \\
\hline $\begin{array}{l}\text { - SNIE } \\
\text { http://www.snie.sep.gob.mx } \\
\end{array}$ & $\begin{array}{l}\text { Sistema Nacional de Información } \\
\text { Educativa; Información relevante sobre } \\
\text { las características, ubicación, } \\
\text { estadística y principales indicadores de } \\
\text { los servicios. }\end{array}$ \\
\hline $\begin{array}{l}\text { PEFEEIE } \\
\text { www.chihuahua.gob.mx } \\
\end{array}$ & $\begin{array}{l}\text { Programa estatal de Fortalecimiento } \\
\text { de la Educación Especial y de la } \\
\text { Integración Educativa; Información del } \\
\text { programa, describiendo el marco } \\
\text { institucional y la situación actual de la } \\
\text { educación especial y de la integración } \\
\text { educativa en el estado de Chihuahua. }\end{array}$ \\
\hline
\end{tabular}




\begin{tabular}{|c|c|}
\hline $\begin{array}{c}\text { ENLACE } \\
\text { http://www.enlace.sep.gob.mx } \\
\end{array}$ & $\begin{array}{l}\text { Evaluación nacional del logro } \\
\text { académico de los centros escolares, } \\
\text { sistema de consulta de resultados de } \\
\text { la prueba ENLACE, de alumnos, } \\
\text { grupos, escuelas por modalidad } \\
\text { educativa de cada entidad o a nivel } \\
\text { nacional. }\end{array}$ \\
\hline $\begin{array}{l}\text { SEECH } \\
\text { http://seech.gob.mx/ }\end{array}$ & $\begin{array}{l}\text { Servicios Educativos del Estado de } \\
\text { Chihuahua; Información de los } \\
\text { maestros y alumnos de los diferentes } \\
\text { niveles y modalidades del sistema } \\
\text { educativo. }\end{array}$ \\
\hline $\begin{array}{l}\text { - Educación Especial SEECH } \\
\underline{\text { http://seech.gob.mx/eduespecial/ }}\end{array}$ & $\begin{array}{l}\text { Información para maestros y padres de } \\
\text { familia, sobre los servicios de } \\
\text { educación especial, así como cursos } \\
\text { de actualización, boletín informativo, } \\
\text { ligas de interés, revistas, etc. } \\
\text { relacionadas a la educación especial.. }\end{array}$ \\
\hline $\begin{array}{l}\text { Centro Huerta del Rey } \\
\text { http://www.centrohuertadelrey.com/ }\end{array}$ & $\begin{array}{l}\text { Revista digital de ámbito internacional } \\
\text { para profesionales. Centro español } \\
\text { para ayuda a al desarrollo del } \\
\text { superdotado }\end{array}$ \\
\hline $\begin{array}{l}\text { - InclusiveTLC } \\
\text { http://www.inclusivetlc.com/ }\end{array}$ & $\begin{array}{l}\text { Reino Unido. Información de TLC } \\
\text { inclusivo especializado en atender las } \\
\text { necesidades especiales, software, } \\
\text { interruptores y dispositivos de acceso } \\
\text { a la computadora, ayudas simples de } \\
\text { la comunicación y de la tecnología } \\
\text { asistida de principiantes con } \\
\text { inhabilidad física, debilidad sensorial, o } \\
\text { inhabilidad severa de aprendizaje. }\end{array}$ \\
\hline $\begin{array}{l}\text { - CREA Sistemas Informáticos } \\
\text { http://www.crea-si.com/esp/inicio.php }\end{array}$ & $\begin{array}{l}\text { Soluciones informáticas y desarrollo de } \\
\text { sistemas; Aplicaciones informáticas } \\
\text { basadas en técnicas de visión artificial } \\
\text { para hardware de bajo coste la } \\
\text { webcam. }\end{array}$ \\
\hline $\begin{array}{l}\text { - Directorio de recursos en Internet } \\
\text { http://roble.pntic.mec.es/ fsoto/indice.htm }\end{array}$ & $\begin{array}{l}\text { Ofrece una serie de información y } \\
\text { enlaces relacionado a las NEE y las } \\
\text { diferentes discapacidades. }\end{array}$ \\
\hline $\begin{array}{l}\text { Programa Nacional de Fortalecimiento de la } \\
\text { Educación especial y de la Integración Educativa. } \\
\text { PNFEEyIE } \\
\text { http://normalista.ilce.edu.mx/normalista/index.htm }\end{array}$ & $\begin{array}{l}\text { Ofrece información de Documentos de } \\
\text { la operatividad de los servicios de } \\
\text { educación especial, así como manual } \\
\text { de asistencia tecnológica, de } \\
\text { accesibilidad, y para la familia. }\end{array}$ \\
\hline $\begin{array}{l}\text { Red Normalista } \\
\text { http://normalista.ilce.edu.mx/normalista/index.htm }\end{array}$ & $\begin{array}{l}\text { Consiste en una red de servicios } \\
\text { informáticos aplicados a la tarea } \\
\text { educativa que permitirá la interacción y } \\
\text { colaboración entre escuelas normales, } \\
\text { escuelas de educación básica, centros } \\
\text { de maestros y otras instituciones } \\
\text { educativas, a la que puede acceder } \\
\text { cualquier usuario de Internet } \\
\text { interesado en temas de educación. }\end{array}$ \\
\hline $\begin{array}{l}\text { - Tecnoneet } \\
\text { http://www.tecnoneet.org/ } \\
\end{array}$ & $\begin{array}{l}\text { Foro de la tecnología educativa y } \\
\text { atención a la diversidad. Espacio para } \\
\text { intercambio de experiencias, } \\
\text { metodología y conocimientos, sobre } \\
\text { los avances tecnológicos y estrategias } \\
\text { de intervención en el ámbito de las TIC } \\
\text { y las NEE. }\end{array}$ \\
\hline
\end{tabular}

Cuadro 16: Relación de Organismos en Red. 


\begin{tabular}{|c|c|}
\hline \multicolumn{2}{|l|}{ BIBLIOTECAS } \\
\hline $\begin{array}{l}\text { - } \quad \text { Biblioteca Nacional de México } \\
\text { http://biblional.bibliog.unam.mx/bib/biblioteca.html } \\
\end{array}$ & $\begin{array}{l}\text { Sitio informativo sobre los servicios } \\
\text { que ofrece esta biblioteca: catálogo, } \\
\text { adquisiciones, salas de video, } \\
\text { hemeroteca, acervo bibliográfico, } \\
\text { mapoteca, salas de ciegos. }\end{array}$ \\
\hline $\begin{array}{l}\text { - NEEdirectorio. Necesidades Educativas Especiales } \\
\text { en la Red. } \\
\text { http://www.needirectorio.com/ }\end{array}$ & $\begin{array}{l}\text { Portal NEEdirectorio es una puerta de } \\
\text { acceso a recursos, páginas web e } \\
\text { información relacionada con } \\
\text { educación especial y las necesidades } \\
\text { educativas especiales. "Documentos" } \\
\text { ofrece un especio abierto donde se } \\
\text { recogen artículos sobre } \\
\text { investigaciones, experiencias } \\
\text { didácticas, de formación, de } \\
\text { innovación educativa. }\end{array}$ \\
\hline $\begin{array}{l}\text { - Biblioteca de Literatura Infantil y Juvenil } \\
\text { http://www.cervantesvirtual.com/seccion/bibinfantil/ }\end{array}$ & $\begin{array}{l}\text { El usuario puede encontrar un } \\
\text { catalogo en línea con diferentes títulos } \\
\text { de literatura infantil y juvenil. Los libros } \\
\text { se encuentran en formato electrónico } \\
\text { y se pueden descargar gratuitamente, } \\
\text { cuneta también con hemeroteca, } \\
\text { catalogo de libros de investigación, } \\
\text { fonoteca, área de videos y información } \\
\text { sobre talleres de lectura y escritura. } \\
\text { Acceso al Centro de estudios y } \\
\text { promociones de la lectura y literatura } \\
\text { infantil. }\end{array}$ \\
\hline $\begin{array}{l}\text { Enciclonet } \\
\text { http://www.enciclonet.com/ }\end{array}$ & $\begin{array}{l}\text { Es un proyecto en internet que ofrece } \\
\text { a los usuarios hispanohablantes de } \\
\text { todo el mundo, de una forma } \\
\text { dinámica, flexible y sin fronteras, el } \\
\text { acceso a los contenidos } \\
\text { enciclopédicos más extensos y } \\
\text { profundos en idioma español: los } \\
\text { contenidos en la Universal Micronet. }\end{array}$ \\
\hline $\begin{array}{l}\text { - Biblioteca Nacional de Maestros } \\
\text { http://www.bnm.me.gov.ar/ }\end{array}$ & $\begin{array}{l}\text { Sitio que brinda información sobre } \\
\text { colecciones que ofrece, acervos } \\
\text { bibliográficos, hemerotecas y } \\
\text { mediatecas; así como servicios en } \\
\text { línea, proyectos de investigación y } \\
\text { eventos académicos en el ámbito de } \\
\text { la educación. }\end{array}$ \\
\hline $\begin{array}{l}\text { - Biblioteca Nacional de la Republica Argentina } \\
\text { http://www.cervantesvirtual.com/portal/BNA/ }\end{array}$ & $\begin{array}{l}\text { Sitio argentino que describe, los } \\
\text { acervos y servicios que ofrece la } \\
\text { biblioteca para buscar y acceder a la } \\
\text { información, así como actividades } \\
\text { académicas y estudios en la Escuela } \\
\text { Nacional de Bibliotecarios. }\end{array}$ \\
\hline $\begin{array}{l}\text { - } \text { Biblioteca Miguel de Cervantes } \\
\text { http://www.cervantesvirtual.com/portal/BNA }\end{array}$ & $\begin{array}{l}\text { Tiene recopilado material de todo tipo } \\
\text { relacionado con Cervantes y su } \\
\text { mundo, está dividida en secciones; } \\
\text { autores, obras, estudios, diccionarios, } \\
\text { fototeca, imágenes y enlaces de } \\
\text { interés, además contiene secciones } \\
\text { de noticias, agradecimientos, } \\
\text { realización y mapa del sitio. }\end{array}$ \\
\hline
\end{tabular}




\begin{tabular}{|c|c|}
\hline $\begin{array}{l}\text { - } \text { Bibliotecas de la UNAM } \\
\text { http://bidi.unam.mx }\end{array}$ & $\begin{array}{l}\text { Biblioteca digital donde se pueden } \\
\text { encontrar más de } 56,000 \text { recursos } \\
\text { electrónicos, donde destacan las } \\
\text { colecciones: base de datos } \\
\text { especializados, revistas electrónicas, } \\
\text { libros, tesis digitales, y otros recursos. }\end{array}$ \\
\hline $\begin{array}{l}\text { Bibliotécnic Consultores } \\
\text { http://www.bibliotecnic.org/sitio/ }\end{array}$ & $\begin{array}{l}\text { Sitio peruano que brinda información, } \\
\text { consultorías, enlaces, publicaciones, } \\
\text { artículos, asesorías, capacitación, } \\
\text { cursos en línea y foros de discusión } \\
\text { en torno de la educación, la Sociedad } \\
\text { de la Información y la Comunicación. }\end{array}$ \\
\hline $\begin{array}{c}\text { Elaleph.com } \\
\text { http://www.elaleph.com/biblioteca.cfm }\end{array}$ & $\begin{array}{l}\text { Ofrece información sobre la historia } \\
\text { del elaleph.com. En esta biblioteca se } \\
\text { puede acceder a un catálogo en línea } \\
\text { de un acervo de libros que pueden } \\
\text { descargar de manera gratuita, } \\
\text { también tiene un apartado para } \\
\text { comprar libros. También ofrece cursos } \\
\text { de talleres con costo, acceso al club } \\
\text { de lectura. Existe un servicio para } \\
\text { publicar obras literarias, etc. }\end{array}$ \\
\hline $\begin{array}{c}\bullet \quad \text { Educarchile } \\
\text { http://www.educarchile.cl } \\
\end{array}$ & $\begin{array}{l}\text { Ofrece información recursos, servicios } \\
\text { y experiencias educativas que } \\
\text { responden a las necesidades e } \\
\text { intereses de docentes, estudiantes, } \\
\text { familias y especialistas. }\end{array}$ \\
\hline
\end{tabular}

Cuadro 17: Relación de Instituciones en Red. 


\section{MARCO CONTEXTUAL}

\section{CAPÍTULO 2: LA EDUCACIÓN ESPECIAL EN CHIHUAHUA MÉXICO}

En este capítulo presentamos aspectos de la Política Educativa que sustenta la Educación Especial en México, tomando en cuenta los planteamientos Internacionales, Nacionales y Estatales sobre la operatividad de los servicios, establecidos en documentos oficiales como Leyes de Educación, Leyes para las personas con discapacidad, Programas Educativos y Programas de Fortalecimiento de la Educación Especial y de la Integración Educativa, entre otros, también se presenta un panorama general, del contexto social, económico, organizacional, de la modalidad Educación Especial en el Estado de Chihuahua, dado que esta investigación se lleva acabo en este contexto, a continuación presentamos información sobre el marco técnico y operativo desde el que funciona la modalidad de Educación Especial del Subsistema Federalizado en la actualidad en este Estado, para continuar con la información de los servicios escolarizados, de apoyo y de orientación que la conforman. Por ultimo de manera sumamente importante, presentamos en una segunda parte la información relacionada a la formación continua de los profesionales y la participación de los Asesores Técnicos Pedagógicos en los procesos de capacitación y actualización. 


\section{Estado de Chihuahua}

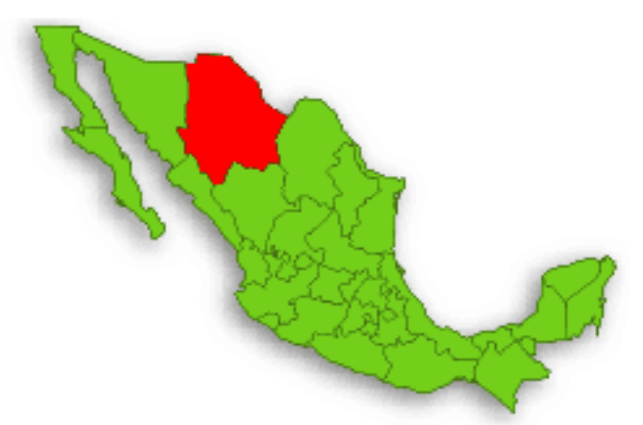

Fig. 24

\section{Ubicación del Estado}

El Estado de Chihuahua, en México, es uno de los 31 Estados federados que conforman a México, está localizado al norte del país, y tiene una superficie de $247,455 \mathrm{~km}^{2}$ lo cual lo convierte en el más extenso del país, su superficie es un poco más extensa que la del Reino Unido. El Estado limita al norte con los de Nuevo México y Texas, al oeste con los estados de Sonora y Sinaloa, al sur con Durango y al este con Coahuila. El Estado de Chihuahua se divide en 67 municipios. Su capital lleva el mismo nombre, Chihuahua y su ciudad más poblada es Ciudad Juárez, ubicada en la frontera, frente a El Paso, Texas. Su orografía está conformada por tres grandes regiones denominadas Sierra, Llanura o Meseta y Desierto, que se sucedan de oeste a este en forma de grandes bandas. Esto le da al clima y la geografía condiciones inmensamente contrastantes y que le dan al estado sus imágenes más conocidas: sus grandes desiertos, sus montañas nevadas y barrancas cubiertas de bosques alpinos. Se encuentra enclavado en el centro del continente, rodeado de grandes cadenas montañosas que lo alejan de las costas y las zonas húmedas, por lo cual el clima es mayormente seco y con lluvias escasas, influyendo notablemente en la hidrografía.

El Instituto Nacional de Estadística, Geografía e Informática (INEGI) en 2005, informa que el total de población del estado de Chihuahua es de 3,241,444 
habitantes, lo cual le da el $11^{\circ}$ lugar entre las entidades federativas de México por población, presentando una edad promedio de la población de 25 años.

El Sistema Educativo del Estado de Chihuahua, se rigen en función del Sistema Educativo Nacional comprende a las instituciones del gobierno y de la sociedad encargada de proporcionar servicios educativos y de preservar, transmitir y acrecentar la cultura de los mexicanos. Lo conforman, según la Ley General de Educación, promulgada en 1993, educandos y educadores; autoridades educativas; planes, materiales y métodos educativos, así como las normas de la educación. Esta integrado también por las instituciones educativas del gobierno y organismos descentralizados, instituciones particulares autorizadas y universidades públicas autónomas.

La Secretaría de Educación Pública (SEP) es la instancia del gobierno federal que tiene como propósito esencial crear condiciones que permitan asegurar el acceso de todos los mexicanos y mexicanas a una educación de calidad, en el nivel y modalidad que la requieran y en el lugar donde la demanden.

En la entidad existe una Secretaría de Educación y Cultura, con la estructura pertinente para coordinar y dar seguimiento a los aspectos relacionados con los distintos niveles y modalidades de la educación, así como para operar los servicios educativos, estatales y federalizados.

La Ley General de Educación distingue los siguientes tipos de servicios educativos: Educación Inicial (0-4 años), Educación Básica (5-14 años; niveles: preescolar, primaria y secundaria). Los tipos y modalidades que ofrecen servicio educativos escolarizadas, no escolarizadas y mixtas son; Educación Especial, Educación Media Superior y Educación Superior; Educación Básica para Adultos, y Formación para el Trabajo.

\subsection{Educación Especial en México}

La Educación Especial ha vivido profundas transformaciones durante el siglo XX impulsadas por los movimientos sociales que han reclamado mayor igualdad entre todos los seres humanos y superar cualquier tipo de discriminación (física, social, cultural, intelectual, escolar, etc.) debido a que lo "normal" se ha concebido como una serie atributos y características típicas reconocidas y establecidas por la sociedad. 
La incorporación dentro del sistema educativo ordinario de las personas con discapacidad se ha realizado poco a poco, buscando fórmulas que facilitaran la integración de estos alumnos, lo cual no ha sido una tarea fácil. Se han planteado diferentes paradigmas de la Educación Especial, desde los años setenta hasta la actualidad.

Las diferentes concepciones nos permiten ver el cambio que se ha venido produciendo en relación a los ejes nucleares que constituyen la Educación Especial, que ha pasado desde poner énfasis en las deficiencias, a centrarse en las adecuaciones curriculares, necesarias para los alumnos que presentan necesidades educativas especiales.

La Educación Especial en México también ha pasado por varios procesos de cambio, actualmente se han tomando en cuenta los planteamientos internacionales y nacionales fundamentando la política educativa de este nivel, como a continuación se menciona.

\subsubsection{Contexto Internacional}

La participación de México en el contexto internacional ha orientado las acciones emprendidas para mejorar las condiciones de vida y educación de las personas con discapacidad. Algunos de los principales documentos que México ha suscrito y que representan compromisos concretos de transformación institucional a favor de este sector de la población son (SEP, 2002).

- La Conferencia Mundial para Todos, Satisfacción de las Necesidades Básicas de Aprendizaje, realizada en Jomtién, Tailandia en 1990.

- Las Normas Uniformes sobre la igualdad de Oportunidades para las Personas con Discapacidad (ONU, 1993). En la cual se establecen los planteamientos de la sociedad internacional con respecto a los derechos humanos de las personas con discapacidad.

- La Declaración de Salamanca de Principios, Política y Práctica para las Necesidades Educativas Especiales, en Salamanca, España en 1994.

Los documentos mencionados constituyen actualmente los elementos que rigen en todo lo relacionado con las políticas de integración educativa desde la década de los noventa como se enuncia en el Programa Estatal de Fortalecimiento de la Educación Especial y de la Integración Educativa (SEC, 2005). 


\subsubsection{Contexto Nacional}

La Constitución de los Estados Unidos Mexicanos garantiza el derecho de todo individuo a recibir educación y suscribe la obligación que el Estado (Federación, Estados y Municipios) tiene de impartir la educación en el nivel de educación básica. La Ley General de Educación en su Artículo 41 señala que:

"La Educación Especial está destinada a individuos con discapacidades transitorias o definitivas, así como a aquellos con aptitudes sobresalientes. Atenderá a los educandos de manera adecuada a sus propias condiciones con equidad social.

Tratándose de menores con discapacidades, esta educación propiciará su integración a los planteles de educación regular mediante la aplicación de métodos, técnicas y materiales específicos. Para quienes no logren esa integración, esta educación procurará la satisfacción de las necesidades básicas de aprendizaje para la autónoma convivencia social y productiva, para lo cual se elaborarán programas de apoyo específicos.

Esta educación incluye educación a los padres o tutores, así como también a los maestros y personal de escuelas de Educación Básica regular que integren alumnos con necesidades especiales de educación".

En un sentido más amplio, la Ley General de las Personas con Discapacidad (Diario oficial de la federación, 10 junio 2005), en su Artículo 5, reconoce los derechos de las personas con discapacidad y establece los principios sobre los que deberán fundamentarse las políticas públicas en este campo. Estos principios son:
a) La equidad
b) La justicia social
c) La equiparación de oportunidades
d) El reconocimiento de las diferencias
e) La dignidad 
f) La integración

g) El respeto

h) La accesibilidad

La Ley General de Discapacidad en el Artículo 2 fracción V, define el principio de equiparación de oportunidades como:

"el proceso de adecuaciones, ajustes y mejoras necesarias en el entorno jurídico, social, cultural y de bienes y servicios, que faciliten a las personas con discapacidad una integración, convivencia y participación en igualdad de oportunidades y posibilidades con el resto de la población". (p.1)

Esta Ley, en el Artículo 10, fracciones I y II, establece la responsabilidad de las autoridades en la elaboración y fortalecimiento de los programas de educación especial y de integración educativa para las personas con discapacidad, garantizando su incorporación y oportuna canalización a todos los niveles del Sistema Educativo, verificando la aplicación de las normas para su integración.

Uno de los ejes fundamentales del Programa de Desarrollo 2007-2012, es promover la igualdad de oportunidades. Para ellos se propone otorgar apoyo integral a las personas con discapacidad para su integración a las actividades productivas y culturales, con plenos derechos e independencia. Con ello propone acciones diferenciadas según el tipo de discapacidad, mismas que permitirán tener un mayor acceso a los servicios y a la inserción laboral, de igual manera contempla garantizar que la población con necesidades educativas especiales, vinculadas a la discapacidad y las aptitudes sobresalientes accedan a servicios de calidad que propicien su inclusión social y desarrollo pleno.

El Programa Nacional de Fortalecimiento de la Educación Especial y de la Integración Educativa (SEP, 2002) define que la misión de los servicios de Educación Especial es: 
"Favorecer el acceso y permanencia en el sistema educativo de los niños, niñas y jóvenes que presenten necesidades educativas especiales, otorgando prioridad a aquellos con discapacidad, proporcionando los apoyos indispensables dentro de un marco de equidad, pertinencia y calidad, que les permita desarrollar sus capacidades al máximo e integrarse educativa, social y laboralmente" (p.27).

\subsubsection{Contexto Estatal}

La Ley para la Atención de las Personas con Discapacidad en el Estado de Chihuahua (Periódico Oficial No 59 del 24 de julio de 2004), en congruencia con el sentido de la legislación a nivel nacional, en el Artículo 2, se propone establecer normas tendientes a regular las acciones para resolver los problemas de las personas con alguna discapacidad, con el propósito de lograr su completa realización personal e integración social. Señala que una prioridad para el estado de Chihuahua es hacer posible el desarrollo integral de las personas con discapacidad y la equiparación de oportunidades en las áreas de integración social, educación, salud, derechos humanos, accesibilidad urbanística y arquitectónica, cultural, recreativa y deportiva.

Por otra parte la Ley Estatal de Educación establece en su Artículo 69 que:

"La educación especial está destinada a personas con necesidades educativas especiales, con o sin discapacidad, así como a aquellas con aptitudes sobresalientes. El Estado y la sociedad promoverán para ellas la igualdad de oportunidades educativas, sociales y laborales, reconociendo su potencial y respetando sus derechos." (p.26)

Al respecto la Ley Estatal de Educación en su Artículo 70, al igual que la Ley General de Educación, en el Articulo 72, especifican los ámbitos de intervención de la educación especial, señalando que la Educación Especial también brindará orientación a padres o tutores, a profesionales de la 
educación y de apoyo en las escuelas de educación básica regular que integren alumnos con necesidades educativas especiales, planteando un continuo de estrategias diferenciadas, atendiendo las distintas modalidades educativas.

El Programa de Fortalecimiento Estatal de la Educación Especial y de la Integración Educativa (SEC, 2005) se vincula con el Plan Estatal de Desarrollo 2004-2010, donde se plantea promover la integración social de las personas con capacidades diferentes, favoreciendo su incorporación al desarrollo e impulsando una cultura de respeto, equidad y reconocimiento a sus derechos, establece que igualar las oportunidades educativas implica compensar las desigualdades sociales de los grupos vulnerables de la población y por otra parte, reconoce que la equidad educativa exige asegurar no solo el acceso, sino la permanencia y el éxito en la educación de calidad.

El Programa Estatal de Educación 2005-2010, al respecto, desarrolla sus líneas de acción orientándolas al logro de una educación de buena calidad que satisfaga las necesidades de la comunidad educativa y de la sociedad en general.

La visión del Programa Estatal es:

"Responder de manera eficiente, pertinente y oportuna a las necesidades del estado y a los retos que plantea la integración exitosa de Chihuahua en el siglo XXI; da oportunidades equitativas a todos los ciudadanos de gestionar su desarrollo personal, familiar y laboral, logrando su máximo potencial a partir de sus características históricas y culturales; incluye las concepciones y prácticas diversas; se articula de manera favorable con el desarrollo social, económico y político; promueve la convivencia pacífica y la vida democrática; propicia el cuidado del medio ambiente; informa puntualmente de sus procedimientos y resultados; desarrolla un enfoque educativo de vanguardia centrado en el aprendizaje; crea condiciones para la generación y aplicación del conocimiento y se integra por instituciones y organizaciones eficientes $y$ flexibles que aprenden constantemente"(p.81). 
Una de las Líneas generales de acción de este programa, señala como prioridad el impulso a los programas de atención a personas con capacidades diferentes que derivan en líneas de acción específicas por nivel educativo.

En relación con la calidad educativa, el Programa Estatal de Educación 20052010 lo relaciona con desarrollar una escuela para todos, estableciendo el marco necesario para actualizar la visión de la integración educativa en el Estado de Chihuahua, con el firme propósito de mejorar las condiciones en que son atendidas las necesidades educativas especiales de los niños, las niñas y los jóvenes del estado, prioritariamente las de aquellos que presentan discapacidad.

La integración educativa plantea que uno de los primeros pasos que se tendrían que realizar para lograr su objetivo, es reconocer que no es un acto de caridad, sino que es un esfuerzo para generar condiciones que permitan que los niños aprendan de acuerdo a sus potencialidades. Al respecto el enfoque del Programa Estatal de Fortalecimiento de la Educación Especial y de la Integración Educativa, se basa en los siguientes fundamentos propuestos por García y otros (2000).

- Respeto a las diferencias; respeto y tolerancia hacia las diferencias como parte de la propia naturaleza del ser humano y de las sociedades.

- Los derechos humanos y la igualdad de oportunidades como derecho irrenunciable de toda persona a participar en los beneficios, obligaciones y oportunidades que le corresponden como ciudadano y miembro de la sociedad.

- La escuela para todos como derecho y la posibilidad de que todos los niños, niñas y jóvenes reciban una educación que satisfaga sus necesidades básicas de aprendizaje, asumiendo que cada sistema educativo debe atender con calidad a la diversidad.

La Integración educativa tiene como objetivo principal crear o mejorar las condiciones para todos los niños, niñas y jóvenes con alguna discapacidad, con aptitudes sobresalientes o con diferencias específicas en su desarrollo, ritmo o estilo de aprendizaje, logren los propósitos educativos y participen en la vida escolar. El Programa Estatal de Fortalecimiento de la Educación Especial y de 
la Integración Educativa (2005) afirma que la integración educativa representa un reto para Educación Básica que ya tiene planteado como una demanda social, por lo cual pretende ofrecer una educación de buena calidad, la integración educativa, impulsar la mejora de las prácticas escolares, promueve el desarrollo de la gestión, impulsa la formación continua de los profesionales de los diferentes niveles y modalidades, así como también promueve la diversificación de las estrategias y los recursos para la enseñanza y el aprendizaje.

De esta manera en el Programa Estatal de Fortalecimiento de la Educación Especial y de la Integración Educativa (SEC, 2005) se establece que:

"El objetivo principal de la Integración Educativa es crear o mejorar las condiciones para todos los niños, niñas y jóvenes con alguna discapacidad, con aptitudes sobresalientes o con diferencias específicas en su desarrollo, ritmo o estilo de aprendizaje, logren los propósitos educativos y participen en la vida escolar". (p.21)

Schmelkes (2002) fundamentalmente que la Integración está vinculada a la calidad ya que:

- Considerar los intereses y necesidades de aprendizaje y desarrollo de los estudiantes tanto en el presente, como en su formación a futuro enfatiza la Relevancia.

- La calidad exige Eficacia, al establecer que todos los estudiantes alcancen los propósitos educativos establecidos y desarrollen su potencial al máximo.

- Establece la Equidad. Reconoce que cada alumno tiene puntos de partida distintos para su aprendizaje y por lo tanto requiere recibir una atención diferenciada, según sus necesidades y capacidades.

- Implica Eficiencia. Requiere el uso óptimo de los recursos disponibles y su diversificación. 
La Inclusión se promueve como una visión más radical de la integración que enfatiza el carácter público de las diferencias de individuos o grupos, que a su vez generan situaciones de desigualdad y limitan sus posibilidades de participación de las oportunidades y beneficios que una sociedad ofrece a todos sus miembros. Puigdellivol (2005) afirma que la integración es la meta y la inclusión es el camino, el medio para llegar a aquella meta.

A partir de la perspectiva de una escuela, una sociedad y una cultura inclusivas, se promueve desde las instituciones mismas la equidad y la justicia social para todos los ciudadanos, independientemente del origen de sus desigualdades. En éste sentido, Marchesi y otros (2005) señalan que una escuela inclusiva será aquella que es capaz de ofrecer respuestas educativas individualizadas adecuadas a todos sus estudiantes.

Para lograr el desarrollo de contextos más incluyentes exige la voluntad política y el compromiso institucional de reducir o eliminar las barreras para el aprendizaje y la participación que impiden a las personas interactuar y desarrollarse en los distintos contextos en los que se encuentran, según sus intereses y necesidades. García y otros (2000) afirman que desde una perspectiva inclusiva el concepto de necesidades educativas especiales no hace más alusión a las dificultades del alumno, sino a las barreras para el aprendizaje o a las oportunidades de participación que el contexto escolar, familiar o social plantea al alumno.

A su vez Shalock y Verdugo (2003) enuncian que la mayor aspiración de una visión inclusiva es el logro de la calidad de vida, entendida ésta como las condiciones que se desean para que un individuo satisfaga sus necesidades fundamentales, incremente su bienestar personal y reduzca la exclusión del funcionamiento mayoritario de la sociedad. El Programa Estatal de Fortalecimiento establece que en la Calidad de Vida se consideran las diferencias culturales y las perspectivas vitales individuales que representan los estados deseables de bienestar a los que se aspira. Desde una perspectiva inclusiva, la calidad en la educación interviene en el nivel de calidad de vida que se ha logrado y éste a su vez está determinado por la capacidad de las instituciones sociales para equiparar las oportunidades de participación, multiplicar y diversificar sus recursos y hacerlos accesibles a todos los ciudadanos. 


\subsection{La Educación Especial en Chihuahua}

La Educación Especial ha vivido profundas transformaciones durante el siglo XX impulsadas por los movimientos sociales que han reclamado mayor igualdad entre todos los seres humanos y superar cualquier tipo de discriminación (física, social, cultural, intelectual, escolar, etc.) debido a que lo "normal" se ha concebido como una serie atributos y características típicas reconocidas y establecidas por la sociedad.

La incorporación dentro del sistema educativo ordinario de las personas con discapacidad se ha realizado poco a poco, buscando fórmulas que facilitaran la integración de estos alumnos, lo cual no ha sido una tarea fácil.

Se han planteado diferentes paradigmas de la Educación Especial, desde los años setenta hasta la actualidad, las diferentes concepciones nos permiten ver el cambio que se ha venido produciendo en relación a los ejes nucleares que constituyen la Educación Especial, que ha pasado desde poner énfasis en las deficiencias, a centrarse en las adecuaciones curriculares necesarias para los alumnos que presentan necesidades educativas especiales.

Torres (1999), afirma que podemos encontrar autores que la plantean como una educación diferente y dirigida a un grupo de sujetos específicos, mientras que otros enfatizan la idea de una acción o conjunto de acciones y servicios dirigidos a todos los sujetos que lo necesiten, en contextos normalizados.

En la actualidad la Educación Especial se desenvuelve entre dos enfoques el enfoque basado en el déficit (orientación centrada en el alumno individualmente considerado) y en el enfoque cultural- integrador (la orientación se centra en el currículum como respuesta educativa a la diversidad). Cada uno de ellos, en base a la representación interpretativa y simplificada de la realidad a la que se refiere, Torres (1999).

De esta manera se ha pasado de la segregación a la normalización e integración de las personas en ambientes menos restrictivos, lo que finalmente dará lugar a la Inclusión educativa, laboral y social basada en modificaciones ambientales. 
La reorientación de la Educación Especial, tuvo como punto de partida el reconocimiento del derecho de las personas a la integración social y del derecho de todos a una educación de calidad, que propicie el máximo desarrollo posible de las potencialidades propias. Este hecho impulsó la transformación de las concepciones acerca de la función de los servicios de Educación Especial y la adopción del concepto de necesidades educativas especiales.

La respuesta educativa a los estudiantes con necesidades educativas especiales debe inscribirse en el continuo general de la respuesta del centro a la diversidad, ya que, por una parte, algunas de las medidas que se requieren son coincidentes con las que se dan a los demás compañeros, y por otra parte, la estancia en un instituto de dichos alumnos se justifica, por que dicho contexto y la calidad de la propuesta educativa les permite proseguir su desarrollo personal y social.

En este sentido, la integración de estos alumnos en el instituto incrementa la complejidad de la elaboración de una propuesta global de centro, puesto que la tipología de alumnos que requieren actuaciones educativas especiales se amplía. La perspectiva ecológica de la escuela como organización que plantea Bronfenbrenner (1989), como marco para la atención a la diversidad establece que; este modelo contempla al niño cognitivamente y socialmente diferente, y que, a su vez, concibe a la escuela como un espacio de innovación, de critica y de interrelación abierta a cada entorno, promoviendo el desarrollo de procesos. González (1993) enuncia que las características que pueden favorecer a una escuela abierta a la diversidad serian:

1. La Flexibilidad; que supone el establecimiento de opciones de diferenciadas en la escuela, buscando la factibilidad de elegir aquellas que mas se ajustan a las características de sus necesidades, de tal manera que las estructuras organizativas, se construirán en el marco base de acción en referencia a las decisiones de carácter curricular que se tomaran en el centro.

2. La Funcionalidad; delimitando las tareas y responsabilidades, que han de establecerse entre todos los miembros involucrados dentro de la comunidad educativa, para atender adecuadamente la diversidad. 
3. La Participación; en la planificación educativa para atender la diversidad a través de: a) El currículum, con estrategias de carácter general como son, los niveles de concreción del currículo, nivel de individualización progresiva de la enseñanza, Proyecto Curricular de Centro, Programación de aula, Reglamento de Organización y Funcionamiento, y en las estrategias internas propias del centro como: los refuerzos educativos, adaptaciones curriculares, optativas, diversificación curricular y programas de garantía social. b) Estrategias específicas para atender tanto las necesidades educativas especiales por ambiente social, como por déficit físicos, psicológicos y sensoriales, buscando con ello el sentido de pertenencia a un grupo para poder así asumir líneas de organización que faciliten la participación.

4. La Comunicación; en el establecimiento de canales de comunicación, que logren favorecer las interrelaciones entre todos los componentes de la comunidad educativa, y entre estos y el contexto donde se ubican. Con ello se busca la creación de un clima de de centro, caracterizado por la eficiencia y el nivel de satisfacción de los Profesores.

En este sentido para el logro de una educación de calidad, la educación especial se apoya la nueva una gestión educativa que se distinga en ser capaz de centrar al conjunto educativo, alrededor de los aprendizaje de los alumnos, y por ello, este asociada a la planeación, organización, la evaluación de procesos y resultados, así como también a las características de los sujetos que les corresponde coordinar y tomar desiciones en los procesos escolares, directivos y docentes, la nueva gestión se establece en el documento, Plan Estratégico de Transformación Escolar (2006c) como; "El conjunto de acciones, relacionadas entre sí, que emprende el equipo directivo-docente de una escuela para promover y posibilitar la consecución de la intencionalidad pedagógica en y con la comunidad educativa"(p.10).

\subsubsection{Plan Estratégico de Transformación Escolar}

En base a este nuevo paradigma de la gestión escolar, la planeación de la escuela, asume un papel relevante, dado que es el proceso que permitirá hacer 
reflexiones sobre el que hacer de la escuela, para después plantearse objetivos, estrategias y compromisos para un futuro al que se desea llegar como escuela, se requiere realizar una evaluación interna, con una perspectiva diagnostica, resaltando las áreas criticas y las oportunidades de mejora, previendo situaciones que pueden obstaculizar el logro de los objetivos deseados, para ello se hace necesario también considerar los medios y recursos con lo que se cuenta, además de reunir condiciones de calidad y equidad, sobre todo que los actores involucrados desarrollen un pensamiento estratégico, cambiando de perspectiva, donde el colectivo se perciba como una organización en todo su conjunto, con una visión común y donde los esfuerzos en conjunto beneficien a todos. El cambio de perspectiva no solo plantea hacer las cosas diferentes, es más que eso, es asegurarse de que los resultados sean óptimos.

La mejora continua de una institución, se fundamenta en la evaluación, que de acuerdo al Plan Estratégico de Transformación (2006c) se evalúan todos los procesos, las actuaciones, el diseño de la planeación, las estrategias, su ejecución y la propia evaluación, lo cual implica:

* Evaluación Inicial; una evaluación inicial o diagnostico, que desarrolla antes de la planeación, es una valoración objetiva sobre el punto de partida en el que se encuentra el centro escolar, identificando los procesos críticos.

* Planeación escolar; Primeramente se reconoce la situación actual del centro, para ello se parte de los resultados de la autoevaluación, necesario para establecer la misión, la visión, los objetivos, las estrategias, metas, acciones, recursos humanos y financieros que se requieren, así mismo se establece el seguimiento y la evaluación a las acciones planteadas. Implica que los involucrados de la comunidad educativa, se comprometan a realizar las acciones en los plazos establecidos.

* Realización; se ponen en practica las estrategias y acciones de mejora que se planearon, lo que implica una revisión o evaluación continua, que permite verificar si se han realizado y si se logro el impacto deseado.

* Verificación; Evaluación y análisis de la información que se recopilo en la planeación y durante su aplicación, se hace una comparación entre los 
resultados obtenidos y los esperados, de ser necesario se aseguran las estrategias que fueron eficaces y se establecen nuevas.

* Retroalimentación; se van incorporando las nuevas prácticas, en el funcionamiento de la escuela, para las nuevas mejoras y reiniciar el proceso de la planeación, para alcanzar nuevas metas. Es de suma importancia documentar lo qué se hace y cómo se hace, de la etapa inicial y actual, tomando en cuenta los procesos, procedimientos y resultados actuales.

La Secretaria de Educación Pública (SEP) ofrece a las instituciones de Educación Básica el Programa Escuelas de Calidad (PEC), que retoma los principios de autogestión, establecida en el Plan Estratégico de Transformación Escolar (2006c) como; la toma de desiciones, el liderazgo compartido, el trabajo en equipo, las prácticas flexibles acordes a la diversidad de la población, la planeación participativa con un enfoque estratégico, la evaluación para la mejora continua, participación responsable y rendición de cuentas, con el propósito de mejorar la calidad de la educación. EI PEC busca también el fortalecimiento y la articulación con los programas federales, estatales y municipales, para que se atiendan a las escuelas públicas que voluntariamente quieren participar en el programa, es por ello que los 28 Centros de Atención Múltiple, como servicios escolarizados de Educación Especial participan en el PEC elaborando el PAT (Plan Anual de Trabajo). De igual manera, es importante mencionar que las demás instituciones y servicios de la modalidad de educación especial en el estado de Chihuahua, como; el Equipo de Apoyo a la Docencia, los equipos de la Coordinación Regional y de las Supervisiones, así como los servicios de apoyo y los servicios de orientación, se basan en los objetivos y en la metodología de este programa, ya que no pueden participar directamente por no ser servicios escolarizados.

La planeación requiere de la participación del colectivo directivo-docente, contando con el apoyo del supervisor, asesores técnicos pedagógicos y directores del nivel entre otros. Los contenidos de la misma, van enfocados al fortalecimiento de la práctica pedagógica, en función de las necesidades educativas de los alumnos, con la visión de mejorar la organización, administración y las formas en que se establece la vinculación con la 
comunidad educativa. Esta planeación, así mismo se establece en el Plan Estratégico de Transformación (2006c), como Plan Estratégico de Transformación Escolar (PETE), este plan permite que los actores involucrados, cuenten con un panorama general de las líneas de trabajo y los resultados establecidos a mediano plazo, es el referente estratégico base para la escuela, contemplando los propósitos y compromisos, concreta sus operaciones en el corto plazo en el Plan Anual de Trabajo.

En el siguiente cuadro se presenta el marco referencial del Programa de escuelas de calidad.

\section{Marco Referencial \\ Estándares del Programa Escuelas de Calidad}

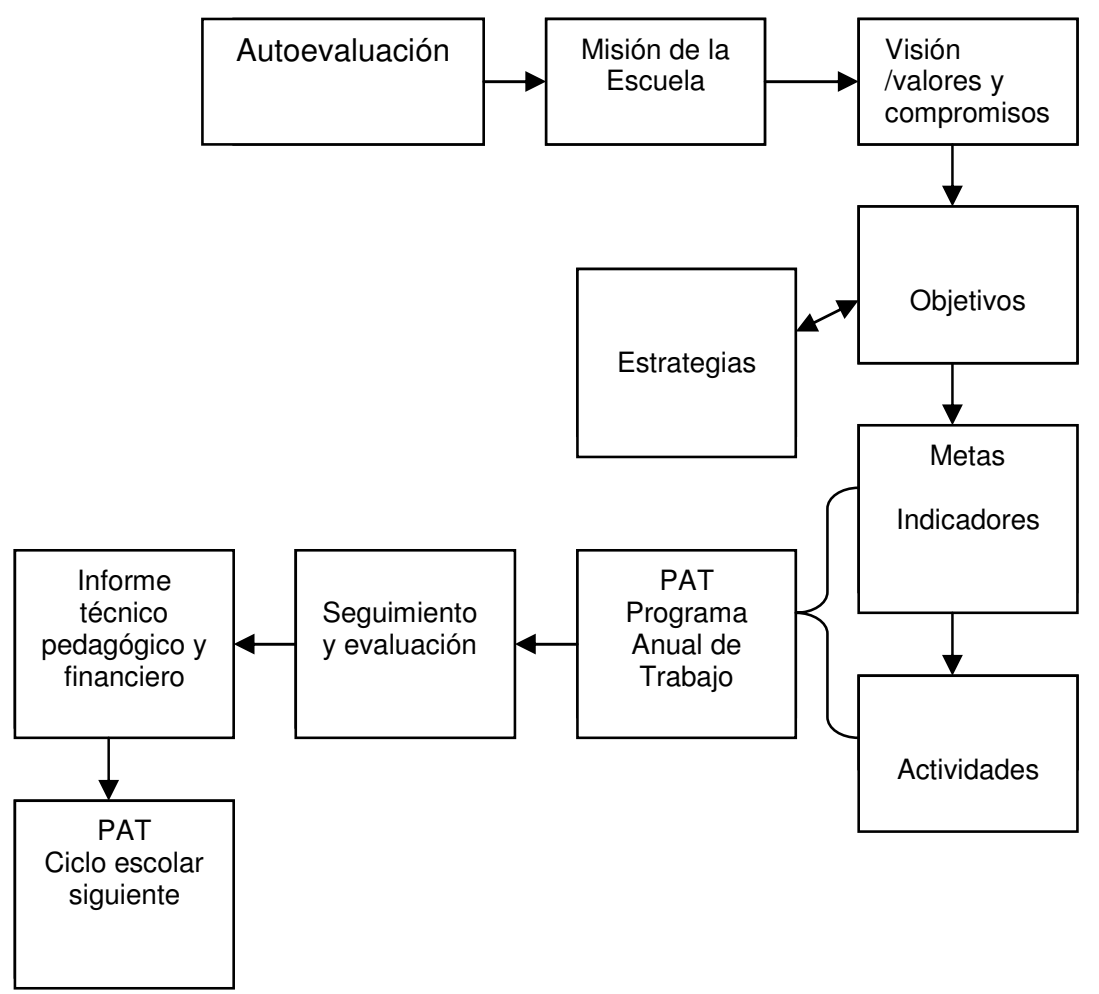

Figura 25

\subsubsection{La Evaluación en el Proceso Enseñanza Aprendizaje}

La Educación Especial no genera un currículo paralelo, ni lo debe requerir para el desarrollo y aprendizaje de los educandos, asumiendo más bien el currículo de Educación Inicial, Preescolar, y Primaria, de la Educación Básica regular y los programas de capacitación para el trabajo, así como el previsto para otros 
niveles y modalidades, realizando las adaptaciones curriculares necesarias, las cuales constituyen un proceso de toma de decisiones compartido, tendiente a ajustar y complementar el currículo común, para dar respuesta a las necesidades educativas especiales de los alumnos, y lograr su desarrollo personal y social.

Para Gimeno (1992), El nuevo paradigma platea el curriculum como respuesta educativa a la diversidad. Al asumir que la escolaridad va más allá de la transmisión de conocimientos, la justificación del currículo no puede quedarse en criterios de representatividad de lo seleccionado respecto a la cultura académica, sino apoyarse, muy fundamentalmente, en otros de carácter social y moral dado que lo que se busca con su implantación es un modelo de hombre y de ciudadano, así mismo establece que en el sentido prescriptivo el currículo es, aquello que debe ser llevado acabo en las escuelas, es el plan o la planificación, por lo cual se organizan los procesos escolares de enseñanza / aprendizaje. Los currículos más equilibrados, son los que el desarrollo personal y social del alumno tenga también importancia y en los que la evaluación se plantee en el progreso de cada alumno, facilitando la integración de los alumnos.

La evaluación como parte de los elementos del currículo es de suma importancia, debido a que en el ámbito educativo la operación de evaluar implica valorar la información, a través de la emisión de un juicio, estimar su valor no material, hace referencia a cualquier proceso por medio del que alguna o varias características de un grupo de alumnos, profesores, materiales, programas u objetivos educativos, reciben la atención de quien evalúa, analizando y valorando sus características y condiciones en función de criterios o puntos de referencia para emitir un juicio relevante para la educación. Al respecto Casanova (1998) plantea la evaluación aplicada a la enseñanza aprendizaje, como un proceso sistemático y riguroso de recogida de información, incorporado al proceso educativo desde su comienzo, permitiendo que sea posible disponer de información continua y significativa para conocer la situación, establecer juicios de valor con respecto a ella, tomando desiciones adecuadas, que permitan proseguir la actividad educativa mejorándola progresivamente. 
La evaluación deberá servir, para reorientar y planificar la práctica educativa, conocer lo que ocurre en el aula a partir de los procesos pedagógicos empleados y su incidencia en el aprendizaje del alumno, reorientando cuantas veces fuera necesario los procesos durante su desarrollo, es una de las funciones más importantes de la evaluación.

Una de las medidas claves para el mejoramiento de la calidad en la educación, es reconsiderar los procesos de evaluación educativa a partir de la creación de instrumentos de evaluación pertinentes y su aplicación sistemática. Esta inquietud se ve plasmada en el Programa de Desarrollo Educativo 20012006 al señalar que la Política de Evaluación y Seguimiento, tendrá como objetivo principal evaluar y dar seguimiento al avance del aprovechamiento de los alumnos y a los factores que influyen en sus resultados, con el propósito de fundamentar el diseño de políticas y la toma de decisiones dirigidas al mejoramiento de la calidad y la equidad de la educación básica.

Entre las líneas de acción propuestas se contempla, en primer término, apoyar el establecimiento y la difusión del ejercicio sistemático de la evaluación escolar, como instrumento de diagnóstico y reorientación de las prácticas educativas en el aula y en la escuela.

Como se sabe, la escuela, tiene el difícil reto de proporcionar una cultura común a todos los alumnos, que evite la discriminación y desigualdad de oportunidades, respetando al mismo tiempo sus características y necesidades individuales. Sin embargo determinadas necesidades individuales, plantean necesidades educativas especiales, que exigen respuestas educativas que se traducen en un conjunto de ayudas, recursos y medidas pedagógicas de carácter extraordinario, distintas de las que demandan la mayoría de los alumnos, ellas se consideran en el proceso de aprendizaje, pero también en la evaluación. El concepto de necesidades educativas especiales implica que cualquier alumno que tenga dificultades de aprendizaje, por la causa que fuere, reciba las ayudas y recursos especiales que necesite, ya sea de forma temporal o permanente en el contexto educativo más normalizado posible. 
Al respecto, las necesidades educativas especiales, se establecen por García y otros (2000) de la siguiente manera:

Las necesidades educativas especiales aparecen, cuando un alumno presenta un ritmo para aprender muy distinto al de sus compañeros, y los recursos disponibles en su escuela son insuficientes para apoyarlo en la adquisición de los contenidos, establecidos en los planes y programas de estudio; por lo tanto requiere de recursos mayores o diferentes que pueden ser:

a) Profesionales: maestros de apoyo, especialistas.

b) Materiales: mobiliario específico, prótesis, material didáctico.

c) Arquitectónicos: construcción de rampas y adaptación de distintos espacios escolares.

d) Curriculares: adecuación de las formas de enseñar del profesorado, de los contenidos e incluso de los propósitos del grado.

El proceso de evaluación centrado en los procesos de enseñanza y aprendizaje nos ofrece una vía adecuada para la evaluación de los alumnos en general, así como de aquellos con necesidades educativas especiales.

Esta evaluación supone un carácter interactivo, el mismo que se relaciona claramente con la concepción de necesidades educativas especiales difundidas en términos de las características y necesidades de los alumnos, en relación con las respuestas que el medio escolar tiene ante ellas. García y otros (2000), enuncian que el proceso de detección de los alumnos que pueden presentar necesidades educativas especiales consiste en:

a) Realización de la evaluación inicial o diagnóstica del grupo. Por medio de pruebas iniciales, el maestro conoce el grado de conocimientos de los alumnos y alumnas de su grupo al principio del ciclo escolar. Esta evaluación se complementa con las observaciones informales que realizan los maestros, de tal manera que no solo se considera el grado de conocimiento de los alumnos, si no las formas en que socializan, los ritmos y estilos de aprendizaje, sus intereses, sus preferencias etc. Partiendo de esta base se hacen los ajustes generales a la programación de clase, para adaptarla a las necesidades observadas. 
b) Evaluación más profunda de algunos niños y niñas. Después de realizar los ajusten generales en la programación, aún así algunos alumnos presentan dificultades para seguir el ritmo de aprendizaje de sus compañeros de grupo. Por lo que el maestro observa de manera más cercana y realiza ajustes a la metodología de tal forma que involucra a estos niños y niñas en actividades que les permita participar con el grupo, disminuyendo la distancia que hay entre ellos y el grupo.

En el proceso de la evaluación inicial, la participación del equipo de apoyo de Educación Especial, es esencial ya que podrá contribuir con el maestro de grupo, en la detección de barreras que están obstaculizando el aprendizaje y la participación de algunos alumnos, al igual que si existen alumnos con discapacidad que requieran ciertos apoyos para ser evaluados. En cuanto a los cambios en la metodología, el equipo de apoyo también, puede ayudar a enriquecer la práctica docente, aportando algunas estrategias que permitan facilitar el aprendizaje y la participación de los alumnos.

\section{Evaluación Psicopedagógica}

Al inicio y durante la escolaridad resulta importante profundizar en el conocimiento de las características personales, familiares y socioculturales de los alumnos. Ello permite detectar la situación inicial de trabajo, y su desarrollo, facilitando la elaboración de una programación idónea y ajustada a las características y necesidades de los alumnos. Si a pesar de los ajustes realizados, algunos alumnos continúan presentando dificultades, será necesario realizar una evaluación más profunda, como es la evaluación psicopedagógica, establecida en las Normas de inscripción, reinscripción, acreditación y certificación para las escuelas de educación, primaria oficiales y particulares incorporadas al Sistema Educativo Nacional (SEP-DGAIR, 2007) como;

"Es el proceso que implica conocer las características del alumno en interacción con el contexto social, escolar y familiar al que pertenece, para identificar las barreras que impiden su participación y aprendizaje y 
así definir los recursos profesionales, materiales, arquitectónicos y/o curriculares que se necesitan para que logre los propósitos educativos. Los principales aspectos que se consideran al realizar la evaluación psicopedagógica son; el contexto del aula y de la escuela, el contexto social y familiar; el estilo de aprendizaje del alumno, sus intereses y motivación para aprender, y su nivel de competencia curricular en las distintas asignaturas" (p. 90).

El proceso de la evaluación psicopedagógica no concluye hasta que se realiza una interpretación de resultados, que surge del análisis, integración e interrelación de la información obtenida por cada uno de los participantes, presentando un sentido global del alumno y su contexto en donde se desarrolla. En las Normas de inscripción, reinscripción, acreditación y certificación para las escuelas de educación primaria oficiales y particulares incorporadas al Sistema Educativo Nacional (SEP-DGAIR, 2007), se instituye el Informe de Evaluación Psicopedagógica como; el Informe que

"recupera la información obtenida en la evaluación psicopedagógica, se precisan las necesidades educativas especiales que presentan los alumnos y se definen los recursos/apoyos profesionales, materiales, arquitectónicos y cuniculares que se necesitan para que el alumno con necesidades educativas especiales logre los propósitos educativos" (p.90).

Partiendo del informe psicopedagógico, es necesario describir los apoyos y recursos que el alumno requiere, para dar respuesta a las necesidades educativas especiales, por ello se elabora la propuesta curricular adaptada, que contempla las principales necesidades del alumno, presentes en la evaluación psicopedagógica y en la planeación para todo el grupo.

\subsubsection{Adecuaciones Curriculares}

En el proyecto curricular del centro se toman en cuenta las adaptaciones curriculares, con una concepción educativa curricular más que rehabilitadora, sin significar esto que no sea necesario tomar decisiones dirigidas a compensar, o reducir las dificultades derivadas de la propia discapacidad, 
según sea el caso. Las adaptaciones curriculares se establecen como un recurso extraordinario, que debe decidirse tras un proceso de evaluación psicopedagógica del alumno, en relación a su contexto específico, de esta manera se fundamenta la necesidad de realizarlas. Cuando un alumno empieza a presentar dificultades en el aprendizaje, es importante no derivarlo a automáticamente a un proceso de evaluación psicopedagógica y adaptación curricular, es necesario considerar, primeramente, una serie de medidas pedagógicas que puedan compensar dichas dificultades. Si estas medidas no dan resultado y el alumno continua presentado dificultades importantes, es el momento de que otros profesionistas intervengan para realizar la evaluación psicopedagógica que oriente el tipo de adaptación a realizar.

Marchesi y otros (2005) establecen que las condiciones del desarrollo y del aprendizaje de los alumnos, junto con las condiciones que existen en la enseñanza que se ofrece, en ocasiones hacen necesario realizar modificaciones en el currículo o proporcionar medios de acceso al mismo, esto constituye un proceso particular en la toma de decisiones del maestro, para cada niño en el contexto concreto en que se desarrolla y aprende, por lo tonto no hay adaptaciones previamente concebidas para las distintas necesidades o problemáticas, a modo de receta. Obviamente que existen ciertas condiciones del desarrollo de los alumnos con algún tipo de discapacidad que tienen repercusiones en su proceso de aprendizaje y que por ello van a requerir cierto tipo de adaptaciones. Sin embargo no se pueden determinar a priori qué modificaciones hay que realizar en las diferentes áreas del currículo o en las estrategias metodologícas, porque cada alumno y contexto educativo es diferente.

En el siguiente cuadro se mencionan las etapas en el proceso de las adecuaciones curriculares. 
Cuadro 18: Etapas en el Proceso de Adaptación Curricular.

\begin{tabular}{|c|c|c|c|}
\hline \multicolumn{4}{|c|}{ Etapas en el proceso de adaptación curricular } \\
\hline $\begin{array}{c}\text { Evaluación } \\
\text { Psicopedagógica }\end{array}$ & NEE & Respuesta Educativa & Seguimiento \\
\hline $\begin{array}{l}\text { Evaluación del } \\
\text { alumno en } \\
\text { interacción con el } \\
\text { contexto en el que se } \\
\text { desarrolla y aprende } \\
\text { para identificar sus } \\
\text { necesidades } \\
\text { educativas la } \\
\text { fundamentar de } \\
\text { respuesta educativa: } \\
\text { - Nivel de de } \\
\text { desarrollo y } \\
\text { competencia } \\
\text { curricular del } \\
\text { alumno. } \\
\text { Factores que } \\
\text { facilitan su } \\
\text { aprendizaje. } \\
\text { Contexto y } \\
\text { respuesta } \\
\text { educativa del } \\
\text { aula y del } \\
\text { centro. } \\
\text { Contexto }\end{array}$ & $\begin{array}{l}\text { Establecer las } \\
\text { necesidades } \\
\text { educativas } \\
\text { individuales que se } \\
\text { consideran } \\
\text { especiales porque } \\
\text { requieren para ser } \\
\text { atendidas recursos } \\
\text { y medidas de } \\
\text { carácter } \\
\text { extraordinario de } \\
\text { forma temporal o } \\
\text { permanente. }\end{array}$ & $\begin{array}{l}\text { Decisiones sobre: } \\
\text { - } \begin{array}{l}\text { Propuesta } \\
\text { curricular }\end{array} \\
\text { - Modificaciones en } \\
\text { el contexto } \\
\text { educativo. } \\
\\
\text { Provisión } \\
\text { ayudas de } \\
\text { personales, } \\
\text { materiales } \\
\text { modalidades de } \\
\text { apoyo }\end{array}$ & $\begin{array}{l}\text { Registro de los } \\
\text { avances y revisión } \\
\text { de las medidas } \\
\text { adoptadas para } \\
\text { introducir los } \\
\text { ajustes necesarios. }\end{array}$ \\
\hline
\end{tabular}

Nota: Cuadro tomado Blanco, R. (2005).

La función de las adaptaciones curriculares en el proceso educativo de los alumnos que presenta necesidades educativas especiales son, de acuerdo a Blanco (2005):

- Asegurar que el alumno reciba los medios y la respuesta educativa que requiere, para progresar dentro del sistema educativo en igualdad de condiciones. 
- Lograr el establecimiento de una relación entre las necesidades educativas individuales y la programación del aula del grupo de referencia, asegurando un mayor grado posible de participación en las actividades y la dinámica del aula.

- Propiciar y coordinar la participación de los diferentes profesionales y servicios que intervienen con el alumno.

- Favorecer y fortalecer la colaboración de la familia.

- Promover al alumno hacia situaciones progresivamente lo más normalizadoras posibles.

Por un lado, se trata de una estrategia de planificación y de actuación docente para responder a las necesidades de cada alumno. Pero, a la vez, se trata de un producto, ya que es una programación que contiene objetivos, contenidos y evaluaciones diferentes para unos alumnos, e incluso organizaciones escolares específicas, orientaciones metodológicas y materiales adecuados.

Las características que definen las adaptaciones curriculares que establece Blanco (2005) son:

1. Es una visión particular del alumno estrechamente relacionada con la programación de su grupo, por ellos se realiza de forma escrita como cualquier programación, de tal forma que pueda sistematizar y sintetizar el proceso, y evaluar la adecuación de las decisiones tomadas; los componentes básicos de este proceso son:

- Le da mayor importancia a la evaluación inicial, para la toma de decisiones, ya que las adaptaciones curriculares se deciden después de esta y tras la aplicación de la evaluación psicopedagógica.

- Se explicitan aquellos elementos en los que es necesario plantear actuaciones no habituales y con especial importancia los relacionados al proceso de desarrollo y aprendizaje del alumno. En ocasiones es necesario centrase principalmente en estrategias metodologías o medios de acceso; en otras, en 
objetivos y contenidos de diversas áreas o de alguna en concreto.

- Son elaboradas conjuntamente entre el profesor Tutor y los especialistas que realizan funciones de apoyo $y$ asesoramiento.

- Información relevante del proceso de evaluación.

- Definición clara de las necesidades educativas especiales.

- Propuesta curricular que especifique, qué, cómo y cuándo enseñar y evaluar en las áreas que se requiera.

- Previsión de recursos materiales, ayudas personales y modalidades de apoyo.

- Colaboración de la familia.

- Seguimiento de las decisiones en todo el proceso.

2. Las decisiones que se tomen deben de ser funcionales y realistas, como un instrumento, que oriente la acción educativa que se va a seguir con el alumno.

3. Pueden clasificarse por su mayor o menor grado de significatividad, lo que se relaciona directamente con el grado de distancia que representa, en relación a las actuaciones que se siguen con el resto de los alumnos de ese grupo de referencia, cuanto más alejado este de el, más significativa será la adaptación.

\section{a) Adecuaciones Curriculares menos Significativas}

Las modificaciones que se realizan en relación al qué, cómo y cuándo enseñar y evaluar, en relación a los objetivos, los contenidos y su secuenciación, la metodología, los criterios y procedimientos de la evaluación son las adaptaciones a los componentes del currículo, y en función de que elementos se modifiquen serán más o menos significativas.

La adaptación para un menor grado de significatividad; se realiza cuando algunas de las necesidades educativas especiales, sólo requieren ser atendidas por una serie de medios, recursos o ayudas técnicas, que permitirán 
al alumno seguir casi totalmente el currículo planteado para todo el grupo en común, favoreciendo de esta manera el desarrollo y aprendizaje de determinadas capacidades y contenidos que de no tenerlos, presentaría serias dificultades para el alumno. Los medios, recursos o ayudas técnicas serian:

- Condiciones físico- ambientales; eliminación de barreras arquitectónicas.

- Materiales, equipamiento y ayudas técnicas; compensan las dificultades derivadas de la discapacidad de los alumnos, permitiéndoles una mayor participación, con mayor grado de autonomía en las actividades

- Códigos de comunicación; esta es una de las adaptaciones mas complejas, debido a que las dificultades de comunicación de algunos alumnos limitan su acceso al currículo y necesitan aprender un código aumentativo, complementario o alternativo al lenguaje oral y escrito, para ello se hace necesario realizar modificaciones al currículo, introduciendo objetivos, contenidos, criterios de evaluación, estrategias, instructivos y materiales específicos para el aprendizaje de dicho código, lo que trae como consecuencia eliminar de forma temporal o permanente otro tipo de contenido menos prioritario para el alumno, al menos durante un tiempo.

Las adaptaciones menos significativas, son aquellas que se realizan en los elementos no prescriptitos del currículo oficial, hacen referencia al cómo enseñar y evaluar, como puede ser, hacer modificaciones en las estrategias metodologícas, diseñar actividades complementarias etc. No obstante pueden existir adaptaciones consideradas no significativas que afectan a los elementos prescriptivos del currículo, como pueden ser: introducir, matizar, o ampliar algunos contenidos, dedicar mayor tiempo al aprendizaje de algunos de los contenidos, eliminar alguno no esencial dentro del área, etc.

Estas modificaciones son frecuentes para los alumnos de un grupo, y como tal deberían formar parte de la práctica habitual de los docentes, en el contexto de dar respuesta a la diversidad. 


\section{b) Adecuaciones Curriculares Significativas.}

Las adaptaciones significativas por el contrario, son aquellas que afectan a los elementos prescriptivos del currículo oficial y, como consecuencia pueden tener efectos en la titulación del alumno, como cuando es necesario realizar varias de estas adaptaciones:

- Dar prioridad a algunas de las capacidades contempladas en los objetivos generales, y en consecuencia, a determinados contenidos y criterios de evaluación. Puede implicar renunciar temporal o definitivamente a otros aprendizajes que son menos relevantes para el alumno.

- Introducir o ampliar determinados aspectos contemplados en objetivos, contenidos y criterios de evaluación. Algunos alumnos tienes que aprender ciertos criterios que no están contemplados en el currículo común, o que forman parte de la propuesta curricular del ciclo o etapa educativa anterior, y por tanto se tienen que introducir en forma individual.

- Eliminar objetivos, contenidos y criterios de evaluación del currículo oficial llegando, en algunos casos a eliminar prácticamente un área o áreas curriculares enteras. En toda área curricular existen contenidos esenciales o nucleares y contenidos que se podrían denominar de detalle 0 profundización. Cuando la eliminación afecta a los primeros habrá que considerar una adaptación significativa.

\section{Propuesta Curricular Adaptada}

Las normas de inscripción, reinscripción, acreditación y certificación para las escuelas de educación primaria, oficiales y particulares (SEP-DGAIR, 2007), que incluyen también a los servicios de Educación Especial, señalan que la Propuesta Curricular Adaptada es el principal sustento para definir la acreditación y promoción de los alumnos, que es un documento indispensable, al considerar el traslado de un alumno de un servicio de educación especial a 
una escuela de educación inicial o básica, así como también para el proceso de acreditación y traslado de los alumnos que presentan necesidades educativas especiales.

En el documento de Orientaciones Generales para el funcionamiento de los servicios de Educación Especial (SEP, 2006d), se contempla la Propuesta Curricular Adaptada (PCA), como la herramienta que permite especificar los apoyos y recursos que la escuela aporta al alumno que presenta necesidades educativas especiales para el logro de su participación y aprendizaje, por lo que su elaboración y seguimiento es primordial, la planeación de la PCA incluye los recursos profesionales, arquitectónicos, materiales, curriculares que el alumno requiere para lograr los propósitos educativos.

En las Unidad de Servicios de Apoyo a la Escuela Regula (USAER), la PAC permite organizar y dar seguimiento a las estrategias que la escuela y los maestros de grupo, con la participación del equipo de apoyo de USAER, realizan con los alumnos con necesidades educativas especiales, en el caso de requerir adecuaciones significativas es indispensable para la toma de decisiones respecto a su promoción.

En los Centros de Atención Múltiple (CAM), la PAC, es responsabilidad del maestro de grupo y comparte esa responsabilidad con la familia del alumno, el director, el resto del equipo multidisciplinario y con los profesionales de otras instituciones que hayan participado, no solamente en la elaboración, si no para la implementación de los apoyos, el seguimiento y la evaluación.

\subsubsection{Organización de Educación Especial}

La modalidad de Educación Especial de los Servicios Educativos del Estado de Chihuahua, están organizados de acuerdo al manual técnico operativo de la misma modalidad, donde se establecen las normas técnicas y administrativas de las instancias operativas.

Actualmente la organización esta conformada por;

* Jefe(a) del Departamento.

* Subjefe Técnico.

* Subjefe de Trámite y Control. 
- Equipo de apoyo a la Docencia conformado por seis Asesores Técnicos Pedagógicos (ATP) Estatales, organizados por áreas especificas de la discapacidad y/o áreas de apoyo, las acciones que realizan son producto del consenso de las reuniones del mismo equipo y de las reuniones de Consejo Técnico Estatal, y/o solicitadas por el personal docente y de apoyo de las zonas escolares de las diferentes regiones, a su cargo en co-responsabilidad con el equipo de la zona.

* Coordinación Regional. Existe una coordinación regional en Ciudad Juárez, se encarga de detectar por medio del diagnostico las necesidades de recursos humanos, materiales, técnicos y financieros de las zonas y servicios, la conforman dos ATP Regionales y 4 zonas escolares.

* Supervisión de Zona Escolar. En el estado existen 18 zonas escolares, en 28 comunidades, conformadas por un Supervisor, que se encarga de detectar por medio del diagnostico las necesidades de recursos humanos, materiales, técnicos y financieros de los servicios, le apoya un ATP de zona, que tiene a carpo la capacitación y actualización de la asesoría técnica de la zona.

El modelo de gestión planteado en el manual técnico operativo, es una gestión participativa mediante consejos técnicos;

- Consejo Técnico Estatal; integrado con la participación del Jefe de Departamento, Subjefes, Coordinación Regional, Equipo de Apoyo a la Docencia, Supervisores de Zona, Asesores Técnicos Pedagógicos Regionales y de Zona.

- Consejo Técnico Regional; integrado por el Coordinador regional, Supervisores de Zona, ATP Regionales y de Zona.

- Consejo Técnico de Zona, integrado por el Supervisor, Asesor Técnico Pedagógico, y Directores de los servicios que conforman la zona.

- Consejo Técnico de Servicio; esta integrado por el Director, los Maestros y Equipo de Apoyo o Multiprofesional del Servicio. 
El Profesor tutor tiene como finalidad en su aula atender a los aspectos del desarrollo, maduración, orientación y aprendizaje de los alumnos, considerándolos individualmente y como un grupo. Por ello debe de conocer a sus alumnos en sus diferentes facetas que conforman su personalidad, así como ser un de unión entre la familia y el centro por un lado, y entre los Profesores que atienden a un mismo grupo de alumnos por otro.

El especialista de Educación Especial denominado profesor de apoyo dentro de su papel de especialista, integrara la ayuda al profesor tutor en el desempeño de su función sin establecimiento de relaciones de jerárquicas.

González (1993), Plantean que partiendo de este sentido la labor del apoyo no es únicamente de los especialistas, ya que los verdaderos protagonistas son los tutores y los de apoyo se irán estableciendo como consultores que complementaran la labor de ellos . Domingo (1997), En este sentido se plantea el trabajo colaborativo desde el profesor de Apoyo con el tutor en base a los siguientes aspectos.

- Ser propiciador de cambio de actitudes en el centro.

- Un banco de recursos didácticos y organizativos especialmente útiles para su objetivo.

- Desempeñar junto con su papel de atención a niños, funciones globales del centro y equipos de docentes con el fin de que la integración y la colaboración entre profesionales sea mas una ideología de centro.

- En la dinámica normal de las clases difuminar las atenciones específicas de apoyo, para llegar a la concepción ideal de doble tutor, rompiendo con la figura de niño de educacion especial, de tutor para la media de la clase y maestro de apoyo ajeno a las dinámicas generales de los ciclos y de las aulas; para centrarse en los procesos de aprendizaje emergentes más que en las dificultades propiamente dichas. 


\section{Formación Académica}

No cabe duda que para mejorar la practica educativa por los directamente implicados en la misma hace necesaria una metodología de trabajo colaborativo, en el que se aborden los problemas desde distintas perspectivas. De esta forma se establece una relación de igualdad en cuanto al nivel de relación pero complementaria y diferenciada en lo que se refiere a las aportaciones, experiencias profesional y formación de los implicados. De acuerdo al Programa Nacional de Fortalecimiento de la Educación Especial y de la Integración Educativa (SEP, 2002), del total del personal académico, aproximadamente el $63 \%$ cuenta con alguna formación profesional en Educación Especial, mientras que el 37\% restante tiene un perfil variado: licenciatura en psicología educativa, pedagogía, educación preescolar, educación primaria, entre otras.

Durante los años setenta y ochenta, en general, el personal que laboraba en los servicios de educación especial de carácter indispensable había realizado estudios de licenciatura o especialización en las Escuelas Normales de Especialización, con la formación previa de profesor de educación básica.

Los planes y programas de las licenciaturas en educación especial que se imparten en las Escuelas Normales datan de 1985, antes de los importantes cambios de orientación de la Educación Especial.

Según el Programa Nacional de Fortalecimiento de la Educación Especial y de la Integración Educativa $(S E P, 2002)$ la formación inicial y la actualización del personal de Educación Especial deben estar encaminadas a dar una respuesta educativa adecuada a las necesidades específicas que presentan los niños, las niñas y los jóvenes con discapacidad, así como a aquellos que presentan necesidades educativas especiales derivadas de otros factores como las aptitudes sobresalientes y los problemas de comunicación o de conducta, entre otros. De la misma manera dicho programa enuncia que : La Subsecretaría de Educación Básica y Normal, en el marco del Programa para la Transformación y el Fortalecimiento Académicos de las Escuelas Normales, renovará los planes y programas de estudio de las licenciaturas relacionadas con educación especial que se imparten en las escuelas normales. Los nuevos planes deberán tener presente la misión de la Educación Especial y las 
características de la población a la que van dirigidos los servicios, con el propósito de que los nuevos maestros cuenten con el perfil que se requiere de acuerdo con las necesidades de la demanda.

Es necesario que dicho personal cuente con estrategias específicas para evaluar y atender a los alumnos con educativas especiales, de manera que identifique las fortalezas y debilidades en las distintas áreas: social, comunicativa, afectiva, académica, etcétera, de los niños, las niñas y los jóvenes con discapacidad, así como de aquellos que muestran un ritmo muy distinto para tener acceso al aprendizaje de los contenidos curriculares debido a otros factores; esta evaluación también debe aportar información sobre el contexto social y escolar que lo rodea. Asimismo, debe permitir que el personal de educación especial, conjuntamente con el de la escuela regular y con los padres y madres de familia, determinen las prioridades y con base en ello establezca los propósitos específicos para el alumno, en una propuesta curricular adaptada.

Además de lo anterior, el personal de Educación Especial debe tener conocimiento de los propósitos y contenidos de la Educación Inicial, Preescolar, Primaria y Secundaria de las distintas modalidades, así como de los programas relacionados con la capacitación para el trabajo con el propósito de que pueda favorecer, mediante orientación al personal de la escuela regular y/o a los padres de familia, además de una atención directa al alumno, si es necesario, que éste tenga acceso a los propósitos generales de la educación, promoviendo su integración a los planteles de educación regular.

\subsubsection{Servicios de Educación Especial}

En el estado de Chihuahua funcionan tres tipos de servicios de educación especial; servicios escolarizados, servicios de apoyo y de orientación. Para la información general que se presenta a continuación de los servicios se tomo en cuenta el manual de orientaciones generales para el funcionamiento de los servicios de Educación Especial (2006d). 


\section{A) Servicios Escolarizados}

Los servicios escolarizados son los Centros de Atención Múltiple (CAM) que ofrecen atención educativa a alumnos y alumnas desde 45 días de nacidos hasta 16 años de edad, que presentan necesidades educativas especiales asociadas a discapacidad múltiple, trastornos generalizados del desarrollo o que por la discapacidad que presentan requieren de adecuaciones curriculares altamente significativas y de apoyos generalizados y/o permanentes, a quienes las escuelas de educación regular no han podido integrar por existir barreras significativas para proporcionarles una atención educativa pertinente y los apoyos específicos para participar plenamente y continuar con su proceso de aprendizaje. Funcionan también los CAM laboral que ofrecen formación para el trabajo a alumnos de 16 a 20 años que presentan discapacidad y/o trastornos generalizados del desarrollo, que no logran integrarse al sistema educativo regular por diversas razones.

El objetivo del CAM es el de satisfacer las necesidades básicas de aprendizaje de los alumnos, con el fin de promover su autónoma convivencia social y productiva, mejorando su calidad de vida.

\section{1.- Organización}

Los CAM en el estado están conformados por un Director, equipo multidisciplinario y personal administrativo.

El equipo multidisciplinario esta compuesto por: Maestros de grupo, que atienden los niveles de educación inicial, preescolar y primaria, Psicólogo, Trabajador social, Maestro de comunicación, Maestro de enlace a la integración educativa, Terapista físico u ocupacional, Maestro de educación física, Maestro de educación artística y auxiliares educativos (niñera).

En cuanto al área de capacitación para el trabajo, el equipo multidisciplinario esta conformado por; Maestro de enlace a la integración educativa, instructores de taller y/o Maestros de formación para el trabajo, así como un Psicólogo $Y$ Trabajador social, esta conformación del personal docente y administrativo se realiza dependiendo de las características del servicio. 
La formación profesional del personal docente es diversa, como se puede observar en el siguiente tabla 1 que se elaboro con la información proporcionada por el departamento de educación especial en agosto 2007; La mayoría de los profesionales son maestros con formación de Licenciados en educación primaria, en segundo lugar se encuentran los psicólogos, en tercer lugar el numero de profesionales con formación de educación básica, es importante resaltar que los profesionales con formación en educación especial o en áreas de educación especial es menor que las demás, por ello la necesidades técnica de actualización y capacitación.

\begin{tabular}{|c|c|c|c|}
\hline \multicolumn{4}{|c|}{ Formación profesional del personal de CAM } \\
\hline Formación & № de personal & Formación & № de personal \\
\hline Educ. Básica & 36 & Lic. Educ. Primaria & 75 \\
\hline Lic. Educ. Preesc. & 26 & Lic.I. Educativa & 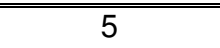 \\
\hline $\begin{array}{c}\text { Lic. Prob. } \\
\text { Aprendizaje }\end{array}$ & 11 & $\begin{array}{c}\text { Lic. Audición y } \\
\text { Lenguaje }\end{array}$ & 6 \\
\hline Lic. Disc. Intelectual & 8 & Lic. Disc. Motora & 3 \\
\hline Educ. Superior & 10 & Lic. Pedagogía & 11 \\
\hline Lic. Educ. Esp. & 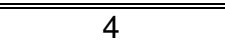 & Educ. Física & 11 \\
\hline Trabajo Social & 31 & Psicología & 43 \\
\hline Maestría & 6 & & \\
\hline
\end{tabular}

Tabla 1: Formación del Profesional del personal de CAM

Los CAM se encuentran ubicados en 18 comunidades del Estado, organizados por regiones, está distribución de los servicios se realiza dependiendo del diagnostico de necesidades de la población de alumnos con necesidades educativas especiales asociados con discapacidad múltiple, trastornos generalizados del desarrollo o que, por al discapacidad que presentan, requieren de adecuaciones curriculares altamente significativas y de apoyos generalizados y/o permanentes.

c) Niveles Educativos y Población que atiende 
Ofrecen educación inicial, preescolar y primaria, así como capacitación laboral y apoyo complementario, dependiendo de las características de la población y el contexto donde se ubica el servicio. Actualmente en el Estado de Chihuahua existen 25 Centros de Atención Múltiple que atienden diferentes niveles educativos, y 2 que atienden únicamente el área laboral en el Estado, para mayor información se elaboro una tabla, donde se puede consultar este aspecto ( Ver Anexo I).

* Educación Inicial

En el nivel de educación inicial de los CAM, se escolarizan alumnos desde 45 días de nacidos hasta los cinco años de edad, dependiendo de la intensidad de los apoyos que necesite y las características del alumno, se podrá integrar al cumplir tres o cuatro años de edad, a una escuela de educación regular o dentro del mismo servicio escolarizado o si requiere apoyos permanentes, continuara en el mismo nivel hasta los cinco años. La atención educativa en este nivel, se basa en la propuesta de Educación Inicial, elaborada por alguna de las instituciones encargadas de llevar acabo esta educación en el país, de ahí que se seleccionara la que mejor se ajuste a las necesidades y características de la población de alumnos que atiende se atienden.

\section{* Educación Preescolar}

En los CAM el nivel de preescolar atiende alumnos de tres a ocho años de edad. La atención educativa se basa en el programa de educación preescolar enriqueciéndolo con propuestas metodológicas y de evaluación específicas en la relación al tipo de población que se atiende, estableciéndose en la propuesta curricular del servicio.

\section{* Educación Primaria}

Educación primaria atiende alumnos de seis a diecisiete años de edad. La atención educativa, se basa en el plan y programas de educación primaria vigente, enriqueciéndolo con propuestas metodológicas y de evaluación especificas en relación a la población que se atiende en este servicio.

Al buscar preferentemente la integración de los alumnos en el CAM, de manera permanente se tiene la posibilidad de integrar parcial o totalmente, de acuerdo 
a la intensidad de los apoyos que requiera y de las características de los alumnos, pudiendo integrarse al a una escuela regular.

\section{* Formación para el Trabajo}

En la formación para el trabajo proporciona capacitación a jóvenes con discapacidad y/o con trastornos generalizados del desarrollo, ya que en algunas instancias que ofertan formación para el trabajo en el estado, aún no han logrado desarrollar los apoyos necesarios para la integración de estos jóvenes. La propuesta educativa se basa en implementar la propuesta de capacitación, que pueda adecuarse, dada las características de la población y a la estructura del CAM, o programas basados en competencias laborales, de ser necesario se pueden incluir aspectos específicos de habilidades adaptativas, sin perder de vista que la prioridad es facilitar el desarrollo de la autonomía y la integración social y laboral de los alumnos.

De igual manera, se integraran al sistema educativo regular, los alumnos que no requieren apoyos generalizados y permanentes.

\section{* Apoyo Complementario}

El apoyo complementario se proporciona a los alumnos, que presentan necesidades educativas especiales asociadas con discapacidad, que se encuentran integrados en una escuela de educación regular y que requieren apoyos específicos que la escuela regular o el servicio de apoyo no puede proporcionar como puede ser: Enseñanza de lenguaje de señas mexicana, o el sistema de comunicación alternativo, etc.

El personal del CAM mantiene una comunicación estrecha con las familias, así como con los maestros de grupo de la escuela regular y con el personal de servicio de apoyo, asesorando para que los contextos familiar y educativo promuevan la participación plena y el aprendizaje de los alumnos.

\section{B) Servicios de Apoyo}

\section{1.- Organización}

Los principales servicios de apoyo de la modalidad de Educación Especial son las Unidades de Servicios de Apoyo a la Escuela Regular (USAER). Su función 
es apoyar el proceso de integración educativa de los alumnos y alumnas que presentan con necesidades educativas especiales, prioritariamente de los que presentan discapacidad y/o aptitudes sobresalientes, en las escuelas de educación regular de los diferentes niveles y modalidades. Funcionan en vinculación con la escuela regular, promoviendo la eliminación de barreras y obstáculos, para el aprendizaje y la participación de los alumnos, realizando un trabajo de gestión escolar flexible, colaborativo, orientando permanentemente a los maestros, la familia y la comunidad educativa.

Los apoyos que ofrece este servicio, tiene la finalidad de lograr que la escuela regular adquiera elementos técnicos-pedagógicos, suficientes para dar respuesta autónoma a las necesidades educativas especiales, favoreciendo el proceso de integración educativa de los alumnos.

\section{a) Formación Profesional}

La formación profesional del personal es diversa como se puede observar en el siguiente tabla 2 que se elaboro con la información proporcionada por el departamento de educación especial en agosto de 2007. Observando que la mayoría de los profesionales tienen Licenciatura en educación primaria, en segundo lugar se encuentran los profesionales con formación de psicología, en tercer lugar están los que tienen formación de educación básica, y con un menor numero de profesionales los que han cursado estudios de alguna área de educación especial, por ello las necesidades técnicas de actualización y capacitación son mayores.

\begin{tabular}{|c|c|c|c|}
\hline \multicolumn{4}{|c|}{ Formación profesional del personal de USAER } \\
\hline Formación & № de personal & Formación & NNo de personal \\
\hline Educ. Básica & 87 & Lic. Educ. Primaria & 277 \\
\hline Lic. Educ. Preesc. & 42 & Lic.I. Educativa & 16 \\
\hline $\begin{array}{l}\text { Lic. Prob. } \\
\text { Aprendizaje }\end{array}$ & 33 & $\begin{array}{l}\text { Lic. Audición y } \\
\text { Lenguaje }\end{array}$ & 25 \\
\hline Lic. Disc. Intelectual & 8 & Lic. Disc. Motora & 0 \\
\hline Educ. Superior & 29 & Lic. Pedagogía & 12 \\
\hline Lic. Educ. Esp. & 6 & Educ. Física & 0 \\
\hline Trabajo Social & 74 & Psicología & 88 \\
\hline
\end{tabular}

Tabla 2: Formación Profesional del personal docente de USAER. 
En el estado funcionan 81 USAER del subsistema federal, que dan apoyo a las escuelas primarias regulares, generalmente y a educación secundaria en algunos casos, además existen USAER del subsistema estatal que atienden escuelas regulares de preescolar, primaria y secundaria.

c) Organización del Personal

El personal de un servicio de apoyo esta conformado por lo menos, por un Director, un equipo de apoyo integrado por; un Maestro de comunicación, un Psicólogo, un Trabajador social, y Maestros de apoyo, en algunas unidades existe Terapista físico, en la medida de lo posible, también participan especialistas de las diferentes discapacidades, si no se cuenta con ello, la USAER asume la responsabilidad de buscar los medios para ofrecer los apoyos necesarios, para la atención especifica de los alumnos que presentan discapacidad.

El supervisor de la zona escolar, es la figura de la cual depende directamente la USAER, de esta manera el supervisor, director, maestros de apoyo mantienen una estrecha relación con sus homólogos de educación regular, dado que es su principal campo de acción.

\section{d) Ubicación y Funcionamiento de USAER}

Las USAER se encuentran ubicadas en 25 comunidades del Estado, organizados por zonas o regiones, para mayor información se elaboro una tabla con esta información que se encuentra en el Anexo II. Está distribución de los servicios se realiza dependiendo del diagnostico de necesidades de alumnos con necesidades educativas especiales, principalmente asociadas a la discapacidad, que asisten a las escuelas de educación regular y que requieren el apoyo de educación especial. Para ello se revisa la información estadística de educación básica, específicamente el cuestionario 911 y el cuestionario de integración educativa.

Cada USAER apoya a 4 escuelas primarias regulares 0 más en algunas ocasiones, así mismo el maestro de apoyo acompaña a una o dos escuelas, dependiendo del número de alumnos con necesidades educativas especiales 
de cada escuela, mientras que el equipo de apoyo, se enfoca a la atención y apoyos específicos de los alumnos con discapacidad integrados, sus maestros y familias. El objetivo del apoyo que proporciona USAER, es eliminar barreras para el aprendizaje y participación de los alumnos, detectados en el informe psicopedagógico, especificándolos en la propuesta curricular adaptada. Durante cualquier periodo del ciclo escolar cuando alguno de los alumnos logra avanzar en la construcción de aprendizajes, de acuerdo a lo planeado en la propuesta curricular adaptada, el personal de apoyo termina el apoyo al maestro, a la familia o al alumno dependiendo del caso, por lo que se ofrece el apoyo a otros alumnos de esa misma escuela o de otra que lo requiera.

\section{C) Servicios de Orientación}

En el documento de Orientaciones generales para el funcionamiento de los servicios de Educación Especial (2006d), se establece que los Servicios de Orientación son los Centros de recursos e Información para la Integración Educativa (CRIIE), que ofrecen información, asesoría y capacitación al personal del Sistema Educativo Nacional, a las familias y a la comunidad en general, sobre las opciones educativas y estrategias de atención, para las personas con necesidades educativas especiales, prioritariamente las que presentan discapacidad $\mathrm{y} / \mathrm{o}$ aptitudes sobresalientes, también ofrece orientación sobre el uso de diversos materiales específicos, dando respuesta a las necesidades educativas de las personas que presentan discapacidad, de igual manera desarrolla proyectos de investigación que propicien la eliminación de barreras para el aprendizaje y la participación en las escuelas.

En el estado existen 3 servicios de orientación (CRIIE), ubicados en las comunidades de Ciudad Juárez, Chihuahua y Parral.

\section{1.- Organización.}

Los CRIIE están ubicados en los centros de maestros de cada una de las comunidades, con el objetivo de aprovechar los recursos de que dispone el centro y contribuir a la vinculación y articulación entre los servicios de 
educación regular y Educación Especial. Dependen técnica y administrativamente en este momento de la coordinación del Programa Estatal de Fortalecimiento de la Educación Especial y de la Integración Educativa de la Secretaria de Educación y Cultura del Estado de Chihuahua.

a) Organización del Personal

EI CRIIE esta conformado en la medida de los posible, por un coordinador, seis especialistas que den atención a las diferentes áreas de discapacidad intelectual, auditiva, visual, motriz, autismo y aptitudes sobresalientes, auxiliar administrativo y personal de intendencia, dependiendo de la demanda y de las necesidades del contexto o del área de influencia. Ya que las acciones que realiza el servicio de apoyo, están determinadas por las demandas de los usuarios, por las acciones de gestión implementadas, y por la vinculación que establecen los especialistas.

Para determinar la ubicación de los CRIIE en el estado, se toman en cuenta algunos criterios de la comunidad como son;

- Mayor accesibilidad y servicios públicos.

- Alta demanda de apoyos de educación especial

- No contar con servicios de educación especial

- Su zona de influencia puede beneficiar a usuarios de toda la región urbano marginal o rural. 


\subsection{La Formación Continua en Educación Básica}

La reforma educativa de 1992 en México, surge después de una aguda crisis de la Educación Básica. En esta reforma los primeros cuatro componentes fueron; la descentralización de los servicios educativos federales a las entidades federativas; la reforma de los planes y programas de estudio de Educación Preescolar, Primaria y Secundaria; el programa de reconocimiento a la labor del magisterio. De manera simultánea se planteo, un cambio organizativo en el sistema educativo nacional y una trasformación de los enfoques pedagógicos y propósitos de Educación Básica. Como la estructura de soporte, el programa de actualización docente buscó estrategias para difundir el enfoque pedagógico del currículum nacional; al mismo tiempo el programa de Carrera Magisterial estableció un escalafón horizontal, con el fin de favorecer la movilidad salarial de los maestros, sin que abandonen su labor en el aula.

En 1995 se agregaron varios elementos al programa de reforma. De esta manera inicio la formulación de iniciativas para trasformar la gestión de las escuelas de Educación Básica, todo ello a partir de la formulación e implantación del proyecto escolar. En este mismo periodo comenzó la reforma de Educación Especial, con la implantación del programa de Integración educativa. Otros programas dejaron de ser experimentales como el programa Red, una ventana al mundo, cuyo objetivo es la introducción, uso y manejo de las TIC en la Educación Básica. El programa de actualización del magisterio pasó de ser un programa emergente, a ser institucional con el Programa Nacional de Actualización de Profesores en Servicio (PRONAP).

En el 2000 se agregaron a la reforma otros programas como el programa Enciclomedia, que dotó de software y hardware a las aulas de quinto y sexto grado de la mayor parte de las escuelas de Educación Primaria del país. También el programa Escuelas de Calidad promovió nuevos enfoques de gestión escolar basados en la auto-evaluación y la participación de los padres de familia, en Educación Preescolar, Primaria y Secundaria. Dentro de estos programas participan los Centros de Atención Múltiple, como servicios escolarizados de Educación Especial. 
Además de estos y otros programas federales, los gobiernos de los Estados han implementado diversas iniciativas según su perspectiva local del desarrollo educativo.

El gobierno federal ha implementado nuevas reformas curriculares en específico, en la Educación Preescolar en el 2004 y en Educación Secundaria en el 2005, al amparo de un perfil de egreso de Educación Básica basadas en la idea de formación por competencias. Son muchos los cambios que se han producido con los programas de reforma, las escuelas se encuentran en un constante cambio y manejo de programas educativos. Ezpeleta (2003) establece que las escuelas, en consecuencia de tan amplio programa de cambios, se han encontrado en un permanente estado de reforma.

Las reformas del sistema educativo en el nivel de Educación Superior se ha realizado con el Programa para la Transformación y el Fortalecimiento Académico de las Escuelas Normales, existiendo nuevos planes de estudio para las licenciaturas de Educación Preescolar, Primaria, Educación Especial y Educación Física. De esta manera las licenciaturas del plan 1997 en Educación Primaria, la licenciatura en Educación Preescolar plan 1999 y la licenciatura de Educación Física del plan 2002, contemplan la asignatura de necesidades educativas especiales.

Es importante resaltar, en este momento, la licenciatura en Educación Especial del plan de estudios 2004, la cual pretende que el estudiante adquiera un conjunto de conocimientos, competencias, habilidades, actitudes y valores que le permitan ejercer su profesión como maestro de educación especial con calidad y con un compromiso. Dando respuesta educativa a las necesidades específicas que manifiestan los alumnos con discapacidad, así como a los que presentan necesidades educativas especiales relacionadas a otros factores.

\subsubsection{Asesoría Técnica Pedagógica}

El Plan Nacional de Desarrollo 2007-2012, establece en su eje 3, el objetivo de elevar la calidad educativa, por medio del reforzamiento de la capacitación de profesores, promoviendo su vinculación directa con las prioridades, objetivos y herramientas educativas en todos los niveles. En congruencia con este plan, el Programa General de la Formación Continua 2007-2008, pretende regular y 
mejorar los servicios de formación continua, ampliando las posibilidades de todas y todos los profesores, de acceder a una formación permanente de alta calidad, con el concurso de actores competentes interesados en contribuir a la actualización de los docentes, enmarcado en el Articulo $3^{\circ}$ Constitucional y la Ley General de Educación.

Para la capacitación y actualización de los maestros en servicio se han diseñado y desarrollado en los últimos años varias estrategias relacionadas a la atención de las necesidades educativas especiales. La Secretaria de Educación Básica en el año 2000, edito el seminario de actualización los profesores de Educación Especial y regular.

La Secretaria de Educación Publica (SEP, 2006a) informa que a partir del 2001 existe el examen del curso nacional de Integración Educativa, además de cursos generales y nacionales dirigidos a maestros de educación inicial, básica y especial, ofertados por el PRONAP, con el propósito de ofrecer técnicasmetodológicas para ofrecer una atención educativa a los alumnos con NEE, por ello se ofrecen talleres generales de actualización con temas relacionados a la atención de esta población. Además también existen más de 46 cursos estatales del programa de Carrera Magisterial para los docentes en servicio, en relación a la atención de alumnos con NEE, que se han elaborado en las 32 entidades del país.

De igual manera para apoyar a los maestros de Educación Inicial y Básica en el proceso de la integración educativa, la Dirección General de la Subsecretaria de Educación Básica también ha elaborado materiales como; colección de libros, videos, documento individual de adecuación curricular, recomendaciones para la escuela sobre el proceso de integración educativa, material didáctico específico para alumnos con discapacidad, etc.

Dentro de los programa de formación continua que existen para Educación Básica esta el programa formando formadores, es un esfuerzo conjunto de la Fundación Televisa, las Asociación de Bancos de México, representada por el programa Bécalos, así como de Excelencia Educativa A.C., el Tecnológico de Monterrey y la Secretaria de Educación, cuyo objetivo es ofrecer capacitación y actualización a profesores y directores de educación básica, para fortalecer sus competencias y habilidades, logrando una transformación en las escuelas. El contenido de los cursos ha sido desarrollado por el Instituto Mexicano para la 
Excelencia Educativa A. C. y el Instituto Tecnológico y de Estudios Superiores de Monterrey en la modalidad en línea. Durante el proceso de aprendizaje el participante cuenta con el apoyo de un profesor tutor especializado en los contenidos académicos. El programa de capacitación consiste, en una beca parcial para participar en los cursos en línea que conforman los diplomados (http://www.cca.org.mx/dds/formandoformadores ).

Las reformas que se han implementado en México, han sido diseñadas por el gobierno federal y su ejecución se ha realizado de manera vertical, desde el centro a la periferia. La Secretaria de Educación Publica (SEP) a implementado los distintos programas, señalando las estrategas, los tiempos y recursos a las entidades federativas, por medio de la estrategia en cascada, como se le conoce en México, de arriba abajo. El carácter cerrado y vertical de los elementos de la reforma, han marcado también la naturaleza de las innovaciones que se han pretendido introducir en el sistema educativo (Tapia, 2008).

En la estrategia de difusión e introducción de los elementos de la reforma, los equipos técnicos de la SEP, capacitan a los equipos técnicos estatales, estos a su vez informan y trasfieren la información a los directivos y miembros de las mesas técnicas del nivel educativo. La estrategia operativa es desarrollada por cada entidad, los equipos estatales y miembros de la mesa técnica, les dan capacitación a los asesores de Centros de Maestros, a los Supervisores escolares a los Asesores Técnicos Pedagógicos de los sectores y zonas escolares, según sea el caso. Estos a su vez informan a los directivos y a una mayor 0 menos parte de profesores frente a grupo, según el programa 0 aspecto del que se trate.

\subsubsection{La Asesoría Técnica en Educación Especial}

En la modalidad de Educación Especial del subsistema federalizado, en el Estado de Chihuahua, la asesoría técnica esta organizada por el equipo Estatales de Asesores Técnicos Pedagógicos (ATP), dependen directamente de la Subjefatura Académica, esta conformado por un asesor del área de comunicación, uno del área de psicología, uno del área de discapacidad motora, uno del área de trabajo social, uno del área de problemas del 
aprendizaje, uno del área de discapacidad visual, uno del área de discapacidad auditiva. La estrategia que utilizan es implementar procesos de capacitación y actualización a los Supervisores, Asesores Técnicos de Región o de zona escolar según sea el caso, así como a directivos y profesionales de los servicios de las 18 zonas escolares del estado. Por otro lado se encuentran los asesores regionales, que dependen de la coordinación de la región norte en ciudad Juárez y esta conformado por dos ATP, organizados en atender a los Supervisores, directores y profesionales de los servicios de educación especial de las 4 zonas escolares de esta región. Así mismo se encuentran los ATP de zona escolar, que dependen directamente del supervisor de zona, proporcionando capacitación y actualización a los directivos y profesionales de los servicios que conforman la zona escolar a la que pertenece. (Ver Anexo III). Estos elementos conforman un grupo reducido cautivo y a la vez disperso de ATP, el cual pese a ser reducido, no deja de ser complejo, dado que está presente esa amalgama de tradiciones educativas sobrepuestas que señala Latapí (2005), en donde aún algunas de las tradiciones no se han desaparecido y otras ya llegaron sin afianzar una en particular. Un abanico de formación profesional es de la que son portadores estos profesionales, van desde normal primaria, licenciatura, especialidad, pasantes de maestría y maestría.

En relación a la formación continua en Educación Especial el Programa Estatal de Fortalecimiento de la Educación Especial y de la Integración Educativa (SEC, 2005), en el objetivo de la línea 3 establece:

"Implementar y desarrollar programas de formación continua en relación con la atención de necesidades educativas especiales, aptitudes sobresalientes y la discapacidad, en el marco de la atención a la diversidad, dirigidos al personal de educación especial, inicial y básica en sus distintas modalidades, impulsar la ampliación de la oferta de formación inicial en el campo de la educación especial en la Entidad' ( $p$, 36).

Para el logro de este objetivo se pretende dentro de las metas, contar con un instrumento de planeación estratégica y operativa en cada uno de los servicios, fortaleciendo el trabajo académico de los Consejos Técnicos de los servicios, 
supervisiones y coordinaciones regionales, alcanzando el 100\%en el 2010, de igual manera establece actualizar anualmente el diagnostico de las necesidades de capacitación y formación continua del personal, diseñando una estrategia anual de capacitación y formación continua tomando en cuenta dicho diagnostico, identificando las necesidades de capacitación y formación continua en relación a la atención de las necesidades educativas especiales, principalmente las asociadas a la discapacidad y a aptitudes sobresalientes de los niveles de educación inicial y básica.

La SEP reconoce que el personal que realiza labores de apoyo técnico tiene el serio problema de que tiene un estatus indefinido, se le improvisa, se le releva constantemente y carece, en muchos de los casos, de preparación específica y competencias mínimas para llevar acabo la formación de los docentes en servicio (SEP.2003). Se reconoce, además que una parte importante del tiempo de los Asesores Técnicos Pedagógicos, adscritos a la supervisión y a las jefaturas de sector se dedican a labores de tipo administrativo y sólo de manera excepcional es destinado es destinado a atender las demandas de asesoría y acompañamiento académico a los maestros y escuelas (SEP, 2005). No se ha logrado construir las condiciones para los aprendizajes de los directivos y docentes, la transformación de sus saberes y sobre todo y lo más importante la transformación en sus prácticas. La administración educativa y sus formas de operación, no han desarrollado mecanismos ni criterios institucionales para realizar el seguimiento y la evaluación de sus acciones.

En el 2005 la SEP se planteó el problema de la ausencia de formación específica de asesoramiento y acompañamiento a las escuelas (SEP, 2005). Reconociendo que no existen programas sistemáticos para desarrollar competencias profesionales, que les permita realizar funciones específicas de asesoramiento a las escuelas. Sin embargo algunos programas formularon lineamientos para la implementación y operación del componente en las escuelas, demandando la actuación práctica de asesoramiento continuo, como en los programas de Integración Educativa, de lectura, de escuelas de Calidad y de Enciclomedia, en Educación Básica.

Con la propuesta de integración del Servicio de Asesoría Académica a la Escuela 2005 y la actualización de la reglas de operación del PRONAP en 
2007 se ha ido construyendo una noción distinta del quehacer, de las funciones y el rol del personal que realiza labores de asesor técnico pedagógico, dado que la concepción común es la de un técnico especialista o experto que domina determinados contenidos o habilidades en función de las puede o debe resolver los problemas que según su especialidad se le planteen y que actúa como reacción a las demandas, en individual, desde un modelo de intervención clínico. En la actualidad se reconoce al Servicio de Asesoría Académica como: "Conjunto de acciones, procesos y relaciones sistemáticas y coordinadas de las instancias y servicios que institucionalmente tienen facultad y responsabilidad de ofrecer apoyo técnico a la escuela" (SEP, 2007a).

Al personal de Apoyo Técnico Pedagógico se le define en las reglas de operación del PRONAP (SEP, 2007a) como:

"Especialistas con conocimientos y dominio de los propósitos educativos de los principios generales y de las bases legales que orientan y norman el Sistema Educativo Nacional en su conjunto, así como de las implicaciones de estos elementos en la enseñanza, en la organización y el funcionamiento cotidiano de la escuela en el nivel, grado y/o modalidad correspondiente"

Tapia (2008) informa que en el 2004 la oferta de acciones de formación para el asesoramiento, específicamente relacionada a equipos técnicos estatales y personal de asesores técnicos pedagógicos se planteo de manera formal, dado que la SEP formulo una iniciativa de ofrecer un paquete de autoformación para asesores técnicos pedagógicos con apoyo en línea, de la especialidad en asesoría pedagógica y procesos de formación continua de maestros de Educación Básica (SEBYN, 2004), o de la especialidad en Gestión y asesoría para la formación continua (SPF, 2006). De igual manera se desarrollo el Centro de Maestros Virtual, como una instancia de apoyo a la formación de asesores de los Centros de Maestros.

La situación de los ATP, al no contar con una línea de trabajo definida dentro de una política nacional, llevo a la SEP en el 2006 a desarrollar el diplomado de asesoría y acompañamiento académico a colectivos escolares, con el apoyo 
de la Organización de Estados Iberoamericanos (OEI), dirigido a personal de los equipos técnicos estatales y personal de ATP de varias entidades del país, entre ellos el Estado de Chihuahua, este diplomado se ha promovido por parte de la SEP con el apoyo de la Universidad Autónoma Metropolitana- Xochimilco en la ciudad de México en el 2007.

Por otro lado y dentro de esta misma línea de formación continua, se diseño la propuesta Orientaciones Generales para construir y operar el Servicio de Asesoría Académica a la Escuela (SEP, 2005) que pretende definir una política educativa, proponer institucionalmente la concepción y orientación del servicio, estableciendo los propósitos, contenidos y beneficiarios, las instancias que lo constituyen, su organización y sus implicaciones, planteando líneas de acción para la asesoría académica en la escuela.

En esta propuesta se considera necesario impulsar el apoyo técnico a las escuelas de educación básica, entre ellas las de educación especial, en el marco de la política educativa para mejorar la calidad y equidad porque:

- Las investigaciones educativas revelan que en muchos contextos el deterioro de la calidad de la educación básica esta asociada a diversos factores, entre ellos a la ausencia y debilitamiento del apoyo técnico a las escuelas.

- El apoyo técnico es una función propia de la gestión institucional, corresponde a todos los actores del sistema educativo apoyar a los centros escolares con el fin de que se cumplan los propósitos educativos establecidos en los planes y programas de estudios, sustentados en el Artículo $3^{\circ}$ constitucional de la Ley General de Educación, y en los lineamientos federales y estatales.

- Los servicios de apoyo externos a las escuelas, representan una instancia intermedia de enlace, para vincular a las autoridades educativas y sus políticas de formación continua con las escuelas.

- Cuando se trata de innovar y actualizar científica y didácticamente a los maestros, los servicios de ayuda externa son necesarios para realizarlos. 
- Los directivos y docentes requieren orientación profesional y crítica, oportuna, permanente y diferenciada, de referentes externos y cercanos, de acuerdo a los contextos, necesidades, experiencias y condiciones particulares de apoyo, para la mejora continua de la enseñanza y el aprendizaje.

\subsubsection{Sistema de Apoyo Técnico a la Educación Básica}

El Sistema de Apoyo Técnico a la Educación Básica es una de sus fortalezas del Sistema Educativo Mexicano, debido a que esta conformado por instancias, como los centros de maestros, los equipos y mesas técnicas y la supervisión escolar; por servicios como la formación continua de la integración educativa, de de atención intercultural y bilingüe, educación artística y educación física; procesos como los de información, y comunicación, los de seguimiento, evaluación y control escolar, y los de apoyo y orientación; también forma parte los recursos humanos, y los materiales de apoyo a la enseñanza, las herramientas de la tecnología, información y comunicación entre otros.

Algunas de las características del Sistema de Apoyo Técnico a la Educación Básica son (SEP, 2005):

- Se obstaculiza la comunicación y el trabajo colaborativo debido a que funciona a través de estructuras rígidas y relaciones jerárquicas.

- Las acciones que realiza son generales y homogéneas frecuentemente, que son definidas y diseñadas a nivel central, por lo que no siempre responde a las necesidades de apoyo heterogéneas de cada plantel, zona escolar o región.

- Se dificulta la formación de las nuevas competencias de directivos y docentes, al llevar acabo acciones masivas en periodos cortos de tiempo.

- Las acciones se realizan a través de las estructuras jerárquicas del sistema educativo, dificultando la participación democrática, informada y convencida de directivos y docentes.

- La mayoría de las acciones las dirige de manera individual, limitando el impacto en las actuaciones de los colectivos escolares. 
- Los apoyos se realizan en la enseñanza, el aprendizaje y el trabajo en el aula, por lo que no siempre afectan la calidad de la educación.

- Suelen hacer duplicidad de acciones, ofreciendo apoyos y servicios que suelen empalmarse en los planteles, ocasionando confusión sobre sus beneficios y propósitos.

- Las acciones y recursos se concentran en los medios urbanos, a pesar que los planteles de los contextos desfavorables enfrentan muchos y graves problemas de enseñanza y aprendizaje.

- El servicio de apoyo técnico no cuenta con mecanismos ni criterios institucionales para realizar el seguimiento y la evaluación de sus acciones, específicamente sobre el impacto en la práctica educativa de directivos y docentes.

- No se dispone de la normatividad, condiciones y mecanismos institucionales necesarios para un buen funcionamiento.

- No cuenta con criterios institucionales para la selección, permanencia, distribución y formación del personal de apoyo técnico.

- No existe un programa sistemático para fortalecer profesionalmente al personal de apoyo técnico, con el propósito de hacer frente a los nuevos cambios educativos, desarrollando las competencias necesarias, aun y cuando cuenta con un buen número de personal.

El funcionamiento actual de la asesoría técnica tiene que ver directamente con la organización y el funcionamiento del mismo sistema educativo, y a la falta de políticas y orientación que permita definir su sentido y el enfoque.

De acuerdo a la evaluación y análisis que se realizo de la asesoría técnica en Educación Básica, se propone la regulación y profesionalización del apoyo técnico mediante la constitución y operación del Servicio de Asesoría Académica a la Escuela, para iniciar la transformación del servicio de asesoría técnica de educación básica, en un servicio especializado y permanente de asesoría y acompañamiento académico para los maestros y las escuelas.

Las orientaciones y lineamientos de la política educativa que fundamentan la nueva visión, así como las bases legales y principios de la educación en México, son (SEP, 2005): 
Equidad del servicio; Considerando las diferencias de las circunstancias de los contextos institucionales y sociales, permitiendo que cada centro pueda mejorar desde sus propias capacidades y condicionamientos, de manera diferenciada.

Participación democrática; Participación democrática de quienes constituyen la comunidad de profesionales de la educación, además de las instancias de formación continua, colectivos escolares y docentes.

Carácter formativo; Se pretende asistir a los centros escolares, para brindar ayudas pertinentes y útiles, que permitan analizar la realidad educativa de cada institución, que permita favorecer la toma de decisiones para mejorar.

La escuela es considerada como el centro de las decisiones, El objetivo del Servicio de Asesoría Académica a la Escuela, es apoyar a los maestros y colectivos escolares para que se cumpla con la misión fundamental que es que todos los niños y jóvenes de educación básica alcancen en el tiempo designado los propósitos establecidos en los planes y programas.

En este sentido Bolivar (1999) delimita tres grandes estrategias de la función del asesor en los procesos de formación/innovación centrada en la escuela:

a) Trabajar "con" en lugar de intervenir "en". En la asesoría un estilo tradicional de la intervención ha sido, en muchos de los casos en forma clínica, dependiendo del supuesto de que la innovación curricular proviene de un experto en contenidos que aporta recetas externas. Al contrario, desde la perspectiva de la escuela como centro de cambio, el asesor se dirige en una relación de colaboración en el trabajo "con" las escuelas, partiendo de un análisis de sus necesidades y opciones de mejora, ofrecer herramientas y procesos de permitan la capacitación de los propios docentes mejorando lo que hacen. La colaboración implica la creación de una relación de igualdad entre asesores y profesores, propiciando la comunicación, provocando una reflexión conjunta de la situación, deliberando de manera conjunta sobre la situación y sobre las decisiones.

b) Más que aplicar, desarrollar. El asesoramiento puede realizarse queriendo mejorar la acción educativa por la aplicación de programas o 
propuestas externas, en este caso la asesoría se reduce a posibilitar la aplicación de programas o curriculum oficial en cada institución, interesando la fidelidad de su propuesta en la práctica, o por el contrario orientarse al desarrollo del curriculum por las escuelas, como un proceso que de solución a los problemas, donde la labor del asesor puede contribuir a que el establecimiento docente sea la unidad básica de formación/innovación, en relación a propiciar procesos de reflexión sobre la práctica.

c) Función de mediación/enlace. También el asesor es un elemento mediador entre el conocimiento pedagógico disponible, las prácticas y conocimientos profesionales de los profesores. Su función es de enlace principalmente, entre el conocimiento acumulado sobre determinados ámbitos y los profesionales que trabajan en él, implica reconocer, por un lado, propuestas, contenidos, o procesos que potencialmente pudieran contribuir en la resolución de problemas, por otro lado, las necesidades, capacidades, contextos de uso, etc., del profesorado de las escuelas. Se pretende de esta manera apoyar y facilitar el proceso de desarrollo currricular, a nivel de establecimiento educativo y de modo cooperativo con los profesores, aportando respuestas concretas para los problemas detectados, en lugar de ofrecer de manera clínica el diagnóstico de los problemas.

Es importante reconocer a los centros como una unidad educativa con propósitos y metas comunes que se establecen por consenso, así como estilos de trabajo articulado y congruente, con propósitos y reglas en la comunidad escolar. Como una unidad básica de cambio que valora el trabajo profesional de los maestros, así como sus demandas y necesidades.

No es sólo que los ATP dominen la legislación educativa, los enfoques y contenidos de los planes y programas, los procesos de de gestión escolar o de la práctica docente, va más allá, es indispensable que al ATP lo que lo defina sea un cúmulo básico de saberes y capacidades de actuación profesional, centrada en su labor de asesoramiento. Tener la capacidad de ver, juzgar y actuar conforme a las necesidades de los profesores, teniendo la posibilidad de asumir diversos roles y conseguir conocimientos diversos sobre la innovación y 
el cambio en la escuela y en las prácticas docentes. Esto a fondo implica, al mismo tiempo, que la asesoría no se quede sólo en la introducción o difusión en cursos de capacitación, talleres, etc., de los elementos de la reforma, sino que verdaderamente se realicen intercambios continuos, acompañamientos constantes, investigaciones, innovaciones, etc., a los Supervisores, Directores, profesores y demás profesionales. Tapia (2008) lo plantea como asumir el desafío de transitar de un modelo dominante de asesoramiento centrado en contenidos a un asesoramiento centrado en procesos.

La asesoría técnica pretende, contribuir a potenciar la capacidad de los propios servicios, para resolver los problemas de la práctica educativa, planteando una relación de cooperación con los servicios y los profesorados, habilitando a los maestros para convertirse en fuentes de conocimiento de otros actores educativos y la oportunidad de aprender a ser colegas y estudiantes, es uno de los muchos retos que demanda el nuevo modelo de formación continua, un reto que contempla también la propuesta de generar conocimientos compartidos basados en problemas de la práctica, y que además le brinde a los docentes un amplio rengo de oportunidades que los lleve a compartir lo que saben, así como aplicar lo que han aprendido en los distintos contextos de enseñanza. 


\section{INVESTIGACIÓN}

\section{CAPÍTULO 3: DISEÑO DE LA INVESTIGACIÓN}

En este capítulo vamos a describir el diseño de la investigación que hemos realizado.

En primer lugar examinaremos el tipo de investigación en el que se encuadra y el proceso de desarrollo de la misma. Dicho proceso se ha proyectado en ocho pasos: 1) Identificación del problema y diagnostico, 2) Formulación de las hipótesis, 3) Planificación de las estrategias, 4) Instrumentos de obtención de la información, 5) Recogida de datos, 6) Análisis e interpretación de datos y resultados, 7) Confirmación o refutación de hipótesis, 8) Conclusiones y propuestas de futuras investigaciones.

Las fases de planificación, implementación y evaluación que se realizaron a lo largo del proceso de investigación, se presentan en ocho pasos:

1. El primer paso consiste en la identificación del problema por medio de los instrumentos apropiados y la formulación del diagnostico.

2. En el segundo paso se desarrolla una propuesta de solución y en base a ésta se elaboran las hipótesis que se pretenden demostrar. La propuesta de solución es el uso de las TIC en la asesoría técnica, una propuesta de mejora y optimización de la asesoría técnica en Educación Especial en el Estado de Chihuahua México.

3. El tercer paso es la planificación de las estrategias que se van a emplear en la implementación del tratamiento que se diseñe. En la presente investigación sobre la propuesta de mejora es la utilización de las TIC en la asesoría técnica, como una propuesta de optimización de la asesoría y capacitación técnica, para lo cual se hace necesario conocer los planteamientos de la política educativa de Educación 
Especial en relación a las TIC, así como el contexto técnico pedagógico y operativo.

4. Diseñar y evaluar la propuesta para mejorar y optimizar la asesoría y capacitación en Educación Especial a través de la implementación de un recurso digital accesible a través de internet.

5. El quinto paso corresponde a la recogida de datos mediante los procedimientos de evaluación e investigación planificados, para lo cual se utilizaran procedimientos cualitativos y cuantitativos. De esta manera además de utilizar la estrategia del análisis de contenido, se aplicarán encuestas a los diferentes profesionales de Educación Especial, tanto del contexto como sobre el diseño del recurso digital.

6. Análisis e interpretación de los datos y los resultados obtenidos en el análisis de contenido de los documentos revisados, las encuestas aplicadas para conocer las dificultades del funcionamiento de los servicios, la evaluación del diseño del recurso digital y de la utilidad del mismo por los usuarios de los servicios.

7. A la vista de dichos datos, el siguiente paso corresponde confirmar o refutar la hipótesis que se planteó ante el problema diagnosticado.

8. Por ultimo, se elaboran las conclusiones que el proceso genera, haciendo una reflexión sobre los anteriores elementos del proceso y proponiendo futuras investigaciones que se pueden inferir del desarrollo de la propia investigación o de los resultados obtenidos.

Estos ocho pasos se representan en el diagrama de la siguiente figura 26 
1) Identificación del problema

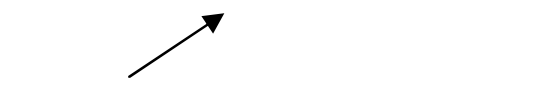

8) Conclusiones y propuesta de

Futuras investigaciones.

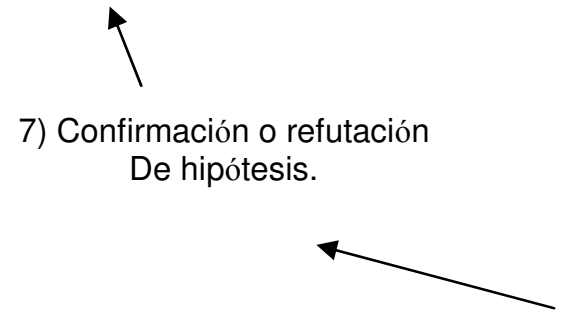

2) Hipótesis

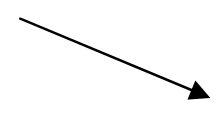

3) Planificación de estrategias.

4) Desarrollo e implementación

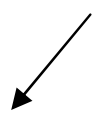

5) Recogida de datos.

6) Análisis e interpretación de datos

$Y$ resultados.

Fig. 26 Pasos de la Investigación.

A continuación desarrollaremos los cuatro primeros pasos de la investigación.

\subsection{Desarrollo de la Investigación}

Los métodos de investigación constituyen el camino para llegar al conocimiento científico, son un procedimiento o conjunto de procedimientos que sirven de instrumento para alcanzar los fines de la investigación. Al respecto Coller (2000) plantea que la metodología más adecuada debe de ser aquella que nos posibilite conocer mejor la realidad estudiada, con el propósito de abordar el problema de investigación y lograr los objetivos que se han planteado.

Según Sabariego y Bisquerra (2004), hacer investigación educativa es aplicar el proceso organizado, sistemático y empírico que establece el método científico, con el fin de comprender, conocer y explicar la realidad, como una base para construir la ciencia y desarrollar el conocimiento científico de la educación. La investigación que se plantea en este trabajo tiene un doble carácter cuantitativo y cualitativo, utilizando diversas técnicas de recogida de información, por lo que se incluyen (Cuestionarios, encuestas, análisis de documentos). 
En está investigación se ha tratado de implementar una Propuesta de mejora y optimización de la Asesoría y Capacitación, con el uso de las TIC, en la Educación Especial.

A lo largo de la investigación los aspectos fueron variando sistemáticamente depurando, integrando y modificando elementos, según las reflexiones, necesidades e inquietudes que fueron apareciendo.

Tomando como punto de partida el objetivo de la investigación, se utilizo el método de investigación descriptivo basado en una metodología cuantitativa, que de acuerdo a Sabariego y Bisquerra (2004), tiene el propósito de describir situaciones, eventos y hechos, en un contexto determinado. Para la investigación cuantitativa describir consiste en medir y evaluar los conceptos o las variables que se pretenden investigar de manera conjunta o individual, y cómo se relacionan estas variables.

Por otra parte se ha apostado por la metodología cualitativa, basada en la Teoría Fundamentada, que de acuerdo a Sabriego, Massot y Dorio, (2004) es uno los principales métodos orientados a la comprensión, su principal finalidad es la de construir teorías, conceptos, hipótesis y proposiciones directamente de los datos, para explicar la realidad.

El diseño de la investigación, por una parte, es exploratorio descriptivo. Es exploratorio porque pretende familiarizarse con el problema de investigación para después deducir que aspectos requieren un análisis pormenorizado en investigaciones posteriores, así como también verificar la factibilidad de la investigación y los medios que se requieren para hacerla, comprobar también qué estrategia o estrategias son las más adecuadas para su análisis, probando anticipadamente alguna o varias estrategias de investigación.

Por otra parte, se ha tratado de implementar a través de una propuesta de mejora, algunos recursos para incidir en el perfeccionamiento de la realidad detectada. 


\subsubsection{Planificación del trabajo}

En la planificación desarrollaremos los distintos pasos del procedimiento que tienen relación con esta investigación. También analizaremos aspectos circunstanciales, influyentes y que se destacan a lo largo de la planificación. De esta manera, se abordará, en un primer lugar la identificación del problema y las soluciones planteadas, a continuación se abordarán algunas de las variables que influyen en el desarrollo del proceso.

\subsubsection{Identificación del problema de estudio y diagnóstico de la situación actual.}

Los esfuerzos de las personas con discapacidad, de sus familias, de las agencias que los apoyan, de los maestros y maestras, del personal de Educación Especial, han promovido cambios en las actitudes sociales, en la legislación, en las oportunidades para el trabajo y en la educación. Sin embargo, de acuerdo al Programa Nacional de Fortalecimiento de la Educación Especial y de la Integración Educativa (SEP, 2002) la formación inicial y la actualización del personal de Educación Especial deben estar encaminadas a dar una respuesta educativa adecuada a las necesidades específicas que presentan los niños, las niñas y los jóvenes con discapacidad, así como a aquellos que presentan necesidades educativas especiales derivadas de otros factores. En relación a esto, el Programa Estatal de Educación del Estado de Chihuahua 2005-2010 identifica como una de las áreas de oportunidad en relación con la atención a las necesidades educativas especiales, en los Servicios de Educación Especial y la Integración Educativa, la necesidad de promover la actualización de los docentes, para mejorar la atención que proporcionan en los servicios.

También se considera necesario la actualización de los docentes de educación inicial, preescolar, primaria y secundaria, con el propósito de que desarrollen competencias en relación con la educación de los niños y jóvenes con necesidades educativas especiales.

En relación a la formación continua, la SEP reconoce que el personal que realiza labores de apoyo técnico tiene el serio problema de poseer un rol 
indefinido, se improvisa, se le releva constantemente y carece, en muchos de los casos, de preparación específica y competencias mínimas para llevar a cabo la formación de los docentes en servicio (SEP.2003). Se reconoce además que una parte importante del tiempo de los Asesores Técnicos Pedagógicos (ATP), adscritos a la supervisión y a las jefaturas de sector se dedican a labores de tipo administrativo y sólo de manera excepcional es destinado a atender las demandas de asesoría y acompañamiento académico a los maestros y escuelas (SEP, 2005). Por lo que no se han logrado construir las condiciones para los aprendizajes de los directivos y docentes, la transformación de sus saberes y, sobre todo lo más importante, la transformación en sus prácticas. La administración educativa y sus formas de operación, no han desarrollado mecanismos ni criterios institucionales para realizar el seguimiento y la evaluación de sus acciones.

En 2005 la SEP se planteó el problema de la ausencia de formación específica de asesoramiento y acompañamiento a las escuelas (SEP, 2005), reconociendo además que no existe una programación sistemática para desarrollar competencias profesionales, que les permita realizar funciones específicas de asesoramiento a las escuelas.

En la modalidad de Educación Especial, el Programa Estatal de Fortalecimiento de la Educación Especial y de la Integración Educativa (SEC, 2005), en relación a la formación continua, establece en el objetivo de la línea 3:

"Implementar y desarrollar programas de formación continua en relación con la atención de necesidades educativas especiales, aptitudes sobresalientes y la discapacidad, en el marco de la atención a la diversidad, dirigidos al personal de Educación Especial, inicial y básica en sus distintas modalidades, impulsar la ampliación de la oferta de formación inicial en el campo de la Educación Especial en la Entidad" (p.36).

Para el logro de este objetivo se pretende dentro de las metas, contar con un instrumento de planeación estratégica y operativa en cada uno de los servicios, fortaleciendo el trabajo académico de los Consejos Técnicos de los servicios, supervisiones y coordinaciones regionales, alcanzando el 100\% en el 2010. De 
igual manera pretende actualizar anualmente el diagnostico de las necesidades de capacitación y formación continua del personal, diseñando una estrategia anual de capacitación y formación continua tomando en cuenta dicho diagnostico, identificando las necesidades de capacitación y formación continua en relación a la atención de las necesidades educativas especiales, principalmente las asociadas a la discapacidad y a aptitudes sobresalientes de los niveles de educación inicial y básica.

En este sentido es necesario potencializar el uso de las Tecnologías de la Información y la Comunicación en el ámbito de la Educación, específicamente en la formación continua, dado que presentan cambios vertiginosos evidentes en nuestra sociedad, y su difusión nos conduce a importantes reformas y mejoras en la calidad de vida de las personas. Al respecto Chacón (2007) plantea que las TIC son también parte integral de la educación, y que su inclusión y uso en este campo permitirá agilizar la divulgación de los hechos, así como también compartir y usar nuevos métodos y estrategias didácticas, así como intercambiar experiencias.

Uno de los antecedentes en relación a la formación continua en México es la incorporación de las TIC a los procesos educativos, ha sido una preocupación constante de la Secretaria de Educación Publica, una muestra de ello es haber considerado este aspecto entre las líneas de política educativa desde 1995 y haber impulsado varias acciones en este campo, como la creación de la Red Escolar, a través del Instituto Latinoamericano de Comunicación Educativa (ILCE). La Coordinación General de Actualización y Capacitación de Maestros, encargada del Programa Nacional para la Actualización Permanente de Maestros en Servicio (PRONAP), elaboró en 1999 una propuesta piloto para utilizar las TIC dentro de la actualización, a través del proyecto Centro de Maestros Virtual, diseñando una página web con el apoyo del ILCE. En mayo del 2000 se montó en un servidor del ILCE la página PRONAP en línea http://pronap.ilce.edu.mx/ , la finalidad es ofrecer a los asesores, directivos, personal de apoyo técnico-pedagógico y maestros de educación:

- Información: Datos generales y específicos sobre el PRONAP (programas de estudio, Centros de Maestros, exámenes nacionales y materiales de apoyo). 
- Actualización y capacitación: Opciones de actualización en línea, etc.

- Asesoría y seguimiento: Posibilidades de diálogo, a través del correo electrónico, para solicitar información, compartir experiencias, plantear necesidades, etc.

- Promoción de materiales: Acercamiento y manejo cotidiano de los acervos publicados por la SEP para profesores de educación básica, como materiales de apoyo, la Biblioteca de Actualización, las series de videos y material multimedia, etc.

Es importante resaltar que las investigaciones realizadas sobre las TIC en la modalidad de Educación Especial en el Estado de Chihuahua son casi nulas y, dado que con relación a las TIC, solamente se ha implementado el Programa de Enciclomedia a partir de este ciclo escolar 2006-2007, en servicios escolarizados de Educación Especial, diseñado para el nivel de educación primaria, con ello se ampliaron las necesidades de actualización y capacitación del personal docente de Educación Especial, en las áreas especificas de las diferentes discapacidades, de los aspectos del currículo y la utilización de las TIC como tecnologías de ayuda en estas áreas.

El Programa Sectorial de Educación 2007-2012 establece en su objetivo 1: "Elevar la calidad de la educación para que los estudiantes mejoren su nivel de logro educativo, cuenten con medios para tener acceso a un mayor bienestar y contribuyan al desarrollo nacional" (p.13).

En Educación Básica se pretende, dentro de sus estrategias, por un lado experimentar e interactuar con los contenidos educativos incorporados a las TIC, así mismo identificar las necesidades de formación continua y superación profesional de los docentes, y de esta manera poner en marcha un programa de capacitación de docentes para la atención adecuada de las innovaciones curriculares, de gestión y especialmente del uso de las TIC. Se pretende concretar una plataforma de servicios de formación continua para los equipos técnicos estatales, asesores y docentes en servicio, así como una oferta de opciones a distancia, mediante el uso de las TIC en todo el país. 
Uno de los aspectos que tienen que ver con la calidad de la asesoría y capacitación técnica es que la Educación Especial en el Estado de Chihuahua, esta conformada por 19 zonas escolares distribuidas en 28 diferentes comunidades, urbanas, urbano marginadas y rurales, lo que dificulta al equipo de asesores técnicos del Estado la atención a los profesionales en lo referente al seguimiento, actualización y /o capacitación de las necesidades planteadas y detectadas. Con esta propuesta de uso de las TIC se pretende que se aprovechen las ventajas de información, comunicación, etc., que se pueden obtener con los recursos digitales de la red.

Este trabajo plantea la importancia de desarrollar una propuesta para mejorar y optimizar la asesoría técnica en la modalidad de Educación Especial a través del uso de las TIC, dadas las necesidades de actualización y capacitación en esta modalidad para lograr impactar en la calidad de la educación de los niños niñas y jóvenes con necesidades educativas especiales prioritariamente asociadas a la discapacidad.

A continuación se presenta una descripción pormenorizada de los objetivos pretendidos, así como las hipótesis, la muestra y los instrumentos para llevar a cabo este trabajo.

\subsubsection{Objetivos}

Los objetivos de esta investigación tienen la finalidad de señalar lo que se pretende y a lo que se aspira en el desarrollo de esta investigación (Sabariego, 2004).

\section{Objetivo General}

- Desarrollar una propuesta de mejora y optimización de la Asesoría Técnica en la modalidad de Educación Especial en el Estado de Chihuahua México, a través del uso de las TIC. 


\section{Objetivos Específicos}

- Analizar el contenido de los documentos oficiales (leyes y programas educativos) sobre el uso de las TIC en Educación Especial.

- Analizar el contexto de la modalidad de Educación Especial en relación a los aspectos técnico-operativos, así como el impacto de la capacitación y actualización de la asesoría técnica.

- Analizar los recursos digitales disponibles en la red orientados al área de actualización y/o capacitación de los docentes de Educación Especial.

- Diseñar un recurso digital accesible a través de la red, como propuesta de apoyo en la actualización y capacitación de la Asesoría Técnica Pedagógica, a los docentes de la modalidad de Educación Especial.

- Implementar el recurso digital en la modalidad de Educación Especial como un apoyo en las acciones de asesoría y capacitación a los Supervisores, Directivos, Docentes y Equipos de Apoyo.

- Evaluar y realizar el seguimiento de la implementación y uso del recurso digital propuesto.

- Analizar los resultados obtenidos a partir del el uso de las TIC en la Asesoría Técnica de Educación Especial en relación a la actualización y capacitación del personal docente.

Tanto el objetivo general como los específicos que son expuestos, están referidos y situados en la modalidad de Educación Especial del subsistema federalizado del Estado de Chihuahua en México. 


\subsubsection{Hipótesis}

Una vez que ha quedado definido el problema y analizado las posibles soluciones, es el momento de formular las hipótesis que propongan una respuesta anticipada al problema, basándonos en los conocimientos que se tienen sobre los aspectos técnicos, operativos, de formación continua etc., de la Educación Especial y sobre el uso de las TIC en la educación y específicamente en la Educación Especial.

Sabariego (2004) establece que las hipótesis son preposiciones generalizadas o afirmaciones comprobables, que se formulan como posibles soluciones de problemas, ofrecen una explicación posible o provisional que toma en cuenta los factores, sucesos o condiciones que el investigador procura comprender.

En este sentido, dada la naturaleza de los hechos objeto de estudio, nos proponemos comprobar el grado de verificación que cumplen las siguientes hipótesis:

1. El uso de las TIC están desaprovechadas, es mínima la utilización que se les da para realizar la actualización y capacitación del personal docente de Educación Especial.

2. Los documentos oficiales que enmarcan la Política Educativa de Educación Especial, plantean el uso de las TIC con finalidades educativas.

3. Los recursos digitales disponibles no se utilizan por falta de conocimiento de los docentes.

4. Los recursos digitales son un buen elemento para la actualización y capacitación.

5. El uso adecuado de los recursos digitales en red apoya las acciones de asesoría y capacitación.

6. El uso adecuado de las TIC proporciona una asesoría técnica de mayor calidad. 
Las variables que forman parte en esta investigación son:

Variables intervinientes:

- Características propias del recurso digital

- Elementos contextuales.

- Aspectos técnicos operativos de los docentes en los diferentes niveles de responsabilidad.

En esta metodología se trata de controlar los efectos de la variable independiente, como en este caso es:

- Las estrategias metodológicas implementadas para el uso del recurso digital.

Sobre la dependiente que son:

- el uso del recurso digital,

- la satisfacción por parte de los docentes,

- habilidades en cuanto al aprendizaje autónomo y colaborativo,

- actitud para la actualización y capacitación y el uso de herramientas tecnológicas y

- la calidad de la asesoría técnica.

\subsubsection{Planificación de los procedimientos de intervención.}

Una vez establecidas las hipótesis se plantean los procedimientos a seguir en la intervención, de acuerdo a las siguientes orientaciones metodológicas:

a) Análisis de la Política Educativa del Estado de Chihuahua, sobre el uso de las TIC en la modalidad de Educación Especial de 1996 a 2010, por medio de la técnica de análisis de contenidos.

b) Análisis del contexto técnico operativo y de capacitación y actualización, de la modalidad de Educación Especial del subsistema federalizado del Estado de Chihuahua, a través de la técnica de la aplicación de una encuesta. 
c) Diseño, aplicación y evaluación de un recurso digital en red como propuesta para mejorar y optimizar la asesoría y capacitación técnica, en la modalidad de Educación Especial.

Como uno de los primeros pasos, se realizaron lecturas y selección de los documentos bibliográficos, se fueron resaltando aspectos importantes relacionados al tema, dichos aspectos se fueron organizando para ir conformando el marco teórico, contextual y referencial.

Después de tener la selección de los documentos bibliográficos, pasamos a seleccionar los documentos que tenían que ver directamente con la Política Educativa en el Estado, durante el periodo de 1996 a 2010, que es donde está establecida la normatividad técnica y operativa de la Educación Especial, encontrando programas educativos de nivel nacional y estatal, así como leyes que rigen la educación a nivel nacional y estatal. De igual manera se seleccionaron las leyes para las personas con discapacidad nacional y estatal, con la finalidad de investigar sobre los planteamientos de la utilización de las TIC en la Educación Especial, utilizando la técnica de Análisis de Contenido.

Tal como se ha manifestado en las hipótesis planteadas, suponemos que sí esta establecida, en la Política Educativa de la modalidad de la Educación Especial, el uso de las TIC. De ahí la importancia que damos al análisis de este aspecto.

Como siguiente paso se decidió que era necesario conocer el contexto de la modalidad de la Educación Especial, específicamente el funcionamiento técnico operativo de los diferentes servicios, al igual que la población profesional que se desempeña en ella, la organización y necesidades en cuanto a asesoría y capacitación, dado que es el contexto especifico donde se plantea la presente investigación, para lo cual se diseñó y aplico una encuesta.

El diseño de un recurso digital, fue la continuación de este trabajo de investigación. Se diseño una página web cuyo nombre es Departamento de Educación Especial de los Servicios Educativos del Estado de Chihuahua, con el programa Macromedia Dreamweaver.

Se hizo necesario, dada que era la primera experiencia que se tenia en este sentido, que el diseño del sitio web fuera evaluado en un primer momento por 
expertos en TIC y en Educación Especial, seleccionando y adecuando una ficha para la catalogación de portales educativos.

Por ultimo se planeo la evaluación final de la utilidad del sitio web, consistiendo al igual que la anterior, en al selección y adecuación de la ficha de Catalogación de Portales Educativos, misma que se aplico a una muestra de los profesionales de la modalidad de Educación Especial en el Estado.

En las hipótesis planteadas creemos que los recursos digitales son un buen elemento para la asesoría y capacitación técnica, usándolo adecuadamente proporciona una asesoría de mayor calidad.

\subsubsection{Muestras e Instrumentos utilizados}

La consecución de los objetivos propuestos y la comprobación de las hipótesis que se formularon, hicieron necesario una selección exhaustiva de la muestra con la que íbamos a trabajar.

Por tanto, resultó prioritario planificar sistemáticamente las fases y pasos en que se iba a desarrollar todo el proceso empírico.

En primer lugar fue necesario determinar los campos y variables objetos de estudio, la delimitación de la población relacionada con dichos campos y la creación o búsqueda de instrumentos de recogida de información, al tiempo que se iniciaba el estudio teórico.

Una vez definido el diseño, podría iniciarse el trabajo pormenorizado de obtención y estudio de datos para llegar a la elaboración de las conclusiones.

\section{Delimitación de la población y muestra}

Para cada una de las fases de la investigación se elaboraron y seleccionaron muestras e instrumentos específicos que mas adelante especificamos, partiendo del objeto de estudio. La aplicación no ha sido simultánea, sino sucesiva, dado que la información obtenida en el primer momento es previa e imprescindible para delimitar el segundo. 
A continuación se presenta cómo ha sido el proceso en relación a la población y muestra, de cada una de las fases que conforman la investigación.

\subsection{Análisis de la Política Educativa del Estado de Chihuahua México, sobre el uso de las TIC en la modalidad de Educación Especial, de 1996 a 2010.}

Las TIC representan un hecho de gran importancia dada su influencia en los cambios que se van generando en nuestra sociedad día con día, su difusión nos conduce a importantes reformas y mejoras en la calidad de vida de las personas. En este sentido en México, dentro de la Política Educativa que fundamenta el quehacer técnico operativo de la modalidad de Educación Especial, se establecen las bases para la integración educativa y la inclusión de las personas con discapacidad, en un marco de igualdad y equiparación de oportunidades en todos los ámbitos de la vida, por ello es importante investigar si en su fundamentación y operatividad se contempla el uso de las TIC dentro de esta Política Educativa, de tal manera que contribuyan al desarrollo integral del ser humano, potenciando sus capacidades, habilidades y aptitudes, permitiendo habilitar, rehabilitar o compensar una o más limitaciones fusiónales, motrices, sensoriales 0 intelectuales de las personas con discapacidad.

En el ámbito educativo son especialmente importantes todas las ayudas técnicas que permitan a los estudiantes acceder y participar significativamente en los procesos de enseñanza y aprendizaje (Alba, 2006).

La investigación parte de la selección y lectura de documentos relacionados con la Política Educativa de la modalidad de Educación Especial, en el Estado de Chihuahua. Los documentos oficiales seleccionados son; dentro del Marco Legal a nivel nacional y estatal, las leyes establecidas en el ámbito educativo y las relacionadas con la atención a las personas con Discapacidad. Así mismo se seleccionaron los Programas Educativos, Nacional, Estatal y los de Fortalecimiento de la Educación Especial y de la Integración Educativa Nacional y Estatal.

Al realizar la lectura y relectura de los documentos se fueron resaltando aspectos importantes relacionados al tema, dichos aspectos se fueron 
organizando en un sistema de relaciones entre conceptos de forma jerárquica. A lo largo de la investigación el sistema fue ajustándose sistemáticamente depurando, integrando y modificando elementos, según las reflexiones, necesidades e inquietudes que fueron apareciendo.

Se tomaron en cuenta los aspectos relacionados a la fundamentación del marco legal, operativo y técnico de la Educación Especial, así como también los aspectos técnicos que involucran el uso de las TIC en la educación y en específico los aspectos técnicos que fundamentan el uso de las TIC en la Educación Especial.

\section{1) Contexto}

Los documentos que conforman el contexto de esta investigación son documentos que se encuentran en formato electrónico o impreso cuyo contenido esta relacionado con la Política Educativa de la Educación Especial en el estado de Chihuahua, en relación al establecimiento del uso de las TIC en esta modalidad. Se trata de Leyes Generales y Estatales, tanto del ámbito educativo como de la atención a las personas con Discapacidad, y de los Programas Educativos Nacional, Estatal y los Programas de Fortalecimiento de la Educación Especial y de la Integración Educativa Nacional y Estatal.

La amplitud del contexto para la selección de la muestra documental, se determino cautelosamente sin perder de vista los objetivos propuestos en esta investigación.

\section{2) Muestreo de documentación.}

Para la realización del muestreo cualitativo del contexto citado se tomaron en cuenta las sugerencias de Tójar (2006) sobre la progresividad, intencionalidad y representación significativa del mismo muestreo. De esta manera, en un primer momento, se realizó una selección inicial de documentos oficiales relacionados con el objeto de estudio, que después de leer, analizar y releer, se fueron depurando, para finalmente determinar los documentos en relación al propósito de esta investigación. 
Se seleccionaron ocho documentos en este proceso, cuatro documentos son Leyes de Educación y para las personas con Discapacidad y cuatro son Programas de Educación, conformando la muestra de documentos a analizar.

\subsection{Análisis del contexto de la modalidad de la Educación Especial} en el Estado de Chihuahua, en relación a los aspectos técnicos operativos y el impacto de la capacitación y actualización de la Asesoría Técnica.

\section{1.)- Población}

La población de esta fase de la investigación se ubica en el ámbito educativo de la modalidad de Educación Especial del subsistema federalizado, los datos que se presentan a continuación son proporcionados por el Departamento de Educación Especial, correspondientes al ciclo escolar 2007-2008.

La población que conforma esta modalidad abarca, un Jefe de Departamento, un Subjefe Técnico, un Subjefe de Tramite y Control, un Equipo de Apoyo a la Docencia compuesto por 9 Asesores Técnicos Pedagógicos a nivel estatal y el personal administrativo, así mismo existe una Coordinación Regional en uno de los municipios con mayor numero de zonas y servicios de educación especial, conformada por un Coordinador y 2 Asesores Técnicos Pedagógicos Regionales. Son 19 zonas escolares, conformadas por un Supervisor, un Asesor Técnico Pedagógico de zona y una Secretaria o personal administrativo generalmente en cada una de las zonas, atendiendo 28 comunidades del Estado de Chihuahua como se observa en el cuadro 19 Cada zona escolar esta conformada por Servicios de Apoyo, como son las Unidades de Servicios de Apoyo a la Escuela Regular (USAER), Servicios Escolarizados, como son los Centros de Atención Múltiple (CAM) y, en algunos casos, por Servicios de Orientación como son los Centros de Recursos e Información para la Integración Educativa (CRIIE). 


\section{Estado de Chihuahua México}

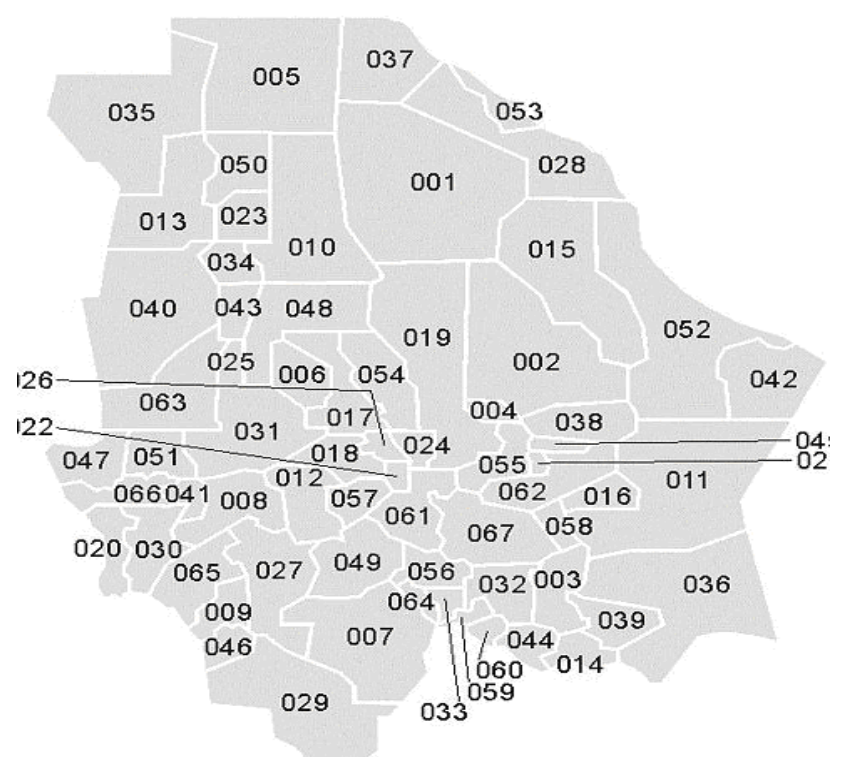

\begin{tabular}{||c|c|c||c||c|c||}
\hline \multicolumn{7}{|c|}{ Ubicación de los Servicios de Educación Especial } \\
\hline \hline № & Comunidad & Zona & No & Comunidad & Zona \\
\hline 002 & Aldama & 16 & 027 & Guachochi & 18 \\
\hline 003 & Valle de Allende & 15 & 031 & Guerrero & 12 \\
\hline 005 & Ascensión & 13 & 032 & Parral & 7,11 \\
\hline 006 & Bachíniva & 12 & 036 & Jiménez & 15 \\
\hline 007 & Balleza & 18 & 037 & Juárez & $1,2,9,17$ \\
\hline 009 & Bocoyna & 12 & 040 & Madera & 12 \\
\hline 010 & Buenaventura & 13 & 045 & Meoqui & 5 \\
\hline 011 & Camargo & 8 & 048 & Namiquipa & 6 \\
\hline 013 & Casas Grandes & 13 & 050 & Nuevo Casas Grandes & 13 \\
\hline 016 & La Cruz & 8 & 052 & Ojinaga & 16 \\
\hline 017 & Cuauhtémoc & 6 & 059 & San Fco. del Oro & 7 \\
\hline 019 & Chihuahua & $3,4,10,16$ & 060 & Santa Bárbara & 11 \\
\hline 021 & Delicias & 5 & 062 & Saucillo & 8 \\
\hline 024 & Santa Isabel & 3 & 035 & Janos & 13 \\
\hline \hline
\end{tabular}

Cuadro 19: Ubicación de los Servicios de Educación Especial

Existen 81 USAER ubicadas en 26 comunidades, con un total de 787 profesionales, entre los cuales se encuentran; Directivos, Maestros de Apoyo, Maestros de Comunicación, Psicólogos, Trabajo Social, Terapistas Físicos (en algunas unidades), y personal administrativo, atendiendo 6612 alumnos con necesidades educativas especiales (NEE) asociadas principalmente a la discapacidad $\mathrm{y} / \mathrm{o}$ a las aptitudes sobresalientes integrados en escuelas de educación primaria regular. 
En el Estado existen $28 \mathrm{CAM}$ que atienden uno o varios niveles educativos, ubicados en 18 comunidades del Estado, con 434 profesionales, como son: Directivos, Maestros de Grupo, Instructores de Taller, Maestros de Comunicación, Psicólogos, Trabajo social, Terapistas Físico, y el personal administrativo, atendiendo 1327 alumnos que presentan NEE con discapacidad severa o múltiple, trastornos generalizados del desarrollo o que por la discapacidad requieren adecuaciones curriculares altamente significativas y de apoyos generalizados y/o permanentes. Así mismo se cuenta con 3 CRIIE ubicados en 3 comunidades, con 15 asesores, actualmente los CRIIE están a cargo del Programa Estatal de Fortalecimiento de la Educación Especial y de la Integración Educativa.

\section{2) Muestra}

Para la selección de la muestra, Sabariego (2004) afirma que desde la perspectiva cuantitativa el primer paso para seleccionar la muestra es establecerla con claridad y delimitar las características de contenido, de lugar y tiempo de la población.

La muestra para la aplicación de la encuesta en esta parte de la investigación, se estableció en función del objetivo de la Investigación, se conformo con 511 profesionales de las 19 zonas escolares de la modalidad de Educación Especial abarcando:

\begin{tabular}{|c|c||}
\hline \multicolumn{2}{|c|}{ Profesionales de Educación Especial } \\
\hline \hline No & Servicio \\
\hline 8 & Equipo de Apoyo a la Docencia \\
\hline 1 & Coordinación Regional \\
\hline 16 & Supervisión de Zona \\
\hline 11 & Centro de Atención Múltiple \\
\hline 126 & Unidad de Apoyo a la Escuela Regular \\
\hline \hline 337 & Centro de Recursos e Información para la \\
Integración Educativa
\end{tabular}

Tabla3: Resumen de la Muestra de Población del Personal de Educación Especial. 
El resumen de la tabla 1 presenta información de la muestra seleccionada, integrada de la siguiente manera; Equipo de Apoyo a la Docencia, compuesto por 8 Asesores Técnicos Pedagógicos (ATP) estatales; la Coordinación Regional 1 ATP regional; las Supervisiones de zona participaron, 16 Supervisores y 11 ATP de zona; 126 profesionales de CAM entre ellos, Directivos, Maestros de Grupo, Instructor de Taller, y el equipo de apoyo integrado por el Maestro de Comunicación, Psicólogo, Trabajo Social, Terapista Físico y Maestros de Educación Física. Igualmente forma parte de esta muestra 337 profesionales del servicio de apoyo USAER integrado por Directivos, Maestro de Apoyo y equipo de apoyo integrado por Maestro de Comunicación, Psicólogo, Trabajo social y Terapista Físico. De los servicios de orientación CRIIE participaron 12 Asesores.

Para determinar la representatividad, la muestra, ésta debe tener un tamaño suficiente. En este caso la muestra representa el 39.70\% de la población.

\subsection{Diseño, aplicación y evaluación de un recurso digital como} propuesta para mejorar y optimizar la asesoría y capacitación técnica, en la modalidad de Educación Especial.

La disponibilidad de recursos didácticos en distintos soportes tecnológicos, obliga a que la evaluación educativa responda de manera científica al tema de la calidad de este tipo de entornos educativos. Según García-Valcárcel (2003), la evaluación de medios deberá tener en cuenta todos los componentes curriculares: las características de los alumnos, el papel del profesor, el contexto en el que se van a utilizar, etc. Además señala, que las estrategias a utilizar se pueden concretar en:

- Auto-evaluación por los productores.

- Consulta a expertos.

- Evaluación por los usuarios.

En cuanto a las técnicas e instrumentos, se pueden utilizar los instrumentos conocidos de la evaluación educativa para la recogida de la información: cuestionarios y escalas de opinión y valoración, entrevistas con diferente grado 
de estructuración, la observación sistémica de forma directa o mediante grabaciones en vídeos, etc.

En cuanto a la evaluación de calidad, podemos distinguir dos dimensiones (Marqués, 2004):

- Las características intrínsecas de los entornos (evaluación objetiva).

- La forma en la que se utilizan estos entornos en un contexto formativo concreto. Es decir, se evalúa los resultados formativos que se obtienen y la forma en que se ha utilizado (evaluación contextual).

Tomando en cuenta los aspectos antes mencionados, se selecciono el instrumento para evaluar en un primer momento el sitio web, después se selecciono la población y muestra de expertos para la evaluación, para finalmente llevar acabo dicha evaluación.

\section{1) Población}

Para la evaluación del diseño del sitio web por expertos, se considero que la población fueran profesionales, dentro del ámbito educativo, expertos en el área de las TIC y/o de Educación Especial, por lo que la población de profesionales son: Profesores expertos en el área de las TIC y de Educación Especial de Universidades de España y de México, así mismo se contemplaron de la modalidad de Educación Especial del subsistema federalizado del Estado de Chihuahua, al Jefe del Departamento, Supervisores, Asesores Técnicos del Estado, Regionales y de Zona, así como Maestros de Grupo de los Servicios Escolarizados CAM, Maestros de Apoyo de los Servicios de Apoyo USAER y Profesionales de los Equipos de Apoyo, Director del área de computo de los Servicios Educativos del Estado de Chihuahua y a un profesional técnico en el área.

Para el segundo momento de evaluación correspondiente a la utilidad del sitio web, la población se conformó por los diferentes profesionales de Educación Especial antes mencionados, por ser los principales usuarios del sitio. 


\section{2) Muestra de expertos}

La selección de la muestra de expertos se determino después de la unidad de análisis y definiendo la población de los expertos, en función de esto se concretó al azar el subgrupo de la población de interés (Hernández y otros, 2007) partiendo del objetivo de la investigación.

La muestra seleccionada a la cual se le hizo la solicitud a participar por medio de correo electrónico, consistió en 8 Profesores de diferentes Universidades de España y de México, entre los cuales 4 son del área de Educación Especial y 4 expertos en TIC, de igual manera se solicito la participación en la evaluación del sitio web a: 1 Jefe de Departamento de Educación Especial, 6 Asesores Técnicos a nivel Estatal, 4 Supervisores, 2 Asesores Técnicos Regionales, 3 Asesores Técnicos de Zona, 5 Directores, 5 Maestros de Grupo de los Servicios Escolarizados CAM, 5 Maestros de Apoyo de los Servicios de Apoyo de USAER, y profesionales del equipo de apoyo como Trabajadores Sociales, Psicólogos y Maestros de Comunicación, de la modalidad de Educación Especial, además de 1 Director y 1 Técnico del departamento de Computo de los Servicios Educativos del Estado de Chihuahua.

La muestra definitiva de la población que participo en esta parte de la investigación, cuyo objetivo es la evaluación del diseño del sitio web del Departamento de Educación Especial de los Servicios Educativos del Estado de Chihuahua, está integrada por 22 expertos, profesionales de educación como se puede observar en la siguiente tabla 4 .

\begin{tabular}{|c||c||c||}
\hline \multicolumn{2}{|c|}{ Relación de Expertos } \\
\hline \hline Frecuencia & \multicolumn{1}{|c||}{ Institución } & \multicolumn{1}{c|}{ Área } \\
\hline \hline 1 & Universidad & $\begin{array}{l}\text { Tecnología de la Información y de } \\
\text { la Comunicación. }\end{array}$ \\
\hline \hline 6 & \multicolumn{1}{|c|}{ Universidad } & Educación Especial \\
\hline \hline 1 & $\begin{array}{l}\text { Coordinación Regional de Educación } \\
\text { Especial }\end{array}$ & Educación Especial \\
\hline
\end{tabular}




\begin{tabular}{|c||l||l||}
\hline 3 & $\begin{array}{l}\text { Supervisión de Zona de Educación } \\
\text { Especial }\end{array}$ & Educación Especial \\
\hline \hline 2 & $\begin{array}{l}\text { Unidades de Servicio de Apoyo a la } \\
\text { Escuela Regular USAER }\end{array}$ & Educación Especial (Dirección) \\
\hline \hline 1 & Centro de Atención Múltiple CAM & Educación Especial (Dirección) \\
\hline \hline 2 & Centro de Atención Múltiple CAM & $\begin{array}{l}\text { Educación Especial (Maestro de } \\
\text { Gpo.) }\end{array}$ \\
\hline \hline 2 & $\begin{array}{l}\text { Unidad de Servicios de Apoyo a la } \\
\text { Escuela Regular USAER }\end{array}$ & $\begin{array}{l}\text { Educación Especial (Maestro de } \\
\text { Apoyo) }\end{array}$ \\
\hline \hline 2 & $\begin{array}{l}\text { Unidad de Servicios de Apoyo a la } \\
\text { Escuela Regular. }\end{array}$ & $\begin{array}{l}\text { Educación Especial (Equipo de } \\
\text { Apoyo) }\end{array}$ \\
\hline \hline
\end{tabular}

Tabla 4: Relación de Expertos por Áreas que participaron en la Evaluación del Sitio Web.

\section{3) Muestra de Usuarios}

La selección de la muestra se determino después de la unidad de análisis y de haber definido la población de profesionales de Educación Especial como usuarios, en relación a esto se concretó al azar el subgrupo de la población de interés, con el objetivo de la evaluar la utilidad del sitio web como una propuesta de mejora y optimización de la capacitación y actualización técnica.

A la muestra seleccionada se le hizo la invitación a participar primeramente desde la Jefatura del Departamento por medio de los Supervisores de zona y Directivos de los diferentes servicios, participando profesionales de los diferentes servicios, por ser los principales usuarios, entre los que encontramos: Equipo de Apoyo a la Docencia 6 ATP Estatales, de las 18 Supervisiones de zona que hay actualmente, encontramos 14 supervisores, 7 ATP de zona, 66 Directivos de los diferentes servicios, 61 Maestros de Apoyo de USAER, 26 Maestros de grupo de CAM y 2 Asesores de CRIIE, del equipo de apoyo participaron, 16 Psicólogos, 5 Trabajadores Sociales, 2 Terapistas Físicos y 2 Auxiliares de Maestro.

La muestra total de población que participó en esta fase de la investigación, está integrada por 209 profesionales de Educación Especial (Ver Tabla5). 


\begin{tabular}{|c|c||}
\hline \multicolumn{2}{|c|}{ Relación de Usuarios } \\
\hline Servicio & Frecuencias \\
\hline \hline Equipo de Apoyo a la Docencia & 6 \\
\hline Supervisión & 21 \\
\hline CRIIE & 2 \\
\hline CAM & 57 \\
\hline USAER & 123 \\
\hline
\end{tabular}

Tabla 5: Relación de usuarios del Sitio Web por Servicio

\subsubsection{Técnicas e Instrumentos para la recogida de datos.}

El proceso de la obtención de la información es emergente y cambiante. Al respecto, Massot, Dorio y Sabariego (2004) establecen que a medida que se tiene un mayor contacto con los informantes y se comprende la realidad del objeto de estudio, se va completando y precisando la información.

A continuación presentamos paso a paso las técnicas de recogida de datos que se utilizaron en cada uno de las fases del trabajo.

\subsection{Análisis de la Política Educativa del Estado de Chihuahua} México, sobre el uso de las TIC en la modalidad de Educación Especial, de 1996 a 2010.

La estrategia que se determinó utilizar para recoger y analizar la información es la técnica de "Análisis de Contenido", que de acuerdo a Cabero y Loscertales (2002), tiene como principio el hecho de que los documentos reflejan las actitudes y creencias de las personas e instituciones que los producen, así como también las creencias y actitudes de quienes los reciben. 


\section{1) Análisis de Contenido}

El "Análisis de Contenido" es una técnica para el análisis de la comunicación humana, utilizada para decodificar los mensajes manifiestos, latentes y ocultos plasmados en diferentes documentos. Según Tójar (2006) el análisis de contenido puede ser considerado desde tres diferentes perspectivas:

- La más restrictiva, como una técnica de recogida de datos u obtención de la información, solo o en compañía de otras estrategias puede producir información cualitativa rica para una investigación.

- Desde una perspectiva muy general, puede ser entendido como un autentico método de investigación, puesto que existe mucha tradición al respecto y muchas investigaciones que han utilizado análisis de contenido.

- La tercera perspectiva y la cual adopta Tójar, es la que destaca la capacidad de análisis de contenido como proceso cualitativo generador de información, de interpretación y de conclusiones.

De esta manera se trata de descubrir los significados de un documento, que puede ser textual o también puede ser audiovisual. El propósito es poner de manifiesto los significados, tanto los manifiestos como los latentes y por ello se clasifican y codifican los diferentes elementos en categorías que representan más claramente este sentido.

Cabero y Loscertales (2002) enuncian características que definen el análisis de contenido como; funciona dentro de un esquema general de investigación, no independiente del mismo, dependiendo del marco donde se encuentre insertado será su calidad, así como también de la originalidad, creatividad y conocimiento que utilice el investigador. Su objetivo es ofrecer resultados válidos y fiables, por ello depende de una serie de variables, desde la calidad del instrumento utilizado, hasta el proceso de formación que se siga con los codificadores, puede ser aplicada a diferentes tipos de signos y medios. 
Al respecto Gómez (2000), reuniendo las propuestas de varios autores, establece el proceso de análisis de contenido en etapas técnicas generales, las cuales hemos seguido en esta investigación de la siguiente manera:

\section{a) Análisis previo:}

- Revisión de documentos legislativos y programas educativos para seleccionar los relacionados con la política educativa de Educación Especial.

- Revisión de artículos relacionados con la técnica de Análisis de Contenido, tanto de su fundamentación como de su utilización en investigaciones que se han realizado.

Se identificaron y seleccionaron los documentos, después se realizaron lecturas sucesivas para familiarizarse con los documentos de análisis y su relación con el objeto de estudio.

Finalmente se seleccionaron 8 documentos oficiales representados por Programas Educativos y Leyes de Educación y para las Personas con Discapacidad que permiten establecer el marco de la Política Educativa dentro de la cual se rige la Educación Especial en el estado de Chihuahua, desde 1996 al 2010. En la tabla 6 se enuncian los documentos analizados.

\begin{tabular}{c|c|l|c}
\hline \multicolumn{3}{|c|}{ Documentos de Análisis } \\
\hline \multirow{4}{*}{$\begin{array}{c}\text { Documentos } \\
\text { Legales }\end{array}$} & Documento 1 & $\begin{array}{l}\text { Ley para las Personas con Discapacidad } \\
\text { en el estado de Chihuahua. }\end{array}$ & $\begin{array}{c}\text { Fe de Noviembre de } \\
1996\end{array}$ \\
\cline { 2 - 4 } & Doc. 2 & $\begin{array}{l}\text { Ley General de las Personas con } \\
\text { Discapacidad. }\end{array}$ & 10 Junio de 2005 \\
& Doc. 3 & Ley Estatal de Educación. & 18 de Septiembre de \\
& Doc. 4 & Ley General de Educación. & 22 de Junio de 2006 \\
\hline & Doc.5 & $\begin{array}{l}\text { Programa Estatal de Fortalecimiento de la } \\
\text { Educación Especial y de la Integración } \\
\text { Educativa. }\end{array}$ & $2005-2010$ \\
\hline
\end{tabular}




\begin{tabular}{l|c|l|c}
\hline Programas & Doc. 6 & Programa Estatal de Educación. & $2005-2010$ \\
\cline { 2 - 4 } Educativos & Doc. 7 & Programa Nacional de Educación. & $2001-2006$ \\
\cline { 2 - 4 } & 8 & $\begin{array}{l}\text { Programa Nacional de Fortalecimiento de } \\
\text { la Educación Especial y de la Integración } \\
\text { Educativa. }\end{array}$ & 2002 \\
\hline
\end{tabular}

Tabla 6: Relación de documentos para realizar el Análisis de Contenido.

\section{b) Preparación del Material}

Los documentos se desglosaron en unidades de significación de acuerdo a Gómez (2000), tomando como base del tamaño de la unidad cada punto y seguido del texto. Según Gómez (2000) esta etapa se subdivide en tres momentos, que son: la construcción del corpus; la trascripción del material y la selección de un método de análisis. De esta manera se consideraron los 8 documentos oficiales seleccionados y se transcribieron aquellos que se encontraban en material impreso. Una vez que se encontraban todos los documentos en formato digital se procedió a pasarlos a formato txt, necesario para el método de análisis.

Se seleccionó el procedimiento de la aplicación informática del NUD IST 4 , especifico para el análisis del contenido, que de acuerdo a Tójar (2006), es uno de los más utilizados, ya que permite agrupar y organizar la información de forma jerárquica; edita el texto sin desorganizar la codificación, así como se pueden visualizar y realizar informes de codificaciones de diferentes formas. Con este programa se desglosó el contenido, la agrupación en temas y la identificación de categorías y subcategorías.

\section{c) La selección de la unidad de análisis:}

La formulación de las unidades de análisis o categorías de análisis fue la fase más significativa del proceso, se organizó en base a la revisión teórica, los objetivos propuestos, la fundamentación de la técnica de análisis de contenido y un preacercamiento a los textos de análisis.

El modelo utilizado para la definición de las categorías fue inductivo y deductivo, se utilizo el modelo mixto que Tójar (2006) denomina así porque se utilizan categorías previas, que pueden adaptarse, junto a otras inductivas. 
Como principio general se procuró que correspondieran exclusivamente a una sola dimensión y categoría.

El sistema diseñado se denomino: Las TIC en la Educación Especial, conformado por un gran eje que es la categoría de Educación Especial, después se conformaron 34 categorías, de igual manera en cada una de las dos grandes dimensiones conformadas por el Marco Legal y los Programas Educativos, haciendo un total de 69 categorías, lo cual permitió establecer el análisis de cada categoría y la comparación entre estas dos grandes dimensiones.

1. Marco Legal: Se pretende investigar en este aspecto, los fundamentos legales de la operatividad de la Educación Especial y dentro de esta el uso de las TIC, desde 1996 a 2010.

2. Programas: Se pretende indagar sobre la fundamentación y operatividad de la modalidad de Educación Especial y los planteamientos del uso de las TIC entre los años 1996 a 2010.

- Fundamentos: Pretende investigar los aspectos relacionados con los objetivos y visión de la Educación Especial, en específico el planteamiento de la utilización de las TIC se dividió en las siguientes categorías.

- Integración: Busca investigar los aspectos relacionados con la integración de los alumnos, mejorar las condiciones para que logren los propósitos educativos, participen plenamente en la vida escolar, y para ello la importancia del uso de las TIC, por lo que se dividió en las siguientes categorías:

* Relevancia: Indagar si se plantea la acción educativa considerando las siguientes dos categorías:

$>$ Necesidades: Investigar si en los documentos contempla los intereses y necesidades de los alumnos. 
Desarrollo: Investigar si se contempla el desarrollo en todos los aspectos del alumno para su integración.

Eficacia: Pretende indagar si se plantea el logro de los propósitos educativos establecidos en los aspectos relacionados con las siguientes categorías:

> Propósitos educativos: Investigar el logro de los propósitos educativos establecidos para cada nivel educativo.

> Desarrollo: Indagar si se contempla el desarrollo potencial del alumno.

* Equidad: Investigar si enuncia contemplar las necesidades, fortalezas, capacidades y diferencias de los alumnos, por lo que se relaciona con las siguientes categorías.

> Atención diferenciada: Pretende indagar sobre el planteamiento de la diversificación y flexibilización del currículo, en relación específicamente con :

- Necesidades: Investigar si toma en cuenta las necesidades del alumno en cuanto a la equidad.

- Capacidades: Investigar si contemplan las capacidades de los alumnos.

* Eficiencia: Investigar si propone material didáctico diversificado según las necesidades de los alumnos, dentro de éste específicamente la Tecnología o TIC ; se organizo de la siguiente manera:

$>$ Recursos Diferenciados: En este aspecto se pretende investigar sobre lo que se establece en función del uso de los recursos y su diversificación, se dividió en:

- Material Didáctico: Indagar si plantea el uso de materiales específicos y 
la Tecnología o TIC dentro del currículo y en especifico las siguientes categorías :

Específico: Pretende indagar si se plantea el uso de material específico, que se relaciona con aspectos específicos de la discapacidad.

Tecnología: Se pretende averiguar si se contempla el uso de la Tecnología o TIC en la diversificación de material.

- Inclusión: Averiguar si se plantea una educación capaz de ofrecer respuesta educativa a todos sus estudiantes, se organizaron las siguientes categorías:

Equidad: Pretende indagar si se plantea una respuesta educativa adecuada para todos los alumnos y en especifico en el uso las TIC dentro del currículo, por ello se subdividió en:

> Diversificación: Se pretende indagar si se contempla la diversificación de los métodos, técnicas y materiales, por lo que nacen las siguientes categorías:

- Métodos: Investigar si se plantea la diversificación de los métodos de enseñanza -aprendizaje.

- Técnicas: Indagar si se toma en cuenta la diversificación de técnicas de enseñanza aprendizaje.

- Material Didáctico: Pretende establecer si contempla el uso de material didáctico y su diversificación, se divide en:

Específico: Indagar si se contempla este tipo de material específico. 
* Tecnología: Pretende averiguar si se planea el uso de la tecnología.

Contextos: Indagar si este aspecto es abordado para el logro de la inclusión plena.

- Calidad de vida: Pretende indagar si se contempla en específico la accesibilidad; se subdivide en las siguientes categorías:

- Equiparación de oportunidades: Pretende conocer si se contempla este aspecto relacionado en este caso específicamente con la accesibilidad, se relaciona con las siguientes categorías:

Necesidades: Pretende indagar si se toman en cuenta las necesidades fundamentales de todos los alumnos.

Recursos Diversificados: Pretende indagar si se plantea la multiplicación y diversificación de los recursos y materiales para la accesibilidad, por ello se divide en :

- Material Didáctico: Pretende investigar si se plantea el uso de material didáctico diverso para la accesibilidad de los alumnos y por ellos se divide en las siguientes categorías:

4 Especifico: Indagar si esta contemplado el material específico en relación a las necesidades y discapacidad.

Tecnología: Investigar si se plantea el uso de la tecnología para la accesibilidad.

A continuación se presenta el Mapa conceptual de las categorías antes mencionadas: 

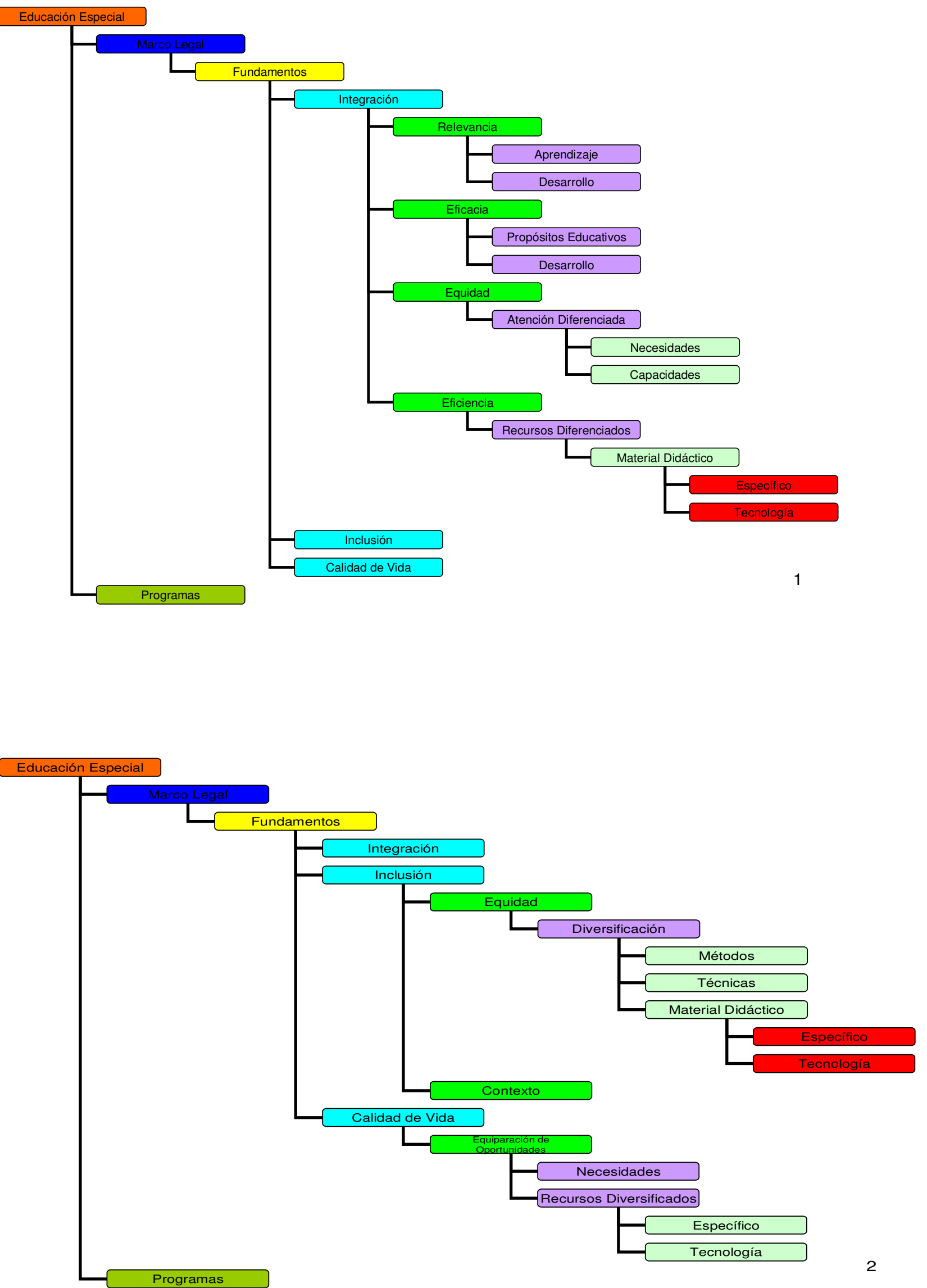


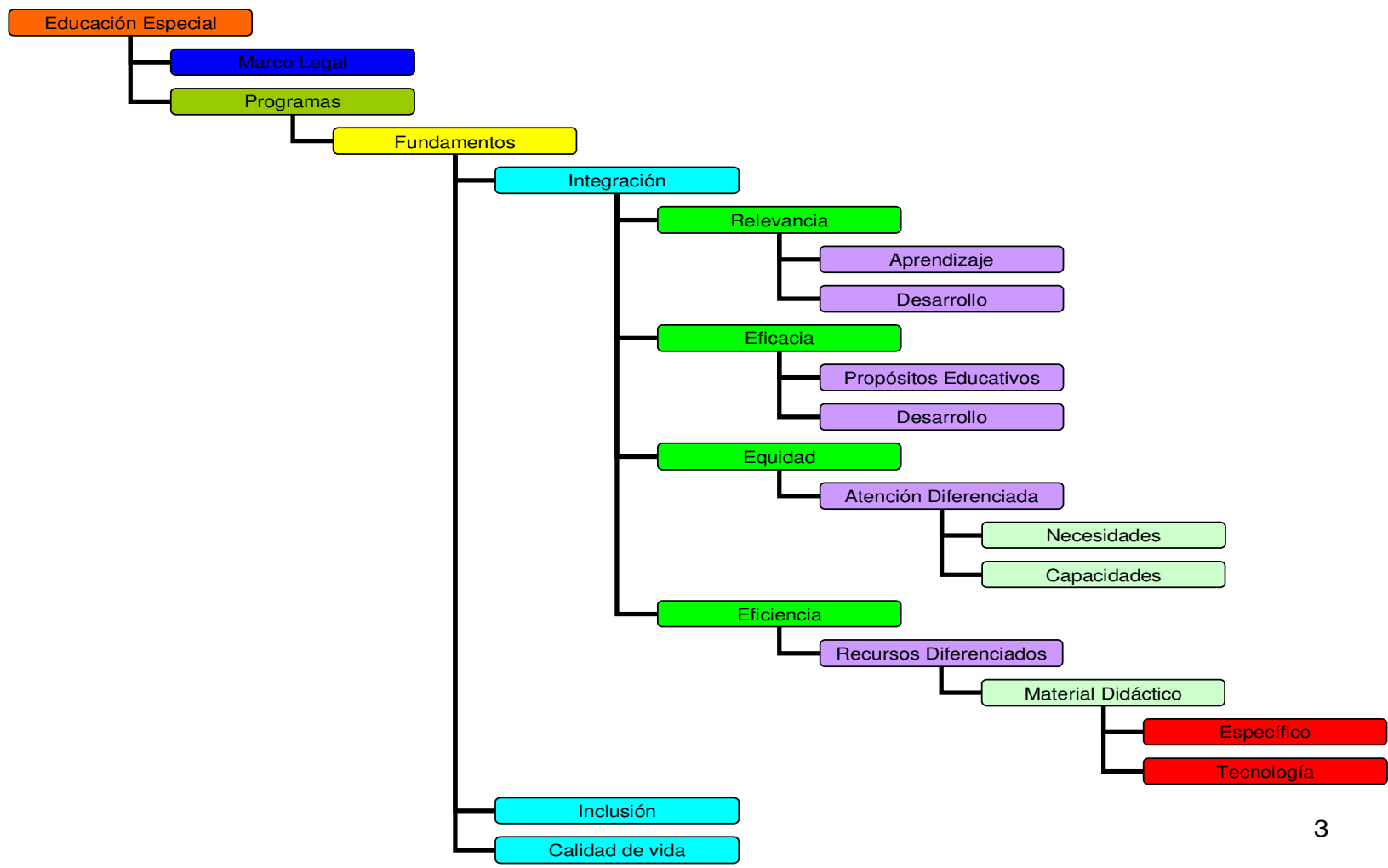

\section{Educación Especial}
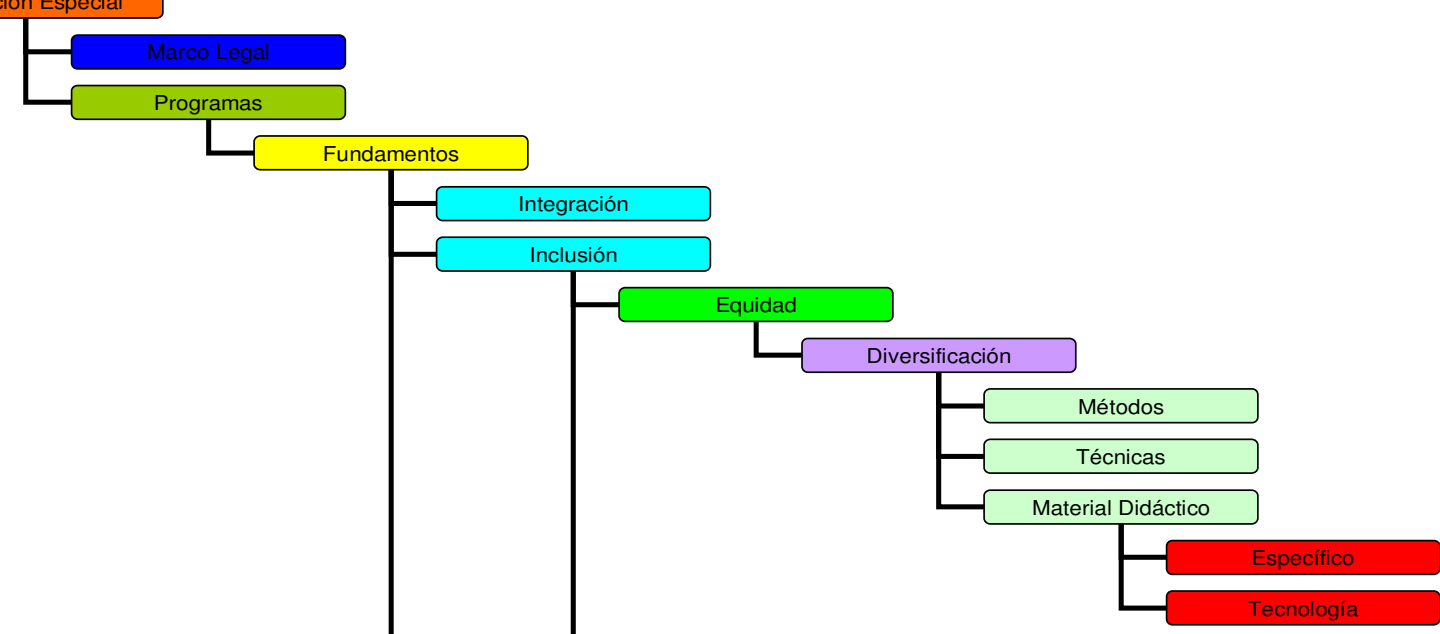

Calidad de vida

$$
\text { Contexto }
$$
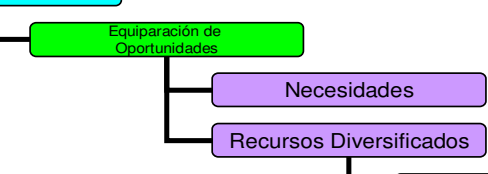

Material Didáctico

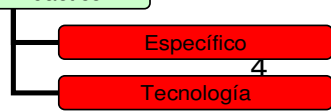




\subsection{Análisis del contexto de la modalidad de la Educación Especial}

en el Estado de Chihuahua, en relación a los aspectos técnicos operativos y el impacto de la capacitación y actualización de la Asesoría Técnica.

La investigación por medio de encuesta es muy utilizada en el ámbito educativo, es por ello que en esta fase de la investigación, se utilizo la técnica de la encuesta para la recogida de la información de la muestra de población seleccionada. Según Torrado (2004), la investigación por encuesta debe traducir las variables sobre las que se desea obtener información en preguntas concretas sobre la realidad. Un cuestionario es un instrumento de recogida de información, compuesto por un número limitado de preguntas mediante el cual el sujeto investigado proporciona información sobre sí mismo y también sobre su entorno.

Para la elaboración de la encuesta se realizaron una serie de tareas propuestas por Torrado (2004).

1. Definición de los objetivos del cuestionario.

En esta fase se realizaron una serie de cuestionamientos sobre cuál sería el propósito de esta encuesta, esto permitió establecer que el objetivo de la aplicación del cuestionario seria indagar, de forma clara y sencilla sobre el contexto de los profesionales de Educación Especial ubicados en los diferentes servicios, en relación a los aspectos técnicos operativos y el impacto de la asesoría técnica.

2. Planificación del cuestionario, detectando sus diferentes apartados.

Al tener claro el objetivo de la encuesta, así como el de la técnica de recogida de información, se diseñó un instrumento que fuera sencillo, con lenguaje acorde a la población a la que va dirigido, sobre aspectos relacionados con la practica, específicamente en las actividades de planeación, evaluación y seguimiento que realiza, además de evaluar aspectos relacionados con la capacitación y actualización que reciben, y con ello la detección de las necesidades técnicas de cada área, en relación a la atención de los alumnos con necesidades educativas especiales (NEE) asociadas principalmente a la discapacidad y/o 
aptitudes sobresalientes, así como el apoyo a los maestros y padres de familia .

3. Elaboración de las preguntas.

Tomando como punto de partida el objetivo de la encuesta, el instrumento para la recolección de los datos esta estructurado por una primera parte que permite establecer los datos generales que permiten describir la muestra, como son Servicio o Institución a la que pertenece, Zona Escolar, Contexto donde se ubica el servicio, Función que desempeña, Años de servicio, Formación Profesional Inicial, Formación Profesional Actual y Experiencia Profesional. En segundo lugar se encuentran organizados 16 aspectos, de los cuales 9 son preguntas cerradas, admitiendo la posibilidad de una única respuesta o de varias dependiendo del tema. De igual manera conforman también el cuestionario 7 preguntas abiertas. La preguntas se diseñaron relacionando aspectos técnico operativos de la práctica de los diferentes profesionales y al impacto de asesoría técnica que se ha venido realizando.

4. Análisis de calidad de las preguntas.

La encuesta fue evaluada previamente por la Jefa del Departamento de Educación Especial, 3 Asesores Técnicos, 2 Supervisores de Zona, y 4 maestros, para determinar si el instrumento cumplía con el objetivo de indagar el contexto de los profesionales de educación especial de los diferentes servicios, en relación a los aspectos técnicos operativos y el impacto de la asesoría técnica, así como su contenido, organización, cantidad y calidad en los indicadores, para después realizar los ajustes necesarios al instrumento.

5. Análisis de la fiabilidad y validez del cuestionario

Cuando el cuestionario o encuesta ya esta elaborado, es necesario analizar su validez, al respecto Cea (2001) establece que antes de la fiabilidad, los indicadores deben de ser validados, eso es que han de proporcionar una representación adecuada del concepto teórico que miden. De esta manera para garantizar la validez se aplico anticipadamente a 15 profesionales de Educación Especial, para evaluar el contenido, la estructura de los criterios, el tiempo que se utilizaba para 
realizarlo, y la claridad de los indicadores, todo ello en relación a validar si se cumplía el objetivo para el cual fue elaborado.

6.- Redacción final de la encuesta.

La encuesta definitiva, contempla una primera parte de datos generales, así mismo se encuentran organizados en 16 items, de los cuales 9 son preguntas cerradas, admitiendo la posibilidad de una única respuesta y otros de opción múltiple, de igual manera conforman también el cuestionario 7 preguntas abiertas (Ver Anexo IV). El contenido y el lenguaje que se utilizo son adecuados a los aspectos técnicos operativos que se manejan en Educación Especial, lo cual se comprobó en la prueba piloto.

\section{1) Procedimiento de análisis de la información generada por el cuestionario.}

El análisis de los datos cuantitativos del cuestionario en base a las preguntas cerradas de la encuesta, aplicada a 511 profesionales de Educación Especial, se lleva a cabo a través de un análisis descriptivo de frecuencias y medias de los item.

Los 9 items aluden a temas relacionados a los aspectos técnicos operativos y el impacto de la capacitación y actualización de la modalidad de Educación Especial en el Estado de Chihuahua, admiten la posibilidad de una única respuesta o varias dependiendo del tema (Ver Anexo IV).

El análisis descriptivo de los datos nos permitirá descubrir y describir los aspectos relacionados a los aspectos técnico operativos como son las actividades que realizan los diferentes profesionales y el tiempo que dedicas a ellas, la participación en el proyecto curricular de centro, si realiza actividades de seguimiento y evaluación, en cuento a la capacitación y actualización si recibe cursos, si son adecuados, si se realiza seguimiento, en relación al contenido, actividades y tiempo que se dedica a ello, la que institución que proporciona los cursos, las necesidades técnicas y las propuestas de mejora del servicio. 


\section{b) Análisis Documental de Contenido}

El análisis de datos constituye una etapa clave en el proceso de la investigación cualitativa que aparece unido a la recogida de la información, de acuerdo a Bisquerra (2004). El material seleccionado consiste en las respuestas a las preguntas abiertas de la encuesta aplicada. El procedimiento que se utilizo es la estrategia de análisis de contenido considerada por Tójar (2006), como un proceso cualitativo de análisis que genera información, interpretación y conclusiones de un documento. Dicho análisis nos permitirá descubrir y describir los aspectos relacionados a las actividades sobre proyecto curricular de centro, evaluación y seguimiento que realizan los diferentes profesionales de la modalidad de educación especial, así como la visión que se tiene sobre la capacitación y actualización que reciben durante el ciclo escolar.

\section{Preparación del material.}

La preparación del material se realizo por medio de una trascripción escrita en formato digital de las encuestas aplicadas, seleccionando el contenido de las preguntas abiertas, para luego realizar el desglose de cada uno de los temas dividiéndolos en frases conformando las unidades de significación, después se conformó en un documento sin texto necesario para el método de análisis, de igual manera y al mismo tiempo se fue realizando un preanálisis, permitiendo la conformación de agrupaciones de acuerdo a los temas y estableciendo las primeras categorías.

Se selecciono el procedimiento del programa informático NUD IST 4, para analizar el contenido que de acuerdo a Tójar (2006), permite agrupar y organizar la información, edita el texto sin desorganizar la codificación, además de que permite realizar informes de codificaciones de diferentes formas estableciendo porcentajes de unidades de frecuencias de las codificaciones, con este programa se desgloso el contenido de cada uno de los temas y la identificación de las categorías y subcategorías correspondientes a los temas analizados.

Selección de las unidades de análisis. 
Para la codificación de los datos en primer lugar, se realizo un análisis de cada uno de los temas atendiendo a las respuestas de los diferentes profesionales, profundizando en cada uno de ellos, lo que permitió ir conformando el sistema de categorías, que como establece Hernández y otros (2007), implica clasificar y sobre todo requiere asignar unidades de análisis a categorías de análisis. Fue necesario ir observando diferencias y similitudes entre las unidades de registro de cada uno de los temas, siendo esta fase la mas significativa del proceso, ya que conforme se va realizando esta relación se van seleccionando y retomando categorías, basándose en la revisión teórica, los objetivos propuestos, la fundamentación de la técnica de análisis de contenido y el preacercamiento a los textos de análisis.

\section{Categorías:}

\section{1) Elaboración del Proyecto Curricular de Centro.}

Categorías que aluden a los aspectos que toman en cuenta los diferentes profesionales de los servicios de educación especial para la elaboración del proyecto curricular de centro o institución. Fue incluido el item 3 del cuestionario ("Mencione los aspectos que toma en cuenta para la elaboración del proyecto curricular de centro o institución").

- Autoevaluación: Evaluación inicial de la gestión escolar partiendo de las necesidades y fortalezas de la escuela, de los alumnos, los maestros, el contexto familiar, social, económico y cultural, así como los recursos materiales y humanos con los que se cuenta.

- Propósitos Educativos: Objetivos, metas, estrategias y actividades planeadas de acuerdo a los propósitos de la atención educativa de los alumnos con NEE conforme a los principios y fines de la educación. 


\section{2) Evaluación y Seguimiento.}

Categorías que se refieren a las actividades de evaluación y seguimiento que realizan los profesionales de educación especial. Dentro de estas categorías están incluidas las respuestas a los item: 5 ("Enuncie cuáles son las actividades de seguimiento que realiza".) y 7 del cuestionario ("Enuncie cuáles son las actividades de evaluación que realiza".).

- Tipos de Evaluación: Según el momento en que se realiza la evaluación por los diferentes actores tanto del proceso del alumno, como del contexto educativo, familiar y social, puede ser inicial, procesual, final y psicopedagógica.

- Instrumentos y estrategias: Articulación de los instrumentos y las estrategias utilizadas en los diferentes momentos de la evaluación, dirigidas a los alumnos y a los contextos educativos, familiar y social que facilitan o dificultan el proceso enseñanza aprendizaje.

- Seguimiento: Proceso de obtención de información permanente a lo largo del ciclo escolar para fortalecer o modificar y enriquecer los aspectos que se consideran en el plan anual de trabajo, proyecto áulico y propuesta curricular adaptada.

\section{3) Capacitación y Actualización de los Profesionales}

Las siguientes categorías se refieren a los aspectos de los contenidos y el seguimiento de la capacitación y actualización que reciben los diferentes profesionales de la modalidad de Educación Especial, así como si es adecuada o no para ellos. Dentro de estas categorías están incluidas las respuestas a los item 11.- (“¿Considera que la capacitación y actualización que recibe es la adecuada en relación a los contenidos?”), 12.- (“¿Considera que el seguimiento de la capacitación y asesoría que recibe es adecuada en relación a las actividades, contenido y tiempo en que se realiza?”), y 13.- (“¿Considera que la capacitación y la actualización que recibe es la adecuada?”). 
- Sl: Es la adecuada

> Necesidades: Los contenidos de la capacitación y actualización contemplan las necesidades de las instituciones, de los alumnos, los maestros, los diferentes profesionales y áreas de atención de los servicios de educación especial.

Propósitos Educativos: La capacitación y actualización se apega a los propósitos educativos de la educación, centrándose principalmente en educación especial.

> Tiempo: La capacitación y el seguimiento a la misma, se realiza al inicio, durante y al final de ciclo escolar.

- NO: No es adecuada.

> Necesidades: Los contenidos de la capacitación y actualización no contemplan las necesidades de las instituciones, de los alumnos, los maestros, los diferentes profesionales y áreas de atención de los servicios de educación especial.

Propósitos Educativos: La capacitación y actualización no se apega a los propósitos de la educación especial.

Tiempo: La capacitación y actualización que se proporciona es insuficiente, en cantidad y calidad.

\section{4) Propuestas de Mejora}

Las siguientes categorías surgen del análisis de las respuestas de la pregunta 15 de la encuesta (“¿Qué sugiere para mejorar el servicio?”). 
- Técnico Pedagógico: Aspectos relacionados a la capacitación y actualización sobre NEE, aspectos específicos de la discapacidad, en las diferentes áreas y funciones, así como realizar evaluación y seguimiento a las necesidades técnicas.

- Organización: Mayor organización de los servicios, tener una actitud de compromiso por todos los involucrados, y trabajo colaborativo.

- Administrativo: Planteamientos de las necesidades de recursos humanos, materiales, didácticos y financieros de los diferentes servicios de educación especial.

- Vinculación: Solicitud de vinculación con autoridades educativas de los diferentes niveles, con instituciones gubernamentales y no gubernamentales que tienes relación con la atención a los alumnos con NEE asociados principalmente a la discapacidad.

A continuación se presenta un mapa conceptual de las categorías que se diseñaron para la realización del Análisis de Contenido de las respuestas abiertas del cuestionario. 


\section{PROYECTO}

URRICULAR (1)

Autoevaluación

(1.1)

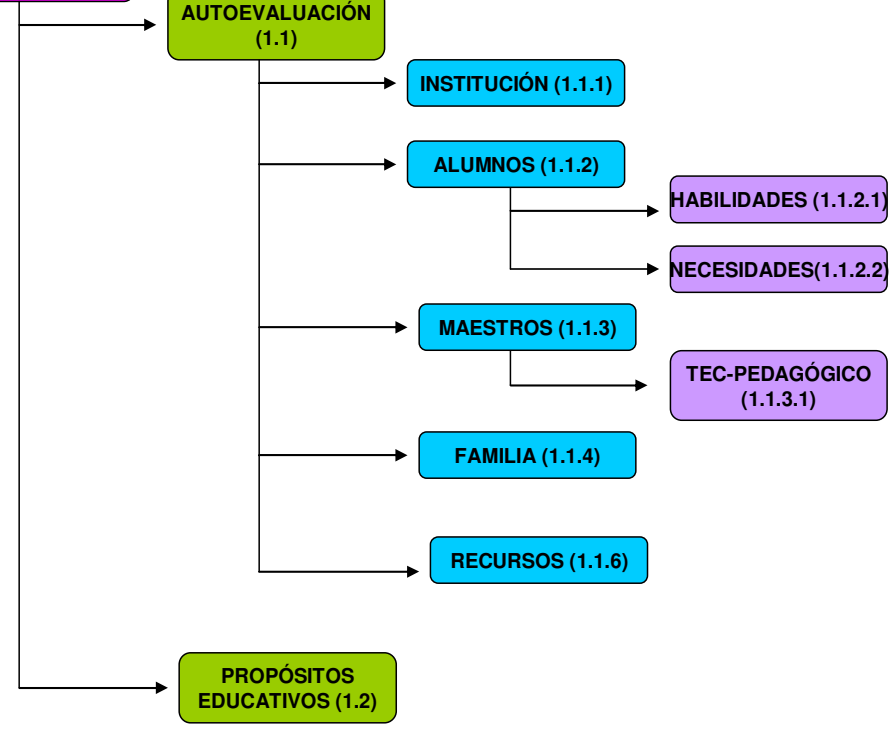

SEGUIMIENTO (1)

TIPOS DE

EVALUACIÓN(1.1) EVALUACIÓN (1.1.1)

EVALUACIÓN(1.1.2)

PSICOPEDAGOGICA

INSTRUMENTOS $Y$

ESTRATEGIAS(1.2)

$\longrightarrow$ ALUMNOS (1.2.1)

MAESTROS(1.2.2)

FAMILIA (1.2.3)

GRUPO (1.2.4)

$\rightarrow$ INSTITUCIÓN(1.2.5)

SEGUIMIENTO(1.3)

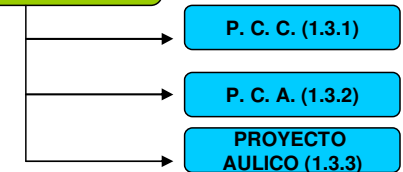



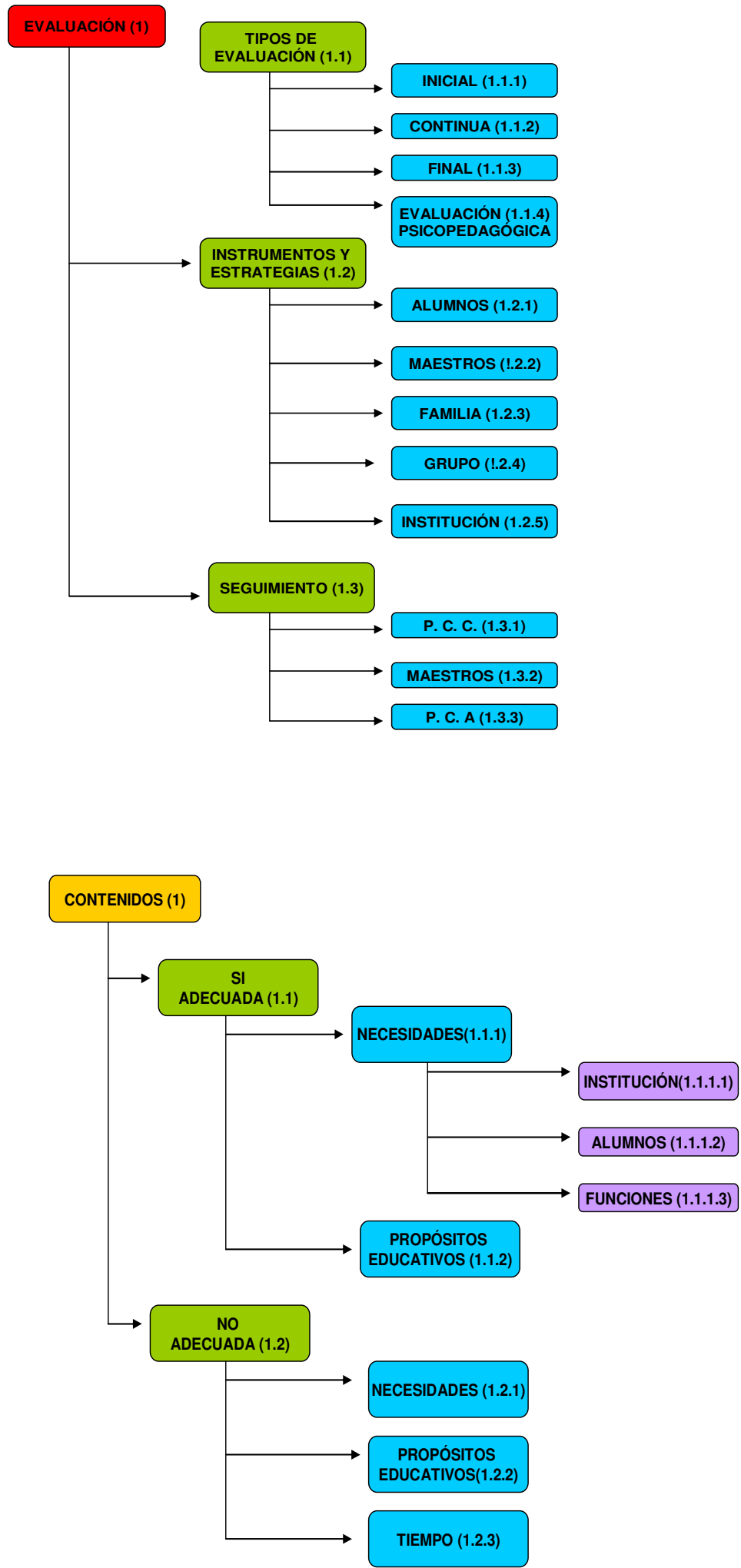

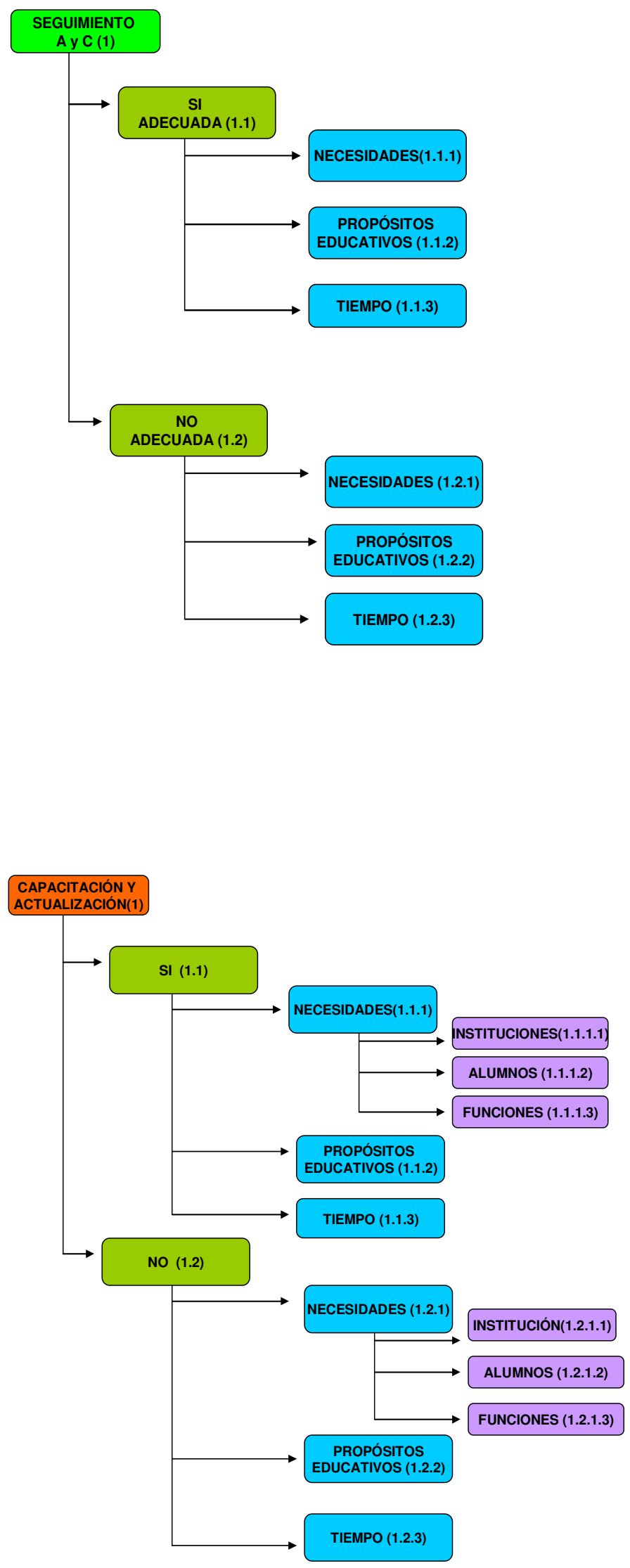


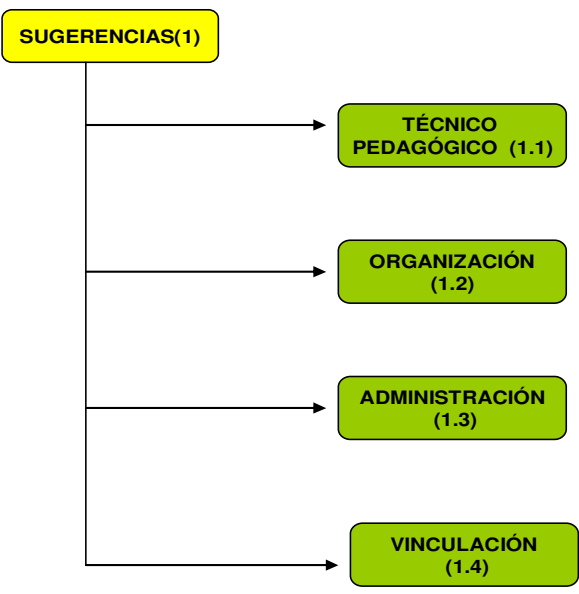

3.1.1.6.3. Diseño, aplicación y evaluación de un recurso digital en red, como propuesta para mejorar y optimizar la asesoría y capacitación técnica, en la modalidad de Educación Especial.

\section{1.-Diseño del Recurso Digital}

a).- Aspectos del diseño del espacio web como recurso digital.

Los portales educativos son espacios web que ofrecen múltiples servicios a los miembros de la comunidad educativa (profesores, alumnos, gestores de centros, familias, etc.), tales como información, instrumentos para la búsqueda de datos, recursos didácticos, herramientas para la comunicación interpersonal, formación, asesoramiento, entretenimiento, etc.

El diseño instructivo para la Web hace referencia a toda una serie de factores que como establece Santiago Campión (2002), el diseño instructivo aporta la adecuada coherencia pedagógica y didáctica que hacen que los materiales no sean simples textos electrónicos. 
Las teorías constructivistas parten de que los alumnos elaboran sus propios conocimientos mediante la interpretación de su experiencia personal de aprendizaje, tomando en cuenta sus creencias y conocimientos previos. En el constructivismo, aprendemos, cuando somos capaces de elaborar una representación personal sobre un objeto de la realidad o contenido que pretendemos aprender (Solé y Coll, 2000). Este enfoque parte de Piaget con el constructivismo cognitivo y Bruner y Vigotsky con el constructivismo social. Estas dos corrientes han encontrado en las TIC un medio especialmente apropiado para su aplicación (Crook, 1994; Jonassen, 1994a).

Una perspectiva de diseño tradicional establece un sistema cerrado en muchos aspectos, sobre todo orientados a los resultados. En cambio desde una perspectiva constructivista es necesario utilizar estrategias y crear materiales de carácter menos perceptivo, los contenidos deben de ser menos específicos, el alumno determina el camino que quiere seguir en el aprendizaje y la evaluación se ejerce sobre los procesos y no necesariamente sobre el producto, con un criterio menos cuantitativo.

La Web como un entorno de aprendizaje constructivista.

En los últimos años ha habido un gran interés en explorar el uso de la Web como medio educativo, como consecuencia se ha dedicado una atención especial al diseño instructivo de materiales para el aprendizaje a través de la WWW. La Web puede ser empleada desde un enfoque objetivista de la enseñanza como constructivista. La capacidad multimedia y su estructura de hipervínculos hacen que la Web sea apropiada para el constructivismo. De a cuerdo a Jonassen (1994b) un entorno de aprendizaje como este debe poseer las siguientes características.

- Promover múltiples características de la realidad.

- Evitar la simplificación excesiva de la instrucción mediante la representación de la complejidad natural del mundo real.

- Centrarse en la construcción del conocimiento, no en la reproducción.

- Presentar tareas autenticas en contexto. 
- Proporcionar entornos de aprendizaje basados en casos del mundo real, en lugar de series de instrucciones predeterminadas.

- Fomentar la reflexión práctica.

- Permitir la construcción del conocimiento a partir del contexto y el contenido.

- Apoyar la construcción del conocimiento en colaboración, mediante la negociación social entre los participantes y no mediante la competencia por el reconocimiento.

El Internet con todas las oportunidades y servicios que ofrece, se comprueba que satisface las características constructivistas expuestas. Es importante resaltar la forma en que la aparición del Internet ha revolucionado el campo de la información, la comunicación y el conocimiento, de tal manera que es relativamente sencillo y fácil que los alumnos y maestros se involucren en tareas que soportan un aprendizaje significativo. Además, otra de las características de la WWW, que puede ayudar en el proceso de enseñanza y aprendizaje, es la similitud existente entre la estructura de la red y la mente humana.

Desde una perspectiva colaborativa el diseño de web educativos debe tener estar marcado y elaborado por los criterios de calidad de materiales web (García-Valcárcel, 2003), estos criterios se tomaron en cuenta para el diseño de la página web de Educación Especial, tomando como punto de partida el objetivo de dicha página, considerando una serie de características que atienden a diversos aspectos funcionales, técnicos, estéticos y pedagógicos como son:

- Facilidad de uso.

- Calidad del entorno audiovisual.

- Calidad de los contenidos.

- Sistema de navegación, amigable.

- Bidireccionalidad.

- Potencialidad comunicativa.

- Originalidad.

- Capacidad de motivación.

- Adecuación a los usuarios. 
- Potencialidad de los recursos didácticos.

- Fomentar la iniciativa y el autoaprendizaje.

- Estructura hipertextual y multimedia.

\section{Diseño de la Interfaz del Sitio Web}

Para el diseño de un sitio web en general, es necesario hacer referencia al concepto de usabilidad, éste es un concepto clave en la IOP. La usabilidad de un sitio está relacionada estrechamente con la facilidad que éste sitio puede ofrecer para llevar acabo las tareas propuestas con eficacia y con agrado (Nielsen, 2000).

Partiendo de conclusiones de varias investigaciones presentadas por Nielsen (1997) en relación al tema de la usabilidad de un sitio web, se tomaron en cuenta al momento de diseñar la página web, como son:

- La mayoría de los usuarios no leen, sino que ojean la información.

- Los usuarios son impacientes y no quieren que se les entretenga con detalles triviales.

- La velocidad de la descarga de un sitio web es decisiva para la evaluación positiva de un sitio.

- Los elementos de animación a menudo resultan molestos.

- Los sitios que utilizan marcos tienen menos captación que los que no los utilizan.

- Los fondos de página muy destacados distraen la lectura.

- Las últimas tendencias reportan que los usuarios se desplazan más que antes a lo largo de la pantalla, pero con todo y ello no se diseño una página con demasiadas pantallas.

\section{b).- Características de la página web del Departamento de Educación} Especial de los Servicios Educativos del Estado de Chihuahua.

Con el objetivo de desarrollar una propuesta de mejora y optimización de la Asesoría Técnica de la modalidad de Educación Especial en el Estado de Chihuahua, se diseño una página web dispuesta en la red a partir del mes Febrero del 2008 en la dirección: http://www.seech.gob.mx/eduespecial/ con el 
nombre de Departamento de Educación Especial de los Servicios Educativos del Estado de Chihuahua.

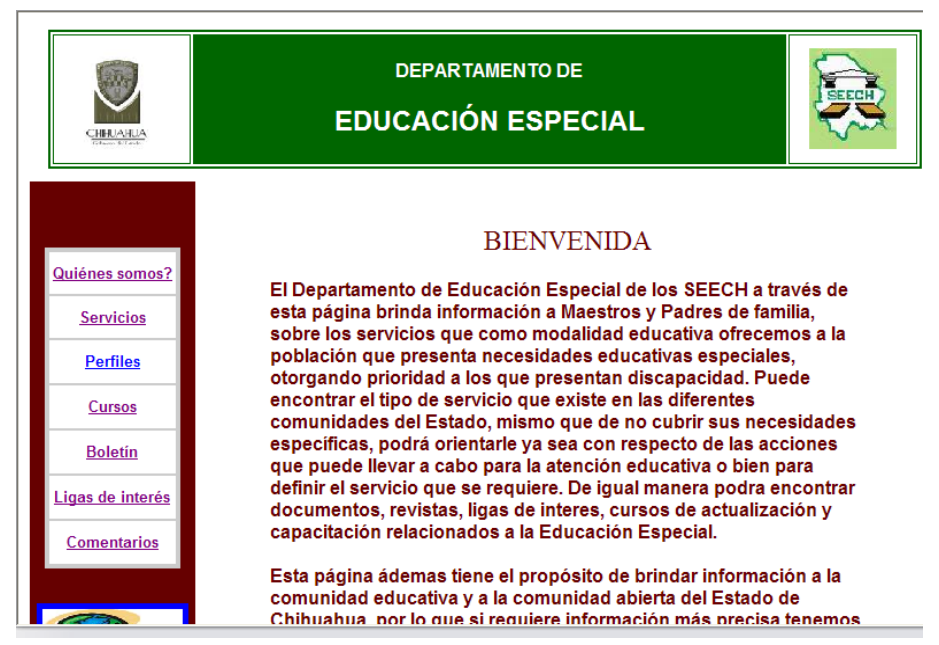

Figura 27 Presentación del Sitio Web

Para el diseño del recurso digital se siguieron una serie de pasos que a continuación se mencionan.

- Entrevista con la jefa del Departamento de Educación Especial del subsistema federalizado, para establecer formalmente la propuesta de la investigación y establecer los aspectos que serian necesarios incluir, tomando en cuenta las necesidades de los servicios en el Estado, como son:

- Información sobre los servicios de Educación Especial, su propósito, población que atiende, ubicación, zona escolar, directivo, etc.

- Cursos y talleres referentes a las diferentes áreas y discapacidades, debido a el diagnostico de necesidades técnicas aplicado al personal docente, al inicio del ciclo escolar 2007-2008.

- Documentos de consulta relacionados al marco técnico operativo de la modalidad de educación especial, a nivel internacional, nacional y estatal.

- Posibilidad de establecer enlaces, comunicación, consultas etc. con instituciones relacionadas a la educación básica y en específico a la Educación Especial. 
- Investigación de páginas web educativas a nivel nacional e internacional como son:

\section{Nombre de la Página Web}

-Secretaria de Educación Pública

$-I N I C O$

-ProNAP Unidad Estatal de Formación Continua.

-Servicios Educativos del Estado de Chihuahua.

-Secretaria de Educación y Cultura del Estado de Chihuahua.

- Inclusive TLC

-EducaRed

-Red Normalista

-Tecnoneet

-Educarchile

-Tecnologia Educativa Web Pere Marqués

\section{Dirección}

http://www.sep.gob.mx/index.jsp

http://inico.usal.es

http://pronap.chihuahua.gob.mx

http://seech.gob.mx/

http://www.chihuahua.gob.mx/sec/

http://www.inclusivetlc.com/

http://www.educared.net

http://normalista.ilce.edu.mx/normalista/index.htm

http://www.tecnoneet.org/

http://www.educarchile.cl

http://dewey.uab.es/pmarques/

- Investigar requisitos para diseñar una página oficial, en la Secretaria de Educación y Cultura del estado de Chihuahua, como logotipos oficiales, colores, correo electrónico etc.

La elaboración de los materiales educativos al ser publicados en la red presentan algunas ventajas del Internet que fueron aprovechadas (GarcíaValcárcel ,2003) para diseñar el sitio web como son:

- La posibilidad de comunicación, por medio de buzón de correo electrónico se puede establecer comunicación con la Jefa del Departamento de Educación Especial y con los asesores técnicos Estatales del Equipo de Apoyo a la Docencia, para plantear sus necesidades técnicas $y / 0$ operativas, solicitar capacitación y/o asesoría, solicitar información, documentos, compartir opiniones, etc. 
- Es un entorno propicio de aprendizaje para el trabajo cooperativo entre los profesionales de las Zonas escolares o de los servicios, con los ATP Estatales, Regionales o de Zona escolar, etc. dependiendo las necesidades de los profesionales, apoyándose en la información que esta a disposición en el sitio web, para satisfacer necesidades técnicas operativas que requieran.

- El acceso a la página web es fácil y económico, pudiendo tener acceso a toda la información publicada, relacionada al ámbito educativo y específicamente a la Educación Especial.

- Información a Maestros, Padres de Familia y comunidad en general, sobre los servicios que ofrece la Educación Especial en el Estado como son los Centros de Atención Multiple (CAM), Las Unidades de Servicios de Apoyo a la Escuela Regular (USAER), y los Centros de Recursos e Información para la Integración Educativa, la población que se atiende en los diversos servicios y la ubicación en el Estado.

- Documentos de consulta que requieren los Maestros sobre la Política Educativa de Educación Especial, revistas de educación a nivel nacional e internacional.

- Desarrollar habilidades que permitan buscar, seleccionar y organizar la información que cada profesional y padre de familia requiere.

- Enlaces de ligas de interés para los Maestros y profesionales de Educación Especial, de organismos e Instituciones educativas que tienen relación directa con el ámbito educativo, como: la Secretaria de Educación Publica, Programa Nacional para la Actualización Permanente de Maestros en Servicio. Unidad Estatal de Formación Continua, Instituto Nacional para la Evaluación de la Educación, Sistema Nacional de Información Educativa, Programa Estatal de Fortalecimiento de la Educación Especial y de la Integración Educativa, Evaluación Nacional del Logro Académico en Centros Escolares, Servicios Educativos del Estado de Chihuahua, Instituto Universitario de Integración en la Comunidad de la Universidad de Salamanca España, Fundación ONCE para la Cooperación e Integración Social de las personas con discapacidad, entre otras. 
- Uno de los aspectos de mayor importancia por el que se diseño el sitio web la modalidad de Educación Especial en el Estado de Chihuahua, es la necesidad apremiante en cuanto a la formación continua. El Programa Estatal de Fortalecimiento de la Educación Especial y de la Integración Educativa (2005) establece en su objetivo especifico de la línea 3, "Implementar y desarrollar programas de formación continua en relación con la atención de necesidades educativas especiales, aptitudes sobresalientes y la discapacidad, en el marco de la atención a la diversidad, dirigidos al personal de educación especial, inicial y básica en sus distintas modalidades. Impulsar la ampliación de la oferta de formación inicial en el campo de la Educación Especial en la entidad" (p.36).

De igual manera especifica, que la modalidad de Educación Especial, deberá diseñar e implementar a partir del 2006 y hasta el 2010 por lo menos una estrategia anual de capacitación y formación continua, dirigida al personal de Educación Especial, en base al diagnostico de necesidades de capacitación y formación continua del personal de Educación Especial, es por ello que se elaboraron cursos y talleres, diseñados por los Asesores Técnicos Estatales de la modalidad de Educación Especial, por aspectos relacionados a la discapacidad y a áreas específicas como son: Discapacidad Auditiva, Discapacidad Motora, Necesidades Educativas Especiales asociadas a problemas de Comunicación y Lenguaje, Área de Aprendizaje, Área de Trabajo Social y Área de Psicología. Tanto la planeación de los cursos y talleres, como las antologías de los mismos, se encuentran a disposición en la página web para quien los requiera, ya que estos cursos además de estar en el sitio web se implementan directamente con algunos servicios.

- Interactividad con los materiales y con las personas.

- Familiarización con al tecnología al utilizar el recurso digital. 


\section{Diseño Técnico Instructivo del Material.}

Es importante el diseño instructivo y su reflejo a la hora de definir los contenidos de la información y el objetivo de la misma a través de la WWW . Una vez que se definieron los elementos que iban a ser el soporte de la instrucción efectiva de los contenidos, pasamos a definir la forma reflejar todo en la página web de la modalidad de Educación Especial. Para ello fue necesaria la creación de distintas páginas con el contenido multimedia y los enlaces oportunos, utilizando el programa Macromedia Dreamweaver.

El formato de las páginas web es el denominado HTML (Hyper Text Marked Language). El HTML es un lenguaje de codificación sistemática, es decir de comunicación del significado de la información, que tiene la ventaja de que es relativamente sencillo para novatos. El lenguaje HTML nos permitió especificar los atributos de la página (color, tamaño, posición, etc.) de los distintos componentes de la página web (textos, tablas, etc.) y para establecer los vínculos entre los distintos bloques de contenido dentro de la misma página y con páginas externas, de igual manera de añadieron imágenes relacionadas a los temas (Díaz Marín, (2002).

La web se basa en un modelo de intercambio de información entre dos partes; un cliente que es nuestro ordenador en el que tenemos instalado el navegador que utilizamos para comunicarnos y un servidor que es en este caso, el ordenador remoto de los Servicios Educativos del Estado de Chihuahua al que se le solicita la información. La comunicación se puede establecer gracias a un protocolo común. La WWW trabaja con diversos protocolos cada uno es utilizado de acuerdo a un propósito especifico y limitado, así el protocolo FTP (File Transfer Protocol) es el utilizado para la trasferencia entre dos ordenadores y el protocolo SMPT (Simple Mail Transfer Protocol) utilizado para la transferencia de correo electrónico. Los navegadores como Internet Explorer o Netscape, se comunican con los servidores mediante el protocolo HTTP (Hiper Text Transfer Protocol). Por medio del protocolo HTTP del ordenador del cliente, que es el que busca la información, puede solicitar al servidor básicamente lo siguiente (Díaz Martín, 2002):

- Documentos que están alojados en el servidor, como toda la información y documentos que conforman el sitio web. 
- Descargar algún componente que podrá ejecutarse en el ordenador del usuario que lo requiere, cuando éste accede a esta página web.

- La ejecución de alguno de los programas en el ordenador remoto (servidor) pudiendo realizar determinadas acciones como cliente o usuario.

- La descarga de programas o documentos varios para instalarlos o emplearlos en el ordenador del usuario cuando lo requiera.

\section{Edición de la página Web}

Para editar la página no fue necesario conocer el lenguaje HTML, ni ningún otro tipo de lenguaje, ya que como señala Pérez (2001) los programas que se utilizan en la actualidad para editar páginas web se pueden emplear sin escribir una sola línea de código. Como anteriormente se menciono se utilizo el programa Macromedia Dreamweaver, el manejo del programa se realizo por iconos y menús, como cualquier otro programa de edición de textos o gráficos, facilitando numerosas herramientas y funciones de edición de código.

El programa Macromedia Dreamweaver nos permitió tener la posibilidad de redactar el contenido textual de acuerdo al objetivo de la página que es; aportar información a Maestros y Padres de Familia sobre los servicios que ofrece la modalidad de educación especial de los Servicios Educativos del estado de Chihuahua, la población que es atendida en los diferentes Servicios y la ubicación de los mismos. De igual manera se pueden encontrar documentos sobre la Política Educativa, revistas de educación a nivel nacional e internacional, una recopilación de diferentes ligas de interés, diversos cursos de actualización para los Maestros, un boletín informativo y un buzón de correo, incluyendo enlaces externos e internos.

En los últimos años se ha incrementado el interés en relación al diseño de sitios en la web dedicados a la enseñanza, debido a este suceso se han realizado algunos estudios (Lohr, 2000; Skaalid, 2001) con la intención de definir las líneas que hay que seguir a la hora de diseñar páginas web, que no sólo respondan a los objetivos instructivos para los que se crearon, sino que además sean atractivas y fáciles de utilizar, como en este caso. 


\section{Diseño de la Interfaz del Sitio Web}

Para la creación del sitio web se presenta los tres tipos de principios claves de percepción, para la creación de interfaces específicamente destinadas a la instrucción (Lohr 2000).

\section{- El principio de la figura y el fondo:}

Es importante establecer una clara distinción entre la información más y menos relevante. Ésta es la forma en que nuestra mente trata de organizar la información inconscientemente. Una forma de conseguir hacer esta distinción es por medio del contraste, ya sea por color o por tipografía (tamaño o tipo de fuentes, etc.). Una de las formas de destacar lo que se requería, fue utilizando elementos gráficos de distribución, como las tablas enmarcadas que hacen resaltar el contenido que encierran. El contraste visual como se presentan los elementos de la página es importante en la apreciación de lo que es más o menos importante, sobre todo tomando en cuenta que es lo primero que captan los lectores, al contrario de los objetos parpadeantes deslizantes o en continuo movimiento no son importantes para el usuario, ya que puede ser asociado con la publicidad al ser un mecanismo demasiado explicito para atraer la atención (Hassan, 2002). Se realizo un diseño con un equilibrio gráfico y de organización que permite despertar interés y motivarción del usuario, de forma sencilla y práctica sin ser aburrido por exceso o falta de contrastes.

\section{- Principio de la jerarquía:}

Partiendo de este principio la información se presenta en bloques o capas dispuestas de manera jerárquica. Para definir la jerarquía de la información se utilizaron diversas técnicas como.

- Se utilizo una estructura de cuadricula y se coloco la información de más rango en zonas de interfaz más relevantes. Esas zonas relevantes están determinadas por la jerarquización visual, de esta manera cuanto más cercas al ángulo superior izquierdo más relevancia visual se dará a la información. 
- Se empleo la misma estructura a lo largo de todas las páginas que comprenden la página web, de tal manera que el usuario siempre se encuentre orientado.

- Se utilizaron los mismos colores y formatos tipográficos que permitieron indicar la jerarquización de la información, usando los mismos atributos para elementos semejantes.

- Se indica al usuario donde se encuentra en cada momento y la relación jerárquica de esa página con el resto de la estructura del sitio.

- Se emplearon menús y tablas de contenidos que permiten a comprender la organización jerárquica del sitio.

- El principio de la Gestalt:

En relación a este principio, se agrupo la información, integrando las partes en un todo, empleando las siguientes técnicas en el diseño del sitio web:

- Se utilizo siempre la misma combinación de colores en todas las páginas que conforman el sitio.

- Se utilizo siempre el mismo tipo de fuente.

- Se utilizaron gráficos para crear una identidad visual en todas las páginas.

- Aplicación de la ley de la proximidad, dado que la mente suele percibir como una unidad aquello que se encuentra cerca en el espacio.

- Para conectar la información se utilizaron líneas.

- De igual manera se repiten elementos del diseño en cada página del sitio.

- Se utilizaron tablas, índices, etc. que para proveer a los usuarios de gran variedad de imágenes e información. 
Tomando en cuenta todo lo anterior, ahora nos centraremos en el diseño de la actividad instructiva concreta de la página web. (Oliver, Herrington y Omari, 1996; Latham, 1998; Milheim y Harvey, 1998; Lynch y Horton, 2001; Ko y Rossen, 2001) enfocándolo en los siguientes aspectos:

\section{El contenido de la página}

El contenido de la página está relacionado con el propósito de la misma, tomando en cuenta los siguientes aspectos:

Extensión: Dado que pocos usuarios leen textos largos en la pantalla, el contenido de la página es concreto y conciso. La información se presenta en párrafos pequeños para una mejor comprensión.

Fragmentación: la fragmentación en una página se produce cuando la información de la misma y los materiales para el aprendizaje se presentan separados e incoherentes. Para superar la fragmentación en la página que se diseño, se ofrece una introducción en la cual se informa sobre el objetivo de la misma y lo que se puede encontrar en ella, además de que la estructura presenta un menú con hipervínculos del contenido facilitando la relación entre ellos.

Referencia: la página cuenta con enlaces a otros documentos relacionados con el contenido y propósito de la misma.

\section{La composición de la página:}

Para la composición de la página web del Departamento de Educación Especial de los Servicios Educativos del Estado de Chihuahua se contemplaron los siguientes aspectos:

\section{Distribución:}

Para la distribución de los contenidos se tomo en cuenta la jerarquización de la información, así como también la presentación en la jerarquización visual. La 
página se dividió en zonas, relacionando el contenido de la información con la presentación visual, destacando la información para los diferentes usuarios como lo son los Maestros y los Padres de familia principalmente y la comunidad en general.

En el diseño de la página se tuvo cuidado de no saturarla con textos y/o imágenes más de las necesarias, utilizando tablas que permiten la distribución de la información, de tal manera que la información se visualiza y se lee con facilidad.

\section{Longitud de la página:}

Una página web no tienen limite de longitud, pero no es recomendable que exceda en gran medida la pantalla porque esto obliga a avanzar con el cursor, además de que obliga al lector a memorizar lo que no esta a la vista. Esta página no excede en gran medida la pantalla, el usuario puede tener la mayoría de la información a la vista en la pantalla.

\section{Tipografía, instrucciones y multimedia:}

En cuanto a la tipología, se utilizo de manera homogénea el mismo tipo de letra, aun y cuando para resaltar algunos aspectos se utilizo negritas, no en exceso, para no dejar de tener el efecto que se buscaba.

Se utilizaron tablas para la instrucción permitiendo organizar el contenido de la información y una mejor navegación por la página. Así mismo se utilizaron imágenes y fotografías en formatos GIF y JPG referidas a la información presentada.

La posibilidad de añadir elementos multimedia es una de las ventajas de la Web. El formato multimedia que se utilizo para la página no requiere de ningún programa adicional.

La Web es un espacio en constante movimiento donde no dejan de aparecer nuevos sitios dedicados a la educación y a facilitar la incorporación de las nuevas tecnologías en el aula, ofreciéndose en muchos casos, de manera gratuita a los docentes de todo el mundo. Esto significa que los sitios web que aquí proponemos para consulta pueden ir cambiando con el tiempo o desaparecer, así como aparecer otros sitios con nuevas y mejores 
herramientas. Consideramos que la selección que aquí se presenta es representativa y sirve de guía para los usuarios.

\section{La administración de los materiales en la web.}

Los materiales que se encuentran en el sitio a disposición de los usuarios son documentos relacionados a la Política Educativa de Educación Especial Nacional y Estatales, como: son los Programas Educativos, Leyes de Educación, Leyes para las Personas con Discapacidad, Antologías de Diferentes Cursos relacionados a diferentes discapacidades y a áreas específicas como Psicología y Trabajo Social, Revistas de educación y/o de Investigación Nacionales e Internacionales, Información de Instituciones Educativas que tienen relación directa con la formación continua de los Maestros y Información de Organismos relacionados a la educación en general y en especifico con la Educación Especial.

A continuación se especifican las herramientas del sitio web diseñado.

- Menú lateral que facilita la navegación a través de los distintos contenidos y recursos. Como son: ¿Quienes somos?, Servicios, Perfiles, Cursos, Boletín, Ligas de Interés y Comentarios.

- Información general sobre: ¿Quienes somos? Misión y Visión de la modalidad de Educación Especial.

- Servicios: primeramente se presenta información sobre los propósitos educativos de cada servicio, así como la población y niveles educativos que atiende, igualmente se presenta información de las zonas escolares y de los servicios de Educación Especial en el Estado, la información esta organizada bajo tres criterios de búsqueda que son; por escuela, por zona escolar o por comunidad de acuerdo a los requerimientos del usuario.

- El aspecto de Perfiles presenta información especifica del sitio de utilidad para a Maestros y a Padres simplificando la navegación de la información por el sitio. 
- Cursos: en este especio se presentan cursos diseñados por los ATP del estado sobre Discapacidad auditiva, motora, NEE asociadas a problemas de Comunicación y Lenguaje, Área de Aprendizaje y cursos sobre áreas específicas como son Psicología y Trabajo Social. Todos los cursos se pueden bajar directamente del sitio.

En este mismo espacio de cursos se encuentran documentos de corte nacional y estatal relacionados con la Política Educativa como son: Programas Educativos, Leyes de educación y para las personas con Discapacidad. De igual manera se encuentran revistas nacionales e internacionales relacionadas a la educación en general y en específico a la Educación Especial. Algunos de los documentos se pueden bajar directamente y otros se enlazan al sitio respectivo.

- Boletín: se presenta el boletín de la modalidad de Educación Especial que contiene información de las actividades que se llevan acabo en el Estado de Chihuahua, en relación a la vinculación con diferentes organizaciones e instituciones.

- Ligas de Interés: las ligas de interés se presentan en una tabla con información sobre diferentes instituciones y organismos de nivel nacional e internacional relacionados a la educación en general y particularmente a la Educación Especial, con un vínculo a cada sitio que se presenta.

- Comentarios: en este especio el usuario tiene la posibilidad de enviar comentarios, solicitudes, etc. al departamento de Educación Especial, pudiendo establecer comunicación por medio de correo electrónico.

- Correo electrónico: el sitio contiene un vínculo directo para enviar correo electrónico sobre necesidades técnicas, solicitudes de algún servicio, etc. que requiera el usuario.

Es importante señalar que se ira actualizando el sitio web conforme a los cambios que se requieran de personal, técnicos operativos, etc. 


\section{2.-Evaluación del Diseño del Sitio Web por Expertos}

Con esta finalidad se diseño y aplicó una encuesta que responde a una finalidad descriptiva especifica y concreta, como un primer acercamiento al sitio web, para posteriormente poder estudiarlo con mayor profundidad.

La encuesta nos permite recoger información de los sujetos a partir de la formulación de preguntas a través de una entrevista personal, por teléfono o correo electrónico como en este caso.

Con el propósito de evaluar desde un punto de vista técnico pedagógico el sitio web diseñado con el objetivo de fortalecer la capacitación y actualización de la asesoría técnica, se ha utilizado la técnica de evaluación por expertos.

Determinamos realizar las encuestas por internet dado que las fortalezas de realizar una encuesta por internet son (Torrado, 2004):

- El bajo coste y mayor rapidez.

- No se requiere de entrevistadores, evitando los posibles sesgos del entrevistador.

- Al entrevistador le produce mayor sensación anonimato.

- Permite acceder a las poblaciones de difícil acceso.

- Evita errores de codificación etc.

- Facilita el análisis cuantitativo de la información recogida.

La encuesta que se utilizo tanto para la evaluación de expertos como para evaluar la utilidad del portal es una adaptación de la Ficha para la Catalogación y Evaluación de Portales Educativos diseñada por Pere Marqués-USAB, 2004 (Ver Anexo V). Para la selección y adaptación de la misma se tomaron en cuenta algunas características de presentación especiales, ya que como menciona Torrado (2004) es un tipo de encuesta de autocumplimentación por lo tanto:

- El aspecto de la encuesta es fácil y atractivo de responder, inicia con una introducción donde se presenta el nombre del portal y los principales servicios que proporciona, después se utilizaron tablas para la 
organización de las preguntas y respuestas, diferenciando las partes del cuestionario.

- La redacción es clara, tanto en las instrucciones como en las preguntas, utilizando frases como "marque con una cruz donde proceda la valoración".

- La distribución del contenido facilita su cumplimentación, las cuestiones referentes al mismo tema están juntas, son preguntas sencillas organizadas por temas como son: Aspectos Funcionales, Aspectos Técnicos y Estéticos, y Aspectos Pedagógicos, que se deben evaluar a partir de una escala de 4 valores;

- Baja: Si considera que la característica del aspecto que se está evaluando esta mal.

- Correcta: Si considera que la característica del aspecto evaluado es correcta.

- Alta: Si considera que la característica de este aspecto esta muy bien.

- Excelente: Si considera que es casi inmejorable la característica de este aspecto.

Por ultimo se realizará la evaluación global, donde además de establecer una valoración numérica, se recogen observaciones complementarias que quiera hacer el evaluador.

- Al final de la encuesta se informa que su participación es importante y que su valioso criterio en la valoración del instrumento servirá de aporte y sustentación para los cambios pertinentes a que haya lugar, a fin de mejorar la calidad del portal y se agradece su participación.

Junto con el cuestionario incluimos una carta de presentación (Ver Anexo V) donde explicamos quienes somos y damos a conocer claramente el objetivo de la encuesta y su importancia. También se presenta de manera explicita los aspectos que conforman la encuesta y los parámetros de evaluación que se utilizan, así como la importancia de su colaboración y el agradecimiento. 
En la selección y modificación de la encuesta se tomaron en cuenta una serie de aspectos como son:

- El objetivo de la encuesta es evaluar, en un primer momento, el portal educativo, diseñado como una Propuesta para la mejora y optimización de la Asesoría Técnica en la modalidad de Educación Especial en el Estado de Chihuahua en México, por expertos en las áreas de las TIC y de Educación Especial.

- Al tener claro el objetivo de la encuesta, así como la técnica de recogida de información, se selección y adecuo, la Ficha para la Catalogación de Portales Educativos de Pere Marqués-UAB (2004), que contempla varios aspectos relacionados al diseño de portales educativos como son: Aspectos Funcionales, Técnicos y Estéticos, y Pedagógicos, a los cuales se les realizo adecuaciones necesarias al diseño del sitio.

- El instrumento para la recolección de datos esta estructurado por 19 items, admitiendo una única posibilidad de respuesta, las cuales puedes ser contestadas marcando con una $x$ alguna de las 4 respuestas que aparecen como son: Baja, Correcta, Alta y Excelente. En otro de los apartados aparece la posibilidad de hacer observaciones sobre aspectos positivos, aspectos negativos u otras observaciones en relación al portal.

- El análisis de la validez y fiabilidad de la encuesta se determino al ser utilizado un instrumento que ya ha sido validado, antes de la fiabilidad, los indicadores se validan proporcionado una representación adecuada del concepto teórico que miden (Cea, 2001), cumpliendo el objetivo para el cual fue diseñado y seleccionado.

- La redacción final para su aplicación consta de 19 items, admitiendo una sola respuesta, otro de los aspectos que contiene son las observaciones de aspectos positivos y negativos, el lenguaje utilizado es adecuado al ámbito de la educación y las TIC.

Se dio seguimiento a las encuestas que se enviaron por medio del correo electrónico, siendo necesario enviarlos en dos ocasiones, dando de plazo de un mes y medio para responder. 


\section{3.-Evaluación de la Utilidad del Sitio Web por Usuarios}

Como anteriormente se mencionó la encuesta que se selecciono es la Ficha de Catalogación de Portales Educativos de Pere Marqués-USAB (2004), en esta ocasión las adecuaciones que realzamos tienen el propósito de evaluar la utilidad del sitio web, desde el punto de vista técnico pedagógico, diseñado con el objetivo de fortalecer la capacitación y actualización de la asesoría técnica en Educación Especial.

Con las adecuaciones realizadas a la ficha se establecieron las características específicas de la encuesta (Ver Anexo VI) como son:

- El aspecto de la encuesta esta elaborado con un lenguaje fácil y atractivo de responder, inicia con la presentación de los datos generales del encuestado como son: Servicio y/o Institución, Zona, Ubicación y Función.

- El siguiente aspecto es la presentación de la encuesta, donde se especifica los aspectos que evalúa, además del objetivo de la misma, si conoce la página o no, además de hacer una invitación a entrar en ella, presentando la dirección del sitio y aspectos generales que contiene.

- La redacción es clara tanto en las instrucciones, como en las preguntas, utilizando frases como "marquen con una cruz donde proceda la valoración".

- La distribución del contenido facilita su cumplimentación, están juntas las cuestiones de cada tema, son preguntas sencillas, organizadas por temas como son: Aspectos Funcionales, Aspectos Técnicos y Estéticos, y Aspectos Pedagógicos, que se deben evaluar a partir de una escala de 4 valores:

- Baja: Si considera que las características del aspecto que se está evaluando esta mal.

- Correcta: Si considera que la característica del aspecto evaluado es correcta.

- Alta: Si considera que la característica de este aspecto esta muy bien. 
- Excelente: Si considera que es casi inmejorable la característica de este aspecto.

Al final se presenta la evaluación global, donde además de establecer una valoración numérica, se recogen observaciones complementarias que el evaluador quiera hacer.

Para la selección y adecuación de la encuesta se tomaron en cuenta una serie de fases como son:

- El objetivo de la encuesta es evaluar la utilidad del portal educativo, diseñado como una Propuesta para la mejora y optimización de la Asesoría Técnica en la modalidad de Educación Especial en el Estado de Chihuahua en México, por diferentes profesionales de Educación Especial.

- Al tener claro el objetivo de la encuesta, así como la técnica de recogida de la información, se selecciono la Ficha para la Catalogación de Portales Educativos de Pere Marques-UAB (2004), que contempla varios aspectos relacionados a la utilidad como son: Aspectos Funcionales, Técnicos y Pedagógicos, los cuales se adecuaron contemplando aspectos relacionados a la utilidad desde el punto de vista técnico pedagógico.

- El instrumento para la recolección de datos esta compuesto de 19 Items, admitiendo una única posibilidad de respuesta, con una escala de 4 valores que son: Baja, Correcta, Alta y Excelente. En otro de los apartados aparece la posibilidad de hacer observaciones sobre aspectos destacables y mejorables del portal.

- La validez y fiabilidad se determino al ser al utilizar un instrumento que ya ha sido validado, proporcionando una representación adecuada del concepto teórico que van a medir.

- Finalmente la encuesta consta de 19 items, admitiendo una sola respuesta, además de observaciones de los aspectos destacables y mejorables, utilizando un lenguaje adecuado. 
La aplicación del instrumento se llevo acabo en el mes de septiembre del 2008, después de haber presentado el sitio web puesto en la red, en reuniones de consejo técnico estatal, reuniones de consejo técnico regional, reuniones de consejo técnico de zona escolar y en reuniones técnicas de los diferentes servicios. También se dio promoción y difusión en los diferentes servicios, por parte de los ATP Estatales, en la capacitación de los mismos cursos que se encuentran en el portal. 


\section{CAPÍTULO 4: ANÁLISIS DE RESULTADOS DE LA INVESTIGACIÓN}

Las técnicas de análisis de datos recopilados son de carácter tanto cuantitativo y cualitativo de acuerdo al objeto de estudio, ya que rebasa la simple recolección y tabulación de datos, suponiendo un elemento interpretativo del significado. Al respecto Massot, Dorio y Sabariego (2004) establecen que a medida que se tiene un mayor contacto con los informantes y se comprende la realidad del objeto de estudio se va completando y precisando la información.

Las estrategias que se determinaron utilizar en esta investigación, como ya se ha mencionado es la técnica de Análisis de Contenido, por ser considerada adecuada a los propósitos de la misma, así como también la técnica cuantitativa de análisis descriptivo de datos.

Los objetivos propuestos y la comprobación de las hipótesis que se formularon en esta investigación, hicieron necesario una selección de la muestra de la población con la que trabajamos, así como la creación, selección y adecuación de los instrumentos de recogida de información.

Instrumentos que se utilizaron:

A. Análisis de Contenido de los documentos de 1996 a 2010, relacionados a la Política Educativa de la modalidad de Educación Especial en el Estado de Chihuahua, sobre el uso de las TIC .

B. Diseño y aplicación de una encuesta para conocer el contexto y operatividad técnica de los servicios de la modalidad de Educación Especial, así como también evaluar el impacto de la capacitación y actualización.

C. Diseño de un recursos digital en red para la modalidad de Educación Especial, como una propuesta de mejora de la asesoría técnica, selección y adecuación de una encuesta para evaluar en un primer momento el diseño el sitio web por expertos, y en un segundo momento para evaluar la utilidad del sitio web por usuarios. 
A continuación presentamos los resultados obtenidos en cada uno de las fases que se llevaron acabo a lo largo de la investigación.

\subsection{Análisis de la Política Educativa del estado de Chihuahua México, sobre el uso de las TIC en la modalidad de Educación Especial, de 1996 a 2010.}

Una de las primeras de fases de esta investigación fue la realización de lecturas y selección de documentos bibliográficos relacionados al tema de las TIC en la educación y específicamente en la Educación Especial, Política Educativa de la modalidad de Educación Especial, Normatividad técnica operativa de Educación Especial, Formación continua, entre otros.

Para la realización del muestreo documental, seleccionamos los documentos que están relacionados directamente a la Política Educativa de la modalidad de Educación Especial en el Estado de Chihuahua. Los documentos oficiales seleccionados se presentan a continuación en el cuadro 20.

\begin{tabular}{|c|c|c|}
\hline \multicolumn{3}{|c|}{ Documentos de la Política Educativa. } \\
\hline Tipo & Nombre & Fecha \\
\hline \multirow{4}{*}{$\begin{array}{l}\text { Documentos } \\
\text { Legales }\end{array}$} & $\begin{array}{l}\text { Ley para las Personas con Discapacidad con } \\
\text { Discapacidad en el Estado de Chihuahua. }\end{array}$ & $\begin{array}{c}30 \text { de Noviembre de } \\
1996\end{array}$ \\
\hline & Ley General de las Personas con Discapacidad. & 10 de Junio del 2005 \\
\hline & Ley Estatal de Educación. & $\begin{array}{l}18 \text { de Septiembre de } \\
2004\end{array}$ \\
\hline & Ley General de Educación. & 22 de Junio de 2006 \\
\hline \multirow{4}{*}{$\begin{array}{l}\text { Programas } \\
\text { Educativos }\end{array}$} & $\begin{array}{l}\text { Programa Estatal de Fortalecimiento de la } \\
\text { Educación Especial y de la Integración Educativa. }\end{array}$ & $2005-2010$ \\
\hline & Programa Estatal de Educación. & $2005-2010$ \\
\hline & Programa Nacional de Educación. & 2001-2006 \\
\hline & $\begin{array}{l}\text { Programa Nacional de Fortalecimiento de la } \\
\text { Educación Especial y de la Integración Educativa. }\end{array}$ & 2002 \\
\hline
\end{tabular}

Cuadro 20: Relación de documentos de la Política Educativa de Educación Especial.

El objetivo de está selección de documentos, es investigar sobre los planteamientos de la utilización de las TIC en la normatividad técnica y operativa de la Educación Especial, establecida en los documentos que 
conforman la Política Educativa de 1996 a 2005, para lo cual se utilizo la técnica de "Análisis de Contenido", que nos permitió decodificar los mensajes, latentes y ocultos de los diferentes documentos, generando interpretaciones, información y conclusiones.

Se realizaron lecturas y relecturas de los documentos, con lo que fueron saliendo aspectos importantes relacionados al tema de investigación, dichos temas se fueron organizando en un sistema de relaciones entre conceptos de forma jerárquica. El sistema de relaciones fue variando sistemáticamente, depurando, integrando y modificando elementos, de acuerdo a las reflexiones, necesidades e inquietudes que fueron apareciendo.

Para realizar el análisis de contenido seleccionamos el programa informático NUD IST 4 permitiendo agrupar y organizar la información en forma jerárquica, desglosando el contenido, agrupando los temas, identificando categorías y subcategorías.

La selección y formulación de las categorías de análisis es una de las fases más significativa de este proceso, organizándola en base a la revisión teórica, los objetivos propuestos, la fundamentación de la técnica de análisis de contenido y el preacercamiento a los textos de análisis.

El sistema de categorías se denomino: Las TIC en la Educación Especial, el principal eje es la categoría de Educación Especial, del cual emergen dos subcategorías que son por un lado el Marco Legal y por otro los Programas Educativos, cada una de ellas están conformadas por 34 categorías respectivamente, haciendo un total de 69 categorías, que nos permitieron establecer el análisis de cada una de ellas y la comparación entre las dos grandes dimensiones.

Una vez delimitadas las unidades de análisis de aquí en adelante llamas indistintamente categorías, se paso a la codificación de las unidades de significación en función de su frecuencia de aparición en el texto. De esta forma se estructuró y sistematizó toda la información disponible, sobre cada una de las categorías definidas. 


\subsubsection{Información de los Resultados}

El análisis de resultados se establece en base a la información que reporta el NUD IST 4 una vez terminado el proceso. Esta información está referida a la frecuencia de cada categoría, en las unidades de registro de cada documento con su respectivo porcentaje, así como también el porcentaje que representa la frecuencia total de los 8 documentos analizados, permitiendo establecer una comparación entre las dos grandes categorías.

Finalmente el proceso de análisis de los datos se completó en esta etapa en donde se interpretaron los resultados presentados en graficas y/o tablas que dan una visión específica y global, permitiendo formular una serie de conclusiones. En el Anexo VII se pueden ver las tablas de las unidades de análisis de cada documento.

En la tabla 5 se presenta la información de cada uno de los documentos analizados, de acuerdo a las categorías establecidas, presentando las frecuencias y porcentajes en relación al total de las unidades de registro.

\begin{tabular}{|l|c|c||c||}
\hline \multicolumn{1}{|c|}{ Documento } & $\begin{array}{c}\text { Total de } \\
\text { Unidades } \\
\text { de Registro }\end{array}$ & Frecuencias & $\begin{array}{c}\text { \% Según } \\
\text { Unidades de } \\
\text { Registro }\end{array}$ \\
\hline $\begin{array}{l}\text { Ley para personas con Discapacidad en el } \\
\text { Estado de Chihuahua. }\end{array}$ & 145 & 12 & 8,3 \\
\hline \hline Ley General de las personas con Discapacidad. & 161 & 22 & 14 \\
\hline Ley estatal de Educación. & 793 & 12 & 1,5 \\
\hline \hline Ley General de Educación. & 296 & 15 & 5,1 \\
\hline $\begin{array}{l}\text { Programa Estatal de Fortalecimiento de la } \\
\text { Educación Especial y de la Integración } \\
\text { Educativa. }\end{array}$ & 219 & 38 & 3,4 \\
\hline \hline Programa Estatal de Educación 2005-2010. & 638 & 22 & 2,8 \\
\hline \hline Programa Nacional de Educación 2001-2006. & 2761 & 78 & $\mathbf{4 , 8}$ \\
\hline $\begin{array}{l}\text { Programa Nacional de Fortalecimiento de la } \\
\text { educación Especial y de la Integración } \\
\text { Educativa. }\end{array}$ & 320 & 56 & $\mathbf{2 5 5}$ \\
\hline \hline \\
Total
\end{tabular}

Tabla 7: Resultados del Análisis de las Frecuencias de las Categorías de los Documentos. 
La tabla 7 es el resultado del análisis de las frecuencias de las categorías establecidas, en relación al total de unidades de registro, donde se puede observar que los Programas Educativos tienen un porcentaje mayor, dado que se enuncia más la utilización de las TIC que en las Leyes.

A continuación se muestra en gráfica, la comparación entre las dos grandes categorías, Marco Legal y Programas, con el porcentaje calculado según las 5333 unidades de registro del total de los 8 documentos oficiales resultados del NUDIST.

\section{- Educación Especial}

En la gráfica 1 se muestra las dos grandes dimensiones definidas en el Sistema de Categorías, observando que los Programas Educativos, tiene un mayor sustento en las categorías sobre el uso de las TIC, con un 3,6\%, del total de unidades de registro, en comparación con el Marco Legal que se reporta un $1,1 \%$

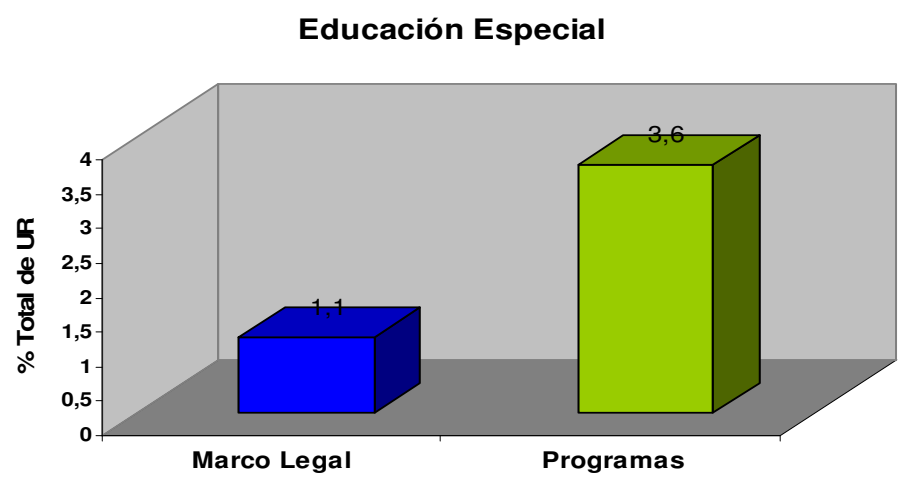

Gráfica 1: Resultado del análisis de las categorías "Marco Legal" y "Programas".

\section{- Fundamentos}

El análisis de los fundamentos de las dos grandes categorías, reporta un mayor porcentaje de las categorías de los Programas Educativos. La categoría Integración representa un 3,5\% del total de unidades de registro, siendo la más beneficiada, seguida por la Inclusión y la Calidad de Vida con un porcentaje de 1,5 (Ver Gráfica 2). 
Las categorías del Marco Legal se observan con un porcentaje menor, en la Integración se reporta un $0,99 \%$ del total de unidades de registro, mientras que en la Inclusión presenta un de 0,30\% y en Calidad de Vida 0,26\% de las unidades.

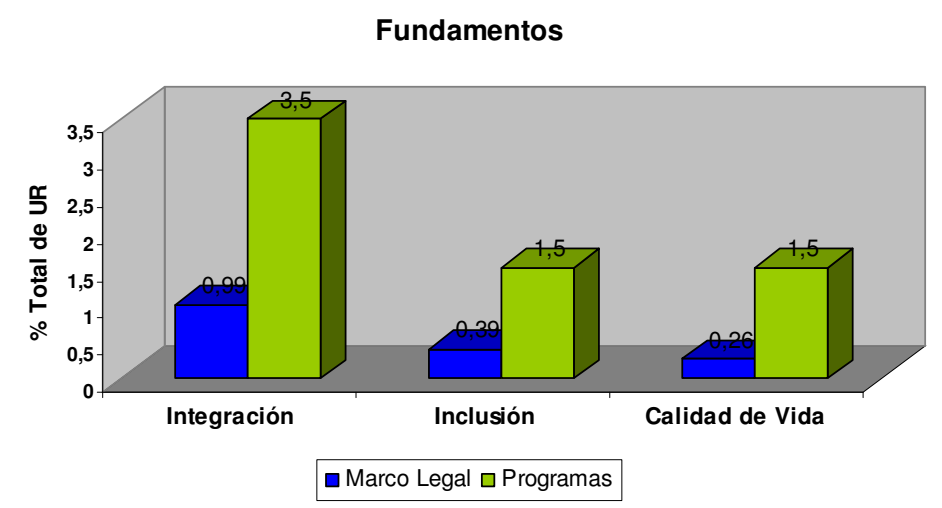

Gráfica 2: Resultado del análisis de las categorías "Integración"," Inclusión" y "Calidad de Vida".

\section{- Integración}

En la grafica 3, se muestra el desglose de la categoría Integración; la Relevancia que contempla las necesidades y el desarrollo del alumno, en los Programas presenta el mayor porcentaje con 1,4 del total de unidades de registro. La Eficacia que refleja el planteamiento de los propósitos educativos, refleja un porcentaje de 0,32 del total de unidades de registro en los Programas y de $0,3 \%$ unidades de aparición en el Marco Legal, observando una diferencia mínima entre ellos. Por otro lado la categoría de la Equidad que contempla la atención diferenciada para los alumnos, tomando en cuenta las necesidades y capacidades de cada uno, reporta un $1 \%$ en los Programas, a diferencia del Marco Legal que reporta un $0,3 \%$. Así mismo la categoría que corresponde a la Eficiencia que se relaciona con los recursos diferenciados y el material didáctico dentro del cual esta el material especifico y el uso de las TIC, sobresale con un $1,3 \%$ de unidades de registro relacionadas a los Programas Educativos, en comparación al Marco Legal que reporta un $0,23 \%$ de unidades de aparición. 


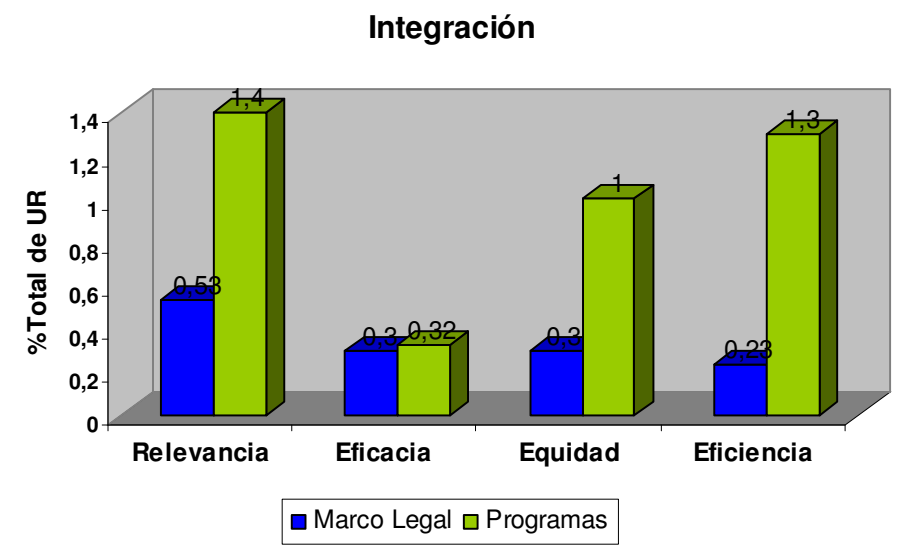

Gráfica 3: Resultado del análisis de las categorías "Relevancia", "Eficacia", "Equidad" y "Eficiencia".

\section{- Inclusión}

La categoría Equidad dentro de la Inclusión que se refiere a contemplar la diversificación de métodos, técnicas y material didáctico, contemplando el uso de las TIC, se menciona mayormente en los Programas Educativos reportando un porcentaje de 1,5 unidades, mientras que en los documentos del Marco Legal se enuncia un porcentaje de 0,38 unidades. Por otro lado la categoría de Contexto presenta un mínimo el porcentaje de unidades de registro en el Marco Legal, que es de 0.02 unidades, mientras que en los Programas no esta representado en ninguna, reportando un porcentaje de 0 unidades. Los datos se presentan en la gráfica 4.

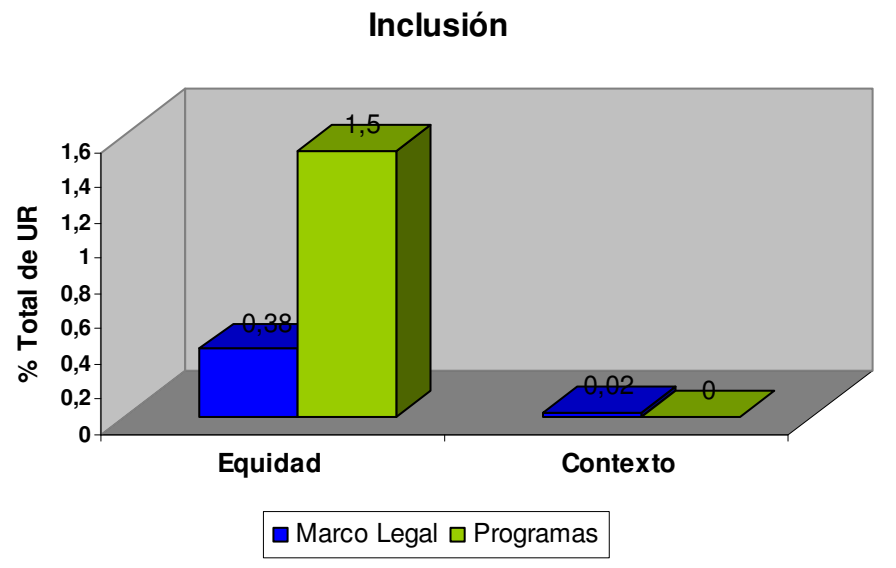

Gráfica 4: Resultados del análisis de las categorías "Equidad" $y$ "Contexto" 
El Material Didáctico tiene un mayor número de unidades de registro, relacionado a la diversificación del material y utilización de las TIC, sobre todo en los Programas Educativos siendo de un 1,3\%, mientras que en el Marco Legal es de 0,24\%. Por otro lado las Técnicas de enseñanza y aprendizaje, también se contemplan un mayor número en los Programas, siendo de un $0,3 \%$, mientras que en el Marco Legal es de un 0,17\%. Así mismo en la categoría de Métodos el Programa reporta un $0,47 \%$ del total de unidades de registro, en comparación del Marco Legal que es de un 0,04\% de unidades. (Ver Gráfica 5).

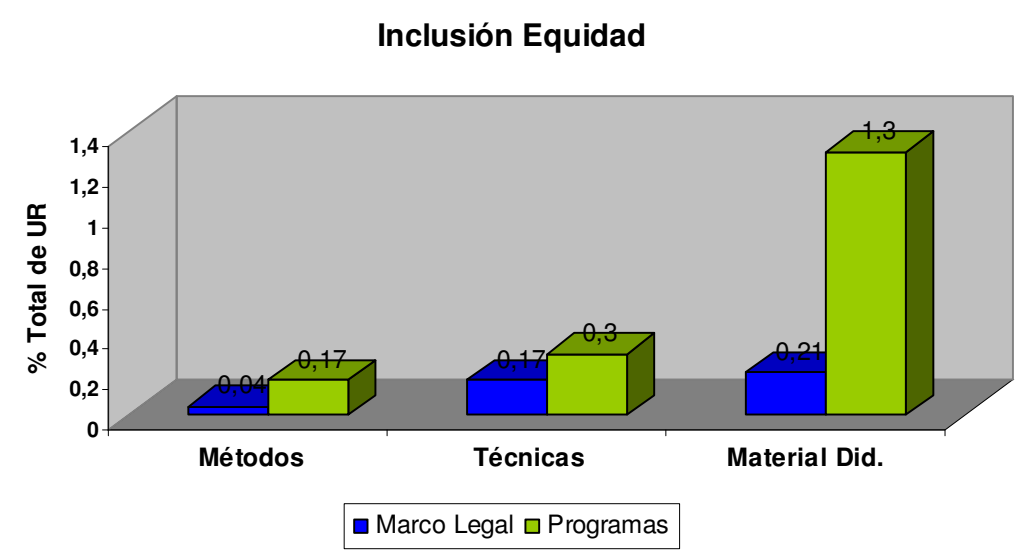

Gráfica 5: Resultados de los análisis de las categorías de "Métodos", "Técnicas" y "Material Didáctico"

\section{- Calidad de Vida}

El análisis del contenido de los documentos indica que en la categoría de Calidad de vida, la equiparación de oportunidades que contempla las Necesidades fundamentales de los alumnos, mostrando en los Programas Educativos un mayor porcentaje de aparición siendo de un 0,21 del total de las unidades de registro, en comparación al 0,08\% que tiene el Marco Legal (Ver Gráfica 6). Así mismo los Recursos Diversificados para la educación relacionados a la multiplicación y diversificación de los recursos, entre los que se encuentra el uso de las TIC, tienen una mayor aparición en los Programas siendo de un 1,3\%, mientras que un $0,23 \%$ se presenta en el Marco Legal. 


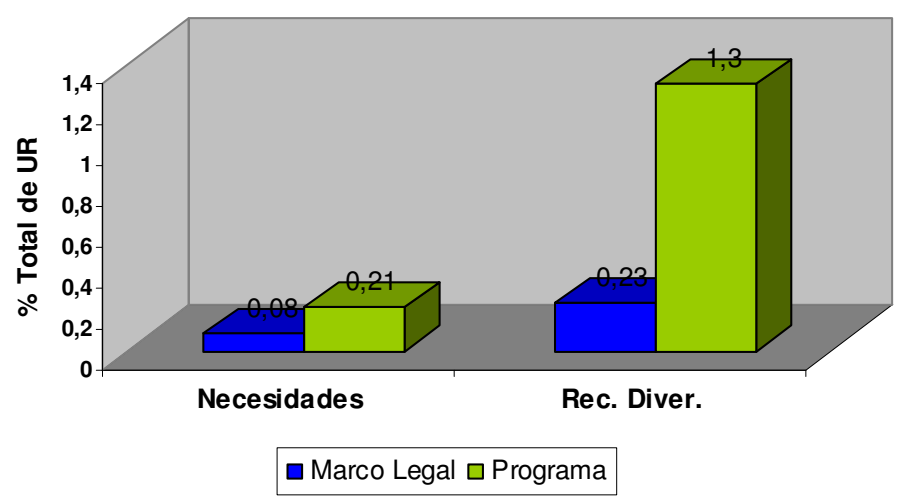

Gráfica 6: Resultados del análisis de las categorías "Necesidades" y "Recursos Diferenciados

El material específico relacionado a la atención de las diferentes discapacidades, aparece en un mínimo porcentaje sobre todo en el Marco Legal, siendo de un $0,02 \%$ de unidades de aparición, en comparación con los Programas, aun y cuando es un porcentaje mínimo de 0,54 en relación al total de unidades de registro. Por otro lado el uso de la tecnología utilizada en la diversificación de los recursos y materiales educativos, así como en la accesibilidad, aparece con un mayor porcentaje en los Programas Educativos indicando un $0.70 \%$, mientras que el Marco Legal tiene un $0,21 \%$ de unidades de registro (Ver Gráfica 7).

Es importante resaltar que al igual que en la categoría de Material Didáctico Específico, la Tecnología para la accesibilidad, aparece en un porcentaje mínimo en relación al 100\% de unidades analizadas.

Calidad de Vida Material Didáctico

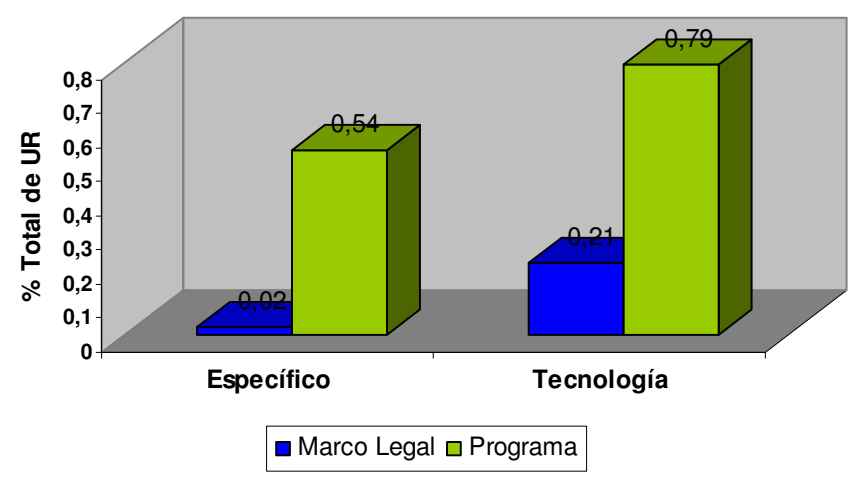

Gráfica 7: Resultados de los análisis de las categorías Material "Específico" y "Tecnología" 


\section{Conclusiones}

En esta fase de la investigación se utilizo la técnica de Análisis de Contenido, en los documentos representativos de la Política Educativa, de la modalidad de Educación Especial en el Estado de Chihuahua en México, en relación al uso de las TIC con finalidades educativas, conformado por Leyes de Educación y para la atención de las Personas con Discapacidad, así como por los Programas Educativos Nacional, Estatales y por los Programas de Fortalecimiento de la Educación Especial y de la Integración Educativa Nacional y Estatal.

Los resultados obtenidos reportan las siguientes conclusiones:

- El uso de las TIC en la Educación Especial esta establecido en un mínimo porcentaje en la Política Educativa, principalmente en los Programas Educativos, relacionado con la diversificación de los recursos, material didáctico y la accesibilidad, en la atención a las necesidades educativas especiales de los alumnos principalmente asociados a discapacidad y las aptitudes sobresalientes.

- Se le otorga mayor importancia a categoría de la Integración, cuyo objetivo es el de mejorar las condiciones de todos los alumnos atendidos por Educación Especial, tomando en cuenta su ritmo y estilo de aprendizaje para el logro de los propósitos educativos y su participación plena en el ámbito escolar, para lo cual se propone la diversificación de los recursos entre ellos la utilización de las TIC.

- La Inclusión aparece en un segundo lugar con un porcentaje mínimo de frecuencias, sobre todo esta presente en los Programas de Fortalecimiento de la Educación Especial y de la Integración Educativa Nacional y Estatal, esto es importante de resaltar ya que a partir de una visión de escuela inclusiva se promueve la equidad, ofreciendo una respuesta educativa a todos sus alumnos, con el compromiso de transformar o diversificar los aspectos que sean necesario, el uso de las TIC toman aquí un papel importante como parte de la diversificación de los materiales didácticos utilizando tecnologías de ayuda. 
- En los resultados la Calidad de Vida como categoría, también se ve reflejada al igual que la Inclusión en los Programas, en este aspecto la utilización de las TIC esta relacionada a su utilización para la equiparación de oportunidades, multiplicar y diversificar los materiales y recursos para la accesibilidad de todos los ciudadanos.

- Las categorías que se establecieron en el mapa conceptual resultaron demasiado explicitas para el análisis.

Se considera necesario puntualizar que el uso de las TIC como tecnologias de ayuda o asistencia en la Educación Especial, pueden ser utilizadas para apoyar la atención de los alumnos con necesidades educativas especiales, con o sin Discapacidad así como las Aptitudes Sobresalientes dentro del currículo, para el logro de los propósitos educativos. Al respecto Alba (2006) plantea que las TIC basadas en las telecomunicaciones, aportan varias formas de utilización que permitirán generar nuevas formas de comunicación, interacción con la información y la socialización en los contextos educativos.

\subsection{Análisis del contexto de la modalidad de la Educación Especial, en el Estado de Chihuahua, en relación a los aspectos técnicos operativos y el impacto de la capacitación y actualización de la Asesoría Técnica.}

En esta fase de la investigación se realizo el análisis del contexto de la modalidad de Educación Especial en el Estado de Chihuahua en México, específicamente el funcionamiento técnico operativo de los servicios, la formación académica de los diferentes profesionales, su organización, las necesidades relacionadas con la capacitación y actualización de la asesoría técnica y necesidades técnicas, por medio de el diseño y aplicación de un cuestionario.

\section{1.- Muestra de población}


La muestra de población de esta etapa de la investigación esta conformada por profesionales de las 19 zonas escolares de la modalidad de Educación Especial durante el ciclo escolar 2007-2008, seleccionada al azar, participando un total de 511 profesionales abarcando: 8 Asesores Técnicos Pedagógicos (ATP) Estatales, 1 ATP de la Coordinación Regional, 16 Supervisores de zona escolar, 11 ATP de zona, 126 profesionales de los Centros de Atención Múltiple entre los que encontramos, Directivos, Maestros de Grupo y profesionales del Equipo de Apoyo, 337 profesionales de las Unidades de Servicios de Apoyo a la Escuela Regular entre ellos, Directores, Maestros de Apoyo, de comunicación, Psicólogos, Trabajadores Sociales y 12 Asesores de Centro de Recursos e Información para la Integración Educativa.

\section{2.-Instrumento de recogida de información}

El instrumento que se utilizo para recoger la información es un cuestionario, tomando en cuenta los siguientes aspectos (Ver Anexo IV).

Objetivo: Indagar de forma clara y sencilla, el contexto de los profesionales de Educación Especial ubicados en los diferentes servicios, en relación a los aspectos técnicos operativos y el impacto de la asesoría técnica.

Planificación: Se diseño un instrumento que fuera sencillo, con un lenguaje acorde a los profesionales a los que iba dirigido, con aspectos relacionados con la práctica docente, específicamente en las acciones de planeación, evaluación y seguimiento, además de evaluar aspectos relacionados a la capacitación y actualización que reciben, detectando de igual manera las necesidades técnicas, en relación a la atención de las necesidades educativas especiales asociadas principalmente a la discapacidad y/o aptitudes sobresalientes, así como el apoyo a los maestros y padres de familia.

Elaboración y Organización de las preguntas. 
Las preguntas se elaboraron tomando como punto de partida el objetivo de la encuesta. En una primera parte se presentan los aspectos generales de la muestra como son:

- Servicio y/o Institución.

- Contexto.

- Ubicación.

- Función.

- Años de Servicio.

- Formación Inicial.

- Formación Actual.

- Experiencia Profesional.

La segunda parte del instrumento presenta 16 items, de los cuales 9 son preguntas cerradas, admitiendo la posibilidad de una única respuesta o de opción múltiple dependiendo del tema, y 7 son preguntas abiertas, todas están relacionadas a los aspectos técnico operativos, las necesidades técnicas y al impacto de la asesoría técnica de la modalidad de Educación Especial.

\section{a) Recogida e interpretación de los datos.}

El análisis de los resultados se llevo acabo de forma cuantitativa y cualitativa, con las preguntas cerradas se realizo un análisis descriptivo, mientras que con las preguntas abiertas se utilizo la técnica de Análisis de Contenido.

El material que nos permito la recogida de los datos son las 511 encuestas aplicadas a los diferentes profesionales de Educación Especial, seleccionando 9 de los items del cuestionario para realizar un análisis de datos cuantitativo, de acuerdo al objeto de estudio se apoyándonos en el método descriptivo, con la recolección y tabulación de los datos, que supone un elemento interpretativo del significado, que nos permitió medir y evaluar los conceptos presentados en dicha encuesta. Los 9 items seleccionado son: 
- item 1: "Seleccione las funciones que realiza, indicando el tiempo que dedica a cada una de ellas", proporcionando una relación de funciones con la escala de valor de; Ninguno, Poco, Regular, Mucho.

- Item 2: “¿Participa en la elaboración del proyecto curricular de centro o institución?", las opciones de respuesta son Si y No.

- Item 4: "De acuerdo a su función ¿Realiza actividades de seguimiento?”, las opciones de respuesta son, Si y No.

- Item 6.- “¿Realiza actividades relacionadas a la evaluación?”, las opciones de respuesta son, Si y No.

- Item 8.-"De acuerdo a su función, ¿Cuál es el porcentaje de tiempo que utiliza en cada uno de los siguientes aspectos?, Planeación, Evaluación, Seguimiento".

- Item 9.-"En el centro o institución que trabaja, ¿Recibe cursos de actualización?", las opciones de respuesta son, Si y No.

- Item 10.- "Si su respuesta es afirmativa, ¿Quién le proporciona estos cursos?", las opciones de respuesta son;

- Centro de Maestros.

- Equipo de apoyo a la docencia.

- Supervisor.

- $\operatorname{Director(a).~}$

- Asesor(a) técnico de zona, región.

- Jefe de Departamento.

- Otros.

-item 14.- "De acuerdo a su función, “¿Cuáles son sus necesidades técnico-operativas?", las opciones de respuesta son;

- Aspectos específicos de la

- Adecuaciones curriculares discapacidad

- Planeación

- Proyecto Curricular de Aula

- Integración

- Planes y Programas

- Evaluación y Seguimiento

- Proyecto Curricular de Centro

- Aptitudes Sobresalientes

- Control Escolar

- N.E.E.

- Otras

-item 15.- "¿Cree que puede mejorar el servicios que ofrece el centro o institución en la que trabaja?", las opciones de respuesta son; Si y No. 
Los 9 items aluden a temas relacionados a los aspectos técnicos operativos y el impacto de la capacitación y actualización de la modalidad de Educación Especial en el Estado de Chihuahua, admiten la posibilidad de una única respuesta o varias dependiendo del tema.

El material seleccionado en el cual utilizamos la técnica de Análisis de Contenido son las 511 encuestas aplicadas a los diferentes profesionales de Educación Especial, centrándonos en las 7 items abiertos relacionadas a las actividades sobre proyecto curricular de centro, evaluación, y seguimiento, por un lado y por otro, lo referente a la capacitación y actualización, dentro de la asesoría técnica.

El material se preparó por medio de transcripciones escritas en formato digital, seleccionando el contenido de las preguntas respectivas para luego realizar el desglose de cada de los temas dividiéndolos en frases, llegando a conformar las unidades de significación. El siguiente paso fue conformar un documento sin texto e ir realizando un preanálisis, lo cual permitió ir agrupando el documento de acuerdo a temas y estableciendo las primeras categorías.

El programa que utilizamos para realizar el análisis el contenido de las preguntas es el NUD IST 4, este programa permitió agrupar y organizar la información, edita el texto sin desorganizar la codificación, además de que permite realizar informes de la codificación de diferentes formas estableciendo porcentajes de las unidades de frecuencia de las codificaciones, desglosando el contenido de cada uno de los temas y la identificación de las categorías y subcategorías de los temas analizados.

Las categorías de análisis se conformaron de la siguiente manera (el mapa conceptual de las categorías se encuentra el capítulo anterior): 
-Aspectos que toma en cuenta para la elaboración del Proyecto Curricular de Centro o Institución (item 3):

\section{Proyecto Curricular de Centro}

- Autoevaluación.

- Propósitos Educativos.

-Evaluación y Seguimiento que realizan los profesionales de la modalidad Educación Especial. (Están incluidos los item: 5 "Enuncie cuáles son las actividades de seguimiento que realiza" y 7 "Enuncie cuáles son las actividades de evaluación que realiza"):

* Evaluación y Seguimiento.

- Tipos de Evaluación.

- Instrumentos u estrategias.

○ Seguimiento.

- Aspectos del Contenido y Seguimiento de la Capacitación y Actualización que reciben los diferentes profesionales de la modalidad de Educación Especial. (Están incluidas en las respuestas de los items 11.- “¿Considera que la capacitación y asesoría que recibe es adecuada en relación a los contenidos?”, 12.- “¿Considera que el seguimiento de la capacitación y asesoría que recibe es adecuada en relación a las actividades, contenido y tiempo en que se realiza?", y 13.- “¿Considera que la capacitación y la actualización que recibe es la adecuada?").

\section{Capacitación y Actualización:}

○ SI: Es adecuada.

$>$ Necesidades.

> Propósitos Educativos.

$>$ Tiempo.

- NO: No es la adecuada.

Necesidades. 
$>$ Propósitos Educativos.

$>$ Tiempo.

- Sugerencias para mejorar el servicio (item 16).

\section{* Sugerencias:}

- Técnico Pedagógico.

- Organización.

- Administrativo.

- Vinculación.

\subsubsection{Informe de los Resultados}

\section{A) Resultados de carácter cuantitativo}

Se elaboró la codificación del cuestionario necesario para la realización del análisis de los datos (Ver Anexo V).

La información será presentada en tablas y gráficas con estadísticos descriptivos sobre las variables, permito realizar el siguiente análisis de resultados.

\section{- Servicios}

El mayor porcentaje de personal docente encuestado pertenece al servicio de USAER en un 65,9\%, debido a que en la modalidad de Educación Especial existen un mayor número de servicios con estas características, en segundo lugar se encuentra el personal de CAM con un $24,7 \%$ contemplando al Directivo, Maestros de Grupo y Equipo de Apoyo. En tercer lugar con un 5,3\%, se encuentra el personal que conforma del equipo de supervisión como es el Supervisor y Asesor Técnico de Zona. A continuación en orden ascendente se encuentra con un 1,6\% de los encuestados el personal de Asesores Técnicos Estatales que son los que forman el Equipo de Apoyo a la Docencia, dependiendo directamente del Departamento de Educación Especial, con un 
2,3\% los asesores del servicio de orientación CRIIE y por ultimo se observa con el menor porcentaje la Coordinación Regional, por haber solo una en este momento en el Estado (Ver Tabla 8).

\begin{tabular}{l|c|c}
\hline \multicolumn{3}{c}{ Ubicación del Personal Docente } \\
\hline \multicolumn{1}{c|}{ Servicio } & Frecuencias & \% de Personal \\
\hline Equipo de Apoyo a la Docencia & 8 & 1,6 \\
\hline Coordinación Regional & 1 & 0,2 \\
\hline Supervisión & 27 & 5,3 \\
\hline USAER & 337 & 65,9 \\
\hline CAM & 126 & 24,7 \\
\hline CRIIE & 12 & 2,3 \\
\hline
\end{tabular}

Tabla 8: Resultado de Frecuencias del Personal Docente de cada Servicio.

\section{- Zonas Escolares}

Las encuestas a los diferentes profesionales se aplicaron en las 19 zonas escolares de la modalidad de Educación Especial, ubicadas en 9 municipios. El mayor porcentaje se realizo en las zonas 2 y 17 de cd. Juárez con un 10,6\%, como se observa en la tabla 9, abarcando los servicios escolarizados CAM, de apoyo USAER y los equipos de Supervisión, con un menor porcentaje de personal encuestado esta la zona 18 de Guachóchi, debido a que es una de las zonas con menor numero de servicios.

\begin{tabular}{|c|c|c|c|}
\hline \multicolumn{4}{|c|}{ Personal Docente por Zona Escolar } \\
\hline Zona & Ubicación & $N$ & $\%$ \\
\hline Zona 1 & Juárez & 20 & 3,9 \\
\hline Zona 2 & Juárez & 54 & 10,6 \\
\hline Zona 3 & Chihuahua & 35 & 6,8 \\
\hline Zona 4 & Chihuahua & 23 & 4,5 \\
\hline Zona 5 & Delicias & 10 & 2,0 \\
\hline Zona 6 & Cuauhtémoc & 29 & 5,7 \\
\hline Zona 7 & Parral & 20 & 3,9 \\
\hline Zona 8 & Camargo & 28 & 5,5 \\
\hline Zona 9 & Juárez & 20 & 3,9 \\
\hline Zona 10 & Chihuahua & 33 & 6,5 \\
\hline Zona 11 & Parral & 33 & 6,5 \\
\hline Zona 12 & San Juanito Bocoyna & 34 & 6,7 \\
\hline Zona 13 & Nvo. Casas Grandes & 23 & 4,5 \\
\hline Zona 14 & Chihuahua & 27 & 5,3 \\
\hline Zona 15 & Jiménez & 32 & 6,3 \\
\hline Zona 16 & Chihuahua & 18 & 3,5 \\
\hline Zona 17 & Juárez & 54 & 10,6 \\
\hline Zona 18 & Guachóchi & 4 & 0,8 \\
\hline Zona 19 & Delicias & 14 & 2,7 \\
\hline
\end{tabular}

Tabla 9: Frecuencias del Personal Docente por Zonas Escolar. 


\section{- Contexto}

El mayor porcentaje con un $84,5 \%$ de profesionales encuestado, se encuentra en servicios ubicados en el contexto urbano, por ser donde se encuentran la mayoría de zonas escolares y servicios de Educación Especial y un menor porcentaje en el área rural (Ver Tabla 10).

\begin{tabular}{l|c|c}
\hline \multicolumn{3}{c}{ Contexto de los Servicios } \\
\hline \multicolumn{1}{c|}{ Contexto } & $\boldsymbol{N}$ & $\%$ \\
\hline Urbano & 432 & 84,5 \\
\hline Urbano Marginal & 53 & 10,4 \\
\hline Rural & 26 & 5,1 \\
\hline
\end{tabular}

Tabla 10: Resultado del Análisis de Frecuencias de los Contextos de los Servicios.

\section{- Funciones}

En la tabla11 se presentan las diferentes funciones que desempeñan los profesionales encuestados, pudiendo obtener una muestra de la mayoría de las funciones que se desempeñan en Educación Especial. Los resultados muestran un porcentaje de $38 \%$ de Maestros de Apoyo de los servicios USAER, debido a que existen un mayor numero de servicio de este tipo, y en un menor porcentaje tanto Asesores Técnicos Regionales, dado que solamente hay dos en el Estado y los Maestros de Educación Física, por no formar parte de la plantilla de personal en la mayoría de los servicios escolarizados.

\begin{tabular}{|c|c|c|}
\hline \multicolumn{3}{|c|}{ Funciones del Personal Docente } \\
\hline Función & $\mathbf{N}$ & $\%$ \\
\hline Maestro de Apoyo & 194 & 38,0 \\
\hline Director & 73 & 14,3 \\
\hline Psicólogo & 55 & 10,8 \\
\hline Maestro de Grupo & 52 & 10,2 \\
\hline Trabajador Social & 41 & 8,0 \\
\hline Maestra de Comunicación & 34 & 6,7 \\
\hline Supervisor & 16 & 3,1 \\
\hline Asesor Técnico de Zona & 11 & 2,2 \\
\hline Asesor Técnico Estatal & 8 & 1,6 \\
\hline Asesor Técnico CRIIE & 8 & 1,6 \\
\hline Terapista Físico & 5 & 1,0 \\
\hline Auxiliar de Maestra & 5 & 1,0 \\
\hline Otros; Personal Administrativo & 3 & 0,6 \\
\hline Instructor de Taller & 2 & 0,4 \\
\hline Asesor Técnico Regional & 1 & 0,2 \\
\hline Maestro de Educación Física & 1 & 0,2 \\
\hline
\end{tabular}




\section{- Antigüedad}

Uno de los aspectos importantes que reflejar la experiencia en el sector educativo del personal docente encuestado, es la antigüedad, reportando que la mayoría de los encuestados tienen una gran experiencia con más de 20 años trabajando en el sector educativo, lo que se refleja en un $31,9 \%$. En segundo lugar con un $28,6 \%$ se encuentran los profesionales que han trabajado entre 5 a 10 años y en un menor porcentaje los que han trabajado de 10 a 15 años, hasta inicios del ciclo escolar 2007-2008 (Ver Tabla12).

\begin{tabular}{|c|c|c|}
\hline \multicolumn{3}{|c|}{ Antigüedad del Personal } \\
\hline Antigüedad & $N$ & \% de Personal \\
\hline 0 a 5 años & 92 & 18,0 \\
\hline 5 a 10 años & 146 & 28,6 \\
\hline 10 a 15 años & 48 & 9,4 \\
\hline 15 a 20 años & 62 & 12,1 \\
\hline Más de 20 años & 163 & 31,9 \\
\hline
\end{tabular}

Tabla 12: Frecuencias en relación a la Antigüedad del Personal Docente.

\section{- Formación Académica.}

En la gráfica 8 se muestra el análisis y comparación en formación del personal al inicio de su contratación como profesional de educación y la formación que actualmente tienen, reportando una mayor preparación en la actualidad que al inicio de su contratación, ahora existen profesionales con estudios de Doctorado en un $0,2 \%$ y Maestría en un $14,7 \%$, de igual manera se informa que el mayor porcentaje en la actualidad $(29,4 \%)$ se encuentra en los maestros con Licenciatura en Educación Primaria , dado que en un inicio era de $23,7 \%$. En lo referente a Licenciatura de Educación Especial, importante en este ramo ya que es donde desempeñan su labor docente, los índices de maestros se ha incrementado en un porcentaje mínimo de 5,7\% a un $11,5 \%$. El porcentaje menor son los profesionales que son estudiantes de alguna de las carreras mencionadas. Es importante mencionar que la actualización en las diferentes carreras profesionales, permite contar actualmente con profesionales con mayor preparación que apoyen la labor docente, participando en la elaboración del proyecto del centro, aportando sus conocimientos y experiencia en las reuniones técnicas, etc., con el fin de lograr una educación de mayor calidad. 


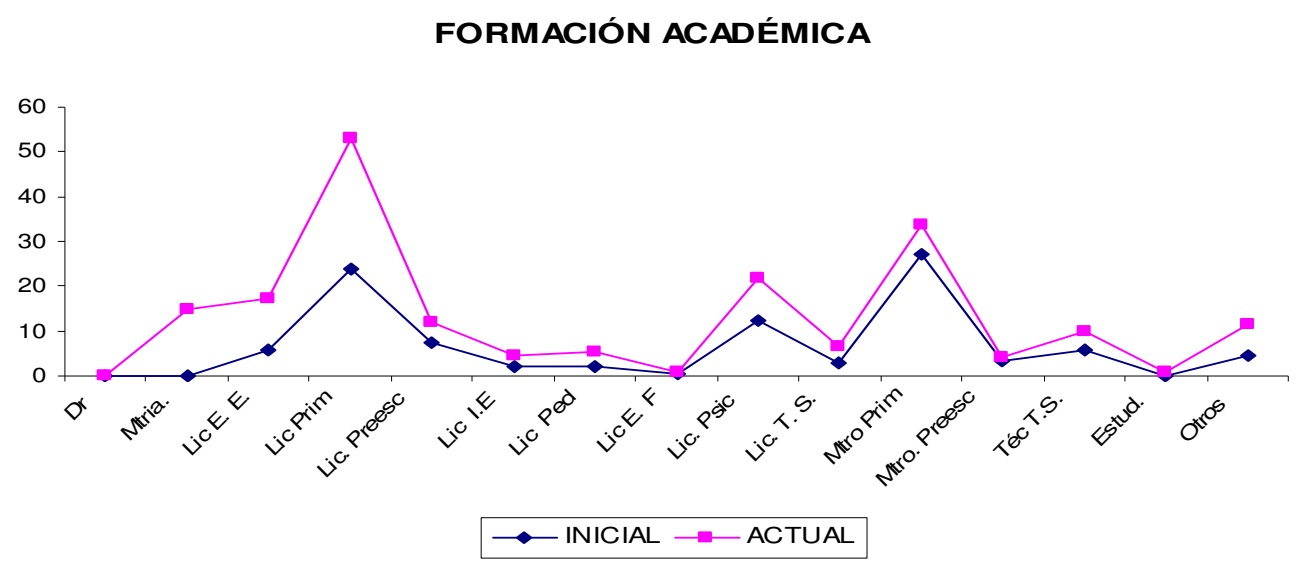

Gráfica 8: Frecuencias de la Formación Académica Inicial y Actual.

\section{- Experiencia Profesional}

En la tabla 13 se muestra la experiencia de los profesionales encuestados, en los diferentes niveles educativos, durante los años que llevan trabajando en el ámbito educativo, observando que el mayor numero de profesionales tiene experiencia en la modalidad de Educación Especial y en segundo lugar con un 153 los profesionales con experiencia en Educación Básica, abarcando los niveles de Educación Inicial, Educación preescolar, Educación Primaria y Secundaria. Aunado a esto la tabla 14 informa que los profesionales tienen experiencia en el desempeño de diferentes funciones, sobresaliendo los 180 maestros de Educación Especial con experiencia en las diferentes áreas como son; maestros de Apoyo, maestros de comunicación, maestros de discapacidad intelectual, maestros de audición y maestros de neuromotores. Con un menor número de frecuencias encontramos a los Coordinadores de programas educativos y a los Terapistas Físicos como se muestra en la tabla. Es importante resaltar que la mayoría de los profesionales han abarcado diferentes niveles educativos y funciones en el transcurrir de sus años de servicio. 


\begin{tabular}{|c|c|c|}
\hline \multicolumn{3}{|c|}{ Experiencia por Niveles Educativos } \\
\hline Nivel Educativo & Frecuencias & $\%$ \\
\hline Educ. Básica & 153 & 29,9 \\
\hline Educ. Media Terminal & 9 & 1,7 \\
\hline Educación Superior & 17 & 3,3 \\
\hline Educación Especial & 511 & 100 \\
\hline Particulares & 22 & 4,3 \\
\hline Instituciones de Gobierno & 22 & 4,3 \\
\hline
\end{tabular}

Tabla 13: Resultado del Análisis de las Frecuencias de la Experiencia por Nivel Educativo

\begin{tabular}{l|c|c}
\hline \multicolumn{3}{c}{ Experiencia por Función } \\
\hline \multicolumn{1}{c|}{ Función } & Frecuencias & $\%$ \\
\hline Supervisor & 8 & 1,5 \\
\hline Coordinador Programa & 4 & 0,7 \\
\hline Asesor Técnico & 37 & 7,2 \\
\hline Director & 51 & 9,9 \\
\hline Maestro de Grupo & 87 & 17 \\
\hline Maestro Educ Especial & 180 & 35,2 \\
\hline Psicólogo/a & 23 & 4,5 \\
\hline Trabajo Social & 18 & 3,5 \\
\hline Terapia Física & 4 & 0,7 \\
\hline
\end{tabular}

Tabla 14: Resultado del Análisis de las Frecuencias de la Experiencia Profesional.

\section{- Aspecto Técnico Operativo}

\section{- Tiempo}

Las diferentes funciones y roles que se desarrollan en Educación Especial, implica la realización de diferentes actividades como las que presentan en la tabla 15, reportando que por los diferentes profesionales, se privilegia la Planeación en cuanto al tiempo que se dedica para su realización, con la mayor puntuación que muestra la media de un 3,28 . Con una media de 3,11 encontramos, en segundo lugar, el Seguimiento que se realiza a las actividades educativas, en tercer lugar se encuentra la Comunicación que se realiza por los encuestados en las diferentes funciones que desarrollan. Es necesario puntualizar que en un cuarto lugar se encuentra la Intervención Educativa que se lleva acabo en los diferentes servicios de Educación Especial, aun y cuando es una de la principal actividad. Por ultimo destacar la puntuación mínima de 1,61 de media, relacionada al tiempo que se dedica a las actividades relacionadas a la Política. 


\begin{tabular}{l|c|c|c|c||c||}
\hline \multicolumn{7}{|c||}{ Tiempo invertido en cada Actividad } \\
\hline \multicolumn{1}{|c|}{ Función } & \multicolumn{4}{c||}{ Tiempo } \\
\hline \multicolumn{1}{|c|}{$\begin{array}{c}\text { NINGUNO } \\
(1)\end{array}$} & $\begin{array}{c}\text { Poco } \\
(2)\end{array}$ & $\begin{array}{c}\text { REGULAR } \\
(3)\end{array}$ & $\begin{array}{c}\text { MUCHO } \\
(4)\end{array}$ & \\
\hline Planeación & 6,7 & 3,28 & 34,4 & 53 & 3,28 \\
\hline Seguimiento & 7,2 & 3,11 & 41,3 & 42,5 & 3,11 \\
\hline Comunicación & 11,7 & 3,0 & 39,1 & 39,9 & 3,0 \\
\hline Intervención & 13,1 & 2,97 & 39,1 & 38,9 & 2,97 \\
\hline Información & 11,5 & 2,85 & 46,4 & 28,4 & 2,85 \\
\hline Técnica & 15,7 & 2,84 & 40,5 & 32,9 & 2,84 \\
\hline Evaluación & 16,4 & 2,80 & 41,1 & 30,9 & 2,80 \\
\hline Asesoría & 16,6 & 2,66 & 41,9 & 24,3 & 2,66 \\
\hline Gestión Esc. & 18,4 & 2,58 & 34,8 & 24,9 & 2,58 \\
\hline Investigación & 13,5 & 2,57 & 50,7 & 13,7 & 2,57 \\
\hline Enlace & 21,1 & 2,55 & 34,6 & 24,9 & 2,55 \\
\hline Innovación & 18,4 & 2,53 & 46,8 & 16,4 & 2,53 \\
\hline Adm. & 22,3 & 2,48 & 38,2 & 19,6 & 2,48 \\
\hline Diseño y & & & & & \\
Desarrollo de & & & & & \\
Cursos y/o & & & & & \\
Talleres & 26,2 & 2,30 & 33,5 & 15,1 & 2,30 \\
\hline Asistencia & 23,1 & 2,28 & 32,3 & 14,1 & 2,28 \\
\hline Control & 42,1 & 2,05 & 30,1 & 12,1 & 2,05 \\
\hline Desarrollo de & & & & & \\
Proyectos y & & & & & 1,93 \\
Programas & 50,9 & 1,93 & 21,7 & 16,0 & 1,88 \\
\hline Supervisión & 47,0 & 1,88 & 26,0 & 8,4 &, 01 \\
\hline Política & 48,9 & 1,61 & 13,9 & 2,2 & \\
\hline Otras & 1,0 &, 01 & 0,0 & 0,0 & \\
\hline & & & & & \\
\hline
\end{tabular}

Tabla 15: Tiempo invertido en cada una de las Actividades Técnico Operativas.

En la gráfica 9 se complementa la información anterior, presentando el tiempo que dedican a las diferentes actividades por los profesionales de Educación Especial, de acuerdo al puntaje de media obtenido en el análisis de los datos, se observa claramente que la mayor puntuación de media es el tiempo que se emplea en la Planeación con 3,28, mientras que la de menor valor de media es la Política, debido a que la mayoría de los profesionales no se involucran directamente en esta actividad. 
Tiempo utilizado en Actividades Técnico Operativas

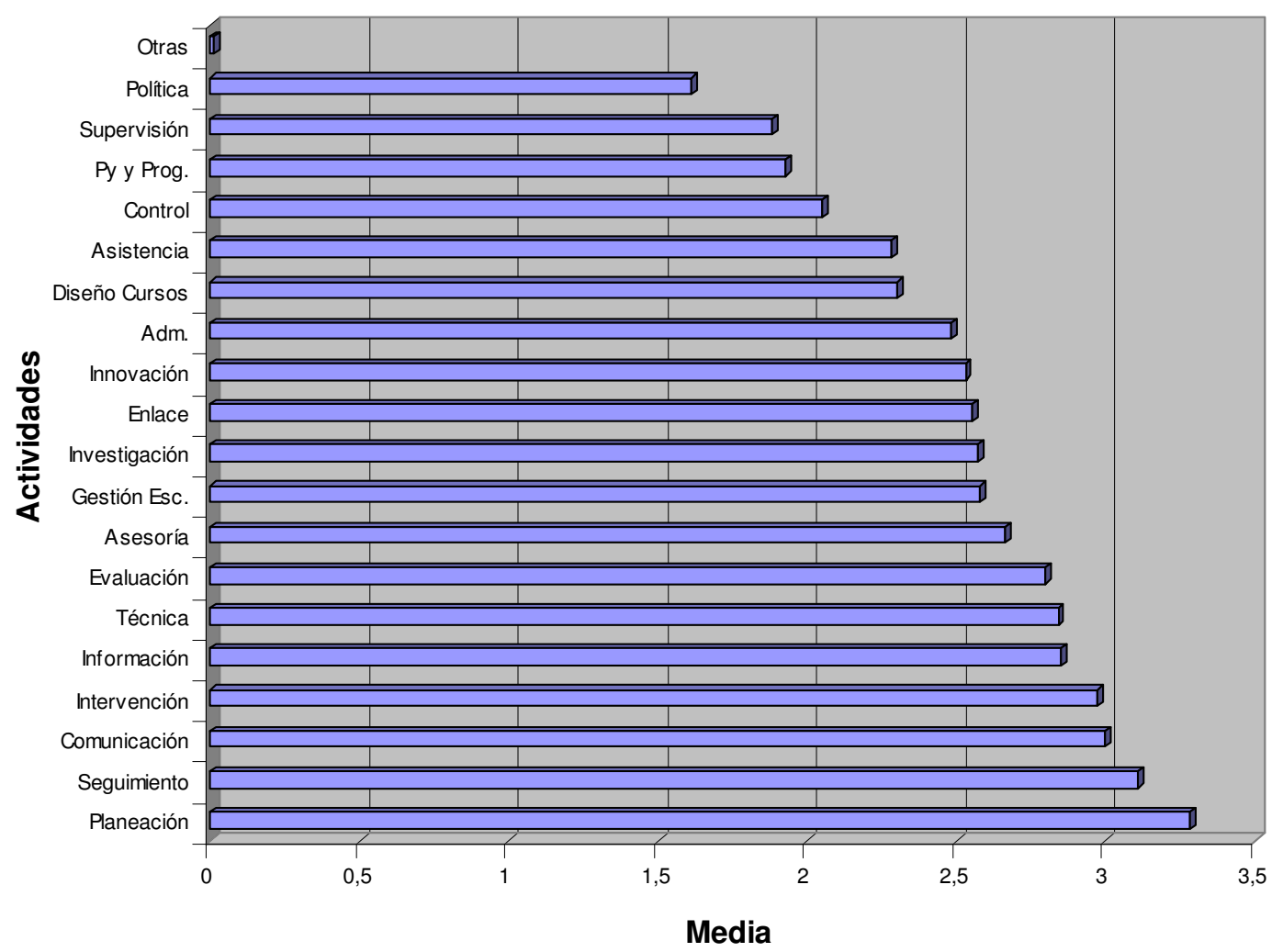

Gráfica 9: Resultados de Medias del Tiempo utilizado en Actividades Técnico Operativas

En la tabla 16 se presenta de una forma más específica el tiempo que los profesionales dedican a las actividades de Planeación, Evaluación y Seguimiento. El mayor porcentaje de tiempo invertido por los diferentes profesionales se utiliza en las actividades de Seguimiento con un 39,49, después en la Planeación de las actividades $(34,9)$ y por ultimo en la Evaluación $(28,3)$.

\begin{tabular}{l|c|c|c|c}
\hline \multicolumn{5}{c}{ Porcentaje de Tiempo } \\
\hline Actividades & $<\mathbf{3 0 \%}$ & $\mathbf{3 0} \mathbf{a} \mathbf{6 0} \%$ & $>\mathbf{6 0 \%}$ & Media \\
\hline Seguimiento & 43,0 & 45,8 & 11,1 & 39,49 \\
\hline Planeación & 57,3 & 33,0 & 9,6 & 34,94 \\
\hline Evaluación & 78,6 & 15,3 & 6,3 & 28,38 \\
\hline
\end{tabular}

Tabla 16: Tiempo dedicado a las actividades de Planeación, Evaluación y Seguimiento. 


\section{- Actividades}

La mayoría de los profesionales refieren que realizan actividades de seguimiento, como se observa en la tabla 17 con un $95,9 \%$, desde sus diferentes funciones, utilizando diferentes instrumentos y estrategias para su realización, también se informa que un 94,9\% participan en la elaboración del Proyecto Curricular del Centro o de la Institución a la que pertenecen, sobre todo al inicio del ciclo escolar, y un $94,7 \%$ realizan actividades relacionadas con la evaluación en diferentes momentos y utilizando diferentes instrumentos y estrategias.

\begin{tabular}{l|c|c|c}
\hline \multicolumn{4}{c}{ Actividades de los Profesionales } \\
\hline \multicolumn{1}{c|}{ Actividades } & Si & No & NC \\
\hline $\begin{array}{l}\text { Proyecto curricular de } \\
\text { centro }\end{array}$ & 94,9 & 4,1 & 1 \\
\hline Seguimiento & 95,9 & 2,9 & 1,2 \\
\hline Evaluación & 94,7 & 2,2 & 3,1 \\
\hline
\end{tabular}

Tabla 17: Resultados del las Actividades de los Profesionales.

\section{- Capacitación y Actualización.}

- Cursos

Los profesionales manifiestan haber tomado cursos con diferentes Instituciones del sector educativo en un $89,4 \%$, entre las que se destacan, en primer lugar el Centro de Maestros, institución que tiene como uno de sus propósitos la capacitación y actualización de los profesionales de educación. Así mismo se informa que el Director de los diferentes servicios de Educación Especial proporciona capacitación, con un porcentaje importante de 44,6\%, por ser considerada la primera instancia de capacitación y actualización de un servicio. Una de las principales actividades de los Asesores Técnicos Pedagógicos de Zona o Región, es la impartición de cursos presentando un 43,4\%, los Supervisores de zona un 29,4\%. El Equipo de Apoyo a la Docencia, como Asesores Técnicos Pedagógicos del Estado, cuyo propósito fundamental es la capacitación y actualización de los diferentes profesionales del Estado presentando un $23,9 \%$. Es importante hacer notar que el $11,9 \%$ de los 
profesionales informan que los cursos de capacitación y actualización que reciben de acuerdo a sus necesidades técnicas, son proporcionados por la misma institución o servicio al que pertenecen y por la autocapacitación (Ver Tabla18).

\begin{tabular}{|c|c|c|}
\hline \multicolumn{3}{|c|}{ Cursos de Capacitación y Actualización } \\
\hline & $\mathrm{N}$ & $\%$ \\
\hline Recibe cursos & 457 & 89,4 \\
\hline \multicolumn{3}{|l|}{ Por parte de: } \\
\hline - Centro de Maestros & 280 & 54,8 \\
\hline - Director & 228 & 44,6 \\
\hline $\begin{array}{ll}\text { - } & \text { Asesor Técnico de Zona o } \\
& \text { Región }\end{array}$ & 222 & 43,4 \\
\hline - $\quad$ Supervisor & 150 & 29,4 \\
\hline - Equipo de Apoyo a la Docencia & 122 & 23,9 \\
\hline - Institución a la que pertenece & 61 & 11,9 \\
\hline - Instituciones Particulares & 34 & 6,7 \\
\hline - Programas de Educación & 28 & 5,5 \\
\hline - Jefe del Departamento & 20 & 3,9 \\
\hline - Consejo Técnico & 19 & 3,7 \\
\hline - Escuela Primaria & 7 & 1,4 \\
\hline - $\quad$ Carrera Magisterial & 3 & 0,6 \\
\hline
\end{tabular}

Tabla 18: Resultado sobre los Cursos de Capacitación y Actualización.

\section{- Valoración}

Un 53\% de los diferentes profesionales encuestados consideran que la capacitación y actualización que reciben es la que requieren, tomando en cuenta las necesidades técnicas de los servicios, así como los propósitos educativos y el tiempo que se invierte en ella, ver tabla 19. De igual manera informan que los contenidos de la capacitación son adecuados en un $74,2 \%$, debido a que toma en cuenta las necesidades, no así el seguimiento a los cursos, que se queda en un porcentaje del $41,3 \%$ los que si consideran que es adecuado.

\begin{tabular}{cl|c}
\hline \multicolumn{2}{c}{ Valoración de la Capacitación y Actualización } \\
\hline \multicolumn{1}{|c|}{ Aspectos } & \% Adecuada \\
\hline$\bullet$ & Es la que requiere & 53,0 \\
\hline & $\begin{array}{l}\text { En relación a los } \\
\text { contenidos }\end{array}$ & 74,2 \\
\hline$\bullet$ & En relación al seguimiento & 41,3 \\
\hline
\end{tabular}

Tabla 19: Resultados de la valoración de la Capacitación y Actualización. 


\section{- Necesidades Técnicas}

La principal necesidad técnica de los diferentes profesionales encuestados es la relacionada a los aspectos específicos de las diferentes discapacidades (Intelectual, Auditiva, Motora y Visual), siendo una de las prioridades, debido a que la población que se atienden en los diferentes servicios de Educación Especial presenta NEE asociados principalmente a la discapacidad. En segundo lugar se reporta las adecuaciones curriculares con un 54,6\%, en tercer lugar se encuentran las necesidades técnicas sobre las Aptitudes Sobresalientes, tal y como se refleja en la tabla 20 y con un mínimo porcentaje se encuentra la capacitación para trabajar con el Programa Enciclomedia.

\begin{tabular}{cl|c|c}
\hline \multicolumn{3}{c}{ Necesidades Técnicas } \\
\hline \multicolumn{1}{c|}{ Necesidades } & N & $\%$ \\
\hline$\bullet$ & Aspectos específicos de la discapacidad & 333 & 65,2 \\
\hline$\bullet$ & Adecuaciones curriculares & 279 & 54,6 \\
\hline$\bullet$ & Aptitudes sobresalientes & 266 & 52,1 \\
\hline$\bullet$ & Proyecto curricular de aula & 193 & 37,8 \\
\hline$\bullet$ & Evaluación y seguimiento & 189 & 37,0 \\
\hline$\bullet$ & Planes y programas & 149 & 29,2 \\
\hline$\bullet$ & N.E.E & 139 & 27,2 \\
\hline$\bullet$ & Planeación & 121 & 23,7 \\
\hline$\bullet$ & Integración & 88 & 17,2 \\
\hline$\bullet$ & Proyecto curricular de centro & 88 & 17,2 \\
\hline$\bullet$ & Control escolar & 46 & 9,0 \\
\hline$\bullet$ & Enciclomedia & 9 & 1,8 \\
\hline
\end{tabular}

Tabla 20: Resultado del Análisis de las Necesidades Técnicas.

\section{- Propuestas de Mejoras}

Es importante mencionar que la mayoría $(97,3 \%)$ de los profesionales encuestados consideran que el servicio donde trabajan como se puede observar en la tabla 21; Coordinación, Equipo de Apoyo a la Docencia, Zona escolar, Servicio escolarizado CAM, servicio de apoyo USAER y servicio de orientación CRIIE, se puede mejorar sobre todo con un trabajo colaborativo y actitud positiva por parte de todos los involucrados. 


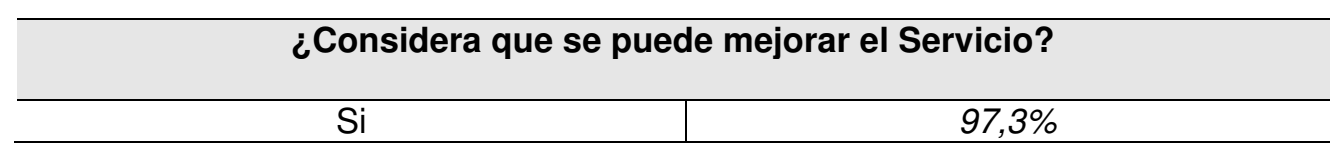

Tabla 21: Resultados ¿Cree que se puede mejorar el servicio que ofrece el centro o institución en que trabaja?.

Para complementar los resultados anteriores a continuación se presentan los resultados del Análisis de Contenido de las preguntas abiertas informando lo siguiente.

\section{B) Informe de los resultados cuantitativos.}

Una vez que se establecieron las unidades de análisis o categorías, se procedió a la codificación de las unidades de registro, estableciendo las frecuencias de su aparición en cada tema conformado un documento, de esta forma se fue estableciendo y estructurando la información disponible, en función a las categorías finalmente establecidas.

Este proceso se completo en esta etapa final, presentando la interpretación de los resultados de acuerdo a las categorías establecidas y con el apoyo del programa NUDIST 4, organizando los resultados del análisis en tablas que permiten dar una visión general y especifica, para establecer las conclusiones.

En el Anexo IV se presenta la codificación de las unidades de registro de los ítems sujetos de análisis.

\section{- Elaboración del Proyecto Curricular de Centro}

En la tabla 22 se observan los resultados del análisis de las unidades de frecuencia, sobre los aspectos que toma en cuenta los diferentes profesionales para la elaboración del Proyecto Curricular de Centro o Institución, en relación a las siguientes categorías. 
* Proyecto Curricular de Centro:

- Autoevaluación:

Los profesionales reportan que toman en cuenta la autoevaluación de la escuela en un $70 \%$ de las unidades de registro, para la elaboración del Proyecto Curricular del Centro, en relación a; en un $39 \%$ a las necesidades y fortalezas de la institución de Educación Especial y/o de educación regular a las que se les proporciona el apoyo por parte de USAER, en un $29 \%$ a las habilidades y necesidades de los alumnos con NEE principalmente en los aspectos relacionados a la discapacidad, de igual manera se toman en cuenta las necesidades técnico pedagógicas de los maestros en un $15 \%$, por otro lado dada la importancia de la participación de la familia en los procesos de atención de los alumnos, se reporta en un $1.6 \%$ de las unidades de registro, posibilitando atender posteriormente las necesidades de los mismo, los recursos materiales, didácticos, tecnológicos y de accesibilidad, se toman en cuenta en la autoevaluación un $3.5 \%$, necesarios para la atención educativa de los alumnos.

- Propósitos Educativos:

En esta categoría se reporta que un $14 \%$ de las unidades de registro contemplan en la elaboración del Proyecto Curricular de Centro los propósitos educativos de la educación y, específicamente, de la Educación Especial, que se encuentra enmarcada por la Política Educativa Nacional y Estatal establecida en Programas de Fortalecimiento de la Educación Especial y de la Integración Educativa.

\begin{tabular}{l|c|c}
\hline \multicolumn{3}{c}{ Proyecto Curricular de Centro } \\
\hline \multicolumn{1}{c}{ Total de Unidades de Registro: 515 } & \% según U de R \\
\hline \multicolumn{1}{c}{ Categoría } & Frecuencia & 70 \\
\hline 1.1.-Autoevaluación & 360 & 39 \\
\hline 1.1.1 Institución & 199 & 29 \\
\hline 1.1.2 Alumnos & 149 & 15 \\
\hline 1.1.3 Maestros & 77 & 1.6 \\
\hline 1.1.4 Familia & 8 & 3.5 \\
\hline 1.1.5 Recursos & 18 & 14 \\
\hline 1.2.- Propósitos & 71 & \\
Educ. & &
\end{tabular}

Tabla 22: Cuadro de Registro de las Unidades de Frecuencias del Proyecto Curricular de Centro. 


\section{- Seguimiento}

La tabla 23 permite analizar los resultados, de las categorías del item sobre las actividades de seguimiento que realizan los diferentes profesionales de Educación Especial, informando lo siguiente:

\section{* Seguimiento:}

- Tipos de evaluación:

Los profesionales encuestados reportan que durante el ciclo escolar realizan actividades de seguimiento, en un $27 \%$ de las unidades de registro, relacionado a los diferentes momentos en que realizan la evaluación y a los aspectos que consideran evaluar, en relación al proceso de enseñanza aprendizaje de los alumnos con NEE y sus contextos.

- Instrumentos y estrategias:

El mayor porcentaje de las actividades de seguimiento que realizan los diferentes profesionales de Educación Especial, en un $63 \%$ de las unidades de registro, son la selección y aplicación de los diferentes instrumentos y estrategias, principalmente utilizadas con los alumnos, reportando un $35 \%$, por otro lado en el seguimiento a los maestros tanto de Educación Especial como de Educación Básica se utilizan en un $17 \%$, en los grupos un $5.1 \%$, con las familias de los alumnos que son atendidos por los servicios de Educación Especial un $20 \%$, en el seguimiento a las instituciones educativas de Educación Especial, realizado por el Coordinador, Supervisor, Directivo y/o ATP de zona, región o Estatal, así como a las instituciones de Educación Básica que apoya el servicio de USAER, se aplican en un $16 \%$.

- Seguimiento:

En esta categoría se reporta un $22 \%$ en general, relacionado con las acciones de evaluación y seguimiento que realizan los Supervisores de zona, Directores de servicios, ATP de zonas, de regiones y/o 
Estado, al Proyecto Curricular de Centro en un $12 \%$, el seguimiento al Proyecto Curricular de Aula en un $5.1 \%$. Por otro lado el seguimiento de la Propuesta Curricular Adaptada que realizan a los diferentes profesionales a los alumnos con NEE se reporta en un $8,6 \%$.

\begin{tabular}{l}
\hline \multicolumn{3}{c}{ Actividades de Seguimiento } \\
\begin{tabular}{l|c|c}
\hline \multicolumn{1}{c}{ Total de Unidades de Registro: 514} & \% según Ude $R$ \\
\hline \multicolumn{1}{c}{ Categoría } & Frecuencia & 27 \\
\hline 1.1 Tipos de Evaluación & 140 & 63 \\
\hline 1.2. Instrumentos y & 324 & 35 \\
Estrategias & 180 & 17 \\
\hline 1.2.1. Alumnos & 88 & 20 \\
\hline 1.2.2. Maestros & 104 & 5.1 \\
\hline 1.2.3. Familia & 26 & 16 \\
\hline 1.2.4. Grupo & 84 & 22 \\
\hline 1.2.5. Institución & 113 & 12 \\
\hline 1.3. Seguimiento & 63 & 8.6 \\
\hline 1.3.1. Proyecto Centro & 44 & 5.1 \\
\hline 1.3.2. PCA & 26 & \\
\hline 1.3.3. Proyecto Áulico & &
\end{tabular}
\end{tabular}

Tabla 23: Registro de las Unidades de Frecuencia de las Actividades de Seguimiento

\section{- Evaluación}

Resultados del análisis de las unidades de frecuencia, de las diferentes categorías del item sobre las actividades de evaluación que llevan acabo los diferentes profesionales, conforme a la tabla 24 .

\section{* Evaluación:}

- Tipos de evaluación:

En esta categoría se reporta un $28 \%$ de las unidades de registro, relacionado a la aplicación de diferentes tipos de evaluación, como la inicial que se realiza al inicio del ciclo escolar, tanto para los alumnos como para el colectivo escolar y el contexto, reportando un 14\%. En cuanto a la evaluación continua el porcentaje es mayor, informando de un $18 \%$, considerada como una valoración continua y sistemática de datos del funcionamiento de un centro, del proceso de aprendizaje de un alumno, de la eficacia de un profesor, durante el ciclo escolar. La evaluación final en reporta un $9.4 \%$, establecida como la recogida de información y datos al final del ciclo escolar, y un 10\%, como se observa 
en la tabla 24, se refiere a la evaluación psicopedagógica, proceso que implica conocer las características del alumno con NEE en interacción con el contexto social, escolar y familiar al que pertenecen, identificando las barreras que impiden su participación y aprendizaje.

- Instrumentos y estrategias:

En las actividades de evaluación al igual que en las de seguimiento, se observa un mayor porcentaje de unidades de registro, en relación a la selección y aplicación de instrumentos y estrategias que utilizan los diferentes profesionales, reportando un $51 \%$, relacionado a que un $41 \%$ utilizan los instrumentos y estrategias en la evaluación de los alumnos, un 6.7\%, se utilizan en los maestros tanto de Educación Especial como de Básica, donde se encuentran alumnos con NEE integrados, un $6.4 \%$ específicamente, en la evaluación de las familias de los alumnos de los diferentes servicios de Educación Especial, así mismo un 6.7\% son aplicados en los grupos, privilegiando la observación tanto con los alumnos de CAM, como con los alumnos que se encuentran integrados en Educación Básica por los diferentes profesionales de USAER o CRIIE. Un menor porcentaje de unidades de registro como se observa en la tabla 24 , de un $5.4 \%$, se refiere a la aplicación de instrumentos y estrategias en la evaluación de las instituciones, tanto de Educación Especial como de Educación Básica, realizada en este caso por los Supervisores, ATP y Directivos principalmente.

\section{- Seguimiento:}

Las actividades de seguimiento como parte de la evaluación, presentan un $23 \%$, dentro de este porcentaje un $7.9 \%$ se relaciona a los momentos de evaluación realizan a los servicios por medio del seguimiento a los objetivos, metas y estrategias planteadas en el Proyecto Curricular del Centro, por medio de visitas periódicas, reuniones técnicas, reuniones interdisciplinarias, con servicios de Educación Especial y de Educación Básica, así como también en reuniones de consejos técnicos de servicio, zona y/o estatal. De igual manera se observa un $5.2 \%$, relacionado al seguimiento a los maestros, equipos de apoyo, directivos, ATP y 
supervisores en cuanto a los programas, objetivos, metas y estrategias, planeadas y su impacto en la atención de los alumnos, maestros y padres de familia. Finalmente se reporta el seguimiento a la Propuesta Curricular Adaptada de los alumnos presentando un $12 \%$, de las unidades de registro, lo que permite replantear y mejorar la atención educativa.

\begin{tabular}{|c|c|c|}
\hline \multicolumn{3}{|c|}{ Actividades de Evaluación } \\
\hline Total de Unidades de Registro: 519 & & \\
\hline Categoría & Frecuencia & \% según $U$ de $R$ \\
\hline 1.1- Tipos de Evaluación & 141 & 28 \\
\hline 1.1.1.Inicial & 72 & 14 \\
\hline 1.1.2.Continua & 91 & 18 \\
\hline 1.1.3.Final & 49 & 9.4 \\
\hline 1.1.4.Psicopedagógica & 52 & 10 \\
\hline 1.2.-Instrumentos y Estrategias & 267 & 51 \\
\hline 1.2.1. Alumnos & 212 & 41 \\
\hline 1.2.2. Maestros & 35 & 6.7 \\
\hline 1.2.3. Familia & 33 & 6.4 \\
\hline 1.2.4. Grupo & 35 & 6.7 \\
\hline 1.2.5. Institución & 28 & 5.4 \\
\hline 1.3. Seguimiento & 118 & 23 \\
\hline 1.3.1. Proyecto curricular de centro & 63 & 7.9 \\
\hline 1.3.2. Profesionales Educ. & 27 & 5.2 \\
\hline 1.3.3. PCA & 64 & 12 \\
\hline
\end{tabular}

Tabla 24: Registro de Unidades de Frecuencia de las Actividades de Evaluación.

\section{- Capacitación y Actualización de los Profesionales}

Análisis de las respuestas a los cuestionamientos relacionados a la Capacitación y Actualización, que reciben los diferentes profesionales de Educación Especial aportando los siguientes resultados.

\section{- Contenidos}

Resultados del análisis de las unidades de frecuencia, de las categorías de la pregunta, referente a si la capacitación y actualización que recibe es adecuada en relación a los contenidos, de acuerdo al total de unidades de registro presentados en la tabla 25. 
* Contenidos de la Capacitación y Actualización:

- Adecuados:

El contenido de la capacitación y actualización que reciben los diferentes profesionales de Educación Especial, se consideran adecuados en un $63 \%$, siendo el mayor porcentaje del total de unidades de registro, como se observa en la tabla, relacionados a:

\section{Necesidades:}

Los profesionales informan que la capacitación que se imparte $\mathrm{Si}$ tiene en cuenta las necesidades en un $45 \%$, relacionadas a las necesidades de la Institución un 36\%, de los alumnos con NEE en un $4,8 \%$, y en las necesidades de los maestros, equipos de apoyo, directivos, etc., en un $6.3 \%$, en correspondencia a la operatividad técnica de los diferentes servicios de Educación Especial.

\section{Propósitos educativos:}

Se considera que los contenidos de la capacitación y actualización que reciben los diferentes profesionales, Si es adecuada, en un $21 \%$, apegándose a los fines y principios de la educación en México, tomando en cuenta los planes y programas de Educación Básica y los Programas de Fortalecimiento de la Educación Especial, nacional y Estatal.

\section{- NO adecuada}

Un 19\% de las unidades de registro reportan que los diferentes profesionales NO consideran adecuados los contenidos de la capacitación y actualización que reciben en relación a:

\section{Necesidades:}

Los diferentes profesionales de Educación Especial informan en un $7.1 \%$, como se observa en la tabla 25 , que las necesidades de las instituciones, de los maestros, de los equipos de apoyo, de los alumnos y de los padres de familia, NO son tomadas en cuenta en 
los contenidos de la capacitación que reciben durante el ciclo escolar.

\section{Propósitos educativos:}

De igual manera se considera en un 9.9\%, que los contenidos de la capacitación y actualización NO contemplan los planes y programas de Educación Básica, ni información sobre las diferentes discapacidades, relacionadas a la población que se atiende en cada uno de los servicios de Educación Especial.

Tiempo:

Como se observa en al tabla 25 en un $5.5 \%$ de las unidades de registro, el tiempo que se utiliza para dar los cursos $\mathrm{NO}$ es adecuado, ya que la capacitación es insuficiente, informando que además en algunas ocasiones no es lo que se requiere, dedicando mucho del tiempo invertido en la capacitación en tecnicismos, por lo que no siempre se logra ponerlos en práctica.

\section{Contenidos en la Capacitación y Actualización}

\begin{tabular}{l|c|c}
\hline \multicolumn{1}{c}{ Total de Unidades de Registro: 523} & \multicolumn{2}{c}{ \% según $U$ de $R$} \\
\hline 1.1.-Adecuada & Frecuencia & 63 \\
\hline 1.1.1. Necesidades & 330 & 45 \\
\hline 1.1.1.1. Institución & 237 & 36 \\
\hline 1.1.1.2. Alumnos & 188 & 4.8 \\
\hline 1.1.1.3. Funciones & 25 & 6.3 \\
\hline 1.1.2. Propósitos Educativos & 33 & 21 \\
\hline 1.2.- No Adecuada & 111 & 19 \\
\hline 1.2.1. Necesidades & 100 & 7.1 \\
\hline 1.2 .2$. Propósitos & 37 & 9.9 \\
\hline 1.2.3. Tiempo & 52 & 5.5 \\
\hline
\end{tabular}

Tabla 25: Registro de las Unidades de Frecuencia de la Capacitación Actualización en relación a los Contenidos.

\section{- Seguimiento de la Capacitación y Asesoría}

Resultados del análisis de las unidades de frecuencia de acuerdo al total de unidades de registro de las categorías del item 12, referente a SI el 
seguimiento de la capacitación y asesoría que recibe es adecuada, como se observa en la tabla 26.

Seguimiento de la Capacitación y Actualización:

- Adecuado:

En un 33\% se observa que los profesionales de Educación Especial, SI consideran adecuado el seguimiento que se realiza a la capacitación y asesoría, tomando en cuenta:

\section{Necesidades:}

Para realizar el seguimiento se informa que se toman en cuenta las necesidades de las instituciones y de los profesionales, reportando un $18 \%$, logrando impactar en la práctica docente, siguiendo los procesos educativos y fortaleciendo los aspectos técnicos operativos de los diferentes servicios de Educación Especial.

\section{Propósitos Educativos:}

Los encuestados consideran en un $4.1 \%$, que el seguimiento que se realiza a la capacitación y asesoría SI es adecuado, dado que parte de la planeación que se realiza en el trayecto formativo de la institución, dado que considera las necesidades técnicas de cada servicio al inicio del ciclo escolar, partiendo de los principios y fines de la educación, y con ello los planes y programas de Educación Básica.

\section{Tiempo:}

El $12 \%$ de las unidades de registro se refieren a que el seguimiento y los cursos se realizan SI son adecuados, realizándose al inicio, como durante y al final del ciclo escolar, aunque no son suficiente dadas las necesidades de cada contexto educativo. 


\section{- NO es adecuado:}

Es importante resaltar que los encuestados consideran con un $43 \%$, que el seguimiento que se realiza a la capacitación y asesoría, tanto en las actividades, como en el contenido y tiempo utilizado NO es adecuado, en relación a:

\section{$>$ Necesidades:}

En esta categoría se observa que un 3.7\%, informan que el seguimiento a la capacitación y asesoría No es la adecuada, debido a que no se basa en las necesidades de los servicio de Educación Especial, ni en las necesidades de los alumnos con NEE asociadas principalmente a la discapacidad, ni en las necesidades de los diferentes profesionales.

\section{> Propósitos Educativos:}

Los encuestados consideran que el seguimiento a la capacitación y asesoría No es la adecuada, reportando un 3.5\%, considerando que no atiende los lineamientos técnicos de la Educación Especial, específicamente en lo relacionado a las diferentes áreas de atención y funciones, como maestros de apoyo, de grupo, de comunicación, terapistas físico, psicólogo, trabajador social, etc., que desempeñan los diferentes profesionales.

\section{Tiempo:}

El tiempo es la categoría que presenta un mayor porcentaje de unidades de registro, establecido en un $41 \%$, informando por un lado que No se recibe capacitación alguna, por otro lado que la poca capacitación que se imparte es insuficiente, de tal manera que No hay seguimiento a la capacitación y asesoría que se llega a proporcionar a los diferentes profesionales de los servicios de Educación Especial. 
Seguimiento de la Capacitación y Asesoría

\begin{tabular}{l|c|c}
\hline \multicolumn{1}{c}{ Total de Unidades de Registro: 515} & \% según U de $R$ \\
\hline 1.1. SI Adecuada & Frecuencia & 33 \\
\hline 1.1.1. Necesidades & 170 & 18 \\
\hline 1.1.2. Propósitos Educativos & 95 & 4.1 \\
\hline 1.1.3. Tiempo & 21 & 12 \\
\hline 1.2. No Adecuada & 64 & 43 \\
\hline 1.2.1. Necesidades & 235 & 3.7 \\
\hline 1.2.2. Propósitos Educativos & 19 & 3.5 \\
\hline 1.2.3. Tiempo & 210 & 41 \\
\hline Tabla 26: Registro de las Unidades de Frecuencia del Seguimiento a la \\
Capacitación y Asesoría.
\end{tabular}

\section{- Capacitación y Actualización adecuada.}

Resultados del análisis de las unidades de frecuencia, de las categorías del item 13, referente a SI la capacitación y actualización que recibe es la que requieren, de acuerdo al total de unidades de registro como se observa en la tabla 27.

Los diferentes profesionales encuestados informan en un $45 \%$ de las unidades de registro, que la Capacitación y Actualización que reciben SI es adecuada por tomar en cuenta los siguientes aspectos;

\section{Capacitación y Actualización:}

\section{Necesidades:}

Consideran que se toman en cuanta las necesidades en un $38 \%$, relacionadas a las necesidades de las instituciones en un $23 \%$ tanto de Educación Especial como de Educación Básica, con un porcentaje de $1.5 \%$ se consideran las necesidades de los alumnos y con un $15 \%$ las necesidades de los profesionales, en cuanto a las diferentes funciones y áreas de la modalidad de Educación Especial. 


\section{$>$ Propósitos Educativos:}

La capacitación y actualización SI es la que se requiere, porque aborda aspectos específicos de las diferentes discapacidades, así como también toma en cuenta los Programas de Fortalecimiento de la Educación Especial y de la Integración Educativa, observando un $6 \%$.

\section{Tiempo:}

Los diferentes profesionales consideran que la capacitación y actualización es la que requieren, más sin embargo consideran en un $4.2 \%$, que el tiempo que se utiliza en dicha capacitación es insuficiente, dadas las necesidades técnicas que existen, solicitando un mayor tiempo y sistematicidad en las capacitaciones.

Los encuestados refieren que la capacitación y actualización No es la que se requiere en un 35\%, como se observa en la tabla, en relación a las siguientes categorías:

\section{Necesidades:}

Se observa que en un $24 \%$, que la capacitación y actualización que se proporciona a los diferentes profesionales de Educación Especial NO es la que se requiere, ya que no parte de las necesidades reales de las instituciones, considerando los servicios escolarizados, los servicios de orientación y los servicios de apoyo, en un $9.4 \%$ de las unidades de registro, así mismo en un $4.6 \%$ no se toman en cuenta las necesidades de los alumnos con NEE, asociados principalmente a la discapacidad, de igual manera se informa que en un $12 \%$, no contempla las necesidades de las funciones que desempeñan los diferentes profesionales.

\section{Propósitos Educativos:}

Los encuestados consideran en un $4.8 \%$, que la capacitación y actualización que se proporciona No tiene relación con los programas educativos, ni con los aspectos específicos de las diferentes discapacidad que se atienden en Educación Especial. 
Tiempo:

En este aspecto se reporta que un $11 \%$ de las unidades de registro, el tiempo que se emplea en la capacitación, es poco o ninguno, informando que no hay ninguna capacitación, por lo que los diferentes profesionales solicitan una mayor capacitación y actualización.

\begin{tabular}{|c|c|c|}
\hline \multicolumn{3}{|c|}{ Capacitación y Actualización adecuada } \\
\hline \multicolumn{3}{|c|}{ Total de Unidades de Registro: 520} \\
\hline Categoría & Frecuencia & \% según U de $R$ \\
\hline 1.1.- SI & 236 & 45 \\
\hline 1.1.1. Necesidades & 200 & 38 \\
\hline 1.1.1.1 Institución & 120 & 23 \\
\hline 1.1.1.2 Alumnos & 8 & 1.5 \\
\hline 1.1.1.3 Funciones & 80 & 15 \\
\hline 1.1.2. Propósitos Educativos & 31 & 6 \\
\hline 1.1.3. Tiempo & 22 & 4.2 \\
\hline 1.2.- No & 181 & 35 \\
\hline 1.2.1 Necesidades & 126 & 24 \\
\hline 1.2.1.1 Instituciones & 49 & 9.4 \\
\hline 1.2.1.2 Alumnos & 24 & 4.6 \\
\hline 1.2.1.3 Funciones & 63 & 12 \\
\hline 1.2.2 Propósitos Educativos & 25 & 4.8 \\
\hline 1.2.3 Tiempo & 55 & 11 \\
\hline
\end{tabular}

\section{- Propuestas de Mejoras}

Análisis de las sugerencias para mejorar los servicios de Educación Especial propuestas por los diferentes profesionales de los servicios, aportando los siguientes resultados (Ver Tabla 28).

Resultados del análisis de las unidades de frecuencia de las categorías del item 15, relacionada a las sugerencias que proponen los diferentes profesionales para mejorar los servicios de educación especial relacionado a aspectos de: 
* Sugerencias:

- Técnico Pedagógico:

Una de sugerencias con mayor porcentaje se relacionada a los aspectos técnicos pedagógicos reportando un $44 \%$, solicitando mayor capacitación sobre las NEE y aspectos específicos de cada una de las discapacidades, así como también en aspectos relacionados a las áreas de apoyo como son: trabajo social, psicología, terapia física y/o comunicación.

- Organización:

En los aspectos relacionados a la organización reporta un 11\%, solicitando mayor compromiso y colaboración de todos los involucrados en la Educación Especial y con ello optimizar la organización de la atención de los servicios sobre todo los Centros de Atención Múltiple y USAER.

\section{- Administrativo:}

Un $4.5 \%$ de las sugerencias se refiere a las solicitudes de recursos humanos para completar la plantilla de personal docente y del equipo de apoyo de los servicios, de igual manera solicitan mayor apoyo en recursos materiales, didácticos y financieros, que se requieren en los servicios escolarizados, de orientación y de apoyo de Educación Especial para una mejor calidad en la educación que se proporciona.

\section{- Vinculación:}

La vinculación de los diferentes niveles educativos, organismos gubernamentales y no gubernamentales, son necesarios para complementar la atención e integración de los alumnos con NEE asociados principalmente a la discapacidad $\mathrm{y} / \mathrm{o}$ a las aptitudes sobresalientes, en los diferentes sectores de la comunidad, por ello es considerada en un $4.7 \%$. 


\begin{tabular}{l|c|c}
\hline \multicolumn{3}{c}{ Sugerencias } \\
\hline Total de Unidades de Registro: 515 & Frecuencia & \% según U de $R$ \\
\hline Categoría & 226 & 44 \\
\hline 1.1Técnico Pedagógico & 59 & 11 \\
\hline 1.2 Organización & 23 & 4.5 \\
\hline 1.3 Administrativo & 24 & 4.7 \\
\hline 1.4 Vinculación & & \\
\hline
\end{tabular}

Tabla 28: Registro de las Unidades de Frecuencias de las Sugerencias.

\section{Conclusiones}

En parte de la investigación es de corte cuantitativo y cualitativo en el marco del ámbito educativo, basándonos por un lado en el aspecto cuantitativo, utilizando el método descriptivo, mientras que en el cualitativo nos apoyamos en la técnica de Análisis de Contenido, en una muestra de población de diferentes profesionales de Educación Especial, entre los que se encuentran supervisores, ATP Estatales, regionales y de zona, directivos, maestros de grupo, de apoyo, de comunicación, psicólogos, etc., con el objetivo de conocer el contexto de los profesionales de la modalidad de Educación Especial en el Estado de Chihuahua, en relación a los aspectos técnicos operativos y el impacto de la capacitación y actualización de la asesoría técnica a través de la encuesta.

Los resultados obtenidos reportan las siguientes conclusiones:

- La mayoría del personal encuestado de Educación Especial, tiene una experiencia de más de 20 años, principalmente desempeñándose en Educación Especial, aun y cuando han desarrollado otros puestos 0 funciones en diferentes niveles desde Educación Básica, abarcando Educación Inicial, Preescolar, Primaria y Secundaria, hasta el nivel de Educación Superior.

- La formación profesional dentro de el ámbito educativo, de los diferentes profesionales de Educación Especial, hace notar que tienen interés por superarse, dado que se ha mejorado la preparación de cuando inician a trabajar a la actualidad, encontrando profesionales con estudios de Doctorado o Maestría, mayor numero de profesionales que terminaron la Licenciatura en Educación Primaria y en Educación Especial. 
- En los aspectos Técnico y Operativos podemos resaltar lo siguiente: la actividad a la cual se dedica más tiempo, es a la planeación, aun y cuando en cuanto al porcentaje de tiempo que se utiliza sobresale la actividad de seguimiento, luego la planeación y después la evaluación.

\section{$>$ Seguimiento:}

El seguimiento reporta un mayor porcentaje de tiempo, y es la actividad que más profesionales desarrollan, relacionada a los diferentes tipos de evaluación que realizan, a los instrumentos y estrategias que emplean, principalmente utilizadas con los alumnos con necesidades educativas especiales (NEE), por otro lado también se informa que el seguimiento se realiza al Proyecto Curricular de Centro por parte de los supervisores, ATP de zona, región o estatal, así como por los directivos principalmente.

\section{Proyecto Curricular de Centro:}

En la participación de la elaboración del Proyecto Curricular de Centro o Institución por los diferentes profesionales, aparece en un segundo lugar, relacionado a la autoevaluación de la escuela, detectando las necesidades y fortalezas de la institución, ya sea de Educación Especial, o de Educación Básica que cuentan con el apoyo de Unidad de Servicios de Apoyo a la Escuela Regular (USAER), un mínimo porcentaje de profesionales toma en cuenta los recursos materiales, didácticos y de accesibilidad que requieren los alumnos con NEE asociados principalmente a la discapacidad. Por otro lado en un menor porcentaje, se contemplan los propósitos educativos principalmente los establecidos en los Programas de Fortalecimiento de la Educación Especial y de la Integración Educativa, tanto Nacional como Estatal.

\section{Evaluación:}

Las actividades de Evaluación presentan una minima diferencia del Seguimiento y del Proyecto Curricular de Centro, la evaluación se contempla por los diferentes profesionales, principalmente en la utilización de instrumentos y estrategias de evaluación sobre todo para 
los alumnos, después se contemplan los diferentes tipos de evaluación, en la cual sobresale la evaluación inicial tanto a los alumnos, como para los colectivos escolares, y el seguimiento referido principalmente al que se utiliza con los planteamientos establecidos en el Proyecto Curricular de Centro.

\section{- Capacitación y actualización}

Los diferentes profesionales informan que la mayoría de ellos, han recibido cursos de capacitación y actualización en diferentes instituciones del sector educativo, principalmente del Centro de Maestros o por los directivos de los servicios al que pertenecen, de igual manera se informan que el contenido de los cursos son adecuados y son los que requieren, tomando en cuenta las necesidades de los alumnos y las de las instituciones tanto de Educación Especial como de Educación Básica, y menor porcentaje la de los maestros y equipos de apoyo.

-Seguimiento: la mayoría de los diferentes profesionales encuestados reportan que en general el seguimiento que se realiza en la capacitación y actualización, no es el adecuado, debido principalmente a que no reciben capacitaciones por los Asesores Técnicos Pedagógicos (ATP) y a que lo poco que se recibe además de ser insuficiente no se hace seguimiento, para atender las necesidades técnico operativas de los servicios.

- Necesidades Técnicas. Las necesidades técnicas de los diferentes profesionales son principalmente las relacionadas a los aspectos específicos de las diferentes discapacidades, después las adecuaciones curriculares y las aptitudes sobresalientes. Donde se reporta menos necesidad es en los aspectos del Programa Enciclomedia, dado que es un programa que se implementa en los Centros de Atención Múltiple (CAM) a partir del ciclo escolar 2006-2007 y esta diseñado para Educación Primaria, seria importante proporcionar capacitación a todos los CAM del Estado sobre los diferentes programas, como de tecnologías de ayuda para apoyo de la atención de alumnos con NEE, principalmente asociados a discapacidad y aptitudes sobresalientes.

- Sugerencias: 
Los profesionales de Educación Especial consideran que se puede mejorar el servicio de la institución a la que pertenecen, con una actitud positiva de parte de todos los involucrados y trabajando colaborativamente principalmente. Sugieren mayor capacitación y actualización en aspectos específicos de las diferentes discapacidades, así como en las áreas de apoyo como son; trabajo social, psicología, terapia física y comunicación.

\subsection{Diseño, aplicación y evaluación de un recurso digital como propuesta para mejorar y optimizar la asesoría y capacitación técnica, en la modalidad de educación Especial.}

En esta fase de la investigación se llevo a cabo el diseño de un recurso digital en red para la modalidad de Educación Especial como una propuesta de mejora de la asesoría técnica, la aplicación de una encuesta para evaluar en un primer momento el diseño el sitio web por expertos, y en un segundo momento la aplicación de una nueva encuesta para evaluar la utilidad del sitio web por usuarios.

\section{1.- Diseño del recurso digital}

Con la finalidad de hacer una propuesta de mejora y optimización de la Asesoría Técnica en Educación Especial en el estado de Chihuahua, diseñamos una página web dispuesta en la red a partir del mes de Febrero del 2008 en la dirección: http://www.seech.gob.mx/eduespecial/ cuyo nombre es Departamento de Educación Especial de los Servicios Educativos del Estado de Chihuahua, con presentación oficial.

Para la realización de esta página seguimos una serie de pasos que se presentan en el capitulo anterior, para finalmente diseñar un sitio que contiene: Las herramientas con que cuenta el sitio web son:

-Es un entorno propicio para el aprendizaje autónomo y colaborativo entre los profesionales de las distintas zonas y/o entre los miembros de cualquier servicio llámese CAM, USAER, CRIIE, Supervisión, etc., apoyándose en la 
información que esta en el sitio, en atención a las necesidades técnicas que puedan tener.

-Menú lateral que facilita la navegación a través de distintos contenidos y recursos como son; Quienes somos?, Servicios, Perfiles, Cursos, Boletín, Ligas de Interés y Comentarios.

- Información general sobre Quienes somos en Educación Especial, presentando información sobre la misión y la visión.

- Servicios: Presentación de cada uno de los servicios de Educación Especial, especificando sus propósitos educativos y población que atiende, también se presenta información de las distintas zonas escolares y los servicios que conforman cada una de ellas, abarcando la ubicación, domicilio, nombre del directivo, etc.

-Perfiles: En esta parte se encuentra información específica para Maestros y Padres de Familia simplificando la navegación por el sitio web.

-Cursos: En esta área se pueden encontrar cursos sobre diferentes áreas como son; Discapacidad Auditiva, Discapacidad Motora, NEE asociadas a problemas de Comunicación y Lenguaje, Área de Aprendizaje y cursos sobre áreas especificas como son Psicología y Trabajo Social. Dichos cursos fueron diseñados por los Asesores Técnicos Pedagógicos del Estado, para desarrollarlos con algunos servicios durante el ciclo escolar 2007-2008 principalmente.

En este mismo espacio se encuentran documentos relacionados a la Política Educativa Nacional y Estatal, así como revistas internacionales y nacionales relacionadas a la educación en general y en específico a la Educación Especial, algunos documentos tienen la posibilidad de bajarlos directamente y otros se enlazan al sitio respectivo para bajarlos.

-Boletín: Se presenta el boletín de Educación Especial, mismo que se edita en el Estado, presentando información relacionada a las actividades de vinculación principalmente que realiza el Departamento, así como actividades donde participan los servicios tanto de CAM como de USAER.

-Ligas de Interés: Se presenta una relación de ligas de interés para los diferentes profesionales de Educación especial, relacionadas a instituciones y organismos de la educación en general y de la Educación Especial en particular, Internacionales, Nacionales y Estatales. 
-Comentarios: Es un especio donde el usuario tiene la posibilidad de contactar directamente desde la página, enviando sus comentarios, solicitudes, etc. al Departamento de Educación Especial.

-Correo electrónico: En el sitio se puede encontrar un vínculo directo para comunicarse por medio de correo electrónico con el Departamento de Educación Especial.

El sitio web se ira actualizando conforme las necesidades que se presenten.

\section{2.- Evaluación del Diseño y Utilidad del Sitio Web.}

Se describen los hechos realizados para la evaluación tanto del diseño del sitio web del Departamento de Educación Especial de los Servicios Educativos del estado de Chihuahua, como una Propuesta para la mejora y optimización de la Asesoría Técnica en la modalidad de Educación Especial en el Estado de Chihuahua en México, como la utilidad del mismo.

El instrumento que se determino utilizar es la Ficha de Catalogación de Portales Educativos de Pere Marqués-UAB (2004) con algunas adecuaciones debido a las características del sitio web, en primer momento para la evaluación del diseño del sitio web por los expertos.

\section{a) Instrumentos para la evaluación del diseño del Sitio Web}

La encuesta para la evaluación del diseño del sitio web finalmente, consta de 19 preguntas cerradas y un aspecto abierto para realizar observaciones (Ver Anexo V). Dentro de su organización presenta cuatro espacios bien determinados como son:

- Identificación:. En la primera parte de la encuesta se presenta el Nombre de la página que es. 
"Departamento de Educación Especial de los Servicios Educativos del Estado de Chihuahua".

Figura 28: Primera parte de la encuesta.

- Principales servicios que proporciona: Se presenta un listado de los servicios que proporciona el portal a sus destinatarios de la siguiente manera.

"Información a Maestros y Padres de Familia sobre los servicios que ofrece la
modalidad de Educación Especial de los Servicios Educativos del Estado de
Chihuahua México y la población que atiende en los diversos servicios. De igual
manera informa sobre la ubicación de los centros en el Estado. Así mismo se
encuentran documentos sobre la Política Educativa, revistas de educación nacionales
e internacionales, una recopilación sobre las diferentes ligas de interés para los
Maestros, diversos cursos de actualización para Maestros, un boletín informativo y un
buzón de correo".

Figura 29: Información de la encuesta.

- Evaluación: Se presenta una tabla con Aspectos Funcionales, Técnicos y Pedagógicos, que deberán evaluarse basándose en una escala de 4 valores:

- BAJA: si la característica que se evalúe está mal.

- CORRECTA: si este aspecto está bien, correcto.

- ALTA: si este aspecto está bien.

- EXCELENTE: si resulta casi inmejorable en este aspecto.

Figura 30: Escala de valores de la encuesta.

- Observaciones y evaluación global: donde además de establecer una valoración numérica se recogen observaciones complementarias que quiera hacer el evaluador.

\begin{tabular}{l}
\hline OBSERVACIONES: \\
-Aspectos Positivos del Portal. \\
-Aspectos Negativos del Portal. \\
-Otras Observaciones. \\
\hline \multicolumn{4}{||}{ VALORACIÓN GLOBAL } \\
\hline \hline
\end{tabular}




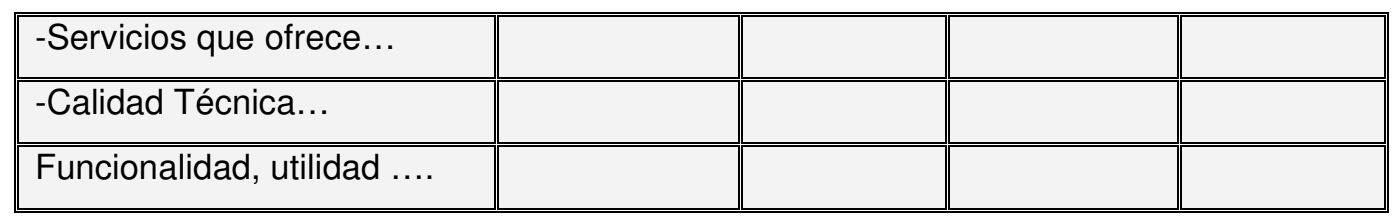

Figura 31: Observación y Valoración Global.

El instrumento se envío por correo electrónico a la muestra de población de expertos, otorgando un periodo de tiempo de mes y medio para contestarlo.

El objetivo de esta encuesta es la evaluación del diseño del sitio web en red por expertos en el área de TIC y de Educación Especial, para realizar las modificaciones que sean necesarias y pertinentes, tomando en cuenta el propósito del mismo.

\section{b) Instrumento para evaluar la utilidad del Sitio Web}

Como ya se dijo anteriormente, seleccionamos también la Ficha de Catalogación de Portales Educativos de Pere Marqués-UAB (2004) para la evaluación de la utilidad del sitio web por usuarios, considerando que contenía elementos necesarios para nuestro propósito, con algunas adecuaciones, debido a las características del sitio y del objetivo de la evaluación.

La encuesta para evaluar la utilidad del portal educativo, consta de 19 preguntas cerradas y un aspecto para realizar observaciones (Ver Anexo VI). Su organización presenta 5 espacios específicos como son:

- Datos generales: En esta primera parte se solicitan los datos generales del encuestado como son:

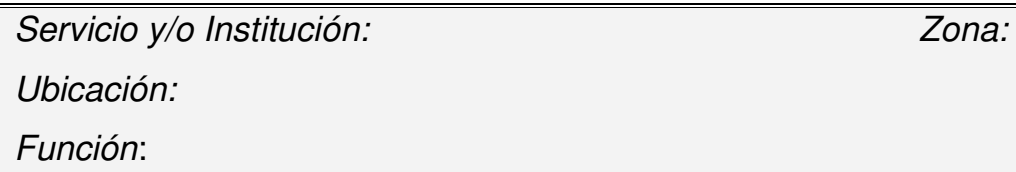

Figura 32: Datos Generales de la encuesta.

- Presentación de la encuesta: Se presenta información sobre los aspectos que contempla la encuesta, para la evaluación del portal educativo. 
Las preguntas que aparecen en esta encuesta se refieren a aspectos funcionales, técnicos, pedagógicos y una valoración global de la página Web del Departamento de Educación Especial de los SEECH.

Figura 33: Presentación de la encuesta.

- Invitación a conocer la página web: Primeramente se hace un cuestionamiento sobre si conoce tiene información de la página, después se invita a conocerla y se presenta una reseña general de lo que se puede encontrar en ella.

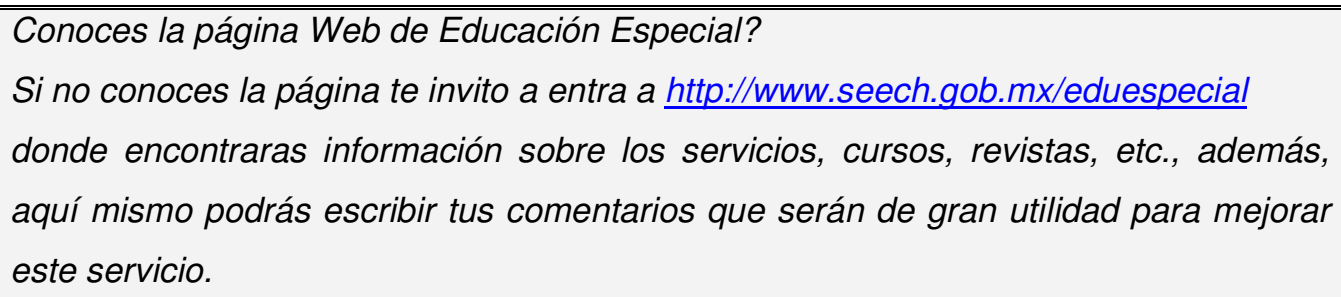

Figura 34: Invitación a conocer el sitio web.

- Evaluación: se presenta una tabla con los aspectos que se van a evaluar como son; Aspectos Funcionales, Aspectos Técnicos y Aspectos Pedagógicos, que deberán evaluarse basándose en una escala de 4 valores:

- BAJA: si la característica que se evalúe está mal.

- CORRECTA: si este aspecto está bien, correcto.

- ALTA: si este aspecto está bien.

- EXCELENTE: si resulta casi inmejorable en este aspecto.

Figura 35: Valores de la Evaluación

- Observaciones y evaluación global: en ese espacio además de establecer la valoración numérica se recogen observaciones complementarias que quiera hacer el evaluador.

\section{OBSERVACIONES:}

-Aspectos destacables del portal. 


\begin{tabular}{|l||l||l|l|l||}
\hline \multicolumn{4}{|l||}{-Aspectos mejorables del portal. } \\
\hline \hline & EXCELENTE & ALTA & CORRECTA & BAJA \\
\hline \hline -Utilidad... & & & & \\
\hline \hline -Calidad Técnica... & & & & \\
\hline $\begin{array}{l}\text { Funcionalidad, utilidad para } \\
\text { los usuarios.... }\end{array}$ & & & & \\
\hline
\end{tabular}

Figura 36: Observaciones y Valoración Global

El instrumento se aplico a la muestra mencionada durante el mes de septiembre, por directivos y supervisores de los servicios de Educación Especial.

\subsubsection{Informe de los resultados de la evaluación del diseño y utilidad del sitio Web de Educación Especial.}

\section{a) Resultados de la evaluación del diseño del sitio web.}

Los resultados de la evaluación del diseño del sitio web de Educación Especial, realizada por la muestra definitiva de 22 expertos en las áreas de TIC y de Educación Especial, se presenta en una serie de tablas y gráficas donde se exponen los resultado de las frecuencias en porcentajes y media del análisis descriptivo de los diferentes aspectos de la encuesta aplicada.

En el Anexo E se presenta la codificación de los ítems de la encuesta.

\section{Aspectos Funcionales.}

En la evaluación realizada por los expertos del Aspecto Funcional del Portal Educativo, se observa el porcentaje mayor relacionado a la relevancia del sitio, con el $50 \%$ de las frecuencias y una media de 3,50, considerada entre la valoración de excelente y alta, con el menor porcentaje se reportan los canales de comunicación bidireccional (Ver Tabla 29). 


\begin{tabular}{|l|c|c|c|c||c||}
\hline \multicolumn{7}{|c|}{ Aspectos Funcionales. } \\
\hline \multicolumn{1}{|c|}{ Aspectos } & Excelente (4) & Alta (3) & Correcta(2) & Baja(1) & Media \\
\hline -Relevancia. & 50 & 50 & 0 & 0 & 3,50 \\
\hline -Facilidad de navegación & 36,4 & 40,9 & 18,2 & 4,5 & 3,09 \\
\hline -Múltiples enlaces externos & 22,7 & 50 & 27,3 & 0 & 2,95 \\
\hline $\begin{array}{l}\text {-Canales de comunicación } \\
\text { bidireccional }\end{array}$ & 18,2 & 31,8 & 31,8 & 18,2 & 2,32 \\
\hline -Servicios de apoyo on-line & 31,8 & 36,4 & 27,3 & 4,5 & 2,91 \\
\hline $\begin{array}{l}\text {-Ausencia o poca } \\
\text { publicidad }\end{array}$ & 50 & 9,1 & 36,4 & 4,5 & 3,05 \\
\hline
\end{tabular}

Tabla 29: Frecuencias y Media de los Aspectos Funcionales del Diseño del Sitio Web.

En relación a los Aspectos Funcionales se presenta igualmente la gráfica 10 donde los expertos consideran, en la funcionalidad del sitio web, en primer lugar la relevancia, con una media de 3,5 considerando que es la primera página de la modalidad de Educación Especial, a continuación la facilidad de la navegación por la página, con una media de 3,09, después se considero la ausencia de publicidad con una media de 3,05, dado que es un sitio que es considerado Oficial al pertenecer a los Servicios Educativos del Estado de Chihuahua, no puede contener publicidad de otro tipo. Después se consideraron los múltiples enlaces externos en el diseño del sitio, con una media de 2,95, luego se ubico el servicio de apoyos on-line con una media de 2,91 y por ultimo con una media de 2,32 el aspecto de comunicación referido a los canales de comunicación bidireccional.

\section{Evaluación del Diseño del Sitio Web Aspectos Funcionales}

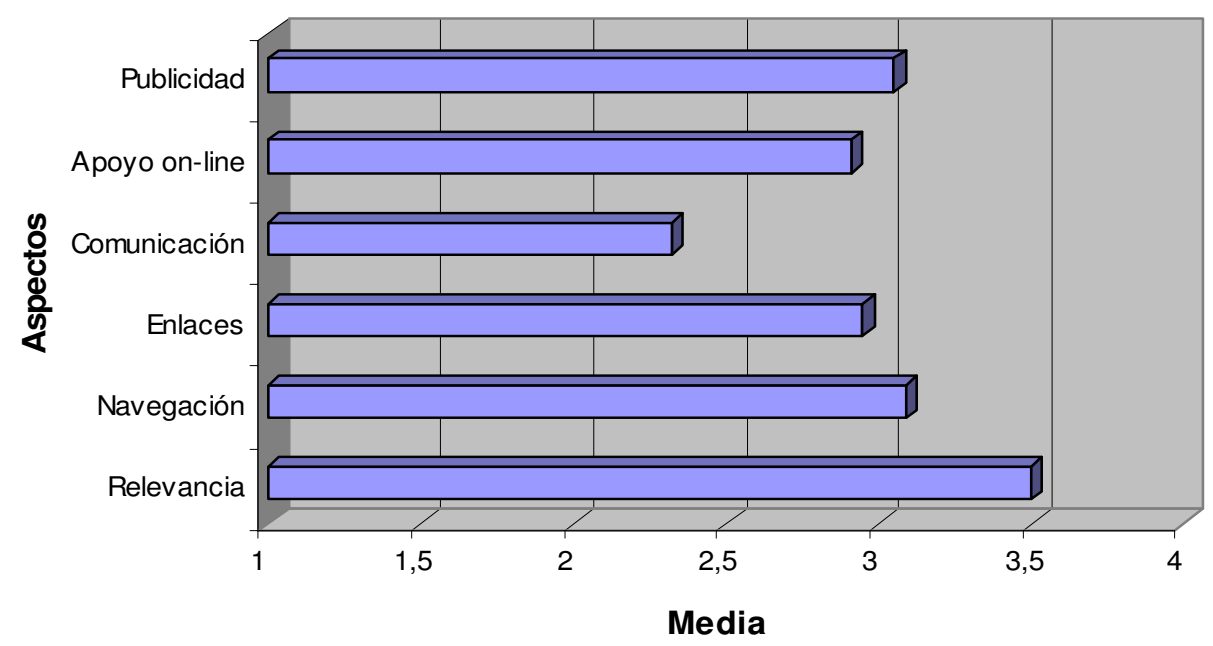

Gráfica 10: Evaluación de los Aspectos Funcionales del Diseño del Sitio Web. 


\section{Aspectos Técnicos y Estéticos}

En los resultados de porcentajes de frecuencias y media de los Aspectos Técnicos y Estéticos del sitio web, en la evaluación del diseño realizada por los expertos, el mayor porcentaje por frecuencia y media lo presenta los hipertextos descriptivos y actualizados con una media de 3,05, con el menor porcentaje de frecuencias y media, se consideraron los elementos multimedia, ya que son mínimos con los que se cuenta (Ver Tabla 30).

\begin{tabular}{|l|c|c|c|c|c||}
\hline \multicolumn{7}{|c|}{ Aspectos Técnicos y Estéticos } \\
\hline \multicolumn{1}{|c|}{ Aspectos } & Excelente & Alta & Correcta & Baja & Media \\
\hline $\begin{array}{l}\text { Entorno audiovisual: } \\
\text { presentación }\end{array}$ & 4,5 & 68,2 & 27,3 & 0 & 2,77 \\
\hline $\begin{array}{l}\text { Elementos multimedia: } \\
\text { calidad, cantidad }\end{array}$ & 18,2 & 36,4 & 27,3 & 4,5 & 2,41 \\
\hline $\begin{array}{l}\text { Calidad y estructuración de } \\
\text { los contenidos }\end{array}$ & 31,8 & 36,4 & 22,7 & 9,1 & 2,82 \\
\hline $\begin{array}{l}\text { Hipertextos descriptivos y } \\
\text { actualizados }\end{array}$ & 36,4 & 31,8 & 31,8 & 0 & 3,05 \\
\hline $\begin{array}{l}\text { Ejecución fiable, velocidad } \\
\text { y visualización adecuada }\end{array}$ & 9,1 & 45,5 & 27,3 & 18,2 & 2,45 \\
\hline Originalidad & 40,9 & 13,6 & 45,5 & 0 & 2,95 \\
\hline
\end{tabular}

Tabla 30: Frecuencias y Media de los Aspectos Técnicos y Estéticos del Diseño del Sitio Web.

En los resultados del análisis de las medias de la evaluación del sitio web realizada por los expertos, se considero con una mayor puntuación de 3,05 de media, el aspecto relacionado a los hipertextos descriptivos y actualizados, a continuación se considero la originalidad de la página con una media de 2,95. En orden ascendente con una media de 2,82 , se considero la calidad y estructuración de los contenidos, después se ubico la presentación con una media de 2,77, después con una media de 2,45 en penúltimo lugar, se consideró la ejecución fiable, velocidad y visualización adecuada y por ultimo con una media menor de 2,41 los elementos multimedia en cantidad y calidad, dado que cuenta con un mínimo (Ver Gráfica 11). 


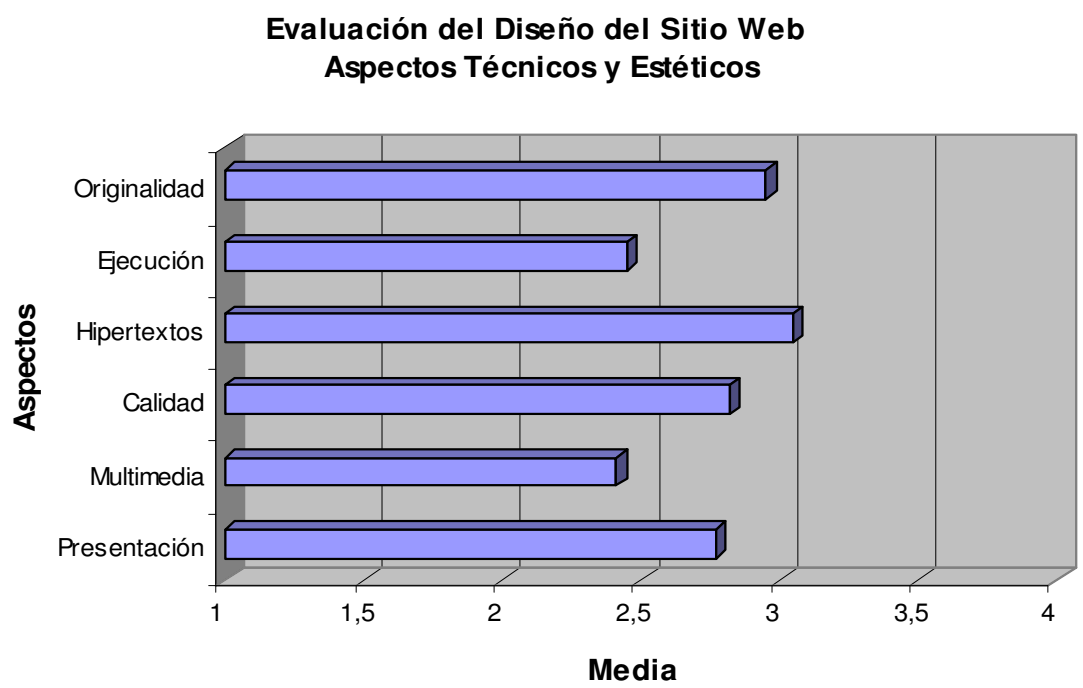

Gráfica 11: Evaluación de los Aspectos Técnicos y Estéticos del Diseño del Sitio Web.

\section{Aspectos Pedagógicos.}

En la tabla 31 se presenta el análisis de los resultados de la evaluación del sitio web, realizada por los expertos, de los Aspectos Pedagógicos informando que el porcentaje de frecuencias mas alto en la escala de excelente, se presenta en la adecuación del sitio web a los destinatarios, de los contenidos que contiene, así como de las actividades, con una media de 3,32, así mismo encontramos que el porcentaje de frecuencia más bajo y de media lo presenta la potencialidad de los recursos didácticos.

\begin{tabular}{|l|c|c|c|c||c||}
\hline \multicolumn{7}{|c|}{ Aspectos Pedagógicos } \\
\hline \hline \multicolumn{1}{|c|}{ Aspectos } & Excelente & Alta & Correcta & Baja & Media \\
\hline $\begin{array}{l}\text { Atractivo, capacidad de } \\
\text { motivación, interés. }\end{array}$ & 50 & 22,7 & 27,3 & 0 & 3,23 \\
\hline $\begin{array}{l}\text { Adecuación a los destinatarios } \\
\text { de los contenidos, actividades. }\end{array}$ & 45,5 & 40,9 & 13,6 & 0 & 3,32 \\
\hline $\begin{array}{l}\text { Recursos para buscar } \\
\text { información }\end{array}$ & 40,9 & 40,9 & 18,2 & 0 & 3,23 \\
\hline $\begin{array}{l}\text { Potencialidad de los recursos } \\
\text { didácticos. }\end{array}$ & 13,6 & 45,5 & 27,3 & 13,6 & 2,45 \\
\hline
\end{tabular}

Tabla 31: Frecuencias y Media de los Aspectos Pedagógicos del Diseño del Sitio Web. 
Complementando lo anterior sobre la evaluación de los Aspectos Pedagógicos de la página, evaluados por los expertos, se presenta el resultado del análisis de las medias en la gráfica 12, otorgando mayor importancia a los aspectos sitio web adecuado a los destinatarios, en este caso maestro y padres de familia con una media de 3,32. En segundo lugar se consideraron el aspecto atractivo, la capacidad de motivación e interés de la página para los usuarios y los recursos que ofrece para buscar información con una media de 3,23 y por ultimo la potencialidad de los recursos didácticos con una media de 2,45.

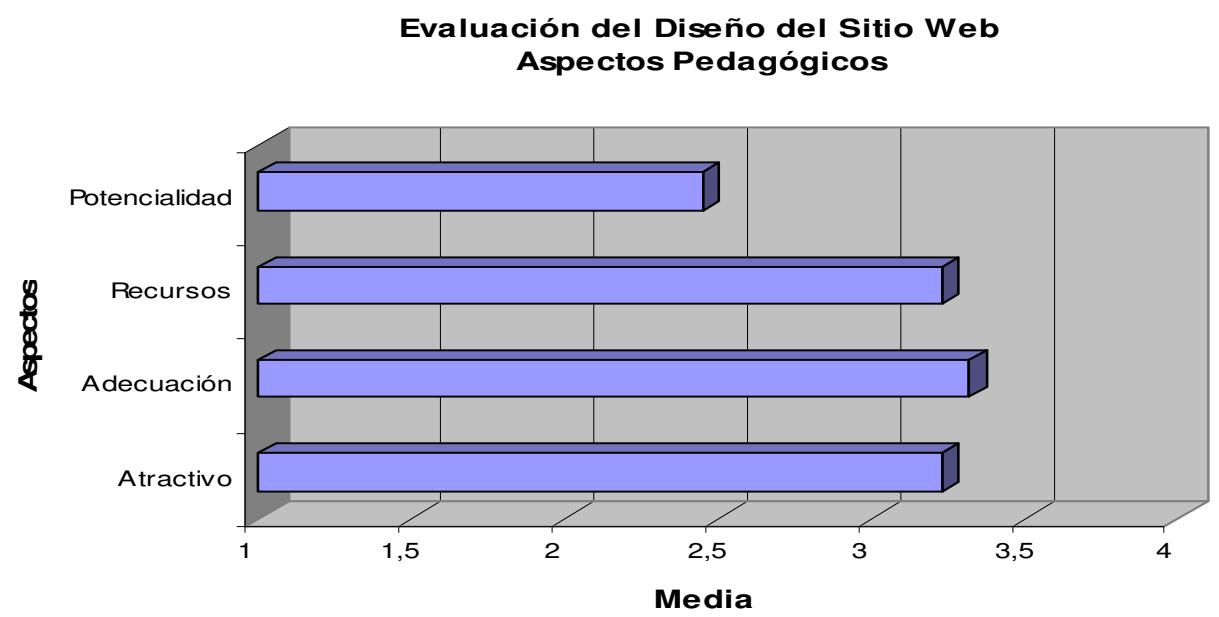

Gráfica12: Evaluación de los Aspectos Pedagógicos del Diseño del Sitio Web.

\section{Valoración Global}

La Valoración Global se presenta en la tabla 32 como resultado del análisis de la evaluación realizada por lo expertos, reportando que el mayor porcentaje de frecuencias en la escala de excelente, lo presenta el aspecto de la Funcionalidad del sitio web, con un $50 \%$ y una media de 3,41 , relacionado a la relevancia, ausencia de publicidad, facilidad de navegación, servicios de apoyo on-line, a los enlaces, y los canales de comunicación con que se cuenta en el sitio. Con el menor porcentaje de frecuencias $(27,3)$ y media $(3,09)$, se encuentra la Calidad técnica, relacionado a originalidad del sitio, a la cantidad y calidad de los elementos multimedia que contiene, a la ejecución fiable, velocidad adecuada, calidad de los contenidos y a los hipertextos. 


\begin{tabular}{|l|c|c|c|c|c||}
\hline \multicolumn{7}{|c|}{ Valoración Global } \\
\hline \multicolumn{1}{|c|}{ Aspectos } & Excelente & Alta & Correcta & Baja & Media \\
\hline Los servicios que ofrece & 36,4 & 59,1 & 4,5 & 0 & 3,32 \\
\hline Calidad técnica & 27,3 & 54,5 & 18,2 & 0 & 3,09 \\
\hline $\begin{array}{l}\text { Funcionalidad, utilidad para sus } \\
\text { usuarios }\end{array}$ & 50 & 40,9 & 9,1 & 0 & 3,41 \\
\hline
\end{tabular}

Tabla 32: Frecuencias y Medias de la Valoración Global del Diseño del Sitio Web.

En la gráfica 13 se presentan los resultados del análisis de la media de la Valoración General que realizaron los expertos, reportando que la mayor es de 3,41 , relacionada al aspecto de la Funcionalidad y utilidad para los usuarios, considerando que el portal es relevante, tiene facilidad de navegación, múltiples enlaces, servicios on-line y posibilidades de comunicación bidireccional. En segundo lugar se consideraron los Servicios que ofrece $(3,32)$, presentando los contenidos adecuados a los destinatarios, recursos para buscar información y potencialidad de los recursos didácticos. Por ultimo con una media de 3,09 se ubico la Calidad Técnica considerando los hipertextos, la originalidad, la calidad y estructuración de los contenidos, la presentación, la ejecución y la calidad de los elementos multimedia.

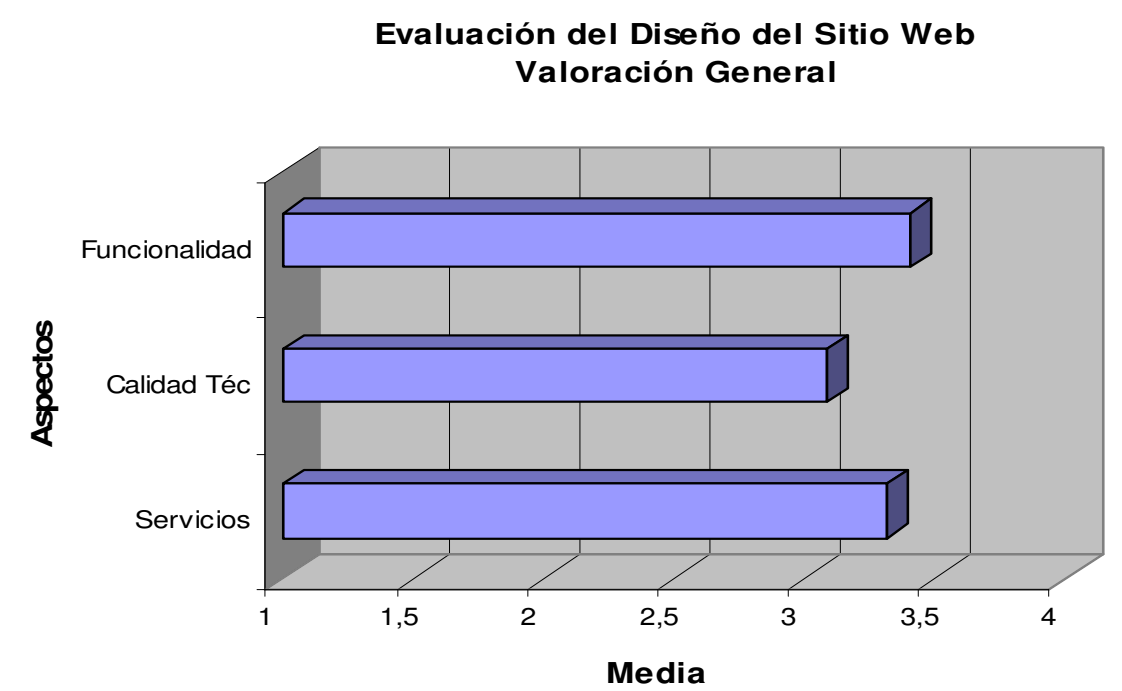

Gráfica 13: Valoración Global del Diseño del Sitio Web. 


\section{Observaciones}

\section{- Aspectos positivos}

El resultado de las observaciones que realizaron los expertos sobre el portal educativo, en relación a los aspectos positivos, el 90,9\% de los expertos consideraron que el portal es sencillo de utilizar, la información se localiza de manera rápida y puntual, es claro, preciso y de lenguaje sencillo, con contenidos necesarios, que aporta información sobre los servicios de Educación Especial (Ver Figura 29), los tipos de servicios que existen en el Estado, su ubicación, nombre del Directivo, etc., y propicia la investigación, capacitación, autocapacitación y actualización, presentando documentos, enlaces, cursos y talleres vinculados a las necesidades técnicas operativas actuales, relacionados a las áreas de discapacidad auditiva y motora, psicología, comunicación y lenguaje, aprendizaje y trabajo social de la modalidad de Educación Especial. Sobre todo se considera importante que se puede acceder a la información cuando se requiera.

\section{- Aspectos negativos.}

En relación a aspectos negativos de las observaciones, el $22,7 \%$ de los expertos informan que faltan un mayor número de recursos, debido a que se considera que el diseño es muy lineal, a la lentitud al abrir los cursos y que no hay vínculos de salida (Ver Figura 29). De igual manera se sugiere hacer un weblogs integrado al sitio web, como una propuesta de resolución de casos.

\section{- Observaciones generales.}

De manera general en las observaciones finales de los expertos, se considera un buen trabajo y felicitan al Departamento de Educación Especial por contar finalmente con un recurso como éste, haciendo hincapié en la utilidad de la información, de los cursos y talleres actualizados, las ligas de interés y documentos que contiene, también se solicita que se actualice continuamente, 
así mismo se sugiere poner noticias relevantes y actualizadas, donde se puede visualizar el titulo de cada noticia (Ver Figura 29).

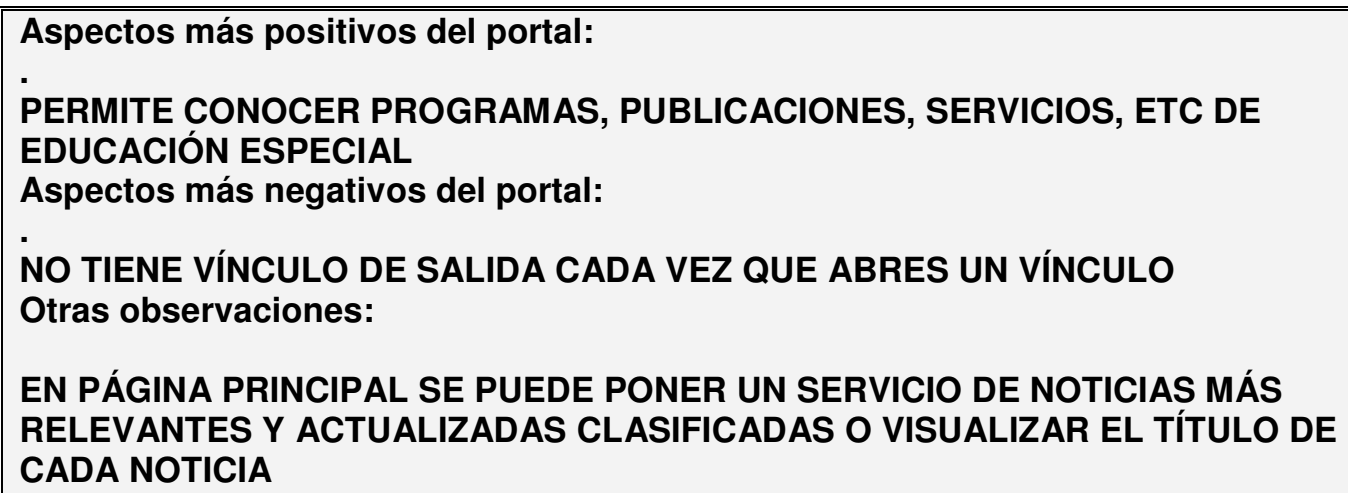

Figura 29: Observaciones de un experto.

\section{Conclusiones:}

En evaluación del diseño del sitio web del Departamento de Educación Especial de los Servicios Educativos del Estado de Chihuahua en México, fue realizada por 22 expertos de TIC y/o Educación Especial, en los aspectos funcionales se considera principalmente relevante poder contar en la actualidad con un sitio web para Educación Especial, considerando así mismo su originalidad dentro de los aspectos técnicos y estéticos, de igual manera se considera un sitio que donde el contenido de la información que se puede encontrar esta adecuada a los destinatarios, valorando sobre todo su funcionalidad y utilidad.

Para que el portal sea más adecuado a su objetivo, se considera necesario ampliar y diversificar los recursos, mejorar la navegación, la calidad técnica considerando los hipertextos, la ejecución, la calidad y cantidad del contenido, la presentación y la calidad de los elementos multimedia.

Tomando en cuenta esta evaluación se realizaron algunos cambios en el sitio web, los cursos que se diseñan se presentaran en formato web para hacer más ágil el acceso y la velocidad para abrirlos, se coloco mayor información para los maestros tanto en las ligas de interés, como en los documentos, como son:

-Vínculos a información relacionada a las TIC y Educación Especial, así como a la Red Normalista. 
-Se amplio la información en el aspectos de los cursos con documentos de Orientaciones Generales para el Funcionamiento de los Servicios de Educación Especial, .Orientaciones para Fortalecer los Procesos de Evaluación en la zona Escolar, Orientaciones Generales para Elaborar la Normatividad, Plan Estratégico de Transformación, Material de trabajo y propuesta para alumnos con Aptitudes Sobresalientes, manual de Accesibilidad, Propuesta para trabajo con la Familia, Asistencia Tecnológica, revistas internacionales del sector educativo, vínculos a Bibliotecas, etc.

La sencillez del diseño del sitio web, es debido a que no poseo la formación técnica para el diseño de materiales multimedia. Así que para realizar mayores modificaciones se consultara a un técnico en el tema, además de consultar y pedir autorización a los encargados del Departamento de cómputo de los Servicios Educativos del Estado de Chihuahua ya que debido a que es un sitio web oficial requiere cumplir algunos requisitos.

\section{b) Resultados de la evaluación de la utilidad del sitio Web.}

Los datos cuantitativos recogidos en esta parte de la investigación han sido aportados por la encuesta y por el análisis descriptivo de los datos. El interés de estos datos responde a nuestro deseo de conocer la opinión de los usuarios, en este caso diferentes profesionales de Educación Especial, sobre la utilidad del sitio web del Departamento de Educación Especial de los Servicios Educativos del Estado de Chihuahua.

En el Anexo VI se encuentra la codificación de la encuesta.

El resultado del análisis permitió conformar una serie de tablas y gráficas donde se presentan los datos.

\section{Servicios}

Los servicios que participaron en la evaluación de la utilidad del sitio web de Educación Especial se presentan en la gráfica 14, informando que el mayor numero de profesionales participantes son del servicio de USAER, con un $58,9 \%$, por ser el tipo de servicio con el que más se cuenta en el Estado, 
después el personal de CAM con un 27,3\%, y en menor porcentaje esta el servicio de CRIIE dado que solamente existen 3 en el Estado.

\section{Evaluación de la Utilidad del Sitio Web Servicios de Educación Especial}

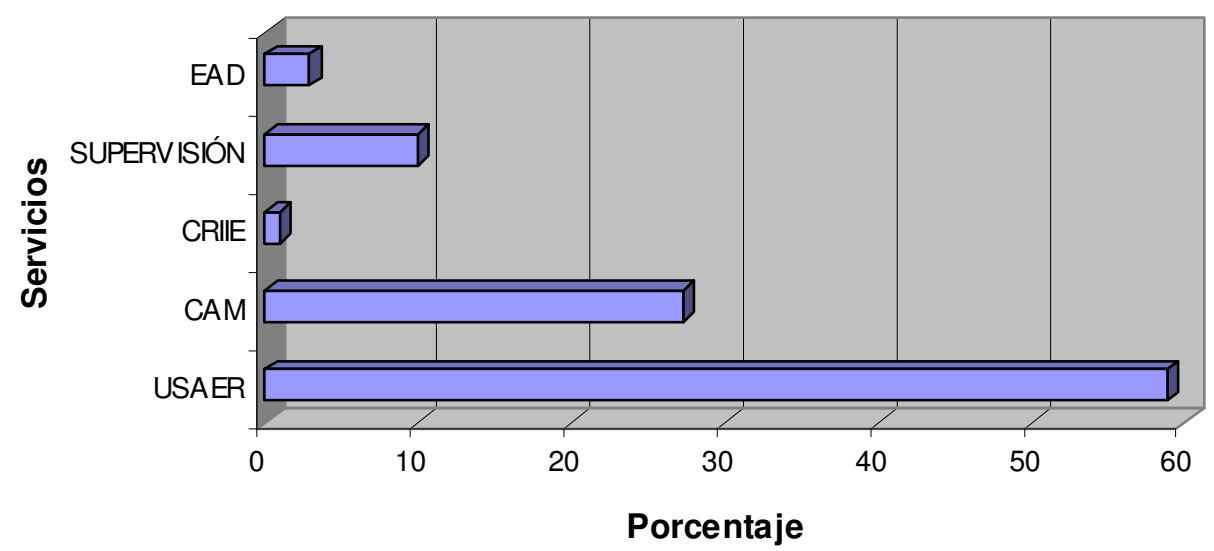

Gráfica 14: Servicios de Educación Especial que participaron en la Evaluación de la utilidad del Sitio Web.

La gráfica 15 complementa la información de los servicios, presentando las funciones de los diferentes profesionales encuestados, observando que el mayor porcentaje de frecuencias lo reflejan los Directivos con un 31,6\% tanto de USAER como de CAM, después aparecen los Maestros de Apoyo de USAER con un $29,2 \%$, los Maestros de Grupo de CAM con 12,4\%, Psicólogos un $7,7 \%$ pertenecientes a los diferentes servicios, también se observa que de los 18 supervisores que es el total de zonas en el Estado actualmente, participaron 16, con un porcentaje en relación a la muestra de 7,7, el menor número de participantes lo encontramos en los auxiliares de maestros de CAM. 


\section{Evaluación de la Utilidad del Sitio Web \\ Profesionales Participantes}

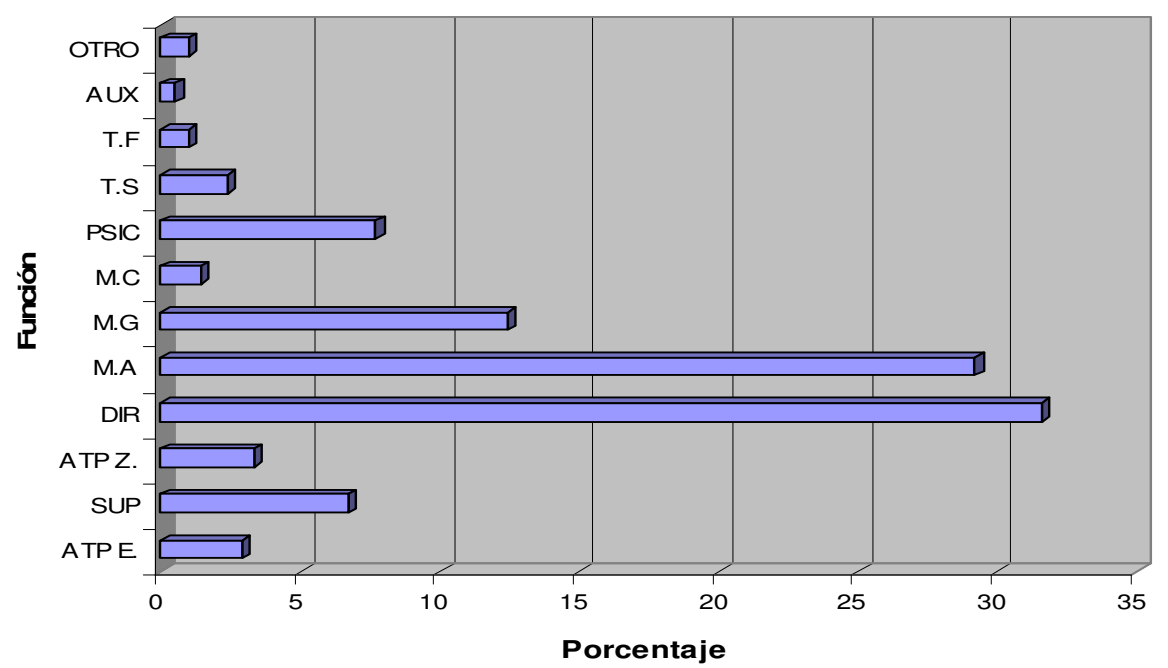

Gráfica 15: Profesionales por Función, que participaron en la Evaluación de la utilidad del Sitio Web.

En la tabla 33 se presenta el número de personal por zona escolar que participo en esta parte de la investigación de los diferentes servicios de Educación Especial, participando todas las zonas del Estado, con un mayor porcentaje $(11,5)$ la zona 9 de cd. Juárez, después las zona $3(8,1 \%)$ de Chihuahua, luego la zona 4 y 7 con un porcentaje de 6,7, y con el mínimo porcentaje de participación se encuentra la zona 8 de Camargo y 13 de Nuevo Casas Grandes.

\begin{tabular}{|c|c|c||}
\hline \multicolumn{3}{|c|}{ Relación de personal por Zona Escolar } \\
\hline Zona Escolar & Frecuencias & Porcentaje \\
\hline Zona 1 & 11 & 5,3 \\
\hline Zona 2 & 7 & 3,3 \\
\hline Zona 3 & 17 & 8,1 \\
\hline Zona 4 & 14 & 6,7 \\
\hline Zona 5 & 11 & 5,3 \\
\hline Zona 6 & 11 & 5,3 \\
\hline Zona 7 & 14 & 6,7 \\
\hline Zona 8 & 4 & 1,9 \\
\hline
\end{tabular}




\begin{tabular}{|c|c|c|}
\hline Zona 9 & 24 & 11,5 \\
\hline \hline Zona 10 & 16 & 7,7 \\
\hline \hline Zona 11 & 10 & 4,8 \\
\hline Zona 12 & 13 & 6,2 \\
\hline \hline Zona 13 & 3 & 1,4 \\
\hline Zona 14 & 12 & 5,7 \\
\hline Zona 15 & 6 & 2,9 \\
\hline Zona 16 & 8 & 3,8 \\
\hline \hline Zona 17 & 13 & 6,2 \\
\hline Zona 18 & 13 & 6,2 \\
\hline \hline
\end{tabular}

Tabla 33: Personal por Zona Escolar que participaron en la Evaluación de la utilidad del Sitio Web.

En la gráfica16 se presentan el análisis de los datos relacionados al item ¿Conoce la página?, informando de que la mayoría $(76,1 \%)$ de los profesionales encuestados. Si conocen la página web de Educación Especial y un $21,5 \%$, no tenía conocimiento de ella. Aun y con este resultado consideramos que es importante promover la difusión y utilización de la página en todos los servicios y con todos los profesionales, promoviendo el autoaprendizaje y el aprendizaje colaborativo, relacionado a la capacitación y actualización.

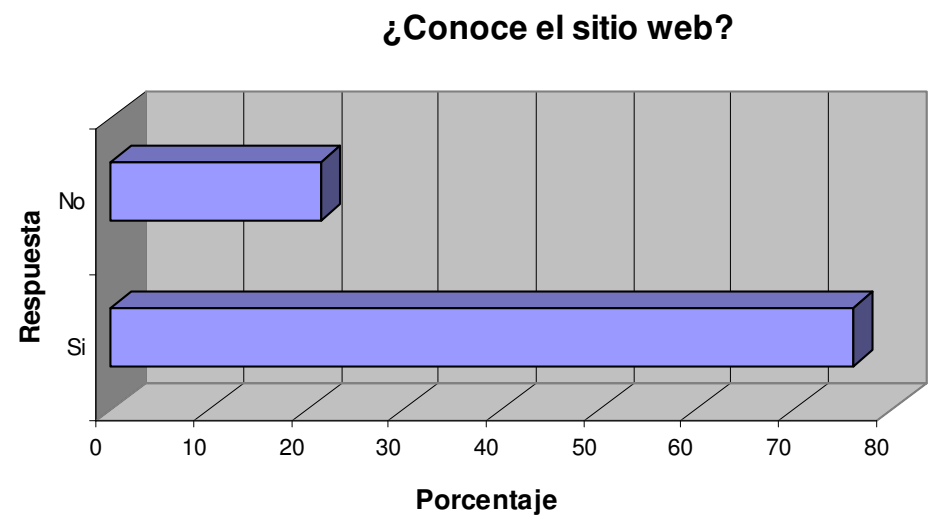

Grafica 16: ¿Conoce la página web?, de la Evaluación de la utilidad del Sitio Web. 


\section{Aspectos Funcionales}

Uno de los aspectos que se evalúo de la utilidad del sitio web es el relacionado al Aspecto Funcional, en el análisis de resultados que realizamos de las encuesta de los diferentes profesionales, se observa que la facilidad de uso es considerada por la mayoría con una media de 2,83 y un porcentaje de frecuencias de 45 en la valoración de Alta, seguida de la utilidad de los enlaces $(2,71)$ y el aspectos ha sido evaluado con más bajo porcentaje son los canales de comunicación $(2,53)$, como se puede ver en la tabla 34 .

\section{Aspectos Funcionales Utilidad}

\begin{tabular}{|l|c|c|c|c|c||}
\hline Aspectos & Excelente (4) & Alta (3) & Correcta (2) & Baja (1) & Media \\
\hline $\begin{array}{l}\text { Interés del contenido y de } \\
\text { los servicios que ofrece }\end{array}$ & 15,8 & 45 & 31,6 & 2,9 & $\mathbf{2 , 6 4}$ \\
\hline Facilidad de uso & 23,4 & 44 & 27,8 & 1,9 & $\mathbf{2 , 8 3}$ \\
\hline Utilidad de los enlaces & 21,1 & 37,3 & 36,8 & 1,4 & $\mathbf{2 , 7 1}$ \\
\hline Canales de comunicación & 13,4 & 36,4 & 43,5 & 2,9 & $\mathbf{2 , 5 3}$ \\
\hline $\begin{array}{l}\text { Utilidad de los servicios de } \\
\text { apoyo on-line }\end{array}$ & 15,8 & 34,9 & 42,6 & 3,3 & $\mathbf{2 , 5 6}$ \\
\hline
\end{tabular}

Tabla 34: Frecuencias y Medias de la Evaluación de la utilidad del Sitio Web de los Aspectos Funcionales.

Para complementar la información de la tabla presentamos la grafica 17 donde se pueden observar los diferentes aspectos que abarcan la funcionalidad del sitio web y que fueron evaluados por los diferentes profesionales, mostrando que la mayoría consideró la facilidad de uso con una media de 2,83 , dado que es un sitio de fácil acceso, seguida por la utilidad de los enlaces con una media de 2,71 referido sobre todo a las ligas de interés y a los documentos de cursos, revistas etc., lo que se relaciona con el siguiente aspecto que es el interés del contenido y de los servicios que ofrece con una media de 2,64, el aspectos que consideró con el puntaje más bajo de media son los canales de comunicación, dado que son mínimos. 


\section{Evaluación de la Utilidad del Sitio Web \\ Aspectos Funcionales}

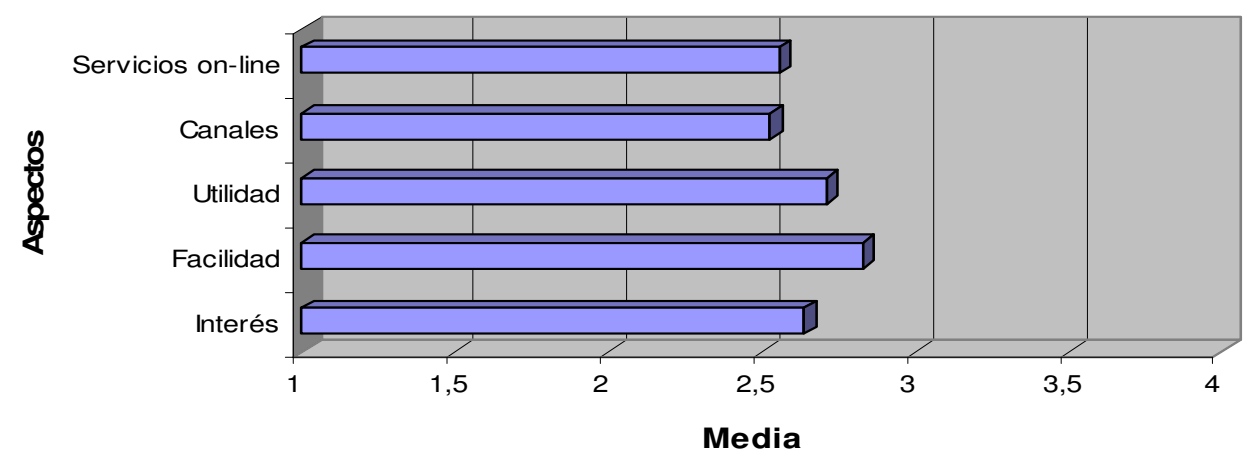

Grafica 17: Evaluación de la utilidad de los Aspectos Funcionales del Sitio Web.

\section{Aspectos Técnicos y Estéticos}

Los resultados del análisis respecto al Aspecto Técnico y Estético expuestos en la tabla 35, informan que los diferentes profesionales consideran en su mayoría la Calidad y estructuración de los contenidos, con el mayor porcentaje de frecuencias en la valoración de Alta $(39,2)$ y una media de 2,68 , debido a la información técnica- operativa y de Política Educativa etc. que contiene el sitio web, en segundo lugar con una minima de diferencia en la media $(2,41)$, se considera la Ejecución fiable, velocidad y visualización adecuada y por ultimo la Originalidad de los aspectos técnicos y estéticos, por la sencillez del diseño.

\begin{tabular}{|l|c|c|c|c|c|}
\hline \multicolumn{7}{|c|}{ Aspectos Técnicos y Estéticos } \\
\hline Aspectos & Excelente (4) & Alta (3) & Correcta (2) & Baja (1) & Media \\
\hline $\begin{array}{l}\text { Calidad y estructuración de } \\
\text { los contenidos }\end{array}$ & 18,7 & 39,2 & 36,8 & 2,4 & $\mathbf{2 , 6 8}$ \\
\hline $\begin{array}{l}\text { Ejecución fiable, velocidad y } \\
\text { visualización adecuada }\end{array}$ & 18,2 & 23,4 & 44 & 10 & $\mathbf{2 , 4 1}$ \\
\hline Originalidad & 16,7 & 25,4 & 41,1 & 6,2 & $\mathbf{2 , 3 2}$ \\
\hline
\end{tabular}

Tabla 35: Frecuencias y medias de la Evaluación de utilidad de los Aspectos Técnicos y Estéticos del Sitio Web. 
En la siguiente grafica 18 del análisis de resultados de medias de los Aspectos Técnicos y Estéticos del sitio web de Educación Especial, podemos observar que la Calidad y estructuración de los contenidos presenta la media más alta $(2,68)$, aun y cuando hay una minima diferencia con los aspectos de Ejecución $(2,41)$ y de Originalidad $(2,32)$.

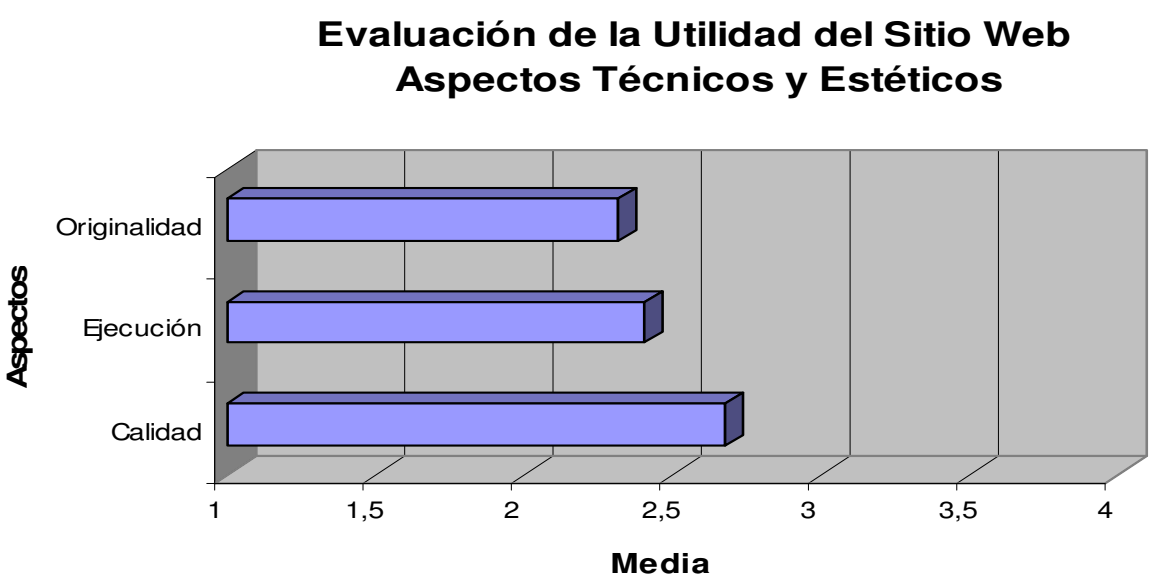

Gráfica 18: Evaluación de la utilidad de los Aspectos Técnicos y Estéticos del Sitio Web.

\section{Aspectos Pedagógicos.}

Los resultados del análisis de los porcentajes de frecuencias y media de los Aspectos Pedagógicos se presentan en la tabla 36, entre los aspectos evaluados por los diferentes profesionales de Educación Especial hay una minima diferencia, haciendo hincapié en que se considera que fomenta el Autoaprendizaje con el mayor porcentaje $(40,7)$ en la valoración de alta y media $(2,69)$, es importante puntualizar que los profesionales de Educación Especial consideran con el menor puntaje de media $(2,47)$ el hecho de que el sitio web posibilite el trabajo colaborativo. 


\begin{tabular}{|l|c|c|c|c|c|}
\hline \multicolumn{7}{|c|}{ Aspectos Pedagógicos } \\
\hline Aspectos & Excelente (4) & Alta (3) & Correcta (2) & Baja (1) & Media \\
\hline $\begin{array}{l}\text { Planteamientos pedagógicos } \\
\text { actuales.. }\end{array}$ & 14,8 & 45,5 & 32,5 & 3,3 & $\mathbf{2 . 6 4}$ \\
\hline $\begin{array}{l}\text { Atractivo, capacidad de } \\
\text { motivación.. }\end{array}$ & 11 & 45,5 & 33 & 7,2 & $\mathbf{2 , 5 4}$ \\
\hline $\begin{array}{l}\text { Adecuación a los } \\
\text { destinatarios de los } \\
\text { contenidos.. }\end{array}$ & 13,9 & 36,4 & 41,6 & 4,3 & $\mathbf{2 , 5 2}$ \\
\hline $\begin{array}{l}\text { Utilidad de los recursos para } \\
\text { buscar información ...... }\end{array}$ & 15,8 & 42,1 & 33 & 5,3 & $\mathbf{2 , 6 1}$ \\
\hline $\begin{array}{l}\text { Potencialidad de los recursos } \\
\text { didácticos: cursos, } \\
\text { programas, documentos...... }\end{array}$ & 11,5 & 51,2 & 28,2 & 5,7 & $\mathbf{2 , 6 2}$ \\
\hline Fomenta el autoaprendizaje & 22,5 & 40,7 & 23,4 & 10 & $\mathbf{2 , 6 9}$ \\
\hline $\begin{array}{l}\text { Posibilita el trabajo } \\
\text { colaborativo }\end{array}$ & 11,5 & 42,1 & 32,5 & 9,6 & $\mathbf{2 , 4 7}$ \\
\hline
\end{tabular}

Tabla 36: Frecuencias y Medias de la Evaluación de la utilidad de los Aspectos Pedagógicos del Sitio Web.

En la gráfica 19 se puede observar el resultado del análisis de media de los Aspectos Pedagógicos, donde el mayor puntaje de media lo presenta el Autoaprendizaje $(2,69)$, seguido de los Planteamientos Pedagógicos actuales $(2,64)$, como son los documentos de la Política Educativa, cursos, revistas, etc., la Potencialidad del sitio web $(2,62)$, luego la Utilidad de los recursos para buscar información $(2,61)$, después se consideró lo Atractivo del sitio, y su capacidad de motivación $(2,54)$, así como la Adecuación de los contenidos de acuerdo a los destinatarios $(2,52)$ y por ultimo el Posibilitar el trabajo colaborativo $(2,47)$. Como se puede observar las diferencias entre los aspectos es mínima. 


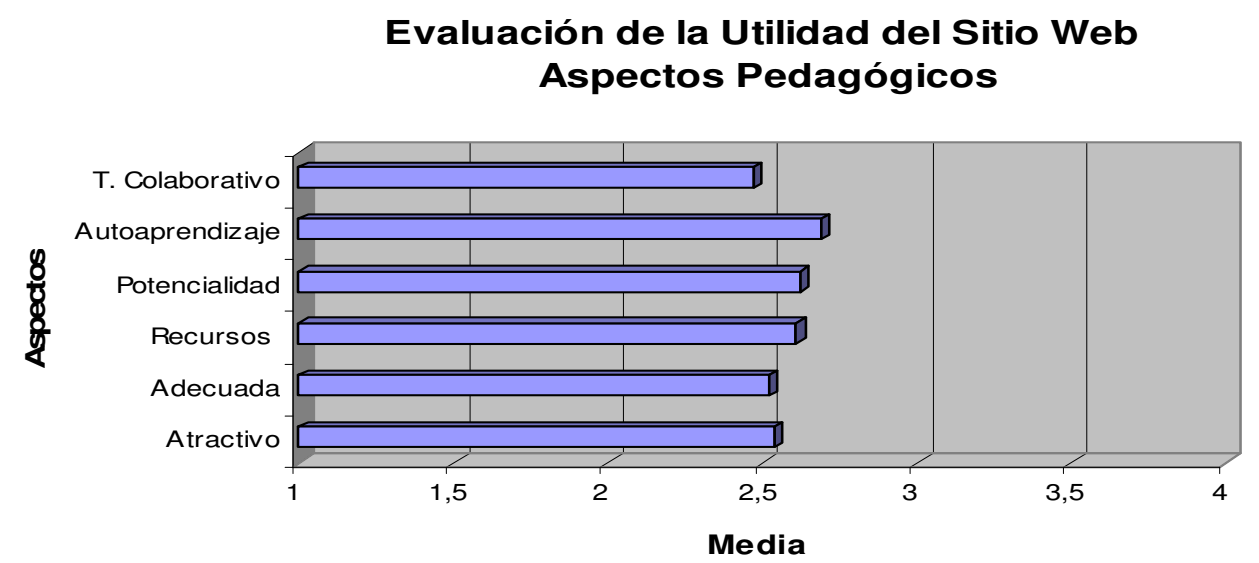

Gráfica 19: Evaluación de la utilidad de los Aspectos Pedagógicos del Sitio Web.

\section{Valoración Global}

La Valoración Global abarca aspectos que se han evaluado anteriormente complementando la información de los resultados de análisis de las frecuencias y medias presentes en la tabla 37 , la puntuación de media más alta es del Aspecto de Utilidad de los recursos, con una media de 2,89, después con una mínima diferencia $(2,85)$ se consideró la Funcionalidad, utilidad para los usuarios, relacionado principalmente a la facilidad de uso, a la utilidad de los enlaces, al interés de los servicios que ofrece, etc., y por ultimo se consideró la Calidad técnica, ejecución y originalidad.

\begin{tabular}{|l|c|c|c|c|c||}
\hline \multicolumn{7}{|c|}{ Valoración Global } \\
\hline Aspectos & Excelente (4) & Alta (3) & Correcta (2) & Baja (1) & Media \\
\hline Utilidad de los recursos & 24,9 & 47,4 & 23 & 1,9 & $\mathbf{2 , 8 9}$ \\
\hline Calidad Técnica & 16,3 & 49,8 & 28,2 & 1,4 & $\mathbf{2 , 7 2}$ \\
\hline $\begin{array}{l}\text { Funcionalidad, utilidad para } \\
\text { sus usuarios ........ }\end{array}$ & 29,2 & 36,4 & 28,7 & 1,9 & $\mathbf{2 , 8 5}$ \\
\hline
\end{tabular}

Tabla 37: Valoración Global de la utilidad del Sitio Web.

El resultado del análisis de media de los aspectos de la Valoración Global de la utilidad del sitio web, realizada por profesionales de Educación Especial, reporta con un mayor puntaje de media $(2,89)$ la Utilidad de los recursos que contiene el sitio, seguida con una minima diferencia $(2,85)$ la Funcionalidad por la utilidad para los usuarios y por ultimo la Calidad Técnica con una media de 2,72 (Ver Gráfica 20). 


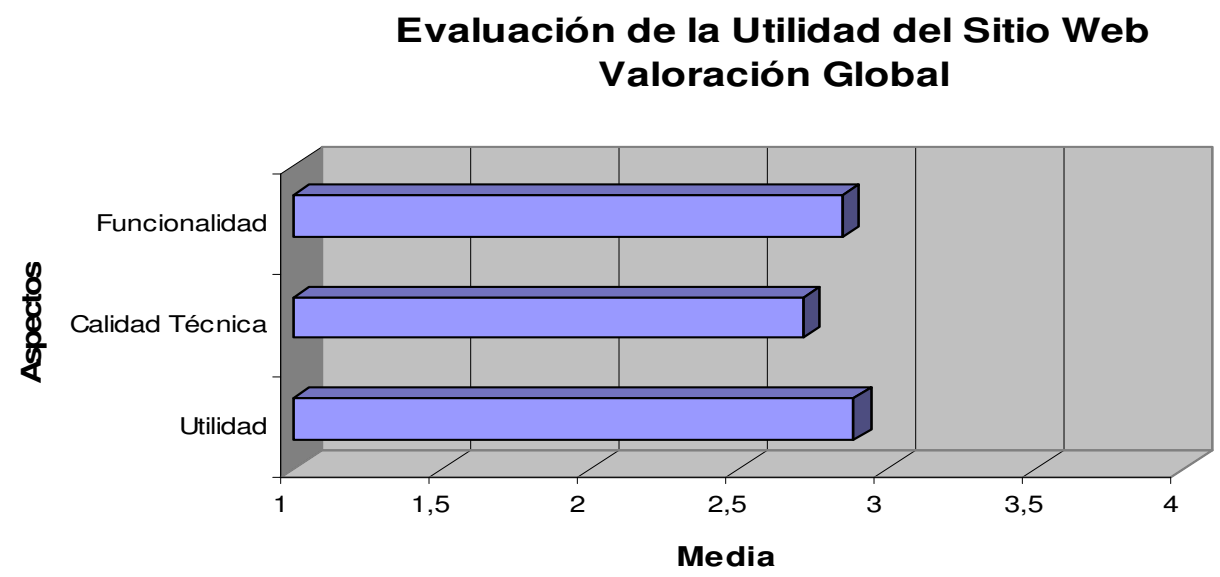

Gráfica 20: Valoración Global de la utilidad del sitio web.

\section{Observaciones}

\section{a) Aspectos destacables del sitio web.}

Los aspectos que se considerados destacables del sitio web, por el 77,9\% de los usuarios encuestados de los diferentes servicios de Educación Especial son:

-Fácil acceso

-La importancia de contar con el portal educativo y poder difundir a la comunidad educativa y en general el trabajo de Educación Especial.

-La facilidad y sencillez, con una buena presentación, con vocabulario accesible y adecuado a los usuarios.

- Los documentos e información para Padres de Familia y Maestros que contiene.

-La información sobre la Misión, y Visión de Educación Especial.

- Se considera destacable las ligas de interés, el contenido de los cursos actualizados, el material de consulta, la posibilidad de comunicación con el Departamento de educación Especial por medio del correo electrónico y del espacio de comentarios.

-Consideran el uso de las TIC favorable, posibilitando desarrollar competencias en el uso y manejo de las nuevas tecnologías. 
-Opción de supervisión académica.

-Contiene muchas opciones para la capacitación y autocapacitación.

-Los materiales de los cursos están siempre disponibles.

\section{b) Aspectos Mejorables del sitio web}

En relación a los aspectos mejorables del sitio web, un 53,5\% de los diferentes profesionales encuestados consideran que los aspectos mejorables del sitio web son:

-La actualización de los nombres de los supervisores y directivos, así como la organización de las zonas escolares debido a los cambios en las plantillas de personal en este ciclo escolar 2008-2009.

- Ampliación de los cursos incluyendo; Discapacidad Intelectual, Formación Laboral, Aptitudes Sobresalientes, Autismo, Lenguaje de Signos, Discapacidad Múltiple.

- Solicitan que se presente información sobre estrategias concretas y que la información sea más práctica.

-En cuanto al diseño del sitio web, se sugiere que se mejore el diseño, con mayor atractivo visual incorporando fotos, videos, audio y mayor número recursos y de enlaces.

-De igual manera consideran que se debe hacer mayor difusión en cada uno de los servicio del Estado, impactando en el miedo que se tiene al uso de las $\mathrm{TCl}$.

\section{Conclusiones}

La evaluación de la utilidad del sitio web del Departamento de Educación Especial de los Servicios Educativos del Estado de Chihuahua, diseñado como una propuesta para mejorar y optimizar la capacitación y actualización dentro de la asesoría técnica, fue evaluado por una muestra de 209 profesionales de Educación Especial, pertenecientes a las 18 zonas escolares y desempeñando diferentes funciones dentro de los servicios.

Después de realizar el análisis de resultados de los datos aportados, podemos decir que: 
-En su mayoría de los profesionales conocen el sitio web, y consideran importante poder contar con un sitio web específico de Educación Especial, sin embargo consideramos que es necesaria una mayor difusión.

-Se considera que es un sitio web fácil y sencillo de utilizar, que contiene un vocabulario accesible y adecuado, valorando la calidad y estructuración de los contenidos, considerando la información técnica operativa que contiene adecuada a la modalidad de Educación Especial.

-Dentro de los aspectos pedagógicos se considera que el sitio web fomenta el autoaprendizaje, presentando planteamientos pedagógicos actuales como los cursos y los documentos, promoviendo el uso de las TIC, así mismo se consideran de utilidad los recursos para buscar información como son las ligas de interés, y por ultimo con un mínimo porcentaje se consideró el hecho de que propicie el aprendizaje colaborativo.

-La calidad del sitio requiere de mayores recursos, presentación visual, fotos, video, mejorar la ejecución, velocidad y visualización.

-Actualizar los datos de los servicios de Educación Especial continuamente, añadir los cursos sobre; Discapacidad Intelectual, Aptitudes Sobresalientes, Autismo, Lengua de Signos y Discapacidad Múltiple. 


\section{CAPÍTULO 5: $\quad$ CONCLUSIONES}

En el siguiente capítulo, tras analizar los resultados de nuestra investigación, presentamos la confirmación de las hipótesis de nuestro experimento. Para finalizar, se expondrán las conclusiones y recomendaciones finales de este trabajo, así como las futuras investigaciones que pueden dar continuidad a la que aquí se ha desarrollado.

El campo de las TIC en Educación Especial en México es aún incipiente y con un gran camino que recorrer, especialmente en lo relacionado a su investigación y aplicación.

La investigación que se realizó fue desarrollar una propuestas de mejora y optimización de la Asesoría Técnica en la modalidad de Educación Especial en el Estado de Chihuahua México, a través del uso de las TIC, con un doble carácter cuantitativo y cualitativo, utilizando diversas técnicas de recogida de información.

\subsection{Confirmación de las hipótesis}

En los resultados expuestos anteriormente, concluimos sobre las hipótesis:

1. Se confirma que el uso de las TIC están desaprovechadas, es minima la utilización que se les da para realizar la actualización y capacitación del personal docente de Educación Especial, debido a que los Asesores Técnicos Pedagógicos mínimamente las utilizan como en uso de correo electrónico o para hacer alguna presentación y se centran principalmente en la asesoría técnica presencial, debido a los miedos que aún se tienen en la utilización de las TIC.

2. Se corrobora que los documentos oficiales que enmarcan la Política Educativa de Educación Especial, plantean el uso de las TIC con finalidades educativas, tanto en las leyes de educación y discapacidad como en los programas educativos. 
3. Confirmamos que los recursos digitales disponibles no se utilizan por falta de conocimiento de los docentes, debido principalmente a la falta de capacitación y el miedo que se tiene a las TIC.

4. Se corrobora que los recursos digitales en red son un buen elemento para la actualización y capacitación, por la capacidad de la red para el almacenamiento, actualización difusión y búsqueda de información que brindan la posibilidad de actualizarse, de aprender de manera formal e informal, participando en comunicaciones de correo electrónico, foros, chat, etc.

5. Se confirma que el uso adecuado de los recursos digitales en red apoya las acciones de asesoría y capacitación, debido a que la web ofrece un número ilimitado de posibilidades para la comunicación, favoreciendo el autoaprendizaje y formas más creativas de aprender, permitiendo la interacción independientemente del tiempo y el espacio entre sus usuarios.

6. Se corrobora que el uso adecuado de las TIC proporciona una asesoría técnica de mayor calidad, dada la posibilidad del incremento de información actualizada que se puede tener a disposición, como cursos, documentos, vínculos con instituciones, etc., rompiendo el tiempo y el espacio, formando parte de una comunidad de conocimiento.

\subsection{Conclusiones}

En el proceso de análisis e interpretación de los datos ya hemos recogido algunas conclusiones a modo de resultados. Vamos ahora a extractar aquellas que consideramos más relevantes en función de los objetivos de la investigación.

- La propuesta de mejora y optimización de la Asesoría Técnica en la modalidad de Educación Especial, a través del uso de las TIC, para lo cual se diseño un recurso digital en red, demuestra ser una estrategia de utilidad en la capacitación y actualización, debido a que por un lado, proporciona y promueve información actualizada de aspectos técnicos operativos, dispuestos en cualquier momento y por otro lado, fomenta el 
autoaprendizaje de los diferentes profesionales, que trabajan en Educación Especial.

- El diseño del recurso digital en red, es sencillo y fácil de utilizar, con un lenguaje acorde a los usuarios a los que va dirigido, la información técnica que contiene, como los cursos sobre aspectos específicos de algunas discapacidades y sobre áreas de atención como psicología, trabajo social, comunicación y aprendizaje, es adecuada y actualizada, los recursos de búsqueda de información como las ligas de interés son de utilidad. Es necesario estar actualizando la información de los supervisores y directivos de los servicios, de los cursos, documentos, etc., cuando sea necesario y consultar técnicos en informática para incorporar mayores y mejores recursos multimedia, mejorando la calidad técnica.

- El uso de las TIC en Educación Especial, desde el punto de vista educativo, están establecidas en un mínimo porcentaje en los documentos de la Política Educativa, principalmente en los Programas Educativos, en relación a la diversificación de los recursos, materiales educativos y la accesibilidad, en la atención a los alumnos con necesidades educativas especiales, principalmente asociadas a la discapacidad y las aptitudes sobresalientes.

- Consideramos importante puntualizar que el uso de las TIC como tecnologías de asistencia en Educación Especial, pueden ser utilizadas en la diversificación de los recursos, pudiendo llegar a ser un elemento importante para mejorar la calidad de vida de las personas con discapacidad, llegando a ser un elemento, en algunos casos, para acceder al currícula escolar, haciendo posible su comunicación, o facilitando su integración social y laboral.

- El contexto de la modalidad de Educación Especial del subsistema federalizado, en el Estado de Chihuahua, se caracteriza porque la mayoría del personal directivo, docente y de apoyo, cuentan con más de 20 años de servicio en el sector educativo, habiendo tenido experiencia en diferentes niveles y modalidades, en Educación Inicial, Preescolar, Primaria, Secundaria y/o Educación Superior. Son profesionistas que ingresaron en Educación Especial con una formación básica, que se han 
interesado por superarse profesionalmente, logrando terminar estudios de licenciatura en Educación Primaria, Educación Especial, Maestría, Doctorado, entre otros.

- En cuanto a los aspectos técnicos operativos la actividad que realizan los diferentes profesionales es la planeación. Se participa en actividades de elaboración de proyecto curricular de centro, en la planeación, autoevaluación detectando las necesidades y fortalezas de la institución, de igual manera se realizan actividades de evaluación y seguimiento, utilizando diferentes instrumentos y estrategias, principalmente en la atención educativa de los alumnos con necesidades educativas especiales.

- En cuanto a la capacitación y actualización, podemos decir que es proporcionada por diferentes instituciones, sobre todo por el Centro de Maestros, no por los Asesores Técnicos Pedagógicos (ATP) considerando que el contenido de los cursos y capacitación es adecuado, de acuerdo a las necesidades de los alumnos que se atienden y a las necesidades de las instituciones. El seguimiento de la asesoría técnica no es adecuado, debido por un lado a la falta de capacitación por los ATP y por otro al insuficiente seguimiento y acompañamiento que se realiza a los diferentes servicios de Educación Especial.

- Las necesidades técnicas están enfocadas principalmente a los aspectos específicos de las diferentes discapacidades, las adecuaciones curriculares y las aptitudes sobresalientes, debido principalmente a la falta de preparación profesional en áreas de discapacidad. Por otro lado se plantea la necesidad de mayor capacitación de las áreas de Psicología, Trabajo Social y Comunicación. Por ello se incluyen los cursos relacionados a estos temas en el sitio web.

En nuestra opinión la incorporación de las TIC por los diferentes profesionales de Educación Especial, requiere que se posean nuevas competencias docentes relacionadas con conocimientos sobre los procesos de comunicación y de significado que generan las TIC, sobre las diferentes formas de trabajar las nuevas tecnologías en las distintas áreas y disciplinas, al igual que tener 
conocimientos técnicos suficientes que le permitan rehacer y estructurar materiales del mercado pudiéndolo adaptar a las necesidades por un lado de los propios alumnos con necesidades educativas especiales y por otro de las instituciones. Es importante que se puedan fortalecer los procesos de aprendizaje profesionalmente de manera permanente a través de la red, en cualquier espacio y tiempo.

\subsection{Recomendaciones}

Después de haber realizado todo este proceso de investigación, se plantean las siguientes recomendaciones.

- Continuar con la propuesta del recurso digital en red para la mejora y optimización de la asesoría técnica, actualizando el sitio web en cuanto a información de documentos y cursos que se requieren, consultar a técnicos en el tema para incluir mayores y mejores recursos.

- Diseñar desde el sitio web, cursos en línea por medio de una plataforma, para la formación continúa complementar el apoyo a la capacitación y actualización de los maestros.

- Capacitar a los profesionales de los diferentes servicios en cuanto a la asistencia tecnológica, por un lado utilizando y adecuando el equipamiento que proporciona el Programa Enciclomedia, en los servicios escolarizados para optimizar su utilización en beneficio de la atención de los alumnos con discapacidad, y por otro lado con los servicios de apoyo para la atención a los alumnos integrados, ya sea en el aula de informática o con el programa de Enciclomedia

- Hacer propuestas en el congreso del Estado de Chihuahua, relacionadas con los documentos legales como las leyes generales y estatales, para que se contemple en las futuras actualizaciones de estás, los nuevos retos que enfrenta la Educación Especial y las aportaciones de las TIC en el logro de una educación de mejor calidad.

- Proponer al Departamento de Educación Especial del subsistema federal, que se implementen y promuevan acciones de investigación en función al uso de las TIC en esta modalidad. 
Para finalizar, convencida de que existen múltiples vías sin explorar en el terreno de las TIC en Educación Especial, ya sea en la capacitación y actualización de los profesionales, como en la atención de los alumnos con necesidades educativas especiales principalmente asociados a discapacidad, utilizando la asistencia tecnológica. Me gustaría animar a los diferentes profesionales de Educación Especial a que les pierdan el miedo, y conozcan los beneficios que les pueden aportar personal y profesionalmente en este mundo actual. 


\section{REFERENCIAS}

Alba, P. C. (2001).Utilización de recursos tecnológicos como respuesta a la diversidad. En J. M. Sancho (Coord.). Para una Tecnología Educativa. (pp.221-239). Barcelona: Horsori.

Alba, P. C. Recursos y Materiales Didácticos para el siglo XXI: Multimedia, Telemática y otras Tecnologías vestidas de seda. Revista Complutense de Educación, 9, 1, (15-28). [En línea] Disponible en: http://dewey.uab.es/pmarques/EVTE/calba2.doc . [Consulta: 5 de abril 2007].

Alba P. C. (2004). Navegando hacia una educación accesible. Universidad Complutense de Madrid. [En línea] Disponible en: http://www.tecnoneet.org/docs/2004/calba04.pdf. [Consulta: 12 de abril 2005].

Alba, P. C. (2006). Una Educación sin barreras Tecnológicas TIC y Educación Inclusiva. En J. M. Sancho, G. (Coord.). Para una Tecnología Educativa (pp. 169-198). Madrid: Akal.

Alcantud, F., Ferrer, A., Romero, R. y Asensi, C. (1999). Multimedia based instruction of reading comprehension skills for deaf using sing language as scaffolding. En C. Buhler y H. Knops, (eds). Assistive Technology on the Threshold of the New Millennium, IOS Prees, 443-448.

Alcantud, F. (2000). Nuevas Tecnologías. Viejas esperanzas. En Nuevas Tecnologías, Viejas esperanzas: Las Nuevas Tecnologías en el ámbito de la discapacidad y las necesidades educativas especiales (pp. 17-27). Conserjería de Educación y Universidades de la Región de Murcia. Acta del I Congreso Internacional de Nuevas Tecnologías y Necesidades Educativas Especiales (TECNONEET).

Alcantud, F., Ávila, V., Martínez, R. y Romero, R. (2001a). Estudio del Impacto de las Nuevas Tecnologías en las personas con discapacidad. IMSERSO. Servei de Publicacions de la Universitat de Valencia.

Alcantud, F., Ávila, V. y Romero, R. (2001b). Análisis de accesibilidad y usabilidad de páginas web para usuarios ciegos. En F. Alcantud y M. Lobato (eds). Odisea de la comunicación. (Páginas: 684-691) Sociedad Española de Comunicación Alternativa y Aumentativa isaac-Esp.

Alcantud, F., Ávila, V., Martínez, R. y Romero, R. (2002). Win Watch: Sistema de control del laboratorio de usabilidad. Servei de Publicacions de la Universitat de València. 
Alcantud, F. (2004). Las Tecnologías de la Información y de la Comunicación y los Trastornos Generalizados del Desarrollo. Universidad de Valencia TECNONEET. Disponible en:

http://www.tecnoneet.org/docs/2004/falcantud04.pdf. [Consulta: 22 de Julio 2006].

Alonso A. J. (2004). Tecnología de la Información y la Comunicación en la educación de los alumnos superdotados. [En línea]. Disponible en: http://www.tecnoneet.org/tecno2004.php [Consulta: 3 de marzo de 2006].

Ayers, E.L. and Grisham, C. M. (2004). Why it Has Not Paid Off As We Had Hoped (Yet). Virginia. Edu. Volume VIII Number 1, Spring 2004. [En línea] Disponible en: http://www.itc.virginia.edu/virginia.edu/spring04/hope.htm. [Consulta: 23 de abril 2006].

Barberá, O. y San José, V. (1990). Juegos de simulación por ordenador: un útil para la enseñanza a todos los niveles. Revista Enseñanza de las Ciencias, 8 (1), Barcelona, pp. 46-51.

Bax, S. (2003). CALL-past, present and future. System 31, 13-28. [En línea]. Disponible en: http://www.sciencedirect.com. [Consulta: 3 de mayo 2005].

Berg, C., Junker, A., Rothman, A., Leininger, R. and McMillian, G. (1999). The cyberlink-super (TM) interface: Development of a hands-free continuous/discrete multi-channel computer input device. US Air Force Research Laboratory.

Bernardo, I., Bernardo, A. y Herrero, J. (2005). Nuevas tecnologías y educación especial. Psicothema, 17. 64-70.

Bisquerra, R. (2004). Metodología de la Investigación Educativa. Madrid: La Muralla.

Blanco, R. (2005). La atención a la diversidad en el aula y las adaptaciones del currículo. En A. Marchesi, C. Coll, y J. Palacios (Comp.). Desarrollo Psicológico y Educación: 3 Trastornos del desarrollo y Necesidades Educativas Especiales (pp. 411-437). Madrid: Alianza.

Bolívar, B. A. (1999). El Asesoramiento Curricular a los Establecimientos Educacionales: De los Enfoques Técnicos a la Innovación y Desarrollo. Revista Enfoques Edllcacional sV01.2Nㅇ Departamento de Educación Facultad de Ciencias Sociales Universidad de Chile. [En línea] Disponible en: $\quad$ http://www.formaciondocente.org.mx/Bibliotecadigital/categoria1.htm. [Consulta: 04 de abril 2005].

Bonilla, E. (2000). Reforma y calidad de la educación básica: el papel del currículo y de los materiales didácticos en la adquisición de las competencias básicas, en SEP (2000), Memoria del quehacer educativo. 1995-2000, tomo I, México,. 91-125. 
Boone, R. A., Higgins, K. y Notari, A. (1996). Hypermedia pre-reading lessons: learded-centered software for kindergarten. Journal of Computing in Childhood Education, 7. 39-69.

Booth, T. y Ainscow, M. (2002). Guía para la evaluación y mejora de la educación inclusiva. Desarrollando el aprendizaje y la participación en las escuelas. Consorcio Universitario para la Educación Inclusiva. Departamento de Psicología Evolutiva y de la Educación. Facultad de Formación del Profesorado y educación. Universidad de Madrid. (De la versión original en lengua inglesa: CSIE Ltd. ISBN. 1872001-82-3).

Borbones, R. y Golano, M. (1998). The group: an instrument of intervention for the global development of the child with Down's syndrome in the process of social inclusion. Down Syndrome : Research \& Practice, 5. 88-92.

Bronfenbrenner, U. (1989). La Ecología del Desarrollo Humano. Barcelona: Paidós

Bruce, B.C. \& Levin, J.A. (2003). Roles para las nuevas tecnologías en el arte del lenguaje: investigación, comunicación, construcción y expresión. En J. Flood. D. Lapp, Squire J.R. \& J.R Jensen (eds.). Manual de investigación sobre la enseñanza de las artes de lenguaje Inglés, 2 edición (pp. 649-657). Mahwah, N.J: Lawrence Erlbaum Associates.

Buckley, S. (1995). Aprendizaje de la lectura como enseñanza del lenguaje en niños con Síndrome de Down: resultados y significado teórico. En J. Perera (dir.). Síndrome de Down. Aspectos específicos. Barcelona: Masson.

Byrne, A., Buckley, S., Macdonald, J. y Bird, G. (1995). Investigating the literacy, language and memory skills of children with Down's syndrome. Down Syndrome: Research and Practice, 3. 53-8.

Cabero, J. (2000). Las Nuevas Tecnologías para la mejora educativa. Sevilla: Kronos.

Cabero, A. J. (2001). Tecnología Educativa: Diseño y utilización de los medios en la enseñanza. Barcelona: Paidós.

Cabero, A. J. y Loscertales, A. F. (2002). Elaboración de un sistema categorial de análisis de contenido para analizar la imagen del profesor y la enseñanza en la prensa [En línea]. Disponible en: http://www.tecnologiaedu.us.es . [Consulta: 5 de enero 2007].

Cabero, A. J. (2004). Reflexiones sobre las Tecnologías como instrumentos culturales. En F. Martínez, y M. Prendes, (Coord.). Nuevas Tecnologías y Educación (pp. 15-19). Madrid: Pearson. 
Cabra de Luna, M. (2002). Congreso Europeo sobre las personas con Discapacidad. Consulta 20 de marzo 2004.

Carretero, M. (1993). Constructivismo y educación, capitulo 2, Luis Vives, España, pp. 33-62.

Castelles, M.(1997). La era de la información. Economía, sociedad y cultura. Vol. 1 La sociedad red. Madrid: Alianza.

Casanova R. M. A. (1998). Por el camino de la calidad: la evaluación en los centros educativos. Aula de Innovación educativa, 69, 47-50

Cea, D. M. A. (2001). Metodología Cuantitativa, Estrategias y técnicas de investigación Social. Madrid: Síntesis.

CEAPAT: Centro Estatal de Autonomía Personal y Ayudas Técnicas. [En línea]. Disponible en: http://www.ceapat.org/index.jsp [Consulta: 20 de febrero 2005].

Cebeiro, B., Casal, L. y Fernández, C. (2003). Posibilidades de las TIC para la Formación Continua de Trabajadores. Departamento de Didáctica y Organización Escolar. Universidad de Santiago de Compostela. [En línea] Disponible en: http://www.dii.etsii.upm.es/ntie/pdf/cebreiro.pdf [Consulta: 20 marzo 2006].

Cebrián de la Serna, M. (2003). Análisis, prospectiva y descripción de las nuevas competencias que necesitan las instituciones educativas y los profesores para adaptarse a la sociedad de la información, consultado en Revista Pixel Bite, 20. [En línea] Disponible en: http://www.sav.us.es/pixelbit/pixelbit/articulos/n20/n20art/art2007.htm [Consulta: 15 de marzo 2005].

Colle, R. (2000). Análisis de Contenido. Universia.net. [En línea]. Disponible en:

http://www1.universia.net/CatalogaXXI/pub/ir.asp?IdURL=37963\&IDC=1001

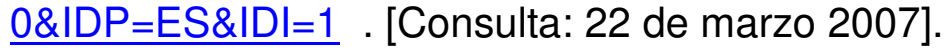

Condillac, R.A. (1999). Untangling the web: Finding information about the treatment of autism on the world wide web. Journal on Developmental Disabilities. Apr; Vol 6(2): 84-87.

Corn, A.L. \& Wall, R.S.(2002). Access to Multimedia Presentations for Students with Visual Impairments. Journal of Impairment Blindness, Vol. 96, 4, 197211.

Crawford, M.R.y Schster, J.M. (1993). Using microswitches to teach toy use. Journal of Developmental and Physical Disabilities.5, 349-368. 
Crook, C. (1994). Computers and the Collaborative Experience of Learning. Routledge, London.

Chacón, M. A. (2007). La atención a la diversidad con medios tecnológicosdidácticos. En J. A. Ortega, C. y A. Chacón, M. (Coords). Nuevas Tecnologías para la Educación en la Era Digital. (pp. 261-278). Madrid: Pirámide.

Davidson, J., Elcock, J., y Noyes, P. (1996). A preliminary study of the effect of computer-assisted practice on reading attainment. Journal of Research in Reading, 19. 102-110.

Davies, D. K., Stock, S. E. y Wehmeyer, M. L. (2001). Enhancing independent Internet access for individuals with mental retardation through use of a specialized Web browser: A pilot study. Education and Training in Mental Retardation and Developmental Disabilities. Mar; Vol. 36(1): 107-113.

De Basterrechea, J.P. y Juan Lázaro O. (2005). Influencia de los recursos digitales y los sistemas de comunicación en el modelo de enseñanza ELE. FIAPE. Congreso Internacional: El español, lengua del futuro. Toledo, 2023-2005. [En línea] Disponible en: http://www.mepsyd.es/redele/biblioteca2005/fiape/juan basterrenechea.pdf . [Consulta: 15 de mayo 2006].

De Basterrechea, J. P. (2004). Integración de recursos didácticos digitales en la enseñanza de español: hacia un nuevo paradigma. Acta III Congreso Internacional de la Lengua Española: identidad lingüística y globalización. Rosario, Argentina.

De Pablos, J. (1996). Tecnología y Educación. Barcelona: Cedecs.

De Pablos, J. (2006). El marco del impacto de las Tecnologías de la Información: Herramientas conceptuales para interpretar la mediación tecnológica educativa. Cuadernos de comunicación tecnología y sociedad. № $67,68-74$.

Delors, J. (1996). La educación encierra un tesoro, UNESCO. [En línea]. Disponible en: http://www.unesco.org/education/pdf/DELORS S.PDF [Consulta: 23 de febrero 2005].

Desrochers, M.N, Clemmons, T., Grady, M., Justice, B. (2000). An evaluation of Simulations in Developmental Desabilities (SIDD). Instructional software that provides practice in behavioural assessment and treatment decisions. Journal of Technology en Human Services. Vol. 17(4). 15-27.

Díaz, Martín, J. M. (2002). HTML 4 Guía esencial. Madrid: Pearson Education.

DIM. Portal del grupo de investigación y comunidad virtual de profesores Didáctica, Innovación y Multimedia. Pautas de accesibilidad. [En línea]. 
Disponible en: http://www.pangea.org/dim/accesibilidad/ . [Consulta: 4 de abril 2008].

Domingo, J. y Gallegos, M. (1997). La informática desde la perspectiva de los educadores: Congreso Internacional de Informática Educativa 97. Vol. (1) 665-672.

Domingo, S. J. (1997). El mapa relacional entre el profesor tutor y el profesor de apoyo a la integración: Construcción de un encuentro profesional. En A. Sánchez, P., y J. A. Torres G. (Coords). Educación Especial I: Una perspectiva curricular, organizativa y profesional. (pp. 147-167). Madrid: Pirámide.

Duit, Reinders (2003). Constructivist views of teaching and learning in practice: Teacher's views and classroom behavior, en Papers of Seminar Series: Science Education Research that is relevant for improving school practice, UPN (Ajusco), México.

Duit, Reinders y D. Treagust (1998). Learning in science: From behaviorisms towards social constructivism and beyond, en Fraser, R., Tobin, K. (1998), International Handbook of Science Education, Dordrecht, Kluwer, pp. 3-25.

Eduardo, M. (1992). Aprender con ordenadores en la escuela. Barcelona: ICEHorsori Editorial.

Escoin, J. (2004). La importancia del profesional en el ámbito de las nuevas tecnologías y necesidades educativas especiales. Barcelona: Centro Pont del Dragó-Institut Municipal d'Educació (IME) En línea]. Disponible en: http://www.tecnoneet.org/docs/2002/72002.pdf [Consulta: 15 de marzo 2006].

Ezpeleta M., J. (2003). Lo institucional de la escuela en las políticas de reforma. En Gobernabilidad de los sistemas educativos en América Latina, Buenos Aires: IIPE-UNESCO.

Faragher, R. y Brown, R. I. (2005). Numeracy for adults with Down's syndrome: it's a matter of quality of life. Journal of Intellectual Disability Research. 49. 761-765.

Fernández Batanero, José Mạ. (2004). Las Nuevas Tecnologías como recursos de apoyo al alumnado con discapacidad motora y psíquica. Comunicación y Pedagogía 194.

Flórez, J. (1990). Síndrome de Down. Expresión génica y alteraciones cerebrales. En M. Bueno, S. Molina y A. Seva. (eds.). Deficiencia mental I. Aspectos biomédicos. Barcelona: Expaxs.

Fróhlich, A. (1994). Un espace pour vivre- un espace pour rever. En A. Fróhlich, A.M. Besse y D. Wolf. Des espaces pour vivre. Education et accompagnement des personnes polyandicapées en Europe. 
Fróhlich, A. y Haupt, U. (1982). Estimulación para el desarrollo de niños deficientes (Traducción). Mainz Ed. V. Hase y Kóhler.

Galván, L. (2002). E- Proceso de enseñanza-aprendizaje. [En línea]. Disponible en: http://eae.ilce.edu.mx/e-proceso.pdf. [Consulta: 5 de marzo 2005].

Gallegos C., L. (2001). Currículo de educación básica. Modelos y contenidos curriculares. Ponencia presentada en el Seminario Latinoamericano La enseñanza de la ciencia en la escuela secundaria como parte de la educación básica. Diagnóstico y perspectivas, 27-30 de julio, Cholula, Puebla.

Gallego, D. y Alonso, C.M. (2000). El ordenador como recurso didáctico. Madrid: UNED.

García -Albea, J.E. (1999). Algunas notas introductorias al estudio de la percepción. En E. Munar, j. Roselló y A. Sanchez-Cabaco (coords). Atención y percepción. Madrid: Alianza.

García, C. I., Escalante, H. I., Escandón, M. C., Fernández, T. L., Mustri, D. A., y Puga, V. I. (2000). La Integración Educativa en el aula regular: Principios, finalidades y estrategias. México: SEP/ Fondo mixto de Cooperación Técnica y Científica México-España.

García-Valcárcel, M. A. (2003).Tecnología educativa Implicaciones educativas del desarrollo tecnológico. Madrid: La Muralla.

García, V. J. (2004). Discapacidad visual y tecnología digital en la escuela. Un nuevo paradigma, un nuevo reto y una nueva metodología Red Digital Núm. 5, Diciembre 2004 [En línea] Disponible en: http://vlex.com/vid/273897 Id. vLex: VLEX-273897.

Gardner, H. (1997). Las dificultades planteadas por la escuela. En La mente no escolarizada, Biblioteca del Normalista/ SEP, pp. 157-170.

Gastón, E. El acceso a los contenidos a través de las tecnologías digitales en la escuela. Un nuevo reto para las personas con discapacidad visual. Grupo ACCEDO-ONCE. [En línea]. Disponible en: http://www.raco.cat/index.php/DIM/article/viewFile/73619/85298 . [Consulta: 23 de marzo 2008].

Gimeno, J. (1992). ¿Qué son los contenidos de la enseñanza?. En J. Gimeno, y A. I Pérez: Comprender y transformar la enseñanza. (pp.170-223). Madrid: Morata.

Gómez, M. M. A (2000). Análisis de contenido cualitativo y cuantitativo: Definición clasificación y metodología. Revista de Ciencias Humanas, 20. [En línea] Disponible en: http://utp.edu.co/chumanas/revistas/rev20/gomez.htm . [Consulta: 04 de abril 2007]. 
Gómez, Villa, M. (2002). Diccionario Multimedia de Signos: Programa de Comunicación Total habla signada de B.Schaeffer y Cols. Conserjería de Educación de Murcia.

González, M. D. (1993). Adaptaciones Curriculares. Guía para su elaboración. Málaga: Aljibe.

González R.G. y López Torecillas, M.M. (2004). Uso de las Nuevas tecnologías en la adquisición fonológica, № 3, agosto, [En línea]. Disponible en: http://www.innovaeduca.net. [Consulta: 15 de agosto 2007].

Gorreto, O., D. (2004). Programa para manejar el móvil con chicos con síndrome de down. ASSIDO-Murcia. Asociación para Personas con Síndrome de Down. [En línea]. Disponible en: http://www.tecnoneet.org/docs/2004/3-82004.pdf . [Consulta: 05 de mayo 2006].

Gruender, C. D. y K. Tobin (1991). Promise and prospect. Science Education, 75 (1), 1-8.

Hassan Montero, Y. (2002). Como leen los usuarios en la Web. [En línea]. Disponible en: http://www.nosolousabilidad.com/articulos/como leen usuarios.htm. [Consulta: 06 de octubre 2007].

Heimann, M., Nelson, K., Tjus, T. y Gillberg, C. H. (1995). Increasing reading and communication skills in children with Autism through an interactive multimedia computer program. Journal of Autism and Developmental Disorders, 25. 459-480.

Hernández, S. R., Fernández, C. C., y Baptista, L. P. (2007). Fundamentos de metodología de la investigación. México: McGraw-Hill.

Herrera, G. y Labajo, G. (2001). Dispositivos de Asistenta Portátiles. En F. Alcantud y M. Lobato (Eds). Odisea de la comunicación. (pp. 282-290) Sociedad Española de Comunicación Alternativa y Aumentativa Isaac-Esp.

Hourcade, J.J., Parette, P. (2001). Provising assistive technology information to professionals and families of children with MRDD. Interactive CD-ROM technology, Education and Training in Mental retardation and Developmental Disabilities. Sep. Vol. 36(3). 272-279.

Huguenin, N.H. (200). Reducing overselective attention to compound visual cues with extended training in adolescents with severe mental retardation. Research in Developmental Disabilities. Mar-Apr. Vol. 21(2). 93-113.

Hurtado, M.D. (2003). Las TIC como recurso de acceso a la lecto-escritura.En curso telemático. Acceso a la lecto-escritura. [En línea]. Disponible en: http://www.educarm.es/lecto escritura/curso/06/t06.pdf [Consulta: 15 de agosto 2006]. 
INEGI (2007). Instituto Nacional de Estadística y Geográfica. [En línea] Disponible en: http://www.inegi.gob.mx/inegi/default.aspx [Consulta: 2 de abril 2007].

Inclusive Technology Learning Comunication (2005). [En línea]. Disponible en: http://www.inclusiveTLC.com [Consulta: 15 de marzo 2007].

INICO (2008). Los Visitantes del CERMI eligen la Web del SID como la más accesible. Boletín de Noticias del Instituto Universitario de integración en la Comunidad INICO. Volumen 11, 30, 3.

Jonassen, D.H. (1994a). Thinking technology: Toward a constructivist design model. Educational Technology, 34, 4: 34-37.

Jonassen, D.H. (1994b).Technology as cognitive tools: learners as designers. ITForum Paper. [En línea]. Disponible en: http://itech1.coe.uga.edu/itforum/paper1/paper1.html . [Consulta 15 noviembre 2007].

Junta de Andalucía (2003). Software para la educación especial. Sevilla: Conserjería de Educación y Ciencia.

Kern, L., Delaney, B., Clarke, S., Dunlap, G., Childs, K. (2001). Improving the classroom behavior of students with emotional and behavioural disorders using individualized curricular modifications. Journal of Emotional and Behavioural Disorders. Win; Vol 9(4): 239-247.

Kinsley, T.C. y Langone, J. (1995). Applicatinos of technology for infants, toddlers, and preeschoolers with disabilities. Journal of Special Education technology. 12, 312-324.

Ko, S. y Rossen, S. (2001). Teaching Online. A Practical Guide. Boston, MA: Houghton Mifflin Company.

Lancioni, G.E., O’Reilly, M.F., Singh, N.N., Oliva, D. y Groeneweg, J. (2001). Impact of stimulation versus microswith-based programs on indices of apiñes of people with profound multiple disabilities. Research in Disabilities, 22, 149-160.

Lancioni, G.E., O'Reilly, M.F., Oliva, D. and Coppa, M.M. (2001a). Using multiple microswitches to promote different responses in children with multiple disabilites.Research-in-Developmental-Disabilities. Jul-Ago. Vol. 22(4). 309-318.

Lancioni, G.E., O’Reilly, M.F., Basili,G. (2001). Use of microswitches and speech output Systems with people with severe/profound intellectual or multiple disabilities. A literature review. Research in Developmental Disabilities. Jan-Feb. Vol 22(1). 21-40. 
Latapí, S. P. (2005). Un siglo de educación en México, Biblioteca Mexicana. Textos del diplomado: Desarrollo y evaluación de los Procesos de Formación Continua 2006-2005, UNAM, Xochimilco-DGFCMS.

Levin, J.A. \& Bruce, B.C. (2001). Tecnología de los medios de comunicación: La perspectiva centrada en el alumno. Ponencia presentada en American Educational Research Association, Seattle, WA.

Ley Estatal de Educación. (Decreto No 823/97). (1997, Diciembre 22). Última Reforma Periódico Oficial del Estado, Septiembre, 18 de 2004.

Ley General de Educación (Decreto El Congreso de los Estados Unidos Mexicanos). (1993, Julio 13) Última reforma, Diario de la Federación Junio 22 de 2006.

Ley General de las Personas con Discapacidad. (Decreto El Congreso General de los Estados Unidos Mexicanos). (2005, Junio 10). Nueva Ley Diario Oficial de la Federación. Junio 102005.

Ley Para las Personas con Discapacidad en el Estado de Chihuahua. (Decreto No 370/96). (30 de noviembre de 1996). Nueva Ley, Periódico Oficial del Estado No 96, Mayo 312000.

Lipman, Matthew (1998). Cuatro variaciones sobre las habilidades cognitivas. En Pensamiento complejo y educación. Ediciones de la Torre, traducción. Virginia Ferrer, Madrid, pp. 86-95.

Lohr, L. L. (2000). Three principles of perception for instructional interface design. Educational Technology, 40. 1: 45-52.

López Martín, A. y Lorenzo D.M. (2008). La investigación Educativa en el Aula Hospitalaria: Estudio de caso de intervención escolar, de glioma óptico infantil mediante video conferencia. [En línea] Revista PIXELBIT № 33 Disponible en: http://www.sav.us.es/pixelbit/actual/2.html . [Consulta: 20 agosto 2008].

Loveland, K.A. (2001). Toward an Ecological Theory of Autism. New Jersey: Erlbaum Press.

Lynch, P. y Horton, S. 2001 (1997). Web style manual. Yale Centre for Advanced Instructional Media. [En línea] Disponible en: http://info.med.yale.edu/caim/manual/contents. html . [Consulta 15 de agosto 2007].

MacArthur, C.A. (1999). Word prediction for students with severe spelling problems. SO: Learning Disability Quarterly. Sum: Vol. 22(3). 158-172.

Magnan, A., Bouchafa, H. (1998). L'acquisition des règles de correspondence grapho-phonologique: Etude comparative entre des lecteurs de CP et de CEI et enfants dysphasiques. Approche neuropsychologique des Apprentissages chez l’Enfant. May: Vol. 10(2). [47].53-62. 
Massot, L. I., Dorio, A. I. y Sabariego, P. M. (2004).Estrategias de Recogida y Análisis de la Información. En R. Bisquerra (Coord.). Metodología de la Investigación Educativa (pp.329-365). Madrid: La Muralla.

Marchesi, A., Coll, C. y Palacios, J. (2005). Del lenguaje de la deficiencia a las escuelas inclusivas. En A. Marchesi, C. Coll, y J. Palacios (Comp.). Desarrollo Psicológico y Educación: 3 Trastornos del desarrollo y Necesidades Educativas Especiales (pp. 21 - 43). Madrid: Alianza.

Marqués G. P. (2004). Los Portales educativos: Ficha para su Catalogación y Evaluación. [En línea]. Disponible en: http://dewey.uab.es/pmarques/evaport2.htm. [Consulta: 20 octubre 2006].

Marqués, G. P. (2006a). Nueva cultura, nuevas competencias para los ciudadanos. La alfabetización digital. [En línea]. Disponible en: http://dewey.uab.es/pmarques/competen.htm. [Consulta: 25 de mayo 2006].

Marqués G. P. (2006b), Cambios en los centros: una metamorfosis hacia la escuela del futuro. [En línea]. Disponible en: http://dewey.uab.es/pmarques/perfiles.htm. [Consulta: 25 de mayo 2006].

Marqués G. P. (2007). La Alfabetización Digital. [En línea]. Disponible en: http://dewey.uab.es/pmarques/perfiles.htm. [Consulta: 25 de mayo 2007].

Marqués G. P. (2008a). Posibilidades de las TIC en Educación Especial. [En línea]. Disponible en: http://dewey.uab.es/pmarques/ee.htm [Consulta: 15 de mayo 08].

Marqués G. P. (2008b). Algunos Conceptos de Educación Especial. [En línea]. Disponible en: http://dewey.uab.es/pmarques/ee.htm [Consulta: 15 de mayo 08].

Martínez-Segura, M.J. (2001). La Estimulación Basal en Atención Temprana: Desarrollo Curricular. Revista de Atención temprana. 4(1), 4-10.

Martínez-Segura, M.J. y García-Sanchéz, F.A. (2002). Planificación de la estimulación sensorial para niños con grave afectación. Revista de Atención Temprana, 5, 29-37.

Martínez-Segura, M.J. (2004). Segura Tecnologías de la Información y la Comunicación y estimulación sensoriomotriz en niños con plurideficiencias. [Ėn línea]. Disponible en: http://www.tecnoneet.org/docs/2004/mjose04.pdf . [Consulta: 15 de agosto 2007].

Meece, J. (2000). Desarrollo del niño y del adolescente, capítulo 4, México, SEP/McGraw Hill Interamericana (Biblioteca para la actualización del maestro), pp. 145-160, 127-143. 
Milheim, W.D. y Harvey, D. M. (1998). Design and development of a World Wide Web resource site. Educational Technology, 38, 1, 53-56.

Morin, E. (1999). Los 7 saberes necesarios para la educación del futuro. Barcelona: Piados.

Nadel, L. (1988). The psychobiology of Down's syndrome. Cambridge: MIT Press.

Navarro, S. J. L. y Servet, de Fraga M. (2000). La Informática como herramienta de intervención en los trastornos de audición y el lenguaje. [En línea]. Disponible en: http://www.tecnoneet.org/docs/2000/13-2000.pdf. [Consulta: 5 de mayo 2005].

Nielsen, J. (1997). Changes in web usability since 1994. [En línea]. Disponible en: http://www.useit.com/alertbox/9712a.html. [Consulta: 15/08/2007].

Nielsen, J. (2000). Designing Web usability: The Practice of Simplicity. Indianapolis, Ind.: New Riders.

Ogborn, J. y Miller, R. (1994). Computational issues in modelling. En Mellar, Harvey, Joan Bliss, Richard Boohan, Jon Ogborn y Chris Tompsett (1994) (editors), Learning with artificial worlds. Computer-based modeling in the curriculum, The Falmer Press, Taylor\&Francis, Bristol, PA, pp 33-38.

Oliver, R., Herrington, J. y Omari, A. (1996). Creating Effective Instructional Materials for the World Wide Web. En R. Debreceny y A. Ellis (eds.). Proceedings of AusWeb 96: The Second Australian World Wide Web Conference. Lismore, NSW: Southern Cross University Press: 485-492.

OMS. (2001). Clasificación internacional del funcionamiento, la discapacidad y la salud, CIF, Génova.

ONU. (1993). Normas uniformes sobre la igualdad de oportunidades para las personas con discapacidad.

Ortega C.J.A. (2005). El profesorado ante el reto de las nuevas tecnologías en la Sociedad del Conocimiento. Entrevistado por Ángeles Llorca Diez y publicado en Ensenet.com. Disponible en: http://www.ensenet.com/ . [Consulta: 8 de mayo 2006].

Ortega-Tudela, J. M.,Gómez-Araiza, C. J. (2007). Nuevas Tecnologías y Aprendizaje Matemático en niños con Síndrome de Down: Generalización para la Autonomía: Revista Pixel Bit, 29, 59-72. Disponible en: http://www.sav.us.es/pixelbit/pixelbit/articulos/n29/n29art/art2905.htm [Consulta: 14 de febrero 2008].

Peula, M. (2000): Ayudas técnicas a la comunicación. En F. Peñafiel y J. D. Fernández. (Coords.): Cómo intervenir en Logopedia escolar. Resolución de casos prácticos. Madrid: CCS. 
Pérez, de la Maza L. (2002). Programa de Estructuración Ambiental Por Ordenador para personas con Trastornos del Espectro autista: PEAPO Centro PAUTA, profesor tutor. Psicopedagogo. Disponible en: http://www.tecnoneet.org/docs/2002/3-22002.pdf [Consulta: 2 de julio 2008].

Pérez, G. A. Barquín, R. J. y Angulo, R. J.F. (1999). Desarrollo Profesional de Docente Política, Investigación y Práctica. Madrid: Akal.

Pérez, López, C. (2001). Administración de sitios y páginas Web con Macromedia Dreamweaver 4. Madrid: Ra-Ma.

Poder Ejecutivo Federal. (2007). Plan Nacional de Desarrollo 2007-2012. Gobierno de los Estados Unidos Mexicanos, Presidencia de la Republica. México.

Piaget, Jean (1969). Psicología y Pedagogía. Barcelona: Ariel.

Pozo, J. I. (1994). Teorías Cognitivas del aprendizaje. Madrid: Morata.

Pozo, J. I. y Postigo A. Y. (2000). Ejes procedimentales en el currículo. En Los procedimientos como contenidos escolares, col. Innova, Edebé, Barcelona, pp. 47-95.

Prats, M. A. (2000). Reflexiones educativas. [En línea]. Disponible en: http://www.infonomia.com/tematiques/archivo.asp?idm=1\&idrev=12\&numMa $\underline{x=0}$. [Consulta: 15 de agosto 2005].

Puigdellivol, I. (1998). La Educación Especial en la escuela Integrada: Una perspectiva desde la diversidad. Barcelona: Grao.

Ramonet, I. (1997). Un mundo en crisis. Madrid: Debate.

Reiser, R.A. \& Dempsey, J.V. (2002). Terns and Sigues in Instructional Design and Technology. Upper Sadler River, NJ: Merrill Prentice Hall.

Resnick, L. y Klopfer, L. (1989). Hacia un currículo para desarrollar el pensamiento: una visión general y Hacia un currículo para desarrollar el pensamiento: conclusiones finales. En Currículum y cognición, Aique, Buenos Aires, pp. 15-42 y 325-332.

Redy, P., Luiselli, J.K., Thibadeau, S. (2001). Improving staff performance in a residential child-care setting using computer-assisted feedback. Child-andFamily-Behavior-Therapy. Vol. 23(1). 43-51.

Roig, V. R. (2002). Las nuevas Tecnologías de la Educación: Elementos para una articulación de las Tecnologías de la Información y de la comunicación. Universidad de Alicante: Alcoy. 
Rojano, T. (2000). Mathematics learning in the junior secondary school: student's access to significant mathematical ideas. En Handbook of International Research in Mathematics Education, Lyn.

Romero, Z. R. (2001). Usabilidad y accesibilidad, dos enfoques complementarios. [En línea]. Disponible en: http://acceso.uv.es/accesibilidad/artics/01-usabilidad-accesibilidad.htm [Consulta: 20 de marzo 2005].

Romero Z. R. (2001). Los principios básicos del diseño web accesible Unidad de Investigación ACCESO Publicado en Temalia. 20/04/2001. [En línea] Disponible en: http://acceso.uv.es/accesibilidad/artics/01accesprincipios.htm . [Consulta: 20 de marzo 2005].

Rondal, J.A., Perera, J., Nadel, L. y Comblain, A. (1997). Síndrome de Down: Perspectivas psicológica, psicobiológica y socioeducacional. Madrid: IMSERSO.

Ruiz, C. (1994). El proyecto MUSA. Apanda, 2, 14-19.

Sabariego, P. M. (2004). El Proceso de Investigación (Parte 2). En R. Bisquerra (Coord.). Metodología de la Investigación Educativa (pp.329-365). Madrid: La Muralla.

Sabariego, P.M., y Bisquerra, A.R. (2004). El Proceso de Investigación. En R. Bisquerra (Coord.). Metodología de la Investigación Educativa (pp.293-328). Madrid: La Muralla.

Sabariego, P.M., Massot, L. I. y Dorio, A. I. (2004). Métodos de Investigación Cualitativa. En R. Bisquerra (Coord.). Metodología de la Investigación Educativa (pp.293-328). Madrid: La Muralla.

Salinas, J. (1996). Las redes un desafío para la educación o la educación un desafío para las redes. En J. Cabero, M. Cerdeira, G. Gómez, (coord.). Medios de Comunicación, Recursos y Materiales para la mejora educativa II, Sevilla: Kronos.

Sánchez Montoya, R. (1997). Ordenador y discapacidad. Ed. CEPE. Madrid: Colección Lenguaje y Comunidad.

Sánchez, R.J. y Romance, G.A. (2000). Multimedia. En J.M. Ríos y M. Cebrián de la Serna, (coord). Nuevas Tecnologías de la Información y la Comunicación Aplicadas a la Educación. (p. 2001-211). Málaga: Algibe.

San Martín, A. y Salinas, D. (1997). Escuela, Sociedad y Tecnología: tres polos en tensión, en Revista Kikirikí, 44-45, pp. 4-10, Bogotá.

Sánchez, M. R. (2002). El papel de las nuevas tecnologías en la estimulación de las inteligencias. En F. J. Soto y J. Rodríguez, (coord.). Las nuevas tecnologías en la respuesta educativa a la diversidad (p. 49-61). Murcia: Conserjería de Educación y Cultura. 
Santiago C. R. (2002). Internet y Enseñanza Universitaria: de la gestión del conocimiento a la gestión del aprendizaje. [En línea]. Disponible en: http://congresosdelalengua.es/valladolid/ponencias/nuevas fronteras del e spanol/3 la universidad e internet/campion R.htm. [Consulta: 15 de agosto 2005].

Schaeffer, B. (1986). Lenguaje de Signos y lenguaje oral para niños minusvalidos. En M. Monfort. Investigación y logopedia III simposio de logopedia. Madrid: CEPE.

Schalock, R. L., y Verdugo, M. L. (2003). Calidad de Vida. Manual para profesionales de la educación, salud y servicios sociales. Madrid: Alianza.

Schmelkes, S. (1997). Educación para la vida. Algunas reflexiones en torno al concepto de relevancia de la educación, Conferencia presentada en la mesa Chiapas para la educación organizada por la Secretaría de Educación del estado de Chiapas el 11 de marzo de 1996, en Ensayos sobre educación básica, documento DIE número 50, DIE/CINVESTAV/IPN, México, pp. 5-13.

Schmelkes, S. (2002). Las Necesidades de la Evaluación del Aprendizaje en Educación Básica. En H. Congreso de la Unión, LVIII Legislatura y Secretaria de Educación Pública: La Calidad de la Educación Básica en México: Perspectivas, Análisis y Evaluación. México: Miguel Ángel Porrúa. 2002. p 261-270.

SEBYN. (2004). Mejores Maestros. Reforma al modelo de actualización y capacitación vigente. Propuesta México: Coordinación General de Actualización y Capacitación para Maestros en Servicio.

Secretaria de Educación y Cultura. (2005). Programa Estatal de Educación, 2005-2010.Chihuahua: SEC.

Secretaria de Educación y Cultura. (2005). Programa Estatal de Desarrollo, 2004-2010.Chihuahua: SEC.

Secretaria de Educación y Cultura. (2005). Programa Estatal de Fortalecimiento de la Educación Especial y de la Integración Educativa, 2005- 2010. Chihuahua.SEC.

SEP. (2001). Programa Nacional de Educación, 2001-2006. México: S. E. P.

SEP. (2002). Programa Nacional de Fortalecimiento de la Educación Especial y de la Integración Educativa. Dirección General de Investigación Educativa de la Secretaria de Educación Básica y Normal, México: SEP.

SEP. (2003). Documentos: La actualización de los maestros en servicio. En: Revista Educación 2001. Número 99. 
SEP. (2005). Orientaciones generales para construir y operar el servicio de asesoría académica a la escuela. México, Subsecretaria de Educación Básica. Dirección General de Formación Continua de Maestros en Servicio.

SEP. (2006b). Asistencia Tecnológica. En Todos en la Misma Escuela Asistencia Tecnológica, Secretaría de Educación Pública. Disponible en :http://normalista.ilce.edu.mx/normalista/boletin . [Consulta: 12 de agosto 2007].

SEP. (2006c). Plan estratégico de transformación escolar. Dirección General de Desarrollo de la Gestión e Innovación Educativa de la Subsecretaria de Educación Básica, por la Coordinación Académica del Programa Escuelas de Calidad. México.

SEP. (2006d). Orientaciones generales para el funcionamiento de los servicios de educación especial. Dirección General de Desarrollo de la Gestión e Innovación Educativa de la Subsecretaria de Educación Básica, como parte del Programa de Fortalecimiento de la Educación Especial y la Integración Educativa. México.

SEP. (2007a). Reglas de operación del programa nacional para la actualización permanente de los maestros de educación básica en servicio. México: Diario Oficial de la Federación. (30 DE DICIEMBRE).

SEP. (2007b). Programa Sectorial de Educación 2007-2012. México: Secretaria de Educación Pública.

SEP. (2007c). Reglas de operación del Programa de Fortalecimiento de la Educación Especial y de la Integración Educativa. Acuerdo 422. México Diario Oficial de la Federación. (30 Diciembre 2007).

SEP. Programa Nacional para la Actualización de Maestros en Servicio PRONAP. [En línea]. Disponible en: http://pronap.ilce.edu.mx/ [Consulta: 20 de mayo 2005].

SEP-DGAIR, (2007). Normas de inscripción, reinscripción, acreditación y certificación para las escuelas de educación primaria oficiales y particulares, incorporadas al Sistema Educativo Nacional. México: SEP.

Shilling, W.A. (1997). Young children using computers to make discoveries about written language. Early Childhood Education Journal, 24. 253-259.

Skaalid, B. (2001). Web design for instruction: research-based guidelines. Canadian Journal of Educational Communication, 27, 3: 139-155.

Solé, I. y Coll, C. (2000). Los profesores y la concepción constructivista. En C. Coll, E. Martin, T. Mauri, M. Miras, J. Onrubia, I. Solé, y A. Zabala (eds). El constructivismo en el aula (pp. 7-23). Barcelona: Argó. 
SPF. (2006a). Informe de rendición de cuentas de la administración 2000-2006. México. SEP.

Stevenson, I. y Hasell, D. (1994). Modelling and teacher change. En Mellar, Harvey, Joan Bliss, Richard Boohan, Jon Ogborn y Chris Tompsett (editors). Learning with artificial worlds. Computer-based modelling in the curriculum, The Falmer Press, Taylor\&Francis, Bristol, PA, pp. 207-213.

Talley, S., Lancy, D.F. y Lee, T.R. (1997). Children, story-books and computers. Reading Horizons, 38. 116-128.

Tapia G. G. (2008). Formación para el asesoramiento a las escuelas: Un proceso emergente en México Universidad Iberoamericana León (México) Revista de curriculum y formación del profesorado. [En línea] Disponible en: http://www.ugr.es/ recfpro/rev121COL6.pdf . [Consulta: 15 de julio 2008].

Tecnológico de Monterrey Vicerrectoria de Desarrollo Social. Habilidades para el liderazgo docente y calidad educativa. México. [En línea]. Disponible en: http://www.cca.org.mx/dds/formandoformadores . [Consulta: 20 de agosto 2006].

Tójar, H. J. C. (2006). Investigación Cualitativa comprender y actuar. Madrid: La Muralla.

Toledo, P. (2001). Accesibilidad, informática y discapacidad. Sevilla: Mergablum.

Toledo, P. y Hervás, C. (2007). Las nuevas tecnologias como apoyo a los sujetos con necesidades educativas especiales. En J. Cabero, (coord.). Nuevas tecnologías aplicadas a la educación (p.279-291). Madrid: McGraw.

Torrado, F. M. (2004). Estudios de Encuesta. En R. Bisquerra (Coord.). Metodología de la Investigación Educativa (pp.329-365). Madrid: La Muralla.

Torres, G. J. A., (1999). Educación y Diversidad: Bases Didácticas y Organizativas. Málaga: Aljibe.

Trahtemberg, L. (2002). El impacto previsible de las nuevas tecnologías en la enseñanza y la organización escolar, en Revista Iberoamericana de educación, Septiembre-Diciembre, núm. 24, OEI, Madrid, pp. 37-62.

Trece, J.J., Gips, J., Olivieri, C.P., Pok, L.j. and Consiglio, M.R. (1998). Eye movement control of computer functions. International-Journal-ofPsychophysiology. Aug: Vol. 29(3). 319-325.

UNESCO. (2007). Informe del Director General sobre una versión mejorada del Plan de Acción Global para alcanzar los objetivos de la EPT de aquí a 20015 e informe sobre la marcha de la aplicación del plan. 179 EX/9. 
UNESCO. (2008). Estándares de Competencias en TIC para Docentes. Londres. [En línea]. Disponible http://www.oei.es/tic/UNESCOEstandaresDocentes.pdf . [Consulta: 12 de Mayo 2008].

Urbina, R. S. y Ortega, H.J. (2008) Proyecto para la elaboración de un programa informático de estimulación visual temprana en niños con baja visión. Universitat de les Illes Baleares. [En línea]. Disponible en: http://www.uib.es/depart/gte/dvisual.htm [Consulta: 4 de junio 2008].

Vigotsky, L. S. (1995). Obras completas, t.5, La habana: Pueblo y Educación.

Vigotsky. L. S. (1979). El desarrollo de los procesos psicológicos superiores. Madrid: Grijalbo.

Watkins, A. (2002). Aplicación de las Nuevas Tecnologías a las Necesidades Educativas Especiales. Resumen sobre el proyecto de NNTT en NEE (en inglés ICT en SNE-Information and Communication Technology in Special Needs Education-) Disponible en: http://www.tecnoneet.org/docs/2002/12002.pdf . [Consulta: 15 de marzo 2007].

Yamamoto,J., Miya, T. (1999). Acquisition and transfer of sentence construction in autistic students: Analysis of computer-based teaching. Research in Developmental Disabilities. Sep-Oct: Vol. 20(5). 355-377. 
ANEXOS 


\section{ANEXO I}

COMUNIDADES DE LOS CENTROS DE ATENCIÓN MULTIPLE 


\begin{tabular}{|c|c|c|c|}
\hline \multicolumn{4}{|c|}{ Relación de CAM (2007) } \\
\hline Zona & № CAM & Localidad & № Alumnos \\
\hline 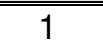 & CAM 19 & Juárez & 53 \\
\hline 1 & CAM 43 & Juárez & 33 \\
\hline$\overline{11}$ & $\begin{array}{c}\text { CAM } \\
\text { LABORAL } 2\end{array}$ & Juárez & 72 \\
\hline 2 & CAM 14 & Juárez & 89 \\
\hline 2 & CAM 20 & Juárez & 42 \\
\hline 3 & CAM 6 & Chihuahua & 42 \\
\hline 4 & CAM 17 & Chihuahua & 17 \\
\hline 5 & CAM 1 & Delicias & 65 \\
\hline 6 & CAM 4 & Cuauhtémoc & 51 \\
\hline$\overline{77}$ & CAM 15 & Santa Bárbara & 21 \\
\hline 8 & $\overline{\text { CAM } 2}$ & Camargo & 29 \\
\hline 9 & CAM 21 & Juárez & 50 \\
\hline 10 & CAM 18 & Chihuahua & 74 \\
\hline 11 & CAM 5 & Parral & 63 \\
\hline 12 & CAM 10 & Madera & 35 \\
\hline 12 & CAM 13 & La Junta Guerrero & 22 \\
\hline 12 & CAM 42 & San Juanito Bocoyna & 30 \\
\hline 13 & CAM 8 & Nvo Casas Grandes & 33 \\
\hline 13 & CAM 41 & Ascensión & 28 \\
\hline 13 & CAM 44 & Buenaventura & 21 \\
\hline 13 & CAM 45 & Puerto Palomas Ascensión & 26 \\
\hline 14 & CAM 7 & Chihuahua & 58 \\
\hline 15 & CAM 9 & Jiménez & 39 \\
\hline$\overline{16}$ & $\overline{\text { CAM } 3}$ & 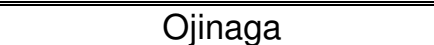 & 35 \\
\hline 16 & CAM 23 & Chihuahua & 62 \\
\hline 16 & CAM 40 & Aldama & 20 \\
\hline 16 & $\begin{array}{c}\text { CAM } \\
\text { LABORAL } 1\end{array}$ & Chihuahua & 71 \\
\hline$\overline{17}$ & CAM 22 & Juárez & 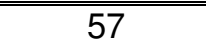 \\
\hline$\overline{c 18}$ & $\overline{C \text { CAM } 11}$ & "Guachochi & $\overline{442}$ \\
\hline
\end{tabular}




\section{ANEXO II \\ UNIDADES DE SERVICIOS DE APOYO A LA ESCUELA REGULAR \\ COMUNIDADES}




\begin{tabular}{|c|c|c|c|c|}
\hline \multicolumn{5}{|c|}{ Relación de USAER (2007) } \\
\hline Zona & USAER & UBICACIÓN & № Personal & № Alumnos \\
\hline 1 & 36 & JUAREZ & 10 & 90 \\
\hline 1 & 37 & JUAREZ & 12 & 77 \\
\hline 2 & 35 & JUAREZ & 10 & 74 \\
\hline 2 & 76 & JUAREZ & 7 & 68 \\
\hline 2 & 87 & JUAREZ & 11 & 79 \\
\hline 3 & 2 & CHIHUAHUA & $\overline{99}$ & 127 \\
\hline 3 & $\overline{40}$ & CHIHUAHUA & 9 & 120 \\
\hline 3 & 41 & CHIHUAHUA & 12 & 77 \\
\hline 3 & 43 & CHIHUAHUA & 10 & 107 \\
\hline 3 & 44 & CHIHUAHUA & 12 & 156 \\
\hline 3 & 154 & CHIHUAHUA & 5 & 53 \\
\hline 4 & 39 & CHIHUAHUA & 12 & 137 \\
\hline 4 & 42 & CHIHUAHUA & 14 & 170 \\
\hline 4 & 45 & CHIHUAHUA & 11 & 113 \\
\hline 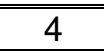 & 46 & CHIHUAHUA & 10 & 144 \\
\hline 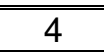 & 84 & CHIHUAHUA & 10 & 1112 \\
\hline 5 & 15 & DELICIAS & 10 & 245 \\
\hline 5 & 16 & DELICIAS & 9 & 40 \\
\hline 19 & 18 & MEOQUI & 11 & 67 \\
\hline 19 & 69 & DELICIAS & 12 & 63 \\
\hline 5 & 88 & DELICIAS & 10 & 34 \\
\hline 19 & 148 & CARDENAS & 8 & 66 \\
\hline 6 & 10 & CUAUHTEMOC & 11 & 56 \\
\hline 6 & 24 & ANAHUAC & 13 & 48 \\
\hline 6 & 25 & CUAUHTEMOC & 10 & 64 \\
\hline 6 & 26 & CUAUHTEMOC & 11 & 84 \\
\hline 6 & 27 & CUAUHTEMOC & 11 & 69 \\
\hline 6 & 85 & CUAUHTEMOC & 10 & 73 \\
\hline 18 & 20 & GUACHOCHI & 9 & 71 \\
\hline 7 & 28 & PARRAL & 11 & 95 \\
\hline 7 & 29 & PARRAL & 12 & 123 \\
\hline 7 & 52 & STA BARBARA & 10 & 88 \\
\hline 7 & 142 & PARRAL & 8 & 93 \\
\hline 7 & 149 & $\begin{array}{l}\text { PARRAL } \\
\end{array}$ & 8 & 95 \\
\hline 8 & 17 & SAUCILLO & 12 & 37 \\
\hline 8 & 22 & CAMARGO & 11 & 56 \\
\hline 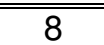 & 23 & CAMARGO & 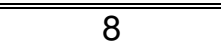 & 33 \\
\hline 8 & 141 & CAMARGO & 8 & 35 \\
\hline 9 & 31 & JUAREZ & 11 & 108 \\
\hline 9 & 32 & JUAREZ & 13 & 139 \\
\hline 9 & 34 & JUAREZ & 10 & 113 \\
\hline 9 & 74 & JUAREZ & 11 & 106 \\
\hline 10 & 50 & CHIHUAHUA & 8 & 37 \\
\hline 10 & 51 & CHIHUAHUA & 13 & 86 \\
\hline$\overline{10}$ & 79 & CHIHUAHUA & 13 & 79 \\
\hline 10 & 105 & CHIHUAHUA & 10 & 46 \\
\hline 10 & 155 & CHIHUAHUA & 5 & 57 \\
\hline$\overline{11}$ & 12 & PARRAL & 9 & 115 \\
\hline 11 & 13 & SAN FCO ORO & 11 & 63 \\
\hline
\end{tabular}




\begin{tabular}{|c|c|c|c|c|}
\hline 11 & 73 & PARRAL & 12 & 88 \\
\hline 11 & 86 & PARRAL & 8 & 56 \\
\hline 11 & 103 & PARRAL & 10 & 98 \\
\hline 18 & 145 & BALLEZA & 8 & 62 \\
\hline 18 & 147 & GUACHOCHI & 7 & 48 \\
\hline 12 & 6 & BACHINIVA & 8 & 63 \\
\hline 12 & 7 & EL LARGO & 7 & 63 \\
\hline 12 & 19 & GUERRERO & 11 & 114 \\
\hline 12 & 71 & A OBREGON & 6 & 87 \\
\hline 12 & 152 & SAN JUANITO & 5 & 69 \\
\hline 13 & 5 & ASCENSION & $\overline{99}$ & $\overline{42}$ \\
\hline 13 & $\overline{14}$ & CASAS GDES & $\overline{99}$ & 75 \\
\hline 13 & 72 & $\begin{array}{l}\text { BUENAVENTURA } \\
\end{array}$ & 9 & 67 \\
\hline 13 & 106 & CASAS GDES & $\overline{11}$ & 82 \\
\hline 13 & 153 & JANOS & 4 & 62 \\
\hline$\overline{14}$ & 8 & CHIHUAHUA & 9 & 97 \\
\hline$\overline{14}$ & $\overline{447}$ & CHIHUAHUA & $\overline{10}$ & 67 \\
\hline$\overline{14}$ & 48 & CHIHUAHUA & 10 & 54 \\
\hline 14 & 49 & CHIHUAHUA & 9 & 77 \\
\hline 14 & 104 & CHIHUAHUA & 10 & 102 \\
\hline 14 & 150 & CHIHUAHUA & 7 & 67 \\
\hline 15 & 11 & VALLE ALLENDE & 10 & 80 \\
\hline 15 & 21 & JIMENEZ & 8 & 82 \\
\hline 15 & 70 & "JIMENEZ & 9 & 94 \\
\hline 15 & 102 & (JIMENEZ & $\overline{77}$ & 83 \\
\hline 16 & 9 & OJINAGA & 10 & 104 \\
\hline 16 & 78 & CHIHUAHUA & 9 & 79 \\
\hline 17 & 30 & JUAREZ & 13 & 88 \\
\hline 17 & 33 & JUAREZ & 12 & 1117 \\
\hline$\overline{177}$ & 38 & IJUAREZ & $\overline{77}$ & 262 \\
\hline 17 & 75 & JUAREZ & 12 & 101 \\
\hline 17 & 77 & JUAREZ & 10 & 94 \\
\hline TOTAL & 81 & 81 & 787 & 6612 \\
\hline
\end{tabular}


ANEXO III

ORGANIGRAMA DE EDUCACIÓN ESPECIAL 


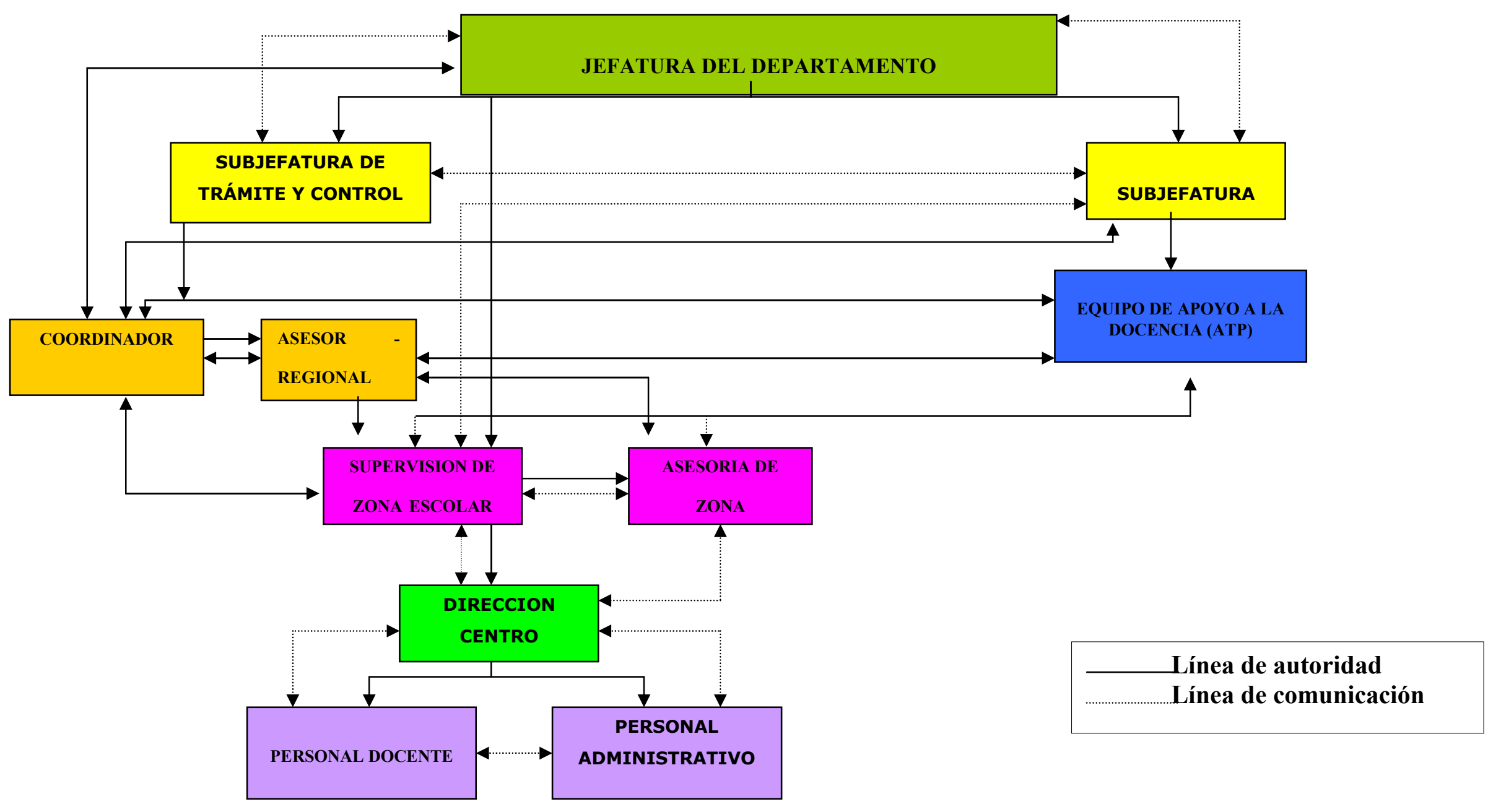


ANEXO IV

CUESTIONARIO EVALUACIÓN DEL CONTEXTO 


\section{CUESTIONARIO}

Servicio y/o Institución: Zona

Contexto:
Urbano
Urbano marginal
Rural

Ubicación:

\section{Función :}

Supervisor

Director(a)

Asesor técnico estatal

Psicólogo

Trabajador(a) social

Otros
Jefe de departamento

Asesor técnico de regional

Asesor técnico de Zona

Años de servicio:
$\square 0$ a 5 años
$\square 5$ a 10
$\square 10$ a 15
$\square 15$ a 20
más de 20

Formación inicial:

Formación actual:

\section{Experiencia} profesional: 
Las preguntas que aparecen en este cuestionario se refieren a aspectos técnicos y operativos.

1.- Seleccione las funciones que realiza, indicando el tiempo que dedica a cada una de ellas.

\begin{tabular}{|c|c|c|c|c|}
\hline$\square$ Administrativa & $\square$ Ninguno & $\square$ Poco & $\square$ Regular & $\square$ Mucho \\
\hline$\square$ Técnica & $\square$ Ninguno & $\square$ Poco & $\square$ Regular & $\square$ Mucho \\
\hline$\square$ Política & $\square$ Ninguno & $\square$ Poco & $\square$ Regular & $\square$ Mucho \\
\hline$\square$ Información & $\square$ Ninguno & $\square$ Poco & $\square$ Regular & $\square$ Mucho \\
\hline$\square$ Comunicación & $\square$ Ninguno & $\square$ Poco & $\square$ Regular & $\square$ Mucho \\
\hline$\square$ Enlace & $\square$ Ninguno & $\square$ Poco & $\square$ Regular & $\square$ Mucho \\
\hline$\square$ Supervisión & $\square$ Ninguno & $\square$ Poco & $\square$ Regular & $\square$ Mucho \\
\hline$\square$ Control & $\square$ Ninguno & $\square$ Poco & $\square$ Regular & $\square$ Mucho \\
\hline$\square$ Evaluación & $\square$ Ninguno & $\square$ Poco & $\square$ Regular & $\square$ Mucho \\
\hline $\begin{array}{l}\square \text { Desarrollo de } \\
\text { Proyectos } \\
\text { y programas } \\
\end{array}$ & $\square$ Ninguno & $\square$ Poco & $\square$ Regular & $\square$ Mucho \\
\hline$\square$ Seguimiento & $\square$ Ninguno & $\square$ Poco & $\square$ Regular & $\square$ Mucho \\
\hline$\square$ Asesoría & $\square$ Ninguno & $\square$ Poco & $\square$ Regular & $\square$ Mucho \\
\hline$\square$ Innovación & $\square$ Ninguno & $\square$ Poco & $\square$ Regular & $\square$ Mucho \\
\hline$\square$ Investigación & $\square$ Ninguno & $\square$ Poco & $\square$ Regular & $\square$ Mucho \\
\hline$\square$ Intervención & $\square$ Ninguno & $\square$ Poco & $\square$ Regular & $\square$ Mucho \\
\hline $\begin{array}{l}\square \text { Asistencia } \\
\text { social }\end{array}$ & $\square$ Ninguno & $\square$ Poco & $\square$ Regular & $\square$ Mucho \\
\hline$\square$ Gestión esc. & $\square$ Ninguno & $\square$ Poco & $\square$ Regular & $\square$ Mucho \\
\hline$\square$ Planeación & $\square$ Ninguno & $\square$ Poco & $\square$ Regular & $\square$ Mucho \\
\hline $\begin{array}{l}\square \text { Diseño y } \\
\text { Desarrollo de } \\
\text { Cursos y/o } \\
\text { Talleres. } \\
\end{array}$ & $\square$ Ninguno & $\square$ Poco & $\square$ Regular & $\square$ Mucho \\
\hline$\square$ Otra: & $\square$ Ninguno & $\square$ Poco & $\square$ Regular & $\square$ Mucho \\
\hline
\end{tabular}


2.- Participa en la elaboración del proyecto curricular del centro o institución?

3.- Mencione los aspectos que toma en cuenta para la elaboración del proyecto curricular de centro o institución.

4.- De acuerdo a su función ¿Realiza actividades de seguimiento?

$$
\text { Si } \quad \square \text { No }
$$

5.- Si su respuesta es afirmativa, enuncie cuáles son las actividades de seguimiento que realiza.

6.- Realiza actividades relacionadas con la evaluación?

$\mathrm{Si}$

No

7.- Si su respuesta es afirmativa, enuncie cuáles son las actividades de evaluación que realiza.

8.- De acuerdo a su función, ¿Cuál es el porcentaje de tiempo que utiliza en cada uno de los siguientes aspectos?

\% Planeación

\% Evaluación

$\%$ Seguimiento 
9.- En el centro o institución que trabaja, ¿Recibe cursos de actualización y capacitación?
$\mathrm{Si}$
No

10.- Si su respuesta es afirmativa, ¿Quién le proporciona estos cursos?
Centro de Maestros
Supervisor
Asesor(a) técnico de de zona, región.
Equipo de apoyo
Director(a)
Jefe de departamento a la docencia
Otros:

11.- ¿Considera que la capacitación y actualización que recibe es adecuada en relación a los contenidos?

Porqué?
$\square \mathrm{Si}$
$\square$ No

12.- ¿Considera que el seguimiento de la capacitación y asesoría que recibe es adecuada en relación a las actividades, contenido y tiempo en que se realiza?

\section{Porqué?}
$\mathrm{Si}$
$\square$ No

13.- ¿Considera que la capacitación y la actualización que recibe es la que usted requiere?

Porqué?
$\mathrm{Si}$
$\square$ No 
14.- De acuerdo a su función, ¿Cuáles son sus necesidades técnicasoperativas?
Aspectos específicos de la
Evaluación y seguimiento discapacidad
Adecuaciones curriculares
Planes y programas
Planeación
Control escolar
Proyecto curricular de aula
$\square$ Proyecto curricular de centro
Integración
N.E.E.
Aptitudes sobresalientes

Otras:

15.- Cree que se puede mejorar el servicio que ofrece el centro o institución en la que trabaja?
$\mathrm{Si}$
No

16.- Si su respuesta es afirmativa, ¿Qué sugiere para mejorar el servicio?

Lugar y fecha: 
[ANEXO IV-1]

[ Codificación de los datos del Cuestionario] 
CODIFICACIÓN ENCUESTA

\begin{tabular}{l}
\begin{tabular}{|c|c|c|c|c|c|c|}
\hline 1 & SERVICIOS \\
\hline DEPTO & COORD & USAER & CAM & CRIEE & SUP & EAD \\
\hline 1 & 2 & 3 & 4 & 5 & 6 & 7 \\
\hline
\end{tabular} \\
\begin{tabular}{|lll}
\hline 2 & ZONAS \\
\hline 1 & a 19
\end{tabular} \\
\hline
\end{tabular}

\begin{tabular}{|c|c|c|}
\hline 3 & CONTEXTO & \\
\hline URBANO & URBANO MARGINAL & RURAL \\
\hline 1 & 2 & 3 \\
\hline
\end{tabular}

\begin{tabular}{|l|c|}
\hline \multicolumn{1}{|c|}{ FUNCIÓN } & \\
\hline NO CONTESTO & 0 \\
\hline SUPERVISOR & 1 \\
\hline DIRECTOR & 2 \\
\hline ASESOR TEC ESTATAL & 3 \\
\hline PSICOLOGO & 4 \\
\hline TRABAJO SOCIAL & 5 \\
\hline ASESOR TEC REGIONAL & 6 \\
\hline ASESOR TEC ZONA & 7 \\
\hline MAESTRO DE APOYO & 8 \\
\hline MAESTRO DE COMUNICACIÓN & 9 \\
\hline TERAPISTA FISICO & 10 \\
\hline MAESTRO DE GRUPO & 11 \\
\hline ASESOR CRIEE & 12 \\
\hline INST TALLER & 13 \\
\hline AUX MAESTRA & 14 \\
\hline MTRO EDUC FISICA & 15 \\
\hline COOR REGIONAL & 16 \\
\hline JEFE DE DEPTO & 17 \\
\hline OTROS & 18 \\
\hline
\end{tabular}

\begin{tabular}{|c|c|c|c|c|}
\hline 5 & \multicolumn{5}{l|}{} \\
\hline 0 a 5 años & 5 a 10 & 10 a 15 & 15 a 20 & Más de 20 \\
\hline 1 & 2 & 3 & 4 & 5 \\
\hline
\end{tabular}

\begin{tabular}{|l|c|}
\hline \multicolumn{2}{|c|}{ FORMACIÓN inicial } \\
\hline NORMAL BÁSICA & 1 \\
\hline NORMAL SUPERIOR & 2 \\
\hline MTRO EDUC PRIMARIA & 3 \\
\hline MTRO EDUC PREESCOLAR & 4 \\
\hline LIC EDUC PRIMARIA & 5 \\
\hline LIC EDUC PREESCOLAR & 6 \\
\hline LIC INTERVENCIÓN EDUC & 7 \\
\hline LIC EDUC FISICA & 8 \\
\hline LIC EDUC ESPECIAL & 9 \\
\hline LIC PSICOLOGÍA & 10 \\
\hline
\end{tabular}




\begin{tabular}{|l|c|}
\hline LIC TRABAJO SOCIAL & 11 \\
\hline TEC TRABAJO SOCIAL & 12 \\
\hline LIC PEDAGOGIA & 13 \\
\hline OTROS & 14 \\
\end{tabular}

\begin{tabular}{|l|c|}
\hline 7 & FORMACIÓN ACTUALES \\
\hline DOCTORADO & 1 \\
\hline MAESTRIA & 2 \\
\hline LIC EDUC ESPECIAL & 3 \\
\hline LIC EDUC PRIMARIA & 4 \\
\hline LIC EDUC PREESC & 5 \\
\hline LIC INCLUSIÓN EDUC & 6 \\
\hline LIC PEDAGÓGIA & 7 \\
\hline LIC EDUC FISICA & 8 \\
\hline LIC PSICOLOGÍA & 9 \\
\hline LIC TRABAJO SOCIAL & 10 \\
\hline MTRO PRIMARIA & 11 \\
\hline MTRO PREESC & 12 \\
\hline TÉCNICO T SOCIAL & 13 \\
\hline ESTUDIANTE & 14 \\
\hline OTROS & 15 \\
\hline
\end{tabular}

\begin{tabular}{|c|c|c|c|c|c|}
\hline \multicolumn{6}{|l|}{ ACCIONES } \\
\hline & $\begin{array}{l}\text { NO } \\
\text { CONTESTO }\end{array}$ & NINGUNO & POCO & REGULAR & MUCHO \\
\hline $\begin{array}{l}8 \\
\text { ADMINISTRATIVA }\end{array}$ & $\mathbf{0}$ & 1 & 2 & 3 & 4 \\
\hline 9 TÉCNICA & & 1 & 2 & 3 & 4 \\
\hline 10 POLÍTICA & & 1 & 2 & 3 & 4 \\
\hline 11 INFORMACIÓN & & 1 & 2 & 3 & 4 \\
\hline $\begin{array}{l}12 \\
\text { COMUNICACIÓN }\end{array}$ & & 1 & 2 & 3 & 4 \\
\hline 13 ENLACE & & 1 & 2 & 3 & 4 \\
\hline 14 SUPERVISIÓN & & 1 & 2 & 3 & 4 \\
\hline 15 CONTROL & & 1 & 2 & 3 & 4 \\
\hline 16 EVALUACIÓN & & 1 & 2 & 3 & 4 \\
\hline $\begin{array}{l}17 \text { DESARROLLO } \\
\text { DE PROYECTOS Y } \\
\text { PROGRAMAS }\end{array}$ & & 1 & 2 & 3 & 4 \\
\hline 18 SEGUIMIENTO & & 1 & 2 & 3 & 4 \\
\hline 19 ASESORÍA & & 1 & 2 & 3 & 4 \\
\hline 20 INNOVACIÓN & & 1 & 2 & 3 & 4 \\
\hline $\begin{array}{l}21 \\
\text { INVESTIGACIÓN }\end{array}$ & & 1 & 2 & 3 & 4 \\
\hline $\begin{array}{l}22 \\
\text { INTERVENCIÓN }\end{array}$ & & 1 & 2 & 3 & 4 \\
\hline 23 ASISTENCIA & & 1 & 2 & 3 & 4 \\
\hline 24 GESTIÓN & & 1 & 2 & 3 & 4 \\
\hline 25 PLANEACIÓN & & 1 & 2 & 3 & 4 \\
\hline
\end{tabular}




\begin{tabular}{|l|l|l|l|l|l|}
\hline $\begin{array}{l}\text { 26 DISEÑO Y } \\
\text { DESARROLLO DE } \\
\text { CURSOS Y/O } \\
\text { TALLERES }\end{array}$ & 1 & 2 & 3 & 4 \\
\hline 27 OTRA & & 1 & 2 & 3 & 4 \\
\hline
\end{tabular}

\begin{tabular}{|l|c|c|c|}
\hline \multicolumn{3}{|c|}{ PARTICIPACIÓN } \\
\hline & NO & SI & NO \\
\hline 28 PY CURRICULAR DE CENTRO & 0 & 1 & 2 \\
\hline 29 ACT SEGUIMIENTO & 0 & 1 & 2 \\
\hline 30 ACT EVALUACIÓN & 0 & 1 & 2 \\
\hline 31 RECIBE CURSOS DE ACT UALIZACIÓN & 0 & 1 & 2 \\
\hline
\end{tabular}

\begin{tabular}{|l|l|l|}
\hline \multicolumn{2}{|c|}{ PORCENTAJES } \\
\hline \multicolumn{2}{|c|}{} \\
\hline $\mathbf{3 2}$ & PLANEACIÓN & 0 a $100 \%$ \\
\hline $\mathbf{3 3}$ & EVALUACIÓN & 0 a $100 \%$ \\
\hline $\mathbf{3 4}$ & SEGUIMIENTO & 0 a $100 \%$ \\
\hline
\end{tabular}

\begin{tabular}{|l|l|c|c|}
\hline \multicolumn{4}{|c|}{ PROPORCIONAN LOS CURSOS } \\
\hline \multicolumn{2}{|l|}{} & NO CONTESTO & SI \\
\hline 35 & CENTRO DE MTROS & 0 & 1 \\
\hline 36 & SUPERVISOR & 0 & 1 \\
\hline 37 & $\begin{array}{l}\text { ASESOR TÉCNICO DE ZONA O } \\
\text { REGION }\end{array}$ & 0 & 1 \\
\hline 38 & EAD & 0 & 1 \\
\hline 39 & DIRECTOR & 0 & 1 \\
\hline 40 & JEFA DE DEPTO & 0 & 1 \\
\hline 41 & OTROS & & 1 \\
\hline
\end{tabular}

\begin{tabular}{|c|l|c|c|c|}
\hline \multicolumn{5}{|c|}{ CAPACITACIÓN Y ACTUALIZACIÓN } \\
\hline & & NO CONTESTO & $S I$ & $N O$ \\
\hline 42 & EN RELACIÓN A LOS CONTENIDOS & 0 & 1 & 2 \\
\hline 43 & SEGUIMIENTO & 0 & 1 & 2 \\
\hline 44 & ES LO QUE REQUIERE & 0 & 1 & 2 \\
\hline
\end{tabular}




\begin{tabular}{|l|l|c|c|}
\hline \multicolumn{4}{|c|}{ NECESIDADES TÉCNICAS OPERATIVAS } \\
\hline & \multicolumn{1}{|l|}{} \\
\hline 45 & $\begin{array}{l}\text { ASPECTOS ESPECIFICOS DE LA } \\
\text { DISCAPACIDAD }\end{array}$ & 0 & 1 \\
\hline 46 & ADECUACIONES CURRICULARES & 0 & 1 \\
\hline 47 & PLANEACIÓN & 0 & 1 \\
\hline 48 & $\begin{array}{l}\text { PROYECTO CURRICULAR DE } \\
\text { AULA }\end{array}$ & 0 & 1 \\
\hline 49 & INTEGRACIÓN & 0 & 1 \\
\hline $\mathbf{5 0}$ & EVALUACIÓN Y SEGUIMIENTO & 0 & 1 \\
\hline $\mathbf{5 1}$ & PLANES Y PROGRAMAS & 0 & 1 \\
\hline $\mathbf{5 2}$ & CONTROL ESCOLAR & 0 & 1 \\
\hline 53 & PROYECTO CURRICULAR DE & 0 & 1 \\
\hline $\mathbf{5 4}$ & NENTRO & & 1 \\
\hline $\mathbf{5 5}$ & APTITUDES SOBRESALIENTES & 0 & 1 \\
\hline 56 & OTRAS & 0 & 0 \\
\hline
\end{tabular}

\begin{tabular}{|l|l|c|c|c|}
\hline \multicolumn{5}{|c|}{ MEJORAR EL SERVICIO } \\
\hline \multicolumn{2}{|l|}{$\begin{array}{l}\text { NO CONTESTO } \\
\text { MEJORAR }\end{array}$} & 0 & 1 & SI \\
\hline 57 & $\begin{array}{l}\text { CREE QUE PUEDE } \\
\text { MEJORAR }\end{array}$ & 2 \\
\hline
\end{tabular}


[ANEXO IV-2]

[Codificación de las Unidades de Registro de los Ítems sujetos de Análisis] 
[ANEXO IV 2-a]

[Ítem 3: Mencione los aspectos que toma en cuenta para la elaboración del Proyecto Currricular de Centro] 
UNIDADES DE REGISTRO DEL ITEM 3, Mencione los aspectos que toma en cuenta para la elaboración del Proyecto Curricular de Centro.

\begin{tabular}{|c|c|c|c|c|}
\hline & & & & UNIDADES DE REGISTRO \\
\hline \multirow{7}{*}{$\begin{array}{l}\text { P.C.C. } \\
\text { (1) }\end{array}$} & \multirow[t]{6}{*}{$\begin{array}{c}\text { AUTOEVALUACIÓN } \\
(1.1)\end{array}$} & $\begin{array}{c}\text { INSTITUCIÓN } \\
(1.1 .1)\end{array}$ & & $\begin{array}{l}5,10,19,22,23,32,35,50,51,58,62-64,66-72,74,81,84,-88,91,92,95-100,102-106,111-117,122,128, \\
133,138,139,145,147,151,153-155,162,163,172,185,188-199,201,202,207-210,215,217,218,221, \\
230,231,236,238-241,243-245,247,249,251-253,256-259,261-265,268,270-272,274-279,284,287, \\
290,294-297,307,312,314,321-326,332,226-339,347-349,352,354,359-361,371-374,379,382,383, \\
389,391-397,399-402,407,417,421,422,428-430,441,445,455-460,465-468,473,476,480,481,485, \\
486,488-491,500,510-512 .\end{array}$ \\
\hline & & $\begin{array}{c}\text { ALUMNOS } \\
(1.1 .2)\end{array}$ & $\begin{array}{c}\text { HABILIDADES } \\
(1.1 .2 .1)\end{array}$ & $6,7,11,14,15,52,108,220,242,292,293,318,363,378,406,447$. \\
\hline & & & $\begin{array}{c}\text { NECESIDADES } \\
(1.1 .2 .2)\end{array}$ & $\begin{array}{l}5-7,11-15,18,19,48,50,51,56,61,64,65,68,85-87,101,105-108,112,122,123,127,136,139,146,152, \\
161,166,173,175,176,178,180,181,218,220,222,223,242,248,250,267,273,281-283,292-295,297, \\
298,300,301,303-309,313-315,318-323,327-335,340-343,353-355,362,367,378-392,395-398,402, \\
404-406,415,416,419,420,423,428,431,446-451,460,461,464,472,474,477,482,486,487,501-505, \\
509 .\end{array}$ \\
\hline & & $\begin{array}{c}\text { MAESTROS } \\
(1.1 .3)\end{array}$ & & $\begin{array}{l}4,5,10,11,31,33,47,68,71,73-75,77,80,81,93,94,106,114,123,124,126,127,129,130,132,137-140 \\
142,148,160,162,165,167,168,176,184,185,218,224,225,255,257,260,261,267,272,280,287,295 \\
302,308,309,333,334,342,344,345,355,390,396,397,403,404,419,431,437,469,472,475,487,492 \\
507,508,514\end{array}$ \\
\hline & & $\begin{array}{c}\text { FAMILIA } \\
(\mathbf{1 . 1 . 4 )}\end{array}$ & & $21,169,172,176,179,287,315,335$ \\
\hline & & $\begin{array}{c}\text { RECURSOS } \\
(1.1 .5)\end{array}$ & & $4,5,114,137,139,166,179,200,211,219,236,277,284,285,286,343,478,479$ \\
\hline & $\begin{array}{c}\text { PROPÓSITOS } \\
\text { EDUCATIVOS } \\
(1.2)\end{array}$ & & & 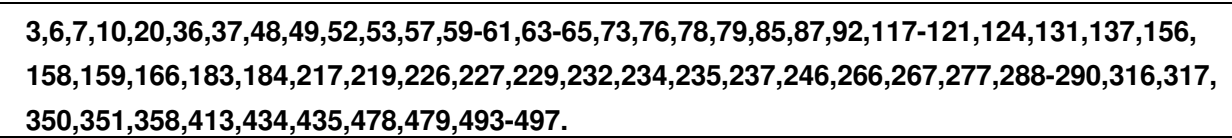 \\
\hline
\end{tabular}


[ANEXO IV 2-b]

[Ítem 5: Enuncie cuáles son las actividades de seguimiento que realiza] 


\begin{tabular}{|c|c|c|c|}
\hline \multicolumn{4}{|c|}{ UNIDADES DE REGISTRO DEL ITEM 5. Enuncie cuáles son las actividades de Seguimiento que realiza. } \\
\hline & & & UNIDADES DE REGISTRO \\
\hline \multirow{10}{*}{$\begin{array}{l}\text { SEGUIMIENTO } \\
\text { (1) }\end{array}$} & $\begin{array}{c}\text { TIPOS DE EVALUACIÓN } \\
(1.1)\end{array}$ & $\begin{array}{c}\text { EVALUACIÓN } \\
(1.1 .1)\end{array}$ & $\begin{array}{l}3,4,6,7,9,12,15,16,22,24,36,44,45,47-50,56,59,65,68,74,76,79,92,96,98,101,112,115-117,122,126,135,139,142, \\
143,147,158,166,167,170,178,180-183,186,198,221,224,230,239,241,242,244,246,249,250,258,259,267,272,279 \\
286,289-292,294,303,310,311,325,328,329,333,334,346,351,358,368,370,378,389,392,396,400,408,410,412,413 \\
417,424-426,441,448,450,470,477,478,485,488,499-506\end{array}$ \\
\hline & & $\begin{array}{l}\text { PSICO. } \\
(1.1 .2)\end{array}$ & $60,128,132,154,189,190,204-207,222,238,295,312,326,337,350,390,418,419,423,484,485,497$, \\
\hline & \multirow[t]{5}{*}{$\begin{array}{l}\text { INSTRUMENTOS } \\
\text { Y } \\
\text { ESTRATEGIAS } \\
\qquad(1.2)\end{array}$} & $\begin{array}{l}\text { ALUMNOS } \\
(1.2 .1)\end{array}$ & $\begin{array}{l}\text { 5,7,10,11,12,18,22-24,27,32-34,43,45,51,53,54,57,58,59,61,63-66,68,69,71,74,81,82,90,91,93,96,101,103,104, } \\
\text { 109,112,122,124,130,133,136,141,149,152,154,157,162,165,168-170,172,174,175,177,184,185,193-195,215, } \\
\text { 219,223,229-231,234,235,239,247-249,260-262,266,268-270,272-274,276,278,280,281,285,287,288,290-293, } \\
296-301,304,308-310,313,315,316,324,327,329,333,335,347,349,352,354,357,362,371-374,380-391,393,399, \\
\text { 404-406,409,414-417,420,430,431,434,438,440,443,446-449,454-458,460-464,468,469,472,473,478,480,481,487, } \\
507,510 .\end{array}$ \\
\hline & & $\begin{array}{l}\text { MAESTROS } \\
(1.2 .2)\end{array}$ & $\begin{array}{l}3,4,11,12,19,20,25,31,37,46,47,51,62,74,75,77,81-83,90,97,101,105,113,123,126,130,138,139,144,152,159,164 \\
177,179,193,194,209,220,225,226,232-234,246,259-261,268,272,281,294,296-299,307,319,330,335,349,354,365 \\
381,384,386,387,390,391,395,396,403,409,433,440,445,452,457,459,462,463,466-469,475,476,483,512\end{array}$ \\
\hline & & $\begin{array}{c}\text { FAMILIA } \\
(1.2 .3)\end{array}$ & $\begin{array}{l}9,11,12,31,35,47,51,62,68,75,77,81-83,91,97,105,109,114,121,122,125,126,130,134,135,141,149,157,164,170, \\
171,173,176,177,180,183,189,190,194,195,219-221,226,232,234,246,249,260,261,268,269,274,281,294,296-299, \\
302,307,308,316,324,329,335,340,349,351,353,357,364-366,371,372,374,380,381,384,386-388,390,391,395,396, \\
399,401,403,405,409-411,422,457,463,465,468,471,472,483,509,\end{array}$ \\
\hline & & $\begin{array}{l}\text { GRUPO } \\
(1.2 .4)\end{array}$ & $2,7,35,44,66,101,121,125,136,140,144,164,223,224,228,308,314,353,354,364,372,380,382,391,443,471$. \\
\hline & & $\begin{array}{c}\text { INSTITUCIÓN } \\
(1.2 .5)\end{array}$ & $\begin{array}{l}2,9,10,26,29,32,33,66,67,70,72,73,76,80,106-108,113,129,131,137,141,160,208,209,216,218,219,226,228,233 \\
240,241,243,245,251,253-257,266,275,282-284,295,305,314,317,318,320,322,323,342,343,348,355,369,374-376, \\
379,385,388,393,407,433,435,445,469,475,476,489-498,511\end{array}$ \\
\hline & \multirow[t]{3}{*}{$\begin{array}{c}\text { SEGUIMIENTO } \\
(1.3)\end{array}$} & $\begin{array}{l}\text { P.C.C } \\
(1.3 .1)\end{array}$ & $\begin{array}{l}11,13,14,23,28,87,88,92,94,95,110,111,145,146,148,151,153,163,173,187,192,196,197,214,222,227,228,241,242, \\
252,262-265,271,300-304,306,321,326,331,336,338,339,344,347,359,361,369,402,411,421-423,427,436,482,489, \\
493,500,507,508\end{array}$ \\
\hline & & $\begin{array}{l}\text { P.C.A } \\
(1.3 .2)\end{array}$ & $\begin{array}{l}\text { 8,15,22,45,85,89,94,118,178,181,189,192,197,204-207,222,242,244,249,277,295,312,313,338-341,350,361,375, } \\
378,402,418,429,448,482,499-502 .\end{array}$ \\
\hline & & $\begin{array}{c}\text { P.AULICO } \\
(1.3 .3)\end{array}$ & $17,155,156,167,168,194,195,197,199,225,242,308,338,363,367.377,397,398,400,402,411,418,424,436,442,444,507$ \\
\hline
\end{tabular}


[ANEXO IV 2-c]

[Ítem 7: Enuncie cuáles son las actividades de evaluación que realiza] 


\begin{tabular}{|c|c|c|c|}
\hline \multirow{2}{*}{\multicolumn{4}{|c|}{$\begin{array}{r}\text { UNIDADES DE REGISTRO DEL ITEM 7. Enuncie cuáles son las actividades de Evaluación que realiza. } \\
\text { UNIDADES DE REGISTRO }\end{array}$}} \\
\hline & & & \\
\hline \multirow{12}{*}{$\begin{array}{l}\text { EVALUACIÓN } \\
\text { (1) }\end{array}$} & \multirow[t]{4}{*}{$\begin{array}{l}\text { TIPOS DE } \\
\text { EVALUACIÓN } \\
\quad(1.1)\end{array}$} & $\begin{array}{l}\text { INICIAL } \\
(1.1 .1)\end{array}$ & $\begin{array}{l}\text { 1-3,28,53,55,58.64,76,79,82,84,92,94,95,97,98,101,107,112,114,117,123,127,128,136,137,139,142,150,159,170, } \\
171,177,178,181,183,187,208,233,234,238,247,250,267,275-277,279,282,300-302,310-312,345,348,385,396,401, \\
402,403,405,416,424,426,472,490,493,\end{array}$ \\
\hline & & $\begin{array}{l}\text { CONTINUA } \\
(1.1 .2)\end{array}$ & $\begin{array}{l}1-3,28,35,47,51,53,58,63,64,76,77,79,80,82,92,99-101,104,110,114,117,125-127,131,133,134,139,150,156,166, \\
167,170,171,177,178,181,183,187,189,192,195-197,199,202,206,208,222,238,242,247,248,251,258,267,277,279, \\
280,282,300-302,306-312,345,348,367,384,396,401-403,405,416,424,426,461,462,472,493,494 .\end{array}$ \\
\hline & & $\begin{array}{l}\text { FINAL } \\
(1.1 .3)\end{array}$ & $\begin{array}{l}\text { 1-3,28,35,53,55,76,79,92,94,95,97,98,101,117,126,127,131,139,170,171,178,181,183,208,242,247,248,267,276, } \\
280,300-302,345,368,372,385,396,402,403,405,416,424,426,472,493,494,\end{array}$ \\
\hline & & $\begin{array}{l}\text { PSICO- } \\
(1.1 .4)\end{array}$ & $\begin{array}{l}28,35,45-47,58,60,61,63,64,97,104,113-116,118,120,123,124,129,151,153,155,156,166,167,172,177,181,198,216, \\
253,281,302,310-312,318,322,336,359,363,364,374,384,385,394,451,472,475,490 .\end{array}$ \\
\hline & \multirow[t]{5}{*}{$\begin{array}{c}\underset{Y}{\text { INSTRUMENTOS }} \\
\text { ESTRATEGIAS } \\
\qquad(1.2)\end{array}$} & $\begin{array}{l}\text { ALUMNOS } \\
(1.2 .1)\end{array}$ & $\begin{array}{l}\text { 5-7,11-18,20,22-24,26-28,31-35,37,47,49-52,54,59,62,65-69,71-75,77,78,81,84,86,90,94,96,98,99,102,103,110,111 } \\
\text { 115,122,128,130,138,140,143,158,160-163,168,169,173,174,185,186,188,189,192,193,199-201,210,226-228,230, } \\
231,234,235,243,244,246,255,256,261,264,268,271-273,275,278,283-286,288-290,294,296,297,299,303-305,316, \\
320,321,323-325,327-329,332-335,337-340,343,344,347,354-356,360,363,365,366,371,376,378-381,386-391,393, \\
399,406,409,410,417,427,431,433,434,436-442,444-446,449-451,453-455,460-462,464-468,470,471,473,474, \\
476-479,483,487-489,492,504,506-509,512,516 .\end{array}$ \\
\hline & & $\begin{array}{l}\text { MAESTROS } \\
(1.2 .2)\end{array}$ & $\begin{array}{l}\text { 4,8,23,24,64,65,69,71,75,93,105,136,144,164,185,200,230,231,238,261,270-273,276,332,337,400,431,449,452, } \\
479,484,489,505\end{array}$ \\
\hline & & $\begin{array}{l}\text { FAMILIA } \\
(\mathbf{1 . 2 . 3 )}\end{array}$ & $\begin{array}{l}36,54,56,57,64,65,78,81,85,87,149,173,174,179,185,194,199,226,230,231,234,271-273,332,347,382,394,449, \\
452,468,478,479,\end{array}$ \\
\hline & & $\begin{array}{l}\text { GRUPO } \\
(1.2 .4)\end{array}$ & $\begin{array}{l}\text { 4,7,37,71,81,93,99,102,105,129,130,136,140,144,164,169,210-213,224,230,231,238,382,394,395,446,447,449, } \\
453,473,510-512 .\end{array}$ \\
\hline & & INSTI (1.2.5) & 4,9,54,56,78,93,229,264,295,298,314,315,317,336,349,357,358,361,363,364,377,392,414,432,448,458,499,519. \\
\hline & \multirow[t]{3}{*}{$\begin{array}{l}\text { SEGUIMIENTO } \\
(1.3)\end{array}$} & $\begin{array}{l}\text { P.C.C. } \\
(1.3 .1)\end{array}$ & $\begin{array}{l}\text { 4,83,93,108,110,112,131,135,154,160,175,180,186,187,190,191,202,214,215,216,229,232,236,239,240,251,260, } \\
263,274,291-293,316,319,341,352,383,398,411,495,503 .\end{array}$ \\
\hline & & PROF (1.3.2) & $48,77,88,91,108,112,123,131,132,176,184,196,202,216,225,241,262,267,295,346,347,353,364,408,418,435,457$. \\
\hline & & $\begin{array}{l}\text { P.C.A } \\
\text { (1.3.3) }\end{array}$ & $\begin{array}{l}84,91,106,109,120,121,124,125,132,136,141,148,150,152,153,155,165,196,197,203,211,212,213,221,223,229,237, \\
240,241,249,250,251,252,253,254,257,259,260,265,266,269,287,288,313,326,330,336,350,351,370,375,404,407, \\
413,415,419,421,423,429,430,485,486,494,495 .\end{array}$ \\
\hline
\end{tabular}




\section{[Anexo IV 2-d]}

[ítem 11: ¿Considera que la capacitación y actualización que recibe es adecuada en relación a los contenidos?] 
UNIDADES DE REGISTRO DEL ITEM 11. ¿Considera que la capacitación que recibe es adecuada en relación a los contenidos?

\begin{tabular}{|c|c|c|c|c|}
\hline & & & & UNIDADES DE REGISTRO \\
\hline \multirow{7}{*}{$\begin{array}{c}\text { CONTENIDOS } \\
\text { (1) }\end{array}$} & \multirow[t]{4}{*}{$\begin{array}{l}\text { SI } \\
\text { ADECUADA } \\
(1.1)\end{array}$} & \multirow[t]{3}{*}{$\begin{array}{l}\text { NECESIDADES } \\
(1.1 .1)\end{array}$} & $\begin{array}{l}\text { INSTITUCIONES } \\
\quad(1.1 .1 .1)\end{array}$ & 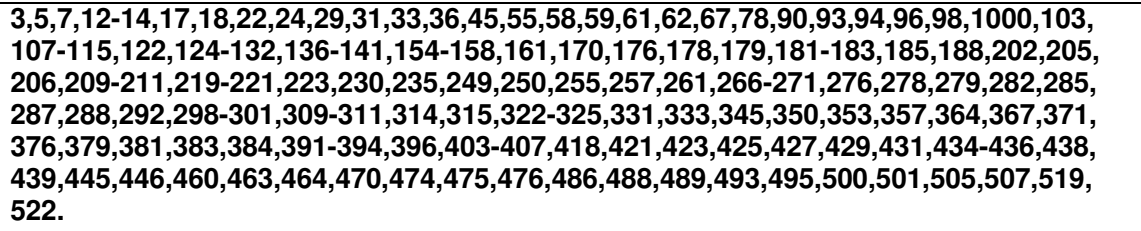 \\
\hline & & & $\begin{array}{l}\text { ALUMNOS } \\
(1.1 .1 .2)\end{array}$ & $\begin{array}{l}\text { 168,175,186,189,296,252,276,284,294,301,302,302,318,321,328,334,335,397,400,424, } \\
441,442,444 .\end{array}$ \\
\hline & & & $\begin{array}{l}\text { FUNCIONES } \\
(1.1 .1 .3)\end{array}$ & $\begin{array}{l}\text { 11,24,48,118,150,159-160,186,189,226,232,237,251,263,265,275,283,295,351,357,364, } \\
372,382,467,485,503,504,508,521 .\end{array}$ \\
\hline & & $\begin{array}{l}\text { PROPOSITOS } \\
\text { EDUCATIVOS } \\
\quad(1.1 .2)\end{array}$ & & $\begin{array}{l}, 16,18,21,25-27,62,65,66,71,73,76,77,78,89,95,102,103,121,123,133,137,143,144,152, \\
153,165,167,172-174,177,180,184,204,207,208,224,225,231,244,246,253,258-260,262- \\
265,271,274,275,280,283,284,286,291,293,295,304,313,336-338,340,341,343,344,347 \\
351,352,369,372,375,380,387-390,401,412,433,440,443,449,451,455,461,467,469,472, \\
473,478,482,484,487,492,499,509,518,523\end{array}$ \\
\hline & \multirow{3}{*}{$\begin{array}{l}\text { NO } \\
\text { ADECUADA } \\
(1.2)\end{array}$} & $\begin{array}{l}\text { NECESIDADES } \\
(1.2 .1)\end{array}$ & & $\begin{array}{l}20,30,47,64,99,134,145,147,148,149,192,193,198,199,238,277,289,290,306,317,326,327 \\
339,365,366,385,413,426,450,454,456,462,466,514,516,520 .\end{array}$ \\
\hline & & $\begin{array}{l}\text { PROPÓSITOS } \\
\text { EDUCATIVOS } \\
\quad(1.2 .2)\end{array}$ & & $\begin{array}{l}\text { 15,35,37,51,56,91,92,97,116,117,134,149,190,191,196,228,238,243,247,248,272,273,297, } \\
\text { 305,307,308,312,332,342-346,348,349,356,365,413,419,420,447,448,453,466,471,479, } \\
481,490,498,514,517\end{array}$ \\
\hline & & $\begin{array}{l}\text { TIEMPO } \\
(1.2 .3)\end{array}$ & & $\begin{array}{l}35,41,42,46,50,63,105,106,142,146,148,151,187,222,229,236,241,242,256,319,326,327, \\
332,339,346,385,402,414,450 .\end{array}$ \\
\hline
\end{tabular}




\section{[ANEXO IV 2-e]}

[Ítem 12: ¿Considera que el seguimiento de la capacitación y asesoría que recibe es adecuada en relación a las actividades, contenido y tiempo?] 
UNIDADES DE REGISTRO DEL ITEM 12. ¿Considera que el seguimiento a la capacitación y asesoría que recibe es adecuada?

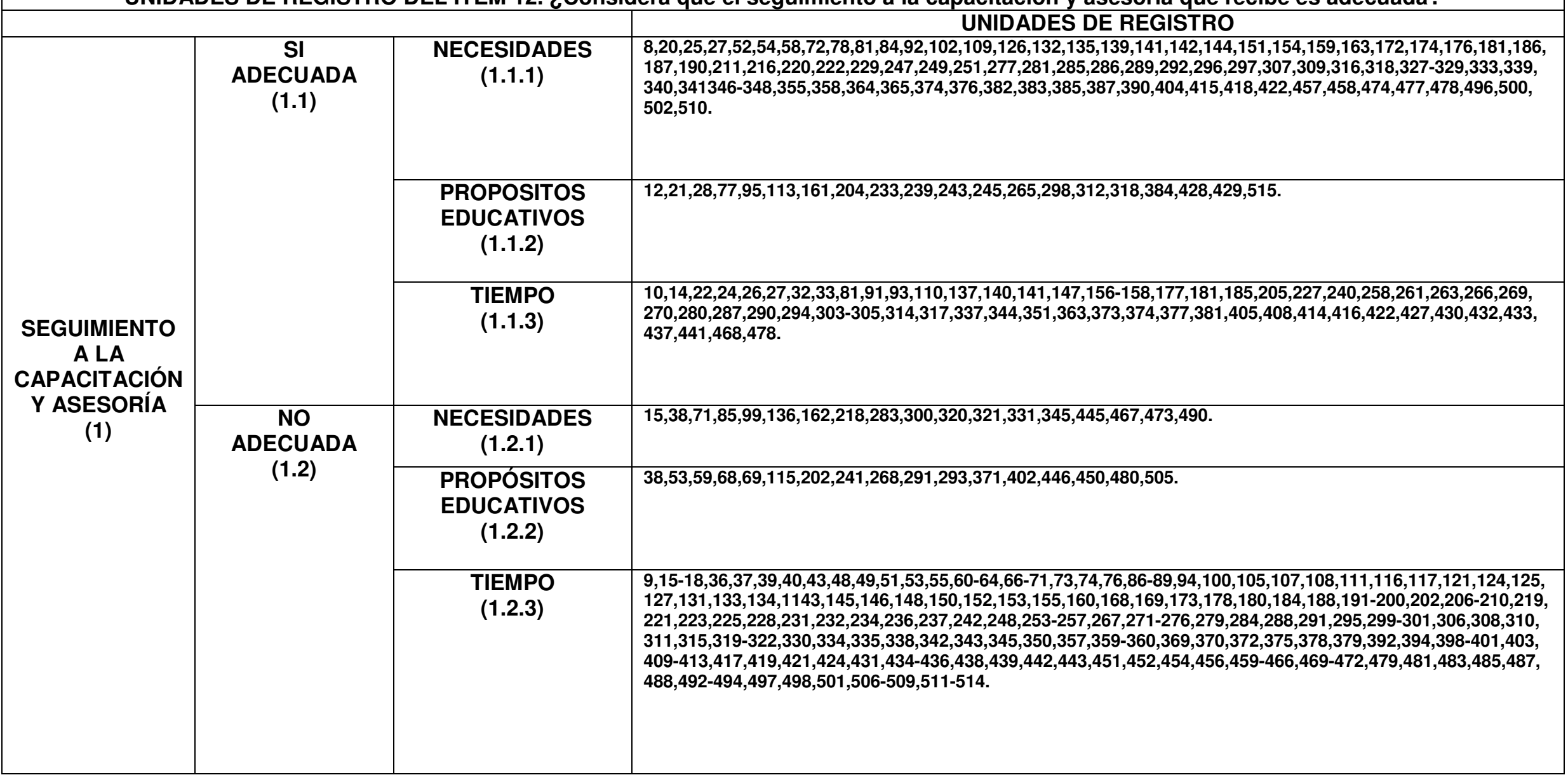


[ANEXO IV 2-f]

[ítem 13: ¿Considera que la capacitación y actualización que recibe es la adecuada?] 
UNIDADES DE REGISTRO DEL ITEM 13, ¿Considera que la capacitación que recibe es la adecuada?

\begin{tabular}{|c|c|c|c|c|}
\hline \\
\hline & & & & UNIDADES DE REGISTRO \\
\hline \multirow{9}{*}{$\begin{array}{l}\text { SEGUIMIENTO } \\
\text { (1) }\end{array}$} & \multirow{4}{*}{$\begin{array}{l}\text { SI ADECUADA } \\
(1.1)\end{array}$} & \multirow{2}{*}{$\begin{array}{l}\text { NECESIDADES } \\
(1.1 .1)\end{array}$} & $\begin{array}{c}\text { ALUMNOS } \\
(1.1 .1 .2)\end{array}$ & $172,217,246,273,276,327,385,440$ \\
\hline & & & $\begin{array}{l}\text { FUNCIONES } \\
(1.1 .1 .3)\end{array}$ & $\begin{array}{l}\text { 5,9,13,49,53,60,77,123,125,126,133,134,136,139,174,177,179,187,190,192,204,210,211, } \\
216,218,220,222,227,239,240,243,245-248,253-255,266,268,273,278,280,288- \\
290,300,303,312,315,337,339,346,361,374,383,386-388,395,408,409,412,416,422,426 \\
\text { 427,434,435,452,467,475,477,479,496,500,514,517. }\end{array}$ \\
\hline & & $\begin{array}{l}\text { PROPÓSITOS } \\
\text { EDUCATIVOS } \\
(1.1 .2)\end{array}$ & & $\begin{array}{l}11,23,25,26,79,115,140,163,181,199,205,229,241,244,249,254,256,258-260,262,264,314, \\
\text { 316,437,441,473,480,504,505,517. }\end{array}$ \\
\hline & & $\begin{array}{c}\text { TIEMPO } \\
(1.1 .3)\end{array}$ & & $6,24,49,59,75,111,119,133,211,241,265,285,308,333,369,379,389,390,391,394,423,461$. \\
\hline & \multirow[t]{5}{*}{$\begin{array}{l}\text { NO ADECUADA } \\
(1.2)\end{array}$} & \multirow[t]{3}{*}{$\begin{array}{l}\text { NECESIDADES } \\
(1.2 .1)\end{array}$} & $\begin{array}{l}\text { SERVICIOS } \\
(1.2 .1 .1)\end{array}$ & $\begin{array}{l}\text { 30,39,69,71,107,135,143,147,150,165,166,169,173,175,191,193,195,200,206,221,232,257, } \\
263,271,272,283,284,287,299,301,311,322,330,335,336,343,363,418,448,460,472,478, \\
488,494,510,513\end{array}$ \\
\hline & & & $\begin{array}{l}\text { ALUMNOS } \\
(1.2 .1 .2)\end{array}$ & $\begin{array}{l}27,29,66,71,88,106,107,202,207,208,271,310,311,344,345,436,445,450,454,455,486,494, \\
507,518 .\end{array}$ \\
\hline & & & $\begin{array}{l}\text { FUNCIONES } \\
(1.2 .1 .3)\end{array}$ & $\begin{array}{l}\text { 14,32,33,34,40,47,51,62,68,84-87,92,99,106,107,114,117,118,124,131,146,148,150,155, } \\
\text { 156,159,164,170,196,197,225,234,242,292,325,326,331,354,355,377,378,397,400,417, } \\
\text { 439,451,453,454,474,476,484,486,495,497,501,508,511,512. }\end{array}$ \\
\hline & & $\begin{array}{l}\text { PROPÓSITOS } \\
\text { EDUCATIVOS } \\
(1.2 .2)\end{array}$ & & $\begin{array}{l}36,66-69,72,85,86,86,145,151,183,231,242,292,330,334,335,376,406,418,444,448,457 \\
463 .\end{array}$ \\
\hline & & $\begin{array}{c}\text { TIEMPO } \\
(1.2 .3)\end{array}$ & & $\begin{array}{l}\begin{array}{l}4,8,16,17,18,22,51,57,64,84,93,99,127,129,143,146,149,152,156,162,183,206,209,231, \\
236,237,301,302,306,319,321 .\end{array}\end{array}$ \\
\hline
\end{tabular}




\section{[ANEXO IV 2-g]}

[Ítem 16: ¿Qué sugiere para mejorar el servicio?] 
UNIDADES DE REGISTRO DEL ITEM 16. ¿Qué sugiere para mejorar el servicio?

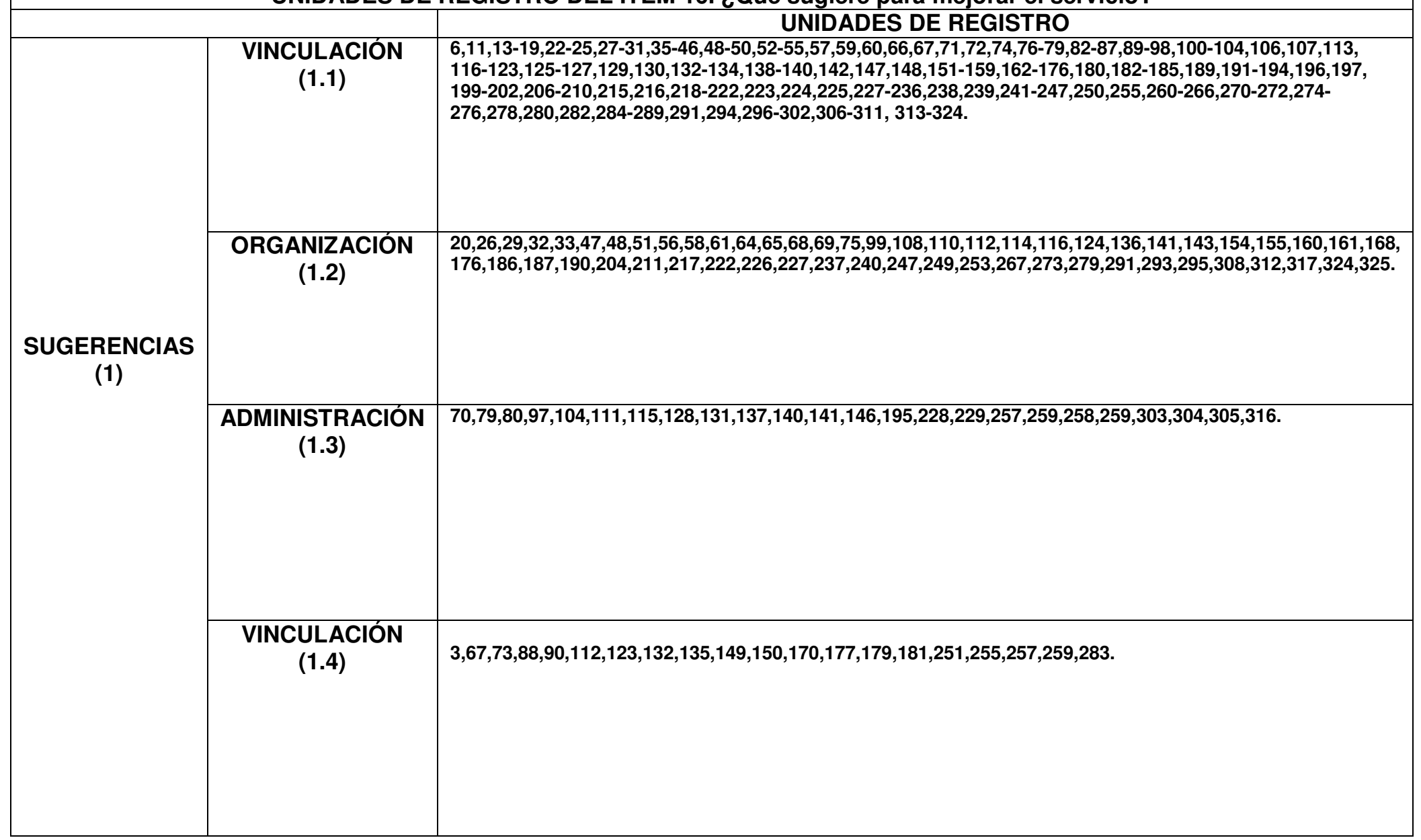


ANEXO $\mathbf{V}$

ENCUESTA DE EVALUACIÓN DEL DISEÑO DEL SITIO WEB 
Estimado Profesor:

Mi nombre es Magda Ofelia Longoria Gandara actualmente soy alumna del Doctorado de Tecnología Educativa de la Universidad de Salamanca y me encuentro realizando el proyecto de tesis bajo la dirección de Dña. Ana GarcíaValcárcel. Como parte de este trabajo de investigación he diseñado una página web como una propuesta para la mejora y optimización de la asesoría técnica en la modalidad de Educación Especial en el estado de Chihuahua en México. Por lo cual solicito a usted su colaboración como experto para evaluar dicha página.

En documento adjunto le envío el instrumento o ficha de evaluación que deberá rellenar y enviarme, la cual es una adaptación de la Ficha para la catalogación y evaluación de Portales Educativos diseñada por Pere Marqués-USAB, 2004.

La ficha presenta una tabla con Aspectos Funcionales, Técnicos y Pedagógicos, que se deben evaluar a partir de la consideración de una escala de 4 valores:

BAJA.- sí la característica que se evalúe esta mal

CORRECTA.- si este aspecto está bien, correcto

ALTA.- si este aspecto está muy bien

EXCELENTE.- si resulta casi inmejorable en este aspecto

Al final se realizará la evaluación global, donde además de establecer una valoración numérica, se recogen observaciones complementarias que quiera hacer el evaluador.

Su valioso criterio en la valoración del instrumento servirá de aporte y sustentación para los cambios pertinentes a que haya lugar, a fin de mejorar la calidad del mismo.

Agradeciendo de antemano su atención y colaboración, se despide de Ud.

\author{
ATENTAMENTE \\ Magda O Longoria Gandara
}


NOMBRE DE LA PÁGINA :

Departamento de Educación Especial de los Servicios Educativos del estado de Chihuahua

http://www.seech.gob.mx/eduespecial

PRINCIPALES SERVICIOS QUE PROPORCIONA:

Información a Maestros y Padres de Familia sobre los servicios que ofrece el nivel de Educación Especial de los Servicios Educativos del Estado de Chihuahua en México y la población que atiende en los diversos servicios. De igual manera informa sobre la ubicación de los centros en el Estado. Así mismo se encuentran documentos sobre la política educativa, revistas de educación a nivel nacional e internacional, una recopilación sobre las diferentes ligas de interés, diversos cursos de actualización para maestros, un boletín informativo y un buzón de correo.

ASPECTOS FUNCIONALES. UTILIDAD

Marque con una $\mathrm{X}$, donde proceda, la valoración.

\begin{tabular}{|l|}
\hline \\
\hline $\begin{array}{l}\text { Relevancia, interés de los servicios que } \\
\text { ofrece...... }\end{array}$ \\
\hline Facilidad de navegación........ \\
\hline Múltiples enlaces externos................. \\
\hline Canales de comunicación bidireccional ........ \\
\hline Servicios de apoyo on-line ............... \\
\hline Ausencia o poca presencia de publicidad ....... \\
\hline
\end{tabular}

ASPECTOS TÉCNICOS Y ESTÉTICOS

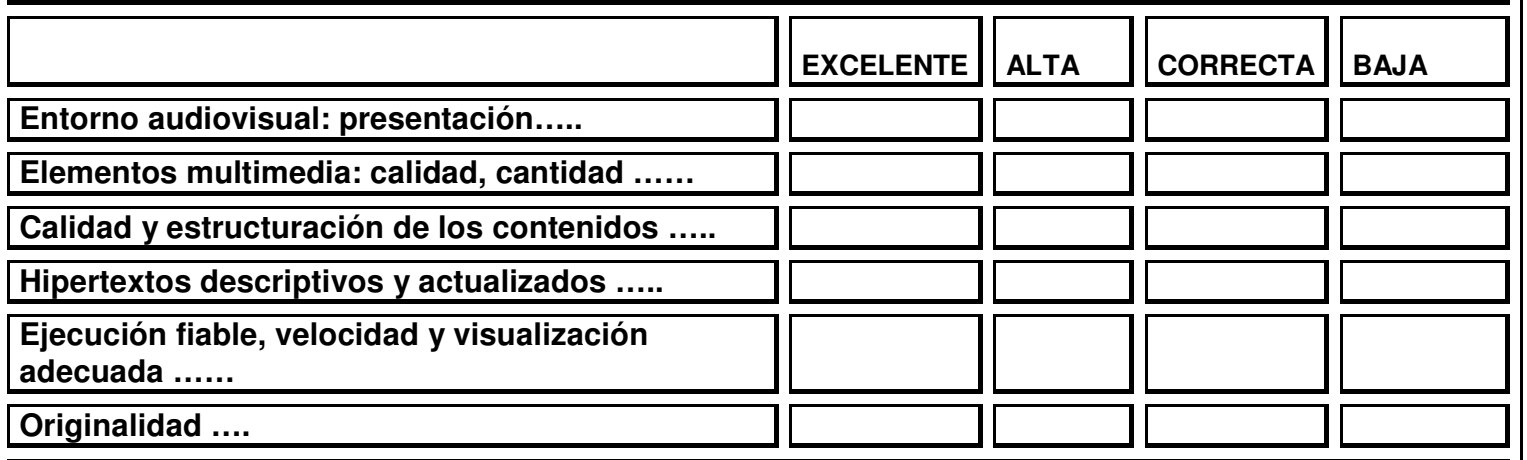

\section{ASPECTOS PEDAGÓGICOS}

\begin{tabular}{|l|l|}
\hline Atractivo, capacidad de motivación, interes ... \\
\hline $\begin{array}{l}\text { Adecuación a los destinatarios de los contenidos, } \\
\text { actividades ...... }\end{array}$ \\
\hline Recursos para buscar información ....... \\
\hline $\begin{array}{l}\text { Potencialidad de los recursos didácticos: cursos, } \\
\text { programas, documentos...... }\end{array}$
\end{tabular}


Aspectos más positivos del portal:

Aspectos más negativos del portal:

.

Otras observaciones:

VALORACIÓN GLOBAL DEL PORTAL

\begin{tabular}{|l|l|l|l|l|l|}
\hline & EXCELENTE \\
\hline \hline Los servicios que ofrece $\ldots \ldots \ldots \ldots \ldots \ldots \ldots \ldots \ldots$ \\
\hline Calidad técnica................................
\end{tabular}

Magda O. Longoria Gandara 
[ANEXO V-1]

[Codificación de la Encuesta para Evaluar el Diseño del Sitio Web] 


\section{CODIFICACIÓN PÁGINA WEB}

\begin{tabular}{|c|c|c|c|c|c|c|}
\hline \multicolumn{7}{|c|}{ ASPECTOS FUNCIONALES. UTILIDAD } \\
\hline \multicolumn{2}{|r|}{ ASPECTOS } & EXCELENTE & ALTA & CORRECTA & BAJA & NC \\
\hline 1 & $\begin{array}{l}\text { Relevancia, interés de los servicios } \\
\text { que ofrece...... }\end{array}$ & 4 & 3 & 2 & 1 & 0 \\
\hline 2 & Facilidad de navegación & 4 & 3 & 2 & 1 & 0 \\
\hline 3 & Múltiples enlaces externos & 4 & 3 & 2 & 1 & $\mathbf{0}$ \\
\hline 4 & $\begin{array}{l}\text { Canales de comunicación } \\
\text { bidireccional }\end{array}$ & 4 & 3 & 2 & 1 & 0 \\
\hline 5 & Servicios de apoyo on-line & 4 & 3 & 2 & 1 & 0 \\
\hline 6 & $\begin{array}{l}\text { Ausencia o poca presencia de } \\
\text { publicidad }\end{array}$ & 4 & 3 & 2 & 1 & 0 \\
\hline \multicolumn{7}{|c|}{ ASPECTOS TÉCNICOS Y ESTÉTICOS } \\
\hline & & EXCELENTE & ALTA & CORRECTA & BAJA & NC \\
\hline 7 & Entorno audiovisual: presentación & 4 & 3 & 2 & 1 & 0 \\
\hline 8 & $\begin{array}{l}\text { Elementos multimedia: calidad, } \\
\text { cantidad }\end{array}$ & 4 & 3 & 2 & 1 & 0 \\
\hline 9 & $\begin{array}{l}\text { Calidad y estructuración de los } \\
\text { contenidos }\end{array}$ & 4 & 3 & 2 & 1 & 0 \\
\hline 10 & $\begin{array}{l}\text { Hipertextos descriptivos y } \\
\text { actualizados }\end{array}$ & 4 & 3 & 2 & 1 & 0 \\
\hline 11 & $\begin{array}{l}\text { Ejecución fiable, velocidad y } \\
\text { visualización adecuada }\end{array}$ & 4 & 3 & 2 & 1 & 0 \\
\hline 12 & Originalidad & 4 & 3 & 2 & 1 & 0 \\
\hline \multicolumn{7}{|c|}{ ASPECTOS PEDAGÓGICOS } \\
\hline & & EXCELENTE & ALTA & CORRECTA & BAJA & NC \\
\hline 13 & $\begin{array}{l}\text { Atractivo, capacidad de motivación, } \\
\text { interés }\end{array}$ & 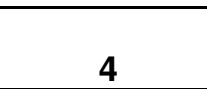 & 3 & 40.1. & 1 & 0 \\
\hline 14 & $\begin{array}{l}\text { Adecuación a los destinatarios de } \\
\text { los contenidos, actividades }\end{array}$ & 4 & 3 & 2 & 1 & 0 \\
\hline 15 & Recursos para buscar información & 4 & 3 & 2 & 1 & 0 \\
\hline 16 & $\begin{array}{l}\text { Potencialidad de los recursos } \\
\text { didácticos: cursos, programas, } \\
\text { documentos }\end{array}$ & 4 & 3 & 2 & 1 & 0 \\
\hline \multicolumn{7}{|c|}{ VALORACIÓN GLOBAL DEL PORTAL } \\
\hline & & EXCELENTE & ALTA & CORRECTA & BAJA & NC \\
\hline 17 & Los servicios que ofrece & 4 & 3 & 2 & 1 & 0 \\
\hline 18 & Calidad técnica & 4 & 3 & 2 & 1 & 0 \\
\hline 19 & $\begin{array}{l}\text { Funcionalidad, utilidad para sus } \\
\text { usuarios }\end{array}$ & 4 & 3 & 2 & 1 & 0 \\
\hline
\end{tabular}




\section{OBSERVACIONES}

Aspectos más positivos del portal:

Aspectos más negativos del portal:

-

Otras observaciones: 
ANEXO VI

ENCUESTA DE EVALUACIÓN DE LA UTILIDAD DEL SITIO WEB 


\title{
DEPARTAMENTO DE EDUCACIÓN ESPECIAL
}

\author{
CUESTIONARIO
}

JUNIO 2008

Servicio y/o Institución:

Zona

Ubicación:

Función:

Las preguntas que aparecen en esta encuesta se refieren a aspectos funcionales, Técnicos, Pedagógicos y una valoración global de la página Web del Departamento de Educación Especial de los SEECH.

\section{Conoces la Nueva Página Web de Educación Especial?}

Si no conoces la página te invito a entra a http://www.seech.gob.mx/eduespecial donde encontraras información de los servicios, cursos, revistas etc, además, aquí mismo podrás escribir tus comentarios que serán de gran utilidad para mejorar este servicio.

La encuesta presenta una tabla con Aspectos Funcionales, Técnicos y Pedagógicos, que se deben evaluar a partir de la consideración de una escala de 4 valores:

BAJA.- Sí la característica que se evalué esta mal

CORRECTA.-Sí este aspecto está bien, correcto

ALTA.- Sí este aspecto está muy bien

EXCELENTE.- Sí resulta casi inmejorable en este aspecto

\begin{tabular}{|l|l|l|l|l|}
\hline \multicolumn{5}{|c|}{ ASPECTOS FUNCIONALES. UTILIDAD } \\
\hline Marque con una X, donde proceda, la valoración. & EXCELENTE & ALTA & CORRECTA & BAJA \\
\hline $\begin{array}{l}\text { Interés del contenido y de los servicios } \\
\text { que ofrece }\end{array}$ & & & & \\
\hline Facilidad de uso & & & & \\
\hline Utilidad de los enlaces & & & & \\
\hline Canales de comunicación & & & \\
\hline $\begin{array}{l}\text { Utilidad de los servicios de apoyo } \\
\text { on-line }\end{array}$ & & & & \\
\hline \multicolumn{2}{|c|}{ ASPECTOS TÉCNICOS Y ESTÉTICOS } & \\
\hline & EXCELENTE & ALTA & CORRECTA & BAJA \\
\hline $\begin{array}{l}\text { Calidad y estructuración de los } \\
\text { contenidos ... }\end{array}$ & & & \\
\hline
\end{tabular}




\begin{tabular}{|l|l|l|l|l|}
\hline $\begin{array}{l}\text { Ejecución fiable, velocidad y } \\
\text { visualización adecuada ..... }\end{array}$ & & & & \\
\hline Originalidad & & & & \\
\hline \multicolumn{2}{|c|}{ ASPECTOS PEDAGÓGICOS } & \\
\hline & EXCELENTE & ALTA & CORRECTA & BAJA \\
\hline Planteamientos pedagógicos actuales.. & & & & \\
\hline Atractivo, capacidad de motivación.. & & & & \\
\hline $\begin{array}{l}\text { Adecuación a los destinatarios de los } \\
\text { contenidos.. }\end{array}$ & & & & \\
\hline $\begin{array}{l}\text { Utilidad de los recursos para buscar } \\
\text { información ....... }\end{array}$ & & & & \\
\hline $\begin{array}{l}\text { Potencialidad de los recursos } \\
\text { didácticos: cursos, programas, } \\
\text { documentos...... }\end{array}$ & & & & \\
\hline Fomenta el autoaprendizaje & & & & \\
\hline Posibilita el trabajo colaborativo & & & \\
\hline \multicolumn{2}{|c|}{ OBSERVACIONES } & & & \\
\hline Aspectos destacables del portal: & & & \\
\hline \\
Aspectos mejorables del portal:
\end{tabular}

\begin{tabular}{|l|l|l|l|l|}
\hline \multicolumn{5}{|c|}{ VALORACIÓN GLOBAL DEL PORTAL } \\
\hline & EXCELENTE & ALTA & CORRECTA & BAJA \\
\hline Utilidad & & & & \\
\hline Calidad Técnica & & & & \\
\hline $\begin{array}{l}\text { Funcionalidad, utilidad para sus } \\
\text { usuarios ......... }\end{array}$ & & & & \\
\hline
\end{tabular}


[ANEXO VI-1]

[Codificación de la Encuesta para Evaluar el Sitio Web] 


\section{CODIFICACIÓN UTILIDAD PÁGINA WEB}

\begin{tabular}{|c|c|c|c|c|c|c|c|}
\hline \multicolumn{1}{|l|}{ 1.- SERVICIOS } \\
$\begin{array}{c}\text { NO } \\
\text { CONTESTO }\end{array}$ & DEPTO & COORD & USAER & CAM & CRIEE & SUP & EAD \\
\hline 0 & 1 & 2 & 3 & 4 & 5 & 6 & 7 \\
\hline
\end{tabular}

\section{2.- ZONAS}

o a 19

\section{3.- UBICACIÓN}

\section{NO CONTESTO}

0

URBANO

URBANO-MARGINAL
2

RURAL 3

\begin{tabular}{|l|c|}
\hline 4.- FUNCIÓN & \\
\hline NO CONTESTO & 0 \\
\hline Jefe de Departamento & 1 \\
\hline Asesor Técnico Estatal & 2 \\
\hline Coordinador Regional & 3 \\
\hline Asesor Técnico Regional & 4 \\
\hline Supervisor (a) & 5 \\
\hline Asesor Técnico de Zona & 6 \\
\hline Director (a) & 7 \\
\hline Maestro de Apoyo & 8 \\
\hline Maestro de Grupo & 9 \\
\hline Maestro de Comunicación & 10 \\
\hline Psicología & 11 \\
\hline Trabajo Social & 12 \\
\hline Terapista Físico & 13 \\
\hline Maestro de Educ. Física & 14 \\
\hline Instructor de Taller & 15 \\
\hline Auxiliar de Maestra & 16 \\
\hline Otros & 17 \\
\hline
\end{tabular}

5.- CONOCE LA PÁG. NO CONTESTO 0

\begin{tabular}{c|c} 
SI & NO \\
\hline 1 & 2 \\
\hline
\end{tabular}

ASPECTOS FUNCIONALES. UTILIDAD

ASPECTOS

\begin{tabular}{|l|l|l|l|l|l|l||}
\hline 6 & $\begin{array}{l}\text { Interés en el contenido y de los } \\
\text { servicios que ofrece. }\end{array}$ & 4 & 3 & 2 & 1 & 0 \\
\hline 7 & Facilidad de uso. & 4 & 3 & 2 & 1 & 0 \\
\hline
\end{tabular}




\begin{tabular}{|c|c|c|c|c|c|c|}
\hline 8 & Utilidad en los enlaces. & 4 & 3 & 2 & 1 & 0 \\
\hline 9 & Canales de comunicación. & 4 & 3 & 2 & 1 & $\mathbf{0}$ \\
\hline $\begin{array}{l}1 \\
0\end{array}$ & $\begin{array}{l}\text { Utilidad de los servicios de apoyo } \\
\text { on-line }\end{array}$ & 4 & 3 & 2 & 1 & 0 \\
\hline \multicolumn{7}{|c|}{ ASPECTOS TÉCNICOS Y ESTÉTICOS } \\
\hline & & EXCELENTE & ALTA & CORRECTA & BAJA & NC \\
\hline 11 & $\begin{array}{l}\text { Calidad y estructuración de los } \\
\text { contenidos. }\end{array}$ & 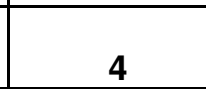 & 3 & 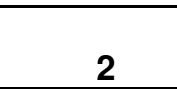 & 1 & 0 \\
\hline 12 & $\begin{array}{l}\text { Ejecución fiable, velocidad y } \\
\text { visualización adecuada }\end{array}$ & 4 & 3 & 2 & 1 & 0 \\
\hline 13 & Originalidad & 4 & 3 & 2 & 1 & 0 \\
\hline \multicolumn{7}{|c|}{ ASPECTOS PEDAGÓGICOS } \\
\hline & & EXCELENTE & ALTA & CORRECTA & BAJA & NC \\
\hline 14 & $\begin{array}{l}\text { Planteamientos pedagógicos } \\
\text { actuales. }\end{array}$ & 4 & 3 & 2 & 1 & $\mathbf{0}$ \\
\hline 15 & Atractivo, capacidad de motivación & 4 & 3 & 2 & 1 & 0 \\
\hline 16 & $\begin{array}{l}\text { Adecuación a los destinatarios de } \\
\text { los contenidos. }\end{array}$ & 4 & 3 & 2 & 1 & $\mathbf{0}$ \\
\hline 17 & $\begin{array}{l}\text { Utilidad de los recursos para buscar } \\
\text { información. }\end{array}$ & & & & & \\
\hline 18 & $\begin{array}{l}\text { Potencialidad de los recursos } \\
\text { didácticos: cursos, programas, } \\
\text { documentos }\end{array}$ & 4 & 3 & 2 & 1 & 0 \\
\hline 19 & Fomenta el autoaprendizaje. & 4 & 3 & 2 & 1 & 0 \\
\hline 20 & Posibilita el trabajo colaborativo. & 4 & 3 & 2 & 1 & 0 \\
\hline \multicolumn{7}{|c|}{ VALORACIÓN GLOBAL DEL PORTAL } \\
\hline & & EXCELENTE & ALTA & CORRECTA & BAJA & NC \\
\hline 21 & Utilidad & 4 & 3 & 2 & 1 & 0 \\
\hline 22 & Calidad técnica & 4 & 3 & 2 & 1 & 0 \\
\hline 23 & $\begin{array}{l}\text { Funcionalidad, utilidad para sus } \\
\text { usuarios }\end{array}$ & 4 & 3 & 2 & 1 & $\mathbf{0}$ \\
\hline
\end{tabular}

\section{OBSERVACIONES}

24.- Aspectos destacables del portal:

25.- Aspectos mejorables del portal: 


\section{ANEXO VII}

CODIFICACIÓN DE LAS UNIDADES DE REGISTRO A LOS DOCUMENTOS SUJETOS DE ANÁLISIS. 
[ANEXO VII-1]

[Documento: Ley para las Personas con Discapacidad en el Estado de Chihuahua] 


\begin{tabular}{|c|c|c|c|c|c|c|c|c|c|}
\hline DOCUMENTO & & & & & & & & & UNIDADES DE REGISTRO \\
\hline \multirow{8}{*}{$\begin{array}{c}\text { LEY PARA } \\
\text { LAS } \\
\text { PERSONAS } \\
\text { CON DISC. } \\
\text { EN EL EDO. } \\
\text { CHIHUAHUA }\end{array}$} & \multirow{8}{*}{$\begin{array}{l}\text { EDUC. } \\
\text { ESP. } \\
1\end{array}$} & \multirow{8}{*}{$\begin{array}{c}\text { MARCO } \\
\text { LEGAL } \\
(11)\end{array}$} & \multirow{8}{*}{$\begin{array}{c}\text { FUNDA- } \\
\text { MENTOS } \\
\left(\begin{array}{lll}1 & 1 & 1\end{array}\right)\end{array}$} & \multirow{8}{*}{$\begin{array}{l}\text { INTEGRACIÓN } \\
\left(\begin{array}{llll}1 & 1 & 1 & 1\end{array}\right)\end{array}$} & \multirow[t]{2}{*}{$\begin{array}{c}\text { RELEVANCIA } \\
\left(\begin{array}{llll}1 & 1 & 1 & 1\end{array}\right)\end{array}$} & $\begin{array}{c}\text { APRENDIZAJE } \\
\left(\begin{array}{llllll}1 & 1 & 1 & 1 & 1 & 1\end{array}\right)\end{array}$ & & & 122 \\
\hline & & & & & & $\begin{array}{c}\text { DESARROLLO } \\
\left(\begin{array}{lll}1111 & 12)\end{array}\right.\end{array}$ & & & $18,25,26,40,47,55,113,120,121$ \\
\hline & & & & & \multirow[t]{2}{*}{$\begin{array}{l}\text { EFICACIA } \\
\left(\begin{array}{llll}1 & 1 & 1 & 1\end{array}\right)\end{array}$} & $\begin{array}{c}\text { PROPÓSITOS } \\
\text { EDUCATIVOS } \\
\left(\begin{array}{lllll}1 & 1 & 1 & 1 & 2\end{array}\right)\end{array}$ & & & \\
\hline & & & & & & $\begin{array}{l}\text { DESARROLLO } \\
\qquad \begin{array}{l}\left(\begin{array}{llll}1 & 1 & 12 & 2\end{array}\right)\end{array}\end{array}$ & & & $25,26,40,47,55,121$ \\
\hline & & & & & \multirow[t]{2}{*}{$\begin{array}{l}\text { EQUIDAD } \\
\left(\begin{array}{lllll}1 & 1 & 1 & 1 & 3\end{array}\right)\end{array}$} & \multirow{2}{*}{$\begin{array}{c}\text { ATENCIÓN } \\
\text { DIFERENCIADA } \\
\left(\begin{array}{lllll}1 & 1 & 1 & 1 & 3\end{array}\right)\end{array}$} & 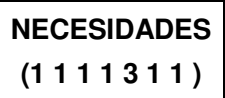 & & 117 \\
\hline & & & & & & & $\begin{array}{c}\text { CAPACIDADES } \\
\left(\begin{array}{lllll}1 & 1 & 1 & 13 & 1\end{array}\right)\end{array}$ & & $18,113,117$ \\
\hline & & & & & \multirow[t]{2}{*}{$\begin{array}{l}\text { EFICIENCIA } \\
\left(\begin{array}{lll}1114)\end{array}\right.\end{array}$} & \multirow{2}{*}{$\begin{array}{c}\text { RECURSOS } \\
\text { DIFERENCIADOS } \\
(1111141)\end{array}$} & \multirow[t]{2}{*}{$\begin{array}{l}\text { MATERIAL DID } \\
\left(\begin{array}{l}1111411)\end{array}\right.\end{array}$} & 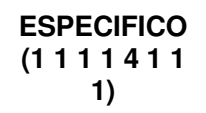 & \\
\hline & & & & & & & & 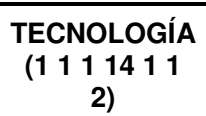 & 20 \\
\hline
\end{tabular}




\begin{tabular}{|c|c|c|c|c|c|c|c|c|c|}
\hline DOCUMENTO & & & & & & & & & UNIDADES DE REGISTRO \\
\hline \multirow{8}{*}{$\begin{array}{c}\text { LEY PARA } \\
\text { LAS } \\
\text { PERSONAS } \\
\text { CON DISC. } \\
\text { EN EL EDO. } \\
\text { CHIHUAHUA }\end{array}$} & \multirow{8}{*}{$\begin{array}{c}\text { EDUC } \\
\text { ESP } \\
1\end{array}$} & \multirow{8}{*}{$\begin{array}{c}\text { MARCO } \\
\text { LEGAL } \\
(11)\end{array}$} & \multirow{8}{*}{$\begin{array}{c}\text { FUNDA- } \\
\text { MENTOS } \\
\left(\begin{array}{lll}1 & 1 & 1\end{array}\right)\end{array}$} & \multirow[t]{5}{*}{$\begin{array}{l}\text { INCLUSIÓN } \\
\text { (1 1 1 1 2) }\end{array}$} & \multirow[t]{4}{*}{$\begin{array}{l}\text { EQUIDAD } \\
\left(\begin{array}{llll}1 & 1 & 1 & 2\end{array}\right)\end{array}$} & \multirow[t]{4}{*}{$\begin{array}{c}\text { DIVERSIF. } \\
\left(\begin{array}{lllll}1 & 1 & 12 & 1 & 1\end{array}\right)\end{array}$} & $\begin{array}{c}\text { MÉTODOS } \\
\text { (1112111) }\end{array}$ & & \\
\hline & & & & & & & 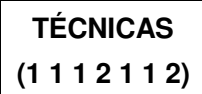 & & \\
\hline & & & & & & & \multirow[t]{2}{*}{$\begin{array}{c}\text { MATERIAL } \\
\text { DID } \\
\left(\begin{array}{l}1112113\end{array}\right)\end{array}$} & 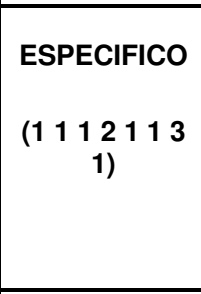 & \\
\hline & & & & & & & & 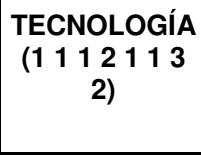 & 20 \\
\hline & & & & & $\begin{array}{c}\text { CONTEXTOS } \\
(111122) \\
\end{array}$ & & & & \\
\hline & & & & \multirow[t]{3}{*}{$\begin{array}{l}\text { CALIDAD } \\
\text { DE VIDA } \\
\left(\begin{array}{llll}1 & 1 & 3\end{array}\right)\end{array}$} & \multirow[t]{3}{*}{$\begin{array}{c}\text { EQUIPARA } \\
\text { RACIÓN DE } \\
\text { OPORTUNIDAD } \\
\left(\begin{array}{lllll}1 & 1 & 1 & 3 & 1\end{array}\right)\end{array}$} & $\begin{array}{c}\text { NECESIDADES } \\
\left(\begin{array}{l}1 \\
1\end{array} \frac{1}{3} 11\right)\end{array}$ & & & \\
\hline & & & & & & \multirow{2}{*}{$\begin{array}{c}\text { RECURSOS } \\
\text { DIVERSIFICA- } \\
\text { DOS } \\
\left(\begin{array}{lllll}1 & 1 & 1 & 1 & 1\end{array}\right)\end{array}$} & \multirow[t]{2}{*}{ 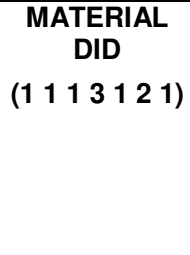 } & $\begin{array}{l}\text { ESPECIFICO } \\
\left(\begin{array}{lll}1 & 1 & 131211\end{array}\right)\end{array}$ & \\
\hline & & & & & & & & $\begin{array}{c}\text { TECNOLOGÍA } \\
\text { (1 11 31212) }\end{array}$ & 20 \\
\hline
\end{tabular}




\section{[ANEXO VII-2]}

[Documento: Ley General de las Personas con Discapacidad] 


\begin{tabular}{|c|c|c|c|c|c|c|c|c|c|}
\hline DOCUMENTO & & & & & & & & & UNIDADES \\
\hline \multirow{10}{*}{$\begin{array}{l}\text { LEY GRAL. } \\
\text { PARA LAS } \\
\text { PERSONAS } \\
\text { CON DISC. }\end{array}$} & \multirow{10}{*}{$\begin{array}{l}\text { EDUC. } \\
\text { ESP. } \\
1\end{array}$} & \multirow{10}{*}{$\begin{array}{c}\text { MARCO } \\
\text { LEGAL } \\
(11)\end{array}$} & \multirow{10}{*}{$\begin{array}{l}\text { FUNDA- } \\
\text { MENTOS } \\
\left(\begin{array}{lll}1 & 1 & 1\end{array}\right)\end{array}$} & \multirow{10}{*}{$\begin{array}{l}\text { INTEGRACIÓN } \\
\left(\begin{array}{llll}1 & 1 & 1 & 1\end{array}\right)\end{array}$} & \multirow[t]{2}{*}{$\begin{array}{c}\text { RELEVANCIA } \\
\left(\begin{array}{llll}1 & 1 & 1 & 1\end{array}\right)\end{array}$} & $\begin{array}{c}\text { APRENDIZAJE } \\
\left(\begin{array}{lllll}1 & 1 & 1 & 1 & 1\end{array}\right)\end{array}$ & & & \\
\hline & & & & & & $\begin{array}{c}\text { DESARROLLO } \\
(111112) \\
\end{array}$ & & & $6,9,55,106$ \\
\hline & & & & & \multirow[t]{4}{*}{$\begin{array}{l}\text { EFICACIA } \\
\left(\begin{array}{llll}1 & 1 & 1 & 1\end{array}\right)\end{array}$} & 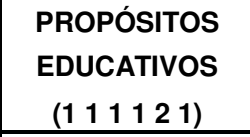 & & & \\
\hline & & & & & & DESARROLLO & & & 98,127 \\
\hline & & & & & & & & & \\
\hline & & & & & & $\left(\begin{array}{llll}1 & 11 & 1 & 12\end{array}\right)$ & & & \\
\hline & & & & & \multirow[t]{2}{*}{$\begin{array}{l}\text { EQUIDAD } \\
\left(\begin{array}{lllll}1 & 1 & 1 & 1 & 3\end{array}\right)\end{array}$} & \multirow{2}{*}{$\begin{array}{c}\text { ATENCIÓN } \\
\text { DIFERENCIADA } \\
\left(\begin{array}{llllll}1 & 1 & 1 & 1 & 3 & 1\end{array}\right)\end{array}$} & 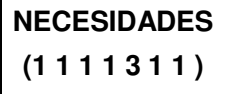 & & \\
\hline & & & & & & & $\begin{array}{l}\text { CAPACIDADES } \\
\left(\begin{array}{l}1111312 \\
\text { (1) }\end{array}\right.\end{array}$ & & $6,13,55,106$ \\
\hline & & & & & \multirow[t]{2}{*}{$\begin{array}{l}\text { EFICIENCIA } \\
\left(\begin{array}{llll}1 & 11 & 14\end{array}\right)\end{array}$} & \multirow[t]{2}{*}{ 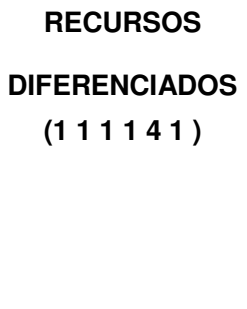 } & \multirow[t]{2}{*}{$\begin{array}{l}\text { MATERIAL DID } \\
\qquad \begin{array}{l}(1111411)\end{array}\end{array}$} & 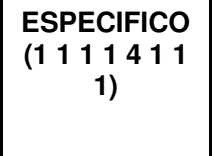 & \\
\hline & & & & & & & & \begin{tabular}{|c|} 
TECNOLOGÍA \\
$\left(\begin{array}{l}1111411 \\
2\end{array}\right)$
\end{tabular} & $4,68,69,77,86,109,113$ \\
\hline
\end{tabular}




\begin{tabular}{|c|c|c|c|c|c|c|c|c|c|}
\hline DOCUMENTO & & & & & & & & & UNIDADES DE REGISTRO \\
\hline \multirow{8}{*}{$\begin{array}{l}\text { LEY GRAL } \\
\text { PARA LAS } \\
\text { PERSONAS } \\
\text { CON DISC. }\end{array}$} & \multirow{8}{*}{$\begin{array}{c}\text { EDUC } \\
\text { ESP } \\
1\end{array}$} & \multirow{8}{*}{$\begin{array}{c}\text { MARCO } \\
\text { LEGAL } \\
(11)\end{array}$} & \multirow{8}{*}{$\begin{array}{l}\text { FUNDA- } \\
\text { MENTOS } \\
\left(\begin{array}{lll}111\end{array}\right)\end{array}$} & \multirow[t]{5}{*}{ 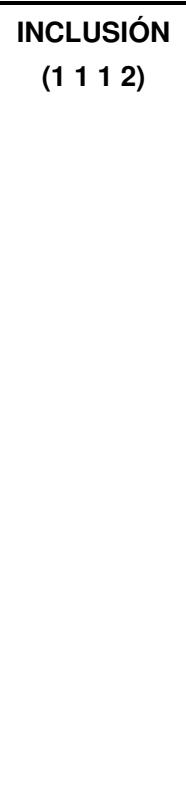 } & \multirow[t]{4}{*}{$\begin{array}{l}\text { EQUIDAD } \\
\left(\begin{array}{llll}1 & 1 & 1 & 2\end{array}\right)\end{array}$} & \multirow[t]{4}{*}{$\begin{array}{l}\text { DIVERSIF. } \\
\left(\begin{array}{llllll}1 & 1 & 1 & 2 & 1 & 1\end{array}\right)\end{array}$} & $\begin{array}{c}\text { MÉTODOS } \\
\text { (11112111) }\end{array}$ & & \\
\hline & & & & & & & 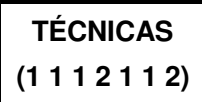 & & $8,44,54,77,82,83,105,115$ \\
\hline & & & & & & & \multirow[t]{2}{*}{$\begin{array}{c}\text { MATERIAL } \\
\text { DID } \\
\left(\begin{array}{llllll}1 & 1 & 12 & 1 & 13\end{array}\right)\end{array}$} & $\begin{array}{l}\text { ESPECIFICO } \\
\begin{array}{c}\left(\begin{array}{c}1 \\
12\end{array} 113\right. \\
1)\end{array}\end{array}$ & \\
\hline & & & & & & & & 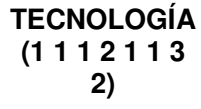 & $4,68,69,77,86,109,113$ \\
\hline & & & & & 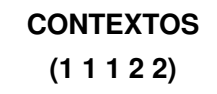 & & & & \\
\hline & & & & \multirow[t]{3}{*}{$\begin{array}{l}\text { CALIDAD } \\
\text { DE VIDA } \\
\left(\begin{array}{llll}1 & 1 & 3\end{array}\right)\end{array}$} & \multirow[t]{3}{*}{$\begin{array}{c}\text { EQUIPARA } \\
\text { RACIÓN DE } \\
\text { OPORTUNIDAD } \\
\left(\begin{array}{llllll}1 & 1 & 1 & 1\end{array}\right)\end{array}$} & $\begin{array}{c}\text { NECESIDADES } \\
\left(\begin{array}{l}1 \\
1\end{array} \frac{13}{1} 1\right)\end{array}$ & & & \\
\hline & & & & & & \multirow{2}{*}{\begin{tabular}{|c} 
RECURSOS \\
DIVERSIFICA- \\
DOS \\
$\left(\begin{array}{c}1113 \\
1\end{array}\right)$
\end{tabular}} & \multirow[t]{2}{*}{$\begin{array}{c}\text { MATERIAL } \\
\text { DID } \\
\left(\begin{array}{lllll}1 & 1 & 13 & 12 & 1\end{array}\right)\end{array}$} & $\begin{array}{l}\text { ESPECIFICO } \\
\left(\begin{array}{lll}1 & 1 & 131211\end{array}\right)\end{array}$ & \\
\hline & & & & & & & & $\begin{array}{l}\text { TECNOLOGÍA } \\
\text { (1 11 31212) }\end{array}$ & $4,68,69,77,86,109,113$ \\
\hline
\end{tabular}




\section{[ANEXO VII-3]}

[Documento: Ley Estatal de Educación] 


\begin{tabular}{|c|c|c|c|c|c|c|c|c|c|}
\hline DOCUMENTO & & & & & & & & & UNIDADES DE REGISTRO \\
\hline \multirow{8}{*}{$\begin{array}{c}\text { LEY } \\
\text { ESTATAL } \\
\text { EDUCACIÓN }\end{array}$} & \multirow{8}{*}{$\begin{array}{c}\text { EDUC. } \\
\text { ESP. } \\
1\end{array}$} & \multirow{8}{*}{$\begin{array}{c}\text { MARCO } \\
\text { LEGAL } \\
(11)\end{array}$} & \multirow{8}{*}{$\begin{array}{l}\text { FUNDA- } \\
\text { MENTOS } \\
\left(\begin{array}{lll}1 & 1 & 1\end{array}\right)\end{array}$} & \multirow{8}{*}{$\begin{array}{l}\text { INTEGRACIÓN } \\
\left(\begin{array}{l}1111\end{array}\right)\end{array}$} & \multirow[t]{2}{*}{$\begin{array}{l}\text { RELEVANCIA } \\
\left(\begin{array}{llll}1 & 111\end{array}\right)\end{array}$} & $\begin{array}{c}\text { APRENDIZAJE } \\
\left(\begin{array}{lllll}1 & 1 & 1 & 1 & 1\end{array}\right)\end{array}$ & & & 272 \\
\hline & & & & & & $\begin{array}{l}\text { DESARROLLO } \\
\left(\begin{array}{l}111112)\end{array}\right.\end{array}$ & & & $4,31,43,254,383$ \\
\hline & & & & & \multirow[t]{2}{*}{$\begin{array}{l}\text { EFICACIA } \\
\left(\begin{array}{llll}1 & 1 & 1 & 1\end{array}\right)\end{array}$} & $\begin{array}{l}\text { PROPÓSITOS } \\
\text { EDUCATIVOS } \\
(1111121) \\
\end{array}$ & & & \\
\hline & & & & & & $\begin{array}{l}\text { DESARROLLO } \\
\qquad \begin{array}{l}(111122 \\
\end{array}\end{array}$ & & & $4,31,688$ \\
\hline & & & & & \multirow[t]{2}{*}{$\begin{array}{l}\text { EQUIDAD } \\
\left(\begin{array}{llll}1 & 1 & 1 & 1\end{array}\right)\end{array}$} & \multirow[t]{2}{*}{$\begin{array}{c}\text { ATENCIÓN } \\
\text { DIFERENCIADA } \\
\left(\begin{array}{lllll}1 & 1 & 1 & 1 & 1\end{array}\right)\end{array}$} & \begin{tabular}{|c|} 
NECESIDADES \\
$\left(\begin{array}{lllllll}1 & 1 & 1 & 1 & 1 & 1\end{array}\right)$
\end{tabular} & & 382.387 \\
\hline & & & & & & & 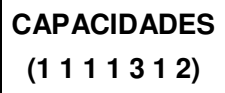 & & $31,32,272,392,688$ \\
\hline & & & & & \multirow[t]{2}{*}{$\begin{array}{c}\text { EFICIENCIA } \\
\left(\begin{array}{llll}1 & 1 & 1 & 14\end{array}\right)\end{array}$} & \multirow{2}{*}{$\begin{array}{c}\text { RECURSOS } \\
\text { DIFERENCIADOS } \\
\left(\begin{array}{llll}1 & 1 & 1 & 14\end{array}\right)\end{array}$} & \multirow[t]{2}{*}{ 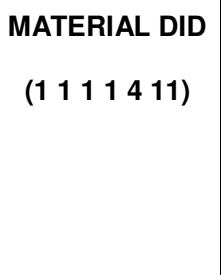 } & 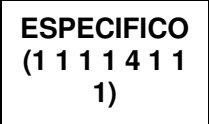 & \\
\hline & & & & & & & & \begin{tabular}{|c|} 
TECNOLOGÍA \\
$\begin{array}{c}(11114411 \\
2)\end{array}$
\end{tabular} & 37 \\
\hline
\end{tabular}




\begin{tabular}{|c|c|c|c|c|c|c|c|c|c|}
\hline DOCUMENTO & & & & & & & & & UNIDADES DE REGISTRO \\
\hline \multirow{8}{*}{$\begin{array}{c}\text { LEY } \\
\text { ESTATAL } \\
\text { EDUCACIÓN }\end{array}$} & \multirow{8}{*}{$\begin{array}{c}\text { EDUC } \\
\text { ESP } \\
1\end{array}$} & \multirow{8}{*}{$\begin{array}{c}\text { MARCO } \\
\text { LEGAL } \\
(111)\end{array}$} & \multirow{8}{*}{$\begin{array}{l}\text { FUNDA- } \\
\text { MENTOS } \\
(111)\end{array}$} & \multirow[t]{5}{*}{$\begin{array}{l}\text { INCLUSIÓN } \\
\left(\begin{array}{lll}1 & 1 & 1\end{array}\right)\end{array}$} & \multirow[t]{4}{*}{$\begin{array}{l}\text { EQUIDAD } \\
\left(\begin{array}{llll}1 & 1 & 1 & 2\end{array}\right)\end{array}$} & \multirow[t]{4}{*}{$\begin{array}{l}\text { DIVERSIF. } \\
\left(\begin{array}{lllll}1 & 1 & 1 & 2 & 1\end{array}\right)\end{array}$} & 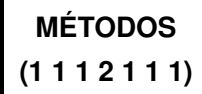 & & \\
\hline & & & & & & & $\begin{array}{c}\text { TÉCNICAS } \\
\left(\begin{array}{llllll}1 & 1 & 1 & 2 & 1 & 1\end{array}\right)\end{array}$ & & \\
\hline & & & & & & & \begin{tabular}{|c|} 
MATERIAL \\
DID \\
$\left(\begin{array}{llllll}1 & 1 & 21 & 1\end{array}\right)$
\end{tabular} & \begin{tabular}{|c|} 
ESPECIFICO \\
$\left(\begin{array}{c}1112113 \\
1)\end{array}\right.$
\end{tabular} & \\
\hline & & & & & & & & 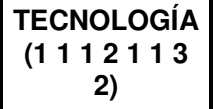 & 37 \\
\hline & & & & & $\begin{array}{c}\text { CONTEXTOS } \\
\left(\begin{array}{llll}11122 \\
\end{array}\right.\end{array}$ & & & & \\
\hline & & & & \multirow[t]{3}{*}{$\begin{array}{l}\text { CALIDAD } \\
\text { DE VIDA } \\
\left(\begin{array}{lll}1 & 113\end{array}\right)\end{array}$} & \multirow[t]{3}{*}{ 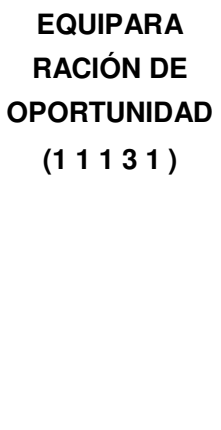 } & 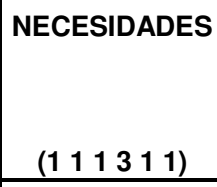 & & & \\
\hline & & & & & & \multirow{2}{*}{$\begin{array}{c}\text { RECURSOS } \\
\text { DIVERSIFICA- } \\
\text { DOS } \\
\left(\begin{array}{llllll}1 & 1 & 1 & 1 & 1\end{array}\right)\end{array}$} & \multirow[t]{2}{*}{\begin{tabular}{|c|} 
MATERIAL \\
DID \\
$\left(\begin{array}{llllll}1 & 1 & 13 & 1 & 1 & 1\end{array}\right)$
\end{tabular}} & \begin{tabular}{|l|} 
ESPECIFICO \\
$(11131211)$
\end{tabular} & \\
\hline & & & & & & & & $\begin{array}{c}\text { TECNOLOGÍA } \\
\left(\begin{array}{l}1 \\
111\end{array} 1212\right)\end{array}$ & 37 \\
\hline
\end{tabular}


[ANEXO VII-4]

[Documento: Ley General de Educación] 


\begin{tabular}{|c|c|c|c|c|c|c|c|c|c|}
\hline DOCUMENTO & & & & & & & & & UNIDADES DE REGISTRO \\
\hline \multirow{7}{*}{$\begin{array}{l}\text { LEY GRAL. } \\
\text { EDUCACIÓN }\end{array}$} & \multirow{7}{*}{$\begin{array}{c}\text { EDUC. } \\
\text { ESP. } \\
1\end{array}$} & \multirow{7}{*}{$\begin{array}{l}\text { MARCO } \\
\text { LEGAL } \\
(11)\end{array}$} & \multirow{7}{*}{$\begin{array}{l}\text { FUNDA- } \\
\text { MENTOS } \\
(111)\end{array}$} & \multirow{7}{*}{$\begin{array}{c}\text { INTEGRACIÓN } \\
(1111)\end{array}$} & \multirow[t]{2}{*}{$\begin{array}{c}\text { RELEVANCIA } \\
\text { (11111) }\end{array}$} & $\begin{array}{c}\text { APRENDIZAJE } \\
(111111) \\
\end{array}$ & & & $9,103,123,133,134$ \\
\hline & & & & & & $\begin{array}{l}\text { DESARROLLO } \\
(111112)\end{array}$ & & & $2,8,9,17$ \\
\hline & & & & & \multirow[t]{2}{*}{$\begin{array}{l}\text { EFICACIA } \\
\left(\begin{array}{ll}11112\end{array}\right)\end{array}$} & $\begin{array}{l}\text { PROPÓSITOS } \\
\text { EDUCATIVOS } \\
\text { (1111121) }\end{array}$ & & & $113,132,133,135,139$ \\
\hline & & & & & & $\begin{array}{c}\text { DESARROLLO } \\
(1111122)\end{array}$ & & & \\
\hline & & & & & $\begin{array}{l}\text { EQUIDAD } \\
\left(\begin{array}{lllll}1 & 1 & 1 & 1 & 3\end{array}\right)\end{array}$ & $\begin{array}{c}\text { ATENCIÓN } \\
\text { DIFERENCIADA } \\
\left(\begin{array}{lllll}1 & 1 & 1 & 1 & 1\end{array}\right)\end{array}$ & 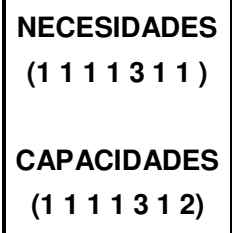 & & 121,123 \\
\hline & & & & & \multirow[t]{2}{*}{$\begin{array}{l}\text { EFICIENCIA } \\
\left.\begin{array}{lllll}(1 & 1 & 1 & 1 & 4\end{array}\right)\end{array}$} & \multirow[t]{2}{*}{$\begin{array}{c}\text { RECURSOS } \\
\text { DIFERENCIADOS } \\
\left(\begin{array}{lllll}1 & 1 & 1 & 1 & 4\end{array}\right)\end{array}$} & \multirow[t]{2}{*}{\begin{tabular}{|c|} 
MATERIAL DID \\
$(11114$ 11)
\end{tabular}} & \begin{tabular}{|c|} 
ESPECIFICO \\
$\left(\begin{array}{c}1 \\
1\end{array} 1411\right.$ \\
$1)$
\end{tabular} & 123 \\
\hline & & & & & & & & 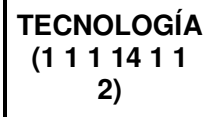 & 14,25 \\
\hline
\end{tabular}




\begin{tabular}{|c|c|c|c|c|c|c|c|c|c|}
\hline DOCUMENTO & & & & & & & & & UNIDADES DE REGISTRO \\
\hline \multirow{8}{*}{$\begin{array}{l}\text { LEY GRAL. } \\
\text { EDUCACIÓN }\end{array}$} & \multirow{8}{*}{$\begin{array}{c}\text { EDUC } \\
\text { ESP } \\
1\end{array}$} & \multirow{8}{*}{$\begin{array}{c}\text { MARCO } \\
\text { LEGAL } \\
(11)\end{array}$} & \multirow{8}{*}{$\begin{array}{l}\text { FUNDA- } \\
\text { MENTOS } \\
(111)\end{array}$} & \multirow[t]{5}{*}{$\begin{array}{c}\text { INCLUSIÓN } \\
\left(\begin{array}{llll}1 & 1 & 1\end{array}\right)\end{array}$} & \multirow[t]{4}{*}{ 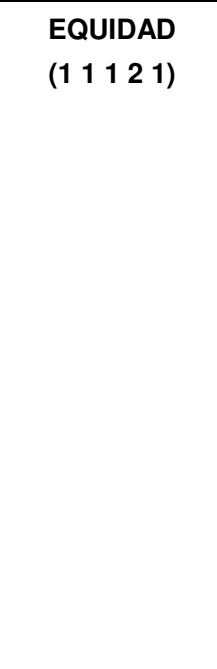 } & \multirow[t]{4}{*}{$\begin{array}{l}\text { DIVERSIF. } \\
\left(\begin{array}{llllll}1 & 1 & 1 & 2 & 1 & 1\end{array}\right)\end{array}$} & 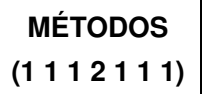 & & 123,135 \\
\hline & & & & & & & $\begin{array}{c}\text { TÉCNICAS } \\
\left(\begin{array}{lllllll}1 & 1 & 1 & 1 & 1 & 1\end{array}\right)\end{array}$ & & 123 \\
\hline & & & & & & & $\begin{array}{c}\text { MATERIAL } \\
\text { DID } \\
\left(\begin{array}{lllll}1 & 112 & 113\end{array}\right)\end{array}$ & $\begin{array}{c}\text { ESPECIFICO } \\
\left(\begin{array}{c}1112113 \\
1)\end{array}\right.\end{array}$ & 123 \\
\hline & & & & & & & & 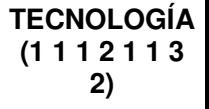 & 14,25 \\
\hline & & & & & $\begin{array}{c}\text { CONTEXTOS } \\
\left(\begin{array}{l}11122 \\
1\end{array}\right)\end{array}$ & & & & \\
\hline & & & & \multirow[t]{3}{*}{$\begin{array}{l}\text { CALIDAD } \\
\text { DE VIDA } \\
\left(\begin{array}{llll}1 & 1 & 1\end{array}\right)\end{array}$} & \multirow[t]{3}{*}{$\begin{array}{c}\text { EQUIPARA } \\
\text { RACIÓN DE } \\
\text { OPORTUNIDAD } \\
\left(\begin{array}{lllll}1 & 1 & 1 & 1 & 1\end{array}\right)\end{array}$} & $\begin{array}{l}\text { NECESIDADES } \\
\left(\begin{array}{lllll}1 & 1 & 1 & 1 & 1\end{array}\right)\end{array}$ & & & $14,121,123$ \\
\hline & & & & & & \multirow{2}{*}{ 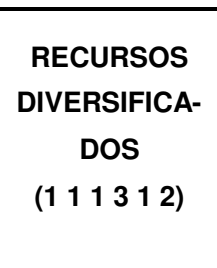 } & \multirow[t]{2}{*}{$\begin{array}{c}\text { MATERIAL } \\
\text { DID } \\
\left(\begin{array}{llllll}1 & 1 & 13 & 1 & 2 & 1\end{array}\right)\end{array}$} & $\begin{array}{l}\text { ESPECIFICO } \\
\left(\begin{array}{l}11131211)\end{array}\right.\end{array}$ & 123 \\
\hline & & & & & & & & $\begin{array}{l}\text { TECNOLOGÍA } \\
\text { (1 11 31212) }\end{array}$ & 14,25 \\
\hline
\end{tabular}


[ANEXO VII -5]

[Documento: Programa Estatal de Fortalecimiento de la Educación Especial y de la Integración Educativa 2005-2010] 


\begin{tabular}{|c|c|c|c|c|c|c|c|c|c|}
\hline DOCUMENTO & & & & & & & & & UNIDAD DE REGISTRO \\
\hline \multirow{8}{*}{$\begin{array}{l}\text { PROGRAMA } \\
\text { ESTATAL } \\
\text { DE FORTAL. } \\
\text { EDUC. ESP. } \\
\text { Y LA INTEG. } \\
\text { EDUCATIVA }\end{array}$} & \multirow{8}{*}{$\begin{array}{c}\text { EDUC. } \\
\text { ESP. } \\
1\end{array}$} & \multirow{8}{*}{$\begin{array}{l}\text { PROG } \\
\left(\begin{array}{ll}1 & 2\end{array}\right)\end{array}$} & \multirow{8}{*}{$\begin{array}{l}\text { FUNDAMEN- } \\
\text { TOS. } \\
\left(\begin{array}{lll}1 & 2 & 1\end{array}\right)\end{array}$} & \multirow{8}{*}{$\begin{array}{c}\text { INTEGRACIÓN } \\
\left(\begin{array}{llll}1 & 2 & 1 & 1\end{array}\right)\end{array}$} & \multirow[t]{2}{*}{ 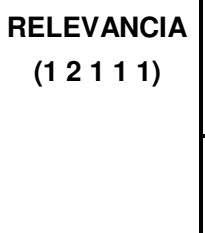 } & $\begin{array}{l}\text { APRENDIZAJE } \\
\left(\begin{array}{lllll}1 & 2 & 1 & 1 & 1\end{array}\right)\end{array}$ & & & $14,44,67,69,76,77,96,109,176$ \\
\hline & & & & & & $\begin{array}{c}\text { DESARROLLO } \\
\left(\begin{array}{lllll}1 & 2 & 1 & 1 & 1\end{array}\right)\end{array}$ & & & $32,37,38,44,65,67,69,187$ \\
\hline & & & & & \multirow[t]{2}{*}{$\begin{array}{l}\text { EFICACIA } \\
\left(\begin{array}{lllll}1 & 2 & 1 & 1 & 2\end{array}\right)\end{array}$} & 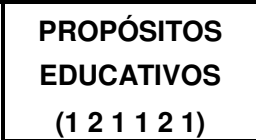 & & & 65,7 \\
\hline & & & & & & 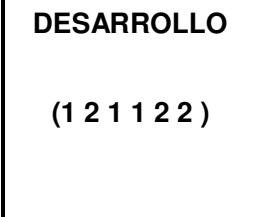 & & & $34,44,70$ \\
\hline & & & & & \multirow[t]{2}{*}{$\begin{array}{l}\text { EQUIDAD } \\
\left(\begin{array}{lllll}1 & 2 & 1 & 1 & 3\end{array}\right)\end{array}$} & \multirow[t]{2}{*}{$\begin{array}{l}\text { ATENCIÓN } \\
\text { DIFERENCIADA } \\
\left(\begin{array}{llllll}1 & 2 & 1 & 1 & 1 & 1\end{array}\right)\end{array}$} & 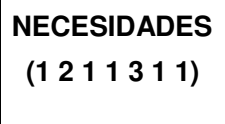 & & $\begin{array}{l}14,27,64,71,76,77,93,96,99,124, \\
146,147,153,189\end{array}$ \\
\hline & & & & & & & $\begin{array}{c}\text { CAPACIDADES } \\
\left(\begin{array}{lllll}1 & 2 & 1 & 13 & 12\end{array}\right)\end{array}$ & & 65,71 \\
\hline & & & & & \multirow[t]{2}{*}{$\begin{array}{l}\text { EFICIENCIA } \\
\left(\begin{array}{llll}1 & 2 & 1 & 14\end{array}\right)\end{array}$} & \multirow[t]{2}{*}{\begin{tabular}{|c|} 
RECURSOS \\
DIFERENCIADOS \\
$\left(\begin{array}{lllll}1 & 2 & 1 & 1 & 4\end{array}\right)$
\end{tabular}} & \multirow[t]{2}{*}{$\begin{array}{c}\text { MATERIAL } \\
\text { DIDACTICO } \\
\left(\begin{array}{llllll}1 & 2 & 1 & 1 & 4 & 1\end{array}\right)\end{array}$} & \begin{tabular}{|c} 
ESPECIFICO \\
$\begin{array}{c}121 \\
1\end{array} 1411$ \\
$1)$
\end{tabular} & $\begin{array}{l}14,118,124,176,178,179,180, \\
181,182,183,184\end{array}$ \\
\hline & & & & & & & & $\begin{array}{c}\text { TECNOLOGÍA } \\
\left(\begin{array}{c}1211411 \\
2\end{array}\right)\end{array}$ & 190 \\
\hline
\end{tabular}




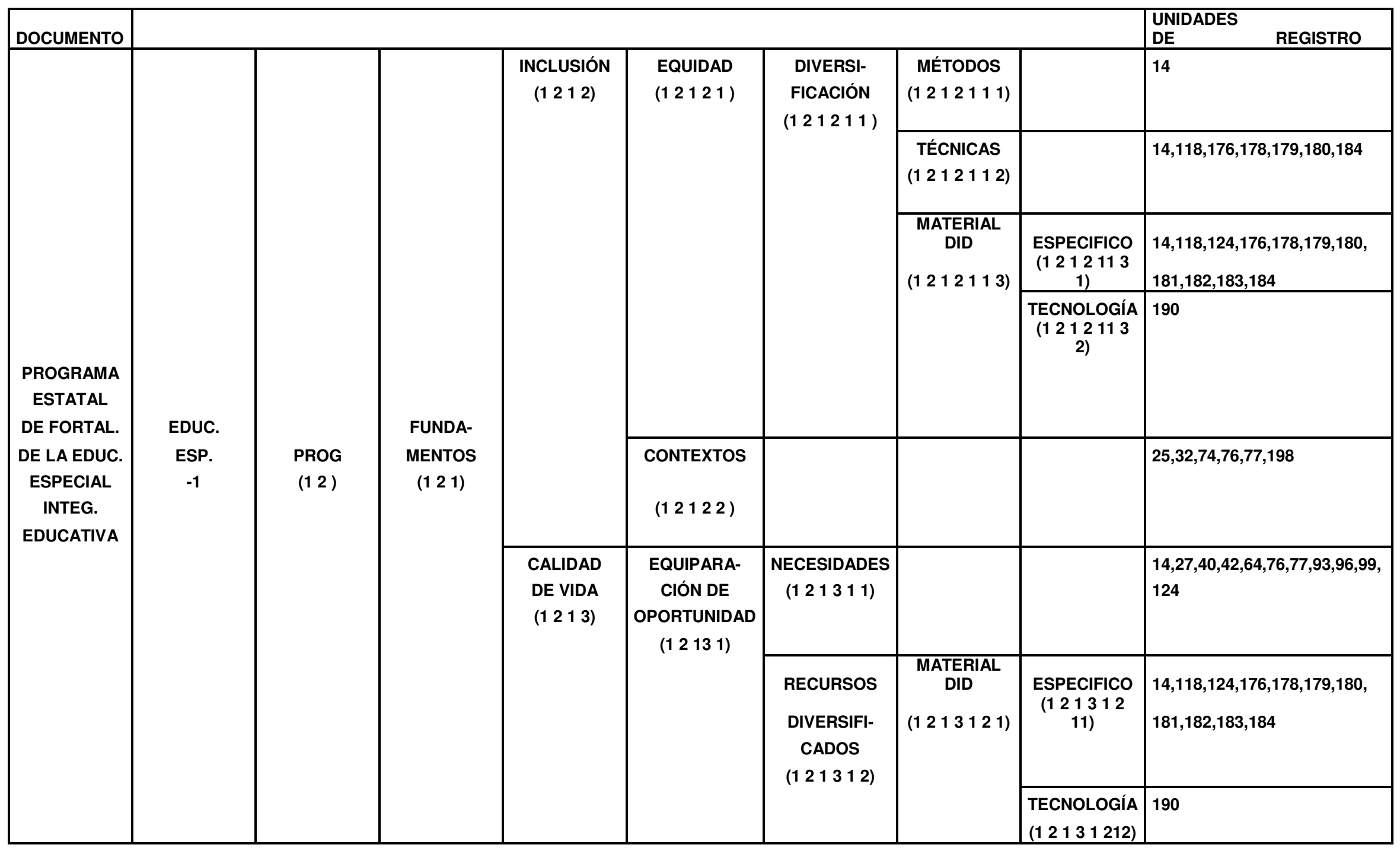


[ANEXO VII -6]

[Documento: Programa Estatal de Educación 2005-2010] 


\begin{tabular}{|c|c|c|c|c|c|c|c|c|c|}
\hline DOCUMENTO & & & & & & & & & \begin{tabular}{|ll} 
UNIDAD & DE \\
\end{tabular} \\
\hline \multirow{8}{*}{$\begin{array}{l}\text { PROGRAMA } \\
\text { ESTATAL DE } \\
\text { EDUCACIÓN }\end{array}$} & \multirow{8}{*}{$\begin{array}{c}\text { EDUC. } \\
\text { ESP. } \\
1\end{array}$} & \multirow{8}{*}{$\begin{array}{l}\text { PROG } \\
\left(\begin{array}{ll}1 & 2\end{array}\right)\end{array}$} & \multirow{8}{*}{ 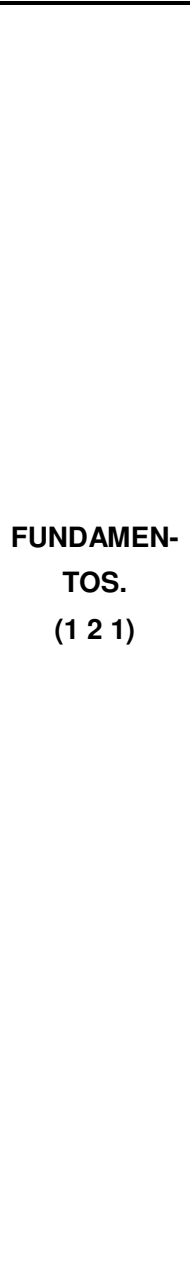 } & \multirow{8}{*}{$\begin{array}{c}\text { INTEGRACIÓN } \\
\left(\begin{array}{llll}1 & 2 & 1 & 1\end{array}\right)\end{array}$} & \multirow[t]{2}{*}{$\begin{array}{l}\text { RELEVANCIA } \\
\left(\begin{array}{lllll}1 & 2 & 1 & 1 & 1\end{array}\right)\end{array}$} & $\begin{array}{l}\text { APRENDIZAJE } \\
\left(\begin{array}{l}1 \\
1\end{array} 21111\right)\end{array}$ & & & $\begin{array}{l}134,262,288,307,309,395,396 \\
407,408\end{array}$ \\
\hline & & & & & & 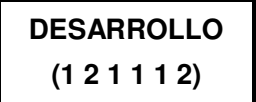 & & & $35,288,396$ \\
\hline & & & & & \multirow[t]{2}{*}{$\begin{array}{l}\text { EFICACIA } \\
\left(\begin{array}{lllll}1 & 2 & 1 & 1 & 1\end{array}\right)\end{array}$} & $\begin{array}{l}\text { PROPÓSITOS } \\
\text { EDUCATIVOS } \\
\left(\begin{array}{lllll}1 & 2 & 1 & 1 & 2\end{array}\right) \\
\end{array}$ & & & \\
\hline & & & & & & $\begin{array}{l}\text { DESARROLLO } \\
\left(\begin{array}{l}121122 \\
\end{array}\right.\end{array}$ & & & 291 \\
\hline & & & & & \multirow[t]{2}{*}{$\begin{array}{l}\text { EQUIDAD } \\
\left(\begin{array}{lllll}1 & 2 & 1 & 1 & 3\end{array}\right)\end{array}$} & \multirow[t]{2}{*}{$\begin{array}{c}\text { ATENCIÓN } \\
\text { DIFERENCIADA } \\
\left(\begin{array}{lllllll}1 & 2 & 1 & 1 & 1 & 1 & 1\end{array}\right)\end{array}$} & $\begin{array}{l}\text { NECESIDADES } \\
\left(\begin{array}{llllll}1 & 2 & 1 & 1 & 3 & 1\end{array}\right)\end{array}$ & & \\
\hline & & & & & & & 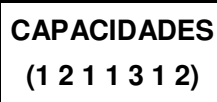 & & 262,347 \\
\hline & & & & & \multirow[t]{2}{*}{ 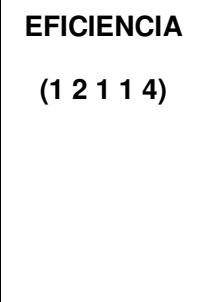 } & \multirow[t]{2}{*}{ 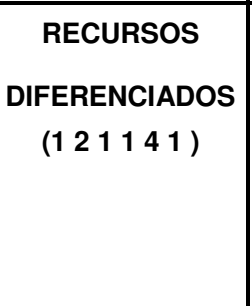 } & \multirow[t]{2}{*}{$\begin{array}{l}\text { MATERIAL } \\
\text { DIDACTICO } \\
\left(\begin{array}{lllll}1 & 2 & 1 & 14 & 1\end{array}\right)\end{array}$} & 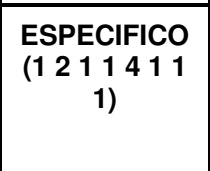 & \\
\hline & & & & & & & & \begin{tabular}{|l} 
TECNOLOGÍA \\
$\left(\begin{array}{c}12114 \\
2\end{array}\right)$
\end{tabular} & $\begin{array}{l}\text { 29,33,271,292,410,423,447, } \\
497,498,499\end{array}$ \\
\hline
\end{tabular}




\begin{tabular}{|c|c|c|c|c|c|c|c|c|c|}
\hline DOCUMENTO & & & & & & & & & $\begin{array}{l}\text { UNIDADES } \\
\text { DE }\end{array}$ \\
\hline \multirow{8}{*}{$\begin{array}{l}\text { PROGRAMA } \\
\text { ESTATAL } \\
\text { EDUCACIÓN }\end{array}$} & \multirow{8}{*}{$\begin{array}{c}\text { EDUC. } \\
\text { ESP. } \\
-1\end{array}$} & \multirow{8}{*}{$\begin{array}{l}\text { PROG } \\
\left(\begin{array}{l}1 \\
1\end{array}\right)\end{array}$} & \multirow{8}{*}{$\begin{array}{l}\text { FUNDA- } \\
\text { MENTOS } \\
\left(\begin{array}{lll}1 & 2 & 1\end{array}\right)\end{array}$} & \multirow[t]{5}{*}{$\begin{array}{l}\text { INCLUSIÓN } \\
\left(\begin{array}{llll}1 & 2 & 1 & 2\end{array}\right)\end{array}$} & \multirow[t]{4}{*}{$\begin{array}{l}\text { EQUIDAD } \\
\left(\begin{array}{lllll}1 & 2 & 1 & 2 & 1\end{array}\right)\end{array}$} & \multirow{4}{*}{$\begin{array}{c}\text { DIVERSI- } \\
\text { FICACIÓN } \\
\left(\begin{array}{llllll}1 & 2 & 1 & 2 & 1 & 1\end{array}\right)\end{array}$} & $\begin{array}{c}\text { MÉTODOS } \\
\left(\begin{array}{l}1212111)\end{array}\right.\end{array}$ & & \\
\hline & & & & & & & $\begin{array}{l}\text { TÉCNICAS } \\
\left(\begin{array}{lll}1 & 2121112\end{array}\right)\end{array}$ & & \\
\hline & & & & & & & 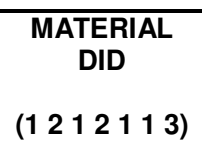 & 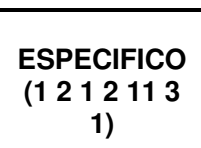 & \\
\hline & & & & & & & & 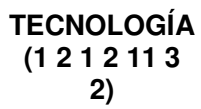 & $\begin{array}{l}29,33,271,292,410,423,447 \\
497,498,499\end{array}$ \\
\hline & & & & & $\begin{array}{l}\text { CONTEXTOS } \\
\left.\qquad \begin{array}{lllll}1 & 2 & 1 & 2 & 2\end{array}\right)\end{array}$ & & & & 288 \\
\hline & & & & \multirow[t]{3}{*}{$\begin{array}{l}\text { CALIDAD } \\
\text { DE VIDA } \\
\left(\begin{array}{llll}1 & 2 & 1 & 3\end{array}\right)\end{array}$} & \multirow[t]{3}{*}{ 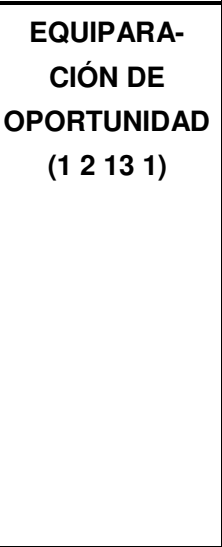 } & $\begin{array}{l}\text { NECESIDADES } \\
\left.\begin{array}{lllllll}1 & 2 & 1 & 3 & 1 & 1\end{array}\right)\end{array}$ & & & \\
\hline & & & & & & \multirow[t]{2}{*}{$\begin{array}{l}\text { RECURSOS } \\
\text { DIVERSIFI- } \\
\text { CADOS } \\
\left.\begin{array}{lllll}1 & 2 & 1 & 1 & 1\end{array}\right)\end{array}$} & \multirow[t]{2}{*}{ 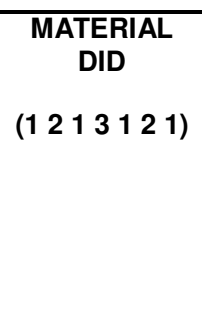 } & 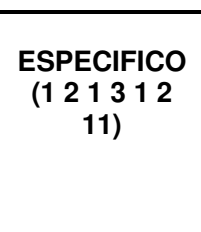 & \\
\hline & & & & & & & & $\begin{array}{l}\text { TECNOLOGÍA } \\
\left(\begin{array}{lll}12 & 13 & 1212\end{array}\right)\end{array}$ & $\begin{array}{l}29,33,271,292,410,423,447, \\
497,498,499\end{array}$ \\
\hline
\end{tabular}




\section{[ANEXO VII-7]}

[Documento: Programa Nacional de Educación 2001-2006] 


\begin{tabular}{|c|c|c|c|c|c|c|c|c|c|}
\hline DOCUMENTO & & & & & & & & & UNIDAD DE REGISTRO \\
\hline \multirow{8}{*}{$\begin{array}{c}\text { PROGRAMA } \\
\text { NACIONAL } \\
\text { DE } \\
\text { EDUCACIÓN }\end{array}$} & \multirow{8}{*}{$\begin{array}{l}\text { EDUC. } \\
\text { ESP. } \\
1\end{array}$} & \multirow{8}{*}{$\begin{array}{l}\text { PROG } \\
\left(\begin{array}{ll}1 & 2\end{array}\right)\end{array}$} & \multirow{8}{*}{$\begin{array}{l}\text { FUNDAMEN- } \\
\begin{array}{c}\text { TOS. } \\
\left(\begin{array}{lll}1 & 2 & 1\end{array}\right)\end{array}\end{array}$} & \multirow{8}{*}{$\begin{array}{c}\text { INTEGRACIÓN } \\
\left(\begin{array}{llll}1 & 2 & 1 & 1\end{array}\right)\end{array}$} & \multirow[t]{2}{*}{$\begin{array}{l}\text { RELEVANCIA } \\
\left.\qquad \begin{array}{lllll}1 & 2 & 1 & 1 & 1\end{array}\right)\end{array}$} & 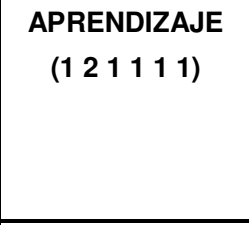 & & & $\begin{array}{l}27,29,32,339,345,349,371,461 \\
498,572,573,577,688,705,858, \\
897,900,911,976,1004,1046, \\
1063,1067,1079,1086,1091 \\
1107,1291 \\
\end{array}$ \\
\hline & & & & & & $\begin{array}{c}\text { DESARROLLO } \\
\left(\begin{array}{lllll}1 & 2 & 1 & 1 & 1\end{array}\right) \\
\end{array}$ & & & $\begin{array}{l}339,891,893,897,1067,1073 \\
1074,1075,1077 \\
\end{array}$ \\
\hline & & & & & \multirow[t]{2}{*}{$\begin{array}{l}\text { EFICACIA } \\
\left(\begin{array}{lllll}1 & 2 & 1 & 1 & 2\end{array}\right)\end{array}$} & 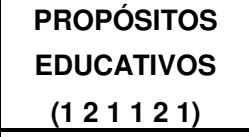 & & & $\begin{array}{l}403,680,705,900,901,1085 \\
1089\end{array}$ \\
\hline & & & & & & 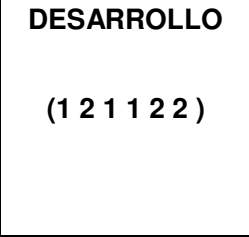 & & & $671,891,893,1067$ \\
\hline & & & & & \multirow[t]{2}{*}{$\begin{array}{l}\text { EQUIDAD } \\
\left(\begin{array}{lllll}1 & 2 & 1 & 1 & 3\end{array}\right)\end{array}$} & \multirow[t]{2}{*}{$\begin{array}{c}\text { ATENCIÓN } \\
\text { DIFERENCIADA } \\
\left(\begin{array}{llllll}1 & 2 & 1 & 1 & 3 & 1\end{array}\right)\end{array}$} & 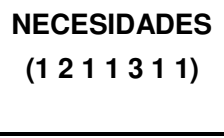 & & $\begin{array}{l}343,566,589,611,662,719,1085 \\
1157\end{array}$ \\
\hline & & & & & & & 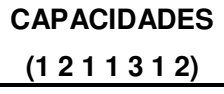 & & $271,348,350,671,1064,1070$ \\
\hline & & & & & \multirow[t]{2}{*}{$\begin{array}{l}\text { EFICIENCIA } \\
\left.\qquad \begin{array}{llll}1 & 2 & 1 & 1\end{array}\right)\end{array}$} & \multirow[t]{2}{*}{ 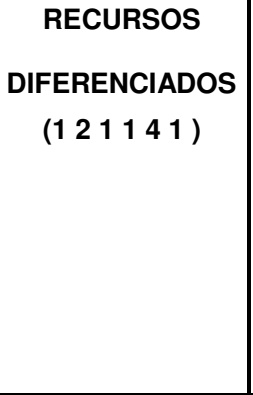 } & \multirow[t]{2}{*}{ 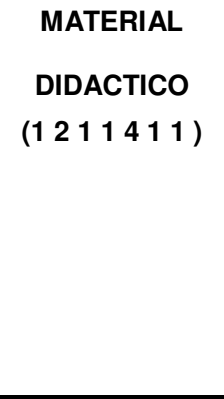 } & $\begin{array}{l}\text { ESPECIFICO } \\
\left(\begin{array}{c}12 \\
1\end{array} 11411\right. \\
1)\end{array}$ & \\
\hline & & & & & & & & $\begin{array}{c}\text { TECNOLOGÍA } \\
\begin{array}{c}1 \\
1\end{array} 211411 \\
2)\end{array}$ & $\begin{array}{l}204,348,362,364,475,476,498, \\
558,559,569,573,582,1013,1015 \\
1018,1019,1021,1022,1091 \\
1156,1356,1358,1360,1361 \\
1362,1371,1374,1392,1394\end{array}$ \\
\hline
\end{tabular}




\begin{tabular}{|c|c|c|c|c|c|c|c|c|c|}
\hline DOCUMENTO & & & & & & & & & \begin{tabular}{|l} 
UNIDADES \\
DE \\
\end{tabular} \\
\hline \multirow{8}{*}{$\begin{array}{l}\text { PROGRAMA } \\
\text { NACIONAL } \\
\text { EDUCACIÓN }\end{array}$} & \multirow{8}{*}{$\begin{array}{c}\text { EDUC. } \\
\text { ESP. } \\
-1\end{array}$} & \multirow{8}{*}{$\begin{array}{c}\text { PROG } \\
\left(\begin{array}{ll}1 & 2\end{array}\right)\end{array}$} & \multirow{8}{*}{$\begin{array}{c}\text { FUNDA- } \\
\text { MENTOS } \\
\left(\begin{array}{lll}1 & 2 & 1\end{array}\right)\end{array}$} & \multirow[t]{5}{*}{$\begin{array}{l}\text { INCLUSIÓN } \\
\left.\quad \begin{array}{lllll}1 & 2 & 1 & 2\end{array}\right)\end{array}$} & \multirow[t]{4}{*}{ 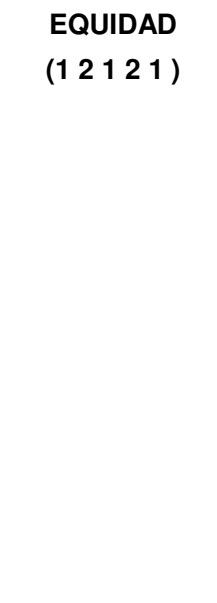 } & \multirow{4}{*}{$\begin{array}{c}\text { DIVERSI- } \\
\text { FICACIÓN } \\
\left(\begin{array}{llllll}1 & 2 & 1 & 2 & 1 & 1\end{array}\right)\end{array}$} & $\begin{array}{l}\text { MÉTODOS } \\
\text { (1 2 } 12111 \text { ) }\end{array}$ & & 1004 \\
\hline & & & & & & & $\begin{array}{c}\text { TÉCNICAS } \\
\left(\begin{array}{llll}1 & 21 & 211 & 12\end{array}\right)\end{array}$ & & \\
\hline & & & & & & & \multirow[t]{2}{*}{ 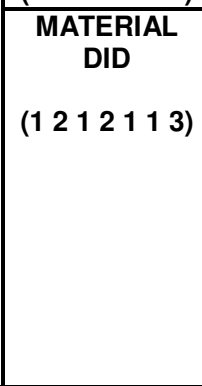 } & 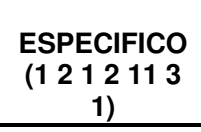 & \\
\hline & & & & & & & & 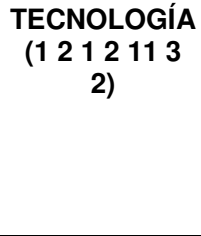 & \begin{tabular}{|l|}
$204,348,362,264,475,476,498$. \\
$558,559,569,573,582,1013,1015$ \\
$1018,1019,1021,1091,1156,1356$ \\
$1360,1361,1362,1371,1374,1392$ \\
1394
\end{tabular} \\
\hline & & & & & $\begin{array}{c}\text { CONTEXTOS } \\
\left.\begin{array}{llllll}1 & 2 & 1 & 2 & 2\end{array}\right)\end{array}$ & & & & 905 \\
\hline & & & & \multirow[t]{3}{*}{$\begin{array}{l}\text { CALIDAD } \\
\text { DE VIDA } \\
\left(\begin{array}{lll}1 & 2 & 13\end{array}\right)\end{array}$} & \multirow[t]{3}{*}{ 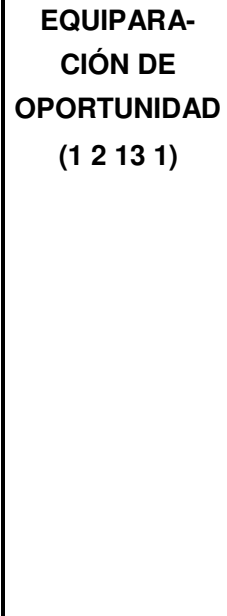 } & $\begin{array}{c}\text { NECESIDADES } \\
\left(\begin{array}{lllll}1 & 2 & 1 & 1 & 1\end{array}\right)\end{array}$ & & & $343,566,589,611,662,719,1085$ \\
\hline & & & & & & \multirow[t]{2}{*}{$\begin{array}{l}\text { RECURSOS } \\
\text { DIVERSIFI- } \\
\text { CADOS } \\
\left(\begin{array}{llllll}1 & 2 & 1 & 3 & 1 & 2\end{array}\right)\end{array}$} & \multirow[t]{2}{*}{ 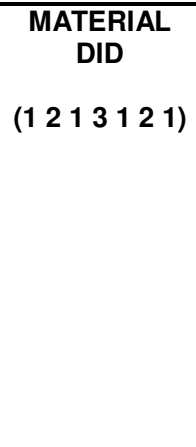 } & 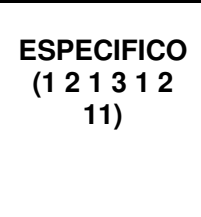 & \\
\hline & & & & & & & & $\begin{array}{l}\text { TECNOLOGÍA } \\
\left.\begin{array}{llllllllll} & 1 & 1 & 1 & 1 & 1 & 212\end{array}\right)\end{array}$ & \begin{tabular}{|l|}
$204,348,362,264,475,476,498$. \\
$558,559,569,573,582,1013,1015$ \\
$1018,1019,1021,1091,1156,1356$ \\
$1360,1361,1362,1371,1374,1392$ \\
1394
\end{tabular} \\
\hline
\end{tabular}


[ANEXO G-8]

[Documento: Programa Nacional de Fortalecimiento de la Educación Especial y de la Integración Educativa] 


\begin{tabular}{|c|c|c|c|c|c|c|c|c|c|}
\hline DOCUMENTO & & & & & & & & & UNIDAD DE REGISTRO \\
\hline \multirow{8}{*}{$\begin{array}{c}\text { PROGRAMA } \\
\text { NACIONAL } \\
\text { DE } \\
\text { FORTAL. DE } \\
\text { LA EDUC. } \\
\text { ESP. } \\
\text { Y INTEG. } \\
\text { EDUCATIVA }\end{array}$} & \multirow{8}{*}{$\begin{array}{c}\text { EDUC. } \\
\text { ESP. } \\
1\end{array}$} & \multirow{8}{*}{$\begin{array}{l}\text { PROG } \\
\left(\begin{array}{ll}1 & 2\end{array}\right)\end{array}$} & \multirow{8}{*}{$\begin{array}{l}\text { FUNDAMEN- } \\
\text { TOS. } \\
\left(\begin{array}{lll}1 & 2 & 1\end{array}\right)\end{array}$} & \multirow{8}{*}{ 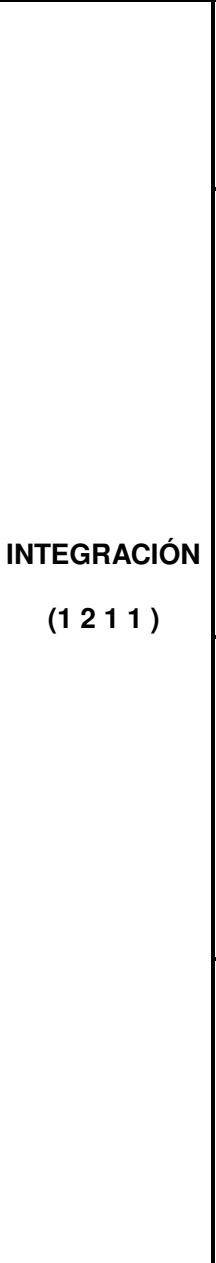 } & \multirow[t]{2}{*}{ 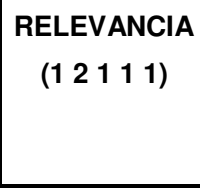 } & $\begin{array}{c}\text { APRENDIZAJE } \\
\left(\begin{array}{lllll}1 & 2 & 1 & 1 & 1\end{array}\right) \\
\end{array}$ & & & $\begin{array}{l}10,15,20,24,25,46,59,114,147 \\
160,180,213,217,224,247 \\
\end{array}$ \\
\hline & & & & & & $\begin{array}{c}\text { DESARROLLO } \\
\left(\begin{array}{l}121112) \\
\end{array}\right.\end{array}$ & & & $25,213,252$ \\
\hline & & & & & \multirow[t]{2}{*}{ 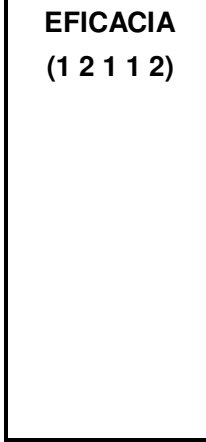 } & 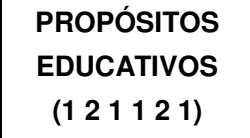 & & & $\begin{array}{l}23,24,117,162,185,196,196,198 \\
230,245\end{array}$ \\
\hline & & & & & & $\begin{array}{l}\text { DESARROLLO } \\
\qquad\left(\begin{array}{lllll}1 & 2 & 1 & 1 & 2\end{array}\right)\end{array}$ & & & 11 \\
\hline & & & & & \multirow[t]{2}{*}{$\begin{array}{l}\text { EQUIDAD } \\
\left(\begin{array}{lllll}1 & 2 & 1 & 1 & 3\end{array}\right)\end{array}$} & \multirow[t]{2}{*}{ 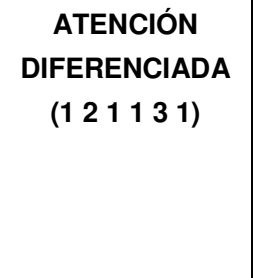 } & 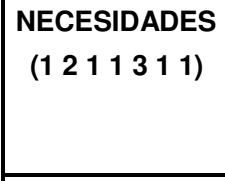 & & $\begin{array}{l}15,25,90,117,140,147,151,153 \\
162,168,169,210,212,213,214, \\
220,221,224,228,230,251,262, \\
306\end{array}$ \\
\hline & & & & & & & 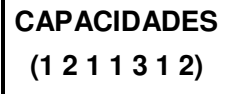 & & 230 \\
\hline & & & & & \multirow[t]{2}{*}{$\begin{array}{l}\text { EFICIENCIA } \\
\left.\qquad \begin{array}{lllll}1 & 2 & 1 & 1 & 4\end{array}\right)\end{array}$} & \multirow[t]{2}{*}{ 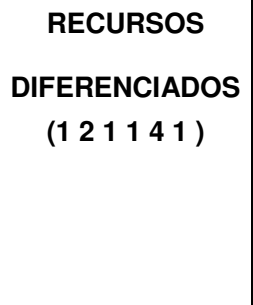 } & \multirow[t]{2}{*}{ 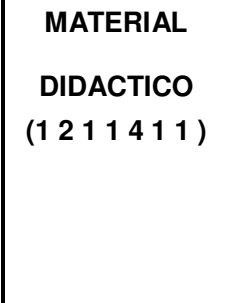 } & $\begin{array}{c}\text { ESPECIFICO } \\
\left(\begin{array}{c}1 \\
1\end{array} 114411\right. \\
1)\end{array}$ & $\begin{array}{l}15,23,24,25,36,80,89,114,132 \\
134,147,149,176,302\end{array}$ \\
\hline & & & & & & & & \begin{tabular}{|c|} 
TECNOLOGÍA \\
$\left(\begin{array}{c}1211411 \\
2\end{array}\right)$
\end{tabular} & 129,149 \\
\hline
\end{tabular}




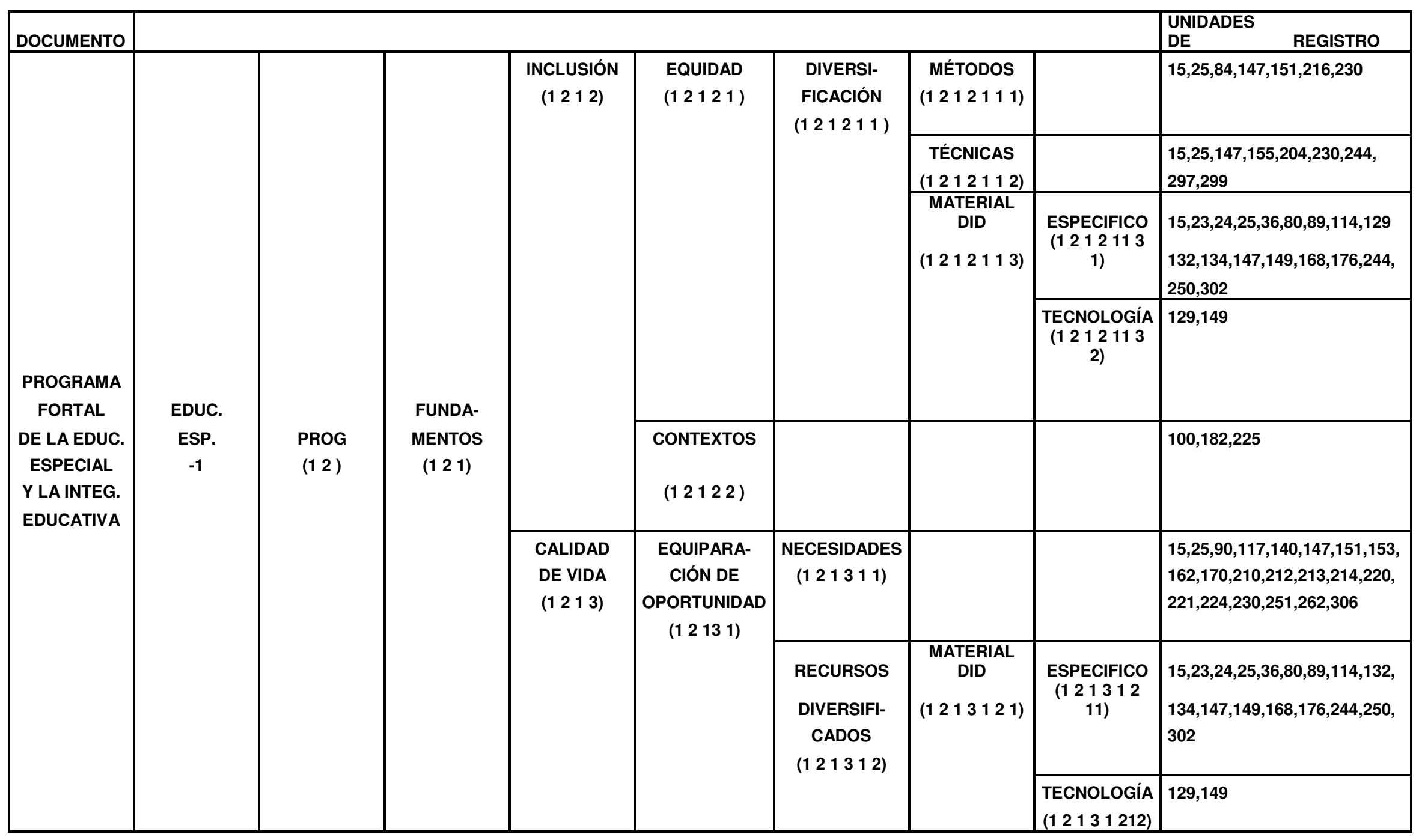

